UNIVERSIDADE DE SÃO PAULO

INSTITUTO DE ASTRONOMIA, GEOFÍSICA E CIÊNCIAS ATMOSFÉRICAS

DEPARTAMENTO DE GEOFÍSICA

GRASIANE LUZ MATHIAS

Enviromagnetic response of marine sediments off NE
Brazil to paleoclimatic and paleoceanographic changes in
the last $85 \mathrm{kyr}$ BP

(Resposta magnética de sedimentos marinhos da margem adjacente ao NE do Brasil às mudanças paleoclimáticas e paleoceanográficas nos últimos 85.000 anos BP)

SÃO PAULO

2015 



\section{Enviromagnetic response of marine sediments off NE Brazil to paleoclimatic and paleoceanographic changes in the last 85 kyr BP}

(Resposta magnética de sedimentos marinhos da margem adjacente ao NE do Brasil às mudanças paleoclimáticas e paleoceanográficas nos últimos 85.000 anos BP)

Tese apresentada ao Instituto de Astronomia, Geofísica e Ciências Atmosféricas da Universidade de São Paulo para obtenção do grau de Doutora em Ciências Geofísicas.

Área de Concentração: Geofísica

Orientador: Prof. Dr. Ricardo Ivan Ferreira da Trindade

SÃO PAULO

2015 
To Wilbor, my partner in crime. 


\section{AKNOWLEDGEMENTS}

I would like to thank my advisor professor Dr. Ricardo Ivan Ferreira da Trindade for his orientation, patience and friendship. Thanks also to my advisor in Germany, professor Dr. Tilo von Dobeneck, for his guidance, serenity, friendship and long discussions.

During my PhD I had the support from Conselho Nacional de Desenvolvimento Científico e Tecnológico (CNPq) with scholarships in Brazil and Germany (SWE) and from MARUM with additional support from a $\mathrm{PhD}$ guest student grant.

The Instituto de Astronomia, Geofísica e Ciências Atmosféricas (IAG-USP) provided the necessary support for my PhD. I particularly thank Teca for making everything easier. The work has benefited from the excellent infrastructure from Laboratório de Paleomagnetismo (USPmag) and the expertise of technicians Daniele Bradt, Plínio Jaqueto, Giovanni Moreira, who are also friends.

The thesis has also befitted from the amazing infrastructure from the Research Group of Marine Geophysics of University of Bremen and the IODP Bremen Core Repository. They granted me with full access to equipments, helped me with measurements and sample preparation and made available the cores used in my work. XRF analyses were performed in the Center for Marine Environmental Science (MARUM) with the invaluable help of Vera Lukies and Ursula Röhl. The members of the Laboratory for Paleo-, Rock and Environmental Magnetics, received me so friendly and made my life abroad pleasant. Thanks particularly to: Liane Brück, Heike Piero, Martina Braun, Christian Hilgenfeldt, Sebastian Razik, Benjamin Baasch. I would like to thank Dr. Janna Just, Dr. Thomas Frederichs, MSc. Sophie Roud and Dr. André Paul for the important and fruitful discussions that contributed immensely not only for the thesis but for my general backround in paleoceanography.

I would like to thank the professor Dr. Cristiano Chiessi for making the contact with the German workgroup possible, and also for his friendship and support during difficult moments in my $\mathrm{PhD}$.

Thanks to Prof. Dr. Igor Ivory Gil Pacca who followed my work from the beginning as an internal reviewer for the important comments about my research.

Many thanks to my friends from the workgroup of Paleomagnetism: Elder Yokoyama, Filipe Terra-Nova, Gelvam Hartmann, Jairo Savian, Janine Carmo, Mariana Rossafa, Karine Carvas, Pedro Franco.

Thanks to my family, always present, always supporting me.

Finally, and most importantly, I would like to thank my husband Wilbor Poletti. His patience, support, encouragement, discussions and mainly love were prime to make this thesis possible. His forbearance to my recurrent bad mood in these final months was a solid prove of his love and respect for me. Thanks also to our little star Alice that is so calm and sweet, and put so many smiles on our face, even in the toughest days. 
"Study the past if you would define the future."

Confucius 


\section{RESUMO}

O NE do Brasil é uma região semi-árida influenciada pela migração para sul da Zona de Convergência Intertropical (ITCZ), que é a principal sistema atmosférico que controla o aumento sazonal da precipitação nessa região. É bem estabelecido que esses períodos úmidos se correlacionam temporalmente com os Eventos Heinrich $(\mathrm{EH})$ - períodos em que ocorre um aumento da deposição de ice-rafted debris no Atlântico Norte. Entretanto, a resposta oceanográfica local a essa descarga de água doce no Atlântico Norte e como isso influencia o transporte de sedimentos ao longo da margem adjacente ao NE do Brasil s"ao ainda motivo de debate na literatura. Este trabalho apresenta dados magnéticos e geoquímicos para quatro testemunhos coletados na parte sul do Oceano Atlântico equatorial, para os últimos $85 \mathrm{ka} \mathrm{BP}$. Os testemunhos estão distribuídos entre as longitudes $38^{\circ} \mathrm{W}$ and $36^{\circ} \mathrm{W}$. Além disso, nós fizemos um estudo de end-members baseado nas curvas de aquisição de IRM, a partir do qual elucidamos as possíveis fontes dos sedimentos. Os parâmetros magnéticos revelam um aumento significativo na concentração de minerais magnéticos durante os stadials, que é acompanhado por uma mudança na proporção relativadas fases magnéticas. Os picos de concentração de minerais magnéticos coincidem com picos nos indicadores geoquímicos utilizados para traçar a intendidade de intemperismo no continente. Portanto, os aumentos no aporte de material magnético para a plataforma coincidem com um aumento na precipitação no continente no NE do Brasil durante os EH. Além da variação da quantidade de material magnético observada, a contribuição relativa de cada fase magnética muda de oeste para leste. Durante os stadials, fases de alta coercividade (como hematita e goetita) são dominantes na porção oeste da região estudada e as fases de baixa coercividade são dominantes a leste. Essa diferença é devida, principalmente, à oxidação diferencial no continente, mas secundariamente nós sugerimos um transporte W-E de material coercivo, causado pelo enfraquecimento da Corrente Norte do Brasil (NBC) durante os stadials logo a leste da desembocadura do Rio Parnaíba, como previsto em alguns modelos paleoclimáticos.

Palavras-chave: NE Brasil, Heinrich Events, magnetismo ambiental 


\begin{abstract}
NE Brazil is a semi-arid region influenced by the southward displacement of the Intertropical Convergence Zone (ITCZ), which is the main atmospheric system that modulates the seasonal increasing in precipitation over this region. It is well established that these wet periods correlate temporally with Heinrich Events (HE) - periods of higher input of ice-rafted debris in the North Atlantic. However, the local oceanographic response to fresh water pulses in the North Atlantic and how this process influences sediment transport along the margin off NE Brazil are still a matter of discussion. We present here rock magnetic and geochemical element data for four marine cores collected in the south equatorial Atlantic Ocean, covering the last $85 \mathrm{ka}$. The cores are distributed between longitude $38^{\circ} \mathrm{W}$ and $36^{\circ} \mathrm{W}$. We also performed end-member analysis based on the IRM acquisition curves bringing a better understanding about sediment sources. Magnetic proxies show a marked increase in concentration of magnetic minerals during stadials, with a concomitant change in the proportion of magnetic mineral types. Peaks in magnetic concentration parameters coincide with peaks in geochemical proxies for weathering intensity on land, being thus compatible with an increase in precipitation in NE Brazil during HE. Yet, the relative contribution of magnetic phases across the NE Brazil margin changes from west to east. During stadials the high-coercive phases (like hematite and goethite) are dominant for cores located in the western part of the study area and low-coercive phases are dominant for the core located further east. This difference is due mainly to differential oxidation over land, but secondarily we suggest a transport from W-E of high coercive material, possibly caused by the weakness of NBC during stadials just to the east of the mouth of the Parnaiba River as predicted in some paleoclimate models.
\end{abstract}

Keywords: NE Brazil, Heinrich Events, environmental magnetism 


\section{SUMMARY}

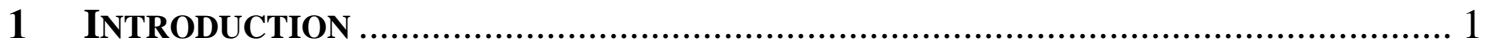

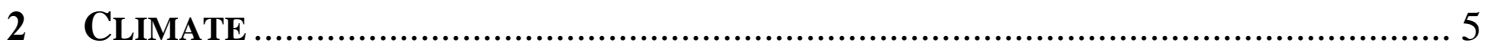

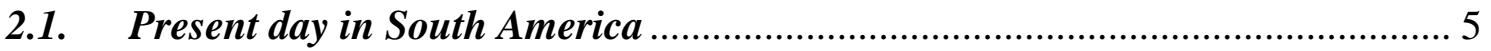

2.2. Holocene in South America ......................................................................... 7

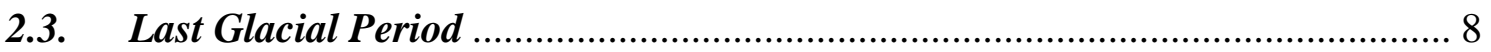

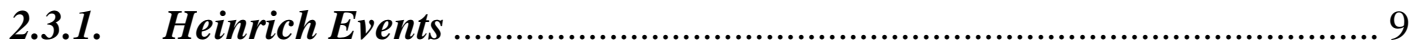

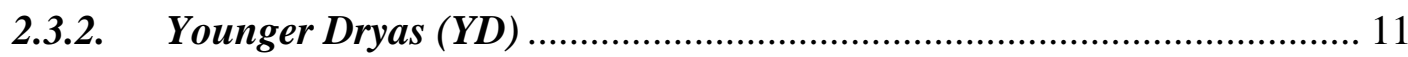

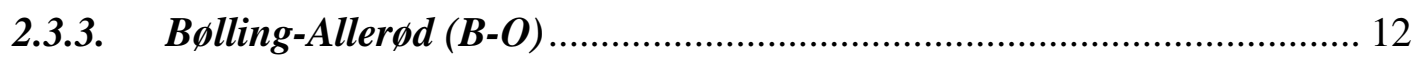

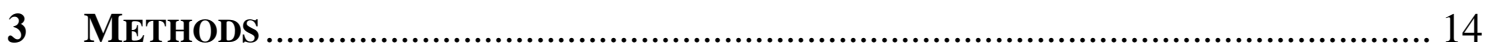

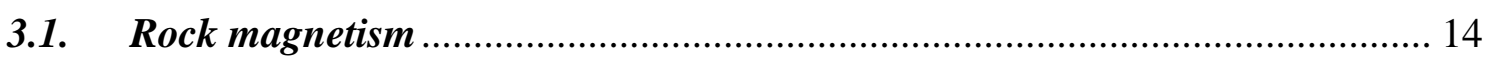

3.2. Unmixing magnetic remanences using IRM acquisition curves ..................... 17

3.3. X-Ray Fluorescence (XRF) and bulk elemental composition (EDP-XRF) .... 19

4 ENVIRONMENTAL MAGNETISM ON CLIMATE STUDIES......................................... 21

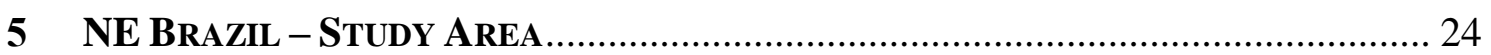

5.1. Geomorphology of the continental shelf, rivers supply and geology .............. 24

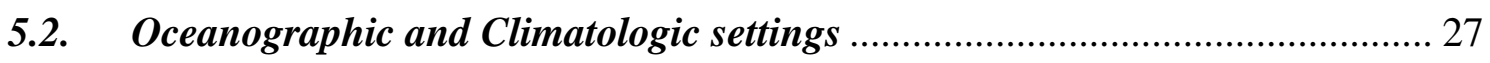

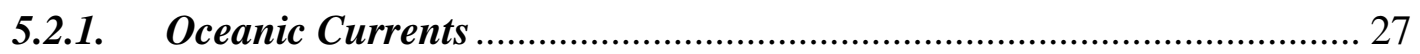

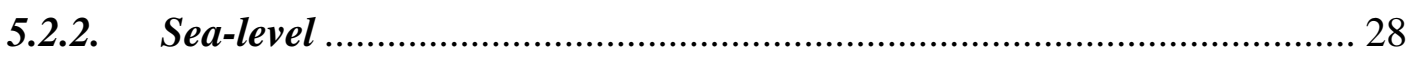

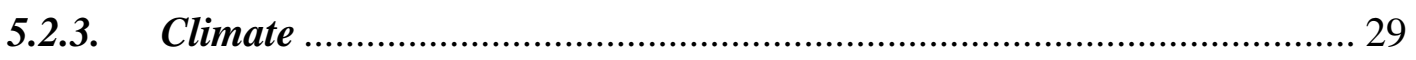

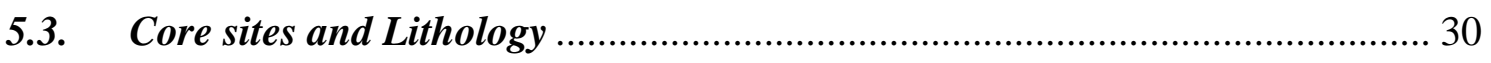

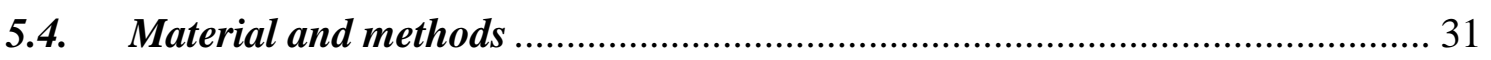

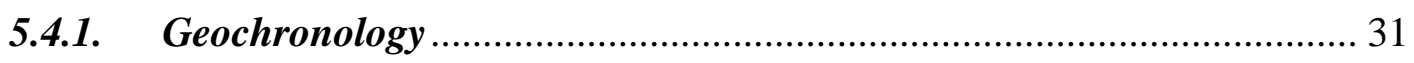

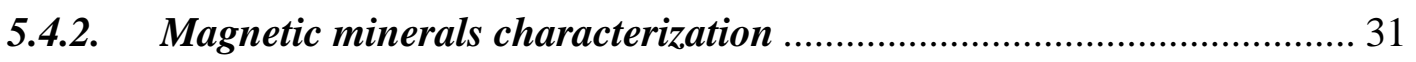

5.4.3. X-Ray Fluorescence (XRF) scanning …......................................... 33

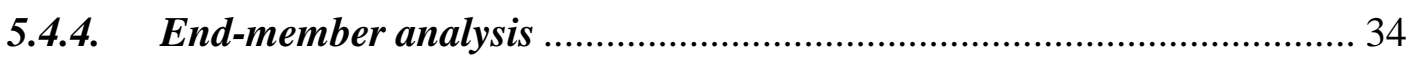

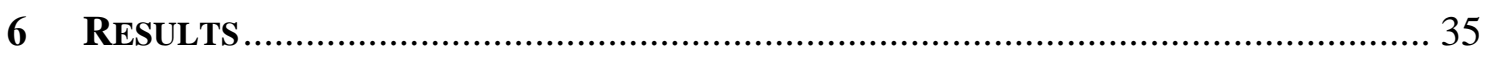

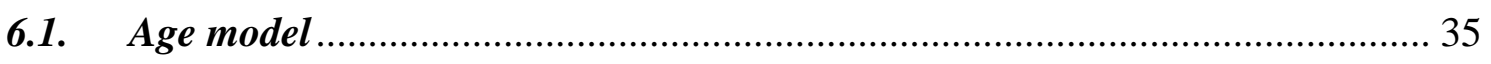

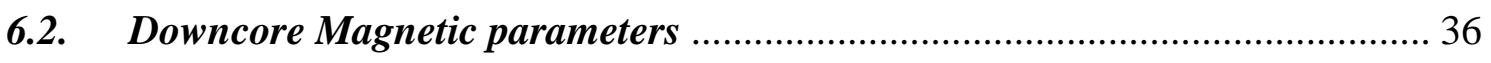

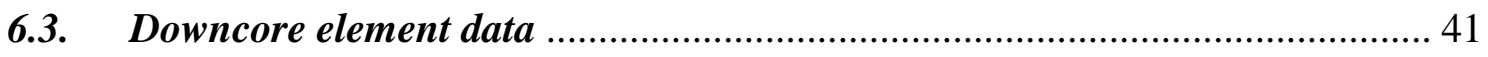

6.4. Magnetic contribution from end-members $(\mathrm{EM})$........................................ 45

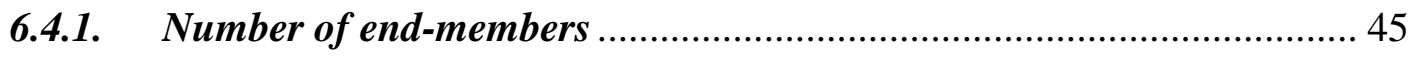

6.4.2. Shape of the IRM acquisition curves from the unmixing ..................... 47 
6.4.3. Magnetic contributions from end-members …................................... 49

6.4.4. Significance of each end-member ...................................................... 52

6.5. Magnetic characterization: hysteresis and low temperature curves ............... 58

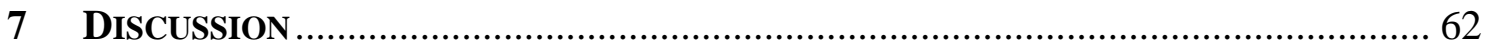

7.1. Deglacial sea-level and hydrographic control on sediment supply .................. 62

7.2. Climate driven sediment pulses, in relation to precipitation ............................ 65

7.3. Climate and paleoceanographic models .............................................................. 72

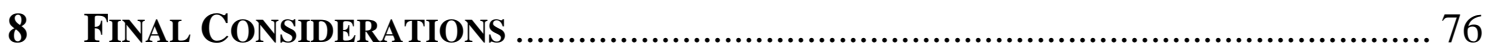

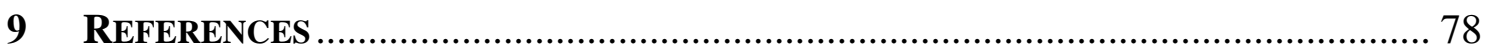

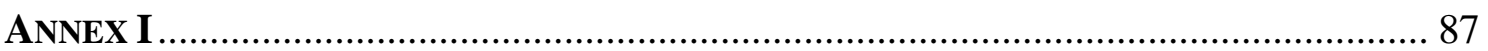

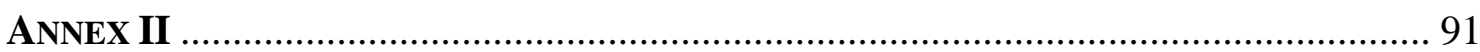

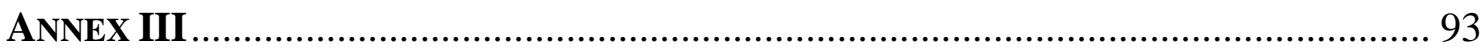

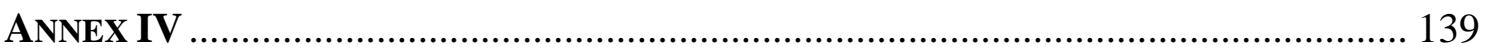

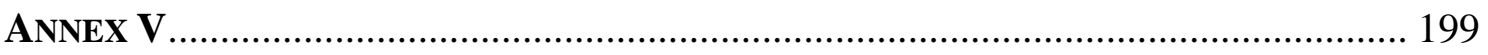

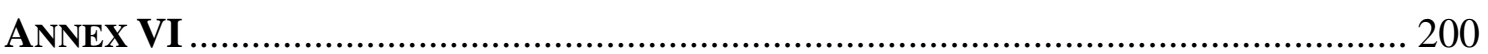

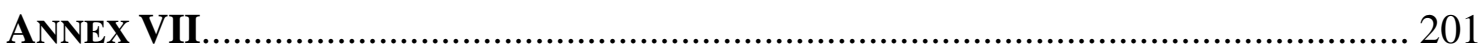

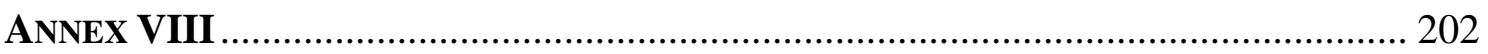




\section{LIST OF FIGURES}

Figure 2.1: Main climate features in South America ..................................................... 5

Figure 2.2: Scheme showing processes that control North Atlantic temperatures, NADW formation and inset of $H E$ 10

Figure 3.1: Linear acquisition plot (LAP); Gradient of acquisition plot (GAP); Standardised

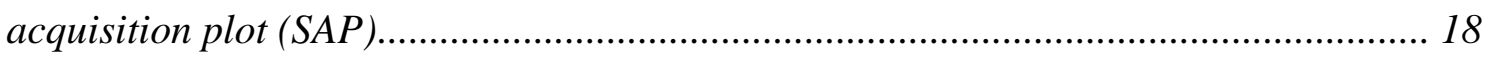

Figure 5.1: Location of the studied cores in the margin off NE Brazil. ....................... 25

Figure 5.2: Geological map of NE Brazil.. ............................................................... 27

Figure 5.3: Sea-level evolution since the Last Glacial Maximum. ............................... 29

Figure 5.4: Sea-level observations from sites in the Atlantic margin off South America and the Caribbean Sea.. 29

Figure 6.1: Age model and sedimentation rate for our cores ...................................... 36

Figure 6.2: Rock magnetic parameters for core GeoB3913-3..................................... 37

Figure 6.3: Rock magnetic parameters for core GeoB3912-1 .................................... 38

Figure 6.4: Rock magnetic parameters for core GeoB3911-3...................................... 39

Figure 6.5: Rock magnetic parameters for core GeoB3910-2 .................................... 40

Figure 6.6: Element ratios [cps] for core GeoB3913-3............................................. 42

Figure 6.7: Element ratios [cps] for core GeoB3912-1............................................. 43

Figure 6.8: Element ratios [cps] for core GeoB3911-3............................................... 44

Figure 6.9: Element ratios [cps] for core GeoB3910-2 ................................................ 44

Figure 6.10: Coefficient of determination $\left(R^{2}\right)$ for our four cores................................ 45

Figure 6.11: Comparison between the shape of the acquisition curves from the end-member analysis and the input data for cores GeoB3913-3, GeoB3912-1 and GeoB3910-2 .... 47 Figure 6.12: Comparison between the shape of the acquisition curves from the end-member analysis from cores GeoB3913-3, GeoB3912-1 and GeoB3910-2... 48

Figure 6.13: downcore contribution and IRM acquisition curves from the end-members calculated for core GeoB3913-3.

Figure 6.14: downcore contribution and IRM acquisition curves from the end-members calculated for core GeoB3912-1.

Figure 6.15: downcore contribution and IRM acquisition curves from the end-members calculated for core GeoB3910-2. 52

Figure 6.16: IRM component analyses of EMI (hematite/goethite). 54 
Figure 6.17: IRM component analyses of EM2 ((titano)magnetite)............................ 55

Figure 6.18: IRM component analyses of EM3 (biogenic magnetite). .......................... 56

Figure 6.19: Low and high field hysteresis loops for for core GeoB3912-1. ............... 58

Figure 6.20: Low temperature measurements curves ................................................ 59

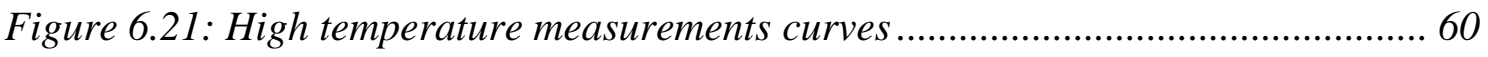

Figure 7.1: Crossplots using magnetic and geochemical parameters for our cores ..... 68

Figure 7.2: Crossplots using the mean value of magnetic and geochemical parameters for wet and dry condition in NE Brazil, and during Holocene. 71

Figure 7.3: Flow velocities along the Equatorial Atlantic off North and Northeast Brazil. 74 


\section{INTRODUCTION}

In the last decades, a big effort has been done aiming to understand the relationship between north and south hemispheres during the last glacial period (10 to $110 \mathrm{kyr}$ BP). Climate changes over annual and decadal scales that take place over the tropics can affect climate in high latitude, but such climate teleconnections over millennium time-scales and the relationship between local and regional oscillations and global forcing are still poorly known (Baker et al., 2001). Climate records show an out-of-phase relationship between north and south hemispheres, which revels a transmission mechanism of temperature and salinity related to changes in thermohaline circulation (THC). This mechanism, defined as 'bipolar seesaw', is governed by the fresh water discharge in the North Atlantic (Broecker, 1998), and it has been the target of many paleoclimatic and paleooceanographic studies in the tropics. Changes in the Atlantic Meridional Overturning Circulation (AMOC), a branch of the THC in the Atlantic Ocean, are the direct causes of temperature oscillation in Greenland (McManus et al., 2004). These decreases in temperature over Greenland result in fresh water discharge into North Atlantic from ice sheet melting, accompanied by massive discharges of ice rafted debris on the North Atlantic Ocean, named Heinrich Events (HE; Heinrich, 1988). Ruddiman (1977) was the first to identify these detritic rich layers (ice-rafted debris) in the North Atlantic, but it was Heinrich (1988) who related these massive discharges of continental material to changes in climate. He attributed the provenance of this material to the Laurentide Ice Sheet (LIS). This relationship between HE and temperature oscillation over Greenland is widely accepted and many studies performed in the tropics revealed that local changes in climate in the past are a response to these changes in the North Atlantic (e.g. H. W. Arz et al., 1999; Gutiérrez et al., 2009; Jennerjahn et al., 2004; Sifeddine et al., 2008).

NE Brazil is a semi-arid region affected nowadays by severe droughts, which interferes directly on the local agriculture and, consequently, on the regional economy. The southward displacement of the Intertropical Convergence Zone (ITCZ) - a convective belt that controls precipitation in the tropics, is the main process that modulates the seasonal increasing in precipitation over this region (e.g. Garreaud et al., 2009). These wet periods (Dupont et al., 2009; Jennerjahn et al., 2004) correlate temporally with the HE. Changes in paleoclimate recorded remotely by marine sequences and related temporally to HE are locally named as Heinrich Stadials (HS). The synchronicity between the southward displacement of the ITCZ and the expansion of ice-sheets in the North Atlantic have been reported by many paleo- climate 
and oceanographic records (Wang et al., 2004; Weldeab et al., 2006) and were also depicted in climatic models (Chiang et al., 2008; Kageyama et al., 2013b; Kageyama et al., 2009).

The enhanced precipitation over NE Brazil resulting from the remote forcing of cold sea temperatures in North Atlantic (Heinrich Stadials - HS) is widely accepted (Arz et al., 1998; H. W. Arz et al., 1999; Behling et al., 2000; Jennerjahn et al., 2004). However, the local oceanographic response to the fresh water pulses in North Atlantic is still a matter of discussion. During low sea-level stands that took place in the last glacial (about $120 \mathrm{~m}$ below the present day sea-level) most of the continental shelf was exposed and the small rivers that presently cross the NE Brazil fed the continental slope (Knoppers et al., 1999). Addressing the ocean response to the southward migration of the ITCZ in the west Atlantic, Arz et al. (1998) related short-term changes in flow patterns and intensity of the North Brazilian Current (NBC) to global climate and oceanic circulation. The NBC dominates the dynamic circulation and sediment transport along the NE Brazilian margin (Figure 5.1). Some authors have shown that the southward migration of the ITCZ is connected to a weak Atlantic Meridional Overturning Circulation (AMOC; McGee et al., 2014; Weldeab et al., 2006). This weakness of the AMOC could affect the strength of the NBC and, consequently, the local circulation in NE Brazil margin.

Magnetic minerals are present in rocks and sediments in minor concentrations, but still they are very sensitive to oscillations in environmental conditions over the past and provide clues about the connection between continent and ocean basins. The use of changes in concentration, grain size and kind of magnetic minerals along marine sedimentary sequences is now a widely used technique for paleoclimatic and paleoceanographic studies (e.g. Just et al., 2014; Kissel et al., 2008), being widely known as "environmental magnetism" or "enviromagnetics" (Evans and Heller, 2003). Magnetic susceptibility is a classical proxy for detrital input, but much more information can be obtained from additional magnetic proxies (Liu et al., 2012). Rock magnetic techniques applied to marine cores may provide evidence about processes that take place over the continent (physical and chemical weathering, pathways - rivers suspended material or dust, etc.) and in the marine depositional environment (sediment re-distribution by currents, diagenesis - reduction of iron oxides, biogenic minerals, etc.). Detailed characterization of the magnetic minerals present in marine sediments is of utmost importance, since in the marine environment the formation of a new magnetic assembly from the detritic iron oxides is ubiquitous and sometimes the primary magnetic assembly is entirely dissolved. Reductive 
conditions, with oxygen depleted and the presence of sulphate, are propitious to the dissolution of iron oxides and formation of iron sulphides (e.g. Kasten et al., 2004). Magnetic reduction compromises the primary signal, and hence the record of the past geomagnetic field and the original record of paleoclimate and source sediment signatures. When the primary magnetic assembly is not completely dissolved, magnetic minerals become a suitable tool to unveil the past history of the climate and oceanography systems and also in identifying sediment sources.

The terrigenous fraction entering continental margins contain iron oxides (i.e. magnetite, hematite), which composes the primary magnetic assembly of the sedimentary sequence. These minerals can provide useful information about the climate of the adjacent continental areas. As an example, the identification of pedogenic magnetic minerals (goethite and hematite) has proven to be very effective to detect changes in moisture availability during soil formation and consequently to infer about continental chemical weathering. In tropical regions, increasing moisture in soils can be generally related to a higher abundance of goethite over hematite (Abrajevitch et al., 2009). During extreme paleoclimatic events, precipitation in the continental area of NE Brazil is well defined (Jennerjahn et al., 2004) and interdigitating layers of magnetic minerals originated during wet (stadial) and dry (interstadial) conditions could be a hint to identify river supply changes. Variations on the magnetic mineralogy respond to changes in precipitation over land and deposition spots on the continental shelf can be a clue about pathways and source areas. Changes in the detrital magnetic minerals go along with variations in chemical element content (e.g., Govin et al., 2012). Fe/Ca and Ti/Al are normally used to track changes in detrital input, the $\mathrm{Al} / \mathrm{Si}$ ratio can be sensible to continental chemical weathering, and coeval changes with magnetic parameters that are indicative of goethite increment (i.e. Hard-IRM and S-Ratio[2.7-0.3]) suggest intense pedogenesis in river's catchment area. $\mathrm{Fe} / \mathrm{K}$ ratio is also a proxy for changes in soil moisture availability, since $\mathrm{K}$ originates mostly from potassium feldspar or illite that typically are preserved or form in dry regions. In the same way, high $\mathrm{Al} / \mathrm{Si}$ ratios are a tool to track soil alteration, since Al-rich minerals (mostly clay) are a product of intensive chemical weathering (Govin et al., 2012).

For a better comprehension about local forcings that influence sediment transport along the margin off NE Brazil, we present here detailed rock magnetic characterization and element data from marine cores collected in the south equatorial Atlantic ocean. We performed magnetic investigation and chemical analysis over four cores collected in the margin off NE Brazil, covering the last $85 \mathrm{kyr}$ BP. The following magnetic parameters were used in this study: 
magnetic susceptibility $(\kappa)$, anhysteretic remanent magnetisation (ARM), isothermal remanent magnetisation (IRM) a $2700 \mathrm{mT}$ e $-300 \mathrm{mT}$ [IRM $2700 \mathrm{mT}$, IRM-300mT], HIRM [Hard IRM= $\mathrm{IRM}_{2700 \mathrm{mT}}-\mathrm{IRM}_{-300 \mathrm{mT}}$ /2], S-Ratio [IRM-300mT/ IRM $2700 \mathrm{mT}$ ], ARM/IRM and Fe/ $\kappa$. To improve the sediment source study we used X-Ray Fluorescence (XFR) measurements with spectrum operating at $10 \mathrm{kV}$ for detecting major elements (i.e. Fe, Ca, Ti) and $30 \mathrm{kV}$ spectrum in order to obtain trace elements data (i.e. $\mathrm{Ni}, \mathrm{Cu}, \mathrm{Zn}$ ) for cores GeoB3913-3, GeoB3912-1 and GeoB3911-3. In addition, we compared geochemical data previously obtained from core GeoB3910-2 with our magnetic data.

The magnetic inventory and soil characterization over NE Brazil has showed significant differences between Parnaíba Basin (west) and Borborema Province (east; Archanjo et al., 2002; Journet et al., 2013; Roud, 2014; WRB, 2006). The identification of climatic pulses along the coast of NE Brazil using enviromagnetic tools permitted us to investigate a possible relationship between rivers supply/longitudinal transport and precipitation enhancement caused by cold events over the North Atlantic. Here we present new magnetic data for four cores recovered from the continental margin off NE Brazil (GeoB3913-3, GeoB3912-1, GeoB39113 and GeoB3910-2). In previous studies performed in NE Brazil margin, $\mathrm{Fe} / \mathrm{Ca}$ and $\mathrm{Ti} / \mathrm{Ca}$ have been published for cores GeoB3912-1 (Arz et al., 1998; Jennerjahn et al., 2004), GeoB3911-3 (H. Arz et al., 1999) and core GeoB3910-2 (Jaeschke et al., 2007). We complemented this data with new geochemical data for core GeoB3913-3 and some additional ratios (Al/Si, Fe/K and Ti/Al) for cores GeoB3912-1, GeoB3911-3 and GeoB3910-2. These four cores are located along a transect from west to east alongside the NE Brazilian coast under direct influence of ITCZ and NBC.

The thesis comprises this introduction, seven additional chapters, and VII annexes. The second chapter describes the climate in South America. The third chapter provides a detailed description of methods used, including magnetic and geochemical methods, and the endmember analysis technique. The fourth chapter reviews the application of magnetic methods to the study of past climate and oceanography. The fifth chapter describes the study region and provides a basic description of materials used in the thesis. The sixth chapter describes all experimental results. In the seventh chapter, results are discussed addressing changes in sealevel, climate and sources in the region for the last $85 \mathrm{kyr}$. The eighth chapter announces the main conclusions and perspectives. In annex, the magnetic and geochemical data are presented in the form of tables. Some tables (Annex V) are presented only in electronic form. 


\section{Climate}

\subsection{Present day in South America}

South America shows several climate processes and systems, with quite complex patterns, as a result of its wide latitudinal extension $\left(10^{\circ} \mathrm{N}-55^{\circ} \mathrm{S}\right)$ and peculiar orographic configuration. The largest atmospheric systems are the Intertropical Convergence Zone (ITCZ) and the South Atlantic Convergence Zone (SAZC; Figure 2.1).

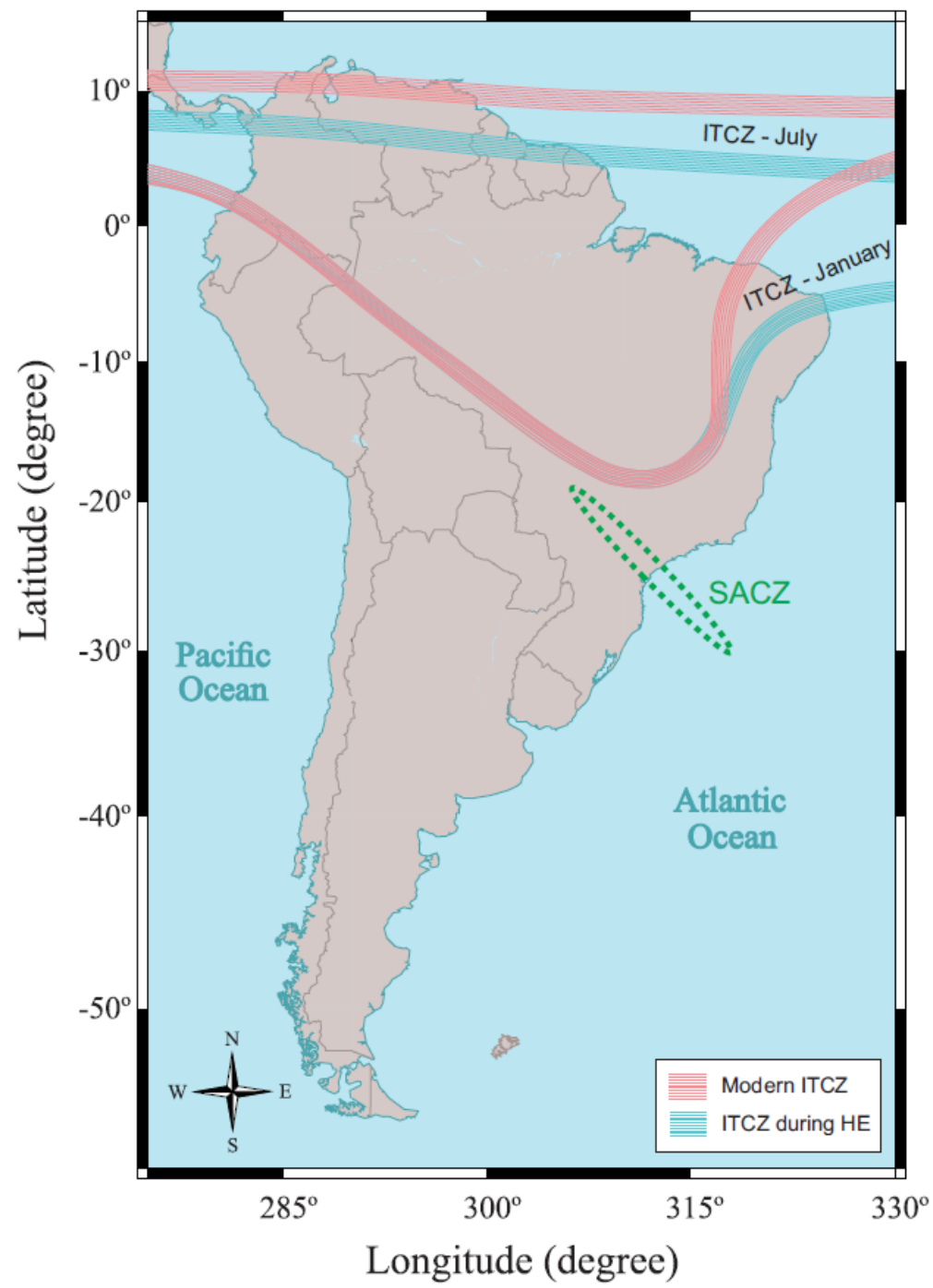

Figure 2.1: Main climate features in South America: South Atlantic Convergence Zone (SACZ) and Intertropical Convergence Zone (ITCZ): modern situation (red) and during the Heinrich Events (HE; blue).Configuration during HE from Jennerjahn et al. (2004). 
These systems act in interannual timescale (Garreaud et al., 2009) and affect the whole South America, changing precipitation patterns over the continent and sea surface temperatures (SST) over the adjacent oceans (McGee et al., 2014; Robertson and Mechoso, 2000). The southward displacement of the ITCZ - a convective belt that controls precipitation in the tropics - is the main process that nowadays modulates the seasonal increasing in precipitation over this region (e.g. Garreaud et al., 2009). The SACZ is a convective summertime system that extends from Amazonia to the southeast forming a moisture belt, characterized by a meridional seesaw in upper-level (Robertson and Mechoso, 2000). According to Nogués-Paegle and Mo (1997) changes in the intensity of SACZ depend on humidity over tropical and subtropical South America. Higher precipitation over high latitudes of South America are associated to intensification of the SACZ (Robertson and Mechoso, 2000).

In addition to these large-scale seasonal systems, some leading modes of global atmospheric variability also present interannual variability, like El Niño Southern Oscillation (ENSO), Antarctic Oscillation (AAO) and Pacific Decadal Oscillation (PDO). ENSO is a large-scale coupled ocean-atmospheric system that takes place over the Pacific Ocean. It affects strongly the west-east temperature gradient over equatorial Pacific, and directly influence the west coast of South America and the temperature over the continent (Garreaud et al., 2009). The ENSO system fluctuates between warm (El Niño) and cold (La Niña) phases, which last about 2-7 yrs and bring forth, respectively, increase or decrease in precipitation in southern South America (Grimm, 2003; Poveda et al., 2006). The high latitude forcing AAO acts south of $20^{\circ} \mathrm{S}$ over tropospheric level, and presents pressure anomalies with opposite signals centred in Antarctica and on a circumglobal band at about $40-50^{\circ} \mathrm{S}$ (Garreaud et al., 2009). AAO varies in intermonthly and interannual timescales, but it plays a role in precipitation only in middle latitudes and southward (Gillett et al., 2006). PDO mode causes fluctuations in precipitation over South America under decadal and interdecadal timescales (Garreaud et al., 2009), and despite its smaller amplitude relative to AAO, it is important for our study since it is associated with interdecadal variability over NE Brazil and SST anomalies in Tropical Atlantic (NoguésPaegle and Mo, 2002).

The asymmetrical heating of land and sea affects seasonally changes in atmospheric circulation and precipitation. Over South America, the warm season shows features that are typical of a monsoon climate. Zhou and Lau (1998) defined a monsoon as "a seasonal reversal in the largescale circulation system driven by differential heating of the continent and the oceans." 
Contrasts between winter and summer seasons exhibit a monsoon-like precipitation cycle over most of South America. Considering the existence of a regional summer monsoon circulation over South America, precipitation is strongly modulated by South America Summer Monsoon (SASM). The geographical extension of the SASM includes the core monsoon region and its areas of influence (i.e. low-pressure system over Chaco region and seasonal precipitation over tropical latitudes; Grimm et al., 2005).

As we mention before, all these systems (ITCZ, SACZ, SASM) can influence climate in South America and cause variability in SST of the adjacent oceans. However, it is important to say that global changes also affect these systems in a way that can impact climate in South America in different ways in low, middle and high latitudes. For instance, Cruz et al. (2009) found a phase difference between northern and southern South America, that was related to high temperature periods in the Atlantic Ocean tropical sector, a weakness of the temperature gradient between the hemispheres and the drift of ITCZ and ENSO systems. Baker et al. (2001) hypothesized that cooling Atlantic tropical waters intensifies the land-sea contrast, which in turn, due its influence over SASM, leads to an increase in precipitation and moisture in the Andean region. Such disconnection between north and south America was related by Robertson and Mechoso (2000) to SST anomalies in tropical and subtropical regions over South Atlantic, which strengthen the meridional temperature and intensifies trade winds.

\subsection{Holocene in South America}

The Holocene in South America is marked by dry conditions and high sea-level. Decrease of summer insolation in the Southern Hemisphere from late to mid-Holocene is one of the key points to explain the increasingly dry conditions in South America. Based on a multiproxy reconstruction, Prado et al. (2013) suggested less important precipitation in the mid Holocene in comparison to the late Holocene due to low austral summer insolation, which would reduce the land-sea temperature contrast and consequently weaken SASM. Increased land-sea temperature gradients during austral summer would enhance the transport of water-vapor to Amazonia (Baker et al., 2001). In more detail, differences between different regions of South America during the Holocene can be delineated. Precipitation in Amazonia south of the equator correlates with interannual and seasonal cycles recorded in Lake Titicaca, which shows maximum aridity between 8 and $5.5 \mathrm{ka}$ BP (Baker et al., 2001). On the other hand, oxygen 
isotopes data from speleothems recorded dry conditions in NE Brazil, whereas the southern tropical South America experienced humid conditions (Cruz et al., 2009). This was assigned to insolation-driven changes in monsoon circulation. These drier conditions are also expressed in the remarkable diminution of terrigenous input after $11 \mathrm{kyr}$ BP (Arz et al., 1998).

\subsection{Last Glacial Period}

The main differences between the Last Glacial Period (110 to $12 \mathrm{kyr}$ BP) and the present-day climate conditions are the ice sheet volume, $\mathrm{CO}_{2}$ levels and changes in seasonal insulation (Ruddinam, 2008). Glacial periods are marked by large and well-defined millennial oscillations, which superimpose on the orbital-scale climate cycle. Orbital control of climate over NE Brazil, has been recorded in the final phase of the last glacial period (Cruz et al., 2009). However, changes in precipitation over NE Brazil recorded by high-resolution marine records, respond well to temperature changes over the North Atlantic (Arz et al., 1998; Jaeschke et al., 2007; Jennerjahn et al., 2004). An important characteristic of these short-time climate changes is that they begin and end up abruptly. In contrast, during interglacial periods such fluctuations are negligible or absent. Many records from ice and marine cores show synchronicity in such millennium fluctuations and result essentially from the coupling between the outer envelopes of the Earth (i.e. air and sea-surface temperatures). Marine records from low latitudes of the South Atlantic Ocean show a clear link between cold events in the North Atlantic and changes in precipitation patterns over the tropics (Arz et al., 1998; Mulitza et al., 2008).

The migration of the ITCZ to the south during the southward expansion of ice-sheets in the North Atlantic has been reported by many paleoclimate and paleooceanographic records (Wang et al., 2004; Weldeab et al., 2006) and were also depicted in climatic models (Kageyama et al., 2013a). Some works have shown that a southward migration of the ITCZ is also connected to a weaker AMOC in the past (McGee et al., 2014; Weldeab et al., 2006). This connection between different components of the climate reinforced the need for a better understanding of the link between abrupt climate changes in the North Atlantic and climate in the tropics.

Ice cores, sedimentary sequences, tree rings, and other sources have shown potential in unveiling climate events that took place in the past. Such high-resolution records made possible to investigate temporal features in detail and reveal extreme changes that occurred in a relatively short time. Abrupt climate event is a rapid change in comparison to the climate forcing, and 
reaches a breaking point (Rahmstorf, 2001). In light of this definition, one could consider the transition between glacial/interglacial intervals, which lasts a few hundred or thousand years, as an abrupt climate change, once temporal scale of Milankovich Cycles is much higher. Concerning this thesis, abrupt events will be considered short-term oscillations (few thousand years) that superimpose on orbital-scale climatic cycles. Following the purposes of this thesis, here we will stick to millennial scale abrupt events (i.e. Heinrich Events, Younger Dryas) in the description that follows.

\subsubsection{Heinrich Events}

The German Hartmut Heinrich (1988) was the first to describe Heinrich Events (HE) after identifying layers anomalously rich in ice-rafted debris (IRD) in marine cores recovered from the North Atlantic. Heinrich (1988) took the ratio of lithic and total entities (fraction $>150 \mu \mathrm{m}$ $-3 \mathrm{~mm}$ ) to show that the amount of IRD increased significantly in the Heinrich Layers, reaching almost $100 \%$. IRD are detrital material transported by icebergs that detach from ice sheets and melt over the ocean depositing this grained material on the deep sea, between pelagic layers. Massive discharges of terrigenous detritus intercalated with marine sediments have been observed before by Ruddiman (1977), which identified an area between latitude $40-55^{\circ}$, named Ruddiman Belt, but its correlation to important changes in climate and oceanographic features on the North Atlantic was done only years later. Heinrich (1988), using $\delta^{18} \mathrm{O}$ in foraminifera shells found an increase in the relative abundance of planktonic foraminifers typical of cold and low salinity waters (Neogloboquadrina pachyderma) during the HE. The source for detrital material in the Ruddiman Belt is linked to the detachment of icebergs from the Laurentide Ice Sheet (LIS), which were transported by the Gulf Current to deep regions of the North Atlantic Ocean (e.g. Bond et al., 1993; Heinrich, 1988).

Remarkable characteristics of HE are an abrupt termination marked by a sudden increase in temperature, and an inset after a gradual decrease in temperature (Figure 2.2). Some papers have suggested, based on models and records from Greenland and Antarctic ice cores, that weakness of North Atlantic Deep Water (NADW) starts with the input of fresh water on the North Atlantic Ocean (e.g. Blunier and Brook, 2001; Bond and Lotti, 1995; Stocker, 2000), whose origin is the LIS. According to Stocker and Marchal (2000), weakness of NADW would imply in cooling of the North Atlantic Ocean, and consequent decrease in icebergs melting rate. As HE took 
place during periods of low temperature at the atmosphere and ocean surface, they reflected an increase in the resistance of icebergs at the cold ocean surface. After these periods, the NADW was re-established causing rapid warming in high latitudes of the northern hemisphere. Figure 2.2 shows a flowchart with the scheme suggested by Stocker and Marchal (2000).

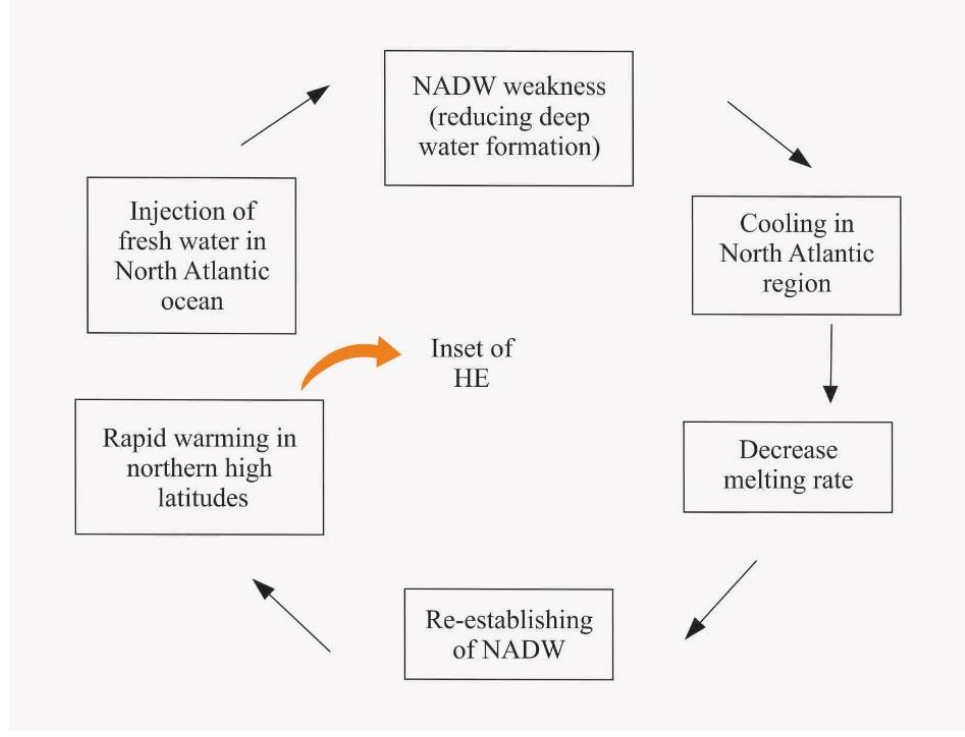

Figure 2.2: Scheme showing processes that control North Atlantic temperatures, NADW formation and inset of HE, according to Stocker and Marchal (2000).

The HE are associated to cold climate periods over the North Atlantic (e.g. Hemming, 2004). Some papers have shown an anti-phase relationship between climate over north and south Atlantic, and reveals the significance of correlating the HE to climate changes on southern Hemisphere (e.g. Broecker, 1998; Stocker, 2000). Abrupt millennial changes in climate over South America have been related to HE by many papers. When this abrupt changes take place on other regions out of North Atlantic Ocean, like the tropics, they are named stadials, and the interval in between is called interstadial. Following this conceptual assumption, we refer to the abrupt events we recorded here as Heinrich Stadials (HS).

The eastern portion of equatorial South Atlantic show that arid conditions are a reflect from HE during the last glacial period (e.g. Itambi et al., 2009; Just et al., 2012a; Mulitza et al., 2008). The last $85 \mathrm{kyr}$ in Central America was marked by arid periods during HE due to southward migration of ITCZ (Hodell et al., 2008). On the other hand, in NE Brazil, wet periods were 
identified by many studies, on the basis of drastic changes on geochemical data, stable isotopes and palynology in sediments, and linked to HE during the last glacial, especially during abrupt climate events (Arz et al., 1998; H. W. Arz et al., 1999; Behling et al., 2000; Jennerjahn et al., 2004).

\subsubsection{Younger Dryas (YD)}

The Weichselian late glacial, also referred to as last glacial-interglacial transition or last termination (15-10 kyr BP), was a period characterized by rapid climate changes. During the last termination, cold periods were interdigitated by interstadials (warm periods), that will be described in the next sub-chapter. Mangerud et al. (1974) were the first to propose a subdivision of the last termination (Weichselian) and the Flandrian (Holocene). Based on a sequence of glacials/interglacials events, these authors divided these two stages in chronozones, named: Bølling, Older Dryas, Allerød, Younger Dryas, Preboreal, Boreal, Atlantic, Subboreal, Subatlantic. Among these warm and cold events, the ones that have important expression globally are the B-O (item 2.3.3) and the YD. The YD was the last abrupt climate response to the transition between the last glacial and the present warm interglacial, therefore it arouse interest and has been largely studied. The last termination is classically sub-divided into a series of stadials named after the occurrence of the characteristic pollen from arctic-alpine plant species Dryas octopetala in lakes of Sweden and Denmark (Carlson, 2013). After that, ice cores from North Atlantic recorded with high resolution the decrease in $\delta^{18} \mathrm{O}$ (reflecting cooling temperature), marking sharply the inset and termination of the YD (Alley, 2000). Records from Greenland are quite precise in determining timing for abrupt climate changes, like YD. At the time of the YD, the insulation was at its maximum (almost the peak) and the sea-level was at about 60-70 m below the present day configuration (Carlson, 2013). The connection between the tropics and the cold-water formation over North Atlantic Ocean is widely accepted nowadays (e.g. Kissel et al., 2013; Weldeab et al., 2006). McManus et al. (2004) identified a collapse in the AMOC during the YD. Due to this strong connection between North and South hemispheres throughout the Atlantic Ocean, it is possible to find the fingerprint of YD in many places around the world. During YD, wet conditions were identified in NE Brazil (H. W. Arz et al., 1999; Jennerjahn et al., 2004), concurrent with higher levels in Lake Titicaca (Baker et $a l ., 2001)$, both consistent with migration to south of the ITCZ. Conversely, dry conditions were 
identified in the eastern margin of tropical Atlantic (Just et al., 2012b; Mulitza et al., 2008). Still in the tropics, increase in sea surface temperature (about $0.25-1.2^{\circ} \mathrm{C}$ ) in the margin off $\mathrm{NE}$ Brazil was recorded by alkenone analysis (Jaeschke et al., 2007).

Although the agreement in literature about ocean reorganization and deep-water formation, there is no consensus about what triggered the YD. The YD is sometimes referred to as Heinrich Event 0 and discussed in the same context as the Heinrich Events. However, YD cold event has not relationship with ice-rafting event. Thiagarajan et al. (2014) show that the structure of the water column in the North Atlantic is very different from the Heinrich-like water masses concerning temperature, ${ }^{13} \delta \mathrm{C}$ and $\Delta^{14} \mathrm{C}$. According to Broecker et al. (2010), most of the covenant accept that YD started from a released of fresh water from Lake Agassiz, which shut down the deep-water formation. These authors consider the YD necessary for the process of transition between glacial and interglacial, as they compared YD with similar events that took place in the context of the last four terminations.

\subsubsection{Bølling-Allerød (B-O)}

The Bølling-Allerød ( 14,7 kyr BP) interstadial is the initial warm phase during the last termination (Weichselian) that is followed by the cold stadial Younger Dryas. This warm climate event comes from the name of the localities Bølling and Allerød, in Denmark. The division of these layers has been widely used to correlate with biostratigraphic, climatostratigraphic and lithostratigraphic records that present the expression of the B-O.

The start of B-O warming is marked by both abrupt temperature rises $\left(\sim 9^{\circ}\right)$ in high latitudes of Northern Hemisphere (Chiessi et al., 2008) and the restart of the AMOC (McManus et al., 2004). The characteristic increase in temperature in Northern Hemisphere during the B-O was concomitant with rise in $\mathrm{CO}_{2}$ in the atmosphere, and some works show that this is probably released from deep ocean carbon reservoirs (Schmitt et al., 2012). On the other hand, Kohler et al. (2014) noticed a dramatic change in the process responsible for $\mathrm{CO}_{2}$ rise in the beginning of B-O and suggest as a source of carbon a long-term immobile permafrost layer, whose abrupt release worked as a positive feedback to warming in Northern Hemisphere. The mechanism that triggered the onset of the B-O is still a matter of discussion. Thiagarajan et al. (2014) showed that B-O event was caused by discharge of warm water in the deep North Atlantic 
Ocean, which also restored the AMOC. Using $231^{\mathrm{Pa}} / 230^{\mathrm{Th}}$ ratio from a sediment core from the subtropical North Atlantic, McManus et al. (2004) recorded an abrupt increase at about 14.7 kyr ago, and attributed it to a rapid resumption of the AMOC, corresponding to the onset of the Bølling-Allerød warm period. Chiessi et al. (2008) using planktic and benthic foraminiferal records suggested the exchange between Atlantic and Indian oceans as the trigger for the resumption of the AMOC and the cause for the B-O event. Liu et al. (2009) addressed the B-O warming to the superposition of climate responses to the transient $\mathrm{CO}_{2}$ forcing, the AMOC recovery from HE1, and an AMOC overshoot. Maybe a better comprehension of the temperature and salinity stratification of North Atlantic before and during B-O is prime to unveil process behind the onset of this abrupt warm period. 


\section{Methods}

\subsection{Rock magnetism}

All substances exhibit a magnetic behaviour. A sediment can be viewed as a pool of diamagnetic and paramagnetic minerals, the matrix, containing ferromagnetic minerals. The ferromagnetic behaviour is the only one that is able to preserve the magnetisation acquired during its formation. This magnetisation is named Natural Remanent Magnetisation (NRM) and it holds information about the direction and intensity of the Earth magnetic field (EMF) in the past (e.g. Tauxe, 2008). The magnetization of a sediment can vary according to the strength and direction of the ancient EMF, but is also controlled by sedimentary processes and composition of the sources. Magnetic mineralogy techniques consist on fast and non-destructive laboratory methods that enable one to characterize the different magnetic fractions in a sediment or rock. The first technique involves applying an alternated magnetic field (AF) on the samples, so that each step of the imparted AF consists of a gradually crescent field and when it reaches a peak, it decreases gradually down to zero. This oscillatory behaviour makes the magnetic moments of the low coercivity minerals become random and consequently the NRM falls away. When the intensity of the NRM is too high, (i.e. for volcanic or igneous rocks) the AF demagnetisation is not enough and thermal demagnetisation is required. For marine sediments, in most of the cases the AF demagnetisation is sufficient. After the NRM decreased to zero it was initiated the procedures aiming to obtain magnetic parameters for environmental magnetism analysis.

Some magnetic parameters obtained from artificial magnetic fields imparted on ferromagnetic materials are able to track changes in grain size, concentration and type of the magnetic particles. In this work, we used two remanent magnetisations for this purpose: Anhysteretic Remanent Magnetization (ARM) and Isothermal Remanent Magnetization (IRM). The ARM is a magnetisation obtained by applying an alternating field (AF) on the magnetic material simultaneously to a low intensity $(0.5-1 \mu \mathrm{T})$ direct field (DC; Evans and Heller, 2003). It provides a parameter efficient in the identification of fine magnetite (e.g. Thompson and Oldfield, 1986). The IRM is acquired in laboratory trough imparting a direct magnetic field in constant temperature, about $23-25^{\circ}$. Curves of IRM acquisition are obtained by imparting progressively higher fields. After each step of high intensity magnetic field induction, the magnetisation of the sample is measured. IRM acquisition curves permit the identification of magnetic minerals with different coercivities (i.e. hematite). In combination with the ARM, the 
IRM can be used as a ratio to differentiate between small (single-domain, SD) and large particles (multi-domain, MD), so that high values of ARM/IRM indicate the presence of SD grains.

Other ratios can be obtained from these parameters and are useful in identifying proportional changes in the coercivity of magnetic minerals. The characterization of different magnetic types is useful to ensure a better quality of the paleomagnetic data and also for distinguishing between different detrital sources of sediments. The ferromagnetic particles comprise two main subbehaviours, ferrimagnetic and anti-ferromagnetic, which correspond to the most important iron oxides present in the crust, respectively, magnetite $\left(\mathrm{Fe}_{3} \mathrm{O}_{4}\right)$ and hematite $\left(\mathrm{Fe}_{2} \mathrm{O}_{3}\right)$. Goethite is another anti-ferromagnetic phase usually present in sediments. Hematite and goethite are formed in the soils due to pedogenic processes during Fe-oxide oxidation (e.g. Abrajevitch et $a l ., 2009)$. The S-Ratio is very effective in detecting proportional amounts of hematite/goethite (high coercivity) regarding magnetite (low coercivity). The ratio between IRM acquired at 300 $\mathrm{mT}$ and saturated IRM (SIRM) is defined according to the following formula:

$$
0.5 *\left[\frac{I R M_{300 m T}}{I R M_{1500 m T}}\right] \quad \text { (Bloemendal et al., 1992) }
$$

Another useful ratio to quantify the high-coercivity magnetic minerals (i.e. hematite, goethite) is the HIRM (Hard-IRM), expressed by the equation:

$$
0.5 *\left[S I R M-I R M_{-300 m T}\right] \quad \text { (Stoner } \text { et al., 1996) }
$$

The HIRM ratio can also be used to detect changes in concentration of the ferrimagnetic minerals (Rowan et al., 2009), and together with the magnetic susceptibility ( $\chi$ ) is able to track the input of detrital material. The magnetic susceptibility is defined by the relationship between applied magnetic field $(\mathbf{H})$ and magnetisation $(\mathbf{M})$ :

$$
\mathbf{M}=\chi \mathbf{H} \quad \text { (e.g. Dunlop and Özdemir, 1997) }
$$

It is dimensionless and usually simplified as a scalar (in fact, it is a second-rank tensor). Apart from the ferromagnetic behaviour, the susceptibility embraces also the contribution of diamagnetic, paramagnetic and superparamagnetic (SP) minerals. Changing frequencies during 
the measurement of the magnetic susceptibility it is possible to detect the presence of SP grains (Dunlop and Özdemir, 1997).

For a better characterization of the magnetic mineralogy we used detailed techniques that make use of analysis in the crystallographic level of magnetic minerals. Changes in the temperature and applied magnetic field can show important transitions inside the structure of the grains and reveal details of magnetic minerals present in the sediments. To do so, we performed hysteresis loops (curves of induced magnetization against the inducing field). to obtain the contribution of all the magnetic particles present in the sample. The width of the curve along the inducing field axis (x-axis) is indicative of the coercivity of the ferromagnetic minerals and presence of paramagnetic grains is detected by using the slope of the curve at its very end, when the magnetisation is saturated (e.g. Dunlop and Özdemir, 1997). Moreover, four magnetic parameters can be extracted from the hysteresis loop and they are very important in accessing information about the size and coercivity of magnetic minerals: saturation magnetization $(M s)$, saturation remanent magnetization $(M r s)$, coercivity $(B c)$ and coercivity of remanence $(B c r)$. The ratios $B c r / B c$ and $M r s / M s$, originally proposed by (Day et al., 1977) for titano-magnetites and displayed in the widely used Day Diagram, are quite useful in identifying different grain sizes of magnetic minerals (Dunlop, 2002). The so-called grain size in magnetics is based in the classification of magnetic minerals according to their domain structure. Thus, very diminute nanometric particles are superparamagnetic (SP), small particles are single-domain (SD), particles with intermediate grain-size are pseudo single-domain (PSD), and large particles are multi-domain (MD). Magnetite, for example has the SP-SD transition at about $0.03 \mu \mathrm{m}$, and SD-MD limit higher than $10 \mu \mathrm{m}$ (Dunlop and Özdemir, 1997). For hematite, the limits are significantly different, with SP-SD threshold size of 0.025-0.03 $\mu \mathrm{m}$ (Özdemir and Dunlop, 2014) and SD-MD > $15 \mu \mathrm{m}$ (Özdemir, 2002). Oxidation degree and changes in composition can also change the limits given above (Dunlop and Özdemir, 1997).

Low temperature curves are useful to identify characteristic transitions in the magnetization due to changes in the crystallographic lattice of some ferromagnetic minerals. These minerals undergo magnetic order/disorder below room temperature that promotes a rearrange of the atoms present in their crystallographic lattice. Certain iron oxides have specific transitions, such as the Verwey transition of magnetite $(\sim 122 \mathrm{~K})$, the Morin transition of hematite $(\sim 262 \mathrm{~K}$; Dunlop and Özdemir, 1997), and the Besnus transition of pyrrhotite ( $32 \mathrm{~K}$; Rochette et al., 1990). Low temperature studies investigating greigite has gained a lot of attention recently (e.g. 
Roberts et al., 2011), after its identification on a broad set of marine sediments. However, until now no low temperature order/disorder transition has been identified for this metastable iron sulphide, but Chang et al. (2009) using synthetic samples found a strong dependency between remanent magnetization intensity at low temperatures and grain size for this mineral.

\subsection{Unmixing magnetic remanences using IRM acquisition curves}

The remanence of sediments is a linear combination of the magnetic contribution of all sources or ferromagnetic minerals. End-member (EM) analysis is an inverse technique used to numerically unmix such components (Just et al., 2012a). The unmixing procedure is used to separate distinct magnetic coercivities of mixed assemblages of minerals, attempting to decompose the magnetic signal into parts representing distinct minerals with specific characteristics. It provides information on different environmental processes that took place during magnetic minerals formation. Assuming that bulk IRM acquisition curves could be modelled using a linear mixture of cumulative log-Gaussian (CLG) functions (Robertson and France, 1994), the unmixing procedure intend to represent the independent coercivity components with different origins (Heslop and Dillon, 2007). Magnetostatic interactions can produce a non-linear behaviour in enviromagnetic processes, but some experimental work have shown that the deviation from a linear behaviour in natural materials is minor (e.g. Heslop et $a l .$, 2006). The unmixing model assumes that the measured magnetisation results from a linear mixture of a fixed number of end-members. The model uses a matrix $\mathbf{S}_{\mathrm{mxl}}$ to represent the remanence curve of each end-member, with $m$ end-members and $l$ steps of applied field, and a second matrix $\mathbf{A}_{\mathrm{nxm}}$ for the abundance $(\mathrm{A} \geq 0)$, where $n$ represents the number of remanence curves or samples, and $m$ represents the number of end-members. The data matrix $\mathbf{X}$ is described by:

$$
\mathbf{X}=\mathbf{A S}
$$

where $\mathbf{X}_{\mathrm{nxl}}$ shows $n$ lines with remanence curves for each sample and $l$ columns with measurement fields. It is important to note that the contribution from each end-members, from the abundance matrix, represents the total magnetization (SIRM), and cannot be interpreted as volume or mass percentages (Just et al., 2012a). 
The characteristic IRM acquisition curve for each specific magnetic mineral must also be defined. The magnetic grain size distribution in a natural material is logarithmic. Therefore it is approximated in IRM acquisition curves by a cumulative log-Gaussian (CLG) function (Robertson and France, 1994). In a sample with mixed magnetic minerals, the contribution of individual magnetic grains add linearly and the final result is a cumulative curve (Kruiver et $a l ., 2001)$. This is the basic principle of the IRM-CLG fitting program developed by Kruiver $e t$ al. (2001), a tool that quantifies the magnetic coercivity components through the analysis of acquisition curves. We used this tool to separate the different contributions present in each EM. This program assumes that the IRM acquisition curve resulting from contributions of different magnetic minerals can be described as a combination of different CLGs. According to this assumption, (i) filed values are converted to their logarithmic values and (ii) the linear ordinate scale is converted to a probability scale (Kruiver et al., 2001).
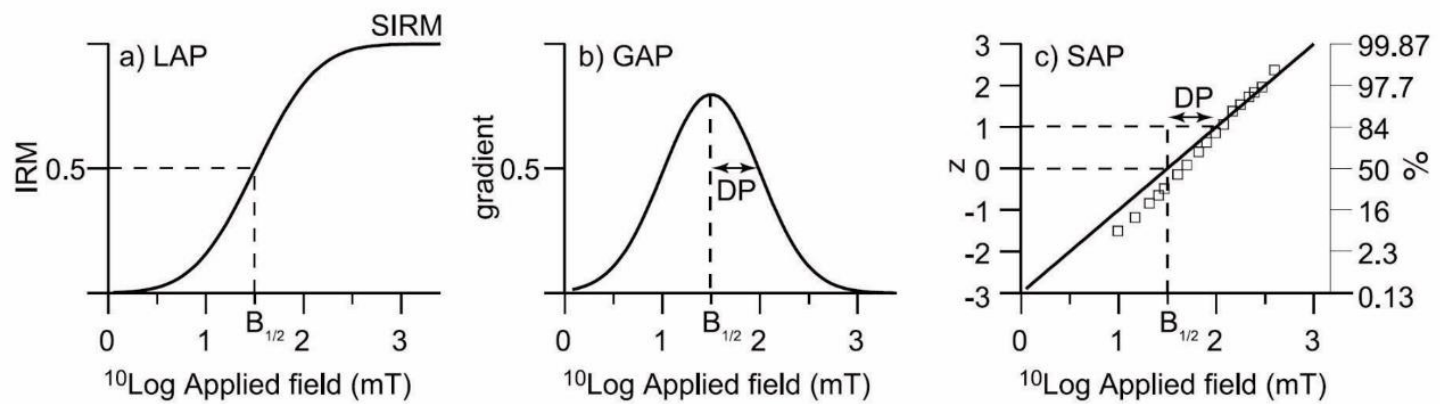

Figure 3.1: (a) Linear acquisition plot (LAP); (b) Gradient of acquisition plot (GAP); (c) Standardised acquisition plot (SAP), the IRM acquisition curve on a probability scale (right-hand ordinate) and corresponding z-score scale (left-hand ordinate). Figure from Kruiver et al. (2001).

The different components of IRM acquisition curves are obtained from their SIRM, mean coercivity $\left(\mathrm{B}_{1 / 2}\right)$ and dispersion (DP, Figure 3.1$)$. $\mathrm{B}_{1 / 2}$ represents the field at which half of the SIRM is reached, and DP is the standard deviation of the logarithmic distribution. In the standardised acquisition plot (SAP) $\mathrm{z}=0$ corresponds to fifty per cent of the cumulative distribution, at field $\mathrm{B}_{1 / 2}$. Increasing $z$ values correspond to $\mathrm{B}_{1 / 2}+\mathrm{DP}$. 


\subsection{X-Ray Fluorescence (XRF) and bulk elemental composition (EDP-XRF)}

Increase in the intensity or number of counts in XRF has being vastly used to trace the supply of terrestrial material to the ocean (Weltje and Tjallingii, 2008). However, since XRF core scanning data is considered to be semi-quantitative (Weltje and Tjallingii, 2008), elemental ratios have been used rather than direct counts, the most common being iron/calcium $(\mathrm{Fe} / \mathrm{Ca})$, titanium/calcium (Ti/Ca), titanium/aluminium (Ti/Al), iron/potassium $(\mathrm{Fe} / \mathrm{K})$ and aluminium/silicon (Al/Si) (Govin et al., 2012). Elemental ratios are more useful than single elements to reconstruct the climate in the past because they can eliminate undesirable effects. For example, the element $\mathrm{Ca}$ is amongst the most commonly used denominators since it accounts for the marine contribution and in this way, elements that reflect purely terrigenous contribution will be better represented. It is also important to stress that several factors, such as sediment colour, water content or instrumental settings, can interfere in the final XRF counting. In this way, the use of element count ratios is useful in comparing trends between different cores, but cannot be interpreted as the absolute values of elemental ratios.

Changes in the content of major elements along marine sedimentary sequences are sensitive to climate variability. In addition to the inorganic material produced in the oceans (i.e. carbonate), marine sediments are composed of terrigenous inputs, which reach the ocean via fluvial and eolian pathways. While arid conditions can be more propitious to dust transport and provide some clues about wind direction and strength, enhanced precipitation and sea level changes affect the amount and quality of the material carried into the oceans by fluvial processes. Ti and Fe contents are related to siliciclastic components and therefore represent changes in terrigenous material in the sediment, whereas Ca represents the marine contribution (carbonate content). Ti/Al ratio is associated with wind intensity and eolian contribution since coarse sediments are enriched in $\mathrm{Ti}$, and $\mathrm{Al}$ is mostly associated with fine-particle clay minerals (Govin et al., 2012).

Major elements have been used also as a signature of weathering processes. In marine sediments $\mathrm{K}$ derives from minerals typical from dry regions, where chemical weathering is less intense, such as potassium feldspar or illite (Zabel et al, 2001). So, high Fe/K values suggest less chemical weathering. Conversely, $\mathrm{Al} / \mathrm{Si}$ ratio is a tracker for intensive weathering, since $\mathrm{Al}$ is mostly associated with fine-grained clays minerals, in particular kaolinite, which is a product of chemical weathering under wet conditions. Higher contents of suspended river material were 
tracked through higher values of $\mathrm{Al} / \mathrm{Si}$ ratio in the margin off Senegal river (Mulitza et al., 2008).

In addition to the usefulness of using element ratios for recording the past climate, the comparison of geochemical data with rock magnetic parameters is helpful for the identification of redox layers present in marine sequences. In margins with high productivity and degradation of organic matter, it is not rare to find redox zones (Kasten et al., 2004). Drops in magnetic parameters to values close to zero can be compared with sulphur or molybdenum data in order to define such redox layers. 


\section{ENVIRONMENTAL MAGNETISM ON CLIMATE STUDIES}

Detailed characterization of magnetic minerals as a proxy for reconstructions of climate, ocean circulation and sediment source is called environmental magnetism. The environmental magnetism comprises the characterization of the magnetic inventory when transport, deposition and transformation of magnetic grains are influenced by environmental processes in the atmosphere, lithosphere and hydrosphere (Verosub and Roberts, 1995). Magnetic mineralogy characterization makes possible to unveil processes that took place in the past and identify distinct magnetic contributions. Iron is one of the most abundant minerals in the terrestrial crust, but even considering that ferromagnetic particles are present in minor concentration, the methods for magnetic investigation are highly sensitives in detecting the presence of soil minerals, atmospheric particles and biogenic material and many areas in science use this tool, like geophysics, oceanography, climatology, sedimentology, etc. Thus, the characterization of different magnetic contributions is useful in the identification of magnetic particles present in small amounts in sediments, concerning mineralogical types, relative proportion between them, granulometry and preferential orientation. The magnetic parameters are a good tool in monitoring changes in many order of magnitude that occur even for small differences in concentration of the magnetic carriers (Verosub and Roberts, 1995). Such changes can be result of variation in depositional environment, and makes environmental magnetism an effective tool in the characterization of climate and ocean circulation in the past.

The pathways between source area and the spot for deposition has crucial impact over magnetic properties. The oceans are a natural repository for particulate and dissolved materials originated from land weathering, and marine sedimentary sequences are very important to preserve the history of processes that took place over continents and oceans. Therefore, quantitative and qualitative analyses of the magnetic carriers in sediments makes possible to separate magnetic grains in autochthone or allochthonous. Depositional (e.g. transport, source area, selection, reworking) and post-depositional (e.g. compacting, diagenesis, fluid migration) processes are determinant during building of sedimentary sequences. The classification of marine sediments is based on different criteria, like source area, grains size, chemical characteristics of its constituents, minerals assembly, etc. Considering its source area and mineralogical composition, marine sediments can be divided in: lithogenic, which are detrital particles transported to the oceans and classified as terrigenous or volcanogenic; biogenics, the ones 
formed by organisms or by shell accumulation; autigenic, that precipitate direct in the solution and cosmogenic, which are not considered in this study (Schulz and Zabel, 2006). The source of magnetic minerals present in a marine sedimentary sequences can be land weathering (primary assembly) or in situ from biogeochemistry processes (secondary assembly), which can erase the primary carriers partially or totally.

The investigation about the properties of magnetic minerals along sedimentary sequences is being widely used in the last decades for paleo-climatic and -oceanographyc studies (e.g. Just et al., 2012a; Kissel et al., 2008). According to Bloemendal et al. (1992), the study of environmental magnetism in marine sediments can be divided in four categories: (i) investigation of origin of NRM to certify the reliability of data for earth magnetic field studies; (ii) the use of techniques for rock magnetism to investigate about diagenesis and magnetic minerals formation; (iii) study of biogenic minerals; and (iv) the use of magnetic properties as an indicator of content variations in terrigenous and for correlation between different cores from the same site. Since eight's, when the first works have been done (Henshaw and Merril, 1980; Thompson and Oldfield, 1986) many techniques of magnetic mineralogy has been developed aiming to characterize the origin of magnetic carriers in rocks and sediments, and better understand the primary magnetisation acquired by these geological material. (Grousset et al., 1993) published the first study using magnetic mineralogy techniques to identify distinct patterns during HE. On this study, the authors analysed the distribution of HE in time and space and they found significant differences between magnetic susceptibility for cores inside and outside of Ruddiman Belt. Susceptibility peaks were attributed to high abundance of detrital material from melting icebergs. Magnetic parameters have been useful in sediments that covers the Marine Isotope Stage 3 (MIS 3) due to some geochronological problems inherent to this period (e.g. Spötl et al., 2006). An example for that is the correlation between susceptibility and ARM with $\delta^{18} \mathrm{O}$ data from foraminifer shells, in which Kissel et al. (1999) identified four HE during MIS 3. Magnetic particles can be transported by deep currents and thus, magnetic parameters provide clues about ocean circulation. Kissel et al. (2008) used ARM oscillations to track the pathway of the North Atlantic Deep Water (NADW) and infer about strength of the convective process and deep water formation. These authors studied also the link between NADW strength and climate changes of short term.

The use of environmental magnetism pointed previously, has shown effectiveness in studies about paleo-climate and -oceanography, and sediment source/transport. Thus, we make use 
here of the parameters presented in sub-chapter 3.2 (Rock magnetism) aiming to understand past environmental processes that took place in our study sites. In addition to these magnetic parameters, with the purpose of better understand climate changes, we use $\mathrm{Fe} / \kappa$ ratio, which is useful to check the proportion of Fe bulk regarding the ferromagnetic contribution. According to Razik et al. (2013), in sediments that does not show signal of diagenetic magnetite dissolution, $\mathrm{Fe} / \mathrm{\kappa}$ ratio can be used as a tool to track changes in sediment source and weathering conditions. Thereby, this ratio bring forth also some evidence about the presence of hematite/goethite concerning magnetite grains. 


\section{NE BraZIL - Study Area}

\subsection{Geomorphology of the continental shelf, rivers supply and geology}

The Northeast Coast is about $3300 \mathrm{~km}$ long and stretches from latitude $3^{\circ}$ to $13^{\circ} \mathrm{S}$ between the Parnaíba River to the west and the São Roque Cape to the east (Figure 5.1). It has a complex geomorphology as result of pre-Cenozoic geological structuring and morphoclimatic evolution, combined with climatic and eustatic fluctuations that took place during the Pleistocene (Gomes and Vital, 2010; Vital et al., 2010b; Vital et al., 2008). The continental shelf off NE Brazil is narrow (40 km width), and dominated by biogenic carbonates sedimentation (Vital et al., 2010ba). Its shelf break was defined by the same authors at about 70-80 $\mathrm{m}$ around Touros High (Figure 5.1), with smaller values (40-50 m) westwards. Based on its complex geomorphology, and on sedimentological and bathymetric data, Gomes and Vital (2010) and Gomes et al. (2014) divided the continental shelf off NE Brazil into three sectors with different gradients: inner, from 0-15 m (1:1400); middle, from 15-25 m (1:1000); and outer, from 25-40 m (1:250). In the boundary between middle and outer shelves, Gomes and Vital (2010) identified an extensive line marked by old beach rocks. Towards the open sea, steep gradient was found in the continental slope, with 1:4 at the upper slope above $300 \mathrm{~m}$ depth, and 1:11 below $300 \mathrm{~m}$ (Gomes et al., 2014). Moreover, important incised-valley systems draw up the margin off NE Brazil. These channels reflect the presence of relevant rivers that reached the break of the present day continental shelf and deposited sediments directly into the outer continental shelf, like incisedvalley system of Piranhas-Açu River (Vital et al., 2010b) and estuary-incised valley system of Apodi-Mossoró River (Vital et al., 2010a). 


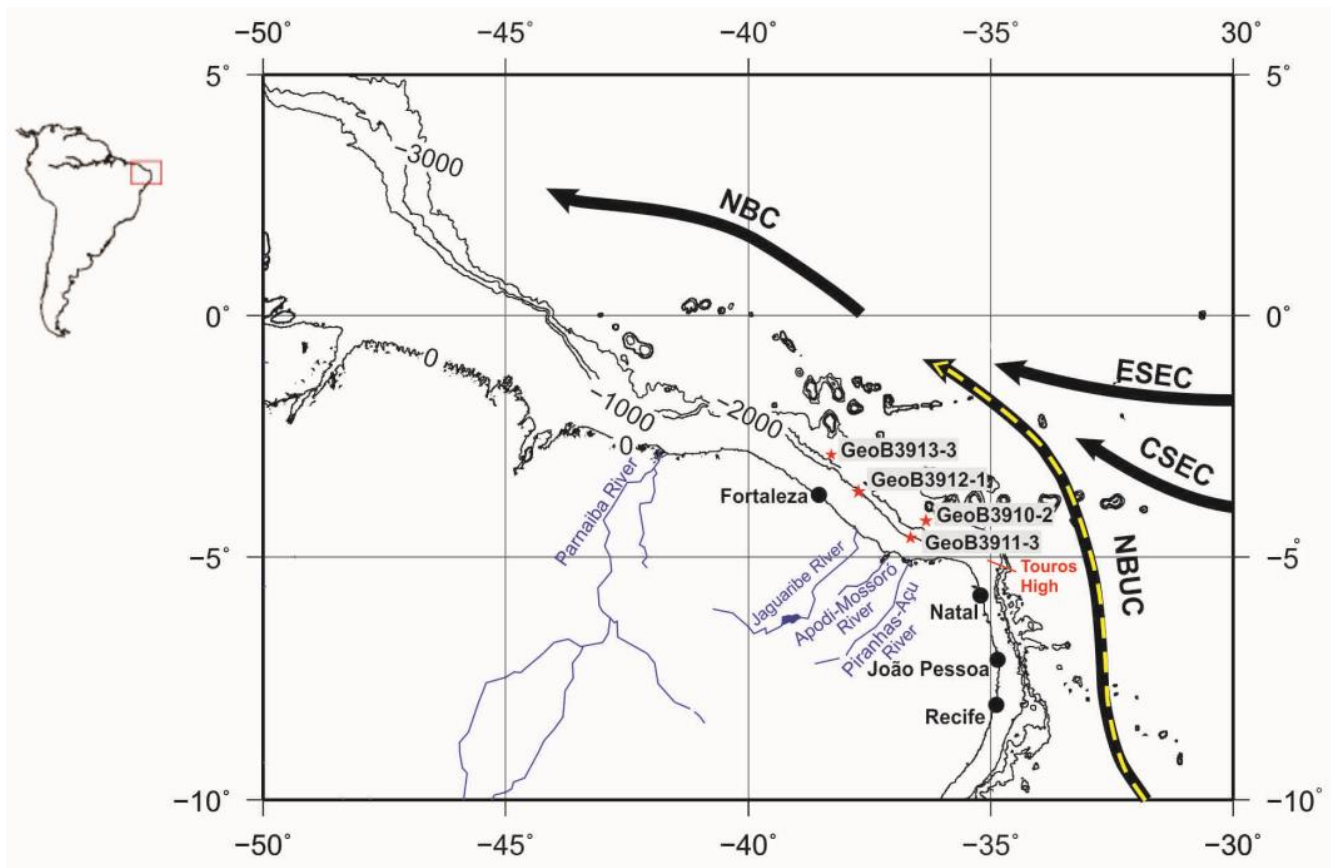

Figure 5.1: Location of the studied cores in the margin off NE Brazil. The arrows are a schematic representation of the layers 0-100 m (central and equatorial branches of the SEC and NBC), 100-500 m (SEC, NBUC and NBC) and 500-1200 $\mathrm{m}$ (NBC and EIC (flowing at about $\left.0^{\circ} \mathrm{S}\right)$.

Among the rivers that debouch into NE Brazilian continental shelf, the Parnaíba River represents the second most important hydrographic region, embracing an area of $333.056 \mathrm{~km}^{2}$ (3.9\% of the Brazilian territory). According to the National Water Agency of Brazil (ANA, 2014), the Parnaíba River is $1400 \mathrm{~km}$ long and drains $99 \%$ of Piauí State. To the east, the Jaguaribe River is the main terrigenous supplier to the continental shelf adjacent to Ceará State (Figure 5.1). It is responsible for about $50 \%$ of the total fluvial outflow to this adjacent region (Dias et al., 2013). The drainage basin of Jaguaribe River covers an area of $75.669 \mathrm{~km}^{2}$ and its extension is about $610 \mathrm{~km}$ (Gatto et al., 1999). Further east, the Piranhas-Açu and the ApodiMossoró Rivers also debouch in the continental shelf off NE Brazil. Their drainage basins are quite smaller than Parnaiba's one, but geomorphological studies performed in the adjacent margin have showed that the presence of important submarine channels cutting the continental shelf, suggesting their importance in the past (Gomes et al., 2014; Vital et al., 2010a). ApodiMossoró drainage basin occupies an area of $14.276 \mathrm{~km}^{2}$, totalling a volume of 469.714 .600 $\mathrm{km}^{3}$, and the geology over its course is divided in $6.500 \mathrm{~km}^{2}$ of crystalline rocks to the south and $4.500 \mathrm{~km}^{2}$ of sediments to the north (Souza et al., 2012). The drainage basin of Piranhas- 
Açu River, to the east, embraces an area of $43.681 .5 \mathrm{~km}^{2}$, and along its course the main soil units are neosol, vertisol and argisol (ANA, 2010).

Geological domains of NE Brazil change dramatically from west to east. The western domain comprises essentially the Paleozoic to Cenozoic sediments of the Parnaíba basin (dark green, Figure 5.2). The eastern sector correspond to the Borborema Province (red, Figure 5.2), a crystalline basement constituted of Precambrian igneous and metamorphic rocks with granitic intrusions and patches of Cretaceous basaltic flows and dykes (Meju et al., 1999; Oliveira and Medeiros, 2012). The magnetic inventory of basement rocks and granites comprise essentially coarse-grained multi-domain magnetite (Archanjo et al., 2002), whereas the mafic dikes on the eastern part of Borborema Province contain mainly single-domain (SD) and multi-domain (MD) (titano)magnetite (Knesel et al., 2011; Trindade et al., 2006). Soils in the area are highly weathered and enriched in Fe-oxides hematite and goethite (Roud, 2014). In NE Brazil chromic luvisols are common; in the Parnaiba basin red and yellow ferrasols and (ferralic) arenosols are the dominant soil groups (WRB, 2006). A global data compilation of soil mineralogy from Journet et al. (2014) suggests generally high abundance of goethite with concentrations above $5 \%$ in the Parnaiba Basin and lower concentrations of 2-3\% in most areas of the Borborema Province. In contrast, hematite is less abundant in large parts of the Parnaiba Basin (concentrations below 1\%) and higher (between 1-5 \%) in the Borborema Province and at the eastern border of the Parnaiba Basin (Journet et al., 2014). 


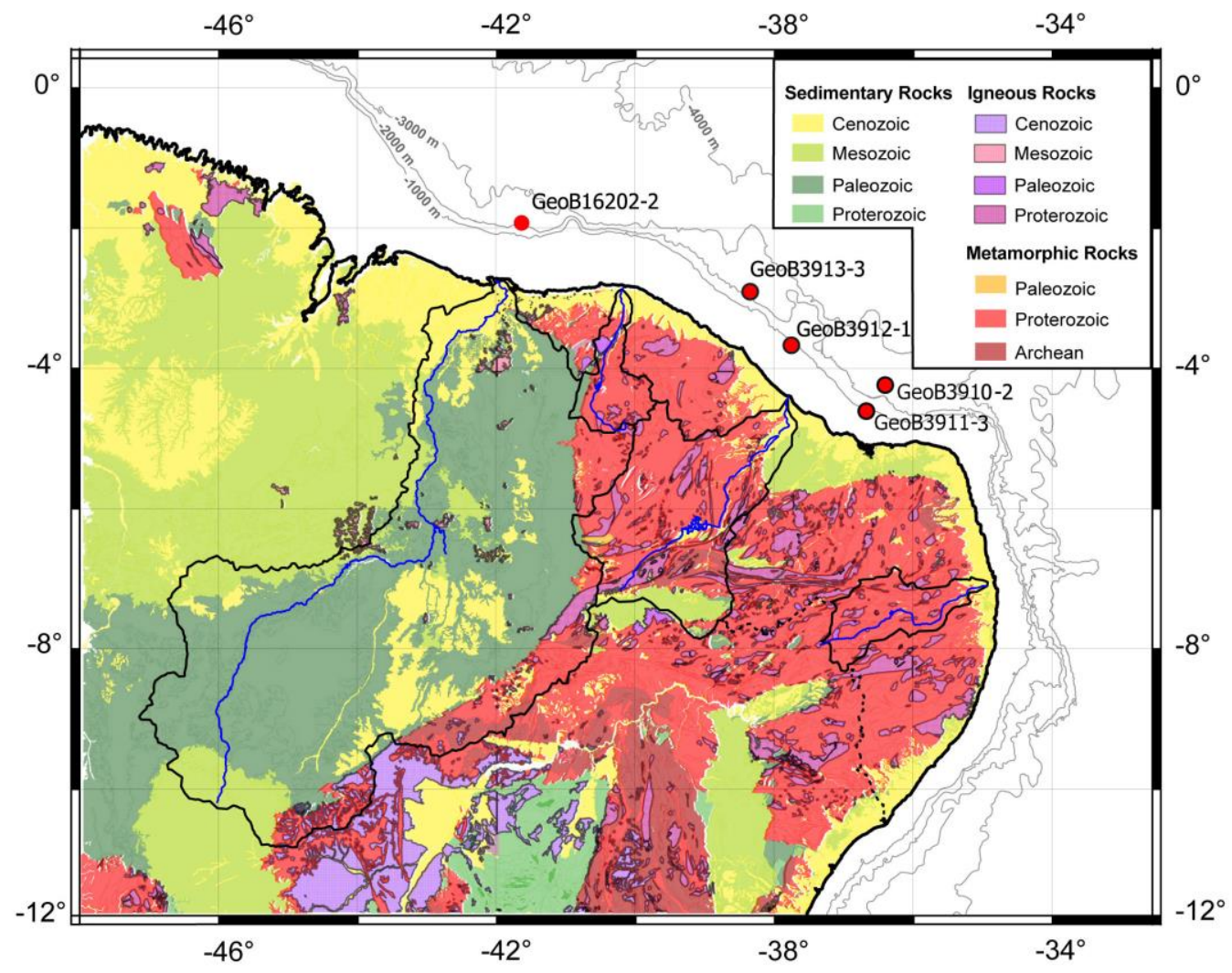

Figure 5.2: Geological map of NE Brazil. Light and dark green areas correspond to Parnaíba Basin, and pink and red ones are the Borborema Province. Modified from Roud (2014).

\subsection{Oceanographic and Climatologic settings}

\subsubsection{Oceanic Currents}

Narrow and open to sea, the NE Brazilian continental shelf is a typical example of passive margin governed by western boundary currents with extreme oligotrophic character (Knoppers et al., 1999; Vital et al., 2010b). The highly complex current circulation of the equatorial Atlantic comprises mainly the water transport from east to west by the North Brazilian Current (NBC) in surface waters and a southward transport driven by the Deep Western Boundary Current (DWBC; Figure 5.1). The NBC is a strong, up to $300 \mathrm{~km}$ wide, northwestward flowing surface current. It is one of the main water flows that cross the equator and is the major source of warm water transfer from the Southern to the Northern hemisphere (Knoppers et al., 1999; Stramma and England, 1999). Still according to the same authors, it is formed by the merging of equatorial and central branches of the South Equatorial Current (ESEC and CSEC, respectively) with the southerly North Brazilian Under Current (NBUC; Figure 5.1). 


\subsubsection{Sea-level}

Differences in the sea-level position along the time result from changes in the volume and shape of the oceans, redistribution of water within the oceans, and to local vertical movement along the coast (Fleming et al., 1998). These three factors operate at different temporal and spatial scales. Redistribution of water during glacial cycles has regional and global influence, and a time scale between $10^{3}$ and $10^{5}$ years (Fleming et al., 1998). Reconstruction of eustatic sealevel curves takes into account ice distribution, considering contribution from glacio- and hydro-isostatic components and estimate sea-level curves for places close or distant from ice sheets. Aiming to show a realistic sea-level curve to represent transgression after the termination of the last glacial cycle, we used the eustatic curve from Fleming et al. (1998), which used data from intermediate and low latitudes, including two sites close to our study area: Jamaica and Barbados. Their data show a gradual increase in sea-level during the last $20 \mathrm{kyr}$ BP (Figure 5.3). Sea-level for Barbados (dark blue dots) at about $18 \mathrm{kyr}$ BP is about $120 \mathrm{~m}$ below the present-day position. In Jamaica (light green dots), the sea-level was about $10 \mathrm{~m}$ below present-day, and kept increasing up to mid-Holocene, when it increases slightly up to the present position.

During the last $20 \mathrm{kyr} \mathrm{BP}$, changes in relative sea-level are a response to the transition from glacial to interglacial stages (Milne et al., 2005). A Holocene curve constructed from observations from many sites along the Atlantic margin off South America and the Caribbean Sea (Figure 5.4), shows a fast increase in sea-level between 8 and 7 kyr BP (Milne et al., 2005). Since 7 kyr BP, sea-level varied much less (Fleming et al., 1998). Spatial variations of sea-level along the Atlantic margin off South America where attributed to ice and ocean mass redistribution along the last $10 \mathrm{kyr} \mathrm{BP}$ (Milne et al., 2005). 


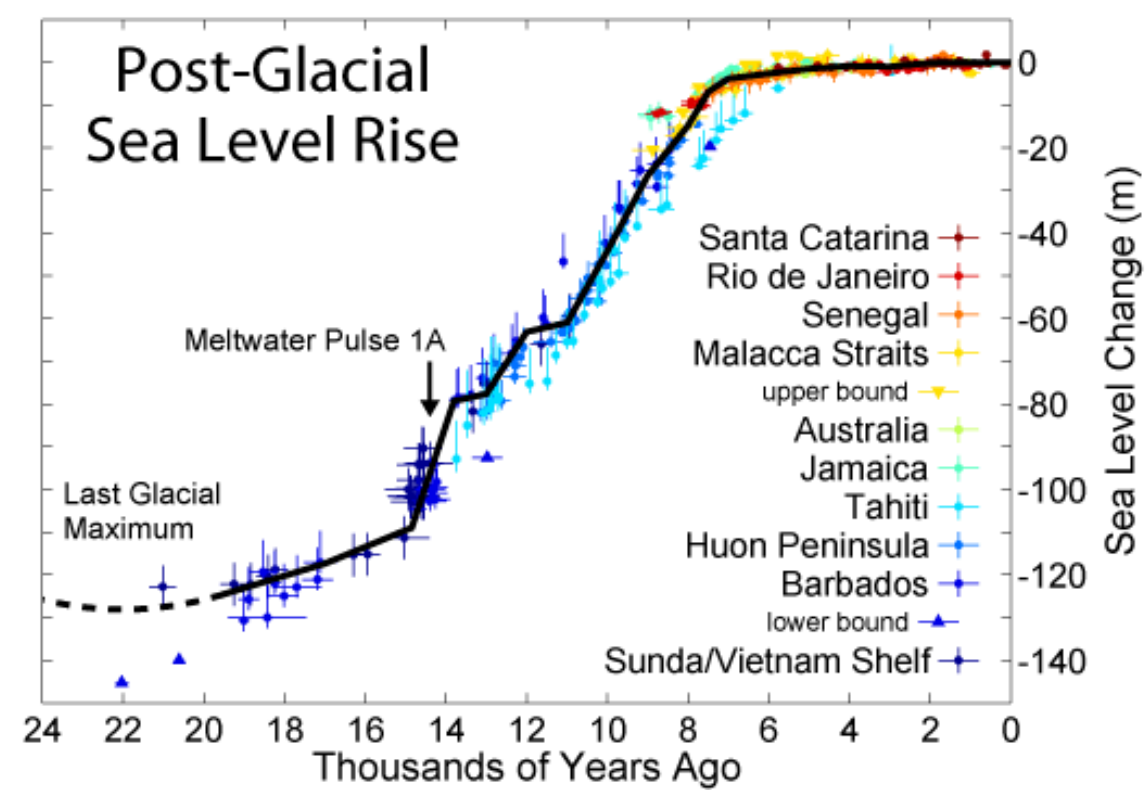

Figure 5.3: Sea-level evolution since the Last Glacial Maximum. Modified from Fleming et al. (1998).

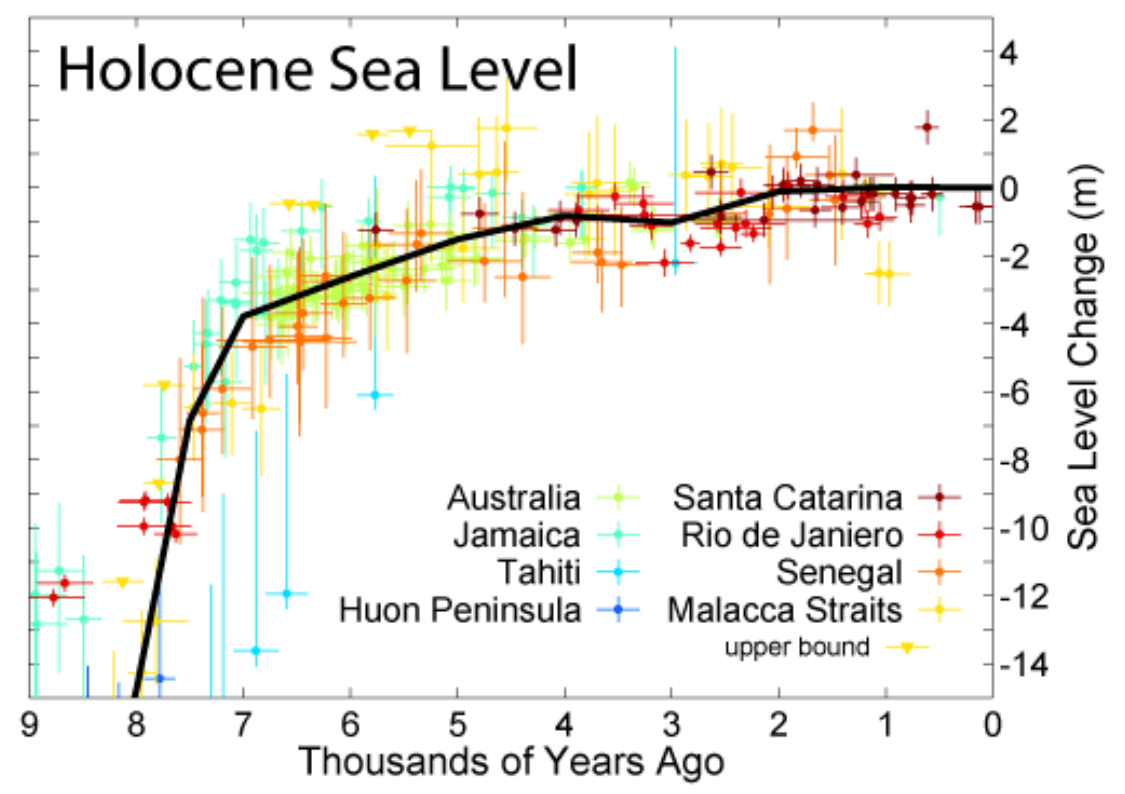

Figure 5.4: Sea-level observations from sites in the Atlantic margin off South America and the Caribbean Sea. Modified from Milne et al. (2005).

\subsubsection{Climate}

In the eastern part of NE Brazil region, the semi-arid climate dominates and "caatinga" vegetation prevails. In addition to the semi-arid climate, the region also presents tropical climate 
in its more western portion. This region experiences between 4-5 months of dry weather (no rain), whilst in the "caatinga" region the dry season can reach six month. The annual mean precipitation over NE Brazil is only a third of the inland values at the same latitude, restricted to austral fall (Nobre and Shukla, 1996). Seasonal changes in the rain regime on this region are widely controlled by the latitudinal displacement of the ITCZ and its displacement southward during austral summer brings forth rainy season in NE Brazil (Garreaud et al., 2009). The ITCZ is a belt of minimum pressure and low-level convergence of the trade winds over the equatorial oceans, and its meridional shift determines the seasonality, intensity and spatial distribution of precipitation throughout the tropics (Garreaud et al., 2009).

\subsection{Core sites and Lithology}

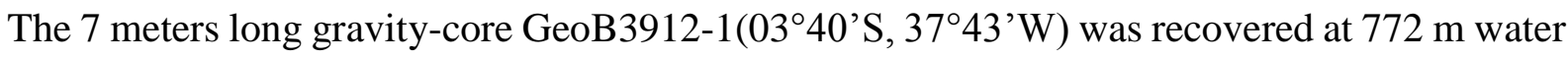
depth (Figure 5.1) and its uppermost part (top $200 \mathrm{~cm}$ ) consists of yellowish brown foraminiferal nannofossil ooze. Below, alternating sections of olive gray and very dark gray sediment occurs, indicating fluctuations in terrigenous and marine (nannofossil) components. Over the whole core length, and especially the lower part, the sediment is bioturbated (Fischer et al., 1996). Core GeoB3913-3 (253,8' S 38 $\left.18,5^{\prime} \mathrm{W}\right)$ is also a gravity core, with 6.45 meters length and recovered from $2288 \mathrm{~m}$ water depth. Its location is to the most west of the study area. In the upper half, core GeoB3913-3 is composed predominantly of strongly bioturbated, light olive brown to gray foraminiferal nannofossil ooze. From 300 to $350 \mathrm{~cm}$ two graded beds with foraminiferal sands at the base and below, down to $525 \mathrm{~cm}$, the layers are tilted by $30^{\circ}$ and are marked by nannofossil ooze with slightly enhanced clay content. From $525 \mathrm{~cm}$ to the end of the core the sediment consists of gray to greenish gray nannofossil ooze with varying content of foraminifera and clay (Fischer et al., 1996). In the east portion of the study area, two gravity cores were analysed. The $693 \mathrm{~cm}$ length gravity core GeoB3910-2 (4 $\left.14,7^{\prime} \mathrm{S} 36^{\circ} 20,7^{\prime} \mathrm{W}\right)$ was collected from the continental slope, at $2362 \mathrm{~m}$ water depth. It is composed of yellowish brown coloured foraminiferal nannofossil ooze in the top $30 \mathrm{~cm}$ and below it consists of grayish clayey nannofossil ooze. In the top $250 \mathrm{~cm}$ interdigitated layers of Fe-oxyhydroxides with 2-3 mm thick were found. The last $50 \mathrm{~cm}$ show disturbed sediments, with shell fragmente in the bottom end (Fischer et al., 1996). The 685 cm-long core GeoB3911-3 (4³6,8' S 36³8,4' W) was recovered from $828 \mathrm{~m}$ water depth and consists of light brownish foraminiferal nannofossil 
ooze on its upper $50 \mathrm{~cm}$. Between 200 and $460 \mathrm{~cm}$ there is an increasing content of terrigenous silt and clay with the sediment color turning to almost black. At about $460 \mathrm{~cm}$ and at the bottom end of the core layers with slightly increased content of nannofossils occur. The core is overall slightly bioturbated (Fischer et al., 1996). The previously mentioned cores were recovered during the METEOR-Cruise M 34/4.

\subsection{Material and methods}

\subsubsection{Geochronology}

The age model for core GeoB3912-1 for the last 40,000 yr was obtained from 12 calibrated radiocarbon accelerator mass spectrometry (AMS) ages from planktonic foraminiferal tests of Globigerinoides sacculifer. For ages bigger than 40,000 $\mathrm{yr}$ it was used three SPECMAP age control points (for detail see Arz et al., 1998). The ages of the top most part of the core were correlated with AMS ages of another core (GeoB3104-1) recovered from the same site in a previous cruise. To estimate the ages for core GeoB3913-3 we have made a correlation with the timescale of core GeoB3912-1. Based on the Fe/Ca ratio, we stablished 76 tie points for correlation between ages and depth (Annex I). For so, we used the software Bremen correlator, built by F. Thomas, using National Instruments LabView facilities. Dating for core GeoB39102 is based on 20 AMS radiocarbon ages, mainly monospecific samples of Globigerinoides sacculifer (for detail see Jaeschke et al., 2007). The stratigraphic framework of core GeoB3911-

3 is exclusively based on reservoir-corrected, U/Th-calibrated, and linearly interpolated ${ }^{14} \mathrm{C}$ ages (H. W. Arz et al., 1999). For the four cores a global time-dependent ocean reservoir correction of about 400 years was used.

\subsubsection{Magnetic minerals characterization}

For magnetic measurements we sampled the cores GeoB3913-3, GeoB3912-1, GeoB3911-3 and GeoB3910-2 in $5 \mathrm{~cm}$ intervals, using $6,2 \mathrm{~cm}^{3}$ plastic cubes.

The volume magnetic susceptibility ( $\kappa$ ) for cores GeoB3913-3, GeoB3912-1 and GeoB3911-3 was measured at each centimetre using a Bartington M.S.2 susceptometer for discrete samples. Aiming to obtain the frequent dependent susceptibility, we performed in the cores from $\mathrm{NE}$ 
Brazil (GeoB-3911-3, GeoB3912-1 and GeoB3913-3) and it involves frequencies values of $0.465 \mathrm{kHz}$ (Low Frequency) and $4.65 \mathrm{kHz}$ (High Frequency) $\pm 1 \%$. We obtained the susceptibility using average value from three measurements intercalated with measurements of the empty space in order to minimize the errors related with the low sensibility of the equipment. For core GeoB3910-2 the volume magnetic susceptibility was measured in 694 data points using a Multi-Sensor Core Logger device, at a measurements frequency of $920 \mathrm{~Hz}$ with a 125 mm loop sensor and a non-magnetic core conveyor system (Fischer et al., 1996).

The natural remanent magnetisation (NRM) of the sediment, anhysteretic remanent magnetisation (ARM) and isothermal remanent magnetisation (IRM) were obtained step-bystep using a $2 \mathrm{G}$ u-channel cryogenic magnetometer $755 \mathrm{R}$ at the Department of Geosciences (FB5), University of Bremen (for details, please see annex II). The ARM is a magnetisation obtained from applying an alternated field (AF) on the magnetic material simultaneously to a low intensity (0.5-1 mT) direct field (DC; Evans and Heller, 2003). It provides a parameter efficient in the identification of fine magnetite (e.g. Thompson and Oldfield, 1986). In this work, we used an axial bias field of $0.05 \mathrm{mT}$. The IRM is acquired imparting high intensity fields under constant temperature - in this work we used room temperature, about $23-25^{\circ}$. It permits the identification of magnetic minerals with high coercivity (i.e. hematite). These artificial magnetisations are useful to generate some magnetic ratios for the environmental magnetism study. In combination with the ARM, the IRM can be used as a ratio to differentiate between small (single-domain) and large particles (multi-domain), so that high values of ARM/IRM indicates the presence of grains SD. Relating the IRM in different magnetisation steps with the SIRM parameter is useful to track proportional changes in the coercivity of the magnetic minerals. In this work we obtained the Hard-IRM (HIRM; [SIRM-IRM-300mT]) and the S-Ratio ([IRM $\left.\left.300 \mathrm{mT} / \mathrm{IRM}_{2700 \mathrm{mT}}\right]\right)$ according to Stoner et al. (1996) and Rowan et al. (2009), respectively. The S-Ratio is very effective in detecting proportional amounts of hematite regarding magnetite, even as the HIRM is useful to identify the presence of high coercivity magnetic minerals.

Hysteresis loops were obtained in the PMC Alternating Gradient Magnetometer MicroMag 2900 at the Department of Geosciences (FB5), University of Bremen. Low (0.3T/-0.3T) and high (1 T/ $-1 \mathrm{~T})$ fields were used, with increment of $5 \times 10^{-3} \mathrm{mT}$. Backfield and high field measurements were also made to obtain parameters Ms, Mrs, Bc and Bcr. All measurements were performed in room temperature $\left(\sim 23^{\circ} \mathrm{C}\right)$. A total 12 samples were measured. They were 
prepared in the form of spheres with about 3-4 mm diameter and $20 \mathrm{mg}$ weight using a special non-magnetic glue.

Low temperature measurements were performed in the Quantum Design Magnetic Properties Measurement System MPMS-XL7 at the Department of Geosciences (FB5), University of Bremen. Temperature ranges from 1.9 up to $400 \mathrm{~K}$ and DC fields vary between plus or minus 7 T. We ran five samples in strategic depths along the core GeoB3912-1. The samples were prepared in gel caps with $5 \mathrm{~mm}$ in diameter and $9 \mathrm{~mm}$ in length. We performed magnetic hysteresis loops in room temperature $(300 \mathrm{~K})$ and in low temperature $(5 \mathrm{~K})$, field-cooling $(\mathrm{FC})$ and zero field-cooling (ZFC) curves, SIRM warming curves (300-400 K) and SIRM cooling/warming (0-300 K). Please find in Annex II the detailed protocols used in our samples, including the steps performed during acquisition and demagnetisation of each remanent magnetisation adopted.

\subsubsection{X-Ray Fluorescence (XRF) scanning}

Towards a better understanding of the weathering processes that took place during enhanced rainfall in NE Brazil, we performed XRF scanning on cores GeoB3911-3, GeoB3912-1 and GeoB3913-3. XFR measurements were performed with spectrum operating at $10 \mathrm{kV}$ for detecting major elements (i.e. $\mathrm{Fe}, \mathrm{Ca}, \mathrm{Ti}$ ), and with $30 \mathrm{kV}$ spectrum in order to obtain trace elements data (i.e. $\mathrm{Ni}, \mathrm{Cu}, \mathrm{Zn}$ ). We scanned entire sections of the cores GeoB3913-3, GeoB3912-1 and GeoB3911-3 at high resolution $(1 \mathrm{~cm})$ with a down-core slit size of $10 \mathrm{~mm}$ at the split surface of the archive half with XRF Core Scanner III (AVAATECH Serial No. 12) at the Center for Marine Environmental Sciences (MARUM), University of Bremen. In cores GeoB3913-3 and GeoB3911-3, we performed the XRF scanning using both spectrum ranges and obtained trace and major elements data. For core GeoB3912-1 we used the previously measured data, with a $2 \mathrm{~cm}$ resolution (Arz et al., 1998). The elements Ti, Fe, Si, K, Ca, Al were measured using X-ray tube settings of $10 \mathrm{kV}$, a current of $0.2 \mathrm{~mA}$, and a sampling time of 20 seconds. Chemical data for core GeoB3910-2 was obtained previously at intervals of $0.4 \mathrm{~cm}$ for elements K, Ca, Ti and Fe (for details see Jaeschke et al., 2007).

Major elements (Al, K, Si, Fe, Ti) measurements from cores will be helpful in elucidating about the differences between soil contributions from the drainage basins of local rivers (Jaguaribe, Apodi-Mossoró and Piranhas-Açu). Chemical data from bulk sediment is a semi-quantitative 
method (Weltje and Tjallingii, 2008), so here we used elemental ratios rather than direct counts. Either way, we compare only the trend of the different curves, not the absolute values. Moreover, other problems may affect the single-element concentration, as dilution processes (Govin et al., 2012), and according to Weltje and Tjallingii (2008) elemental ratios are insensitive to dilution effects. In this work, we used the ratios $\mathrm{Fe} / \mathrm{Ca}, \mathrm{Al} / \mathrm{Si}, \mathrm{Fe} / \mathrm{K}, \mathrm{Ti} / \mathrm{Al}$ and $\mathrm{Ti} / \mathrm{Fe}$.

Aiming to check the presence of possible slumps we used a line-scan camera linked to the Super-Slit XRF-core scanner we obtained digital image for the cores GeoB3913-3, GeoB39122 and GeoB3911-3. The camera is a color line scan 3 CCD device using 3 x 2048 pixel CCD arrays and a beam-splitter. As we observed lamination along the three cores we will not show the data here.

\subsubsection{End-member analysis}

We obtained IRM acquisition curves, cumulative coercivity distributions of the integral magnetic mineral assemblage using an in-line pulse magnetizer and an external pulse magnetizer (Automated 2G Superconducting Rock Magnetometer 755 R) with 30 steps up to $2700 \mathrm{mT}$ using the device from the Center for Marine Environmental Sciences (MARUM), in the Bremen University. Were obtained 138 IRM acquisition curves for core GeoB3910-2, 68 for core GeoB3911-3, 134 curves for core GeoB3912-1 and 109 curves for core GeoB3913-3. We applied a combined end-member (EM) unmixing analysis to 449 IRM acquisition curves aiming to separate the different magnetic contributions according to distinct coercivities. Using the distinct magnetic coercivities of the mixed assemblages, we applied the unmixing procedure attempting to decompose the magnetic signal into parts representing specific provenances that provide information on different environmental processes. We modelled each magnetic contribution using a linear mixture of cumulative log-Gaussian (CLG) functions to represent independent magnetic coercivity components using a software developed by Heslop and Dillon (2007). After that, we used the IRM-CLG fitting program of Kruiver et al. (2001) to quantifying the magnetic coercivity components present in each end-member. In other words, we took the output from IRM-CLG fitting software, which are "synthetic" IRM acquisition curves, and identified the different types of magnetic minerals. 


\section{Results}

\subsection{Age model}

The time range for core GeoB3912-1 is between 2.44 and 85.1 kyr BP (Figure 6.1b, Annex I). Correlation with core GeoB3912-1 enabled to establish the age model for core GeoB3913-3 (Figure 6.1a, Annex I). This core has smaller temporal resolution, with an average sedimentation rate of $5 \mathrm{~cm} / \mathrm{kyr}$. Hence, from the $6.45 \mathrm{~m}$ long core GeoB3913-3, we used only the topmost $3.5 \mathrm{~m}$, which comprises the time interval between 1.29 and $84.6 \mathrm{kyr}$ BP. Sedimentation rates vary significantly for cores GeoB3913-3 and GeoB3912-1 between 5 $\mathrm{cm} / \mathrm{kyr}$ and $25 \mathrm{~cm} / \mathrm{kyr}$. Intervals of increased sedimentation rates $(\sim 15-25 \mathrm{~cm} / \mathrm{kyr})$ coincide with the climatic events Younger Dryas (YD) and the last eight Heinrich Events (HE). Core GeoB3911-3 has higher average sedimentation rate $(\sim 41 \mathrm{~cm} / \mathrm{kyr})$ with two remarkable peaks between 11.1 and $11.3 \mathrm{kyr} \mathrm{BP}$ and 12.1 and $12.2 \mathrm{kyr} \mathrm{BP}$, when sedimentation rates reach about 200 and $530 \mathrm{~cm} / \mathrm{kyr}$, respectively (Figure 6.1c, Annex I). The temporal range for core GeoB3911-3 comprises the period between 0.43 and $22.3 \mathrm{kyr}$ BP and includes the YD and HS1. The YD coincides with the peak about 11 kyr BP, but the HS1 exhibits lower sedimentation rate of about $57 \mathrm{~cm} / \mathrm{kyr}$. The enhanced sedimentation rate observed at about $12 \mathrm{kyr}$ BP suggests a remarkable terrestrial input, and it was related to Bølling-Allerød. Core GeoB3910-2 (Figure $6.1 \mathrm{~d}$, Annex I) has intermediate average sedimentation value of $9.6 \mathrm{~cm} / \mathrm{kyr}$, with coeval peaks of high sedimentation during the HS. Between 16 and $18 \mathrm{kyr}$ the sedimentation rate showed its higher values (higher than $20 \mathrm{~cm} / \mathrm{kyr}$ ), and intervals of about 1000 years of sedimentation rates higher than $15 \mathrm{~cm} / \mathrm{kyr}$ were found at 47, 43 and $23 \mathrm{kyr}$ BP. The topmost interval, which comprises the Holocene, presents the lowest sedimentation rates for the four cores, with values smaller than $5 \mathrm{~cm} / \mathrm{kyr}$ for cores GeoB3912-1 and GeoB3913-3, and about $11 \mathrm{~cm} / \mathrm{kyr}$ for core GeoB3911-3. Core GeoB3910-2 shows high sedimentation rate in the lower Holocene ( 10 $\mathrm{cm} / \mathrm{kyr}$ ) and smaller values during upper Holocene ( about $4 \mathrm{~cm} / \mathrm{kyr}$ ). It is important to notice that during Holocene the further east cores GeoB3911-3 and GeoB3910-2 exhibits gradually higher sedimentation rates than cores in the west, but during Pleistocene this trend does not apply to core GeoB3910-2, which shows sedimentation rate smaller than core GeoB3913-3 and higher than GeoB3912-1. 


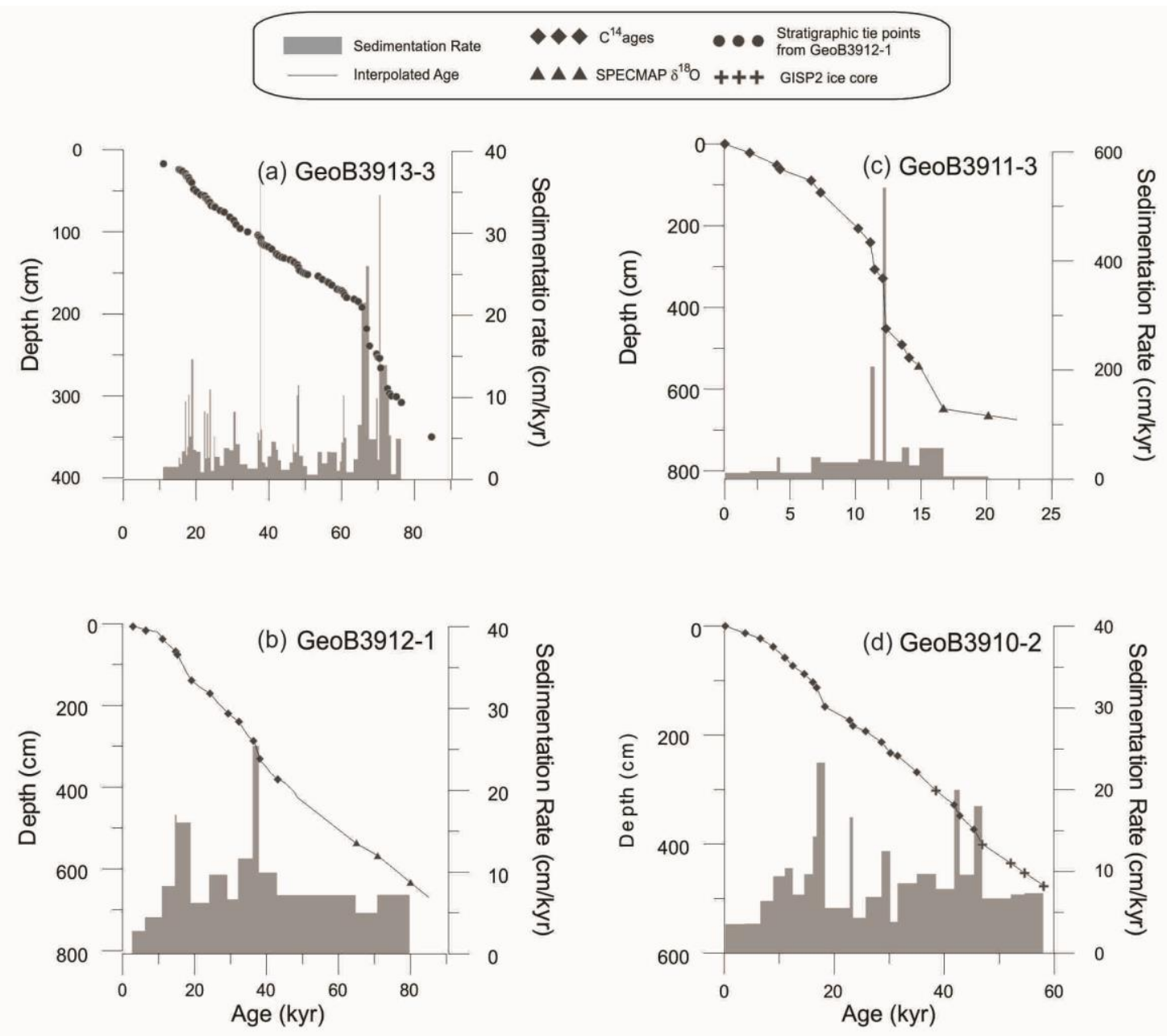

Figure 6.1: Age model (black curves) and sedimentation rate (gray step plots) for cores (a) GeoB3913-3, (b) GeoB3912-1, (c) GeoB391-3 and (d) GeoB3910-2. Diamonds represent calibrated ${ }^{14} \mathrm{C}$ ages, circles represent stratigraphic correlation tie points (GeoB3913-3 was correlated with GeoB3912-1), triangles show SPECMAP $\delta^{18} \mathrm{O}$ (GeoB3912-1 and GeoB3911-3) and crosses represent GISP2 ice core correlation (GeoB3910-2).

\subsection{Downcore Magnetic parameters}

The most significant features we can observe in the rock magnetic parameters for cores GeoB3913-3, GeoB3912-1, GeoB3911-3 and GeoB3910-2 are the remarkable changes in the ferromagnetic content related to the abrupt climate changes, which were related to HE and YD (Figure 6.2 - Figure 6.5). In our four cores, these abrupt events are well defined and magnetic parameters tells us about changes in the concentration, type and size of the magnetic minerals in such periods. Rock magnetic data is in annex III, and is available also in editable format in the digital media. 


\section{Core GeoB3913-3}

All concentration dependent parameters - magnetic susceptibility ( $\kappa), \mathrm{IRM}_{300 \mathrm{mT}}$ and HIRM show baseline values during Pleistocene higher than in Holocene. These are the main recorders for terrestrial input in our cores, and tell us how drastically it dropped during Holocene (Figure 6.2a, b and d). Especially for core GeoB3913-3, this drop happens thousands of years before the inset of Holocene, just after the end of HS1. During YD we does not observe increase in the concentration dependent parameters for this core. The ratio $\mathrm{ARM}_{100 \mathrm{mT}} / \mathrm{IRM}_{100 \mathrm{mT}}$ is useful in identifying changes in the grain size of the magnetic fraction comprised by (titano)magnetite.

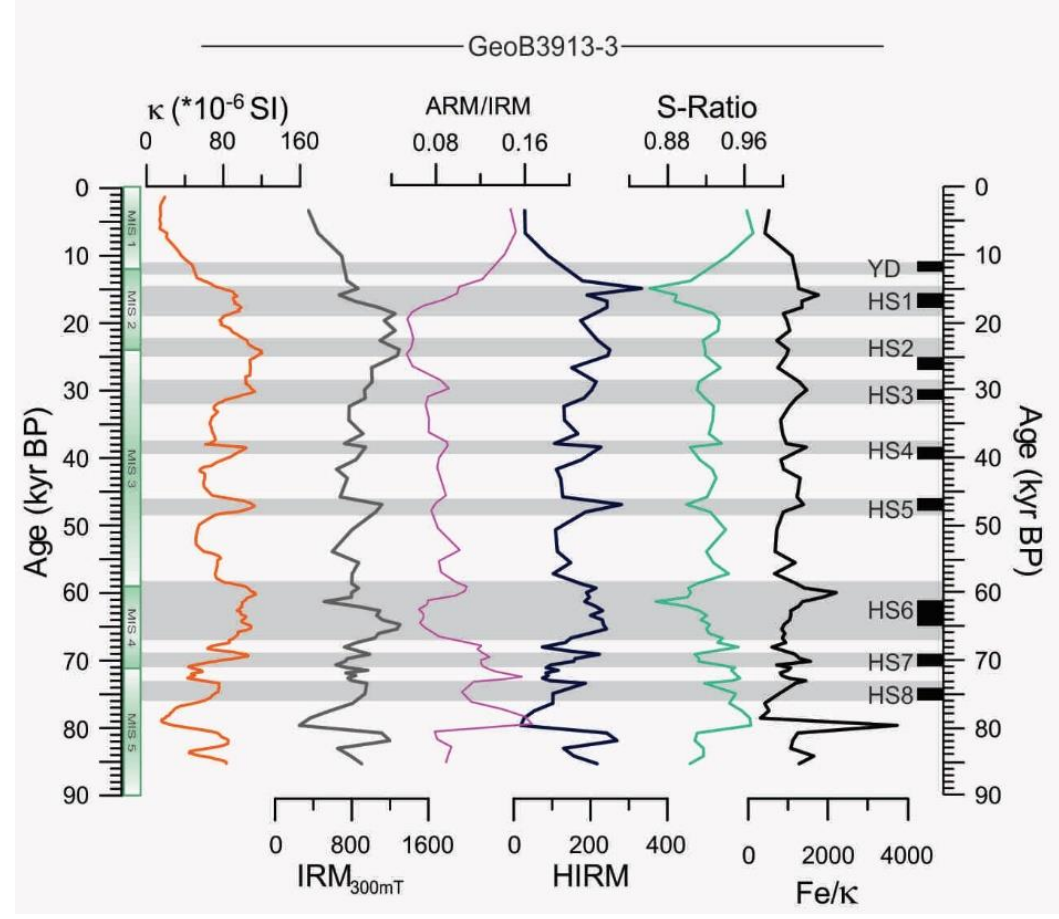

Figure 6.2: Rock magnetic parameters for core GeoB3913-3. Greyish areas mark the Heinrich Stadials (HS) that we matched with Younger Dryas (YD, Fairbanks, 1989) and Heinrich Events (H6 to H8, McManus et al., 1994; H1 to H5, Vidal et al., 1997), represented by the black squares. Greenish areas show the Marine Isotope Stages (Sarnthein et al., 2001).

Changes in $\mathrm{ARM}_{100 \mathrm{mT}} / \mathrm{IRM}_{100 \mathrm{mT}}$ suggest a coarsening trend (MD-like behavior) before to 50 kys BP, during HS6, HS7 and HS8, but for late HS and YD there is a gradual increase, suggesting the prevalence of fine-grained magnetite (Figure 6.2c). In addition to the use of HIRM to detect changes in the concentration of the ferromagnetic particles, together with SRatio, this parameter track variation in the types of magnetic minerals concerning their 
coercivity. S-Ratio decreases and HIRM increases during HS, suggesting the presence of high coercivity minerals (Figure 6.2d and e). Along the Pleistocene, the Fe/ $\kappa$ ratio shows peaks during the YD and HS events, reflecting a more remarkable increment in the bulk iron contribution related to the ferromagnetic contribution (Figure 6.2f). Up to the first half Holocene, we can see gradually small values of $\mathrm{Fe} / \kappa$ ratio.

\section{Core GeoB3912-1}

Likewise, abrupt climate events are well marked by concentration dependent parameters in core GeoB3912-1 (Figure 6.3a, b and d). The parameters $\kappa$ and HIRM decrease significantly up to middle Holocene; however, $\mathrm{IRM}_{300 \mathrm{mT}}$, differently to the other concentration dependent parameters, reaches higher values. The parameter IRM $\mathrm{I}_{300 \mathrm{mT}}$ is effective to verify changes in the concentration of magnetic minerals, but in second instance, it is a grain size dependent. Thus, here it suggests the presence of fine-grained magnetite in late Holocene. The parameter $\mathrm{ARM}_{100 \mathrm{mT}} / \mathrm{IRM}_{100 \mathrm{mT}}$ shows a coarsening of the magnetic fractions during all $\mathrm{HS}$, and especially during Holocene, it reaches the highest values, suggesting the dominance of MD grains (Figure 6.3c). S-Ratio and HIRM also here suggest the presence of high coercivity minerals during HS, yet during Holocene, low/high values of HIRM/S-Ratio reflects the presence of less coercive phases (Figure 6.3d and e). Fe/ $\kappa$ ratio along this core exhibits sharper peaks, marking very well the inset of the HS, and just after YD it drops gradually and reaches smaller baseline values.

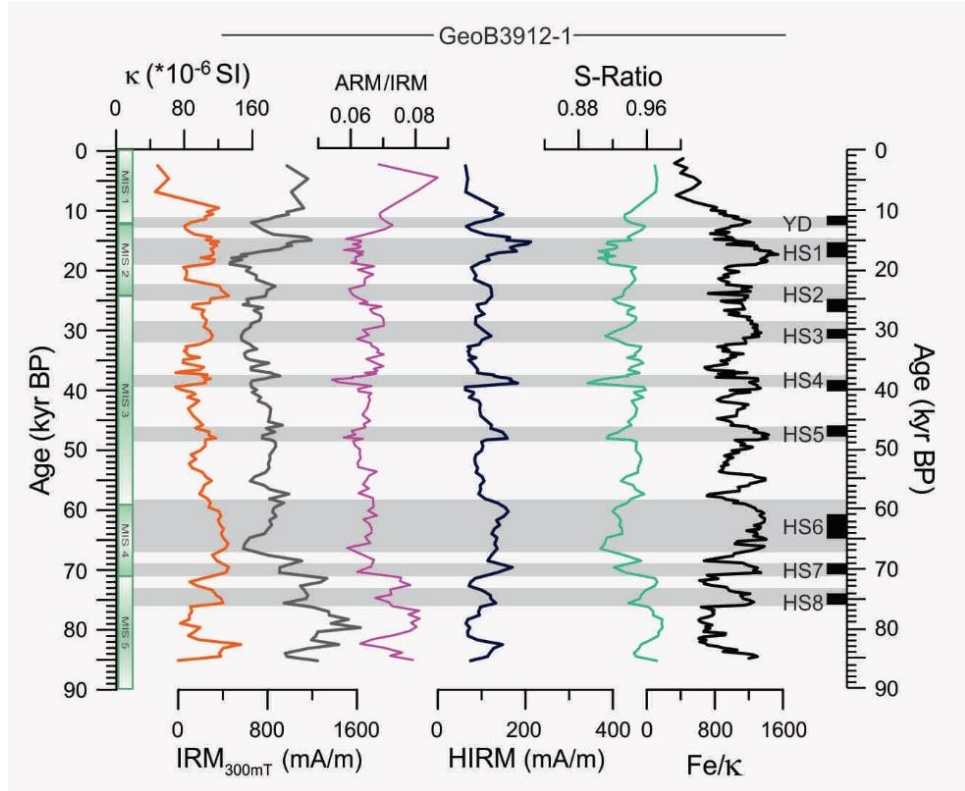

Figure 6.3: Rock magnetic parameters for core GeoB3912-1 (for details see subtitle in Figure 6.2). 


\section{Core GeoB3911-3}

Differently to the other cores, concentration dependent parameters ( $\kappa, \mathrm{IRM}_{300 \mathrm{mT}}$ and HIRM) here present significant drops in the upper part of HS1 and during YD (Figure 6.4a, b and d). It suggests that diagenetic dissolution of magnetite took place in this core. Grain size dependent parameters $\left(\mathrm{IRM}_{300 \mathrm{mT}}\right.$ and $\left.\mathrm{ARM}_{100 \mathrm{mT}} / \mathrm{IRM}_{100 \mathrm{mT}}\right)$ also goes to small values in the upper part of HS1 and during YD, confirming a lost in the primary magnetic content at these depths. Between YD and HS1, the presence of SD-like magnetite is suggested by $\mathrm{ARM}_{100 \mathrm{mT}} / \mathrm{IRM}_{100 \mathrm{mT}}$ ratio (Figure 6.4c). In addition, high values of HIRM were observed during warm period over North Atlantic region Bølling-Allerød (B-A), just before the inset of $\mathrm{YD}$, and suggests the increase in the concentration of magnetic particles. High values of $\mathrm{Fe} / \kappa$ parameter are not source indicator during the abrupt climate events, due the diagenetic processes. During Holocene, decreasing values of $\mathrm{Fe} / \kappa$ ratio suggests the presence of more ferrimagnetic material (Figure 6.4f).

In late Holocene, decrease in $\kappa$ and HIRM reveal a diminution in ferromagnetic concentration; yet IRM $\mathrm{I}_{300 \mathrm{mT}}$ mirrors susceptibility curve, going to higher values up to about $5 \mathrm{kyr} \mathrm{BP}$. After that, it decreases gradually. Maybe in Holocene, this parameter is working more as a grain size indicator than a parameter for changes in concentration.

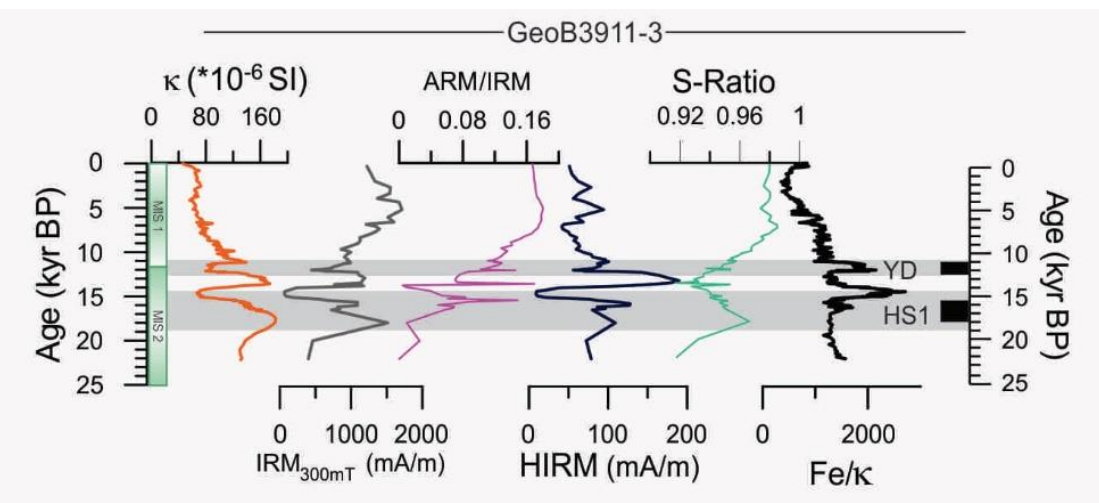

Figure 6.4: Rock magnetic parameters for core GeoB3911-3 (for details see subtitle in Figure 6.2).

\section{Core GeoB3910-2}

Along this core, IRM $\mathrm{IROmT}_{30 \mathrm{~m}}$ resembles susceptibility behavior, exhibiting higher values during the HS and prominent peaks during some events. HIRM also peaks during the abrupt events, suggesting increase in concentration of magnetic minerals. In the upper half of core GeoB3910- 
2 (after $35 \mathrm{ka} \mathrm{BP}$ ), during HS2 and HS3, parameter $\mathrm{ARM}_{100 \mathrm{mT}} / \mathrm{IRM}_{100 \mathrm{mT}}$ suggests the presence of SD-grains. In the lower half, MD-like behaviour was detected in HS4 and HS5. During YD and HS1 ARM $100 \mathrm{mT} / \mathrm{IRM}_{100 \mathrm{mT}}$ shows a variable behaviour, with an abrupt decrease in the beginning and an increase towards the end (Figure 6.5). Core GeoB3910-2 displays a different behaviour before about 35ka BP; curves for parameters S-Ratio and HIRM does not show an anti-coeval behaviour, as expected for anti-phase magnetite vs. hematite (Figure 6.5). During HS5 and HS4, differently of the behaviour in the other abrupt events, S-Ratio increases. Moreover, HIRM increases gradually during HS2 and keeps baseline values during HS3. HS1 in core GeoB3910-2 shows a singular behaviour, with an abrupt decrease of the HIRM parameter in the beginning of this event, followed by an abrupt increase and a gradual decrease towards the end. S-Ratio parameter exhibits the opposite behaviour in the HS1 for core GeoB3910-2. Differently from the other cores, Fe/ $\kappa$ ratio during Holocene in core GeoB39102 exhibits higher baseline values than in the Pleistocene. Fe/ $\kappa$ peaks at $9 \mathrm{kyr} \mathrm{BP}$, and then it decreases gradually. Any signal of diagenesis was detected along this core, so here $\mathrm{Fe} / \mathrm{\kappa}$ ratio can be used as a source or weathering indicator.

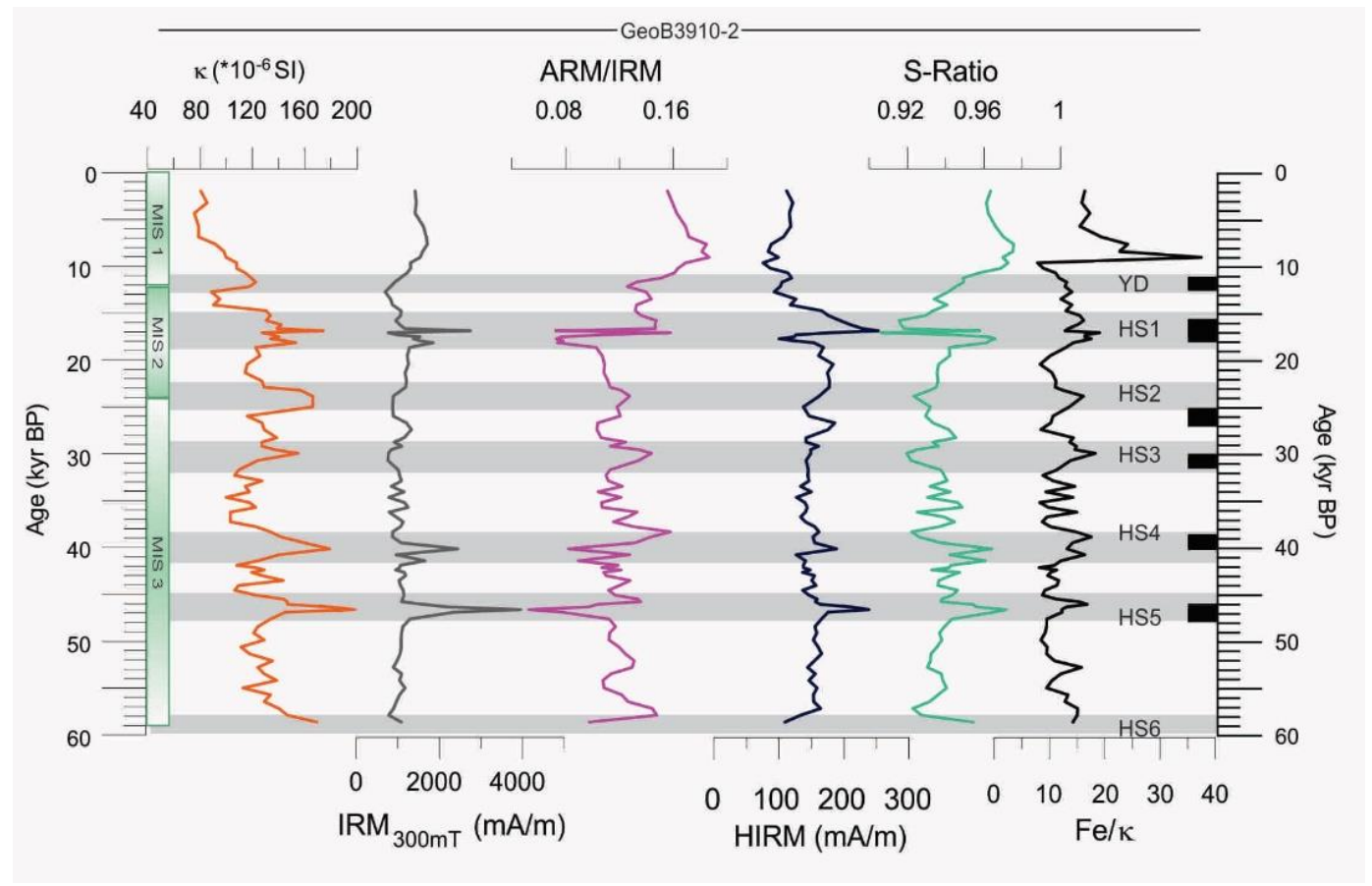

Figure 6.5: Rock magnetic parameters for core GeoB3910-2 (for details see subtitle in Figure 6.2). 


\subsection{Downcore element data}

Similar to the rock magnetic parameters, the element data show remarkable changes during the YD and the HS 1-8 (Figure 6.6 - Figure 6.9). Element data is in annex IV, and is available also in editable format in the digital media.

\section{Core GeoB3913-3}

$\mathrm{Fe} / \mathrm{Ca}$ ratio is the most outstanding and peaks abruptly during the HS, but in core GeoB3913-3 this ratio shows only a slightly during the $\mathrm{YD}$. Al/Si ratio (Figure 6.6a) shows a gradual increase during HS and YD, with values slightly higher than baseline values. During Holocene, both ratios aforementioned show smaller baseline values, especially $\mathrm{Fe} / \mathrm{Ca}$, suggesting drastic reduce in terrigenous input. Fe/K ratio show noticeable peaks during the HSs, mainly during HS1. It is important to note that baseline values of $\mathrm{Fe} / \mathrm{K}$ up to $\mathrm{HS} 1$ are smaller than in the period between about 14 and $5 \mathrm{kyr}$ BP. Fe/K ratio shows the highest values recorded during the middle Holocene (4-7 ka BP). After that, this ratio shows an abrupt decrease. Ti/Al ratio shows a remarkable trend to higher values at about $54 \mathrm{kyr}$ BP, when it clearly assumes higher baseline values. Before this time, slight changes are observed in the Ti/Al ratio during the HS, but afterwards, a sharp increase in this ratio marks the HS; during YD it increases smoothly. A drop in this ratio is observed at middle Holocene. After the inset of the Holocene, all major element exhibits a coeval behaviour, dropping to small values, except Fe/K ratio (purple curves), that drops after its main peak (7-4 ka BP). 


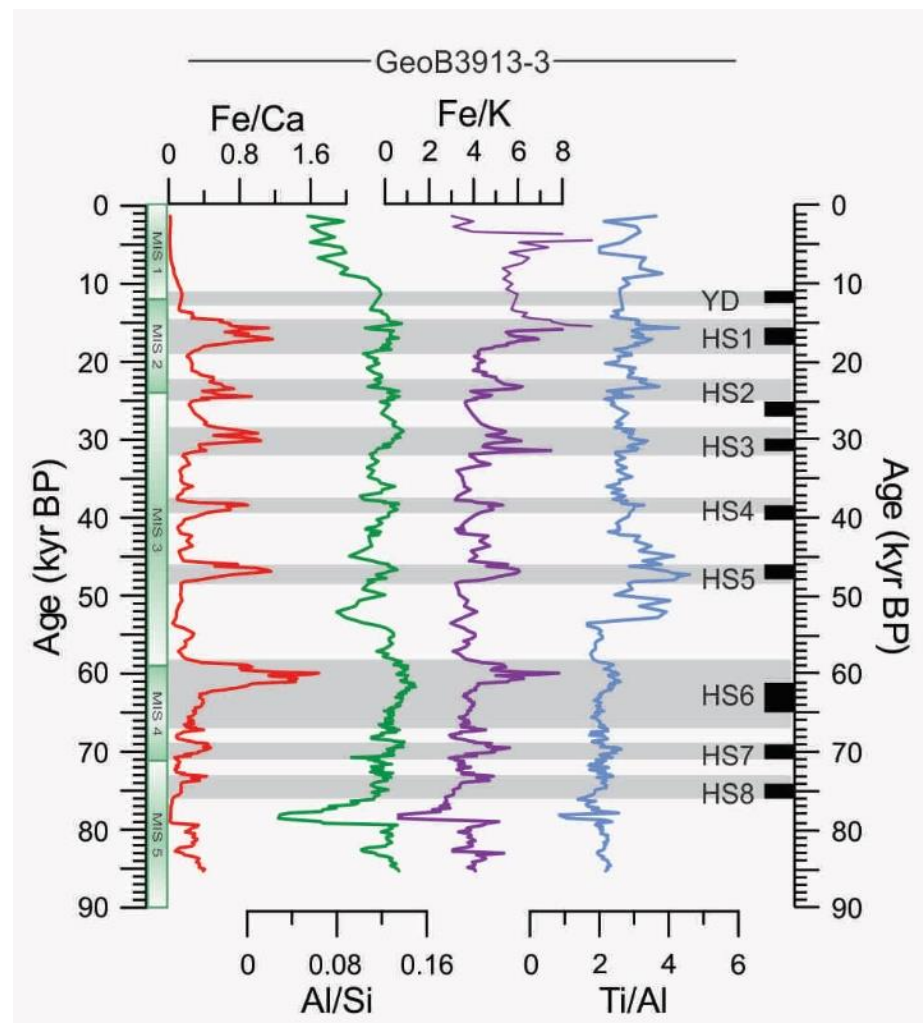

Figure 6.6: Element ratios [cps] for core GeoB3913-3 (for details see subtitle in Figure 6.2).

\section{Core GeoB3912-1}

Core GeoB3912-1 shows the most outstanding peaks in Fe/Ca ratio during HS and YD, confirming an increase in terrigenous input. Al/Si ratio from core GeoB3912-1 shows a sharp increase in the very beginning of the HS and YD and a gradual decrease towards the end (Figure $6.7 \mathrm{~b}) . \mathrm{Fe} / \mathrm{K}$ shows a very abrupt increasing in the beginning of the climatic events, but unlike the $\mathrm{Al} / \mathrm{Si}$ ratio, it holds high values until the very end, when it goes down also sharply. The exception is only for the HS1, when after a sharp increase in the beginning, Fe/K ratio decreases gradually up to the end of the event. Ti/Al ratio increases mildly during HS7 and HS8 and displays an abrupt increase followed by a gradual decrease during YD, HS2, HS3, HS4 and HS5. Distinct behavior is observed during the HS6 and HS1, in which it increases smoothly after the inset of the events and decreases gradually towards the end. 


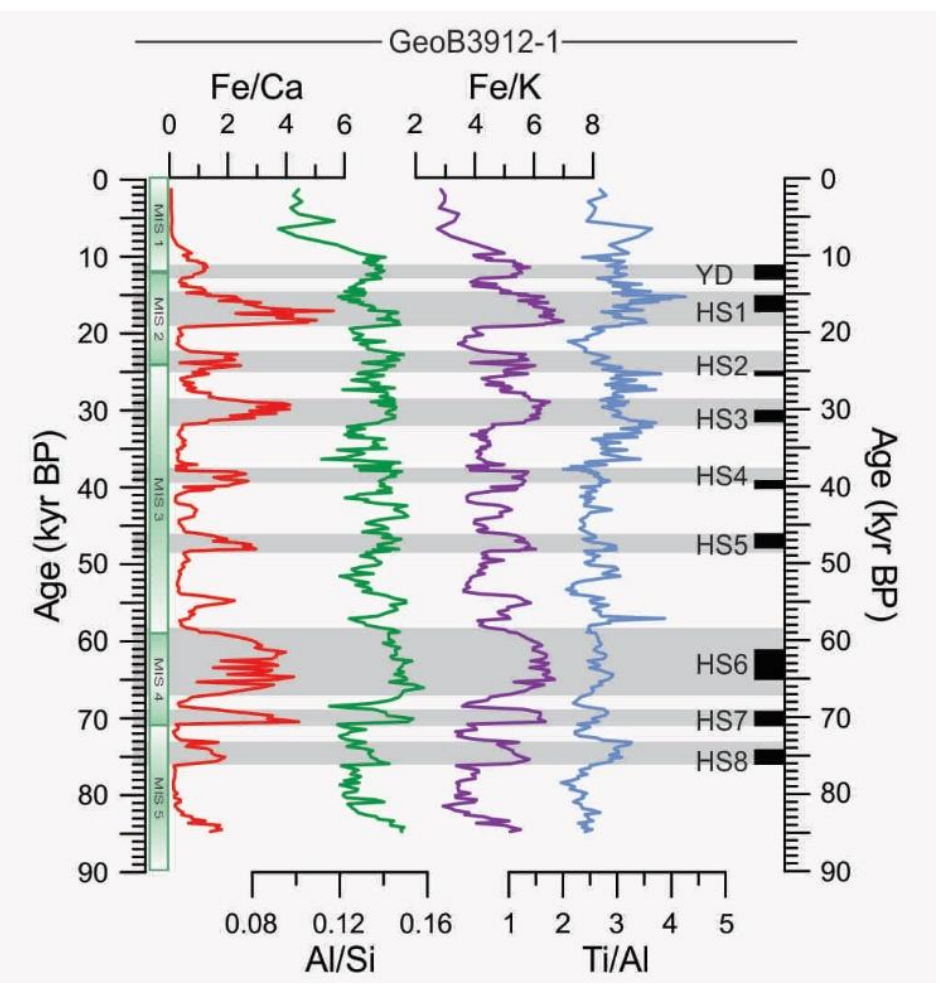

Figure 6.7: Element ratios [cps] for core GeoB3912-1 (for details see subtitle in Figure 6.2).

\section{Core GeoB3911-3}

High peaks of Fe/Ca are also observed in core GeoB3911-3 during HS1 and YD. However, the most outstanding feature in this core is the peak during B-A. This prominent peak also shows up in ratio $\mathrm{Al} / \mathrm{Si}$, and in the opposite way of the other cores, here we observe an abrupt decrease in $\mathrm{Al} / \mathrm{Si}$ ratio during $\mathrm{YD}$. This ratio exhibits more gentle increase during HS1 and a drop to small values in the middle of the stadial. Ti/Al ratio in core GeoB3911-3 (Figure 6.8c) increases smoothly after the inset of YD and HS1, but keeps almost the same baseline values along the core. The most noticeable change in $\mathrm{Ti} / \mathrm{Al}$ ratio along this core happens after $5 \mathrm{kyr} \mathrm{BP}$, when it increases slightly. Detrital phases decrease contribution during Holocene, as showed by Fe/Ca ratio, and also $\mathrm{Al} / \mathrm{Si}$ and $\mathrm{Fe} / \mathrm{K}$. Fe/Ca ratio trend to zero during the whole Holocene. $\mathrm{Al} / \mathrm{Si}$ exhibits decrease that is more evident after middle Holocene, between about 6-2 kyr BP, when it keeps the same values towards the top. Fe/K decreases gradually during the Holocene, up to aout 2 kyr BP, when it increases slightly. 


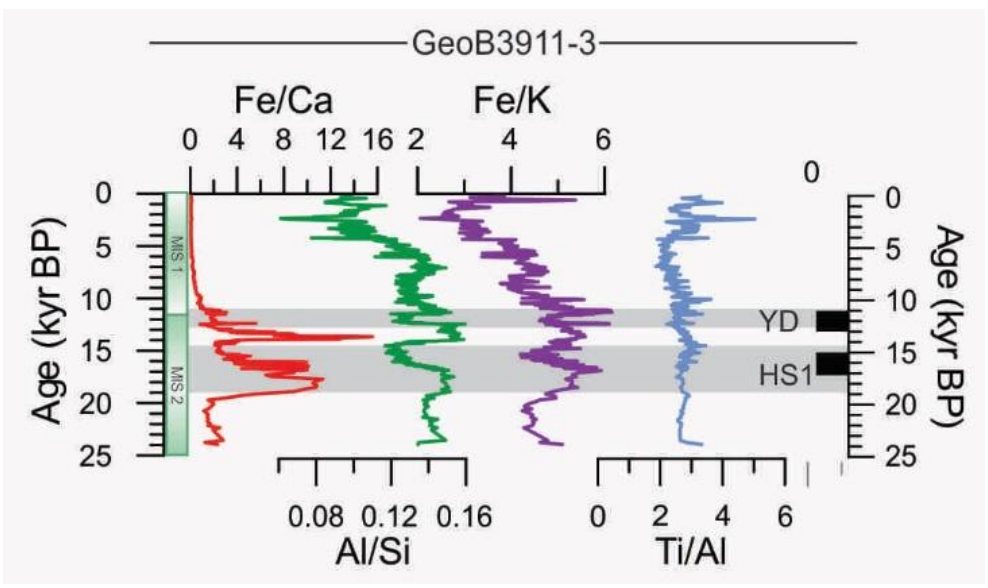

Figure 6.8: Element ratios [cps] for core GeoB3911-3 (for details see subtitle in Figure 6.2).

\section{Core GeoB3910-2}

For core GeoB3910-2, we have only $\mathrm{Fe} / \mathrm{Ca}$ and $\mathrm{Fe} / \mathrm{K}$ element ratios. Both shows remarkable peaks during HS1-HS5 and during YD. After the inset of Holocene these terrigenous indicators drops to almost zero, just like the other cores.

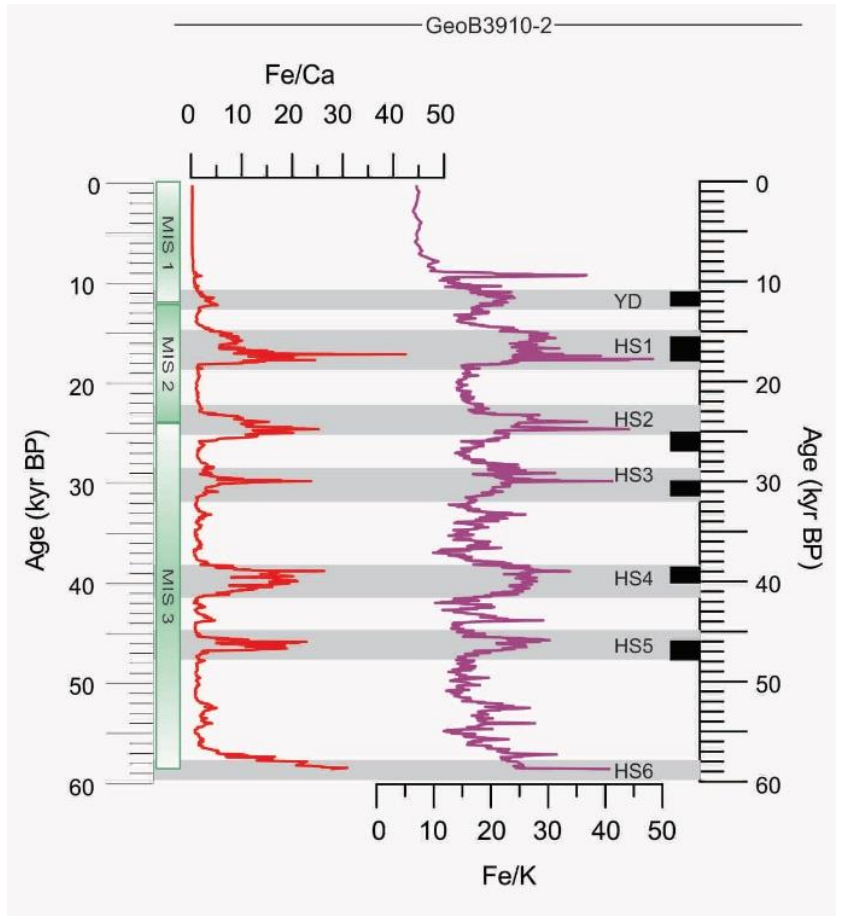

Figure 6.9: Element ratios [cps] for core GeoB3910-2 (for details see subtitle in Figure 6.2). 


\subsection{Magnetic contribution from end-members (EM)}

\subsubsection{Number of end-members}

Before performing the end-member analysis, we investigated the parameters of environmental magnetism, in order to identify secondary magnetic minerals and magnetic mineral diagenesis. A remarkable lost in magnetization can indicate magnetic mineral dissolution related to diagenetic process. Core GeoB3911-3 shows an important decay in magnetization between about 515 and $605 \mathrm{~cm}$ (equivalent to ages 16 and $14 \mathrm{kyr}$ BP in Figure 6.4). Even considering the possibility of diagenesis in core GeoB3911-3, we ran the IRM-unmixer model for this core too. Input data (IRM acquisition curves) for end-member analysis is available in editable format in the media (Annex V). IRM-unmixer calculates a coefficient for the fitting $\left(\mathrm{R}^{2}\right)$ between the matrix of data $(\mathbf{X})$ and the matrices with the model (A and $\mathbf{S}$ ) for each field step. R-Square provides a measure of how well a given model explains the data variance across the applied field range (Heslop and Dillon, 2007). Figure 6.10 shows $\mathrm{R}^{2}$ values for our cores (data available in Annex VI). Parameter $\mathrm{R}^{2}$ shows high values for all end-members options ( $\left.>0.92\right)$, indicating that our data can be modelled by the end-members approach with good quality. We can observe that the highest improvement in $\mathrm{R}^{2}$ takes place between two and three end-members, when values increase from $0.92-0.97$ to $0.94-0.98$. For a higher number of end-members, $\mathrm{R}^{2}$ values increase smoothly until $\mathrm{EM}=9$, when almost all cores show $\mathrm{R}^{2}$ values as high as 0.9 .

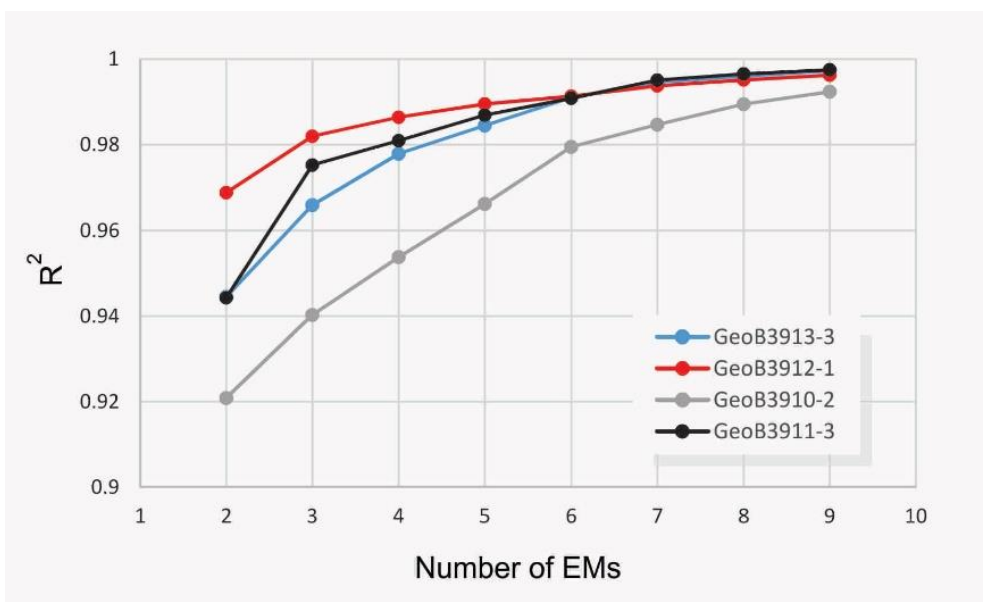

Figure 6.10: Coefficient of determination $\left(R^{2}\right)$ for our four cores.

The IRM-unmixing models also provide the parameter "convexity at termination", that should be as close to "-6" as possible to assure the quality of the end-member modeling. For our four 
cores, but GeoB3911-3 that is partially affected by diagenesis, the model with three endmembers showed convexity closer to -6 (Table 6-1). Therefore, the combination to parameters $\mathrm{R}^{2}$ and convexity suggest that 3 end-members is the best choice for cores GeoB3913-3, GeoB3912-1 and GeoB3910-2. The three end-members model also accounts better for the geological context of the study region (local geology, riverine inputs, etc) and matches the previous qualitative analysis of the magnetic mineralogy. Thus, based on the end-member contributions along the cores we decided to use the three end-members model to represent sediment sources on our study area.

Table 6-1: Convexity values for each end-member calculated during the unmixing process for our four cores.

\begin{tabular}{ccc} 
Core & $\begin{array}{c}\text { Number of } \\
\text { end-members }\end{array}$ & Convexity at termination \\
\hline \multirow{2}{*}{ GeoB3913-3 } & 2 & -6.0222 \\
& 3 & -6.002 \\
GeoB3912-1 & 4 & -3.3562 \\
\hline & 2 & -6.0232 \\
GeoB3910-2 & 3 & -6.0069 \\
& 4 & -5.345 \\
\hline & 2 & -4.8053 \\
GeoB3911-3 & 3 & -5.0134 \\
& 4 & -3.5305 \\
\hline
\end{tabular}

The unmixing process using three end-members for core GeoB3911-3 shows an end-member that does not match any of the end-members from other cores, that we attributed to a diagenetic phase, based on the magnetically depleted interval mentioned before. Considering this diagenetic phase and the higher convexity value for the three end-member analysis of core GeoB3911-3 (Table 6-1), we decided to exclude this core from the sediment source study. The shape of IRM curves for each end-member and their relative abundance for core GeoB3911-3 are presented in the supplementary material, Annex VII. 


\subsubsection{Shape of the IRM acquisition curves from the unmixing}

The unmixing method produces IRM-acquistion curves for each end-member from the analysis of all IRM-acquisition curves (input data to the model). In total, we obtained, respectively: 109, 134 and 138 curves from cores GeoB3913-3, GeoB3912-1 and GeoB3910-2. In Figure 6.11 we show all IRM acquisition curves obtained for our cores and the end-member "synthetic" curves generated by the model (data in annex VIII). As expected, the end-member curves define an envelope that encloses all IRM-acquisition curves. Comparing the shape of end-member acquisition curves among the cores GeoB3913-3, GeoB3912-1 and GeoB3910-2 we also observe a good resemblance between EM1, EM2 and EM3 defined for each core (Figure 6.12).
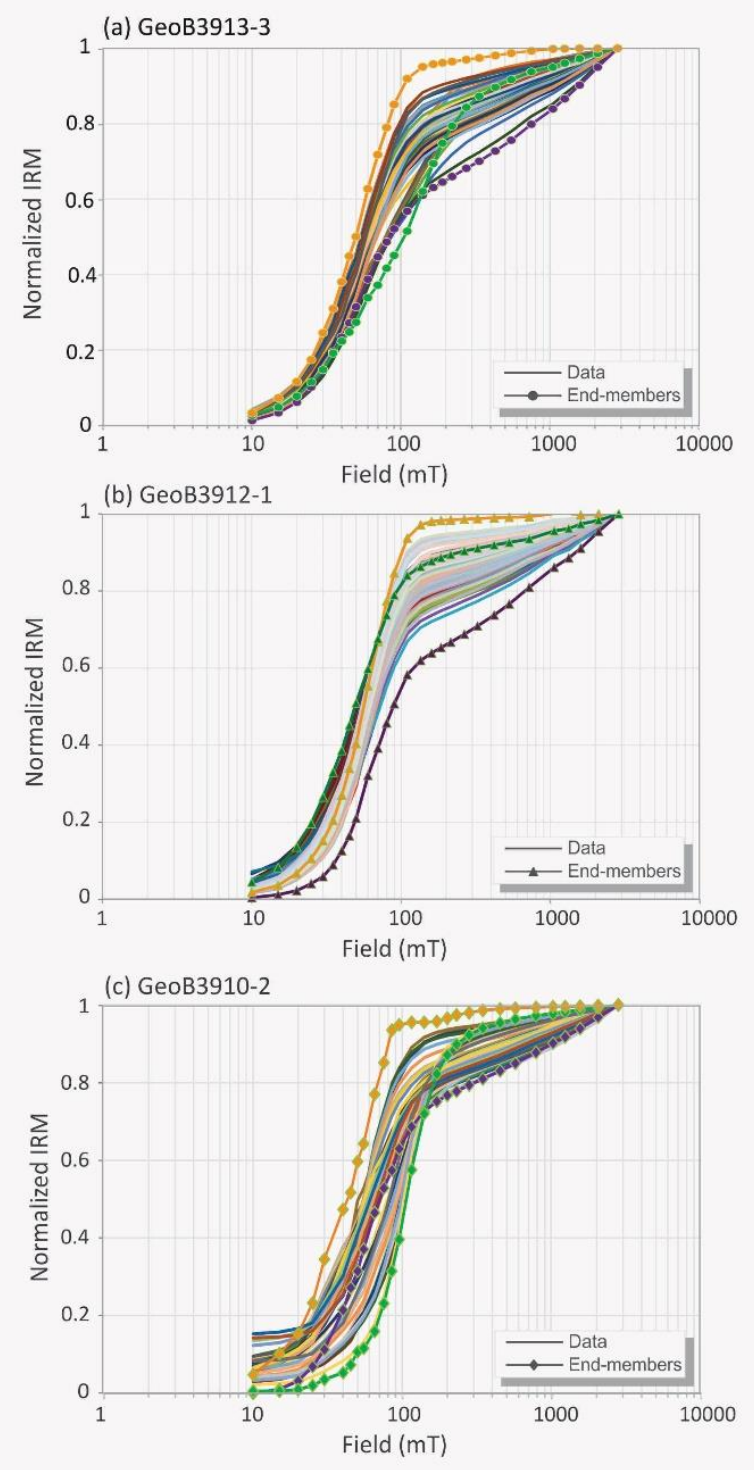

Figure 6.11: Comparison between the shape of the acquisition curves from the end-member analysis and the input data for cores (a) GeoB3913-3, (b) GeoB3912-1 and (c) GeoB3910-2. 
Acquisition curves for EM1 (purple) suggest a mixture of a low coercivity magnetic phase saturated at about $20 \mathrm{mT}$ (i.e. magnetite), and highly coercive phases, which do not reach saturation until $2.8 \mathrm{~T}$ (i.e. goethite and hematite; Figure 6.12a).

(a) EM1

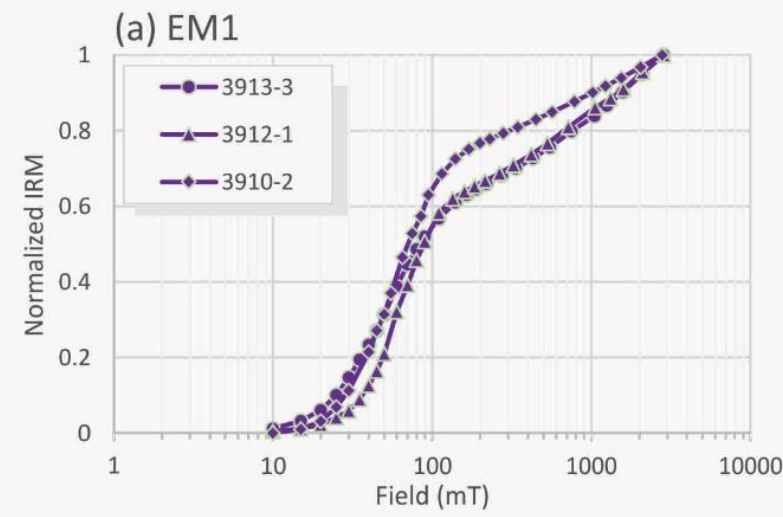

(b) EM2

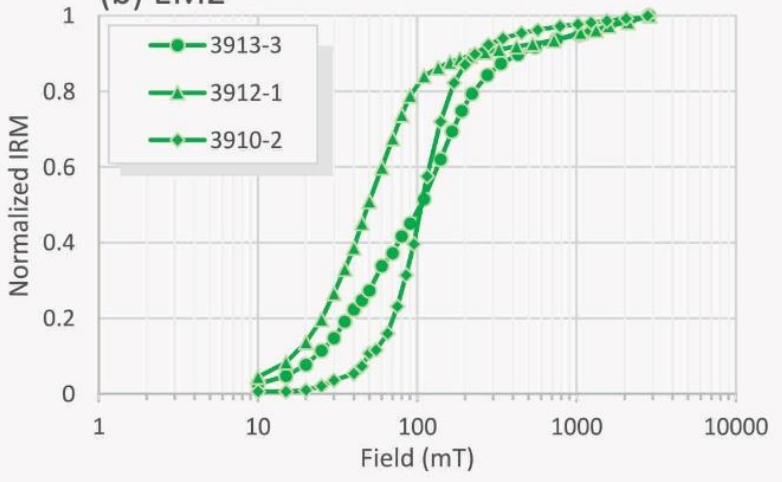

(c) EM3

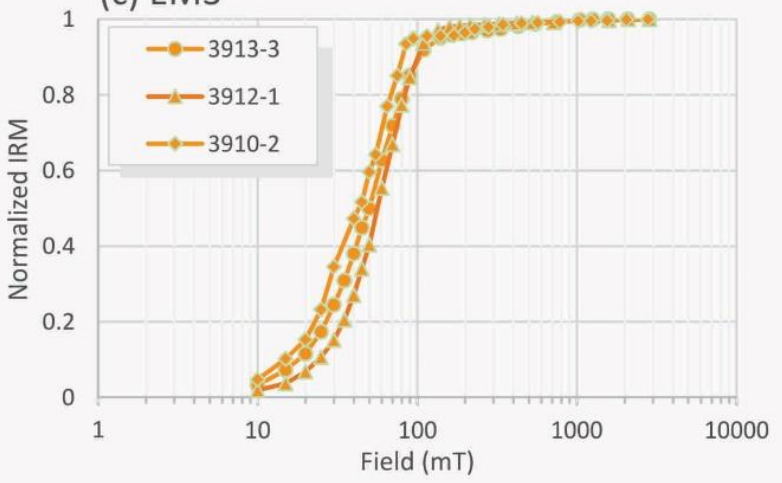

Figure 6.12: Comparison between the shape of the acquisition curves from the end-member analysis from cores GeoB3913-3, GeoB3912-1 and GeoB3910-2. (a) EM1, (b) EM2 and (c) EM3.

EM2 curves (green) show slight differences between cores, but in general these end-members are composed of low coercivity magnetic phases (Figure 6.12b). In cores GeoB3913-3 and GeoB3912-1, EM2 curves start acquisition at about 20 mT, whilst for core GeoB3910-2, 
acquisition starts later at $\sim 40 \mathrm{mT}$. These dissimilarities in the shape of the curves were attributed to the presence of low-coercivity grains with different sizes (SD and MD). For core GeoB39121 , the faster acquisition is likely due to the presence of MD phases. The slower the IRM acquisition, the higher the relative contribution of SD grains.

EM3 curves (orange) showed the highest similarity among cores. In the synthetic IRM curves for EM3 magnetization started to be acquired in very low fields below $20 \mathrm{mT}$, and before 100 $\mathrm{mT}$ the curves reached complete saturation (Figure 6.12c).

\subsubsection{Magnetic contributions from end-members}

Each end-member provided by the IRM-unmixing shows variations in its relative contribution along the core, as described below.

\section{GeoB3913-3}

EM1 is present along the whole core, comprising about 50\% of the magnetic signal (Figure 6.13). Remarkable peaks in EM1 are observed for core GeoB3913-3 during the HS, with values twice higher than baseline values. It is possible to observe sharper peaks in HS5 and HS4 in comparison to the other HS events. Moreover, HS1 exhibits two peaks of high intensity of magnetization, mimicking the behaviour of the environmental magnetic parameters (Figure 6.2). The EM2 is present along the entire core in small amounts. During the Holocene it is higher than in the last glacial. Between 25 and $15 \mathrm{kyr}$ BP the EM2 increases significantly, comprising more than a half of the contribution; it reflects the dominance of (titano)magnetite in this sector of the core (Figure 6.13). The contribution from EM3 does not change significantly along the core but for some marked decrease during HS1 and at the bottom core, at about $78 \mathrm{kyr}$ BP. 


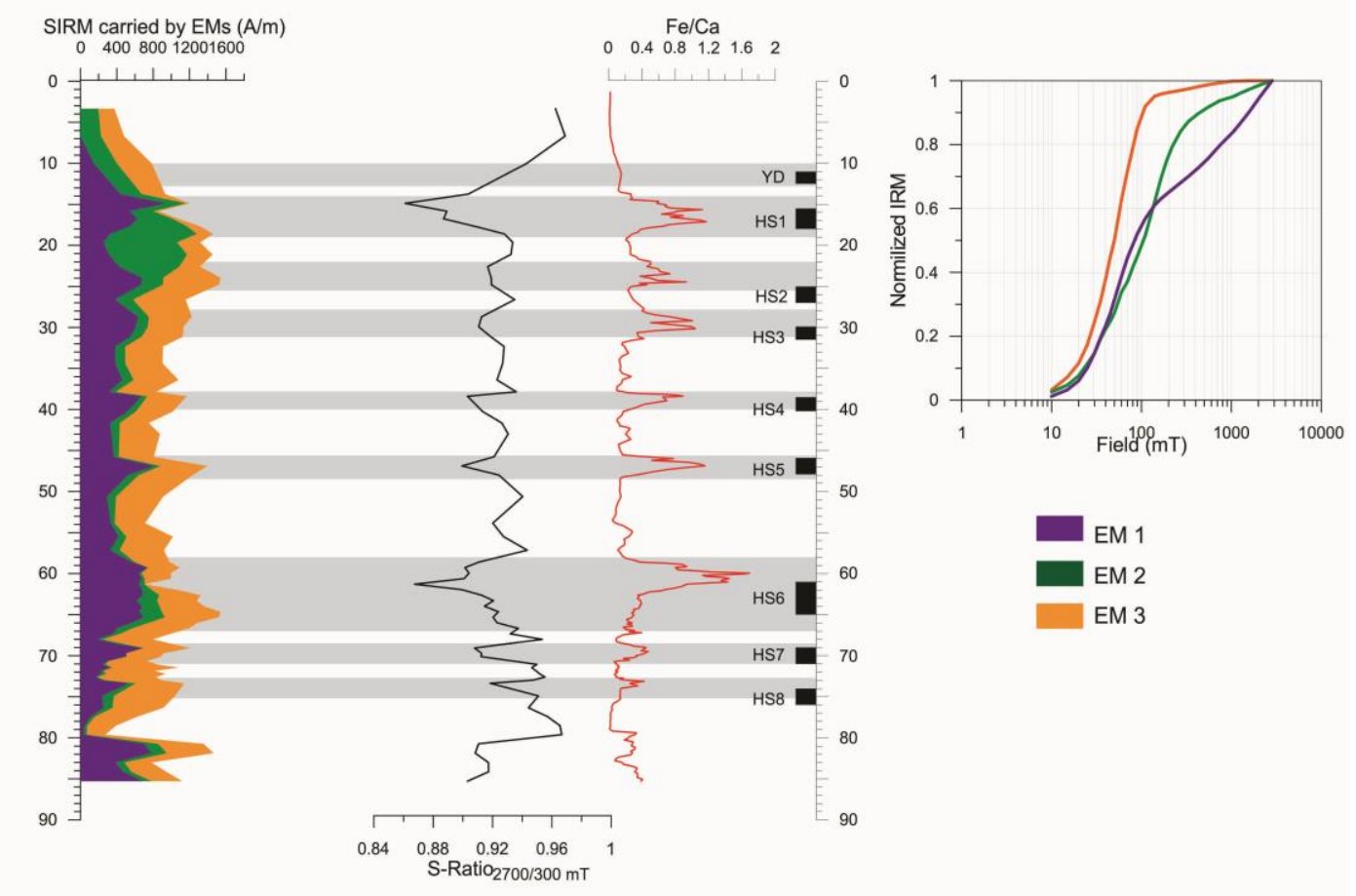

Figure 6.13: (a) downcore contribution and (b) IRM acquisition curves from the end-members calculated for core GeoB3913-3.

\section{GeoB3912-1}

EM1 shows significant peaks during HS in core GeoB3912-1 (Figure 6.14). The intensity of the magnetization increases sharply during the stadials, except for HS3 and HS2. The contribution of EM2 is very important in the base of the core, and decreases smoothly towards the top, whereas the abundance of EM3 shows an opposite behaviour, being smaller at the base and higher at the top of the core, especially during the Holocene. This end-member also shows a decrease during the stadials. 


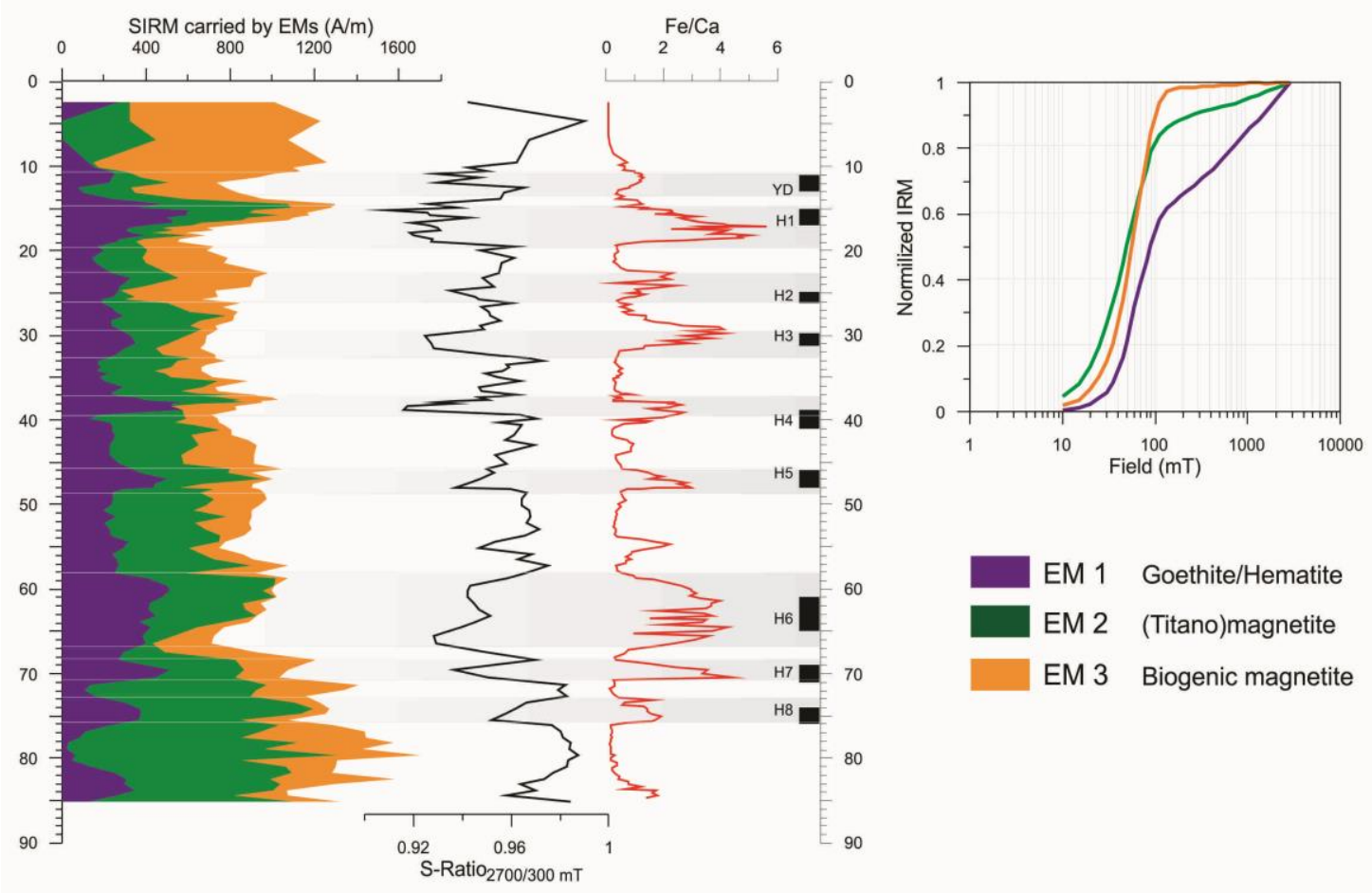

Figure 6.14: (a) downcore contribution and (b) IRM acquisition curves from the end-members calculated for core GeoB3912-1.

\section{GeoB3910-2}

EM1 is the dominant contribution to the magnetic signal along core GeoB3910-2 (Figure 6.15). However, differently from the other cores, this end-member does not peak during stadials. During HS3 and HS2 it does not vary significantly, whereas during HS5, HS4 and HS1 its contribution decreases. The EM1 only peaks remarkably during the younger stages of HS1. In contrast, EM2 increase during the stadials and show significant contribution at these extreme events. The contribution of EM3 along the core is small, but almost constant during the last glacial. EM3 decreases during the stadials, and increases significantly during the Holocene. 


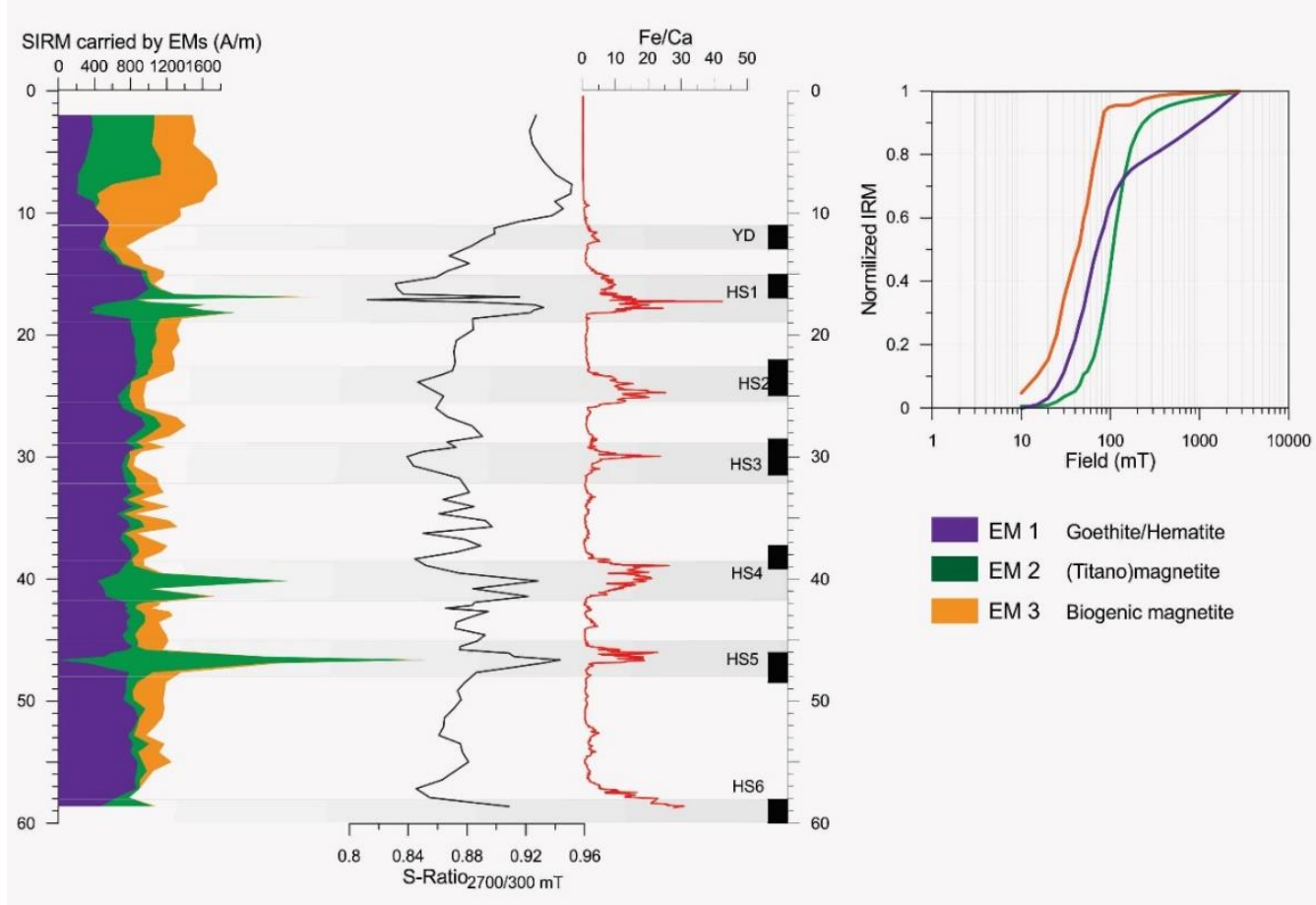

Figure 6.15: (a) downcore contribution and (b) IRM acquisition curves from the end-members calculated for core GeoB3910-2.

\subsubsection{Significance of each end-member}

Here the magnetic mineralogy content is discussed for our end-members according to the shape of the IRM acquisition curves of EM1, EM2 and EM3. Each end-member was deconvolved in individual IRM acquisition curves by direct modelling each EM synthetic curve using the IRMCLG fitting of Kruiver et al. (2001). For each component parameters SIRM, B $1 / 2$ and DP were obtained. Figure 6.16 (EM1), Figure 6.17 (EM2) and Figure 6.18 (EM3) show the component analysis results for each end-member for the three cores. Table 6-2 shows the values of the parameters for each component and for each EM. The assembly of magnetic minerals present in our cores exhibit five components with increasing magnetic hardness, that are combined in different proportions in our three end-members.

Initially, to identify the magnetic minerals present in each of our five components, we used the values of $\mathrm{B}_{1 / 2}$ and DP (Kruiver et al., 2001). The magnetically soft phases correspond to components 1 and 2 and were interpreted as magnetite, due to their $\mathrm{B}_{1 / 2}$ values $<60 \mathrm{mT}$. Component 1 has a consistent peak of $\mathrm{B}_{1 / 2}$ between 13 and $33 \mathrm{mT}$ and DP between 0.12 and 0.30 and correspond to the limits observed by Geiss et al. (2008) for pedogenic magnetite. For end-members 1 and 2 this component is interpreted as related to pedogenic processes. We note, 
however, that component 1 obtained for EM3, that presents a low $\mathrm{B}_{1 / 2}<18 \mathrm{mT}$ and low DP of 0.18-0.25, could be an artefact from the IRM-CLG modeling. The approach of Kruiver et al. (2001) cannot fit left-skewed distributions (Egli, 2003), and an additional low-coercivity component is sometimes needed to fit the data (Just et al., 2012a). Thus, we are cautious about attributing such component to a very soft magnetic mineral, MD magnetite, for end-member 3. The coercivity of our component 2 is between $\sim 47$ and $\sim 57 \mathrm{mT}$. We attributed it to magnetossomes with intermediate coercivity following (Egli, 2004). Component 3 presents an intermediate hardness ( 100-200 $\mathrm{mT})$ and was attributed to fine-grained titano(magnetite). According to Geiss et al. (2008), these values of $\mathrm{B}_{1 / 2}$ suggest the presence of parental material from crystalline rocks. Components 4 and 5 are simple to identify because of their characteristic high values of $\mathrm{B}_{1 / 2}$. Component 4 exhibits $\mathrm{B}_{1 / 2}$ between $\sim 500-700 \mathrm{mT}$ and can be ascribed to hematite. Component 5 shows up $\mathrm{B}_{1 / 2}$ higher than $1500 \mathrm{mT}$ and was interpreted as goethite.

EM1 is a mixture of magnetic minerals with low and high coercivities. In EM1 of cores GeoB3913-3 (Figure 6.16) and GeoB3912-1 (Figure 6.17) two soft components are present: component 1 (pink curve) and component 2 (green curve), with $\mathrm{B}_{1 / 2}$ of $\sim 30$ and $\sim 70 \mathrm{mT}$, respectively. Moreover, two magnetically hard components are present: components 4 (grey curve) and 5 (black curve), with $\mathrm{B}_{1 / 2}$ of about $\sim 600$ and $\sim 1800 \mathrm{mT}$. In core GeoB3910-2 (Figure 6.18), component 1 is absent, but we observed components 2, 4 and 5. Components 1 and 2 account for about 62\% of SIRM in cores GeoB3913-3 and GeoB3912-1, whilst in core GeoB3910-2 the contribution from these magnetically soft phases is of $78 \%$. Component 4 accounts for about $24 \%, 28 \%$ and $15 \%$ of the total SIRM in cores GeoB3913-3, GeoB3912-1 and GeoB3910-1, respectively. The most coercive component 5 has minor contribution in cores GeoB3912-1 and GeoB3910-1 ( 9.8\% and 7\%, respectively); and in core GeoB3913-3 it has the most significant contribution in SIRM, to $\sim 14 \%$. Even considering that the percentage contribution to the total magnetization of hematite/goethite is small in comparison with that of magnetite, these hard phases correspond to an important fraction of the magnetic inventory of the sediments. That is because the intrinsic remanent magnetization of magnetite is about 200 times higher than that of hematite and goethite (Dunlop and Özdemir, 1997). 

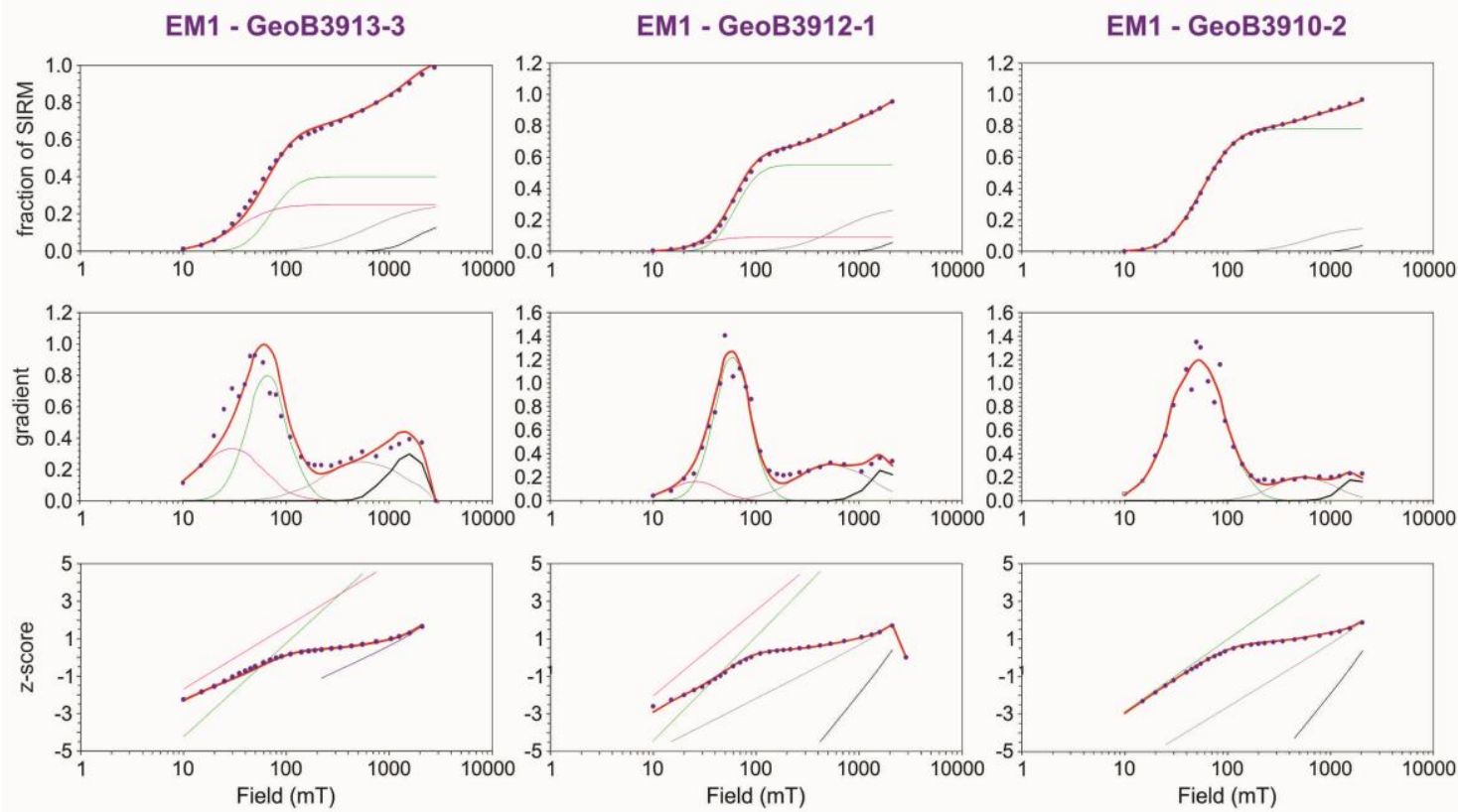

- Raw data - Component $1-$ Component $2-$ Component $3-$ Component $4-$ Component 5 - Sum of components

Figure 6.16: IRM component analyses of EM1 (hematite/goethite). Each column corresponds to one core:

GeoB3913-3 (left), GeoB3912-1 (middle), GeoB3910-2 (right). Different colors indicate the components needed to fit the sum of the components (red curve). Purple dots corresponds to the IRM acquisition curve from the "synthetic" data. (top row) Linear acquisition plot; (middle row) gradient acquisition plot; and (bottom row) standardized acquisition plot.

For EM2 the softer component 1 ( $\mathrm{B}_{1 / 2}$ between 25-32 $\left.\mathrm{mT}\right)$ is present in cores GeoB3913-3 $(\sim 35 \%)$ and GeoB3910-2 ( 6\%) but it is absent in core GeoB3912-1. Component 2 contributes to $90 \%$ of the SIRM in core GeoB3912-1, and the remaining $10 \%$ are made up by component 5 ( $\left.\mathrm{B}_{1 / 2} \sim 1500 \mathrm{mT}\right)$. A component with intermediate hardness, component 3 (blue curve), is present in EM2 and has a contribution of $\sim 52 \%$ and $~ 88 \%$ in cores GeoB3913-3 and GeoB39102, respectively. The component 4 of EM2 is present only in core GeoB3913-3, but the hardest one is absent. In core GeoB3910-1 the magnetically hard component 5 accounts for $\sim 6 \%$ of the SIRM. 

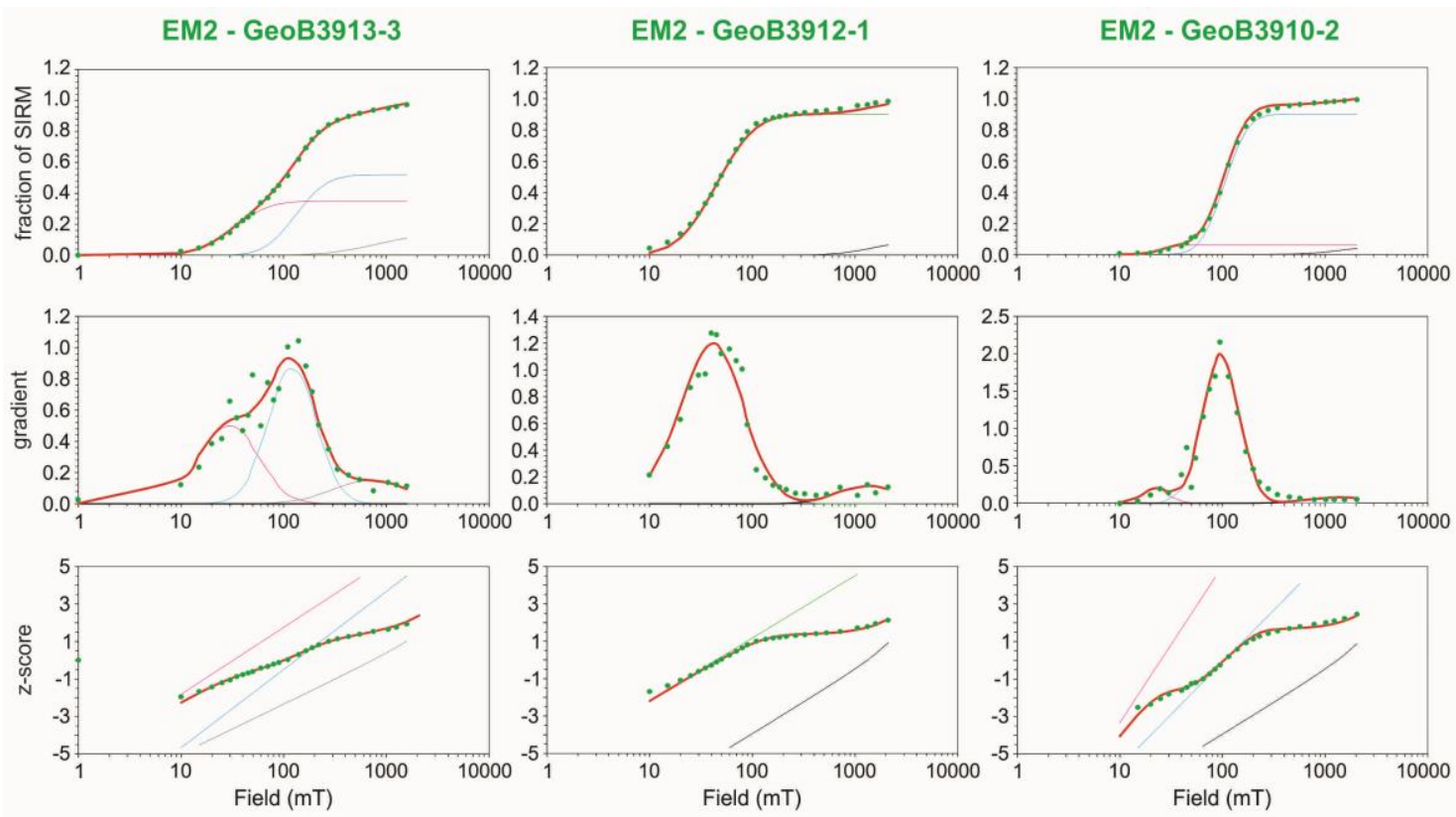

- Raw data - Component $1-$ Component $2-$ Component $3-$ Component $4-$ Component 5 Sum of components

Figure 6.17: IRM component analyses of EM2 ((titano)magnetite). Each column corresponds to one core: GeoB3913-3 (left), GeoB3912-1 (middle), GeoB3910-2 (right). Different colors indicate the components needed to fit the sum of the components (red curve). Green dots corresponds to the IRM acquisition curve from the "synthetic" data. (top row) Linear acquisition plot; (middle row) gradient acquisition plot; and (bottom row) standardized acquisition plot.

EM3 comprises essentially the soft components. Magnetically hard components 4 ( $\mathrm{B}_{1 / 2}$ of 795 $\mathrm{mT})$ and $5\left(\mathrm{~B}_{1 / 2}\right.$ of $\left.1778 \mathrm{mT}\right)$ were introduced with very small contributions of $0.5 \%$ in core GeoB3912-1, to model the high-coercivity part of the SAP diagram of Kruiver et al. (2001). The same was done for core GeoB3913-3, with a contribution of $\sim 3 \%$ of a component $4\left(\mathrm{~B}_{1 / 2}\right.$ of $\sim 500 \mathrm{mT})$. These components in EM3 with very low contribution to the total SIRM are interpreted as artefacts from right-skewed distributions as suggested by Egli (2003). The intermediate component 3 is present only in core GeoB3910-2, comprising 5\% of the SIRM with $\mathrm{B}_{1 / 2}$ of $\sim 200 \mathrm{mT}$. The magnetically soft components are present in EM3 in the three cores with important contributions. Component 2 accounts for 89\% of SIRM in EM3 for core GeoB3912-1, $\sim 88 \%$ of the SIRM (B $\left.{ }_{1 / 2} \sim 50 \mathrm{mT}\right)$ for core GeoB3913-3, and $~ 75 \%$ of the SIRM for core GeoB3910-2. Contributions of component 1 vary between $\sim 9 \%$ and $\sim 20 \%$. 

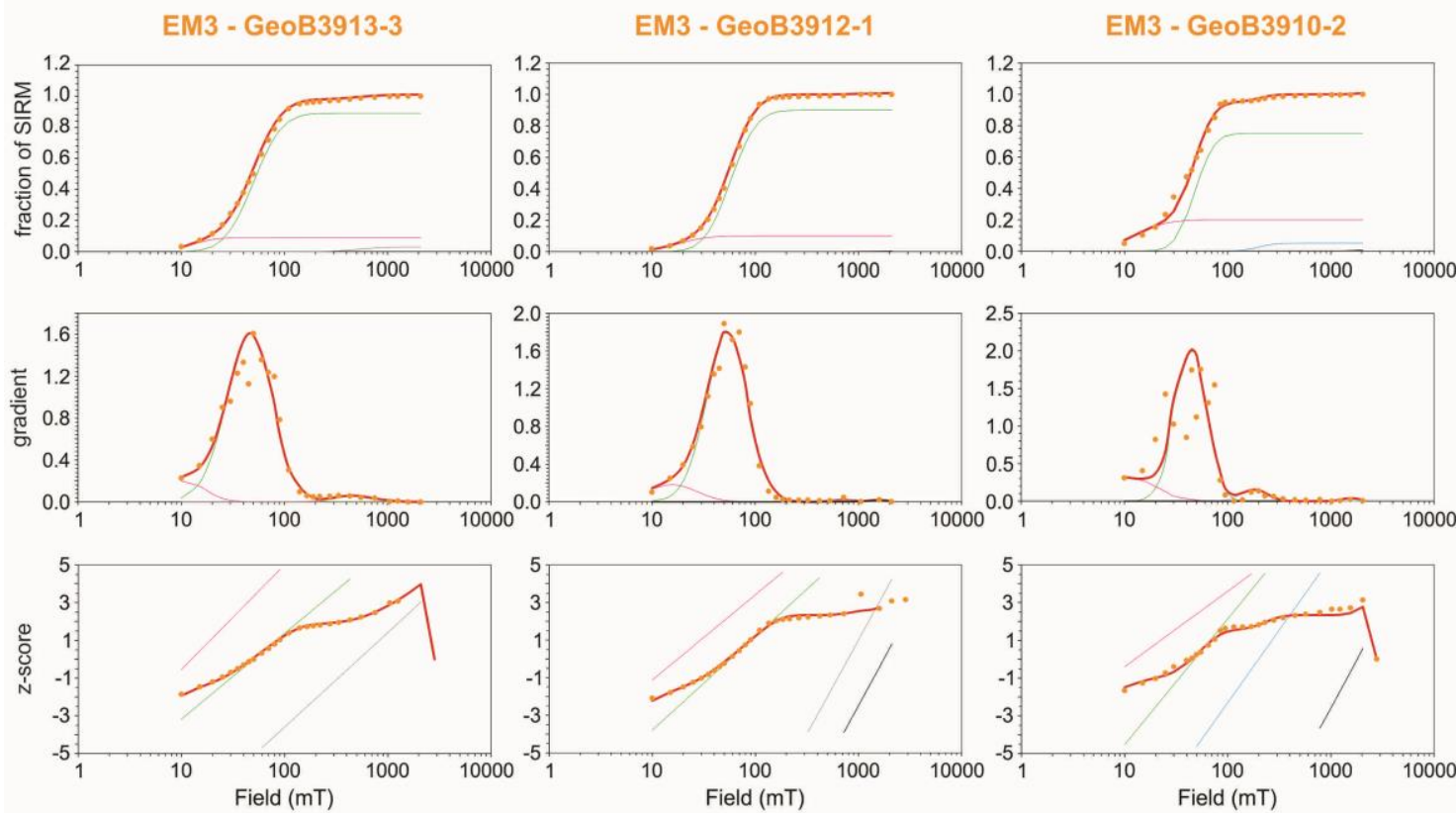

Raw data

C Component 1

Component 2

Component $3 \longrightarrow$ Component 4

- Component 5

Sum of components

Figure 6.18: IRM component analyses of EM3 (biogenic magnetite). Each column corresponds to one core:

GeoB3913-3 (left), GeoB3912-1 (middle), GeoB3910-2 (right). Different colors indicate the components needed to fit the sum of the components (red curve). Orange dots corresponds to the IRM acquisition curve from the “synthetic” data. (top row) Linear acquisition plot; (middle row) gradient acquisition plot; and (bottom row) standardized acquisition plot. 
Table 6-2: Parameters from IRM component analysis (Kruiver et al., 2001) of end-members derived by the unmixing.

\begin{tabular}{|c|c|c|c|c|c|c|c|c|c|c|c|c|c|c|c|c|c|c|c|c|}
\hline & \multicolumn{4}{|c|}{ IRM Component 1} & \multicolumn{4}{|c|}{ IRM Component 2} & \multicolumn{4}{|c|}{ IRM Component 3} & \multicolumn{4}{|c|}{ IRM Component 4} & \multicolumn{4}{|c|}{ IRM Component 5} \\
\hline & $\begin{array}{c}\text { Contrib. } \\
(\%)\end{array}$ & SIRM & $\begin{array}{l}B_{1 / 2} \\
(m T)\end{array}$ & $\begin{array}{c}\mathrm{DP} \\
(\mathrm{mT})\end{array}$ & $\begin{array}{c}\text { Contrib. } \\
(\%)\end{array}$ & SIRM & $\begin{array}{l}\mathrm{B}_{1 / 2} \\
(\mathrm{mT})\end{array}$ & $\begin{array}{c}\text { DP } \\
\text { (mT) }\end{array}$ & $\begin{array}{c}\text { Contrib. } \\
(\%)\end{array}$ & SIRM & $\begin{array}{l}\mathrm{B}_{1 / 2} \\
(\mathrm{mT})\end{array}$ & $\begin{array}{c}\text { DP } \\
(\mathrm{mT})\end{array}$ & $\begin{array}{c}\text { Contrib. } \\
(\%)\end{array}$ & SIRM & $\begin{array}{c}B_{1 / 2} \\
(\mathrm{mT})\end{array}$ & $\begin{array}{c}\text { DP } \\
(\mathrm{mT})\end{array}$ & $\begin{array}{c}\text { Contrib. } \\
(\%)\end{array}$ & SIRM & $\begin{array}{l}B_{1 / 2} \\
(\mathrm{mT})\end{array}$ & $\begin{array}{c}\text { DP } \\
\text { (mT) }\end{array}$ \\
\hline \multicolumn{21}{|c|}{ GeoB3913-3 } \\
\hline EM1 & 3.81 & 0.25 & 32.36 & 0.30 & 38.10 & 0.40 & 70.79 & 0.20 & - & - & - & - & 23.81 & 0.25 & 630.96 & 0.40 & 14.29 & 0.15 & 1778.28 & 0.20 \\
\hline EM2 & 65 & 0.35 & 36 & 0.28 & - & - & - & - & 51.49 & 0.52 & 131.83 & 0.24 & 13.86 & 0.14 & 794.33 & 0.38 & - & - & - & - \\
\hline EM3 & & 0.09 & .59 & 0.18 & 88.12 & 0.89 & 50.12 & 0.22 & - & - & - & - & & 0.03 & 524.81 & 0.20 & 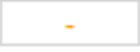 & - & - & - \\
\hline \multicolumn{21}{|c|}{ GeoB3912-1 } \\
\hline EM1 & 8.82 & 0.09 & 28.18 & 0.22 & 53.92 & 0.55 & 63.10 & 0.18 & - & - & - & - & 27.45 & 0.28 & 616.60 & 0.36 & 9.80 & 0.10 & 1995.26 & 0.15 \\
\hline EM2 & - & - & - & - & .00 & 0.90 & 44.67 & 0.30 & - & - & - & - & - & - & - & - & 10.00 & 0.10 & 1584.89 & 0.30 \\
\hline EM3 & 9.90 & 0.10 & 17.78 & 0.22 & 89.11 & 0.90 & 57.54 & 0.20 & - & & & - & 0.50 & 0.01 & 794.33 & 0.10 & 0.50 & 0.01 & 1778.28 & 0.10 \\
\hline \multicolumn{21}{|c|}{ GeoB3910-1 } \\
\hline EM1 & 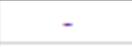 & - & 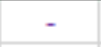 & - & 78.00 & 0.78 & 56.23 & 0.26 & - & - & - & - & 15.00 & 0.15 & 616.60 & 0.30 & 7.00 & 0.07 & 1995.26 & 0.15 \\
\hline EM2 & & 0.06 & 25.12 & 0.12 & - & - & - & - & 88.2 & 0.90 & 104.71 & 0.18 & - & - & - & - & 5.88 & 0.06 & 1584.89 & 0.30 \\
\hline EM3 & 19.80 & 0.20 & 12.59 & 0.25 & 74.26 & 0.75 & 47.86 & 0.15 & 4.95 & 0.05 & 199.53 & 0.13 & - & - & - & - & - & - & - & - \\
\hline
\end{tabular}




\subsection{Magnetic characterization: hysteresis and low temperature curves}

Hysteresis curves and low temperature measurements were obtained for core GeoB3912-1, and brought some hints about magnetic size and type. We selected three samples along the core that represent sections with different behaviour in the "enviromagnetic" parameters (Figure 6.3) and end-members (Figure 6.14). Figure 6.19 shows hysteresis loops corrected for paramagnetic effect for top (G088, $10.5 \mathrm{~cm})$, middle (G093, $321.5 \mathrm{~cm})$ and base $(\mathrm{G} 099,620 \mathrm{~cm})$ of the core. The dominant end-members in theses intervals are EM3, EM1 and EM2, respectively.

(a) $\mathrm{G} 088[10.5 \mathrm{~cm}]$

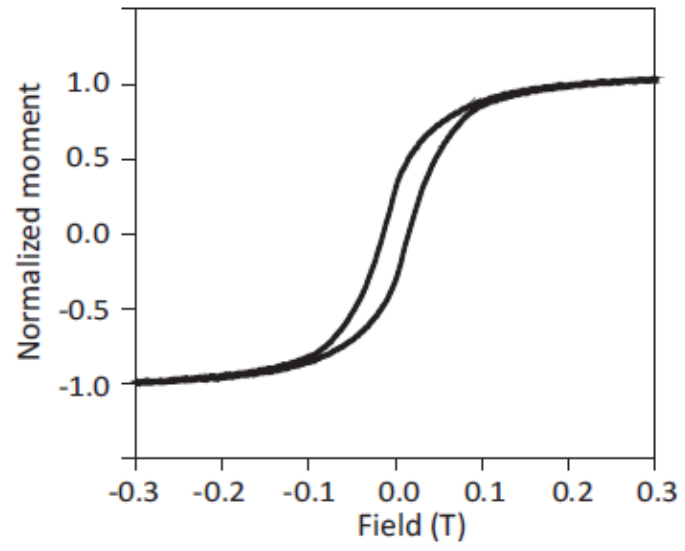

(b) $G 099[620 \mathrm{~cm}]$

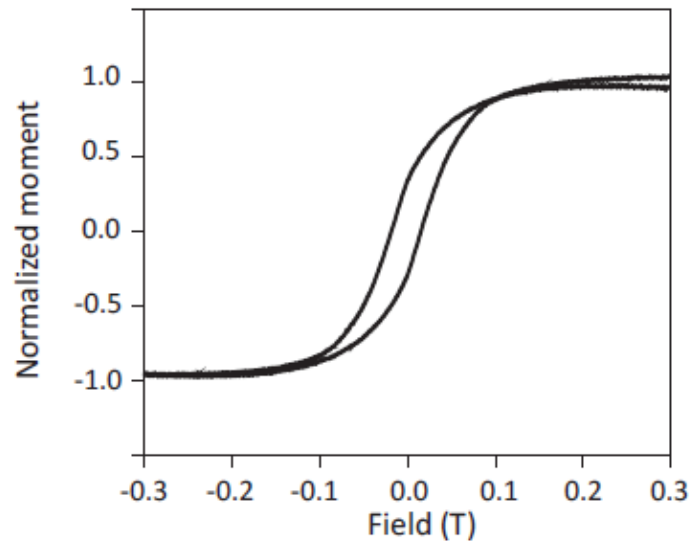

G093 [321.5 cm]

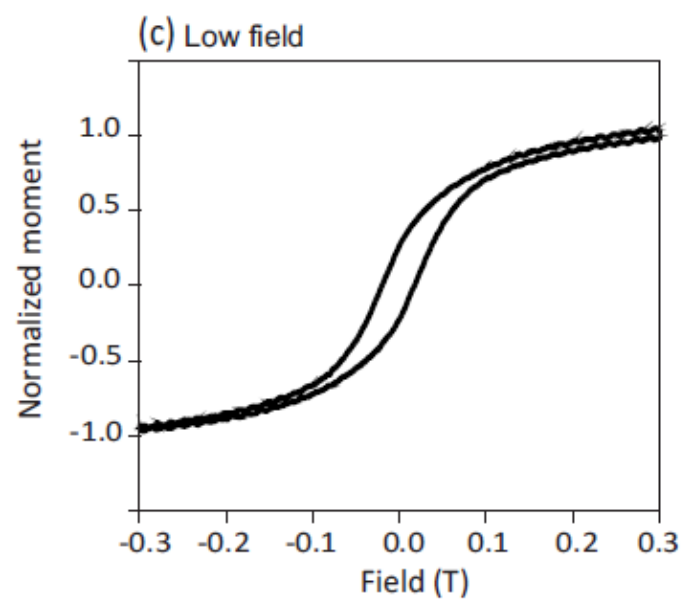

(d) High field

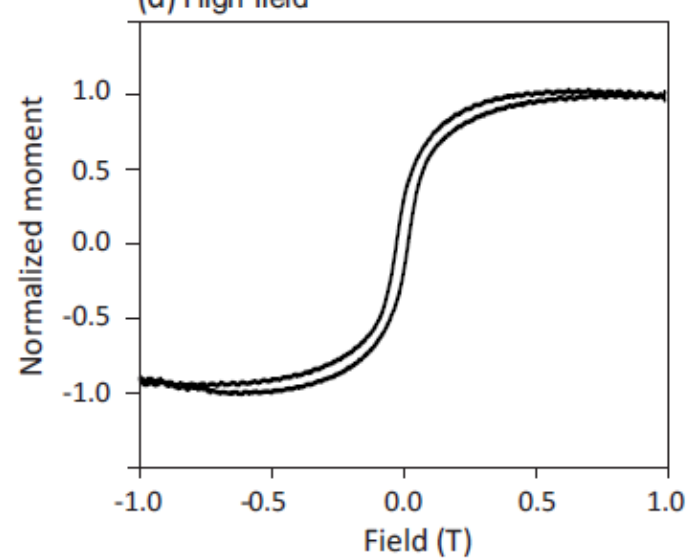

Figure 6.19: Low field (-0.3/0.3T) hysteresis loops for (a) top (b) base and (c) middle, and high field (1T/1T) hysteresis loop for (d) middle part of core GeoB3912-1.

Low field loops (Figure 6.19 a, b and c) show narrow waist especially in sample G088. High field loops were performed for all samples, but here we show only the example for sample G093 (middle of the core, Figure 6.19d). Loops obtained from induced measurements up/down to 
$+1 /-1 \mathrm{~T}$ for our samples saturate fast and do not suggest the presence of highly coercive phases. The high field curve for sample G093 was the only one that exhibited a "wasp-waist" behaviour, suggesting a mixture of magnetic grains with contrasting coercivities (Liu et al., 2012). The different coercivities we identified here can be attributed to magnetic grains with distinct sizes or two types of magnetic minerals with contrasting coercivities, like hematite or goethite and magnetite.

Low temperature measurements were obtained for five samples distributed along the core GeoB3912-1: 20, 75, 335, 510.5 and $630 \mathrm{~cm}$. The corresponding ages for these samples are present in the plots (Figure 6.20).

(a) $20 \mathrm{~cm} \quad[9.5 \mathrm{kyr} \mathrm{BP}]$

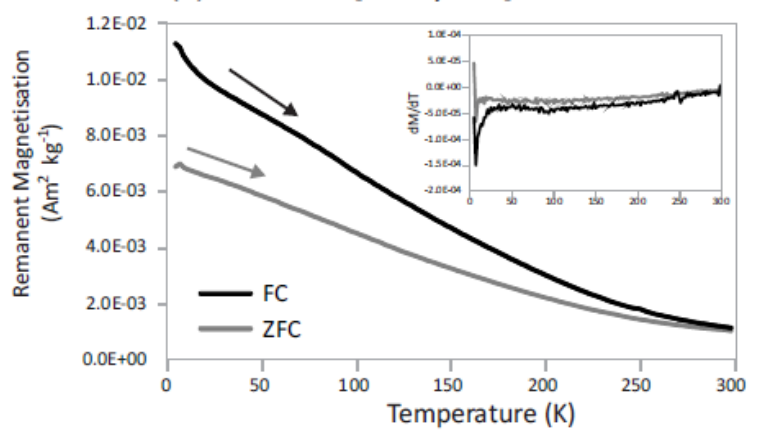

(c) $335 \mathrm{~cm} \quad$ [38.3 kyr BP]

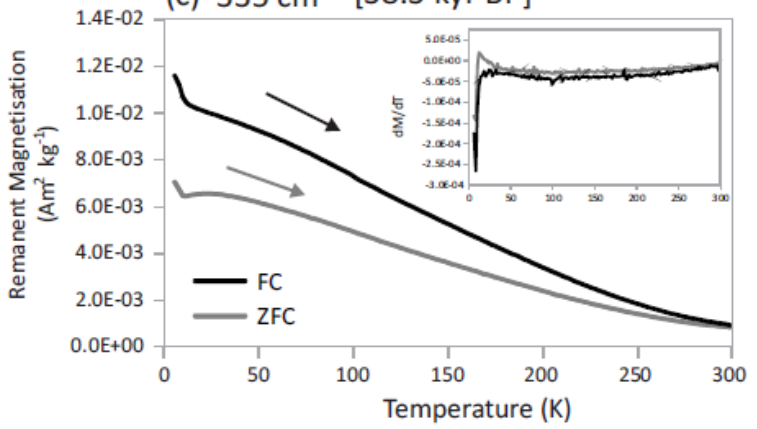

(b) $75 \mathrm{~cm} \quad[15.1 \mathrm{kyr} \mathrm{BP}]$

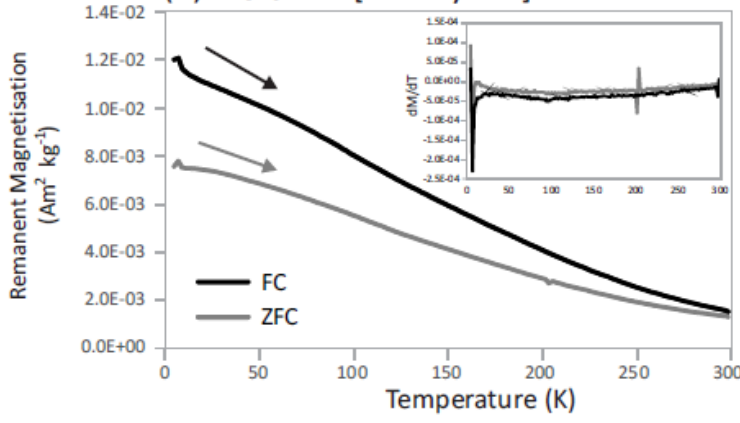

(d) $510.5 \mathrm{~cm}[61 \mathrm{kyr} B P]$

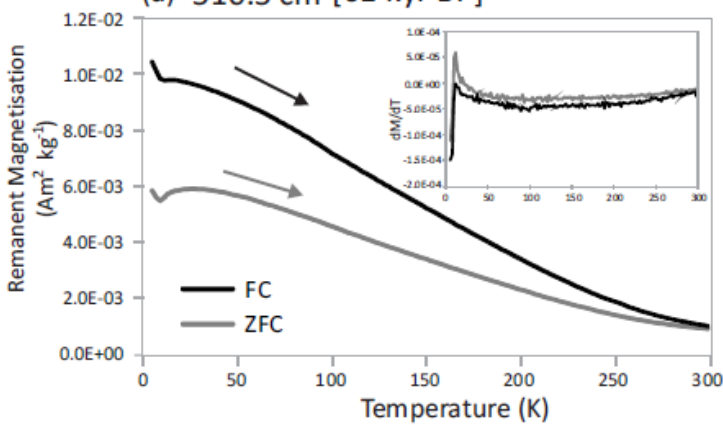

(e) $630 \mathrm{~cm} \quad$ [79.5 kyr BP]

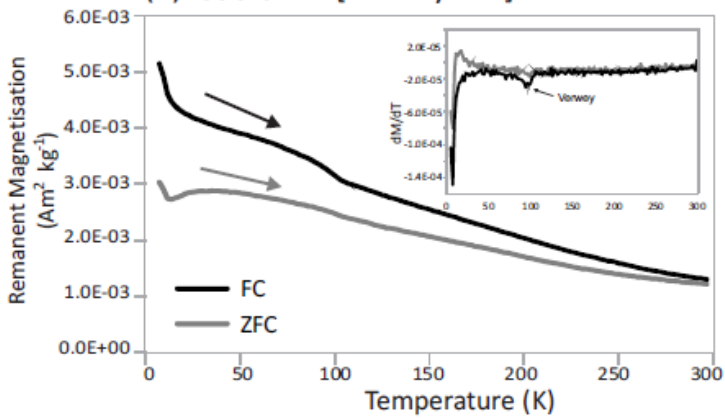

Figure 6.20: Low temperature measurements of samples obtained in intervals with dominant endmember contribution of (a)EM3, (b) EM1 +EM2, (c)EM1, (d)EM1 +EM2 and (e)EM2. 
All our samples exhibit ZFC and FC curves that converge at higher temperatures. The convergence between FC and ZFC warming curves was attributed previously to the presence of goethite (Just et al., 2012a). Sample $630 \mathrm{~cm}$ (EM2) is the only one that shows the Verwey transition at $120 \mathrm{~K}$ (Figure 6.20). It confirms the presence of (titano)magnetite, inferred before based on IRM acquisition curves (Figure 6.17).

(a) $20 \mathrm{~cm} \quad[9.5 \mathrm{kyr} \mathrm{BP}]$

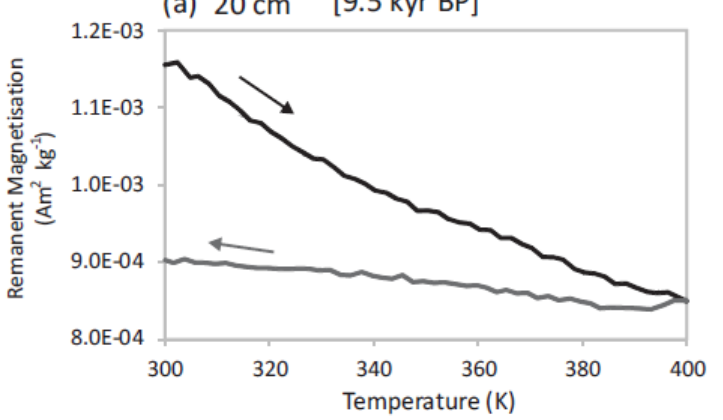

(c) $335 \mathrm{~cm} \quad$ [38.3 kyr BP]

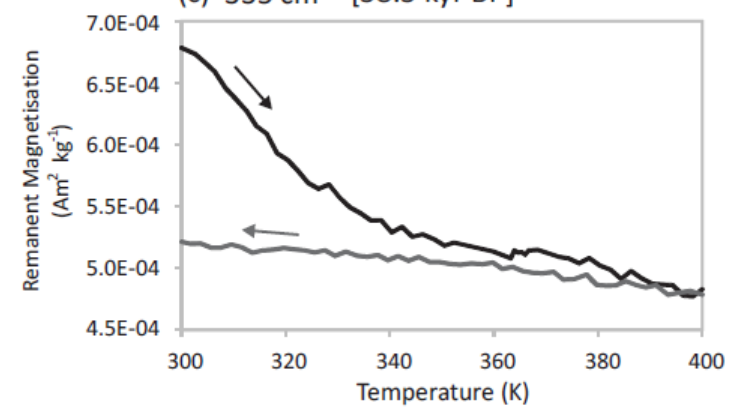

(b) $75 \mathrm{~cm} \quad[15.1 \mathrm{kyr} \mathrm{BP}]$

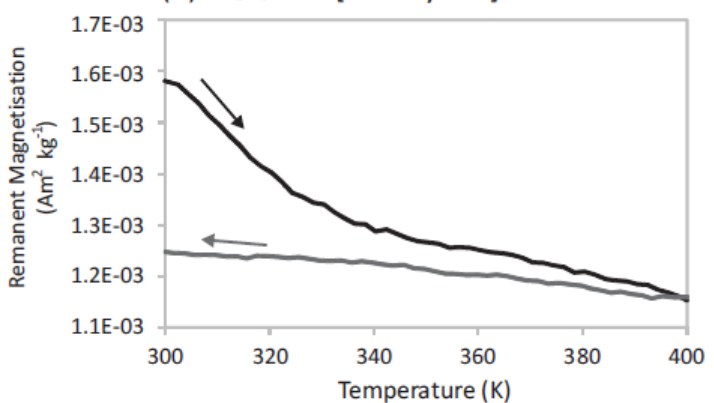

(d) $510.5 \mathrm{~cm}[61 \mathrm{kyr} \mathrm{BP}]$

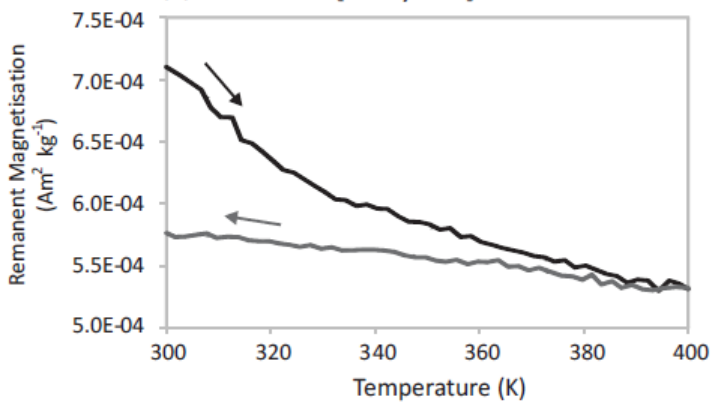

(e) $630 \mathrm{~cm} \quad$ [79.5 kyr BP]

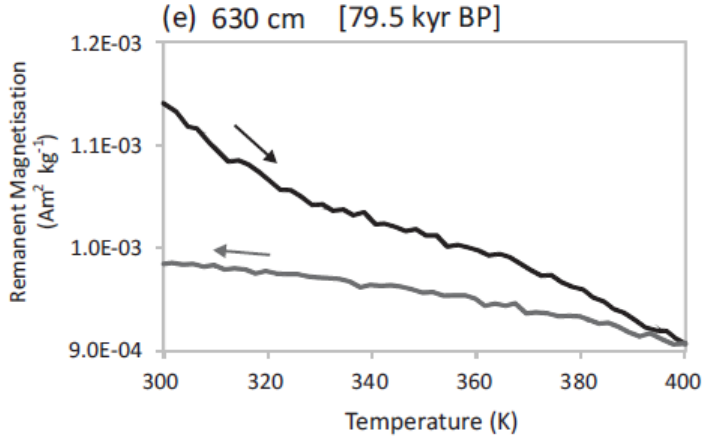

Figure 6.21: High temperature measurements of samples obtained in the intervals with dominant endmember contribution of (a) EM3, (b) EM1 + EM2, (c) EM1, (d)EM1 + EM2 and (e) EM2.

SIRM warming is presented in Figure 6.21, with heating between 300 and $400 \mathrm{~K}$ (black curve), and cooling back (gray curve). Samples 75, 335 and $510.5 \mathrm{~cm}$ (Figure $6.21 \mathrm{~b}, \mathrm{c}$ and d) show a 
significant loss in magnetization after heating up to about $340 \mathrm{~K}$. The Curie temperature for pure goethite is about $120^{\circ} \mathrm{C}$ ( or $390 \mathrm{~K}$ ), but in pedogenically formed goethite Al-substitution is quite normal and it would decrease Curie temperature, as well as the presence of water in the structure (Just et al., 2012a) explaining the transition temperatures observed. It is important to notice that these samples with sharper lost in magnetization have dominance of EM1 (Figure $6.14)$. 


\section{DISCUSSION}

\subsection{Deglacial sea-level and hydrographic control on sediment supply}

Magnetic and chemical data for the Holocene contrast with patterns and baseline values recorded during part of the Last Glacial Period ( 85 up to $12 \mathrm{kyr}$ BP) in our four cores (Figure 6.1 - Figure 6.9). After the onset of Holocene, all indicators of detrital input show a marked decrease, including magnetic susceptibility, HIRM and $\mathrm{Fe} / \mathrm{Ca}$, indicating less terrigenous material being delivered to the continental margin. H. W. Arz et al. (1999) presented previously element data for core GeoB3911-3 and showed a remarkable diminution of terrigenous input after $11 \mathrm{ka} \mathrm{BP}$. These authors attributed this change to the flooding of riverine systems at high sea-level stand, which retained detrital sediments on the continental shelf. In all cores studied here, there is an increase in S-Ratio parameter during the Holocene, with values higher than 0.96, indicating a clear predominance of low-coercivity phases, i.e. magnetite. This increased S-Ratio reflects the presence of SD-magnetite, and suggests the inception of the marine dominance in the margin off NE Brazil. Susceptibility, HIRM and S-Ratio confirm the scenario already described before for NE Brazil margin. However, we observed compositional differences between our cores using some magnetic parameters. For example, IRM $300 \mathrm{mT}$ increases in cores GeoB3912-1 (Figure 6.3), GeoB3911-3 (Figure 6.4) and GeoB3910-2 (Figure 6.5) during the Holocene (gray curve), suggesting the presence of an additional phase of highly-magnetic material in the eastern cores. This additional phase does not appear in core GeoB3913-3, as we observe from its low values of $\operatorname{IRM}_{300 \mathrm{mT}}(<800 \mathrm{~mA} / \mathrm{m}$; Figure 6.2a).

Major element ratios were used as a signature for weathering processes in the source regions. The $\mathrm{Al} / \mathrm{Si}$ ratio tracks weathering intensity, since $\mathrm{Al}$ is mostly associated with fine-grained clay minerals, in particular kaolinite, which is product of chemical weathering under wet conditions (Govin et al., 2012). Smaller baseline values of Al/Si in the Holocene for cores GeoB3913-3, GeoB3912-1 and GeoB3911-3 indicate the dominance of a dry climate over the continent during this epoch (Figure 6.6 - Figure 6.8). Additional information can be provided by the Fe/K ratio. In marine sediments $\mathrm{K}$ is provided by minerals typical from dry regions, such as potassium feldspar or illite (Zabel et al., 2001), thus low $\mathrm{Fe} / \mathrm{K}$ values suggest a decrease in chemical weathering. Mulitza et al. (2008) used Fe/K ratio to distinguish between dust and river supply, the high values of this ratio indicating higher riverine input. A drop in Fe/K ratio during the Holocene is observed in cores GeoB3912-1, GeoB3911-3 and GeoB3910-2 (Figure 6.7 - 
Figure 6.9), attesting to the increasingly drier climate in NE Brazil. Crossplots between Ti and $\mathrm{K}$, show much higher values for $\mathrm{K}$ in core GeoB3910-2 when compared to the other cores during the Holocene, suggesting drier conditions in the eastern part of NE Brazil, where the continental sources for this core are located (Figure 7.1d, bottom panel). Conversely, in core GeoB3913-3, which is sourced from the west, the Fe/K ratio increases up to the middle Holocene and just after that it starts to drop attesting to the complex climate dynamics at the studied region.

Sea level has increased along the NE Brazilian coast by $\sim 120 \mathrm{~m}$ after its minimum low-stand that took place in the last glacial period. Such sea-level rise lead to the drowning of river mouths, and consequently limited the sourcing of sediments to the continental shelf (Knoppers et al., 1999). Recent studies have delineated changes in the geomorphology of the continental shelf off NE Brazil and revealed important features that mark the coast line in the past and the direction of paleo-channels (e.g. Gomes et al., 2014; Vital et al., 2010a; Vital et al., 2010b). It confirms previous works that indicate continental sediment delivery deeper than today $(\mathrm{H}$. W. Arz et al., 1999; Knoppers et al., 1999). The geometry of the coast affected directly the debouching of detrital material to the continental slope off NE Brazil by the incised-valley system of Piranhas-Açu River (Vital et al., 2010b) and estuary-incised valley system of ApodiMossoró River (Vital et al., 2010a), being therefore relevant to explain the longitudinal distribution of sediment along the continental margin by the NBC.

In our cores, the high input of magnetite (increase in S-Ratio parameter) reflects the marine influence (Figure 6.2 - Figure 6.5). During the high stand sea-level, sediments that would reach the continental slope and the abyssal plain are transferred northwestward by the NBC. In this configuration, Apodi-Mossoró and Piranhas-Açu rivers would have been the main source of detrital material to cores GeoB3910-2 e GeoB3911-3, and the Jaguaribe river (or occasionally the Parnaíba river) would feed cores GeoB3912-1 and GeoB3913-3. Differences recorded among the cores in the last $12 \mathrm{ka} \mathrm{BP}$ are correlated to their longitudinal position along the coast and in consequence to their riverine supply. Low IRM $\mathrm{IROmT}_{30 \mathrm{~m}}$ in the westernmost core GeoB39133 (Figure 6.6), recording the lesser amounts of fine-grained magnetite, is probably associated to a higher degree of chemical weathering on land at least until the middle Holocene. The same would be expected for core GeoB3912-1, if one assumes it has the same source. However, the

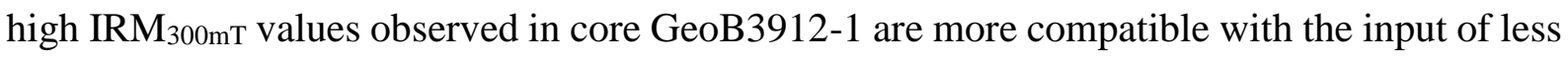
coercive material from Apodi-Mossoró and/or Piranhas-Açu River that could have reached core 
GeoB3912-1 during that time, but not the westernmost core GeoB3913-3. The magnetic minerals present in the soils of the NE Brazil differs significantly from west, in Parnaíba Basin, to east, in Borborema Province. Journet et al. (2014) in a global study for soil mineralogy have shown that coercive magnetic minerals (i.e. hematite and goethite) are dominant in the western part of our study area, whilst in the east the prevalence of (titano)magnetite was reported (Archanjo et al., 2002; Knesel et al., 2011; Trindade et al., 2006). The increase in sedimentation rates during the Holocene would be modulated by changes in precipitation over the source areas, and its consequent impact on rivers supply.

In general, EM1 and EM2 are strongly controlled by continental sources. EM1 is composed mainly by a mixture between highly coercive magnetic phases (i.e. goethite and hematite) originated from mature soils from humid regions (Figure 6.20 and Figure 6.21). EM2 is composed dominantly by fine-grained low-coearcive pedogenic magnetic phases (i.e. magnetite, Figure 6.20e). We attributed the third end-member (EM3) to biogenic magnetite, formed in-situ.

For the late Holocene there is a clear partition between end-members distributions from west to east. Core GeoB3913-3, the westernmost core, shows a gradual decrease in all magnetic contributions after $\sim 15 \mathrm{kyr}$ BP (Figure 6.13). After about $7 \mathrm{kyr}$ BP, EM1 drops to zero and both EM2 and EM3 present even contributions up to almost 3 kyr BP. In core GeoB3912-1 contribution of EM1 also drops significantly at about $7 \mathrm{kyr}$ BP concomitant with a sharp increase in contributions of EM2 and EM3 (Figure 6.14). In this core, EM3 is dominant for the last $10 \mathrm{kyr}$. In the easternmost core GeoB3910-2, EM1 never reaches zero. EM2 and EM3 show a significant increase in EM2 and EM3 at $\sim 8 \mathrm{kyr}$ BP and $\sim 13 \mathrm{kyr}$ BP, respectively. Differences in the timing of delivery increase in EM2 and EM3 as recorded in cores GeoB3912-1 and GeoB3910-2 may be attributed to the gradual sea-level increase, with the deepest core (GeoB3910-2) experiencing stronger variations in their detrital inputs first. Significant changes recorded in all cores at $\sim 7 \mathrm{kyr}$ BP are likely due to the rapid increase in sea-level recorded globally between 8-7 kyr BP. In core GeoB3912-1, there is a marked inverse correlation between EM2 and EM3, with an increase of EM3 concomitant to a decrease in EM2. This trend suggests an increase in marine sources, as we expect from the high stand sea-level in Holocene (Figure 5.3). 


\subsection{Climate driven sediment pulses, in relation to precipitation}

Conditions prevailing during the last glacial period contrasted significantly with those dominating in the Holocene (e.g. H. W. Arz et al., 1999; Baker et al., 2001; Fleming et al., 1998). All four marine cores we present here show wetter climate between 85-12 kyr BP in comparison to the Holocene. This is visible from the baseline values of some magnetic and geochemical parameters, which indicate higher terrestrial input (susceptibility, HIRM, Fe/Ca) and intensive weathering ( $\mathrm{S}$-Ratio, $\mathrm{Fe} / \mathrm{K}$ and $\mathrm{Fe} / \mathrm{\kappa}$ ) during the glacial period (Figure 6.2 - Figure 6.9). Peaks in concentration indicators, such as susceptibility (orange curves) and HIRM (dark blue curves), reflect higher terrigenous input to the continental shelf and slope during HS. The most remarkable changes in magnetic types are observed in parameters that reflect humid conditions on land, like drops in S-Ratio (black curves) and peaks in HIRM (dark blue curves); both suggesting the presence of more coercive magnetic phases, which are formed during weathering (i.e. hematite and goethite). In most of HS, both S-Ratio and HIRM peak in the beginning of the events and then drop gradually towards the end, suggesting changes in the weathering processes and a gradual change in the source of sediments during HS. High values of $\mathrm{Fe} / \mathrm{\kappa}$ ratio (light green curves) during $\mathrm{HS}$ also confirm the presence of antiferrimagnetic minerals (hematite and goethite). It fits the S-Ratio drops mentioned before. IRM $\mathrm{M}_{300 \mathrm{mT}}$ values (gray curves) are mirrored by the S-Ratio parameter, showing the expected decrease in magnetite regarding hematite and goethite during the stadials. The grain-size indicator $\mathrm{ARM}_{100 \mathrm{mT}} / \mathrm{IRM}_{100 \mathrm{mT}}$, does not show coeval changes between the cores during the eight HS recorded here, but it shows smaller values during the Pleistocene in comparison to the Holocene for all cores (pink curves). Core GeoB3913-3 (Figure 6.2) exhibits a $\mathrm{ARM}_{100 \mathrm{mT}} / \mathrm{IRM}_{100 \mathrm{mT}}$ increment from the beginning of HS1, whereas in cores GeoB3912-1 (Figure 6.3) and GeoB3911-3 (Figure 6.4) it starts to increase from the end of HS1, while in core GeoB3910-2 (Figure 6.5) it reaches high values after the middle of HS1. Magnetic parameters for core GeoB3911-3 show some signals of dissolution due its high sedimentation rate (Figure 6.1), with significant terrigenous input. The expected high values of concentration parameters susceptibility and HIRM show an abrupt decrease towards the end of HS1 and during the YD (orange and dark blue curves). High coercivity magnetic minerals would be expected during these wet events, but S-Ratio increases coevally, suggesting the presence of newly formed fine magnetic minerals (Rowan et al., 2009). For the same core, Fe/Ca ratio also shows dissolution of iron towards the end of HS1 and during YD, and the increase in Fe/ $\kappa$ confirms the dissolution 
of ferromagnetic iron in these redox layers (Figure 6.8). During B-A, the parameters that indicate an increase in the concentration of magnetic minerals peak abruptly and the S-Ratio drops, suggesting humid condition over land (Figure 6.4).

Changes in weathering conditions recorded by magnetic indicators were identified also through geochemical proxies. Element data for core GeoB3913-3 exhibit remarkable peaks which are synchronous to HE (Figure 6.6). Cores GeoB3913-3 and GeoB3912-2 (Figure 6.7) recorded an increase in $\mathrm{Al} / \mathrm{Si}$ values during $\mathrm{HS}$, suggesting intensified chemical weathering during humid periods (green curves). We observed more prominent peaks in the eastern core (GeoB3912-1) during HS than in those located to the west (GeoB3913-3). This can be related to differences in precipitation regimes from west to east during the Pleistocene, with a more humid climate in the west during the interstadials (GeoB3913-3) and a more contrasted climate to the east (core BeoB3912-1), with drier interstadials and more humid stadials resulting in the stark contrast in the geochemical signals in core GeoB3912-1.

Well-documented wet conditions prevailing over NE Brazil region resulted in significant terrestrial input triggered by increased precipitation during HE (e.g. Arz et al., 1998; H. W. Arz et al., 1999; Behling et al., 2000; Dupont et al., 2009; Jennerjahn et al., 2004). These changes are the most remarkable climate signature of our records, which show well defined peaks/drops during Heinrich Stadials (HS). Changes in detrital sediments that reach the continental margin off NE Brazil has been recorded previously for some of the cores presented here. Arz et al. (1998), for example, related peaks in Fe/Ca ratio for core GeoB3912-1 to the Heinrich Events (HE) and attributed higher terrigenous input to humid conditions in the continent and resedimentation processes related to short-term sea-level changes. Still for core GeoB3912-1, Jennerjahn et al. (2004) found an asynchronicity between marine and terrestrial signals during the cold events of the North Atlantic, based on a multiproxy record. Element data for core GeoB3911-3 also showed higher terrigenous sediment influx caused by enhanced precipitation and increased riverine input (Figure 6.8; H. W. Arz et al., 1999). Jaeschke et al. (2007) identified peaks in detrital sediments using Ti/Ca ratio for core GeoB3910-1, which they related to HE. In paleoclimate studies, Ti/Al ratio is associated with wind intensity versus riverine supply (Itambi et al., 2009); coarse sediments are enriched in $\mathrm{Ti}$, and $\mathrm{Al}$ is mostly associated with fine-particle clay minerals (Govin et al., 2012). In NE Brazil, the winds blow from NE, following the north-south displacement of the ITCZ, and especially during the HS the trade winds are remarkably intensified (Weldeab et al., 2006). Even with an intensified ITCZ over 
NE Brazil, riverine supply seems to be more important during HS, due to the concurrent humid conditions on land. In core GeoB3912-1 (Figure 6.7), Ti/Al increases during HS as expected during wet stadials, but in core GeoB3911-3 only slight changes were detected (Figure 6.8). The most remarkable change in Ti/Al ratio was observed in core GeoB3913-3, at about $54 \mathrm{ka}$ BP. At this time, Ti/Al values increase significantly to higher baseline values. We attributed this abrupt increase that lasted up to the Holocene to a decrease in the intensity of trade winds.

Differences between stadials and interstadials are noticeable in downcore plots, but we show here some crossplots for our four cores using magnetic and geochemical parameters (Figure 7.1) aiming to make it clearer. Using two magnetic parameters (S-Ratio versus susceptibility; Figure 7.1a) it is possible to see the increase in concentration of magnetic minerals (high susceptibility) concurrent with the increment of low coercive phases (low S-Ratio). In tropical and subtropical regions, where organic carbon content and moisture availability are generally related, the abundance of goethite over hematite can be used as an indicator of higher precipitation, whereas low values imply drier/warmer conditions (Abrajevitch et al., 2009). Jennerjahn et al. (2004) found this correlation between organic carbon and humid conditions during HE in NE Brazil. Thus, during the Pleistocene, a high amount of coercive magnetic minerals in periods of enhanced precipitation can be associated to soil formation, with oxidation of magnetite and formation of hematite and goethite. Crossplotting geochemical and magnetic parameters $\mathrm{Fe} / \mathrm{Ca}$ and $\mathrm{HIRM}$, we observe a linear correlation, reflecting an increase in detrital influx from interstadials to stadials (Figure 7.1, middle panels). HIRM for the western core GeoB3913-3 show the highest values, suggesting higher contribution of oxidized phases from the Parnaíba Basin (Figure 7.1a). Note that this scenario requires that during stadials at least part of the sediments sourcing core GeoB3913-3 to be provided by the Parnaiba river located to the west of the sampling site, and consequently implies either a reversal of the North Brazilian Current (NBC) or a significant reduction in its intensity locally. 


\section{W}

- Stadials - Interstadials $\bullet$ Holocene

(a) GeoB3913-3
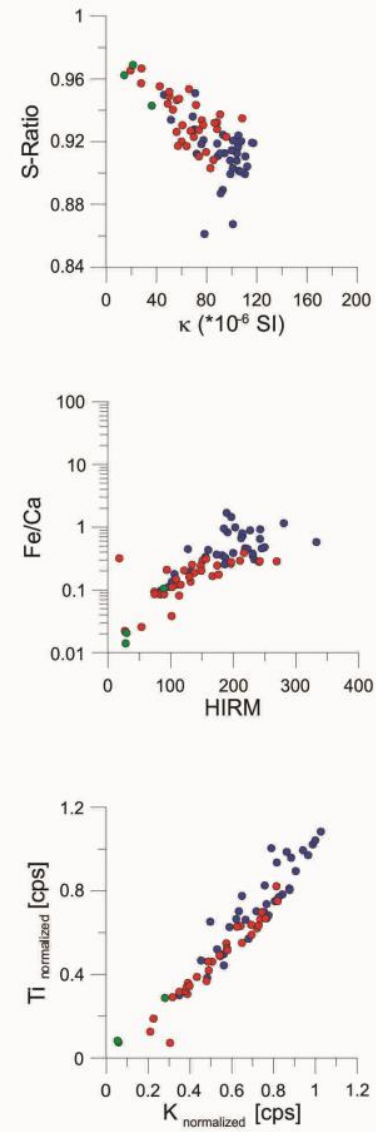

(b) GeoB3912-1
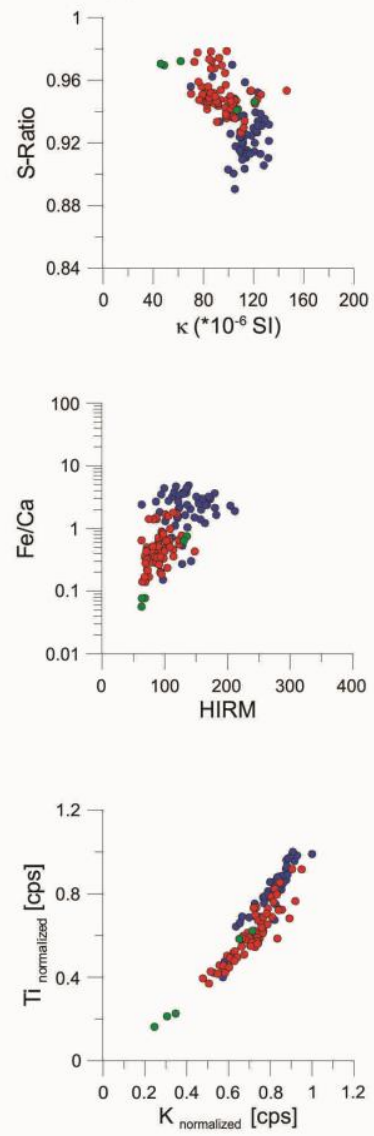

(c) GeoB3911-3
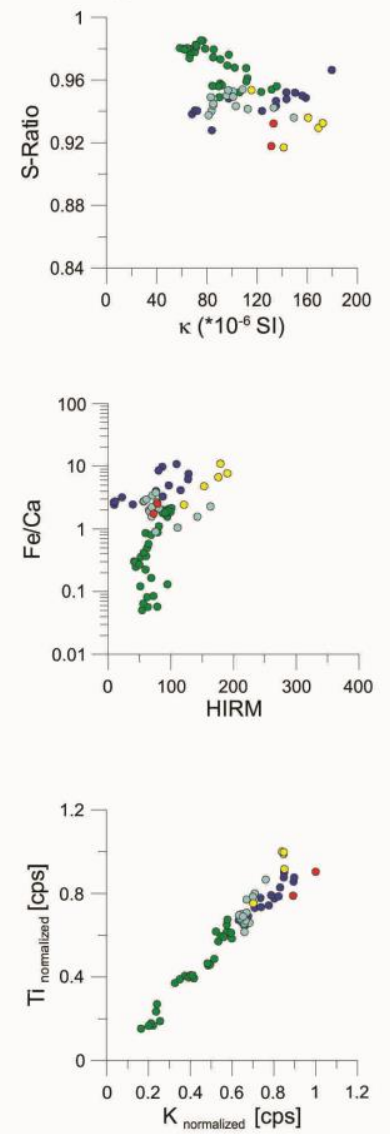

(d) GeoB3910-2
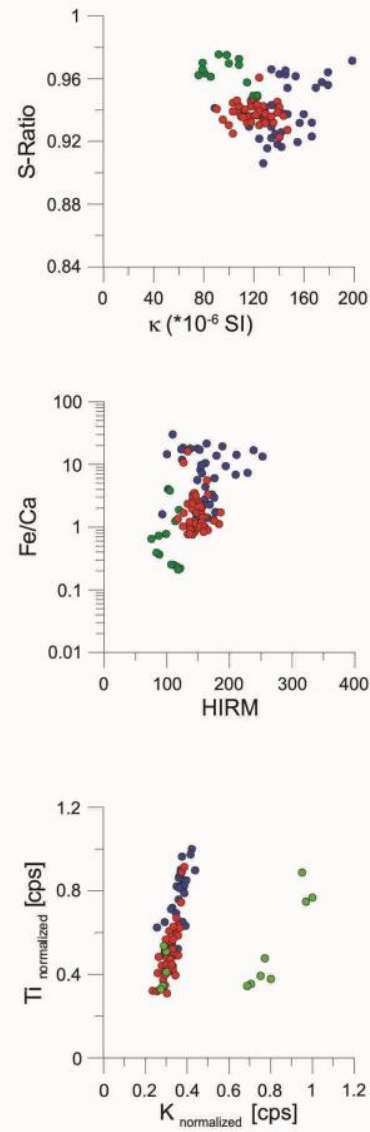

Figure 7.1: Crossplots using magnetic and geochemical parameters for the different cores: (a) GeoB3913-3, (b) GeoB3912-1, (c) GeoB3911-3, and (d) GeoB3910-2.

The increase in precipitation over NE Brazil during HE is widely accepted and also its link to the enhanced terrigenous input. This is clearly demonstrated by the magnetic parameters reported here. The end-member analysis, just like magnetic and geochemical proxies, also indicates drier conditions during the Holocene in the margin of NE Brazil. Peaks in highcoercive EM1 component during HS in cores GeoB3913-3 (Figure 6.13) and GeoB3912-1 (Figure 6.14) are remarkable, especially for core GeoB3912-1, where these peaks are very sharp and reinforce the presence of low-coercive pedogenic magnetite during humid events. In core GeoB3913-3, the same component is absent during the YD, as expected from the rock magnetic parameters S-Ratio and HIRM for the same interval (Figure 6.2). Core GeoB3910-2 shows a very different behaviour in terms of distribution of end-members along the HS. EM1 decreases 
for HS1, HS4 and HS5, and EM2 becomes important at the same intervals (Figure 6.15). The high contribution of EM2 during HS4 and HS5 suggests that the transport of (titano)magnetite from the Borborema Province was more important during these events. They are coeval with a sharp increase in S-Ratio (Figure 6.5), that is compatible with the dominant presence of magnetite and represents an enrichment of a distinct phase during stadials, when compared with the coeval peaks in high-coercive EM1 observed for the other cores. In addition, core GeoB3910-2 shows a contrasting behaviour for HS2 and HS3 when compared to HS1, HS4 and HS5. Suppression of HS2 and HS3 records has also been marked in other proxies in the same region and elsewhere ( $\delta^{18} \mathrm{O}$ in Hulu cave, Cariaco basin reflectance), and has been attributed to periods of lower precipitation during $\mathrm{H} 2$ and $\mathrm{H} 3$, which correspond to periods of low austral autumn insolation (Wang et al., 2004). Another possibility is that HS2 and HS3 represent periods of dislocation of the precipitation dipole between Amazon and NE Brazil (Cheng et al., 2013), when HS would correspond to drier intervals over the eastern sectors of NE Brazil. Note that HS for cores GeoB3913-3 and GeoB3912-1, located in central and western sectors of the studied transect do not show significant differences between HS2 and HS3, and HS1, HS4 and HS5 (Figure 6.13 and Figure 6.14).

\subsection{The W-E source area pattern}

The complex circulation pattern in the western equatorial Atlantic is a response to surface and intermediated waters exchanges between austral and boreal hemispheres, which play an important role in the sea surface temperature (SST) gradient throughout the equator. Droughts in Amazonia and NE Brazil, for instance, have been linked to anomalously warm surface waters in the tropical North Atlantic (Cruz et al., 2009). Likewise, humid periods over NE Brazil during HE have been connected to the southward migration of the ITCZ (e.g. Arz et al., 1998; H. W. Arz et al., 1999; Behling et al., 2000; Dupont et al., 2009; Jennerjahn et al., 2004; Wang et al., 2004). This connection between North Atlantic and tropical Atlantic waters, has been also observed in climate simulations, which suggest that the AMOC almost collapsed during fresh water input over the North Atlantic Ocean (Kageyama et al., 2013a) and could also cause a reversion of the NBC (Chiang et al., 2008). Considering a change in direction of NBC, a difference in sediment sources feeding the continental shelf would be expected. Yet, the magnetic and geochemical parameters reported here do not corroborate a NBC inversion at least 
for the last $85 \mathrm{kyr}$ BP. Our cores show some differences in geochemical and magnetic signals along the coast (Figure 7.2), but we attribute these longitudinal dissimilarities to the weathering degree of different sources associated to the W-E precipitation patterns. Variation in concentration of magnetic minerals from west to east are clear in the crossplots using mean values for S-Ratio versus susceptibility during Holocene, stadials and interstadials (Figure 7.2a). This plot shows higher availability of ferrimagnetic minerals (i.e. magnetite, with high susceptibility values) in the eastern cores; and smaller amounts of this magnetic mineral further west. On this plot, the separation between wet (stadials) and dry (interstadials) trends amid Holocene and Pleistocene epochs is quite clear. S-Ratio values suggest that the oscillation between periods when magnetite dominates and periods when more coercive phases (hematite and goethite) dominate is likely controlled by the climate conditions over the continental source basins rather than by core location. During humid periods (HS) the entire margin off NE Brazil was affected in the same way by increased precipitation over the continent, with only slight differences (Figure 7.2a). Blue symbols, which show samples from stadials, exhibit similar mean values for all the cores. Conversely, during interstadials or in the Holocene epoch (red and green symbols, respectively), mean values for different cores plot more apart from each other. This suggests that during HS, changes in the W-E sediment deposition were more similar along the coast than during interstadials and the Holocene. 

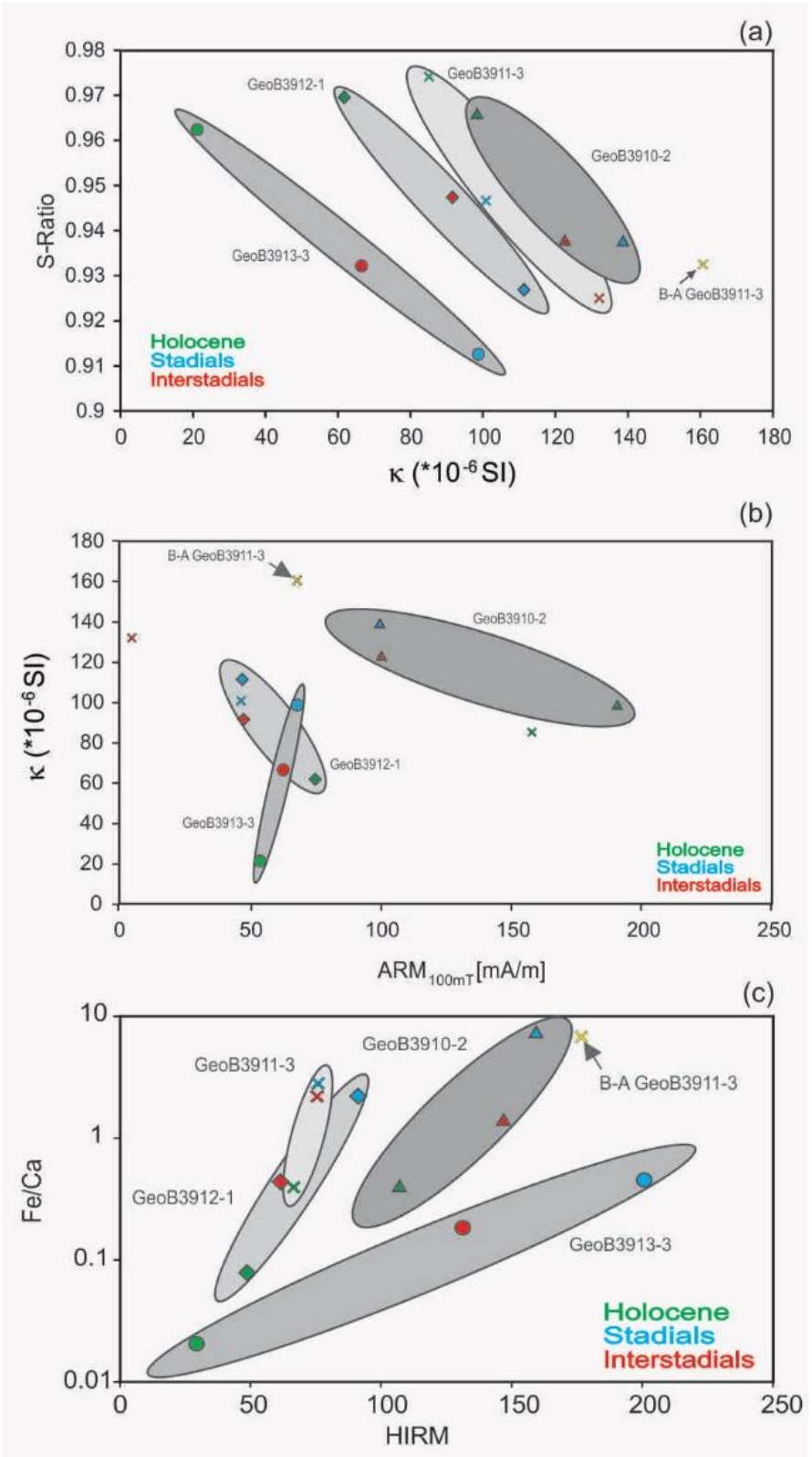

Figure 7.2: Crossplots using the mean value of magnetic and geochemical parameters for wet (stadials, blue) and dry (interstadials, red) condition in NE Brazil, and during Holocene (green). Yellow dots represent BøllingAllerød (B-A) oscillations.

The dominance of fine-grained magnetite in the eastern cores is also evident, based on the parameter $\mathrm{ARM}_{100 \mathrm{mT}}$ (Figure 7.2b). High values of $\mathrm{ARM}_{100 \mathrm{mT}}$ in core GeoB3910-2 suggest the dominance of titano(magnetite), probably related to the source areas in the Borborema Province, whilst in the west there is a clear dominance of coercive phases marked by lower values of parameters such as susceptibility and $\mathrm{ARM}_{100 \mathrm{mT}}$. Studies in soils and bedrocks from 
Parnaíba Basin (Journet et al., 2014) and Borborema Province (Archanjo et al., 2002; Knesel et al., 2011) suggest the presence of more coercive phases in the west and less coercive phases to the east. This tendency is further reinforced by recently published magnetic susceptibility and geochemistry data of a marine sediment core collected to the west of the Parnaíba River's mouth (Nace et al., 2014). In this study, core CDH-86 systematically shows high values of $\mathrm{Ti} / \mathrm{Ca}$ associated to low values of susceptibility for the last $120 \mathrm{ka} \mathrm{BP}$, and the authors attribute this pattern to the prevalence of high coercive magnetic phases hematite and goethite sourced from the Parnaíba Basin. We observed peaks of susceptibility in our four cores during stadials (Figure 6.2 - Figure 6.5, orange curves), but it is remarkable that these peaks are less intense in the cores collected to the west (Figure 7.2a and 7.2b). The fact that Nace ey al. (2014) did not report a more detailed magnetic study prevents us to go further in such a comparison. Still, considering gradually higher values of susceptibility and S-Ratio from west to east, we suggest a change in the main magnetic phase being sourced from the continent.

The main W-E difference among the end-members in our three cores is their contribution during HS. In western cores GeoB3913-3 and GeoB3912-1, EM1 peaks during HS, whilst in core GeoB3910-2 it drops during HS1, HS4 and HS5 (Figure 6.15). During HS2 and HS3 no significant changes are observed between end-member contributions on this core. Sharp peaks of EM1 along core GeoB3912-1 may be a response to intense precipitation over NE Brazil, as suggested before (Jennerjahn et al., 2004). The absence of peaks in $\mathrm{H} 2$ and $\mathrm{H} 3$ along core GeoB3910-2 could be a reflex of the different sourcing in this point. H2 and H3 are typically less intense and shorter events, and in this way not necessarily affected the river catchment area significantly to provide a detectable increase in sediment supply in the eastern region.

\subsection{Climate and paleoceanographic models}

Enhanced precipitation over NE Brazil has been previously attributed to a southward migration of the ITCZ during cold periods recorded in the North Atlantic Ocean. Kageyama et al. (2013a) simulating the input of freshwater in North Atlantic, obtained a consistent response to increased precipitation over tropical Atlantic, related to southward migrations of the ITCZ. The authors based the simulation on six different models, all considering ocean-atmosphere interaction with a resolution between $1^{\circ}-3^{\circ}$, and most of them accounting for free-ocean surface. Analysing three glacial coupled atmosphere-ocean simulations, Kageyama et al. (2009) found a reduction from 
$18 \mathrm{~Sv}$ to $15 \mathrm{~Sv}$ in the AMOC after a decrease of $0.08 \mathrm{~Sv}$ in the flux of fresh water into the North Atlantic Ocean. Model results are corroborated by geochemical data obtained on foraminifer shells from core GeoB3911-3 by Weldeab et al. (2006). These authors show that NBC play a crucial role in the inter-hemispheric heat and salinity exchange. This large current $(\sim 300 \mathrm{~km})$ could have played less important role during the last glacial period, enabling the deposition of terrigenous material far from the coast, in the continental slope (H. W. Arz et al., 1999). Thus, stadials, which are periods with clear prevalence of terrigenous input over the continental slope off NE Brazil, are coincident with AMOC weakness, and consequently, with a decrease in the intensity of the NBC. Chiang et al. (2008), by their turn, proposes that the weakness of the AMOC would promote an abrupt transition in the North tropical Atlantic, reversing the NBC.

Recently, Liedtke (2014) proposed a series of circulation models using the Regional Ocean Model System (ROMS; Shchepetkin, 2003; Shchepetkin and McWilliams, 2005). ROMS is a 3D ocean model that solves the free-surface hydrostatic equations on vertical coordinates that follow the bottom topography (Shchepetkin and McWilliams, 2005). Liedtke (2014) ran four models off NE Brazil: Models 1 and 2 simulate the present-day conditions using wind shear models CODES and Trace21ka project, respectively; and models 3 and 4 simulated paleoceanographic conditions during Heinrich Events (16,000 years BP) and are therefore of great interest to our work. Both used wind stress models from Trace21ka project (50 years average, monthly) but model 4 also used a different shoreline, equivalent to a $120 \mathrm{~m}$ sea-level drop to emulate glacial times (e.g. Knoppers et al., 1999). Oceanographic currents and SST outputs from models 1 and 2 match present-day observations attesting to the robustness of the models. These models show the South Equatorial Current (SEC) along the equator and its countercurrent at around $5^{\circ} \mathrm{N}$ with higher intensity in July (Figure 7.3a). The North Brazilian current (NBC) runs along the coast from southeast to northwest. Model 2 shows current rings around the Ceará Rise that were described previously by Fratantoni and Richardson (2006) and Wilson et al. (2011). Interestingly, for 16,000 years ago there is a significant northward shift of the SEC (Figure 7.3b). In January simulations, it runs at around $4^{\circ} \mathrm{N}$, hits the coast at longitude $44^{\circ} \mathrm{W}$ close to the Parnaiba river mouth, and strongly influences the intensity of the NBC. Right to the east of the Parnaiba mouth, the intensity of the NBC is significantly reduced or, at some points, vectors show reversed directions (flow lines point to the east and southeast). In the present day condition, the SEC is much weaker. It does not affect the NBC, which runs towards the northwest until $56^{\circ} \mathrm{W}$. 

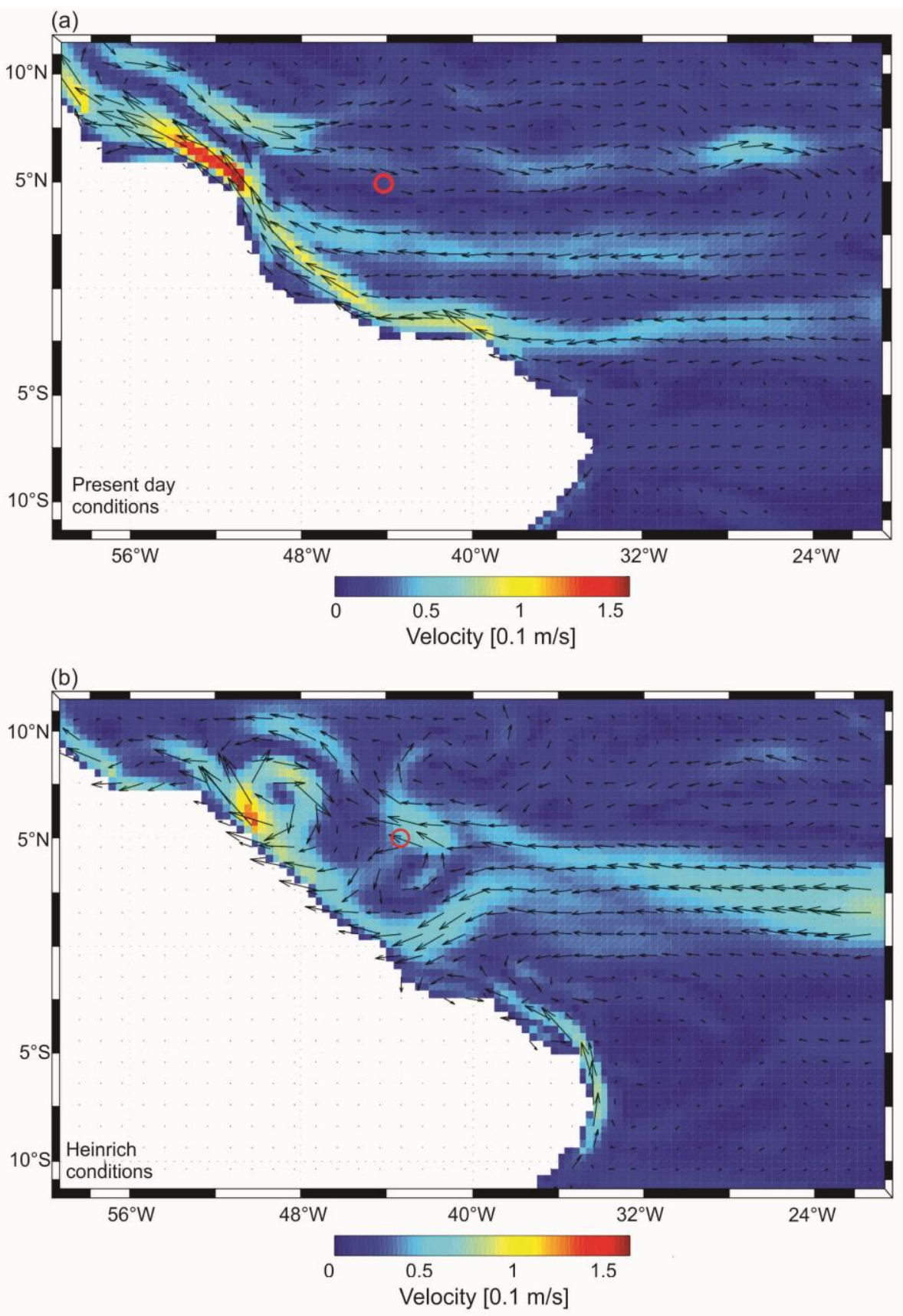

Figure 7.3: Flow velocities along the Equatorial Atlantic off North and Northeast Brazil from Liedtke (2014). (a) simulation 1 for July, (b) simulation 4 for January. Red circle indicates the Ceará Rise.

The inflow of highly coercitive magnetic material sourced by the Parnaiba basin to cores GeoB3913-3 and GeoB3912-1 during Heinrich Events is hard to explain with the present-day 
configuration of oceanographic currents, and the high strength of the NBC. Conversely, with the northward shift of SEC predicted by Lietdke (2014) models during Heinrich Events (Figure $7.3 \mathrm{~b}$ ), that severely affect the strength of the NBC and eventually promotes a local flow inversion right to the east of the Parnaíba mouth, sediments from the Parnaíba river can effectively reach the sites where cores GeoB3913-3 and GeoB3912-1 were sampled. This configuration also explains the contrasting results observed between these cores and cores GeoB3910-2 and GeoB3911-3, where stadials H1, H4 and H5 are marked by a sudden increase in low-coercivity grains (EM2) sourced by the local rivers or from sources situated in the east and transported westward by the NBC. 


\section{Final Considerations}

This thesis describes the longitudinal sediment transport along the margin off NE Brazil for the last $85 \mathrm{kyr} \mathrm{BP}$ using environmental magnetism parameters and major element ratios $(\mathrm{Fe} / \mathrm{Ca}$, $\mathrm{Al} / \mathrm{Si}, \mathrm{Fe} / \mathrm{K}, \mathrm{Ti} / \mathrm{Al}$ ) for four marine cores (GeoB3913-3, geoB3912-1, GeoB3910-2 and GeoB3911-3). These data contribute to a better comprehension about sediment pathways and sources in the margin off NE Brazil, especially concerning differences between abrupt climate events (i.e. HE) and interstadials. End-member analysis based on IRM acquisition curves helped in the source sediment study. The models generated from the end-member analysis, resulting only from IRM acquisition curves, require additional substantiation from a detailed magnetic characterization at strategic depths. To support the interpretation, a magnetic characterization using hysteresis and low temperature curves was performed for core GeoB3912-1at strategic depths. The analysis performed here is hindered by the lack of detailed magnetic studies in the potential sources, a study that was out of the scope of the thesis. Magnetic data from sediment sources in Parnaíba Basin and Borborema Province, would be key to compare with the marine sediments from the continental margin. In a broader sense, reference magnetic data, especially IRM and low temperature curves, from soils formed under different climatic conditions in North and NE Brazil would help significantly in improving the interpretation of marine records from adjacent ocean basins.

The interpretation of the data was made in the light of previously published data and climate models for the western tropical Atlantic. Our results suggest a differential deposition of magnetic minerals along the coast, with highly coercive phases (hematite and goethite) further west, and gradually softer phases (like titanomagnetite) to the east. We attributed this difference mainly to differential oxidation over land, but secondarily we suggest a transport of coercive material from W-E during the stadials, caused by the weakness of NBC and possible changes in the coastal currents. Complete XRF scanning along core GeoB3910-2 is missing and could eventually help to support the interpretation suggested here. In addition, a further comprehension about the longitudinal sediment transport along the margin off NE Brazil, requires the study of magnetic and geochemical proxies along cores collected in an W-E transect wider than that studied here. Ideally, this transect would extend from the Parnaíba River mouth down to the coast east of Rio Grande do Norte State, where the SEC splays into the NS Brazil Current and NW-SE NBC (Figure 5.1). Isotopic data (i.e. $\mathrm{Sm} / \mathrm{Nd}$ and $\mathrm{Rb} / \mathrm{Sr}$ ) from the 
continental shelf and from the mouth of the Parnaíba, Jaguaribe, Apodi-Mossoró and PiranhasAçu rivers could bring new hints about sediment transport and sources, and the influence of the climate on the pathways and weathering on land. It is important to track sources from east, that nowadays transport sediment westward by NBC, especially during July, when this current is stronger due the northward migration of the ITCZ.

Nowadays, the main unsolved problem on the margin off NE Brazil concerns the configuration of the North Brazilian Current (NBC) during the abrupt events that took place during the last glacial. In this thesis, we attempted to address this problem and showed significant variations for a rather small range of longitudes along the coast off NE Brazil which depend on climatic changes on land and on the strength of oceanic currents. Additional magnetic and geochemical data jointly with climate simulations, that consider a set of boundary conditions that permit to understand the fluctuations on the AMOC (i.e. fresh water input in North Atlantic), evaporation and southward migration of the ITCZ (i.e. ocean-atmosphere interaction), sea-level changes, would be necessary to bring new information on this topic. High-resolution models and more paleoclimate records distributed along a wider longitudinal range would certainly improve our understanding about water exchange between the two hemispheres and help in understanding the mechanisms that control climate change on this region. 


\section{REFERENCES}

Abrajevitch, A., der Voo, R.V., Rea, D.K., 2009. Variations in relative abundances of goethite and hematite in Bengal Fan sediments: Climatic vs. diagenetic signals. Marine Geology 267, 191-206. Alley, R.B., 2000. The Younger Dryas cold interval as viewed from central Greenland. Quaternary Science Reviews 19, 213-226.

ANA, N.W.A.o.B.-. 2010. Termo de Referência Piranhas-Açu - versão aprovada pelo comite. ANA, N.W.A.o.B.-. 2014. Região Hidrográfica do Parnaíba.

Archanjo, C.J., Trindade, R., Bouchez, J.L., Ernesto, M., 2002. Granite fabrics and regional-scale strain partitioning in the Serido' belt (Borborema Province, NE Brazil). Tectonics 21.

Arz, H., Pätzold, J., Wefer, G., 1999. The deglacial history of the western tropical Atlantic as inferred from high resolution stable isotope records off northeastern Brazil. Earth and Planetary Science Letters $167,105-117$.

Arz, H.W., Pätzold, J., Wefer, G., 1998. Correlated Millennial-Scale Changes in Surface Hydrography Terrigenous Sediment Yield Inferred from Last-Glacial Marine Deposits off Northeastern Brazil. Quaternary Research 50, 157-166.

Arz, H.W., Pätzold, J., Wefer, G., 1999. Climate changes during the last deglaciation recorded in sediment cores from the northeastern Brazilian continental Margin. Geo-Marine Letters 19, 209-218. Baker, P.A., Seltzer, G.O., Fritz, S.C., Dunbar, R.B., Grove, M.J., Tapia, P.M., Cross, S.L., Rowe, H.D., Broda, J.P., 2001. The history of South American tropical precipitation for the past 25,000 years. Science 291, 640-643.

Behling, H., Arz, H., Pa tzold, J., Wefer, G., 2000. Late Quaternary vegetational and climate dynamics in northeastern Brazil, inferences from marine core GeoB 3104-1. Quaternary Science Reviews 19, 981-994.

Bloemendal, J., King, J.W., Hall, F.R., Doh, S.-J., 1992. Rock Magnetism of Late Neogene and Pleistocene Deep-Sea Sediments: Relationship of Sediment Source, Diagenetic Processes, and Sediment Lithology. Journal of Geophysical Research 97, 4361-4375.

Blunier, T., Brook, E.J., 2001. Timing of millennial-scale climate change in Antarctica and Greenland during the last glacial period. Science 291, 109-112.

Bond, G.C., Broecker, W.S., Johnsen, S., McManus, J.F., Labeyrie, L., Jouzel, J., Bonani, G., 1993. Correlations between climate records from North Atlantic sediments and Greenland ice. Nature 365, 143-147.

Bond, G.C., Lotti, R., 1995. Iceberg Discharges into the North Atlantic on Millenium Time Scales During the Last Glaciation. Science 267, 1005-1010. 
Broecker, W.S., 1998. Paleocean circulation during the last glaciation: A bipolar seesaw?

Paleoceanographic currents 13, 119-121.

Broecker, W.S., Denton, G.H., Edwards, R.L., Cheng, H., Alley, R.B., Putnam, A.E., 2010. Putting the Younger Dryas cold event into context. Quaternary Science Reviews 29, 1078-1081.

Carlson, A.E., 2013. PALEOCLIMATE | The Younger Dryas Climate Event, in: Elias, S.A. (Ed.), Encyclopedia of Quaternary Science, 2nd ed, pp. 126-134.

Chang, L., Roberts, A.P., Rowan, C.J., Tang, Y., Pruner, P., Chen, Q., Horng, C.-S., 2009. Lowtemperature magnetic properties of greigite (Fe3S4). Geochemistry, Geophysics, Geosystems 10, n/an/a.

Cheng, H., Sinha, A., Cruz, F.W., Wang, X., Edwards, R.L., d'Horta, F.M., Ribas, C.C., Vuille, M., Stott, L.D., Auler, A.S., 2013. Climate change patterns in Amazonia and biodiversity. Nature communications $4,1411$.

Chiang, J.C.H., Cheng, W., Bitz, C.M., 2008. Fast teleconnections to the tropical Atlantic sector from Atlantic thermohaline adjustment. Geophysical Research Letters 35, n/a-n/a.

Chiessi, C.M., Mulitza, S., Paul, A., Pätzold, J., Groeneveld, J., Wefer, G., 2008. South Atlantic interocean exchange as the trigger for the Bølling warm event. Geology 36, 919.

Cruz, F.W., Vuille, M., Burns, S.J., Wang, X., Cheng, H., Werner, M., Edwards, R.L., Karmann, I., Auler, A.S., Nguyen, H., 2009. Orbitally driven east-west antiphasing of South American precipitation. Nature Geoscience 2, 1-5.

Day, R., Fuller, M., Schmidt, V.A., 1977. Hysteresis properties of titanomagnetites: grain size and compositional dependence. . Physics of the Earth and Planetary Interiors 13, 260-267.

Dias, F.J.S., Castro, B.M., Lacerda, L.D., 2013. Continental shelf water masses off the Jaguaribe River (4S), northeastern Brazil. Continental Shelf Research 66, 123-135.

Dunlop, D.J., 2002. Theory and application of the Day plot (Mrs/Ms versus Hcr/Hc) 1. Theoretical curves and tests using titanomagnetite data. Journal of Geophysical Research 107.

Dunlop, D.J., Özdemir, Ö., 1997. Rock Magnetism, Fundamentals and Frontiers, Cambridge. Dupont, L.M., Schlütz, F., Ewah, C.T., Jennerjahn, T.C., Paul, A., Behling, H., 2009. Two-step vegetation response to enhanced precipitation in Northeast Brazil during Heinrich event 1. Global Change Biology 16, 1647-1660.

Egli, R., 2003. Analysis of the field dependence of remanent magnetization curves. Journal of Geophysical Research 108.

Egli, R., 2004. Characterization of individual rock magnetic components by analysis of remanence curves. 3. Bacterial magnetite and natural processes in lakes. Physics and Chemistry of the Earth, Parts $\mathrm{A} / \mathrm{B} / \mathrm{C} 29,869-884$.

Evans, M.E., Heller, F., 2003. Environmental Magnetism Principles and Applications of Enviromagnetics. Academic Press, US. 
Fairbanks, R.G., 1989. A 17,000-year glacio-eustatic sea level record: influence of glacial melting rates on the Younger Dryas event and deep-ocean circulation. Nature 342, 637-642.

Fischer, G., Arz, H., Baschek, B., Bassek, D., Costa, E., Dierssen, H., Deeken, A., Diekamp, V., Eichner, C., Engelbrecht, I., Elmeking, K., Figueiredo, A., Flechsenhaar, K., Frederichs, T., Freesemalln, A., Gartemicht, U., Herz, M.v., Hübscher, C., Karwath, B., Kasten, S., KinkeI, H., Kölling, M., Miesner, I., Ratmeyer, V., Schlünz, B., Schneider, R., Schmieder, F., Ruhland, G., M., Z., 1996. Report and preliminary results of Meteor cruise M 34/4,

Recife - Bridgetown, 19.3.-15.4.1996. Berichte, Fachbereich Geowissenschaften, Universität Bremen 80, $105 \mathrm{pp}$.

Fleming, K., Johnston, P., Zwartz, D., Yokoyama, Y., Lambeck, K., Chappell, J., 1998. Refining the eustatic sea-level curve since the Last Glacial Maximum using far- and intermediate-field sites. Earth and Planetary Science Letters 163, 327-342.

Fratantoni, D.M., Richardson, P.L., 2006. The Evolution and Demise of North Brazil Current Rings. Journal of Physical Oceanography 36, 1241-1264.

Garreaud, R.D., Vuille, M., Compagnucci, R., Marengo, J., 2009. Present-day South American climate. Palaeogeography, Palaeoclimatology, Palaeoecology 281, 180-195.

Gatto, L.C.S., Rivas, M.P., Fortunato, F.F., Filho, A.L.S., Oliveira, F.C., Cunha, R.C.M.B., Boas, J.H.V., Pinto, G.C.V.C., Sokolonski, H.H., 1999. Diagnóstico ambiental da Bacia do Jaguaribe. Geiss, C.E., Egli, R., Zanner, C.W., 2008. Direct estimates of pedogenic magnetite as a tool to reconstruct past climates from buried soils. Journal of Geophysical Research 113.

Gillett, N.P., Kell, T.D., Jones, P.D., 2006. Regional climate impacts of the Southern Annular Mode. Geophysical Research Letters 33.

Gomes, M.P., Vital, H., 2010. Revisão da compartimentação geomorfológica da Plataforma Continental Norte do Rio Grande do Norte, Brasil. Revista Brasileira de Geociências 40, 321-329. Gomes, M.P., Vital, H., Bezerra, F.H.R., de Castro, D.L., Macedo, J.W.d.P., 2014. The interplay between structural inheritance and morphology in the Equatorial Continental Shelf of Brazil. Marine Geology 355, 150-161.

Govin, A., Holzwarth, U., Heslop, D., Ford Keeling, L., Zabel, M., Mulitza, S., Collins, J.A., Chiessi, C.M., 2012. Distribution of major elements in Atlantic surface sediments $\left(36^{\circ} \mathrm{N}-49^{\circ} \mathrm{S}\right)$ : Imprint of terrigenous input and continental weathering. Geochemistry, Geophysics, Geosystems 13, n/a-n/a. Grimm, A.M., 2003. The El Niño Impact on the Summer Monsoon in Brazil: Regional Processes versus Remote Influences. American Meteorological Society, 263-280.

Grimm, A.M., Vera, C.S., Mechoso, C.R., 2005. The South American Monsoon System, in: Chang, C.-P., Wang, B., Lau, N.-C.G. (Eds.), The Global Monsoon System: Research and Forecast World Meteorological Organization, Hangzhou, China, pp. 219-238. 
Grousset, F.E., Labeyrie, L., Sinko, J.A., Cremer, M., Bond, G.C., Duprat, J., Cortijo, E., Huon, S., 1993. Patterns of ice-rafted detritus in the glacial North Atlantic. Paleoceanography 8, 175-192. Gutiérrez, D., Sifeddine, A., Field, D.B., Ortlieb, L., Vargas, G., Chávez, F.P., Velazco, F., Ferreira, V., Tapia, P., Salvatteci, R., Boucher, H., Morales, M.C., Valdés, J., Reyss, J.-L., Campusano, A., Boussafir, M., Mandeng-Yogo, M., García, M., Baumgartner, T., 2009. Rapid reorganization in ocean biogeochemistry off Peru towards the end of the Little Ice Age. Biogeosciences, 6, 835-848.

Heinrich, H., 1988. Origin and Consequences of Cyclic Ice Rafting in the Northeast Atlantic Ocean during the Past 130,000 Years. Quaternary Research 29, 142-152.

Hemming, S.R., 2004. Heinrich events: Massive late Pleistocene detritus layers of the North Atlantic and their global climate imprint. Reviews of Geophysics 42.

Henshaw, J.P.C., Merril, R.T., 1980. Magnetic and Chemical Changes in Marine Sediments. Reviews of Geophysics and Space Physics 18, 483-504.

Heslop, D., Dillon, M., 2007. Unmixing magnetic remanence curves withouta prioriknowledge. Geophysical Journal International 170, 556-566.

Heslop, D., Witt, A., Kleiner, T., Fabian, K., 2006. The role of magnetostatic interactions in sediment suspensions. Geophysical Journal International 165, 775-785.

Hodell, D.A., Anselmetti, F.S., Ariztegui, D., Brenner, M., Curtis, J.H., Gilli, A., Grzesik, D.A., Guilderson, T.J., Müller, A.D., Bush, M.B., 2008. An 85-ka record of climate change in lowland Central America. Quaternary Science Reviews 27, 1152-1165.

Itambi, A.C., von Dobeneck, T., Mulitza, S., Bickert, T., Heslop, D., 2009. Millennial-scale northwest African droughts related to Heinrich events and Dansgaard-Oeschger cycles: Evidence in marine sediments from offshore Senegal. Paleoceanography 24, n/a-n/a.

Jaeschke, A., Rühlemann, C., Arz, H., Heil, G., Lohmann, G., 2007. Coupling of millennial-scale changes in sea surface temperature and precipitation off northeastern Brazil with high-latitude climate shifts during the last glacial period. Paleoceanography 22 , n/a-n/a.

Jennerjahn, T.C., Ittekkot, V., Arz, H.W., Behling, H., Pa ‘zold, J., Wefer, G., 2004. Asynchronous Terrestrial and Marine Signals of Climate Change During Heinrich Events. Science 306, 2236-2239. Journet, E., Balkanski, Y., Harrison, S.P., 2013. A new data set of soil mineralogy for dust-cycle modeling. Atmospheric Chemistry and Physics Discussions 13, 23943-23993.

Journet, E., Balkanski, Y., Harrison, S.P., 2014. A new data set of soil mineralogy for dust-cycle modeling. Atmospheric Chemistry and Physics 14, 3801-3816.

Just, J., Dekkers, M.J., von Dobeneck, T., van Hoesel, A., Bickert, T., 2012a. Signatures and significance of aeolian, fluvial, bacterial and diagenetic magnetic mineral fractions in Late Quaternary marine sediments off Gambia, NW Africa. Geochemistry, Geophysics, Geosystems 13, n/a-n/a. 
Just, J., Heslop, D., von Dobeneck, T., Bickert, T., Dekkers, M.J., Frederichs, T., Meyer, I., Zabel, M., 2012b. Multiproxy characterization and budgeting of terrigenous end-members at the NW African continental margin. Geochemistry, Geophysics, Geosystems 13, n/a-n/a.

Just, J., Schefuß, E., Kuhlmann, H., Stuut, J.-B.W., Pätzold, J., 2014. Climate induced sub-basin source-area shifts of Zambezi River sediments over the past 17ka. Palaeogeography,

Palaeoclimatology, Palaeoecology.

Kageyama, M., Merkel, U., Otto-Bliesner, B., Prange, M., Abe-Ouchi, A., Lohmann, G., Ohgaito, R., Roche, D.M., Singarayer, J., Swingedouw, D., Zhang, X., 2013a. Climatic impacts of fresh water hosing under Last Glacial Maximum conditions: a multi-model study. Clim. Past 9, 935-953.

Kageyama, M., Merkel, U., Otto-Bliesner, B., Prange, M., Abe-Ouchi, A., Lohmann, G., Ohgaito, R., Roche, D.M., Singarayer, J., Swingedouw, D., Zhang, X., 2013b. Climatic impacts of fresh water hosing under Last Glacial Maximum conditions: a multi-model study. Climate of the Past 9, 935-953. Kageyama, M., Mignot, J., Swingedouw, D., Marzin, C., Alkama, R., Marti, O., 2009. Glacial climate sensitivity to different states of the Atlantic Meridional Overturning Circulation: results from the IPSL model. Climate of the Past 5, 551-570.

Kasten, S., Zabel, M., Heuer, V., Hensen, C., 2004. Processes and Signals of Nonsteady-State Diagenesis in Deep-Sea Sediments and their Pore Waters., in: Wefer, G., Mulitza, S., Ratmeyer, V. (Eds.), The South Atlantic in the Late Quaternaty

Reconstrution of the Material Budgets and Current Systems. Springer-Verlag Berlin Heidelberg, pp. 431-459.

Kissel, C., Laj, C., Labeyrie, L., Dokken, T., Voelker, A., Blamart, D., 1999. Rapid climatic variations during marine isotopic stage 3: magnetic analysis of sediments from Nordic Seas and North Atlantic. Earth and Planetary Science Letters 171, 489-502.

Kissel, C., Laj, C., Piotrowski, A.M., Goldstein, S.L., Hemming, S.R., 2008. Millennial-scale propagation of Atlantic deep waters to the glacial Southern Ocean. Paleoceanography 23, n/a-n/a. Kissel, C., Van Toer, A., Laj, C., Cortijo, E., Michel, E., 2013. Variations in the strength of the North Atlantic bottom water during Holocene. Earth and Planetary Science Letters 369-370, 248-259.

Knesel, K.M., Souza, Z.S., Vasconcelos, P.M., Cohen, B.E., Silveira, F.V., 2011. Young volcanism in the Borborema Province, NE Brazil, shows no evidence for a trace of the Fernando de Noronha plume on the continent. Earth and Planetary Science Letters 302, 38-50.

Knoppers, B., Ekau, W., Figueiredo, A.G., 1999. The coast and shelf of east and northeast Brazil and material transport. Geo-Marine Letters 19, 171-178.

Kohler, P., Knorr, G., Bard, E., 2014. Permafrost thawing as a possible source of abrupt carbon release at the onset of the Bolling/Allerod. Nature communications 5, 5520. 
Kruiver, P.P., Dekkers, M.J., Heslop, D., 2001. Quantification of magnetic coercivity components by the analysis of acquisition curves of the isothermal remanent magnetisation. Earth and Planetary Science Letters 189, 269-276.

Liedtke, N., 2014. Numerische Simulation der Veränderungen im Nordbrasilstrom während eines Heinrich Ereignisses durch Änderungen im Windfeld, Fachbereich Geowissenschaften. Universität Bremen, Bremen.

Liu, Q., Roberts, A.P., Larrasoaña, J.C., Banerjee, S.K., Guyodo, Y., Tauxe, L., Oldfield, F., 2012. Environmental magnetism: Principles and applications. Reviews of Geophysics 50.

Liu, Z., Otto-Bliesner, B., He, F., Brandy, E.C., Tomas, R., Clark, P.U., Carlson, A.E., LynchStieglitz, J., Curry, W., Brook, E.J., Erickson, D., Jacob, R., Kutzbach, J., Cheng, J., 2009. Transient Simulation of Last Deglaciation with a new mechanism for Bølling-Allerød Warming. Science 325, 310-314.

Mangerud, J., Andersen, S.T., Berglund, B.E., Donner, J.J., 1974. Quaternary stratigraphy of Norden, a proposal for terminology and classification. Boreas 3, 109-127.

McGee, D., Donohoe, A., Marshall, J., Ferreira, D., 2014. Changes in ITCZ location and crossequatorial heat transport at the Last Glacial Maximum, Heinrich Stadial 1, and the mid-Holocene. Earth and Planetary Science Letters 390, 69-79.

McManus, J.F., Bond, G.C., Broecker, W.S., Johnsen, S., Labeyrie, L., Higgins, S., 1994. High resolution climate records from the North Atlantic during the last Interglacial. Nature 371, 326-329. McManus, J.F., Francois, R., Gherardi, J.M., Keigwin, L.D., Brown-Leger, S., 2004. Collapse and rapid resumption of Atlantic meridional circulation linked to deglacial climate changes. Nature 428, 834-837.

Meju, M.A., Fontes, S.L., Oliveira, M.F.B., Lima, J.P.R., Ulugergerli, E.U., Carrasquilla, A.A., 1999. Regional aquifer mapping using combined VES-TEM-AMT/EMAP methods in the semiarid eastern margin of Parnaiba Basin, Brazil. Geophysics 64, 337-356.

Milne, G., Long, A., Bassett, S., 2005. Modelling Holocene relative sea-level observations from the Caribbean and South America. Quaternary Science Reviews 24, 1183-1202.

Mulitza, S., Prange, M., Stuut, J.-B., Zabel, M., von Dobeneck, T., Itambi, A.C., Nizou, J., Schulz, M., Wefer, G., 2008. Sahel megadroughts triggered by glacial slowdowns of Atlantic meridional overturning. Paleoceanography 23, n/a-n/a.

Nace, T.E., Baker, P.A., Dwyer, G.S., Silva, C.G., Rigsby, C.A., Burns, S.J., Giosan, L., OttoBliesner, B., Liu, Z., Zhu, J., 2014. The role of North Brazil Current transport in the paleoclimate of the Brazilian Nordeste margin and paleoceanography of the western tropical Atlantic during the late Quaternary. Palaeogeography, Palaeoclimatology, Palaeoecology 415, 3-13.

Nobre, P., Shukla, J., 1996. Variations of sea surface temperature, wind stress, and rainfall over the tropical Atlantic and South America. Journal of Climate 9, 2464-2479. 
Nogués-Paegle, J., Mo, K.C., 1997. Alternating Wet and Dry Conditions over South America during Summer. American Meteorological Society, 279-291.

Nogués-Paegle, J., Mo, K.C., 2002. Linkages between Summer Rainfall Variability over South America and Sea Surface Temperarure Anomalies. Journal of Climate 15, 1389-1407.

Oliveira, R.G., Medeiros, W.E., 2012. Evidences of buried loads in the base of the crust of Borborema Plateau (NE Brazil) from Bouguer admittance estimates. Journal of South American Earth Sciences 37, 60-76.

Özdemir, Ö., 2002. Thermoremanence and stable memory of single-domain hematites. Geophysical Research Letters 29.

Özdemir, Ö., Dunlop, D.J., 2014. Hysteresis and coercivity of hematite. Journal of Geophysical Research: Solid Earth 119, 2582-2594.

Poveda, G., Waylen, P.R., Pulwarty, R.S., 2006. Annual and inter-annual variability of the present climate in northern South America and southern Mesoamerica. Palaeogeography, Palaeoclimatology, Palaeoecology 234, 3-27.

Prado, L.F., Wainer, I., Chiessi, C.M., Ledru, M.P., Turcq, B., 2013. A mid-Holocene climate reconstruction for eastern South America. Climate of the Past 9, 2117-2133.

Rahmstorf, S., 2001. Abrupt Climate Change. 1-6.

Razik, S., Chiessi, C.M., Romero, O.E., von Dobeneck, T., 2013. Interaction of the South American Monsoon System and the Southern Westerly Wind Belt during the last 14kyr. Palaeogeography, Palaeoclimatology, Palaeoecology 374, 28-40.

Roberts, A.P., Chang, L., Rowan, C.J., Horng, C.-S., Florindo, F., 2011. Magnetic properties of sedimentary greigite (Fe3S4): An update. Reviews of Geophysics 49.

Robertson, A.W., Mechoso, C.R., 2000. Interannual and Interdecadal Variability of the South Atlantic Convergence Zone. Monthly Weather Review 128, 2947-2957.

Robertson, D.J., France, D.E., 1994. Discrimination of remanence-carrying minerals in mixtures, using isothermal remanent magnetisation acquisition curves. Physics of the Earth and Planetary Interiors 82, 223-234.

Rochette, P., Fillion, G., Mattéi, J.-L., Dekkers, M.J., 1990. Margnetic transition at 30-34 Kelvin in pyrrhotite: insight into a widespread occurence of this mineral in rocks. Earth and Planetary Science Letters 98, 319-328.

Roud, S.C., 2014. Magnetic mineral inventory of late Quaternary sediments from the tropical Atlantic off North Brazil: indicator for paleoenvironmental conditions and early diagenesis, Fachbereich Geowissenschaften. Universität Bremen, Bremen, p. 66.

Rowan, C.J., Roberts, A.P., Broadbent, T., 2009. Reductive diagenesis, magnetite dissolution, greigite growth and paleomagnetic smoothing in marine sediments: A new view. Earth and Planetary Science Letters 277, 223-235. 
Ruddiman, W.F., 1977. North Atlantic Ice-Rafting: A Major Change at 75,000 Years Before the Present. Science 196, 1208-1211.

Ruddinam, W.F., 2008. Earth's Climate: Past and Future, 2nd ed. Clancy Marshall, New York. Sarnthein, M., Stattegger, K., Dreger, D., Erlenkeuser, H., Grootes, P.M., Haupt, B.J., Jung, S., Kiefer, T., Kuhnt, W., Pflaumann, U., Schäfer-Neth, C., Schulz, H.D., Schulz, M., Seidov, D., Simstich, J., van Kreveld, S., Vogelsang, E., Völker, A., Weinelt, M., 2001. Fundamental Modes and Abrupt Changes in North Atlantic Circulation and Climate over the last $60 \mathrm{ky}$ - Concepts, Reconstruction and Numerical Modeling. Springer, Berlin.

Schmitt, J., Schneider, R., Elsig, J., Leuenberger, D., Lourantou, A., ChappellazJ., Köhler, P., Joos, F., Stocker, T.F., Leuenberger, M., Fischer, H., 2012. Carbon Isotope Constraints on the Deglacial CO2 Rise from Ice Cores. Science 336, 711-714.

Schulz, H.D., Zabel, M., 2006. Marine Geochemistry. Springer.

Shchepetkin, A.F., 2003. A method for computing horizontal pressure-gradient force in an oceanic model with a nonaligned vertical coordinate. Journal of Geophysical Research 108.

Shchepetkin, A.F., McWilliams, J.C., 2005. The regional oceanic modeling system (ROMS): a splitexplicit, free-surface, topography-following-coordinate oceanic model. Ocean Modelling 9, 347-404. Sifeddine, A., Gutiérrez, D., Ortlieb, L., Boucher, H., Velazco, F., Field, D., Vargas, G., Boussafir, M., Salvatteci, R., Ferreira, V., García, M., Valdés, J., Caquineau, S., Mandeng Yogo, M., Cetin, F., Solis, J., Soler, P., Baumgartner, T., 2008. Laminated sediments from the central Peruvian continental slope: A 500 year record of upwelling system productivity, terrestrial runoff and redox conditions. Progress in Oceanography 79, 190-197.

Souza, A.C.M., Silva, M.R.F., Dias, N.S., 2012. Gestão de recursos hídricos: o caso da Bacia Hidrográfica de Apodi/Mossoro (RN). Irriga, Botucatu, 280-296.

Stocker, T.F., 2000. Past and future reorganizations in the climate system. Quaternary Science Reviews 19, 301-319.

Stocker, T.F., Marchal, O., 2000. Abrupt climate change in the computer:Is it real? Proceedings of the National Academy of Sciences of USA 97, 1362-1365.

Stoner, J.S., Channell, J.E.T., Hillaire-Marcel, C., 1996. The magnetic signature of rapidly deposited detrital layers from the deep Labrador Sea: Relationship to North Atlantic Heinrich layers.

Paleoceanography 11, 309-325.

Stramma, L., England, M., 1999. On the water masses and mean circulation of the South Atlantic Ocean. Journal of Geophysical Research 104, 20,863-820,883.

Tauxe, L., 2008. Essentials of Rock and Paleomagnetism, La Jolla, CA. Thiagarajan, N., Subhas, A.V., Southon, J.R., Eiler, J.M., Adkins, J.F., 2014. Abrupt pre-BollingAllerod warming and circulation changes in the deep ocean. Nature 511, 75-78.

Thompson, R., Oldfield, F., 1986. Environmental magnetism. Allen \& Unwin, London. 
Trindade, R., Dagrellafilho, M., Epof, I., Britoneves, B., 2006. Paleomagnetism of Early Cambrian Itabaiana mafic dikes (NE Brazil) and the final assembly of Gondwana. Earth and Planetary Science Letters 244, 361-377.

Verosub, K.L., Roberts, A.P., 1995. Environmental magnetism- Past, present, and future. Journal of Geophysical Research 1000, 2175-2192.

Vidal, L., Labeyrie, L., Cortijo, E., Arnold, M., Duplessy, J.C., Michel, E., Becqué, S., van Weering, T.C.E., 1997. Evidence for changes in the North Atlantic Deep Water linked to meltwater surges during the Heinrich events. Earth and Planetary Science Letters 146, 13-27.

Vital, H., Furtado, S.F.L., Gomes, M.P., 2010a. Response of the Apodi-Mossoró estuary- incised valley system (NE Brazil) to sea-level fluctuations. Brazilian Journal of Oceanography 58, 13-24. Vital, H., Gomes, M.P., Tabosa, W.F., Frazão, E.P., Santos, C.L.S., Plácido Junior, J.S., 2010b. Characterization of the Brazilian continental shelf adjacent to Rio Grande State, NE Brazil. Brazilian Journal of Oceanography 58, 43-54.

Vital, H., Stattegger, K., Amaro, V.E., Schwarzer, K., Frazão, E.P., Tabosa, W.F., Silveira, I.M., 2008. A modern high-energy siliciclastic-carbonate platform: continental shelf adjacent to Northern Rio Grande do Norte State, Northeastern Brazil. Recent Advances in Models of Siliciclastic ShallowMarineStratigraphy 90, 175-188.

Wang, X., Auler, A.S., Edwards, R.L., Cheng, H., Cristalli, P.S., Smart, P.L., Richards, D.A., Shen, C.C., 2004. Wet periods in northeastern Brazil over the past $210 \mathrm{kyr}$ linked to distant climate anomalies. Nature 432, 740-743.

Weldeab, S., Schneider, R.R., Kolling, M., 2006. Deglacial sea surface temperature and salinity increase in the western tropical Atlantic in synchrony with high latitude climate instabilities. Earth and Planetary Science Letters 241, 699-706.

Weltje, G.J., Tjallingii, R., 2008. Calibration of XRF core scanners for quantitative geochemical logging of sediment cores: Theory and application. Earth and Planetary Science Letters 274, 423-438. Wilson, K.E., Maslin, M.A., Burns, S.J., 2011. Evidence for a prolonged retroflection of the North Brazil Current during glacial stages. Palaeogeography, Palaeoclimatology, Palaeoecology 301, 86-96. WRB, 2006. World reference base for soil resources 2006.

Zabel, M., Schneider, R.R., Wagner, T., Adegbie, A.T., de Vries, U., Kolonic, S., 2001. Late Quaternary Climate Changes in Central Africa as Inferred from Terrigenous Input to the Niger Fan. Quaternary Research 56, 207-217.

Zhou, J., Lau, K.-M., 1998. Does a Monsoon Climate Exist over South America? Journal of Climate $11,1020-1040$. 


\section{ANNEX I - Age Model}

Radiocarbon ages used for the age models calibration

\begin{tabular}{|c|c|c|c|}
\hline \multicolumn{4}{|c|}{ GeoB3910-2 ${ }^{a}$} \\
\hline $\begin{array}{c}\text { Laboratory } \\
I^{\mathrm{b}}\end{array}$ & $\begin{array}{l}\text { Core depth } \\
(\mathrm{cm})\end{array}$ & $\begin{array}{c}\text { 14C Age } \\
(y r \quad B P) \pm 1 \sigma\end{array}$ & $\begin{array}{c}\text { Age } \\
\text { (cal yr BP) }\end{array}$ \\
\hline KIA 6800 & 0 & $165 \pm 30$ & 170 \\
\hline KIA 6799 & 13 & $3530 \pm 35$ & 3800 \\
\hline KIA 6798 & 23 & $5760 \pm 40$ & 6560 \\
\hline KIA 7225 & 38 & $8030 \pm 40$ & 8900 \\
\hline KIA 6815 & 58 & $9690 \pm 60$ & 11020 \\
\hline KIA 6814 & 73 & $10540 \pm 70$ & 12460 \\
\hline KIA 6813 & 88 & $12440 \pm 110$ & 14550 \\
\hline KIA 25825 & 103 & $13150 \pm 70$ & 16100 \\
\hline KIA 25824 & 113 & $13600 \pm 70$ & 16800 \\
\hline KIA 6812 & 148 & $15380 \pm 110$ & 18300 \\
\hline KIA 6811 & 173 & $19600 \pm 170$ & 22800 \\
\hline KIA 25822 & 183 & $20180 \pm 150$ & 23400 \\
\hline KIA 6808 & 193 & $22080 \pm 220$ & 25700 \\
\hline KIA 25821 & 213 & $24730 \pm 260$ & 28600 \\
\hline KIA 25820 & 233 & $26760 \pm 310$ & 30200 \\
\hline KIA 6806 & 238 & $27880 \pm 430$ & 31500 \\
\hline \multirow[t]{2}{*}{ KIA 22411} & 268 & $30460 \pm 430$ & 35000 \\
\hline & 302 & & $38500^{*}$ \\
\hline KIA 6804 & 328 & $38200 \pm 1480$ & 41800 \\
\hline KIA 21829 & 348 & $40600 \pm 820$ & 42800 \\
\hline \multirow[t]{5}{*}{ KIA 21830} & 373 & $44080 \pm 1250$ & 45400 \\
\hline & 400 & & $46900^{*}$ \\
\hline & 435 & & $52100^{*}$ \\
\hline & 453 & & $54600^{*}$ \\
\hline & 478 & & $58000^{*}$ \\
\hline
\end{tabular}

* correlation points to the GISP2 ice core [Grootes at el., 1993]

\begin{tabular}{lccc}
\hline \multicolumn{4}{c}{ GeoB3129-1 $^{c}$} \\
\hline $\begin{array}{c}\text { Laboratory } \\
\text { ID }^{\mathrm{b}}\end{array}$ & $\begin{array}{c}\text { Core depth } \\
(\mathrm{cm})\end{array}$ & $\begin{array}{c}14 \mathrm{C} \text { Age } \\
(\mathrm{yr} \mathrm{BP}) \pm 10\end{array}$ & $\begin{array}{c}\text { Age } \\
(\text { cal yr BP })\end{array}$ \\
\hline KIA 2576 & 22 & $1830 \pm 30$ & 1910 \\
KIA 2575 & 52 & $3610 \pm 50$ & 3980 \\
KIA 2574 & 62 & $3820 \pm 30$ & 4230 \\
KIA 2573 & 90 & $5880 \pm 40$ & 6610 \\
KIA 655 & 119 & $6510 \pm 60$ & 7330 \\
KIA 654 & 207 & $9160 \pm 80$ & 10200 \\
KIA 1872 & 241 & $9650 \pm 60$ & 11130
\end{tabular}




\begin{tabular}{|c|c|c|c|}
\hline KIA 1871 & 307 & $9910 \pm 60$ & 11450 \\
\hline KIA 1861 & 329 & $10430 \pm 60$ & 12090 \\
\hline KIA 1860 & 452 & $10610 \pm 70$ & 12320 \\
\hline KIA 1859 & 491 & $11600 \pm 70$ & 13540 \\
\hline KIA 2614 & 523 & $12040 \pm 70$ & 14090 \\
\hline KIA 2612 & 548 & $12380 \pm 50$ & 14510 \\
\hline \multicolumn{4}{|c|}{ GeoB3911-3 $3^{d}$} \\
\hline $\begin{array}{l}\text { Laboratory } \\
I^{\mathrm{b}}\end{array}$ & $\begin{array}{c}\text { Core depth } \\
(\mathrm{cm})\end{array}$ & $\begin{array}{c}\text { 14C Age } \\
(y r \quad B P) \pm 1 \sigma\end{array}$ & $\begin{array}{c}\text { Age } \\
\text { (cal yr BP) }\end{array}$ \\
\hline KIA 2613 & 543 & $12680 \pm 80$ & 14880 \\
\hline KIA 2611 & 648 & $14610 \pm 110$ & 16720 \\
\hline KIA 1858 & 665 & $16920 \pm 90$ & 20140 \\
\hline \multicolumn{4}{|c|}{ GeoB3104-1 ${ }^{c}$} \\
\hline $\begin{array}{l}\text { Laboratory } \\
\qquad I^{\mathrm{b}}\end{array}$ & $\begin{array}{c}\text { Core depth } \\
(\mathrm{cm})\end{array}$ & $\begin{array}{c}\text { 14C Age } \\
(y r \quad B P) \pm 1 \sigma\end{array}$ & $\begin{array}{c}\text { Age } \\
\text { (cal yr BP) }\end{array}$ \\
\hline KIA 653 & 8 & $2660 \pm 50$ & 2880 \\
\hline KIA 1857 & 20 & $5740 \pm 60$ & 6450 \\
\hline KIA 1856 & 52 & $9660 \pm 50$ & 11140 \\
\hline GrA 3719 & 87 & $12580 \pm 100$ & 14760 \\
\hline KIA 1855 & 97 & $12960 \pm 90$ & 15230 \\
\hline GrA 3720 & 172 & $16120 \pm 160$ & 19150 \\
\hline KIA 651 & 209 & $20540+350 /-330$ & 24280 \\
\hline GrA 3721 & 274 & $25050 \pm 200$ & 29340 \\
\hline KIA 1853 & 292 & $27820+290 /-280$ & 32340 \\
\hline KIA 1852 & 337 & $31690+450 /-420$ & 36370 \\
\hline KIA 650 & 384 & $33400+1840 /-149$ & 38100 \\
\hline GrA 3722 & 462 & $38600+900 /-800$ & 43130 \\
\hline \multicolumn{2}{|c|}{ GeoB3912-1 ${ }^{\mathrm{a}}$} & \multicolumn{2}{|c|}{ GeoB3913-3 } \\
\hline $\begin{array}{c}\text { SPECMAP } \\
\delta^{18} O^{c}\end{array}$ & $\begin{array}{c}\text { Age } \\
\text { (cal yr BP) }\end{array}$ & $\begin{array}{l}\text { Stratigraphic tie } \\
\text { points from core } \\
\text { GeoB3912-1 ( yr } \\
\text { BP) }\end{array}$ & $\begin{array}{c}\text { Age } \\
\text { (cal yr BP) }\end{array}$ \\
\hline 538 & 65000 & 17 & 11034 \\
\hline 568 & 71000 & 24 & 15341 \\
\hline \multirow[t]{9}{*}{633} & 80000 & 25 & 15707 \\
\hline & & 26 & 16212 \\
\hline & & 29 & 17058 \\
\hline & & 32 & 1737 \\
\hline & & 33 & 177 \\
\hline & & 34 & 17947 \\
\hline & & 37 & 18235 \\
\hline & & 40 & 18797 \\
\hline & & 48 & 19339 \\
\hline
\end{tabular}




$\begin{array}{ll}51 & 20146 \\ 55 & 21291 \\ 56 & 22316 \\ 59 & 22673 \\ 60 & 23046 \\ 63 & 23414 \\ 64 & 23777 \\ 68 & 24139 \\ 69 & 25021 \\ 70 & 25208 \\ 74 & 26607 \\ 76 & 27731 \\ 82 & 29262 \\ 86 & 30358 \\ 91 & 30956 \\ 96 & 32093 \\ 100 & 34153 \\ 104 & 37001 \\ 106 & 37348 \\ 108 & 37757 \\ 113 & 37893 \\ 115 & 38217 \\ 116 & 38668 \\ 117 & 39141 \\ 118 & 39759 \\ 121 & 40791 \\ 127 & 4207 \\ 129 & 42608 \\ 131 & 43429 \\ 132 & 44204 \\ 134 & 45776 \\ 136 & 46696 \\ 137 & 46923 \\ 140 & 47799 \\ 143 & 48089 \\ 147 & 48434 \\ 150 & 49443 \\ 151 & 50022 \\ 152 & 50603 \\ 154 & 53517 \\ 158 & 54678 \\ 161 & 56127 \\ 162 & \\ 165 & 565 \\ 170 & \end{array}$




$\begin{array}{cc}171 & 59622 \\ 172 & 60057 \\ 174 & 60492 \\ 177 & 60782 \\ 180 & 61362 \\ 182 & 63394 \\ 185 & 64562 \\ 192 & 656 \\ 218 & 66802 \\ 239 & 67606 \\ 249 & 6961 \\ 253 & 7001 \\ 254 & 7041 \\ 266 & 70755 \\ 291 & 72537 \\ 297 & 73089 \\ 300 & 73641 \\ 301 & 75022 \\ 308 & 76404 \\ 350 & 84696\end{array}$

a Jaechke et al [2007]

${ }^{\mathrm{b}}$ GrA Groningen; KIA Kiel.

c see Arz et al [1998] for detailed information

d see Arz et al [1999] for detailed information 


\section{ANNEX II - Protocols for magnetic mineralogy measurements}

PROTOCOL 1 - Demagnetization of the NRM

Step by step demagnetization of the Natural Remanent Magnetization (NRM) up to $100 \mathrm{mT}$.

Steps:

- $5 \mathrm{mT}$, between 0-30 mT

- $10 \mathrm{mT}$, between 30-80 $\mathrm{mT}$

- $20 \mathrm{mT}$, between 80-100 mT

PROTOCOL 2 - Acquisition of the ARM

Step by step acquisition of the Anisteretic Remanent Magnetization (ARM). This is an artificial magnetization acquired in laboratory through imparting an alternated field concomitant to a direct field (DC). We used field of $0.5 \mu \mathrm{T}$.

Steps:

- $5 \mathrm{mT}$, between 0-30 $\mathrm{mT}$

- $10 \mathrm{mT}$, between 30-80 mT

- $20 \mathrm{mT}$, between 80-100 mT

PROTOCOL 3 - Demagnetization of the ARM

Step by step demagnetization of the Anisteretic Remanent Magnetization (ARM).

Steps:

- $5 \mathrm{mT}$, between 0-30 $\mathrm{mT}$

- $10 \mathrm{mT}$, between 30-80 mT

- $20 \mathrm{mT}$, between 80-100 mT

PROTOCOL 4 - IRM acquisition in low fields

Acquisition of Isotermal Remanent Magnetization (IRM) in low fields (up to $700 \mathrm{mT}$ ).

Steps:

- $5 \mathrm{mT}$, between 0-30 $\mathrm{mT}$

- $10 \mathrm{mT}$, between 30-50 mT 
- $20 \mathrm{mT}$, between 50-100 mT

- $25 \mathrm{mT}$, between 100-150 mT

- $50 \mathrm{mT}$, between 150-300 mT

- $200 \mathrm{mT}$, between 300-700 mT

PROTOCOL 5 - IRM acquisition in high fields

Acquisition of Isotermal Remanent Magnetization (IRM) in high fields (between 1000 and $2500 \mathrm{mT}$ ).

Steps:

- $250 \mathrm{mT}$, between $1000-1500 \mathrm{mT}$

- $200 \mathrm{mT}$, between $1500-2000 \mathrm{mT}$

- $500 \mathrm{mT}$, between 2000-2500 mT 
ANNEX III - Rock magnetic parameters

\section{GeoB3913-3}

\begin{tabular}{|c|c|c|c|c|c|c|c|}
\hline $\begin{array}{l}\text { Depth } \\
{[\mathrm{cm}]}\end{array}$ & $\begin{array}{c}\text { Age } \\
\text { cal [kyr] }\end{array}$ & $\begin{array}{c}\text { kappa } \\
{\left[10^{* *}-6 \mathrm{SI}\right]}\end{array}$ & $\begin{array}{l}\mathrm{IRM}_{\mathbf{3 0 0 m T}} \\
{[\mathrm{mA} / \mathrm{m}]}\end{array}$ & $\begin{array}{c}\text { ARM }_{100} / \text { IRM }_{100} \\
- \\
\end{array}$ & $\begin{array}{c}\text { HIRM }_{[300 \& 2700]} \\
- \\
\end{array}$ & $\begin{array}{c}\text { S-ratio [300\&2700] } \\
- \\
\end{array}$ & $\begin{array}{c}\text { Fe/kappa } \\
{\left[\mathrm{cps} / 10^{* *}-6 \mathrm{sI}\right]}\end{array}$ \\
\hline 5 & 3.3397 & 14.2 & $3.48 \mathrm{E}+02$ & $1.47 \mathrm{E}-01$ & 28.30 & 0.92 & $5.21 \mathrm{E}+02$ \\
\hline 10 & 6.6794 & 21.2 & $4.48 \mathrm{E}+02$ & $1.52 \mathrm{E}-01$ & 29.66 & 0.94 & $4.18 \mathrm{E}+02$ \\
\hline 15 & 10.0191 & 36.2 & $6.93 \mathrm{E}+02$ & $1.42 \mathrm{E}-01$ & 89.29 & 0.89 & $1.10 \mathrm{E}+03$ \\
\hline 20 & 13.7525 & 59.4 & $7.50 \mathrm{E}+02$ & $1.22 \mathrm{E}-01$ & 179.01 & 0.81 & $1.24 \mathrm{E}+03$ \\
\hline 25 & 14.8788 & 78.3 & $8.65 E+02$ & $1.01 \mathrm{E}-01$ & 332.64 & 0.72 & $1.26 \mathrm{E}+03$ \\
\hline 30 & 15.8405 & 92.8 & $6.70 \mathrm{E}+02$ & 9.90E-02 & 190.85 & 0.78 & $1.76 \mathrm{E}+03$ \\
\hline 35 & 16.7612 & 91.2 & $8.32 \mathrm{E}+02$ & 8.70E-02 & 243.01 & 0.77 & $1.34 \mathrm{E}+03$ \\
\hline 40 & 17.6818 & 98.8 & $1.08 \mathrm{E}+03$ & $6.86 \mathrm{E}-02$ & 242.65 & 0.82 & $1.35 \mathrm{E}+03$ \\
\hline 45 & 18.6025 & 88.3 & $1.25 \mathrm{E}+03$ & $5.85 \mathrm{E}-02$ & 210.76 & 0.86 & $8.81 E+02$ \\
\hline 50 & 19.6349 & 76.1 & $1.14 \mathrm{E}+03$ & $5.43 \mathrm{E}-02$ & 174.32 & 0.87 & $9.74 \mathrm{E}+02$ \\
\hline 55 & 21.1142 & 88.2 & $1.25 \mathrm{E}+03$ & $5.74 \mathrm{E}-02$ & 196.05 & 0.86 & $1.04 \mathrm{E}+03$ \\
\hline 60 & 22.5935 & 105 & $1.10 \mathrm{E}+03$ & 5.97E-02 & 218.89 & 0.83 & 7.17E+02 \\
\hline 65 & 23.9478 & 117.1 & $1.30 \mathrm{E}+03$ & $5.75 E-02$ & 250.12 & 0.84 & $1.01 \mathrm{E}+03$ \\
\hline 70 & 24.8018 & 116.2 & $1.28 \mathrm{E}+03$ & $5.36 \mathrm{E}-02$ & 245.50 & 0.84 & $9.61 \mathrm{E}+02$ \\
\hline 75 & 26.608 & 108.3 & $1.01 E+03$ & $5.89 E-02$ & 150.82 & 0.87 & $7.45 E+02$ \\
\hline 80 & 28.7009 & 104.2 & $1.01 \mathrm{E}+03$ & 8.43E-02 & 214.66 & 0.83 & $1.28 \mathrm{E}+03$ \\
\hline 85 & 29.9133 & 110.8 & $9.32 \mathrm{E}+02$ & $9.16 \mathrm{E}-02$ & 203.03 & 0.82 & $1.47 \mathrm{E}+03$ \\
\hline 90 & 31.1256 & 88.4 & $9.40 E+02$ & 7.27E-02 & 182.42 & 0.84 & $1.21 \mathrm{E}+03$ \\
\hline 95 & 32.338 & 70.2 & 7.73E+02 & 7.07E-02 & 130.57 & 0.86 & $1.03 \mathrm{E}+03$ \\
\hline 100 & 34.3699 & 67.2 & 7.70E+02 & 7.37E-02 & 131.95 & 0.85 & $8.16 \mathrm{E}+02$ \\
\hline 105 & 36.4018 & 69.7 & $9.17 E+02$ & 7.34E-02 & 166.86 & 0.85 & $8.62 E+02$ \\
\hline 110 & 37.8395 & 68.9 & $7.23 E+02$ & 8.99E-02 & 106.16 & 0.87 & $9.58 \mathrm{E}+02$ \\
\hline
\end{tabular}




\begin{tabular}{|c|c|c|c|c|c|c|c|}
\hline $\begin{array}{l}\text { Depth } \\
{[\mathrm{cm}]}\end{array}$ & $\begin{array}{c}\text { Age } \\
\text { cal [kyr] }\end{array}$ & $\begin{array}{c}\text { kappa } \\
{\left[10^{* *}-6 \mathrm{SI}\right]}\end{array}$ & $\begin{array}{l}\mathrm{IRM}_{\mathbf{3 0 0 \mathrm { mT }}} \\
{[\mathrm{mA} / \mathrm{m}]}\end{array}$ & $\begin{array}{c}\mathrm{ARM}_{100} / \mathrm{IRM}_{100} \\
-\end{array}$ & $\begin{array}{c}\text { HIRM }_{\text {[300\&2700] }} \\
-\end{array}$ & $\begin{array}{c}\text { S-ratio }_{\text {[300\&2700] }} \\
-\end{array}$ & $\begin{array}{c}\mathrm{Fe} / \mathrm{kappa} \\
{\left[\mathrm{cps} / 10^{* *}-6 \mathrm{SI}\right]}\end{array}$ \\
\hline 115 & 38.3858 & 100.8 & $9.44 \mathrm{E}+02$ & $9.05 E-02$ & 226.85 & 0.81 & $1.46 \mathrm{E}+03$ \\
\hline 120 & 40.2543 & 79.5 & $8.43 E+02$ & $8.26 \mathrm{E}-02$ & 176.72 & 0.83 & $8.21 E+02$ \\
\hline 125 & 41.6504 & 56 & $6.42 \mathrm{E}+02$ & $8.12 \mathrm{E}-02$ & 111.01 & 0.85 & $8.88 \mathrm{E}+02$ \\
\hline 130 & 42.981 & 60.6 & $7.55 \mathrm{E}+02$ & 8.37E-02 & 121.81 & 0.86 & $1.30 \mathrm{E}+03$ \\
\hline 135 & 45.7709 & 77.4 & $6.80 \mathrm{E}+02$ & 8.89E-02 & 127.62 & 0.84 & $1.23 \mathrm{E}+03$ \\
\hline 140 & 46.8805 & 110.4 & $1.11 \mathrm{E}+03$ & $7.98 \mathrm{E}-02$ & 280.66 & 0.80 & $1.39 \mathrm{E}+03$ \\
\hline 145 & 47.9902 & 93 & $1.05 \mathrm{E}+03$ & $7.58 \mathrm{E}-02$ & 187.23 & 0.85 & $8.80 \mathrm{E}+02$ \\
\hline 150 & 50.6124 & 53.1 & $8.02 E+02$ & 8.17E-02 & 108.64 & 0.88 & $7.16 \mathrm{E}+02$ \\
\hline 155 & 53.8464 & 60 & $5.98 \mathrm{E}+02$ & $1.01 \mathrm{E}-01$ & 113.63 & 0.84 & $6.77 \mathrm{E}+02$ \\
\hline 160 & 55.4934 & 73.8 & $8.72 E+02$ & $8.26 \mathrm{E}-02$ & 148.12 & 0.85 & $1.18 \mathrm{E}+03$ \\
\hline 165 & 57.1404 & 71.5 & $8.04 E+02$ & $8.45 \mathrm{E}-02$ & 102.61 & 0.89 & $6.60 \mathrm{E}+02$ \\
\hline 170 & 58.5925 & 88.8 & $7.99 E+02$ & $9.80 \mathrm{E}-02$ & 173.45 & 0.82 & $1.21 \mathrm{E}+03$ \\
\hline 175 & 59.265 & 105.7 & $8.71 E+02$ & $1.08 \mathrm{E}-01$ & 214.19 & 0.80 & $1.41 \mathrm{E}+03$ \\
\hline 180 & 59.9376 & 112.3 & $7.99 E+02$ & $1.06 \mathrm{E}-01$ & 189.41 & 0.81 & $2.21 E+03$ \\
\hline 185 & 60.6101 & 107.1 & $7.95 E+02$ & $9.76 \mathrm{E}-02$ & 196.77 & 0.80 & $1.87 \mathrm{E}+03$ \\
\hline 190 & 61.2826 & 100.9 & $5.13 E+02$ & $7.33 \mathrm{E}-02$ & 185.07 & 0.73 & $1.37 E+03$ \\
\hline 195 & 61.9552 & 98.9 & $8.44 \mathrm{E}+02$ & $7.18 \mathrm{E}-02$ & 212.80 & 0.80 & $1.27 \mathrm{E}+03$ \\
\hline 200 & 62.6277 & 94.3 & $1.09 E+03$ & $6.46 \mathrm{E}-02$ & 231.11 & 0.83 & $1.07 E+03$ \\
\hline 205 & 63.3003 & 101.1 & $1.06 \mathrm{E}+03$ & $6.89 \mathrm{E}-02$ & 199.85 & 0.84 & $1.07 E+03$ \\
\hline 210 & 63.9728 & 100 & $1.12 \mathrm{E}+03$ & $6.85 \mathrm{E}-02$ & 230.87 & 0.83 & $1.04 \mathrm{E}+03$ \\
\hline 215 & 64.6453 & 105.3 & $1.30 \mathrm{E}+03$ & $6.56 \mathrm{E}-02$ & 233.46 & 0.85 & $9.07 E+02$ \\
\hline 220 & 65.3179 & 107.5 & $1.27 E+03$ & 7.00E-02 & 241.27 & 0.84 & $8.42 E+02$ \\
\hline 225 & 65.9904 & 95.6 & $1.08 \mathrm{E}+03$ & 7.65E-02 & 196.24 & 0.85 & $9.21 \mathrm{E}+02$ \\
\hline 230 & 66.6629 & 90.7 & $1.04 \mathrm{E}+03$ & 8.27E-02 & 148.94 & 0.87 & $8.56 \mathrm{E}+02$ \\
\hline 235 & 67.3355 & 86.4 & $8.53 E+02$ & $1.02 \mathrm{E}-01$ & 134.32 & 0.86 & $9.43 E+02$ \\
\hline 240 & 68.008 & 65.9 & $7.23 E+02$ & $1.21 \mathrm{E}-01$ & 74.16 & 0.91 & $5.97 \mathrm{E}+02$ \\
\hline
\end{tabular}




\begin{tabular}{cccccccc}
\hline $\begin{array}{c}\text { Depth } \\
{[\mathrm{cm}]}\end{array}$ & $\begin{array}{c}\text { Age } \\
\text { cal }[\mathrm{kyr}]\end{array}$ & $\begin{array}{c}\text { kappa } \\
{\left[10^{* *}-6 \mathrm{SI}\right]}\end{array}$ & $\begin{array}{c}\text { IRM }_{\mathbf{3 0 0 m T}}[\mathrm{mA} / \mathrm{m}] \\
\text { ARM }_{100} / \mathbf{I R M}_{\mathbf{1 0 0}}\end{array}$ & - & HIRM $_{[300 \& 2700]}$ & S-ratio $_{[300 \& 2700]}$ & $\begin{array}{c}\text { Fe/kappa } \\
{\left[\mathrm{cps} / 10^{* *}-6 \mathrm{SI}\right]}\end{array}$ \\
\hline 245 & 68.5363 & 77.2 & $8.56 \mathrm{E}+02$ & $1.17 \mathrm{E}-01$ & 138.05 & 0.86 & $8.93 \mathrm{E}+02$ \\
250 & 69.0645 & 104 & $9.87 \mathrm{E}+02$ & $1.22 \mathrm{E}-01$ & 222.84 & 0.82 & $1.18 \mathrm{E}+03$ \\
256 & 69.6985 & 90.8 & $7.55 \mathrm{E}+02$ & $1.28 \mathrm{E}-01$ & 160.12 & 0.83 & $1.29 \mathrm{E}+03$ \\
260 & 70.1211 & 72 & $7.32 \mathrm{E}+02$ & $1.21 \mathrm{E}-01$ & 155.72 & 0.82 & $1.56 \mathrm{E}+03$ \\
265 & 70.6493 & 51.5 & $6.34 \mathrm{E}+02$ & $1.21 \mathrm{E}-01$ & 96.57 & 0.87 & $7.15 \mathrm{E}+02$ \\
270 & 71.0621 & 46 & $7.57 \mathrm{E}+02$ & $1.22 \mathrm{E}-01$ & 84.30 & 0.90 & $1.06 \mathrm{E}+03$ \\
275 & 71.4459 & 56.2 & $9.67 \mathrm{E}+02$ & $1.27 \mathrm{E}-01$ & 115.95 & 0.89 & $1.00 \mathrm{E}+03$ \\
280 & 71.8297 & 50.2 & $7.38 \mathrm{E}+02$ & $1.33 \mathrm{E}-01$ & 83.41 & 0.90 & $8.05 \mathrm{E}+02$ \\
285 & 72.2135 & 50.2 & $8.41 \mathrm{E}+02$ & $1.45 \mathrm{E}-01$ & 89.70 & 0.90 & $8.46 \mathrm{E}+02$ \\
290 & 72.5974 & 42.6 & $7.60 \mathrm{E}+02$ & $1.57 \mathrm{E}-01$ & 74.59 & 0.91 & $1.01 \mathrm{E}+03$ \\
295 & 72.9812 & 58.1 & $7.98 \mathrm{E}+02$ & $1.41 \mathrm{E}-01$ & 94.10 & 0.89 & $1.44 \mathrm{E}+03$ \\
300 & 73.365 & 75.8 & $9.56 \mathrm{E}+02$ & $1.14 \mathrm{E}-01$ & 186.41 & 0.84 & $1.19 \mathrm{E}+03$ \\
305 & 74.8989 & 70.9 & $9.38 \mathrm{E}+02$ & $1.03 \mathrm{E}-01$ & 102.13 & 0.90 & $7.82 \mathrm{E}+02$ \\
310 & 76.3444 & 49 & $8.10 \mathrm{E}+02$ & $1.12 \mathrm{E}-01$ & 101.65 & 0.89 & $4.13 \mathrm{E}+02$ \\
315 & 77.4365 & 27.7 & $5.73 \mathrm{E}+02$ & $1.40 \mathrm{E}-01$ & 53.57 & 0.91 & $5.22 \mathrm{E}+02$ \\
320 & 78.5286 & 19.3 & $3.65 \mathrm{E}+02$ & $1.60 \mathrm{E}-01$ & 27.10 & 0.93 & $3.06 \mathrm{E}+02$ \\
325 & 79.6207 & 28 & $2.54 \mathrm{E}+02$ & $1.66 \mathrm{E}-01$ & 18.13 & 0.93 & $3.75 \mathrm{E}+03$ \\
330 & 80.7316 & 73.9 & $1.11 \mathrm{E}+03$ & $7.89 \mathrm{E}-02$ & 242.32 & 0.82 & $1.24 \mathrm{E}+03$ \\
335 & 81.8708 & 85.4 & $1.20 \mathrm{E}+03$ & $8.11 \mathrm{E}-02$ & 269.17 & 0.82 & $1.12 \mathrm{E}+03$ \\
340 & 83.0099 & 64 & $6.53 \mathrm{E}+02$ & $9.39 \mathrm{E}-02$ & 129.69 & 0.83 & $1.07 \mathrm{E}+03$ \\
345 & 84.149 & 57.1 & $7.91 \mathrm{E}+02$ & $9.12 \mathrm{E}-02$ & 156.76 & 0.83 & $1.65 \mathrm{E}+03$ \\
350 & 85.2881 & 83 & $9.03 \mathrm{E}+02$ & $8.91 \mathrm{E}-02$ & 217.13 & 0.81 & $1.28 \mathrm{E}+03$ \\
\hline
\end{tabular}




\section{GeoB3912-1}

\begin{tabular}{|c|c|c|c|c|c|c|c|c|}
\hline $\begin{array}{l}\text { Depth } \\
{[\mathrm{cm}]}\end{array}$ & $\begin{array}{c}\text { Age } \\
\text { cal [kyr] }\end{array}$ & $\begin{array}{c}\text { kappa } \\
{\left[10^{* *}-6 \mathrm{SI}\right]}\end{array}$ & $\begin{array}{l}\text { IRM } \\
{[\mathrm{m} \mathbf{3 0 0 \mathrm { mT }}} \\
{[\mathrm{mA} / \mathrm{m}]}\end{array}$ & $\begin{array}{c}\mathrm{ARM}_{100} / \mathrm{IRM}_{100} \\
-\end{array}$ & $\begin{array}{c}\text { HIRM [300\&2700] } \\
- \\
\end{array}$ & $\begin{array}{c}\text { S-ratio [300\&2700] } \\
- \\
\end{array}$ & $\begin{array}{c}\text { Fe/kappa } \\
{\left[\mathrm{cps} / 10^{* *}-6 \mathrm{SI}\right]}\end{array}$ & $\begin{array}{c}\text { Age } \\
\text { cal }[k y r]\end{array}$ \\
\hline 5 & 2.45 & 48.66 & $9.72 \mathrm{E}+02$ & $6.86 \mathrm{E}-02$ & 63.03 & 0.94 & $4.26 \mathrm{E}+02$ & 1.27 \\
\hline 10.5 & 4.64 & 61.83 & $1.16 \mathrm{E}+03$ & $8.68 \mathrm{E}-02$ & 68.50 & 0.94 & $3.28 \mathrm{E}+02$ & 2.05 \\
\hline 15 & 6.83 & 45.97 & $1.01 \mathrm{E}+03$ & 8.06E-02 & 63.60 & 0.94 & $4.72 E+02$ & 2.84 \\
\hline 20 & 9.54 & 120.70 & $1.12 \mathrm{E}+03$ & 7.20E-02 & 135.40 & 0.89 & $3.99 \mathrm{E}+02$ & 3.66 \\
\hline 25 & 10.19 & 106.72 & $9.73 \mathrm{E}+02$ & 7.01E-02 & 130.44 & 0.88 & $5.56 \mathrm{E}+02$ & 4.44 \\
\hline 30 & 10.57 & 113.71 & $9.88 \mathrm{E}+02$ & $6.90 \mathrm{E}-02$ & 148.84 & 0.87 & $6.30 \mathrm{E}+02$ & 5.23 \\
\hline 35 & 10.95 & 104.57 & $8.77 E+02$ & $6.90 \mathrm{E}-02$ & 133.55 & 0.87 & $5.38 \mathrm{E}+02$ & 6.21 \\
\hline 40.5 & 11.39 & 105.65 & $8.11 \mathrm{E}+02$ & $6.93 \mathrm{E}-02$ & 122.58 & 0.87 & $3.45 \mathrm{E}+02$ & 7.39 \\
\hline 45 & 11.95 & 87.90 & $6.54 \mathrm{E}+02$ & $7.08 \mathrm{E}-02$ & 86.74 & 0.88 & $5.64 \mathrm{E}+02$ & 8.54 \\
\hline 50 & 12.56 & 80.11 & $7.11 \mathrm{E}+02$ & $7.29 \mathrm{E}-02$ & 64.91 & 0.92 & $8.20 \mathrm{E}+02$ & 9.43 \\
\hline 55 & 13.18 & 82.53 & $7.60 \mathrm{E}+02$ & $7.08 \mathrm{E}-02$ & 77.13 & 0.91 & $7.55 \mathrm{E}+02$ & 9.85 \\
\hline 61 & 13.92 & 91.67 & $8.49 \mathrm{E}+02$ & $6.61 \mathrm{E}-02$ & 107.81 & 0.89 & $9.22 \mathrm{E}+02$ & 10.09 \\
\hline 65 & 14.41 & 112.10 & $1.15 E+03$ & $6.24 \mathrm{E}-02$ & 164.20 & 0.87 & $8.78 \mathrm{E}+02$ & 10.27 \\
\hline 70 & 14.88 & 105.65 & 1.19E+03 & $5.86 \mathrm{E}-02$ & 157.00 & 0.88 & $8.57 \mathrm{E}+02$ & 10.42 \\
\hline 75 & 15.16 & 120.70 & $1.03 E+03$ & $6.32 \mathrm{E}-02$ & 211.90 & 0.83 & $9.36 \mathrm{E}+02$ & 10.57 \\
\hline 81 & 15.52 & 110.48 & $9.73 E+02$ & $6.28 \mathrm{E}-02$ & 204.73 & 0.83 & $9.07 E+02$ & 10.72 \\
\hline 85 & 15.77 & 118.28 & $1.01 \mathrm{E}+03$ & 6.07E-02 & 180.10 & 0.85 & $1.03 E+03$ & 10.88 \\
\hline 90.5 & 16.12 & 114.52 & $9.41 \mathrm{E}+02$ & $6.31 \mathrm{E}-02$ & 165.21 & 0.85 & $1.07 \mathrm{E}+03$ & 11.02 \\
\hline 95 & 16.40 & 111.56 & $9.09 \mathrm{E}+02$ & $6.22 \mathrm{E}-02$ & 172.71 & 0.84 & $1.01 \mathrm{E}+03$ & 11.15 \\
\hline 100.5 & 16.74 & 112.90 & $7.51 \mathrm{E}+02$ & 5.79E-02 & 179.71 & 0.81 & $1.07 \mathrm{E}+03$ & 11.34 \\
\hline 105 & 17.01 & 114.52 & $6.79 \mathrm{E}+02$ & $6.38 \mathrm{E}-02$ & 138.16 & 0.83 & $1.15 E+03$ & 11.58 \\
\hline 110.5 & 17.29 & 113.98 & $5.65 \mathrm{E}+02$ & $6.20 \mathrm{E}-02$ & 123.01 & 0.82 & $1.21 \mathrm{E}+03$ & 11.82 \\
\hline 115 & 17.53 & 111.56 & $6.13 E+02$ & 6.36E-02 & 111.93 & 0.85 & $1.14 \mathrm{E}+03$ & 12.07 \\
\hline 121 & 17.87 & 99.73 & $4.78 \mathrm{E}+02$ & $6.15 \mathrm{E}-02$ & 115.09 & 0.81 & $1.12 \mathrm{E}+03$ & 12.32 \\
\hline
\end{tabular}




\begin{tabular}{|c|c|c|c|c|c|c|c|c|}
\hline $\begin{array}{l}\text { Depth } \\
{[\mathrm{cm}]}\end{array}$ & $\begin{array}{c}\text { Age } \\
\text { cal }[k y r]\end{array}$ & $\begin{array}{c}\text { kappa } \\
{[10 * *-6 \mathrm{SI}]}\end{array}$ & $\begin{array}{l}\mathrm{IRM}_{\mathbf{3 0 0 m T}} \\
{[\mathrm{mA} / \mathrm{m}]}\end{array}$ & $\begin{array}{c}\mathrm{ARM}_{100} / \mathrm{IRM}_{100} \\
-\end{array}$ & $\begin{array}{c}\text { HIRM }_{\text {[300\&2700] }} \\
- \\
\end{array}$ & $\begin{array}{c}\text { S-ratio [300\&2700] } \\
-\end{array}$ & $\begin{array}{c}\text { Fe/kappa } \\
{\left[c p s / 10^{* *}-6 \mathrm{SI}\right]}\end{array}$ & $\begin{array}{c}\text { Age } \\
\text { cal }[k y r]\end{array}$ \\
\hline 125 & 18.17 & 115.59 & $5.70 E+02$ & $6.13 \mathrm{E}-02$ & 117.93 & 0.83 & $9.87 \mathrm{E}+02$ & 12.56 \\
\hline 135 & 18.87 & 109.95 & $4.63 E+02$ & $6.02 \mathrm{E}-02$ & 91.75 & 0.83 & $8.87 E+02$ & 13.05 \\
\hline 141 & 19.43 & 79.03 & $6.47 E+02$ & $6.72 \mathrm{E}-02$ & 76.65 & 0.89 & $8.12 \mathrm{E}+02$ & 13.30 \\
\hline 145 & 20.00 & 83.06 & $6.09 \mathrm{E}+02$ & $6.22 \mathrm{E}-02$ & 80.80 & 0.88 & $9.68 \mathrm{E}+02$ & 13.55 \\
\hline 155 & 21.44 & 80.65 & $6.97 E+02$ & $6.44 \mathrm{E}-02$ & 83.20 & 0.89 & $9.32 E+02$ & 14.04 \\
\hline 161.5 & 22.58 & 121.51 & $8.67 E+02$ & $6.42 \mathrm{E}-02$ & 119.38 & 0.88 & $9.38 \mathrm{E}+02$ & 14.28 \\
\hline 165 & 23.23 & 123.39 & $8.00 E+02$ & $5.95 \mathrm{E}-02$ & 122.22 & 0.87 & $1.01 \mathrm{E}+03$ & 14.52 \\
\hline 170.5 & 24.23 & 132.26 & $7.81 E+02$ & $6.06 \mathrm{E}-02$ & 123.53 & 0.86 & $7.95 \mathrm{E}+02$ & 14.74 \\
\hline 175 & 24.74 & 110.75 & $6.15 E+02$ & $6.24 \mathrm{E}-02$ & 116.60 & 0.84 & $1.04 \mathrm{E}+03$ & 14.87 \\
\hline 182 & 25.40 & 109.95 & $6.32 E+02$ & $6.52 \mathrm{E}-02$ & 108.68 & 0.85 & $1.02 E+03$ & 14.99 \\
\hline 190.5 & 26.16 & 89.52 & $7.57 E+02$ & $6.95 \mathrm{E}-02$ & 92.40 & 0.89 & $1.20 \mathrm{E}+03$ & 15.22 \\
\hline 195 & 26.61 & 103.49 & $6.78 \mathrm{E}+02$ & $6.59 \mathrm{E}-02$ & 95.41 & 0.88 & $1.26 \mathrm{E}+03$ & 15.34 \\
\hline 200.5 & 27.22 & 100.54 & $7.39 E+02$ & $6.68 \mathrm{E}-02$ & 106.05 & 0.87 & $1.03 E+03$ & 15.46 \\
\hline 205 & 27.73 & 101.88 & $7.40 E+02$ & $6.94 \mathrm{E}-02$ & 86.99 & 0.89 & $9.41 \mathrm{E}+02$ & 15.59 \\
\hline 210 & 28.29 & 106.18 & $7.28 \mathrm{E}+02$ & 7.01E-02 & 86.50 & 0.89 & $1.29 \mathrm{E}+03$ & 15.83 \\
\hline 215 & 28.85 & 105.11 & $6.50 \mathrm{E}+02$ & $7.02 \mathrm{E}-02$ & 86.06 & 0.88 & $1.28 \mathrm{E}+03$ & 15.96 \\
\hline 220 & 29.37 & 102.96 & $6.46 \mathrm{E}+02$ & $7.02 \mathrm{E}-02$ & 94.48 & 0.87 & $1.29 \mathrm{E}+03$ & 16.09 \\
\hline 225 & 30.06 & 109.68 & $5.89 \mathrm{E}+02$ & 6.37E-02 & 106.17 & 0.85 & $1.30 \mathrm{E}+03$ & 16.21 \\
\hline 230.5 & 30.88 & 113.17 & $5.63 E+02$ & $6.56 \mathrm{E}-02$ & 121.62 & 0.82 & $1.27 \mathrm{E}+03$ & 16.33 \\
\hline 235 & 31.55 & 110.75 & $5.70 \mathrm{E}+02$ & 6.19E-02 & 100.90 & 0.85 & $1.32 \mathrm{E}+03$ & 16.46 \\
\hline 240.5 & 32.30 & 98.39 & $6.42 E+02$ & $6.63 \mathrm{E}-02$ & 94.66 & 0.87 & $1.32 \mathrm{E}+03$ & 16.58 \\
\hline 245 & 32.67 & 81.72 & $6.67 E+02$ & $6.64 \mathrm{E}-02$ & 68.63 & 0.91 & $1.45 E+03$ & 16.71 \\
\hline 250.5 & 33.08 & 83.33 & $7.04 E+02$ & $6.79 E-02$ & 74.11 & 0.90 & $1.42 \mathrm{E}+03$ & 16.83 \\
\hline
\end{tabular}




\begin{tabular}{|c|c|c|c|c|c|c|c|c|}
\hline $\begin{array}{l}\text { Depth } \\
{[\mathrm{cm}]}\end{array}$ & $\begin{array}{c}\text { Age } \\
\text { cal [kyr] }\end{array}$ & $\begin{array}{c}\text { kappa } \\
{\left[10^{* *}-6 \mathrm{SI}\right]}\end{array}$ & $\begin{array}{l}\mathrm{IRM}_{\mathbf{3 0 0 \mathrm { mT }}} \\
{[\mathrm{mA} / \mathrm{m}]}\end{array}$ & $\begin{array}{c}\text { ARM }_{100} / \text { IRM }_{100} \\
-\end{array}$ & $\begin{array}{c}\text { HIRM }_{\text {[300\&2700] }} \\
- \\
\end{array}$ & $\begin{array}{c}\text { S-ratio [300\&2700] } \\
-\end{array}$ & $\begin{array}{c}\text { Fe/kappa } \\
{\left[\mathrm{cps} / 10^{* *}-6 \mathrm{SI}\right]}\end{array}$ & $\begin{array}{c}\text { Age } \\
\text { cal [kyr] }\end{array}$ \\
\hline 255 & 33.41 & 79.84 & $6.22 \mathrm{E}+02$ & $6.86 \mathrm{E}-02$ & 68.88 & 0.90 & $1.46 \mathrm{E}+03$ & 16.95 \\
\hline 265 & 34.15 & 84.68 & $5.97 E+02$ & 7.01E-02 & 71.05 & 0.89 & $1.50 \mathrm{E}+03$ & 17.16 \\
\hline 270 & 34.52 & 98.12 & $6.06 \mathrm{E}+02$ & $6.76 \mathrm{E}-02$ & 87.14 & 0.87 & $1.54 \mathrm{E}+03$ & 17.26 \\
\hline 275 & 34.89 & 79.30 & $6.48 \mathrm{E}+02$ & $6.48 \mathrm{E}-02$ & 70.67 & 0.90 & $1.41 \mathrm{E}+03$ & 17.37 \\
\hline 285 & 36.12 & 102.96 & $6.51 E+02$ & $7.00 \mathrm{E}-02$ & 86.99 & 0.88 & $1.42 E+03$ & 17.58 \\
\hline 290 & 36.56 & 98.12 & $6.54 \mathrm{E}+02$ & $6.71 \mathrm{E}-02$ & 91.53 & 0.88 & $1.40 \mathrm{E}+03$ & 17.68 \\
\hline 295 & 36.86 & 76.61 & $7.66 \mathrm{E}+02$ & $6.82 \mathrm{E}-02$ & 90.01 & 0.89 & $1.38 \mathrm{E}+03$ & 17.81 \\
\hline 300 & 37.04 & 70.16 & $8.34 \mathrm{E}+02$ & $6.77 \mathrm{E}-02$ & 89.99 & 0.90 & $1.36 \mathrm{E}+03$ & 17.95 \\
\hline 305 & 37.21 & 90.05 & $8.43 E+02$ & $6.44 \mathrm{E}-02$ & 104.17 & 0.89 & $1.34 \mathrm{E}+03$ & 18.09 \\
\hline 310 & 37.38 & 106.99 & $8.80 E+02$ & $6.78 \mathrm{E}-02$ & 128.11 & 0.87 & $1.40 \mathrm{E}+03$ & 18.24 \\
\hline 321.5 & 37.77 & 101.61 & $8.16 \mathrm{E}+02$ & $6.36 \mathrm{E}-02$ & 142.11 & 0.85 & $1.40 \mathrm{E}+03$ & 18.52 \\
\hline 325 & 37.89 & 105.65 & $8.04 \mathrm{E}+02$ & $6.05 E-02$ & 158.05 & 0.84 & $1.34 \mathrm{E}+03$ & 18.66 \\
\hline 330.5 & 38.09 & 111.02 & $7.55 E+02$ & $6.06 \mathrm{E}-02$ & 167.35 & 0.82 & $1.30 \mathrm{E}+03$ & 18.80 \\
\hline 335 & 38.32 & 104.03 & $6.64 \mathrm{E}+02$ & $5.42 \mathrm{E}-02$ & 165.01 & 0.80 & $1.28 \mathrm{E}+03$ & 18.94 \\
\hline 340 & 38.75 & 105.11 & $6.50 E+02$ & 5.61E-02 & 182.27 & 0.78 & $1.07 \mathrm{E}+03$ & 19.08 \\
\hline 345 & 39.40 & 69.89 & $6.55 E+02$ & $6.64 \mathrm{E}-02$ & 63.27 & 0.91 & $9.54 \mathrm{E}+02$ & 19.30 \\
\hline 350.5 & 39.89 & 76.08 & $7.03 E+02$ & $6.23 \mathrm{E}-02$ & 62.95 & 0.92 & $9.20 \mathrm{E}+02$ & 19.58 \\
\hline 355 & 40.28 & 88.71 & $6.63 \mathrm{E}+02$ & $6.25 \mathrm{E}-02$ & 81.80 & 0.89 & $9.56 \mathrm{E}+02$ & 19.86 \\
\hline 359 & 40.62 & 93.01 & $6.93 \mathrm{E}+02$ & $6.64 \mathrm{E}-02$ & 81.15 & 0.90 & $1.08 \mathrm{E}+03$ & 20.15 \\
\hline 365 & 41.13 & 83.87 & $7.39 E+02$ & $6.54 \mathrm{E}-02$ & 71.65 & 0.91 & $9.74 \mathrm{E}+02$ & 20.43 \\
\hline 370.5 & 41.73 & 97.31 & $7.14 \mathrm{E}+02$ & $6.59 \mathrm{E}-02$ & 93.11 & 0.88 & $9.02 E+02$ & 20.72 \\
\hline 375 & 42.34 & 91.67 & $7.92 E+02$ & $6.55 \mathrm{E}-02$ & 97.25 & 0.89 & $9.61 \mathrm{E}+02$ & 21.01 \\
\hline 380 & 43.01 & 84.68 & $8.30 E+02$ & $6.52 \mathrm{E}-02$ & 95.11 & 0.90 & $8.46 E+02$ & 21.29 \\
\hline
\end{tabular}




\begin{tabular}{|c|c|c|c|c|c|c|c|c|}
\hline $\begin{array}{l}\text { Depth } \\
{[\mathrm{cm}]}\end{array}$ & $\begin{array}{c}\text { Age } \\
\text { cal [kyr] }\end{array}$ & $\begin{array}{c}\text { kappa } \\
{\left[10^{* *}-6 \mathrm{SI}\right]}\end{array}$ & $\begin{array}{l}\mathrm{IRM}_{\mathbf{3 0 0 m T}} \\
{[\mathrm{mA} / \mathrm{m}]}\end{array}$ & $\begin{array}{c}\text { ARM }_{100} / \text { IRM }_{100} \\
-\end{array}$ & $\begin{array}{c}\text { HIRM [300\&2700] } \\
-\end{array}$ & $\begin{array}{c}\text { S-ratio [300\&2700] } \\
-\end{array}$ & $\begin{array}{c}\text { Fe/kappa } \\
{\left[\mathrm{cps} / 10^{* *}-6 \mathrm{SI}\right]}\end{array}$ & $\begin{array}{c}\text { Age } \\
\text { cal [kyr] }\end{array}$ \\
\hline 385 & 44.20 & 90.32 & $8.20 E+02$ & $6.36 \mathrm{E}-02$ & 98.22 & 0.89 & $8.81 \mathrm{E}+02$ & 21.58 \\
\hline 395 & 45.78 & 101.61 & $9.33 E+02$ & $6.40 \mathrm{E}-02$ & 122.85 & 0.88 & $9.35 \mathrm{E}+02$ & 22.30 \\
\hline 399.5 & 46.30 & 93.01 & $7.88 \mathrm{E}+02$ & $6.45 \mathrm{E}-02$ & 120.78 & 0.87 & $1.23 E+03$ & 22.67 \\
\hline 405 & 46.92 & 109.41 & $8.65 E+02$ & $6.03 \mathrm{E}-02$ & 147.49 & 0.85 & $1.12 \mathrm{E}+03$ & 23.05 \\
\hline 415 & 48.00 & 117.20 & $7.54 \mathrm{E}+02$ & $5.78 \mathrm{E}-02$ & 158.73 & 0.83 & $7.23 E+02$ & 23.79 \\
\hline 420 & 48.23 & 104.84 & $8.30 E+02$ & $6.38 \mathrm{E}-02$ & 110.96 & 0.88 & $1.19 \mathrm{E}+03$ & 24.14 \\
\hline 425 & 48.57 & 104.84 & $8.68 \mathrm{E}+02$ & $6.08 \mathrm{E}-02$ & 100.16 & 0.90 & $1.18 \mathrm{E}+03$ & 24.41 \\
\hline 430 & 49.30 & 104.57 & $8.73 E+02$ & $6.13 \mathrm{E}-02$ & 102.75 & 0.89 & $1.14 \mathrm{E}+03$ & 24.63 \\
\hline 435 & 50.02 & 98.92 & $8.49 E+02$ & $6.29 \mathrm{E}-02$ & 100.06 & 0.89 & $1.15 E+03$ & 24.84 \\
\hline 440 & 50.75 & 87.90 & $8.19 E+02$ & $6.28 \mathrm{E}-02$ & 87.12 & 0.90 & $8.73 E+02$ & 25.03 \\
\hline 450 & 52.21 & 85.75 & $8.07 E+02$ & $6.21 \mathrm{E}-02$ & 86.10 & 0.90 & $1.11 \mathrm{E}+03$ & 25.39 \\
\hline 455 & 52.94 & 89.25 & $8.14 \mathrm{E}+02$ & $6.23 \mathrm{E}-02$ & 90.99 & 0.90 & $1.15 E+03$ & 26.38 \\
\hline 460 & 53.66 & 101.34 & $7.81 E+02$ & $6.80 \mathrm{E}-02$ & 87.42 & 0.90 & $9.12 \mathrm{E}+02$ & 26.60 \\
\hline 465 & 54.39 & 105.11 & $6.84 \mathrm{E}+02$ & $6.57 \mathrm{E}-02$ & 101.18 & 0.87 & $1.01 \mathrm{E}+03$ & 26.83 \\
\hline 470 & 55.11 & 112.10 & $6.46 E+02$ & $6.48 \mathrm{E}-02$ & 105.60 & 0.86 & $1.08 \mathrm{E}+03$ & 27.06 \\
\hline 475 & 55.84 & 103.49 & $7.71 \mathrm{E}+02$ & $6.38 \mathrm{E}-02$ & 96.54 & 0.89 & $9.67 E+02$ & 27.28 \\
\hline 479.5 & 56.49 & 101.88 & $8.19 E+02$ & $6.56 \mathrm{E}-02$ & 97.90 & 0.89 & $1.06 \mathrm{E}+03$ & 27.50 \\
\hline 485 & 57.29 & 97.85 & $9.91 \mathrm{E}+02$ & $6.25 \mathrm{E}-02$ & 93.43 & 0.91 & $1.21 \mathrm{E}+03$ & 27.73 \\
\hline 490.5 & 58.09 & 107.53 & $8.17 E+02$ & $6.68 \mathrm{E}-02$ & 108.31 & 0.88 & $1.18 \mathrm{E}+03$ & 27.95 \\
\hline 495 & 58.75 & 110.75 & $9.46 E+02$ & 6.69E-02 & 136.20 & 0.87 & $1.18 \mathrm{E}+03$ & 28.17 \\
\hline 500.5 & 59.55 & 108.87 & $8.59 E+02$ & $6.71 \mathrm{E}-02$ & 154.33 & 0.85 & $1.24 \mathrm{E}+03$ & 28.40 \\
\hline 505 & 60.20 & 120.97 & $8.43 E+02$ & $6.53 \mathrm{E}-02$ & 160.76 & 0.84 & $1.23 E+03$ & 28.62 \\
\hline 510.5 & 61.00 & 122.85 & $8.76 \mathrm{E}+02$ & $6.81 \mathrm{E}-02$ & 150.45 & 0.85 & $1.22 \mathrm{E}+03$ & 28.84 \\
\hline
\end{tabular}




\begin{tabular}{|c|c|c|c|c|c|c|c|c|}
\hline $\begin{array}{l}\text { Depth } \\
{[\mathrm{cm}]}\end{array}$ & $\begin{array}{c}\text { Age } \\
\text { cal [kyr] }\end{array}$ & $\begin{array}{c}\text { kappa } \\
{\left[10^{* *}-6 \mathrm{SI}\right]}\end{array}$ & $\begin{array}{l}\mathrm{IRM}_{\mathbf{3 0 0 \mathrm { mT }}} \\
{[\mathrm{mA} / \mathrm{m}]}\end{array}$ & $\begin{array}{c}\text { ARM }_{100} / \text { IRM }_{100} \\
-\end{array}$ & $\begin{array}{c}\text { HIRM }_{\text {[300\&2700] }} \\
- \\
\end{array}$ & $\begin{array}{c}\text { S-ratio [300\&2700] } \\
-\end{array}$ & $\begin{array}{c}\text { Fe/kappa } \\
{\left[\mathrm{cps} / 10^{* *}-6 \mathrm{SI}\right]}\end{array}$ & $\begin{array}{c}\text { Age } \\
\text { cal [kyr] }\end{array}$ \\
\hline 515 & 61.65 & 119.89 & $8.18 \mathrm{E}+02$ & 6.39E-02 & 134.19 & 0.86 & $1.30 \mathrm{E}+03$ & 29.06 \\
\hline 525 & 63.10 & 126.34 & $8.03 E+02$ & $6.64 \mathrm{E}-02$ & 128.92 & 0.86 & $1.25 \mathrm{E}+03$ & 29.50 \\
\hline 530.5 & 63.91 & 123.39 & $7.72 \mathrm{E}+02$ & $6.64 \mathrm{E}-02$ & 123.26 & 0.86 & $1.30 \mathrm{E}+03$ & 29.76 \\
\hline 535 & 64.56 & 125.54 & $6.41 E+02$ & $6.44 \mathrm{E}-02$ & 135.21 & 0.83 & $1.27 \mathrm{E}+03$ & 30.06 \\
\hline 545 & 66.40 & 128.23 & $5.84 \mathrm{E}+02$ & 5.89E-02 & 135.73 & 0.81 & $1.24 \mathrm{E}+03$ & 30.66 \\
\hline 550.5 & 67.51 & 112.90 & $8.07 E+02$ & $6.35 \mathrm{E}-02$ & 122.58 & 0.87 & $1.32 \mathrm{E}+03$ & 30.95 \\
\hline 555 & 68.41 & 118.01 & $1.11 \mathrm{E}+03$ & $6.71 \mathrm{E}-02$ & 113.90 & 0.91 & $1.13 \mathrm{E}+03$ & 31.25 \\
\hline 560.5 & 69.51 & 132.26 & $9.09 E+02$ & $6.63 \mathrm{E}-02$ & 169.98 & 0.84 & $1.15 E+03$ & 31.55 \\
\hline 565 & 70.41 & 129.03 & $9.07 E+02$ & $6.20 \mathrm{E}-02$ & 134.90 & 0.87 & $1.16 \mathrm{E}+03$ & 31.85 \\
\hline 570.5 & 71.36 & 102.96 & $1.33 E+03$ & 7.55E-02 & 85.40 & 0.94 & $1.16 \mathrm{E}+03$ & 32.12 \\
\hline 579.5 & 72.61 & 94.62 & $1.09 E+03$ & $7.83 \mathrm{E}-02$ & 71.20 & 0.94 & $9.31 E+02$ & 32.52 \\
\hline 585 & 73.37 & 113.17 & $1.13 \mathrm{E}+03$ & $7.21 \mathrm{E}-02$ & 101.70 & 0.92 & $8.31 \mathrm{E}+02$ & 32.67 \\
\hline 591 & 74.19 & 117.47 & $1.16 \mathrm{E}+03$ & 7.26E-02 & 120.00 & 0.91 & $9.24 \mathrm{E}+02$ & 32.82 \\
\hline 595 & 74.75 & 123.39 & $1.14 \mathrm{E}+03$ & $6.76 \mathrm{E}-02$ & 120.90 & 0.90 & $9.39 \mathrm{E}+02$ & 32.97 \\
\hline 600.5 & 75.51 & 125.54 & $9.46 \mathrm{E}+02$ & $7.18 \mathrm{E}-02$ & 132.55 & 0.88 & $8.94 \mathrm{E}+02$ & 33.12 \\
\hline 605 & 76.13 & 87.10 & $1.19 E+03$ & $7.28 \mathrm{E}-02$ & 97.30 & 0.92 & $9.66 \mathrm{E}+02$ & 33.26 \\
\hline 610.5 & 76.89 & 88.98 & $1.35 E+03$ & 8.11E-02 & 93.10 & 0.94 & $8.94 \mathrm{E}+02$ & 33.40 \\
\hline 615 & 77.52 & 86.02 & $1.35 \mathrm{E}+03$ & 7.78E-02 & 94.80 & 0.93 & $9.76 \mathrm{E}+02$ & 33.55 \\
\hline 620 & 78.21 & 86.02 & $1.52 E+03$ & $8.12 \mathrm{E}-02$ & 69.10 & 0.96 & $1.01 \mathrm{E}+03$ & 33.71 \\
\hline 625 & 78.90 & 75.27 & $1.37 E+03$ & $7.86 \mathrm{E}-02$ & 64.20 & 0.96 & $1.13 \mathrm{E}+03$ & 33.86 \\
\hline 630 & 79.59 & 98.66 & $1.63 E+03$ & 8.03E-02 & 73.00 & 0.96 & $1.05 E+03$ & 34.00 \\
\hline 635 & 80.28 & 92.47 & $1.25 E+03$ & $7.82 \mathrm{E}-02$ & 68.00 & 0.95 & $9.84 \mathrm{E}+02$ & 34.15 \\
\hline 640 & 80.97 & 84.68 & $1.23 E+03$ & $7.35 \mathrm{E}-02$ & 69.30 & 0.95 & $1.04 \mathrm{E}+03$ & 34.30 \\
\hline
\end{tabular}




\begin{tabular}{|c|c|c|c|c|c|c|c|c|}
\hline $\begin{array}{l}\text { Depth } \\
{[\mathrm{cm}]}\end{array}$ & $\begin{array}{c}\text { Age } \\
\text { cal [kyr] }\end{array}$ & $\begin{array}{c}\text { kappa } \\
{\left[10^{* *}-6 \mathrm{SI}\right]}\end{array}$ & $\begin{array}{l}\mathrm{IRM}_{\mathbf{3 0 0 \mathrm { mT }}} \\
{[\mathrm{mA} / \mathrm{m}]}\end{array}$ & $\begin{array}{c}\mathrm{ARM}_{100} / \mathrm{IRM}_{100} \\
-\end{array}$ & $\begin{array}{c}\text { HIRM }_{\text {[300\&2700] }} \\
- \\
\end{array}$ & $\begin{array}{c}\text { S-ratio [300\&2700] } \\
-\end{array}$ & $\begin{array}{c}\text { Fe/kappa } \\
{\left[c p s / 10^{* *}-6 \mathrm{SI}\right]}\end{array}$ & $\begin{array}{c}\text { Age } \\
\text { cal [kyr] }\end{array}$ \\
\hline 645 & 81.66 & 97.31 & $1.19 E+03$ & $6.68 \mathrm{E}-02$ & 91.00 & 0.93 & $1.02 \mathrm{E}+03$ & 34.45 \\
\hline 655 & 83.04 & 125.81 & $1.17 \mathrm{E}+03$ & 7.00E-02 & 127.20 & 0.90 & $9.44 \mathrm{E}+02$ & 34.74 \\
\hline 661 & 83.87 & 121.24 & $9.57 E+02$ & $7.58 \mathrm{E}-02$ & 118.37 & 0.89 & $9.71 E+02$ & 34.89 \\
\hline 665 & 84.42 & 122.85 & $9.73 E+02$ & $7.22 \mathrm{E}-02$ & 113.66 & 0.90 & $8.72 \mathrm{E}+02$ & 35.04 \\
\hline \multirow{19}{*}{670} & & & & & & & $9.49 \mathrm{E}+02$ & 35.54 \\
\hline & & & & & & & $6.81 \mathrm{E}+02$ & 36.12 \\
\hline & & & & & & & $7.00 \mathrm{E}+02$ & 36.34 \\
\hline & & & & & & & $7.29 \mathrm{E}+02$ & 36.50 \\
\hline & & & & & & & $7.90 \mathrm{E}+02$ & 36.62 \\
\hline & & & & & & & $1.03 E+03$ & 36.74 \\
\hline & & & & & & & $1.05 E+03$ & 36.93 \\
\hline & & & & & & & $1.18 \mathrm{E}+03$ & 37.00 \\
\hline & & & & & & & $1.13 E+03$ & 37.07 \\
\hline & & & & & & & $9.29 \mathrm{E}+02$ & 37.15 \\
\hline & & & & & & & $8.40 \mathrm{E}+02$ & 37.21 \\
\hline & & & & & & & $9.59 \mathrm{E}+02$ & 37.28 \\
\hline & & & & & & & $9.72 E+02$ & 37.35 \\
\hline & & & & & & & $1.03 E+03$ & 37.42 \\
\hline & & & & & & & $9.74 \mathrm{E}+02$ & 37.49 \\
\hline & & & & & & & $9.30 \mathrm{E}+02$ & 37.55 \\
\hline & & & & & & & $9.74 \mathrm{E}+02$ & 37.62 \\
\hline & & & & & & & $1.04 \mathrm{E}+03$ & 37.69 \\
\hline & & & & & & & $8.16 \mathrm{E}+02$ & 37.76 \\
\hline
\end{tabular}




\begin{tabular}{|c|c|c|c|c|c|c|c|c|}
\hline $\begin{array}{l}\text { Depth } \\
{[\mathrm{cm}]}\end{array}$ & $\begin{array}{c}\text { Age } \\
\text { cal [kyr] }\end{array}$ & $\begin{array}{c}\text { kappa } \\
{\left[10^{* *}-6 \mathrm{SI}\right]}\end{array}$ & $\begin{array}{l}\mathrm{IRM}_{300 \mathrm{mT}} \\
{[\mathrm{mA} / \mathrm{m}]}\end{array}$ & $\begin{array}{c}\mathrm{ARM}_{100} / \mathrm{IRM}_{100} \\
-\end{array}$ & $\begin{array}{c}\text { HIRM }_{\text {[30082700] }} \\
-\end{array}$ & $\begin{array}{c}\text { S-ratio }_{[30082700]} \\
-\end{array}$ & $\begin{array}{c}\text { Fe/kappa } \\
{\left[\mathrm{cps} / 10^{* *}-6 \mathrm{SI}\right]}\end{array}$ & $\begin{array}{c}\text { Age } \\
\text { cal [kyr] }\end{array}$ \\
\hline & & & & & & & $1.02 \mathrm{E}+03$ & 37.83 \\
\hline & & & & & & & $1.21 E+03$ & 37.89 \\
\hline & & & & & & & $1.27 \mathrm{E}+03$ & 37.96 \\
\hline & & & & & & & $1.30 \mathrm{E}+03$ & 38.03 \\
\hline & & & & & & & $1.29 E+03$ & 38.11 \\
\hline & & & & & & & $1.28 \mathrm{E}+03$ & 38.21 \\
\hline & & & & & & & $1.31 E+03$ & 38.32 \\
\hline & & & & & & & $1.28 \mathrm{E}+03$ & 38.45 \\
\hline & & & & & & & $1.21 \mathrm{E}+03$ & 38.63 \\
\hline & & & & & & & $1.26 \mathrm{E}+03$ & 38.87 \\
\hline & & & & & & & $1.30 \mathrm{E}+03$ & 39.13 \\
\hline & & & & & & & $1.30 \mathrm{E}+03$ & 39.39 \\
\hline & & & & & & & $1.34 \mathrm{E}+03$ & 39.59 \\
\hline & & & & & & & $1.29 E+03$ & 39.77 \\
\hline & & & & & & & $9.79 \mathrm{E}+02$ & 39.94 \\
\hline & & & & & & & $1.19 \mathrm{E}+03$ & 40.11 \\
\hline & & & & & & & $1.21 E+03$ & 40.28 \\
\hline & & & & & & & $1.04 \mathrm{E}+03$ & 40.45 \\
\hline & & & & & & & $1.02 E+03$ & 40.62 \\
\hline & & & & & & & $9.89 E+02$ & 40.79 \\
\hline & & & & & & & $9.56 \mathrm{E}+02$ & 40.96 \\
\hline & & & & & & & $8.89 E+02$ & 41.14 \\
\hline & & & & & & & $8.67 E+02$ & 41.32 \\
\hline & & & & & & & $8.28 E+02$ & 41.54 \\
\hline & & & & & & & $8.69 E+02$ & 41.81 \\
\hline & & & & & & & $1.04 \mathrm{E}+03$ & 42.07 \\
\hline
\end{tabular}




\begin{tabular}{|c|c|c|c|c|c|c|c|c|}
\hline $\begin{array}{l}\text { Depth } \\
{[\mathrm{cm}]}\end{array}$ & $\begin{array}{c}\text { Age } \\
\text { cal [kyr] }\end{array}$ & $\begin{array}{c}\text { kappa } \\
{\left[10^{* *}-6 \mathrm{SI}\right]}\end{array}$ & $\begin{array}{l}\mathrm{IRM}_{\mathbf{3 0 0 m T}} \\
{[\mathrm{mA} / \mathrm{m}]}\end{array}$ & $\begin{array}{c}\mathrm{ARM}_{100} / \mathrm{IRM}_{100} \\
-\end{array}$ & $\begin{array}{c}\text { HIRM }_{\text {[300\&2700] }} \\
- \\
\end{array}$ & $\begin{array}{c}\text { S-ratio [300\&2700] } \\
-\end{array}$ & $\begin{array}{c}\text { Fe/kappa } \\
{\left[c p s / 10^{* *}-6 \mathrm{SI}\right]}\end{array}$ & $\begin{array}{c}\text { Age } \\
\text { cal [kyr] }\end{array}$ \\
\hline & & & & & & & $1.19 \mathrm{E}+03$ & 42.33 \\
\hline & & & & & & & $1.15 E+03$ & 42.88 \\
\hline & & & & & & & $1.07 \mathrm{E}+03$ & 43.22 \\
\hline & & & & & & & $1.05 E+03$ & 44.20 \\
\hline & & & & & & & $8.29 E+02$ & 44.68 \\
\hline & & & & & & & $9.61 \mathrm{E}+02$ & 45.05 \\
\hline & & & & & & & $9.97 E+02$ & 45.32 \\
\hline & & & & & & & $1.01 \mathrm{E}+03$ & 45.55 \\
\hline & & & & & & & $9.89 E+02$ & 45.78 \\
\hline & & & & & & & $1.19 \mathrm{E}+03$ & 46.01 \\
\hline & & & & & & & $1.20 \mathrm{E}+03$ & 46.24 \\
\hline & & & & & & & $1.29 E+03$ & 46.69 \\
\hline & & & & & & & $1.26 \mathrm{E}+03$ & 46.93 \\
\hline & & & & & & & $1.38 \mathrm{E}+03$ & 47.16 \\
\hline & & & & & & & $1.43 E+03$ & 47.39 \\
\hline & & & & & & & $1.36 \mathrm{E}+03$ & 47.61 \\
\hline & & & & & & & $1.39 \mathrm{E}+03$ & 47.80 \\
\hline & & & & & & & $1.42 \mathrm{E}+03$ & 47.99 \\
\hline & & & & & & & $1.33 E+03$ & 48.13 \\
\hline & & & & & & & $1.30 \mathrm{E}+03$ & 48.21 \\
\hline & & & & & & & $1.11 \mathrm{E}+03$ & 48.23 \\
\hline & & & & & & & $1.04 \mathrm{E}+03$ & 48.28 \\
\hline & & & & & & & $1.09 E+03$ & 48.58 \\
\hline & & & & & & & $1.15 \mathrm{E}+03$ & 48.87 \\
\hline
\end{tabular}




\begin{tabular}{|c|c|c|c|c|c|c|c|c|}
\hline $\begin{array}{l}\text { Depth } \\
{[\mathrm{cm}]}\end{array}$ & $\begin{array}{c}\text { Age } \\
\text { cal [kyr] }\end{array}$ & $\begin{array}{c}\text { kappa } \\
{\left[10^{* *}-6 \mathrm{SI}\right]}\end{array}$ & $\begin{array}{l}\mathrm{IRM}_{\mathbf{3 0 0 m T}} \\
{[\mathrm{mA} / \mathrm{m}]}\end{array}$ & $\begin{array}{c}\mathrm{ARM}_{100} / \mathrm{IRM}_{100} \\
-\end{array}$ & $\begin{array}{c}\text { HIRM }_{\text {[300\&2700] }} \\
- \\
\end{array}$ & $\begin{array}{c}\text { S-ratio [300\&2700] } \\
- \\
\end{array}$ & $\begin{array}{c}\text { Fe/kappa } \\
{\left[\mathrm{cps} / 10^{* *}-6 \mathrm{SI}\right]}\end{array}$ & $\begin{array}{c}\text { Age } \\
\text { cal [kyr] }\end{array}$ \\
\hline & & & & & & & $1.10 \mathrm{E}+03$ & 49.15 \\
\hline & & & & & & & $1.18 \mathrm{E}+03$ & 49.73 \\
\hline & & & & & & & $1.00 \mathrm{E}+03$ & 50.03 \\
\hline & & & & & & & $1.08 \mathrm{E}+03$ & 50.32 \\
\hline & & & & & & & $9.90 E+02$ & 50.60 \\
\hline & & & & & & & $9.14 \mathrm{E}+02$ & 50.89 \\
\hline & & & & & & & $1.01 \mathrm{E}+03$ & 51.18 \\
\hline & & & & & & & $9.49 E+02$ & 51.48 \\
\hline & & & & & & & $9.48 \mathrm{E}+02$ & 51.77 \\
\hline & & & & & & & $9.06 \mathrm{E}+02$ & 52.06 \\
\hline & & & & & & & $9.56 \mathrm{E}+02$ & 52.35 \\
\hline & & & & & & & $9.01 \mathrm{E}+02$ & 52.94 \\
\hline & & & & & & & $8.86 \mathrm{E}+02$ & 53.23 \\
\hline & & & & & & & $8.52 \mathrm{E}+02$ & 53.52 \\
\hline & & & & & & & $9.62 E+02$ & 53.81 \\
\hline & & & & & & & $1.24 \mathrm{E}+03$ & 54.10 \\
\hline & & & & & & & $1.27 \mathrm{E}+03$ & 54.39 \\
\hline & & & & & & & $1.39 \mathrm{E}+03$ & 54.68 \\
\hline & & & & & & & $1.39 E+03$ & 54.97 \\
\hline & & & & & & & $1.30 \mathrm{E}+03$ & 55.26 \\
\hline & & & & & & & $1.21 \mathrm{E}+03$ & 55.55 \\
\hline & & & & & & & $1.20 \mathrm{E}+03$ & 55.84 \\
\hline & & & & & & & $1.07 \mathrm{E}+03$ & 56.13 \\
\hline & & & & & & & $1.09 \mathrm{E}+03$ & 56.41 \\
\hline
\end{tabular}




\begin{tabular}{|c|c|c|c|c|c|c|c|c|}
\hline $\begin{array}{l}\text { Depth } \\
{[\mathrm{cm}]}\end{array}$ & $\begin{array}{c}\text { Age } \\
\text { cal [kyr] }\end{array}$ & $\begin{array}{c}\text { kappa } \\
{\left[10^{* *}-6 \mathrm{SI}\right]}\end{array}$ & $\begin{array}{l}\text { IRM } \\
{[\mathrm{mA0mT}} \\
{[\mathrm{mA} / \mathrm{m}]}\end{array}$ & $\begin{array}{c}\text { ARM }_{100} / \text { IRM }_{100} \\
-\end{array}$ & $\begin{array}{c}\text { HIRM }_{\text {[300\&2700] }} \\
-\end{array}$ & $\begin{array}{c}\text { S-ratio [300\&2700] } \\
- \\
\end{array}$ & $\begin{array}{c}\mathrm{Fe} / \mathrm{kappa} \\
{\left[\mathrm{cps} / 10^{* *}-6 \mathrm{SI}\right]}\end{array}$ & $\begin{array}{c}\text { Age } \\
\text { cal [kyr] }\end{array}$ \\
\hline & & & & & & & $1.09 \mathrm{E}+03$ & 56.75 \\
\hline & & & & & & & $7.09 E+02$ & 57.58 \\
\hline & & & & & & & $8.87 E+02$ & 57.87 \\
\hline & & & & & & & $9.32 E+02$ & 58.16 \\
\hline & & & & & & & $1.02 \mathrm{E}+03$ & 58.76 \\
\hline & & & & & & & $1.15 \mathrm{E}+03$ & 58.90 \\
\hline & & & & & & & $1.27 E+03$ & 59.62 \\
\hline & & & & & & & $1.29 E+03$ & 60.06 \\
\hline & & & & & & & $1.34 \mathrm{E}+03$ & 60.21 \\
\hline & & & & & & & $1.38 \mathrm{E}+03$ & 60.50 \\
\hline & & & & & & & $1.35 \mathrm{E}+03$ & 61.07 \\
\hline & & & & & & & $1.38 \mathrm{E}+03$ & 61.36 \\
\hline & & & & & & & $1.38 \mathrm{E}+03$ & 61.66 \\
\hline & & & & & & & $1.38 \mathrm{E}+03$ & 61.95 \\
\hline & & & & & & & $1.34 \mathrm{E}+03$ & 62.23 \\
\hline & & & & & & & $1.26 \mathrm{E}+03$ & 62.52 \\
\hline & & & & & & & $1.34 \mathrm{E}+03$ & 62.81 \\
\hline & & & & & & & $1.32 \mathrm{E}+03$ & 63.11 \\
\hline & & & & & & & $1.18 \mathrm{E}+03$ & 63.40 \\
\hline & & & & & & & $1.29 \mathrm{E}+03$ & 63.69 \\
\hline & & & & & & & $1.30 \mathrm{E}+03$ & 63.98 \\
\hline & & & & & & & $1.25 E+03$ & 64.27 \\
\hline & & & & & & & $1.36 \mathrm{E}+03$ & 64.57 \\
\hline
\end{tabular}




\begin{tabular}{|c|c|c|c|c|c|c|c|c|}
\hline $\begin{array}{l}\text { Depth } \\
{[\mathrm{cm}]}\end{array}$ & $\begin{array}{c}\text { Age } \\
\text { cal [kyr] }\end{array}$ & $\begin{array}{c}\text { kappa } \\
{\left[10^{* *}-6 \mathrm{SI}\right]}\end{array}$ & $\begin{array}{l}\mathrm{IRM}_{\mathbf{3 0 0 \mathrm { mT }}} \\
{[\mathrm{mA} / \mathrm{m}]}\end{array}$ & $\begin{array}{c}\text { ARM }_{100} / \text { IRM }_{100} \\
-\end{array}$ & $\begin{array}{c}\text { HIRM }_{\text {[300\&2700] }} \\
-\end{array}$ & $\begin{array}{c}\text { S-ratio } \\
{[300 \& 2700]} \\
-\end{array}$ & $\begin{array}{c}\mathrm{Fe} / \mathbf{k a p p a} \\
{\left[\mathrm{cps} / 10^{* *}-6 \mathrm{SI}\right]}\end{array}$ & $\begin{array}{c}\text { Age } \\
\text { cal [kyr] }\end{array}$ \\
\hline & & & & & & & $1.40 \mathrm{E}+03$ & 64.86 \\
\hline & & & & & & & $1.06 \mathrm{E}+03$ & 65.20 \\
\hline & & & & & & & $1.04 \mathrm{E}+03$ & 65.60 \\
\hline & & & & & & & $1.38 \mathrm{E}+03$ & 66.00 \\
\hline & & & & & & & $1.32 \mathrm{E}+03$ & 66.40 \\
\hline & & & & & & & $1.20 \mathrm{E}+03$ & 66.80 \\
\hline & & & & & & & $1.03 E+03$ & 67.20 \\
\hline & & & & & & & $1.01 \mathrm{E}+03$ & 67.61 \\
\hline & & & & & & & $8.21 E+02$ & 68.01 \\
\hline & & & & & & & $6.74 \mathrm{E}+02$ & 68.41 \\
\hline & & & & & & & $1.13 E+03$ & 68.81 \\
\hline & & & & & & & $1.19 E+03$ & 69.21 \\
\hline & & & & & & & $1.30 \mathrm{E}+03$ & 69.61 \\
\hline & & & & & & & $1.25 E+03$ & 70.01 \\
\hline & & & & & & & $1.34 \mathrm{E}+03$ & 70.41 \\
\hline & & & & & & & $7.09 E+02$ & 70.81 \\
\hline & & & & & & & $7.74 E+02$ & 71.15 \\
\hline & & & & & & & $8.39 E+02$ & 71.43 \\
\hline & & & & & & & $6.21 E+02$ & 71.71 \\
\hline & & & & & & & $6.88 \mathrm{E}+02$ & 71.99 \\
\hline & & & & & & & $6.75 E+02$ & 72.26 \\
\hline & & & & & & & $7.65 E+02$ & 72.54 \\
\hline & & & & & & & $9.39 \mathrm{E}+02$ & 72.86 \\
\hline & & & & & & & $9.68 \mathrm{E}+02$ & 73.38 \\
\hline & & & & & & & $1.04 E+03$ & 73.64 \\
\hline & & & & & & & $1.21 \mathrm{E}+03$ & 73.92 \\
\hline
\end{tabular}




\begin{tabular}{|c|c|c|c|c|c|c|c|c|}
\hline $\begin{array}{l}\text { Depth } \\
{[\mathrm{cm}]}\end{array}$ & $\begin{array}{c}\text { Age } \\
\text { cal [kyr] }\end{array}$ & $\begin{array}{c}\text { kappa } \\
{\left[10^{* *}-6 \mathrm{SI}\right]}\end{array}$ & $\begin{array}{l}\mathrm{IRM}_{\mathbf{3 0 0 \mathrm { mT }}} \\
{[\mathrm{mA} / \mathrm{m}]}\end{array}$ & $\begin{array}{c}\text { ARM }_{100} / \text { IRM }_{100} \\
-\end{array}$ & $\begin{array}{c}\text { HIRM }_{\text {[300\&2700] }} \\
-\end{array}$ & $\begin{array}{c}\text { S-ratio } \\
{[300 \& 2700]} \\
-\end{array}$ & $\begin{array}{c}\mathrm{Fe} / \mathbf{k a p p a} \\
{\left[\mathrm{cps} / 10^{* *}-6 \mathrm{SI}\right]}\end{array}$ & $\begin{array}{c}\text { Age } \\
\text { cal [kyr] }\end{array}$ \\
\hline & & & & & & & $1.10 \mathrm{E}+03$ & 74.20 \\
\hline & & & & & & & $1.12 \mathrm{E}+03$ & 74.47 \\
\hline & & & & & & & $1.13 E+03$ & 74.75 \\
\hline & & & & & & & $1.20 \mathrm{E}+03$ & 75.02 \\
\hline & & & & & & & $1.26 \mathrm{E}+03$ & 75.30 \\
\hline & & & & & & & $1.22 \mathrm{E}+03$ & 75.58 \\
\hline & & & & & & & $1.15 E+03$ & 75.85 \\
\hline & & & & & & & $6.40 E+02$ & 76.13 \\
\hline & & & & & & & $7.24 \mathrm{E}+02$ & 76.40 \\
\hline & & & & & & & $7.92 \mathrm{E}+02$ & 76.68 \\
\hline & & & & & & & $7.71 E+02$ & 76.96 \\
\hline & & & & & & & $7.90 E+02$ & 77.24 \\
\hline & & & & & & & $7.74 \mathrm{E}+02$ & 77.52 \\
\hline & & & & & & & $7.22 E+02$ & 77.79 \\
\hline & & & & & & & $6.36 \mathrm{E}+02$ & 78.07 \\
\hline & & & & & & & $6.12 E+02$ & 78.35 \\
\hline & & & & & & & $6.32 E+02$ & 78.62 \\
\hline & & & & & & & $6.94 \mathrm{E}+02$ & 78.90 \\
\hline & & & & & & & $7.67 E+02$ & 79.17 \\
\hline & & & & & & & $6.92 E+02$ & 79.45 \\
\hline & & & & & & & $7.42 \mathrm{E}+02$ & 79.73 \\
\hline & & & & & & & $6.83 E+02$ & 80.00 \\
\hline & & & & & & & $6.69 \mathrm{E}+02$ & 80.28 \\
\hline & & & & & & & $9.26 E+02$ & 80.55 \\
\hline & & & & & & & $9.16 E+02$ & 80.83 \\
\hline & & & & & & & $6.69 E+02$ & 81.11 \\
\hline
\end{tabular}




\begin{tabular}{|c|c|c|c|c|c|c|c|c|}
\hline $\begin{array}{l}\text { Depth } \\
{[\mathrm{cm}]}\end{array}$ & $\begin{array}{c}\text { Age } \\
\text { cal [kyr] }\end{array}$ & $\begin{array}{c}\text { kappa } \\
{\left[10^{* *}-6 \mathrm{SI}\right]}\end{array}$ & $\begin{array}{l}\text { IRM } \mathbf{3 0 0 \mathrm { mT }} \\
{[\mathrm{mA} / \mathrm{m}]}\end{array}$ & $\begin{array}{c}\mathrm{ARM}_{100} / \mathrm{IRM}_{100} \\
-\end{array}$ & $\begin{array}{c}\text { HIRM }_{[300 \& 2700]} \\
-\end{array}$ & $\begin{array}{c}\text { S-ratio }{ }_{[300 \& 2700]} \\
-\end{array}$ & $\begin{array}{c}\mathrm{Fe} / \mathrm{kappa} \\
{\left[\mathrm{cps} / 10^{* *}-6 \mathrm{SI}\right]}\end{array}$ & $\begin{array}{c}\text { Age } \\
\text { cal [kyr] }\end{array}$ \\
\hline & & & & & & & $6.12 \mathrm{E}+02$ & 81.38 \\
\hline & & & & & & & $6.98 \mathrm{E}+02$ & 81.66 \\
\hline & & & & & & & $6.22 E+02$ & 81.93 \\
\hline & & & & & & & $6.90 E+02$ & 82.21 \\
\hline & & & & & & & $7.14 \mathrm{E}+02$ & 82.49 \\
\hline & & & & & & & $8.41 E+02$ & 82.76 \\
\hline & & & & & & & $9.17 E+02$ & 83.04 \\
\hline & & & & & & & $1.06 \mathrm{E}+03$ & 83.32 \\
\hline & & & & & & & $8.97 E+02$ & 83.60 \\
\hline & & & & & & & $1.13 \mathrm{E}+03$ & 83.88 \\
\hline & & & & & & & $1.26 \mathrm{E}+03$ & 84.15 \\
\hline & & & & & & & $1.30 \mathrm{E}+03$ & 84.42 \\
\hline & & & & & & & $1.20 \mathrm{E}+03$ & 84.69 \\
\hline
\end{tabular}

\section{GeoB3911-3}

\begin{tabular}{ccccccccc}
\hline $\begin{array}{c}\text { Depth } \\
{[\mathrm{cm}]}\end{array}$ & $\begin{array}{c}\text { Age } \\
\text { cal }[\mathrm{kyr}]\end{array}$ & $\begin{array}{c}\text { kappa } \\
{\left[10^{* *}-6 \mathrm{SI}\right]}\end{array}$ & $\begin{array}{c}\text { IRM }_{\mathbf{3 0 0 m T}} \\
{[\mathrm{mA} / \mathrm{m}]}\end{array}$ & $\begin{array}{c}\text { ARM }_{\text {100/ }} / \mathbf{I R M}_{\mathbf{1 0 0}} \\
-\end{array}$ & $\begin{array}{c}\text { HIRM }_{[300 \& 2700]} \\
-\end{array}$ & $\begin{array}{c}\text { S-ratio }_{[300 \& 2700]} \\
-\end{array}$ & $\begin{array}{c}\text { Fe/kappa } \\
{\left[\mathrm{cps} / 10^{* *}-6 \mathrm{SI}\right]}\end{array}$ & $\begin{array}{c}\text { Age } \\
\text { cal [kyr] }\end{array}$ \\
\hline 5 & 0.43 & 61.10 & $1.22 \mathrm{E}+03$ & $1.67 \mathrm{E}-01$ & $5.12 \mathrm{E}+01$ & 0.96 & $8.42 \mathrm{E}+02$ & 0.087 \\
15 & 1.30 & 66.20 & $1.28 \mathrm{E}+03$ & $1.69 \mathrm{E}-01$ & $5.41 \mathrm{E}+01$ & 0.96 & $6.30 \mathrm{E}+02$ & 0.174 \\
25 & 2.12 & 70.30 & $1.33 \mathrm{E}+03$ & $1.69 \mathrm{E}-01$ & $6.21 \mathrm{E}+01$ & 0.96 & $6.17 \mathrm{E}+02$ & 0.260 \\
35 & 2.81 & 66.30 & $1.55 \mathrm{E}+03$ & $1.71 \mathrm{E}-01$ & $7.82 \mathrm{E}+01$ & 0.95 & $6.71 \mathrm{E}+02$ & 0.347 \\
45 & 3.50 & 64.40 & $1.54 \mathrm{E}+03$ & $1.72 \mathrm{E}-01$ & $6.32 \mathrm{E}+01$ & 0.96 & $8.73 \mathrm{E}+02$ & 0.434 \\
55 & 4.06 & 58.30 & $1.37 \mathrm{E}+03$ & $1.73 \mathrm{E}-01$ & $5.60 \mathrm{E}+01$ & 0.96 & $7.87 \mathrm{E}+02$ & 0.521 \\
65 & 4.49 & 62.20 & $1.67 \mathrm{E}+03$ & $1.76 \mathrm{E}-01$ & $7.21 \mathrm{E}+01$ & 0.96 & $5.53 \mathrm{E}+02$ & 0.608 \\
75 & 5.34 & 66.10 & $1.71 \mathrm{E}+03$ & $1.81 \mathrm{E}-01$ & $9.43 \mathrm{E}+01$ & 0.95 & $5.78 \mathrm{E}+02$ & 0.695 \\
85 & 6.19 & 71.60 & $1.51 \mathrm{E}+03$ & $1.78 \mathrm{E}-01$ & $5.95 \mathrm{E}+01$ & 0.96 & $5.26 \mathrm{E}+02$ & 0.781
\end{tabular}




\begin{tabular}{|c|c|c|c|c|c|c|c|c|}
\hline $\begin{array}{l}\text { Depth } \\
{[\mathrm{cm}]}\end{array}$ & $\begin{array}{c}\text { Age } \\
\text { cal [kyr] }\end{array}$ & $\begin{array}{c}\text { kappa } \\
{\left[10^{* *}-6 \mathrm{SI}\right]}\end{array}$ & $\begin{array}{l}\mathbf{I R M}_{\mathbf{3 0 0 m T}} \\
{[\mathrm{mA} / \mathrm{m}]}\end{array}$ & $\mathrm{ARM}_{100} / \mathrm{IRM}_{100}$ & $\begin{array}{c}\text { HIRM }_{\text {[300\&2700] }} \\
-\end{array}$ & $\begin{array}{c}\text { S-ratio } \\
{[30082700]} \\
-\end{array}$ & $\begin{array}{c}\mathrm{Fe} / \text { kappa } \\
{\left[\mathrm{cps} / 10^{* *}-6 \mathrm{SI}\right]}\end{array}$ & $\begin{array}{c}\text { Age } \\
\text { cal [kyr] }\end{array}$ \\
\hline 95 & 6.73 & 85.30 & $1.60 \mathrm{E}+03$ & $1.78 \mathrm{E}-01$ & $6.86 \mathrm{E}+01$ & 0.96 & $5.32 \mathrm{E}+02$ & 0.868 \\
\hline 105 & 6.98 & 71.00 & $1.21 \mathrm{E}+03$ & 1.77E-01 & $4.39 E+01$ & 0.97 & $5.15 E+02$ & 0.955 \\
\hline 115 & 7.23 & 76.70 & $1.34 \mathrm{E}+03$ & $1.75 \mathrm{E}-01$ & $4.15 E+01$ & 0.97 & $5.56 \mathrm{E}+02$ & 1.042 \\
\hline 125 & 7.53 & 75.10 & $1.40 \mathrm{E}+03$ & $1.74 \mathrm{E}-01$ & $4.27 \mathrm{E}+01$ & 0.97 & $5.51 \mathrm{E}+02$ & 1.129 \\
\hline 135 & 7.85 & 71.50 & $1.34 E+03$ & $1.70 \mathrm{E}-01$ & $4.97 \mathrm{E}+01$ & 0.96 & $4.92 \mathrm{E}+02$ & 1.215 \\
\hline 145 & 8.18 & 78.50 & $1.24 \mathrm{E}+03$ & $1.66 \mathrm{E}-01$ & $5.20 E+01$ & 0.96 & $4.48 E+02$ & 1.302 \\
\hline 155 & 8.50 & 85.00 & $1.12 \mathrm{E}+03$ & $1.57 \mathrm{E}-01$ & $6.05 E+01$ & 0.95 & $4.84 \mathrm{E}+02$ & 1.389 \\
\hline 165 & 8.83 & 97.40 & $1.13 \mathrm{E}+03$ & $1.50 \mathrm{E}-01$ & $5.67 \mathrm{E}+01$ & 0.95 & $4.85 \mathrm{E}+02$ & 1.476 \\
\hline 175 & 9.16 & 90.70 & $1.09 E+03$ & $1.40 \mathrm{E}-01$ & $6.21 E+01$ & 0.95 & $4.77 E+02$ & 1.563 \\
\hline 185 & 9.48 & 96.20 & $9.79 E+02$ & $1.42 \mathrm{E}-01$ & $6.42 E+01$ & 0.94 & $4.86 E+02$ & 1.650 \\
\hline 195 & 9.81 & 111.20 & $8.59 E+02$ & $1.28 \mathrm{E}-01$ & $5.96 \mathrm{E}+01$ & 0.94 & $4.75 \mathrm{E}+02$ & 1.736 \\
\hline 205 & 10.13 & 102.10 & $9.95 E+02$ & $1.36 \mathrm{E}-01$ & $6.84 E+01$ & 0.94 & $4.54 \mathrm{E}+02$ & 1.823 \\
\hline 215 & 10.42 & 112.20 & $9.36 \mathrm{E}+02$ & $1.31 \mathrm{E}-01$ & $7.89 \mathrm{E}+01$ & 0.92 & $4.84 \mathrm{E}+02$ & 1.910 \\
\hline 225 & 10.69 & 111.40 & $9.04 \mathrm{E}+02$ & $1.28 \mathrm{E}-01$ & $8.07 E+01$ & 0.92 & $4.22 \mathrm{E}+02$ & 1.979 \\
\hline 235 & 10.97 & 131.60 & $9.52 E+02$ & $1.23 \mathrm{E}-01$ & $9.67 E+01$ & 0.91 & $4.99 \mathrm{E}+02$ & 2.048 \\
\hline 245 & 11.15 & 135.60 & $9.73 E+02$ & 1.17E-01 & $9.40 E+01$ & 0.91 & $4.45 E+02$ & 2.117 \\
\hline 255 & 11.20 & 123.20 & $9.57 E+02$ & $1.11 \mathrm{E}-01$ & $1.01 \mathrm{E}+02$ & 0.90 & $3.52 E+02$ & 2.186 \\
\hline 265 & 11.25 & 106.00 & $9.40 E+02$ & $1.18 \mathrm{E}-01$ & $9.95 \mathrm{E}+01$ & 0.90 & $4.65 E+02$ & 2.255 \\
\hline 275 & 11.29 & 90.40 & $9.91 \mathrm{E}+02$ & $1.23 \mathrm{E}-01$ & $9.13 E+01$ & 0.92 & $4.99 \mathrm{E}+02$ & 2.324 \\
\hline 285 & 11.34 & 91.90 & $9.40 \mathrm{E}+02$ & $1.18 \mathrm{E}-01$ & $8.94 \mathrm{E}+01$ & 0.91 & $4.39 \mathrm{E}+02$ & 2.393 \\
\hline 295 & 11.39 & 89.10 & $9.88 \mathrm{E}+02$ & $1.25 \mathrm{E}-01$ & $9.54 \mathrm{E}+01$ & 0.91 & $4.67 E+02$ & 2.462 \\
\hline 305 & 11.44 & 84.20 & $9.01 E+02$ & $1.29 \mathrm{E}-01$ & $8.65 E+01$ & 0.91 & $3.87 \mathrm{E}+02$ & 2.531 \\
\hline 315 & 11.68 & 90.10 & $7.99 \mathrm{E}+02$ & $1.24 \mathrm{E}-01$ & $9.07 E+01$ & 0.90 & $4.19 E+02$ & 2.600 \\
\hline 325 & 11.97 & 85.20 & $6.93 E+02$ & $1.12 \mathrm{E}-01$ & $8.09 E+01$ & 0.90 & $4.78 \mathrm{E}+02$ & 2.669 \\
\hline 335 & 12.10 & 83.00 & $5.73 E+02$ & 1.09E-01 & $6.51 E+01$ & 0.90 & $4.69 \mathrm{E}+02$ & 2.738 \\
\hline 345 & 12.12 & 83.50 & $4.84 \mathrm{E}+02$ & $1.13 \mathrm{E}-01$ & $6.60 E+01$ & 0.88 & $4.94 \mathrm{E}+02$ & 2.807 \\
\hline
\end{tabular}




\begin{tabular}{|c|c|c|c|c|c|c|c|c|}
\hline $\begin{array}{l}\text { Depth } \\
{[\mathrm{cm}]}\end{array}$ & $\begin{array}{c}\text { Age } \\
\text { cal [kyr] }\end{array}$ & $\begin{array}{c}\text { kappa } \\
{\left[10^{* *}-6 \mathrm{SI}\right]}\end{array}$ & $\begin{array}{l}\text { IRM } \\
{[\mathrm{mo0mT}} \\
{[\mathrm{mA} / \mathrm{m}]}\end{array}$ & $\begin{array}{c}\mathrm{ARM}_{100} / \mathrm{IRM}_{100} \\
-\end{array}$ & $\begin{array}{c}\text { HIRM }_{\text {[300\&2700] }} \\
-\end{array}$ & $\begin{array}{c}\text { S-ratio } \\
{[30082700]} \\
-\end{array}$ & $\begin{array}{c}\mathrm{Fe} / \text { kappa } \\
{\left[\mathrm{cps} / 10^{* *}-6 \mathrm{SI}\right]}\end{array}$ & $\begin{array}{c}\text { Age } \\
\text { cal [kyr] }\end{array}$ \\
\hline 355 & 12.14 & 81.30 & $4.85 E+02$ & $1.09 \mathrm{E}-01$ & $6.94 \mathrm{E}+01$ & 0.87 & $5.26 \mathrm{E}+02$ & 2.876 \\
\hline 365 & 12.16 & 85.00 & $4.42 E+02$ & $1.02 \mathrm{E}-01$ & $5.60 E+01$ & 0.89 & $5.28 \mathrm{E}+02$ & 2.945 \\
\hline 375 & 12.18 & 85.00 & $4.63 E+02$ & $1.10 \mathrm{E}-01$ & $5.74 E+01$ & 0.89 & $5.08 \mathrm{E}+02$ & 3.014 \\
\hline 385 & 12.19 & 95.70 & $5.50 \mathrm{E}+02$ & $1.09 \mathrm{E}-01$ & $6.10 E+01$ & 0.90 & $4.63 E+02$ & 3.083 \\
\hline 395 & 12.21 & 108.40 & $6.92 \mathrm{E}+02$ & $1.15 \mathrm{E}-01$ & $7.02 \mathrm{E}+01$ & 0.91 & $4.38 \mathrm{E}+02$ & 3.152 \\
\hline 405 & 12.23 & 100.80 & $7.26 \mathrm{E}+02$ & $1.24 \mathrm{E}-01$ & $7.59 E+01$ & 0.91 & $4.04 E+02$ & 3.221 \\
\hline 415 & 12.25 & 103.00 & $6.07 E+02$ & $1.35 \mathrm{E}-01$ & $7.77 E+01$ & 0.89 & $3.70 E+02$ & 3.290 \\
\hline 425 & 12.27 & 100.80 & $6.12 E+02$ & 1.46E-01 & $6.91 \mathrm{E}+01$ & 0.90 & $4.56 \mathrm{E}+02$ & 3.359 \\
\hline 435 & 12.29 & 96.90 & $7.35 \mathrm{E}+02$ & $1.40 \mathrm{E}-01$ & $7.54 E+01$ & 0.91 & $4.50 E+02$ & 3.428 \\
\hline 445 & 12.31 & 112.50 & $8.35 E+02$ & $1.13 \mathrm{E}-01$ & $1.11 E+02$ & 0.88 & $4.37 E+02$ & 3.497 \\
\hline 455 & 12.41 & 133.20 & $1.09 \mathrm{E}+03$ & $8.70 \mathrm{E}-02$ & $1.42 E+02$ & 0.88 & $4.39 E+02$ & 3.566 \\
\hline 465 & 12.73 & 149.30 & $1.11 \mathrm{E}+03$ & 7.65E-02 & $1.63 \mathrm{E}+02$ & 0.87 & $4.72 \mathrm{E}+02$ & 3.635 \\
\hline 475 & 13.04 & 160.60 & $1.19 \mathrm{E}+03$ & $7.22 \mathrm{E}-02$ & $1.76 \mathrm{E}+02$ & 0.87 & $4.74 \mathrm{E}+02$ & 3.704 \\
\hline 485 & 13.35 & 168.90 & $1.16 \mathrm{E}+03$ & $7.03 E-02$ & $1.90 \mathrm{E}+02$ & 0.86 & $4.98 \mathrm{E}+02$ & 3.773 \\
\hline 495 & 13.61 & 172.30 & $1.15 E+03$ & $7.32 \mathrm{E}-02$ & $1.79 E+02$ & 0.86 & $5.05 E+02$ & 3.842 \\
\hline 505 & 13.78 & 141.20 & $7.68 \mathrm{E}+02$ & $1.69 \mathrm{E}-01$ & $1.53 E+02$ & 0.83 & $5.32 \mathrm{E}+02$ & 3.911 \\
\hline 515 & 13.95 & 115.50 & $1.18 \mathrm{E}+03$ & 4.47E-03 & $1.21 \mathrm{E}+02$ & 0.91 & $5.51 \mathrm{E}+02$ & 3.980 \\
\hline 525 & 14.17 & 83.90 & $2.33 E+02$ & $9.14 \mathrm{E}-03$ & $3.93 E+01$ & 0.86 & $5.76 \mathrm{E}+02$ & 4.005 \\
\hline 535 & 14.56 & 68.00 & $6.75 E+01$ & 3.91E-02 & $9.53 E+00$ & 0.88 & $5.29 E+02$ & 4.030 \\
\hline 545 & 14.92 & 70.30 & $6.47 \mathrm{E}+01$ & 4.85E-02 & $8.73 E+00$ & 0.88 & $5.21 \mathrm{E}+02$ & 4.055 \\
\hline 555 & 15.09 & 72.20 & $8.15 E+01$ & $5.41 \mathrm{E}-02$ & $1.10 \mathrm{E}+01$ & 0.88 & $5.60 \mathrm{E}+02$ & 4.080 \\
\hline 565 & 15.27 & 97.30 & $1.90 \mathrm{E}+02$ & $8.31 \mathrm{E}-02$ & $2.20 \mathrm{E}+01$ & 0.90 & $5.87 \mathrm{E}+02$ & 4.105 \\
\hline 575 & 15.44 & 123.90 & $5.63 E+02$ & $6.06 \mathrm{E}-02$ & $7.64 \mathrm{E}+01$ & 0.88 & $6.25 E+02$ & 4.130 \\
\hline 585 & 15.62 & 135.00 & $6.81 E+02$ & 1.49E-01 & $8.71 E+01$ & 0.89 & $6.12 \mathrm{E}+02$ & 4.155 \\
\hline 595 & 15.79 & 143.3 & $1.09 \mathrm{E}+03$ & $8.57 \mathrm{E}-02$ & $1.15 \mathrm{E}+02$ & 0.90 & $5.82 \mathrm{E}+02$ & 4.180 \\
\hline 605 & 15.97 & 135 & $1.07 E+03$ & $7.20 \mathrm{E}-02$ & $1.28 \mathrm{E}+02$ & 0.89 & $6.05 E+02$ & 4.205 \\
\hline
\end{tabular}




\begin{tabular}{|c|c|c|c|c|c|c|c|c|}
\hline $\begin{array}{l}\text { Depth } \\
{[\mathrm{cm}]}\end{array}$ & $\begin{array}{c}\text { Age } \\
\text { cal [kyr] }\end{array}$ & $\begin{array}{c}\text { kappa } \\
{\left[10^{* *}-6 \mathrm{SI}\right]}\end{array}$ & $\begin{array}{l}\mathrm{IRM}_{\mathbf{3 0 0 \mathrm { mT }}} \\
{[\mathrm{mA} / \mathrm{m}]}\end{array}$ & $\begin{array}{c}\mathrm{ARM}_{100} / \mathrm{IRM}_{100} \\
-\end{array}$ & $\begin{array}{c}\text { HIRM }_{[300 \& 2700]} \\
-\end{array}$ & $\begin{array}{c}\text { S-ratio }{ }_{[300 \& 2700]} \\
-\end{array}$ & $\begin{array}{c}\mathrm{Fe} / \text { kappa } \\
{\left[\mathrm{cps} / 10^{* *}-6 \mathrm{SI}\right]}\end{array}$ & $\begin{array}{c}\text { Age } \\
\text { cal }[k y r]\end{array}$ \\
\hline 615 & 16.14 & 143.4 & $1.09 E+03$ & $4.86 \mathrm{E}-02$ & $1.27 \mathrm{E}+02$ & 0.90 & $6.92 \mathrm{E}+02$ & 4.230 \\
\hline 625 & 16.32 & 150.3 & $8.11 \mathrm{E}+02$ & $6.92 \mathrm{E}-02$ & $8.63 \mathrm{E}+01$ & 0.90 & $6.36 \mathrm{E}+02$ & 4.315 \\
\hline 635 & 16.49 & 158.8 & $8.44 \mathrm{E}+02$ & $6.78 \mathrm{E}-02$ & $9.67 \mathrm{E}+01$ & 0.90 & $6.18 \mathrm{E}+02$ & 4.400 \\
\hline 645 & 16.67 & 156 & $7.22 \mathrm{E}+02$ & $5.76 \mathrm{E}-02$ & $8.02 E+01$ & 0.90 & $7.39 \mathrm{E}+02$ & 4.485 \\
\hline 655 & 18.13 & 179.5 & $1.51 \mathrm{E}+03$ & $9.32 \mathrm{E}-03$ & $1.09 \mathrm{E}+02$ & 0.93 & $6.58 \mathrm{E}+02$ & 4.570 \\
\hline 665 & 20.14 & 133 & $4.61 E+02$ & $2.57 \mathrm{E}-02$ & $7.23 E+01$ & 0.86 & $6.67 E+02$ & 4.655 \\
\hline \multirow[t]{20}{*}{675} & 22.17 & 131.30 & $3.99 \mathrm{E}+02$ & $3.03 E-05$ & $7.86 \mathrm{E}+01$ & 0.84 & $7.12 \mathrm{E}+02$ & 4.740 \\
\hline & & & & & & & $7.65 E+02$ & 4.825 \\
\hline & & & & & & & $7.78 \mathrm{E}+02$ & 4.910 \\
\hline & & & & & & & $7.51 E+02$ & 4.995 \\
\hline & & & & & & & $6.72 E+02$ & 5.080 \\
\hline & & & & & & & $7.08 \mathrm{E}+02$ & 5.165 \\
\hline & & & & & & & $7.49 \mathrm{E}+02$ & 5.250 \\
\hline & & & & & & & $7.93 E+02$ & 5.335 \\
\hline & & & & & & & $8.52 E+02$ & 5.420 \\
\hline & & & & & & & $5.57 E+02$ & 5.505 \\
\hline & & & & & & & $6.50 E+02$ & 5.590 \\
\hline & & & & & & & $8.47 E+02$ & 5.675 \\
\hline & & & & & & & $9.00 E+02$ & 5.760 \\
\hline & & & & & & & $5.58 \mathrm{E}+02$ & 5.845 \\
\hline & & & & & & & $8.56 E+02$ & 5.930 \\
\hline & & & & & & & $1.06 \mathrm{E}+03$ & 6.015 \\
\hline & & & & & & & $1.02 E+03$ & 6.100 \\
\hline & & & & & & & $1.07 E+03$ & 6.185 \\
\hline & & & & & & & $1.10 \mathrm{E}+03$ & 6.270 \\
\hline & & & & & & & $1.12 \mathrm{E}+03$ & 6.355 \\
\hline
\end{tabular}




\begin{tabular}{|c|c|c|c|c|c|c|c|c|}
\hline $\begin{array}{l}\text { Depth } \\
{[\mathrm{cm}]}\end{array}$ & $\begin{array}{c}\text { Age } \\
\text { cal [kyr] }\end{array}$ & $\begin{array}{c}\text { kappa } \\
{\left[10^{* *}-6 \mathrm{SI}\right]}\end{array}$ & $\begin{array}{l}\mathrm{IRM}_{\mathbf{3 0 0 \mathrm { mT }}} \\
{[\mathrm{mA} / \mathrm{m}]}\end{array}$ & $\begin{array}{c}\text { ARM }_{100} / \text { IRM }_{100} \\
-\end{array}$ & $\begin{array}{c}\text { HIRM }_{\text {[30082700] }} \\
-\end{array}$ & $\begin{array}{c}\text { S-ratio }{ }_{[300 \& 2700]} \\
-\end{array}$ & $\begin{array}{c}\mathrm{Fe} / \text { kappa } \\
{\left[\text { cps } / 10^{* *}-6 \mathrm{SI}\right]}\end{array}$ & $\begin{array}{c}\text { Age } \\
\text { cal }[k y r]\end{array}$ \\
\hline & & & & & & & $1.09 \mathrm{E}+03$ & 6.440 \\
\hline & & & & & & & $9.29 E+02$ & 6.525 \\
\hline & & & & & & & $9.35 \mathrm{E}+02$ & 6.610 \\
\hline & & & & & & & $9.95 E+02$ & 6.635 \\
\hline & & & & & & & $8.55 E+02$ & 6.660 \\
\hline & & & & & & & $8.40 E+02$ & 6.684 \\
\hline & & & & & & & $8.74 \mathrm{E}+02$ & 6.709 \\
\hline & & & & & & & $8.00 E+02$ & 6.734 \\
\hline & & & & & & & $8.23 E+02$ & 6.759 \\
\hline & & & & & & & $7.00 \mathrm{E}+02$ & 6.809 \\
\hline & & & & & & & $8.28 E+02$ & 6.833 \\
\hline & & & & & & & $9.00 \mathrm{E}+02$ & 6.858 \\
\hline & & & & & & & $8.88 \mathrm{E}+02$ & 6.883 \\
\hline & & & & & & & $8.91 E+02$ & 6.908 \\
\hline & & & & & & & $9.32 E+02$ & 6.933 \\
\hline & & & & & & & $9.98 E+02$ & 6.958 \\
\hline & & & & & & & $1.08 \mathrm{E}+03$ & 6.982 \\
\hline & & & & & & & $1.08 E+03$ & 7.007 \\
\hline & & & & & & & $9.28 \mathrm{E}+02$ & 7.032 \\
\hline & & & & & & & $9.46 \mathrm{E}+02$ & 7.057 \\
\hline & & & & & & & $1.04 \mathrm{E}+03$ & 7.082 \\
\hline & & & & & & & $1.06 \mathrm{E}+03$ & 7.107 \\
\hline & & & & & & & $1.13 E+03$ & 7.131 \\
\hline & & & & & & & $1.11 E+03$ & 7.156 \\
\hline & & & & & & & $1.18 \mathrm{E}+03$ & 7.181 \\
\hline & & & & & & & $1.08 \mathrm{E}+03$ & 7.206 \\
\hline
\end{tabular}




\begin{tabular}{|c|c|c|c|c|c|c|c|c|}
\hline $\begin{array}{l}\text { Depth } \\
{[\mathrm{cm}]}\end{array}$ & $\begin{array}{c}\text { Age } \\
\text { cal [kyr] }\end{array}$ & $\begin{array}{c}\text { kappa } \\
{\left[10^{* *}-6 \mathrm{SI}\right]}\end{array}$ & $\begin{array}{l}\mathrm{IRM}_{\mathbf{3 0 0 \mathrm { mT }}} \\
{[\mathrm{mA} / \mathrm{m}]}\end{array}$ & $\begin{array}{c}\text { ARM }_{100} / \text { IRM }_{100} \\
-\end{array}$ & $\begin{array}{c}\text { HIRM }_{\text {[30082700] }} \\
-\end{array}$ & $\begin{array}{c}\text { S-ratio }{ }_{[300 \& 2700]} \\
-\end{array}$ & $\begin{array}{c}\mathrm{Fe} / \text { kappa } \\
{\left[\text { cps } / 10^{* *}-6 \mathrm{SI}\right]}\end{array}$ & $\begin{array}{c}\text { Age } \\
\text { cal }[k y r]\end{array}$ \\
\hline & & & & & & & $1.11 \mathrm{E}+03$ & 7.231 \\
\hline & & & & & & & $1.10 \mathrm{E}+03$ & 7.256 \\
\hline & & & & & & & $1.16 \mathrm{E}+03$ & 7.280 \\
\hline & & & & & & & $1.12 E+03$ & 7.305 \\
\hline & & & & & & & $1.10 E+03$ & 7.330 \\
\hline & & & & & & & $1.12 \mathrm{E}+03$ & 7.363 \\
\hline & & & & & & & $1.11 E+03$ & 7.395 \\
\hline & & & & & & & $1.19 E+03$ & 7.428 \\
\hline & & & & & & & $1.19 E+03$ & 7.460 \\
\hline & & & & & & & $1.18 \mathrm{E}+03$ & 7.493 \\
\hline & & & & & & & $1.15 E+03$ & 7.526 \\
\hline & & & & & & & $1.18 \mathrm{E}+03$ & 7.558 \\
\hline & & & & & & & $1.19 E+03$ & 7.591 \\
\hline & & & & & & & $1.14 \mathrm{E}+03$ & 7.624 \\
\hline & & & & & & & $1.09 E+03$ & 7.656 \\
\hline & & & & & & & $9.83 E+02$ & 7.689 \\
\hline & & & & & & & $1.03 E+03$ & 7.721 \\
\hline & & & & & & & $1.11 \mathrm{E}+03$ & 7.754 \\
\hline & & & & & & & $1.15 \mathrm{E}+03$ & 7.787 \\
\hline & & & & & & & $1.11 E+03$ & 7.819 \\
\hline & & & & & & & $1.16 E+03$ & 7.852 \\
\hline & & & & & & & $1.15 E+03$ & 7.884 \\
\hline & & & & & & & $1.05 E+03$ & 7.917 \\
\hline & & & & & & & $1.11 \mathrm{E}+03$ & 7.950 \\
\hline & & & & & & & $1.07 E+03$ & 7.982 \\
\hline & & & & & & & $1.09 \mathrm{E}+03$ & 8.015 \\
\hline
\end{tabular}




\begin{tabular}{|c|c|c|c|c|c|c|c|c|}
\hline $\begin{array}{l}\text { Depth } \\
{[\mathrm{cm}]}\end{array}$ & $\begin{array}{c}\text { Age } \\
\text { cal [kyr] }\end{array}$ & $\begin{array}{c}\text { kappa } \\
{\left[10^{* *}-6 \mathrm{SI}\right]}\end{array}$ & $\begin{array}{l}\text { IRM }_{300 \mathrm{mT}} \\
{[\mathrm{mA} / \mathrm{m}]}\end{array}$ & $\begin{array}{c}\mathrm{ARM}_{100} / \mathrm{IRM}_{100} \\
-\end{array}$ & $\begin{array}{c}\text { HIRM }_{\text {[30082700] }} \\
-\end{array}$ & $\begin{array}{c}\text { S-ratio } \\
{[300 \& 2700]} \\
-\end{array}$ & $\begin{array}{c}\mathrm{Fe} / \text { kappa } \\
{\left[\mathrm{cps} / 10^{* *}-6 \mathrm{SI}\right]}\end{array}$ & $\begin{array}{c}\text { Age } \\
\text { cal [kyr] }\end{array}$ \\
\hline & & & & & & & $1.09 \mathrm{E}+03$ & 8.048 \\
\hline & & & & & & & $1.10 \mathrm{E}+03$ & 8.080 \\
\hline & & & & & & & $1.14 \mathrm{E}+03$ & 8.113 \\
\hline & & & & & & & $1.18 \mathrm{E}+03$ & 8.145 \\
\hline & & & & & & & $1.13 \mathrm{E}+03$ & 8.178 \\
\hline & & & & & & & $1.25 \mathrm{E}+03$ & 8.211 \\
\hline & & & & & & & $1.27 E+03$ & 8.243 \\
\hline & & & & & & & $1.16 \mathrm{E}+03$ & 8.276 \\
\hline & & & & & & & $1.12 E+03$ & 8.308 \\
\hline & & & & & & & $1.06 \mathrm{E}+03$ & 8.341 \\
\hline & & & & & & & $1.03 E+03$ & 8.374 \\
\hline & & & & & & & $1.09 E+03$ & 8.406 \\
\hline & & & & & & & $1.09 \mathrm{E}+03$ & 8.439 \\
\hline & & & & & & & $1.08 \mathrm{E}+03$ & 8.471 \\
\hline & & & & & & & $1.11 E+03$ & 8.504 \\
\hline & & & & & & & $1.15 E+03$ & 8.537 \\
\hline & & & & & & & $1.16 \mathrm{E}+03$ & 8.569 \\
\hline & & & & & & & $1.15 \mathrm{E}+03$ & 8.602 \\
\hline & & & & & & & $1.22 \mathrm{E}+03$ & 8.635 \\
\hline & & & & & & & $1.28 \mathrm{E}+03$ & 8.667 \\
\hline & & & & & & & $1.23 \mathrm{E}+03$ & 8.700 \\
\hline & & & & & & & $1.27 \mathrm{E}+03$ & 8.732 \\
\hline & & & & & & & $1.16 \mathrm{E}+03$ & 8.765 \\
\hline & & & & & & & $1.13 E+03$ & 8.798 \\
\hline & & & & & & & $9.91 \mathrm{E}+02$ & 8.830 \\
\hline & & & & & & & $9.80 \mathrm{E}+02$ & 8.863 \\
\hline
\end{tabular}




\begin{tabular}{|c|c|c|c|c|c|c|c|c|}
\hline $\begin{array}{l}\text { Depth } \\
{[\mathrm{cm}]}\end{array}$ & $\begin{array}{c}\text { Age } \\
\text { cal }[k y r]\end{array}$ & $\begin{array}{c}\text { kappa } \\
{\left[10^{* *}-6 \mathrm{SI}\right]}\end{array}$ & $\begin{array}{l}\mathrm{IRM}_{\mathbf{3 0 0 \mathrm { mT }}} \\
{[\mathrm{mA} / \mathrm{m}]}\end{array}$ & $\begin{array}{c}\text { ARM }_{100} / \text { IRM }_{100} \\
-\end{array}$ & $\begin{array}{c}\text { HIRM }_{\text {[300\&2700] }} \\
-\end{array}$ & $\begin{array}{c}\text { S-ratio } \\
{[300 \& 2700]} \\
-\end{array}$ & $\begin{array}{c}\mathrm{Fe} / \text { kappa } \\
{\left[\text { cps } / 10^{* *}-6 \mathrm{SI}\right]}\end{array}$ & $\begin{array}{c}\text { Age } \\
\text { cal }[k y r]\end{array}$ \\
\hline & & & & & & & $9.88 \mathrm{E}+02$ & 8.895 \\
\hline & & & & & & & $1.11 \mathrm{E}+03$ & 8.928 \\
\hline & & & & & & & $1.13 E+03$ & 8.961 \\
\hline & & & & & & & $1.15 E+03$ & 8.993 \\
\hline & & & & & & & $1.12 \mathrm{E}+03$ & 9.026 \\
\hline & & & & & & & $1.10 E+03$ & 9.059 \\
\hline & & & & & & & $1.09 E+03$ & 9.091 \\
\hline & & & & & & & $1.04 E+03$ & 9.124 \\
\hline & & & & & & & $1.13 E+03$ & 9.156 \\
\hline & & & & & & & $1.04 E+03$ & 9.189 \\
\hline & & & & & & & $1.06 E+03$ & 9.222 \\
\hline & & & & & & & $1.10 E+03$ & 9.254 \\
\hline & & & & & & & $1.08 E+03$ & 9.287 \\
\hline & & & & & & & $1.08 \mathrm{E}+03$ & 9.319 \\
\hline & & & & & & & $1.06 \mathrm{E}+03$ & 9.352 \\
\hline & & & & & & & $1.11 E+03$ & 9.385 \\
\hline & & & & & & & $1.10 E+03$ & 9.417 \\
\hline & & & & & & & $1.10 E+03$ & 9.483 \\
\hline & & & & & & & $1.07 E+03$ & 9.515 \\
\hline & & & & & & & $1.13 E+03$ & 9.548 \\
\hline & & & & & & & $1.22 E+03$ & 9.580 \\
\hline & & & & & & & $1.30 E+03$ & 9.613 \\
\hline & & & & & & & $1.28 \mathrm{E}+03$ & 9.646 \\
\hline & & & & & & & $1.21 E+03$ & 9.678 \\
\hline & & & & & & & $1.20 E+03$ & 9.711 \\
\hline & & & & & & & $1.23 \mathrm{E}+03$ & 9.743 \\
\hline
\end{tabular}




\begin{tabular}{|c|c|c|c|c|c|c|c|c|}
\hline $\begin{array}{l}\text { Depth } \\
{[\mathrm{cm}]}\end{array}$ & $\begin{array}{c}\text { Age } \\
\text { cal }[k y r]\end{array}$ & $\begin{array}{c}\text { kappa } \\
{\left[10^{* *}-6 \mathrm{SI}\right]}\end{array}$ & $\begin{array}{l}\text { IRM }{ }_{300 \mathrm{mT}} \\
{[\mathrm{mA} / \mathrm{m}]}\end{array}$ & $\begin{array}{c}\text { ARM }_{100} / \text { IRM }_{100} \\
-\end{array}$ & $\begin{array}{c}\text { HIRM }_{\text {[30082700] }} \\
-\end{array}$ & $\begin{array}{c}\text { S-ratio } \\
{[30082700]} \\
-\end{array}$ & $\begin{array}{c}\mathrm{Fe} / \text { kappa } \\
{\left[\mathrm{cps} / 10^{* *}-6 \mathrm{SI}\right]}\end{array}$ & $\begin{array}{c}\text { Age } \\
\text { cal [kyr] }\end{array}$ \\
\hline & & & & & & & $1.10 \mathrm{E}+03$ & 9.776 \\
\hline & & & & & & & $1.10 \mathrm{E}+03$ & 9.809 \\
\hline & & & & & & & $1.16 \mathrm{E}+03$ & 9.841 \\
\hline & & & & & & & $1.08 \mathrm{E}+03$ & 9.874 \\
\hline & & & & & & & $9.64 \mathrm{E}+02$ & 9.906 \\
\hline & & & & & & & $1.19 \mathrm{E}+03$ & 9.939 \\
\hline & & & & & & & $1.20 \mathrm{E}+03$ & 9.972 \\
\hline & & & & & & & $1.13 E+03$ & 10.004 \\
\hline & & & & & & & $1.09 \mathrm{E}+03$ & 10.037 \\
\hline & & & & & & & $1.12 \mathrm{E}+03$ & 10.070 \\
\hline & & & & & & & $1.19 E+03$ & 10.102 \\
\hline & & & & & & & $1.24 \mathrm{E}+03$ & 10.135 \\
\hline & & & & & & & $1.31 E+03$ & 10.167 \\
\hline & & & & & & & $1.24 \mathrm{E}+03$ & 10.200 \\
\hline & & & & & & & $1.23 \mathrm{E}+03$ & 10.227 \\
\hline & & & & & & & $1.11 E+03$ & 10.255 \\
\hline & & & & & & & $1.14 \mathrm{E}+03$ & 10.282 \\
\hline & & & & & & & $1.05 E+03$ & 10.309 \\
\hline & & & & & & & $1.16 \mathrm{E}+03$ & 10.337 \\
\hline & & & & & & & $1.16 \mathrm{E}+03$ & 10.364 \\
\hline & & & & & & & $1.17 E+03$ & 10.391 \\
\hline & & & & & & & $1.14 \mathrm{E}+03$ & 10.419 \\
\hline & & & & & & & $1.17 \mathrm{E}+03$ & 10.446 \\
\hline & & & & & & & $1.24 \mathrm{E}+03$ & 10.474 \\
\hline & & & & & & & $1.14 \mathrm{E}+03$ & 10.501 \\
\hline & & & & & & & $1.25 \mathrm{E}+03$ & 10.528 \\
\hline
\end{tabular}




\begin{tabular}{|c|c|c|c|c|c|c|c|c|}
\hline $\begin{array}{l}\text { Depth } \\
{[\mathrm{cm}]}\end{array}$ & $\begin{array}{c}\text { Age } \\
\text { cal }[k y r]\end{array}$ & $\begin{array}{c}\text { kappa } \\
{\left[10^{* *}-6 \mathrm{SI}\right]}\end{array}$ & $\begin{array}{l}\text { IRM }{ }_{300 \mathrm{mT}} \\
{[\mathrm{mA} / \mathrm{m}]}\end{array}$ & $\begin{array}{c}\text { ARM }_{100} / \text { IRM }_{100} \\
-\end{array}$ & $\begin{array}{c}\text { HIRM }_{\text {[30082700] }} \\
-\end{array}$ & $\begin{array}{c}\text { S-ratio } \\
{[30082700]} \\
-\end{array}$ & $\begin{array}{c}\mathrm{Fe} / \text { kappa } \\
{\left[\mathrm{cps} / 10^{* *}-6 \mathrm{SI}\right]}\end{array}$ & $\begin{array}{c}\text { Age } \\
\text { cal [kyr] }\end{array}$ \\
\hline & & & & & & & $1.30 \mathrm{E}+03$ & 10.556 \\
\hline & & & & & & & $1.26 \mathrm{E}+03$ & 10.583 \\
\hline & & & & & & & $1.28 \mathrm{E}+03$ & 10.610 \\
\hline & & & & & & & $1.27 E+03$ & 10.638 \\
\hline & & & & & & & $1.34 \mathrm{E}+03$ & 10.665 \\
\hline & & & & & & & $1.22 \mathrm{E}+03$ & 10.692 \\
\hline & & & & & & & $1.18 \mathrm{E}+03$ & 10.720 \\
\hline & & & & & & & $1.11 \mathrm{E}+03$ & 10.747 \\
\hline & & & & & & & $1.08 \mathrm{E}+03$ & 10.774 \\
\hline & & & & & & & $1.09 \mathrm{E}+03$ & 10.802 \\
\hline & & & & & & & $1.20 E+03$ & 10.829 \\
\hline & & & & & & & $1.09 \mathrm{E}+03$ & 10.856 \\
\hline & & & & & & & $1.06 \mathrm{E}+03$ & 10.884 \\
\hline & & & & & & & $1.12 \mathrm{E}+03$ & 10.911 \\
\hline & & & & & & & $1.12 \mathrm{E}+03$ & 10.939 \\
\hline & & & & & & & $1.15 \mathrm{E}+03$ & 10.966 \\
\hline & & & & & & & $1.22 \mathrm{E}+03$ & 10.993 \\
\hline & & & & & & & $1.09 \mathrm{E}+03$ & 11.021 \\
\hline & & & & & & & $1.12 \mathrm{E}+03$ & 11.048 \\
\hline & & & & & & & $1.18 \mathrm{E}+03$ & 11.075 \\
\hline & & & & & & & $1.18 \mathrm{E}+03$ & 11.103 \\
\hline & & & & & & & $1.07 E+03$ & 11.130 \\
\hline & & & & & & & $1.23 E+03$ & 11.135 \\
\hline & & & & & & & $1.32 \mathrm{E}+03$ & 11.140 \\
\hline & & & & & & & $1.15 \mathrm{E}+03$ & 11.145 \\
\hline & & & & & & & $1.15 E+03$ & 11.149 \\
\hline
\end{tabular}




\begin{tabular}{|c|c|c|c|c|c|c|c|c|}
\hline $\begin{array}{l}\text { Depth } \\
{[\mathrm{cm}]}\end{array}$ & $\begin{array}{c}\text { Age } \\
\text { cal }[k y r]\end{array}$ & $\begin{array}{c}\text { kappa } \\
{\left[10^{* *}-6 \mathrm{SI}\right]}\end{array}$ & $\begin{array}{l}\text { IRM }{ }_{300 \mathrm{mT}} \\
{[\mathrm{mA} / \mathrm{m}]}\end{array}$ & $\begin{array}{c}\text { ARM }_{100} / \text { IRM }_{100} \\
-\end{array}$ & $\begin{array}{c}\text { HIRM }_{\text {[30082700] }} \\
-\end{array}$ & $\begin{array}{c}\text { S-ratio } \\
{[30082700]} \\
-\end{array}$ & $\begin{array}{c}\mathrm{Fe} / \text { kappa } \\
{\left[\mathrm{cps} / 10^{* *}-6 \mathrm{SI}\right]}\end{array}$ & $\begin{array}{c}\text { Age } \\
\text { cal [kyr] }\end{array}$ \\
\hline & & & & & & & $1.15 \mathrm{E}+03$ & 11.154 \\
\hline & & & & & & & $1.13 \mathrm{E}+03$ & 11.159 \\
\hline & & & & & & & $1.12 \mathrm{E}+03$ & 11.164 \\
\hline & & & & & & & $9.80 E+02$ & 11.169 \\
\hline & & & & & & & $9.86 E+02$ & 11.174 \\
\hline & & & & & & & $1.09 \mathrm{E}+03$ & 11.178 \\
\hline & & & & & & & $1.17 \mathrm{E}+03$ & 11.183 \\
\hline & & & & & & & $1.18 \mathrm{E}+03$ & 11.188 \\
\hline & & & & & & & $1.19 \mathrm{E}+03$ & 11.193 \\
\hline & & & & & & & $1.29 \mathrm{E}+03$ & 11.198 \\
\hline & & & & & & & $1.30 \mathrm{E}+03$ & 11.203 \\
\hline & & & & & & & $1.35 E+03$ & 11.208 \\
\hline & & & & & & & $1.37 E+03$ & 11.212 \\
\hline & & & & & & & $1.38 \mathrm{E}+03$ & 11.217 \\
\hline & & & & & & & $1.32 \mathrm{E}+03$ & 11.222 \\
\hline & & & & & & & $1.32 \mathrm{E}+03$ & 11.227 \\
\hline & & & & & & & $1.39 \mathrm{E}+03$ & 11.232 \\
\hline & & & & & & & $1.37 E+03$ & 11.237 \\
\hline & & & & & & & $1.42 \mathrm{E}+03$ & 11.242 \\
\hline & & & & & & & $1.34 \mathrm{E}+03$ & 11.246 \\
\hline & & & & & & & $1.39 \mathrm{E}+03$ & 11.251 \\
\hline & & & & & & & $1.40 \mathrm{E}+03$ & 11.256 \\
\hline & & & & & & & $1.34 \mathrm{E}+03$ & 11.261 \\
\hline & & & & & & & $1.45 \mathrm{E}+03$ & 11.266 \\
\hline & & & & & & & $1.56 \mathrm{E}+03$ & 11.271 \\
\hline & & & & & & & $1.44 \mathrm{E}+03$ & 11.275 \\
\hline
\end{tabular}




\begin{tabular}{|c|c|c|c|c|c|c|c|c|}
\hline $\begin{array}{l}\text { Depth } \\
{[\mathrm{cm}]}\end{array}$ & $\begin{array}{c}\text { Age } \\
\text { cal [kyr] }\end{array}$ & $\begin{array}{c}\text { kappa } \\
{\left[10^{* *}-6 \mathrm{SI}\right]}\end{array}$ & $\begin{array}{l}\text { IRM }{ }_{300 \mathrm{mT}} \\
{[\mathrm{mA} / \mathrm{m}]}\end{array}$ & $\begin{array}{c}\text { ARM }_{100} / \text { IRM }_{100} \\
-\end{array}$ & $\begin{array}{c}\text { HIRM }_{\text {[300\&2700] }} \\
-\end{array}$ & $\begin{array}{c}\text { S-ratio }{ }_{[300 \& 2700]} \\
-\end{array}$ & $\begin{array}{c}\mathrm{Fe} / \text { kappa } \\
{\left[\mathrm{cps} / 10^{* *}-6 \mathrm{SI}\right]}\end{array}$ & $\begin{array}{c}\text { Age } \\
\text { cal [kyr] }\end{array}$ \\
\hline & & & & & & & $1.60 \mathrm{E}+03$ & 11.280 \\
\hline & & & & & & & $1.60 \mathrm{E}+03$ & 11.285 \\
\hline & & & & & & & $1.58 \mathrm{E}+03$ & 11.290 \\
\hline & & & & & & & $1.61 \mathrm{E}+03$ & 11.295 \\
\hline & & & & & & & $1.63 \mathrm{E}+03$ & 11.300 \\
\hline & & & & & & & $1.62 E+03$ & 11.305 \\
\hline & & & & & & & $1.61 \mathrm{E}+03$ & 11.309 \\
\hline & & & & & & & $1.67 E+03$ & 11.314 \\
\hline & & & & & & & $1.60 \mathrm{E}+03$ & 11.319 \\
\hline & & & & & & & $1.56 \mathrm{E}+03$ & 11.324 \\
\hline & & & & & & & $1.56 \mathrm{E}+03$ & 11.329 \\
\hline & & & & & & & $1.57 \mathrm{E}+03$ & 11.334 \\
\hline & & & & & & & $1.69 \mathrm{E}+03$ & 11.338 \\
\hline & & & & & & & $1.62 E+03$ & 11.343 \\
\hline & & & & & & & $1.67 E+03$ & 11.348 \\
\hline & & & & & & & $1.75 \mathrm{E}+03$ & 11.353 \\
\hline & & & & & & & $1.71 \mathrm{E}+03$ & 11.358 \\
\hline & & & & & & & $1.75 \mathrm{E}+03$ & 11.363 \\
\hline & & & & & & & $1.63 \mathrm{E}+03$ & 11.368 \\
\hline & & & & & & & $1.64 \mathrm{E}+03$ & 11.372 \\
\hline & & & & & & & $1.67 \mathrm{E}+03$ & 11.377 \\
\hline & & & & & & & $1.73 E+03$ & 11.382 \\
\hline & & & & & & & $1.74 \mathrm{E}+03$ & 11.387 \\
\hline & & & & & & & $1.76 \mathrm{E}+03$ & 11.392 \\
\hline & & & & & & & $1.70 \mathrm{E}+03$ & 11.397 \\
\hline & & & & & & & $1.68 \mathrm{E}+03$ & 11.402 \\
\hline
\end{tabular}




\begin{tabular}{|c|c|c|c|c|c|c|c|c|}
\hline $\begin{array}{l}\text { Depth } \\
{[\mathrm{cm}]}\end{array}$ & $\begin{array}{c}\text { Age } \\
\text { cal }[k y r]\end{array}$ & $\begin{array}{c}\text { kappa } \\
{\left[10^{* *}-6 \mathrm{SI}\right]}\end{array}$ & $\begin{array}{l}\text { IRM }{ }_{300 \mathrm{mT}} \\
{[\mathrm{mA} / \mathrm{m}]}\end{array}$ & $\begin{array}{c}\text { ARM }_{100} / \text { IRM }_{100} \\
-\end{array}$ & $\begin{array}{c}\text { HIRM }_{\text {[30082700] }} \\
-\end{array}$ & $\begin{array}{c}\text { S-ratio } \\
{[30082700]} \\
-\end{array}$ & $\begin{array}{c}\mathrm{Fe} / \text { kappa } \\
{\left[\mathrm{cps} / 10^{* *}-6 \mathrm{SI}\right]}\end{array}$ & $\begin{array}{c}\text { Age } \\
\text { cal [kyr] }\end{array}$ \\
\hline & & & & & & & $1.73 \mathrm{E}+03$ & 11.406 \\
\hline & & & & & & & $1.71 E+03$ & 11.411 \\
\hline & & & & & & & $1.69 \mathrm{E}+03$ & 11.416 \\
\hline & & & & & & & $1.82 \mathrm{E}+03$ & 11.421 \\
\hline & & & & & & & $1.80 \mathrm{E}+03$ & 11.426 \\
\hline & & & & & & & $1.75 E+03$ & 11.431 \\
\hline & & & & & & & $1.77 E+03$ & 11.435 \\
\hline & & & & & & & $1.81 E+03$ & 11.440 \\
\hline & & & & & & & $1.83 \mathrm{E}+03$ & 11.445 \\
\hline & & & & & & & $1.83 E+03$ & 11.450 \\
\hline & & & & & & & $1.88 \mathrm{E}+03$ & 11.479 \\
\hline & & & & & & & $1.86 \mathrm{E}+03$ & 11.508 \\
\hline & & & & & & & $1.94 \mathrm{E}+03$ & 11.537 \\
\hline & & & & & & & $1.90 \mathrm{E}+03$ & 11.566 \\
\hline & & & & & & & $1.90 \mathrm{E}+03$ & 11.595 \\
\hline & & & & & & & $1.75 E+03$ & 11.625 \\
\hline & & & & & & & $1.72 \mathrm{E}+03$ & 11.654 \\
\hline & & & & & & & $1.75 E+03$ & 11.683 \\
\hline & & & & & & & $1.79 \mathrm{E}+03$ & 11.712 \\
\hline & & & & & & & $1.73 E+03$ & 11.741 \\
\hline & & & & & & & $1.79 E+03$ & 11.770 \\
\hline & & & & & & & $1.81 E+03$ & 11.799 \\
\hline & & & & & & & $1.85 \mathrm{E}+03$ & 11.828 \\
\hline & & & & & & & $1.93 E+03$ & 11.857 \\
\hline & & & & & & & $1.85 \mathrm{E}+03$ & 11.886 \\
\hline & & & & & & & $1.82 \mathrm{E}+03$ & 11.915 \\
\hline
\end{tabular}




\begin{tabular}{|c|c|c|c|c|c|c|c|c|}
\hline $\begin{array}{l}\text { Depth } \\
{[\mathrm{cm}]}\end{array}$ & $\begin{array}{c}\text { Age } \\
\text { cal [kyr] }\end{array}$ & $\begin{array}{c}\text { kappa } \\
{\left[10^{* *}-6 \mathrm{SI}\right]}\end{array}$ & $\begin{array}{l}\text { IRM }{ }_{300 \mathrm{mT}} \\
{[\mathrm{mA} / \mathrm{m}]}\end{array}$ & $\begin{array}{c}\text { ARM }_{100} / \text { IRM }_{100} \\
-\end{array}$ & $\begin{array}{c}\text { HIRM }_{\text {[300\&2700] }} \\
-\end{array}$ & $\begin{array}{c}\text { S-ratio }{ }_{[300 \& 2700]} \\
-\end{array}$ & $\begin{array}{c}\mathrm{Fe} / \text { kappa } \\
{\left[\mathrm{cps} / 10^{* *}-6 \mathrm{SI}\right]}\end{array}$ & $\begin{array}{c}\text { Age } \\
\text { cal [kyr] }\end{array}$ \\
\hline & & & & & & & $1.83 \mathrm{E}+03$ & 11.945 \\
\hline & & & & & & & $1.85 E+03$ & 11.974 \\
\hline & & & & & & & $1.90 \mathrm{E}+03$ & 12.003 \\
\hline & & & & & & & $1.90 \mathrm{E}+03$ & 12.032 \\
\hline & & & & & & & $1.90 \mathrm{E}+03$ & 12.061 \\
\hline & & & & & & & $1.95 E+03$ & 12.090 \\
\hline & & & & & & & $1.89 \mathrm{E}+03$ & 12.092 \\
\hline & & & & & & & $1.90 \mathrm{E}+03$ & 12.094 \\
\hline & & & & & & & $1.89 \mathrm{E}+03$ & 12.096 \\
\hline & & & & & & & $1.94 \mathrm{E}+03$ & 12.097 \\
\hline & & & & & & & $1.89 \mathrm{E}+03$ & 12.099 \\
\hline & & & & & & & $1.84 \mathrm{E}+03$ & 12.101 \\
\hline & & & & & & & $1.85 \mathrm{E}+03$ & 12.103 \\
\hline & & & & & & & $1.88 \mathrm{E}+03$ & 12.105 \\
\hline & & & & & & & $1.94 \mathrm{E}+03$ & 12.107 \\
\hline & & & & & & & $1.86 \mathrm{E}+03$ & 12.109 \\
\hline & & & & & & & $1.90 \mathrm{E}+03$ & 12.111 \\
\hline & & & & & & & $1.87 \mathrm{E}+03$ & 12.112 \\
\hline & & & & & & & $1.92 \mathrm{E}+03$ & 12.114 \\
\hline & & & & & & & $1.94 \mathrm{E}+03$ & 12.116 \\
\hline & & & & & & & $1.92 \mathrm{E}+03$ & 12.118 \\
\hline & & & & & & & $1.85 E+03$ & 12.120 \\
\hline & & & & & & & $1.76 \mathrm{E}+03$ & 12.122 \\
\hline & & & & & & & $1.75 E+03$ & 12.124 \\
\hline & & & & & & & $1.77 \mathrm{E}+03$ & 12.126 \\
\hline & & & & & & & $1.85 \mathrm{E}+03$ & 12.127 \\
\hline
\end{tabular}




\begin{tabular}{|c|c|c|c|c|c|c|c|c|}
\hline $\begin{array}{l}\text { Depth } \\
{[\mathrm{cm}]}\end{array}$ & $\begin{array}{c}\text { Age } \\
\text { cal }[k y r]\end{array}$ & $\begin{array}{c}\text { kappa } \\
{\left[10^{* *}-6 \mathrm{SI}\right]}\end{array}$ & $\begin{array}{l}\text { IRM }{ }_{300 \mathrm{mT}} \\
{[\mathrm{mA} / \mathrm{m}]}\end{array}$ & $\begin{array}{c}\text { ARM }_{100} / \text { IRM }_{100} \\
-\end{array}$ & $\begin{array}{c}\text { HIRM }_{\text {[30082700] }} \\
-\end{array}$ & $\begin{array}{c}\text { S-ratio } \\
{[30082700]} \\
-\end{array}$ & $\begin{array}{c}\mathrm{Fe} / \text { kappa } \\
{\left[\mathrm{cps} / 10^{* *}-6 \mathrm{SI}\right]}\end{array}$ & $\begin{array}{c}\text { Age } \\
\text { cal [kyr] }\end{array}$ \\
\hline & & & & & & & $1.78 \mathrm{E}+03$ & 12.129 \\
\hline & & & & & & & $1.74 \mathrm{E}+03$ & 12.131 \\
\hline & & & & & & & $1.80 \mathrm{E}+03$ & 12.133 \\
\hline & & & & & & & $1.82 \mathrm{E}+03$ & 12.135 \\
\hline & & & & & & & $1.90 \mathrm{E}+03$ & 12.137 \\
\hline & & & & & & & $1.97 E+03$ & 12.139 \\
\hline & & & & & & & $2.09 \mathrm{E}+03$ & 12.140 \\
\hline & & & & & & & $2.06 \mathrm{E}+03$ & 12.142 \\
\hline & & & & & & & $1.99 \mathrm{E}+03$ & 12.144 \\
\hline & & & & & & & $1.90 \mathrm{E}+03$ & 12.146 \\
\hline & & & & & & & $1.95 E+03$ & 12.148 \\
\hline & & & & & & & $1.95 E+03$ & 12.150 \\
\hline & & & & & & & $1.95 E+03$ & 12.152 \\
\hline & & & & & & & $1.97 E+03$ & 12.154 \\
\hline & & & & & & & $1.88 \mathrm{E}+03$ & 12.155 \\
\hline & & & & & & & $2.00 E+03$ & 12.157 \\
\hline & & & & & & & $1.98 \mathrm{E}+03$ & 12.159 \\
\hline & & & & & & & $2.02 E+03$ & 12.161 \\
\hline & & & & & & & $1.98 \mathrm{E}+03$ & 12.163 \\
\hline & & & & & & & $2.15 E+03$ & 12.165 \\
\hline & & & & & & & $2.03 E+03$ & 12.167 \\
\hline & & & & & & & $1.92 \mathrm{E}+03$ & 12.169 \\
\hline & & & & & & & $1.95 E+03$ & 12.170 \\
\hline & & & & & & & $1.98 \mathrm{E}+03$ & 12.172 \\
\hline & & & & & & & $2.01 E+03$ & 12.174 \\
\hline & & & & & & & $1.98 \mathrm{E}+03$ & 12.176 \\
\hline
\end{tabular}




\begin{tabular}{|c|c|c|c|c|c|c|c|c|}
\hline $\begin{array}{l}\text { Depth } \\
{[\mathrm{cm}]}\end{array}$ & $\begin{array}{c}\text { Age } \\
\text { cal }[k y r]\end{array}$ & $\begin{array}{c}\text { kappa } \\
{\left[10^{* *}-6 \mathrm{SI}\right]}\end{array}$ & $\begin{array}{l}\mathrm{IRM}_{\mathbf{3 0 0 \mathrm { mT }}} \\
{[\mathrm{mA} / \mathrm{m}]}\end{array}$ & $\begin{array}{c}\text { ARM }_{100} / \text { IRM }_{100} \\
-\end{array}$ & $\begin{array}{c}\text { HIRM }_{\text {[30082700] }} \\
-\end{array}$ & $\begin{array}{c}\text { S-ratio }{ }_{[300 \& 2700]} \\
-\end{array}$ & $\begin{array}{c}\mathrm{Fe} / \text { kappa } \\
{\left[\mathrm{cps} / 10^{* *}-6 \mathrm{SI}\right]}\end{array}$ & $\begin{array}{c}\text { Age } \\
\text { cal }[k y r]\end{array}$ \\
\hline & & & & & & & $1.93 \mathrm{E}+03$ & 12.178 \\
\hline & & & & & & & $1.90 \mathrm{E}+03$ & 12.180 \\
\hline & & & & & & & $1.83 E+03$ & 12.182 \\
\hline & & & & & & & $1.86 \mathrm{E}+03$ & 12.183 \\
\hline & & & & & & & $1.91 E+03$ & 12.185 \\
\hline & & & & & & & $1.86 \mathrm{E}+03$ & 12.187 \\
\hline & & & & & & & $1.84 E+03$ & 12.189 \\
\hline & & & & & & & $1.76 E+03$ & 12.191 \\
\hline & & & & & & & $1.93 E+03$ & 12.193 \\
\hline & & & & & & & $1.80 \mathrm{E}+03$ & 12.195 \\
\hline & & & & & & & $1.87 E+03$ & 12.197 \\
\hline & & & & & & & $1.92 E+03$ & 12.198 \\
\hline & & & & & & & $1.99 E+03$ & 12.200 \\
\hline & & & & & & & $1.86 \mathrm{E}+03$ & 12.202 \\
\hline & & & & & & & $1.62 E+03$ & 12.204 \\
\hline & & & & & & & $1.49 E+03$ & 12.206 \\
\hline & & & & & & & $1.44 E+03$ & 12.208 \\
\hline & & & & & & & $1.40 \mathrm{E}+03$ & 12.210 \\
\hline & & & & & & & $1.41 \mathrm{E}+03$ & 12.212 \\
\hline & & & & & & & $1.53 E+03$ & 12.213 \\
\hline & & & & & & & $1.67 E+03$ & 12.215 \\
\hline & & & & & & & $1.73 E+03$ & 12.217 \\
\hline & & & & & & & $1.77 E+03$ & 12.219 \\
\hline & & & & & & & $1.76 \mathrm{E}+03$ & 12.221 \\
\hline & & & & & & & $1.83 E+03$ & 12.223 \\
\hline & & & & & & & $1.86 \mathrm{E}+03$ & 12.225 \\
\hline
\end{tabular}




\begin{tabular}{|c|c|c|c|c|c|c|c|c|}
\hline $\begin{array}{l}\text { Depth } \\
{[\mathrm{cm}]}\end{array}$ & $\begin{array}{c}\text { Age } \\
\text { cal [kyr] }\end{array}$ & $\begin{array}{c}\text { kappa } \\
{\left[10^{* *}-6 \mathrm{SI}\right]}\end{array}$ & $\begin{array}{l}\mathrm{IRM}_{\mathbf{3 0 0 \mathrm { TT }}} \\
{[\mathrm{mA} / \mathrm{m}]}\end{array}$ & $\begin{array}{c}\text { ARM }_{100} / \text { IRM }_{100} \\
-\end{array}$ & $\begin{array}{c}\text { HIRM }_{\text {[30082700] }} \\
-\end{array}$ & $\begin{array}{c}\text { S-ratio } \\
{[300 \& 2700]} \\
-\end{array}$ & $\begin{array}{c}\mathrm{Fe} / \text { kappa } \\
{\left[\text { cps } / 10^{* *}-6 \mathrm{SI}\right]}\end{array}$ & $\begin{array}{c}\text { Age } \\
\text { cal [kyr] }\end{array}$ \\
\hline & & & & & & & $1.88 \mathrm{E}+03$ & 12.227 \\
\hline & & & & & & & $1.77 E+03$ & 12.228 \\
\hline & & & & & & & $1.84 \mathrm{E}+03$ & 12.230 \\
\hline & & & & & & & $1.91 \mathrm{E}+03$ & 12.232 \\
\hline & & & & & & & $1.86 \mathrm{E}+03$ & 12.234 \\
\hline & & & & & & & $1.82 \mathrm{E}+03$ & 12.236 \\
\hline & & & & & & & $1.92 E+03$ & 12.238 \\
\hline & & & & & & & $1.77 E+03$ & 12.240 \\
\hline & & & & & & & $1.72 E+03$ & 12.241 \\
\hline & & & & & & & $1.77 E+03$ & 12.243 \\
\hline & & & & & & & $1.75 E+03$ & 12.245 \\
\hline & & & & & & & $1.72 E+03$ & 12.247 \\
\hline & & & & & & & $1.82 \mathrm{E}+03$ & 12.249 \\
\hline & & & & & & & $1.87 E+03$ & 12.251 \\
\hline & & & & & & & $1.86 \mathrm{E}+03$ & 12.253 \\
\hline & & & & & & & $1.86 \mathrm{E}+03$ & 12.255 \\
\hline & & & & & & & $1.88 \mathrm{E}+03$ & 12.256 \\
\hline & & & & & & & $1.87 E+03$ & 12.258 \\
\hline & & & & & & & $1.90 E+03$ & 12.260 \\
\hline & & & & & & & $1.95 E+03$ & 12.262 \\
\hline & & & & & & & $1.86 \mathrm{E}+03$ & 12.264 \\
\hline & & & & & & & $1.75 E+03$ & 12.266 \\
\hline & & & & & & & $1.83 E+03$ & 12.268 \\
\hline & & & & & & & $1.78 \mathrm{E}+03$ & 12.270 \\
\hline & & & & & & & $1.90 E+03$ & 12.271 \\
\hline & & & & & & & $2.03 E+03$ & 12.273 \\
\hline
\end{tabular}




\begin{tabular}{|c|c|c|c|c|c|c|c|c|}
\hline $\begin{array}{l}\text { Depth } \\
{[\mathrm{cm}]}\end{array}$ & $\begin{array}{c}\text { Age } \\
\text { cal }[k y r]\end{array}$ & $\begin{array}{c}\text { kappa } \\
{\left[10^{* *}-6 \mathrm{SI}\right]}\end{array}$ & $\begin{array}{l}\text { IRM }{ }_{300 \mathrm{mT}} \\
{[\mathrm{mA} / \mathrm{m}]}\end{array}$ & $\begin{array}{c}\text { ARM }_{100} / \text { IRM }_{100} \\
-\end{array}$ & $\begin{array}{c}\text { HIRM }_{\text {[30082700] }} \\
-\end{array}$ & $\begin{array}{c}\text { S-ratio } \\
{[30082700]} \\
-\end{array}$ & $\begin{array}{c}\mathrm{Fe} / \text { kappa } \\
{\left[\mathrm{cps} / 10^{* *}-6 \mathrm{SI}\right]}\end{array}$ & $\begin{array}{c}\text { Age } \\
\text { cal [kyr] }\end{array}$ \\
\hline & & & & & & & $1.92 \mathrm{E}+03$ & 12.275 \\
\hline & & & & & & & $1.75 \mathrm{E}+03$ & 12.277 \\
\hline & & & & & & & $1.56 \mathrm{E}+03$ & 12.279 \\
\hline & & & & & & & $1.45 E+03$ & 12.281 \\
\hline & & & & & & & $1.52 \mathrm{E}+03$ & 12.283 \\
\hline & & & & & & & $1.55 E+03$ & 12.284 \\
\hline & & & & & & & $1.68 \mathrm{E}+03$ & 12.286 \\
\hline & & & & & & & $1.62 E+03$ & 12.288 \\
\hline & & & & & & & $1.66 \mathrm{E}+03$ & 12.290 \\
\hline & & & & & & & $1.57 E+03$ & 12.292 \\
\hline & & & & & & & $1.62 E+03$ & 12.294 \\
\hline & & & & & & & $1.55 E+03$ & 12.296 \\
\hline & & & & & & & $1.51 E+03$ & 12.298 \\
\hline & & & & & & & $1.49 E+03$ & 12.299 \\
\hline & & & & & & & $1.53 \mathrm{E}+03$ & 12.301 \\
\hline & & & & & & & $1.46 \mathrm{E}+03$ & 12.303 \\
\hline & & & & & & & $1.46 \mathrm{E}+03$ & 12.305 \\
\hline & & & & & & & $1.48 \mathrm{E}+03$ & 12.307 \\
\hline & & & & & & & $1.48 \mathrm{E}+03$ & 12.309 \\
\hline & & & & & & & $1.48 \mathrm{E}+03$ & 12.311 \\
\hline & & & & & & & $1.40 E+03$ & 12.313 \\
\hline & & & & & & & $1.40 \mathrm{E}+03$ & 12.314 \\
\hline & & & & & & & $1.30 E+03$ & 12.316 \\
\hline & & & & & & & $1.37 \mathrm{E}+03$ & 12.318 \\
\hline & & & & & & & $1.37 \mathrm{E}+03$ & 12.320 \\
\hline & & & & & & & $1.32 \mathrm{E}+03$ & 12.351 \\
\hline
\end{tabular}




\begin{tabular}{|c|c|c|c|c|c|c|c|c|}
\hline $\begin{array}{l}\text { Depth } \\
{[\mathrm{cm}]}\end{array}$ & $\begin{array}{c}\text { Age } \\
\text { cal }[k y r]\end{array}$ & $\begin{array}{c}\text { kappa } \\
{\left[10^{* *}-6 \mathrm{SI}\right]}\end{array}$ & $\begin{array}{l}\text { IRM }{ }_{300 \mathrm{mT}} \\
{[\mathrm{mA} / \mathrm{m}]}\end{array}$ & $\begin{array}{c}\text { ARM }_{100} / \text { IRM }_{100} \\
-\end{array}$ & $\begin{array}{c}\text { HIRM }_{\text {[30082700] }} \\
-\end{array}$ & $\begin{array}{c}\text { S-ratio } \\
{[30082700]} \\
-\end{array}$ & $\begin{array}{c}\mathrm{Fe} / \text { kappa } \\
{\left[\mathrm{cps} / 10^{* *}-6 \mathrm{SI}\right]}\end{array}$ & $\begin{array}{c}\text { Age } \\
\text { cal [kyr] }\end{array}$ \\
\hline & & & & & & & $1.28 \mathrm{E}+03$ & 12.383 \\
\hline & & & & & & & $1.28 \mathrm{E}+03$ & 12.414 \\
\hline & & & & & & & $1.25 E+03$ & 12.445 \\
\hline & & & & & & & $1.25 \mathrm{E}+03$ & 12.476 \\
\hline & & & & & & & $1.31 \mathrm{E}+03$ & 12.508 \\
\hline & & & & & & & $1.31 \mathrm{E}+03$ & 12.539 \\
\hline & & & & & & & $1.28 \mathrm{E}+03$ & 12.570 \\
\hline & & & & & & & $1.29 \mathrm{E}+03$ & 12.602 \\
\hline & & & & & & & $1.25 \mathrm{E}+03$ & 12.633 \\
\hline & & & & & & & $1.25 \mathrm{E}+03$ & 12.664 \\
\hline & & & & & & & $1.30 \mathrm{E}+03$ & 12.695 \\
\hline & & & & & & & $1.31 E+03$ & 12.727 \\
\hline & & & & & & & $1.27 E+03$ & 12.758 \\
\hline & & & & & & & $1.32 \mathrm{E}+03$ & 12.789 \\
\hline & & & & & & & $1.25 \mathrm{E}+03$ & 12.821 \\
\hline & & & & & & & $1.20 E+03$ & 12.852 \\
\hline & & & & & & & 1.19E+03 & 12.883 \\
\hline & & & & & & & $1.17 \mathrm{E}+03$ & 12.914 \\
\hline & & & & & & & $1.27 \mathrm{E}+03$ & 12.946 \\
\hline & & & & & & & $1.31 E+03$ & 12.977 \\
\hline & & & & & & & $1.40 E+03$ & 13.008 \\
\hline & & & & & & & $1.37 E+03$ & 13.039 \\
\hline & & & & & & & $1.27 E+03$ & 13.071 \\
\hline & & & & & & & $1.32 \mathrm{E}+03$ & 13.102 \\
\hline & & & & & & & $1.28 \mathrm{E}+03$ & 13.133 \\
\hline & & & & & & & $1.33 E+03$ & 13.165 \\
\hline
\end{tabular}




\begin{tabular}{|c|c|c|c|c|c|c|c|c|}
\hline $\begin{array}{l}\text { Depth } \\
{[\mathrm{cm}]}\end{array}$ & $\begin{array}{c}\text { Age } \\
\text { cal [kyr] }\end{array}$ & $\begin{array}{c}\text { kappa } \\
{\left[10^{* *}-6 \mathrm{SI}\right]}\end{array}$ & $\begin{array}{l}\text { IRM }{ }_{300 \mathrm{mT}} \\
{[\mathrm{mA} / \mathrm{m}]}\end{array}$ & $\begin{array}{c}\text { ARM }_{100} / \text { IRM }_{100} \\
-\end{array}$ & $\begin{array}{c}\text { HIRM }_{\text {[300\&2700] }} \\
-\end{array}$ & $\begin{array}{c}\text { S-ratio }{ }_{[300 \& 2700]} \\
-\end{array}$ & $\begin{array}{c}\mathrm{Fe} / \text { kappa } \\
{\left[\mathrm{cps} / 10^{* *}-6 \mathrm{SI}\right]}\end{array}$ & $\begin{array}{c}\text { Age } \\
\text { cal [kyr] }\end{array}$ \\
\hline & & & & & & & $1.40 \mathrm{E}+03$ & 13.196 \\
\hline & & & & & & & $1.42 \mathrm{E}+03$ & 13.227 \\
\hline & & & & & & & $1.37 \mathrm{E}+03$ & 13.258 \\
\hline & & & & & & & $1.34 \mathrm{E}+03$ & 13.290 \\
\hline & & & & & & & $1.31 \mathrm{E}+03$ & 13.321 \\
\hline & & & & & & & $1.30 \mathrm{E}+03$ & 13.352 \\
\hline & & & & & & & $1.25 \mathrm{E}+03$ & 13.384 \\
\hline & & & & & & & $1.32 \mathrm{E}+03$ & 13.415 \\
\hline & & & & & & & $1.37 \mathrm{E}+03$ & 13.446 \\
\hline & & & & & & & $1.34 \mathrm{E}+03$ & 13.477 \\
\hline & & & & & & & $1.23 \mathrm{E}+03$ & 13.509 \\
\hline & & & & & & & $1.34 \mathrm{E}+03$ & 13.626 \\
\hline & & & & & & & $1.46 \mathrm{E}+03$ & 13.643 \\
\hline & & & & & & & $1.24 \mathrm{E}+03$ & 13.660 \\
\hline & & & & & & & $1.30 E+03$ & 13.678 \\
\hline & & & & & & & $1.40 \mathrm{E}+03$ & 13.695 \\
\hline & & & & & & & $1.50 \mathrm{E}+03$ & 13.712 \\
\hline & & & & & & & $1.54 \mathrm{E}+03$ & 13.729 \\
\hline & & & & & & & $1.57 \mathrm{E}+03$ & 13.746 \\
\hline & & & & & & & $1.56 \mathrm{E}+03$ & 13.763 \\
\hline & & & & & & & $1.50 \mathrm{E}+03$ & 13.781 \\
\hline & & & & & & & $1.41 \mathrm{E}+03$ & 13.798 \\
\hline & & & & & & & $1.41 \mathrm{E}+03$ & 13.815 \\
\hline & & & & & & & $1.47 \mathrm{E}+03$ & 13.832 \\
\hline & & & & & & & $1.49 \mathrm{E}+03$ & 13.849 \\
\hline & & & & & & & $1.43 E+03$ & 13.867 \\
\hline
\end{tabular}




\begin{tabular}{|c|c|c|c|c|c|c|c|c|}
\hline $\begin{array}{l}\text { Depth } \\
{[\mathrm{cm}]}\end{array}$ & $\begin{array}{c}\text { Age } \\
\text { cal }[k y r]\end{array}$ & $\begin{array}{c}\text { kappa } \\
{\left[10^{* *}-6 \mathrm{SI}\right]}\end{array}$ & $\begin{array}{l}\text { IRM }{ }_{300 \mathrm{mT}} \\
{[\mathrm{mA} / \mathrm{m}]}\end{array}$ & $\begin{array}{c}\text { ARM }_{100} / \text { IRM }_{100} \\
-\end{array}$ & $\begin{array}{c}\text { HIRM }_{\text {[30082700] }} \\
-\end{array}$ & $\begin{array}{c}\text { S-ratio } \\
{[30082700]} \\
-\end{array}$ & $\begin{array}{c}\mathrm{Fe} / \text { kappa } \\
{\left[\mathrm{cps} / 10^{* *}-6 \mathrm{SI}\right]}\end{array}$ & $\begin{array}{c}\text { Age } \\
\text { cal [kyr] }\end{array}$ \\
\hline & & & & & & & $1.50 \mathrm{E}+03$ & 13.884 \\
\hline & & & & & & & $1.58 \mathrm{E}+03$ & 13.901 \\
\hline & & & & & & & $1.55 E+03$ & 13.918 \\
\hline & & & & & & & $1.55 E+03$ & 13.935 \\
\hline & & & & & & & $1.50 \mathrm{E}+03$ & 13.953 \\
\hline & & & & & & & $1.57 E+03$ & 13.970 \\
\hline & & & & & & & $1.59 \mathrm{E}+03$ & 13.987 \\
\hline & & & & & & & $1.53 E+03$ & 14.004 \\
\hline & & & & & & & $1.52 \mathrm{E}+03$ & 14.021 \\
\hline & & & & & & & $1.53 E+03$ & 14.038 \\
\hline & & & & & & & $1.69 \mathrm{E}+03$ & 14.056 \\
\hline & & & & & & & $1.84 \mathrm{E}+03$ & 14.073 \\
\hline & & & & & & & $2.02 E+03$ & 14.090 \\
\hline & & & & & & & $2.04 E+03$ & 14.130 \\
\hline & & & & & & & $1.84 \mathrm{E}+03$ & 14.169 \\
\hline & & & & & & & $2.05 E+03$ & 14.209 \\
\hline & & & & & & & $2.15 E+03$ & 14.248 \\
\hline & & & & & & & $2.15 E+03$ & 14.288 \\
\hline & & & & & & & $2.21 E+03$ & 14.327 \\
\hline & & & & & & & $2.39 E+03$ & 14.367 \\
\hline & & & & & & & $2.34 \mathrm{E}+03$ & 14.406 \\
\hline & & & & & & & $2.45 E+03$ & 14.446 \\
\hline & & & & & & & $2.34 \mathrm{E}+03$ & 14.485 \\
\hline & & & & & & & $2.35 E+03$ & 14.525 \\
\hline & & & & & & & $2.42 \mathrm{E}+03$ & 14.564 \\
\hline & & & & & & & $2.71 E+03$ & 14.604 \\
\hline
\end{tabular}




\begin{tabular}{|c|c|c|c|c|c|c|c|c|}
\hline $\begin{array}{l}\text { Depth } \\
{[\mathrm{cm}]}\end{array}$ & $\begin{array}{c}\text { Age } \\
\text { cal }[k y r]\end{array}$ & $\begin{array}{c}\text { kappa } \\
{\left[10^{* *}-6 \mathrm{SI}\right]}\end{array}$ & $\begin{array}{l}\text { IRM }{ }_{300 \mathrm{mT}} \\
{[\mathrm{mA} / \mathrm{m}]}\end{array}$ & $\begin{array}{c}\text { ARM }_{100} / \text { IRM }_{100} \\
-\end{array}$ & $\begin{array}{c}\text { HIRM }_{\text {[30082700] }} \\
-\end{array}$ & $\begin{array}{c}\text { S-ratio } \\
{[30082700]} \\
-\end{array}$ & $\begin{array}{c}\mathrm{Fe} / \text { kappa } \\
{\left[\mathrm{cps} / 10^{* *}-6 \mathrm{SI}\right]}\end{array}$ & $\begin{array}{c}\text { Age } \\
\text { cal [kyr] }\end{array}$ \\
\hline & & & & & & & $2.61 \mathrm{E}+03$ & 14.643 \\
\hline & & & & & & & $2.42 E+03$ & 14.683 \\
\hline & & & & & & & $2.32 E+03$ & 14.722 \\
\hline & & & & & & & $2.16 \mathrm{E}+03$ & 14.762 \\
\hline & & & & & & & $2.05 E+03$ & 14.801 \\
\hline & & & & & & & $2.19 E+03$ & 14.841 \\
\hline & & & & & & & $2.27 E+03$ & 14.880 \\
\hline & & & & & & & $2.30 \mathrm{E}+03$ & 14.898 \\
\hline & & & & & & & $2.43 E+03$ & 14.915 \\
\hline & & & & & & & $2.29 E+03$ & 14.933 \\
\hline & & & & & & & $2.11 E+03$ & 14.950 \\
\hline & & & & & & & $1.99 \mathrm{E}+03$ & 14.968 \\
\hline & & & & & & & $2.03 E+03$ & 14.985 \\
\hline & & & & & & & $2.10 E+03$ & 15.003 \\
\hline & & & & & & & $2.11 E+03$ & 15.020 \\
\hline & & & & & & & $2.26 \mathrm{E}+03$ & 15.038 \\
\hline & & & & & & & $2.29 E+03$ & 15.055 \\
\hline & & & & & & & $2.36 \mathrm{E}+03$ & 15.073 \\
\hline & & & & & & & $2.18 \mathrm{E}+03$ & 15.090 \\
\hline & & & & & & & $2.21 E+03$ & 15.108 \\
\hline & & & & & & & $2.29 E+03$ & 15.125 \\
\hline & & & & & & & $2.02 E+03$ & 15.143 \\
\hline & & & & & & & $1.88 \mathrm{E}+03$ & 15.160 \\
\hline & & & & & & & $1.99 \mathrm{E}+03$ & 15.178 \\
\hline & & & & & & & $1.95 \mathrm{E}+03$ & 15.195 \\
\hline & & & & & & & $1.83 E+03$ & 15.213 \\
\hline
\end{tabular}




\begin{tabular}{|c|c|c|c|c|c|c|c|c|}
\hline $\begin{array}{l}\text { Depth } \\
{[\mathrm{cm}]}\end{array}$ & $\begin{array}{c}\text { Age } \\
\text { cal [kyr] }\end{array}$ & $\begin{array}{c}\text { kappa } \\
{\left[10^{* *}-6 \mathrm{SI}\right]}\end{array}$ & $\begin{array}{l}\text { IRM }{ }_{300 \mathrm{mT}} \\
{[\mathrm{mA} / \mathrm{m}]}\end{array}$ & $\begin{array}{c}\text { ARM }_{100} / \text { IRM }_{100} \\
-\end{array}$ & $\begin{array}{c}\text { HIRM }_{\text {[300\&2700] }} \\
-\end{array}$ & $\begin{array}{c}\text { S-ratio }{ }_{[300 \& 2700]} \\
-\end{array}$ & $\begin{array}{c}\mathrm{Fe} / \text { kappa } \\
{\left[\mathrm{cps} / 10^{* *}-6 \mathrm{SI}\right]}\end{array}$ & $\begin{array}{c}\text { Age } \\
\text { cal [kyr] }\end{array}$ \\
\hline & & & & & & & $1.73 E+03$ & 15.230 \\
\hline & & & & & & & $1.69 E+03$ & 15.248 \\
\hline & & & & & & & $1.67 E+03$ & 15.266 \\
\hline & & & & & & & $1.72 \mathrm{E}+03$ & 15.283 \\
\hline & & & & & & & $1.55 \mathrm{E}+03$ & 15.301 \\
\hline & & & & & & & $1.52 \mathrm{E}+03$ & 15.318 \\
\hline & & & & & & & $1.62 \mathrm{E}+03$ & 15.336 \\
\hline & & & & & & & $1.43 E+03$ & 15.353 \\
\hline & & & & & & & $1.40 \mathrm{E}+03$ & 15.371 \\
\hline & & & & & & & $1.38 \mathrm{E}+03$ & 15.388 \\
\hline & & & & & & & $1.32 \mathrm{E}+03$ & 15.406 \\
\hline & & & & & & & $1.33 \mathrm{E}+03$ & 15.423 \\
\hline & & & & & & & $1.34 \mathrm{E}+03$ & 15.441 \\
\hline & & & & & & & $1.36 \mathrm{E}+03$ & 15.458 \\
\hline & & & & & & & $1.42 \mathrm{E}+03$ & 15.476 \\
\hline & & & & & & & $1.55 \mathrm{E}+03$ & 15.493 \\
\hline & & & & & & & $1.51 \mathrm{E}+03$ & 15.511 \\
\hline & & & & & & & $1.48 \mathrm{E}+03$ & 15.528 \\
\hline & & & & & & & $1.42 \mathrm{E}+03$ & 15.546 \\
\hline & & & & & & & $1.29 \mathrm{E}+03$ & 15.563 \\
\hline & & & & & & & $1.31 \mathrm{E}+03$ & 15.581 \\
\hline & & & & & & & $1.41 \mathrm{E}+03$ & 15.598 \\
\hline & & & & & & & $1.31 \mathrm{E}+03$ & 15.616 \\
\hline & & & & & & & $1.34 \mathrm{E}+03$ & 15.634 \\
\hline & & & & & & & $1.33 \mathrm{E}+03$ & 15.651 \\
\hline & & & & & & & $1.27 \mathrm{E}+03$ & 15.669 \\
\hline
\end{tabular}




\begin{tabular}{|c|c|c|c|c|c|c|c|c|}
\hline $\begin{array}{l}\text { Depth } \\
{[\mathrm{cm}]}\end{array}$ & $\begin{array}{c}\text { Age } \\
\text { cal }[k y r]\end{array}$ & $\begin{array}{c}\text { kappa } \\
{\left[10^{* *}-6 \mathrm{SI}\right]}\end{array}$ & $\begin{array}{l}\text { IRM }{ }_{300 \mathrm{mT}} \\
{[\mathrm{mA} / \mathrm{m}]}\end{array}$ & $\begin{array}{c}\text { ARM }_{100} / \text { IRM }_{100} \\
-\end{array}$ & $\begin{array}{c}\text { HIRM }_{\text {[30082700] }} \\
-\end{array}$ & $\begin{array}{c}\text { S-ratio } \\
{[30082700]} \\
-\end{array}$ & $\begin{array}{c}\mathrm{Fe} / \text { kappa } \\
{\left[\mathrm{cps} / 10^{* *}-6 \mathrm{SI}\right]}\end{array}$ & $\begin{array}{c}\text { Age } \\
\text { cal [kyr] }\end{array}$ \\
\hline & & & & & & & $1.33 \mathrm{E}+03$ & 15.686 \\
\hline & & & & & & & $1.35 \mathrm{E}+03$ & 15.704 \\
\hline & & & & & & & $1.24 \mathrm{E}+03$ & 15.721 \\
\hline & & & & & & & $1.25 \mathrm{E}+03$ & 15.739 \\
\hline & & & & & & & $1.27 E+03$ & 15.756 \\
\hline & & & & & & & $1.37 \mathrm{E}+03$ & 15.774 \\
\hline & & & & & & & $1.42 E+03$ & 15.791 \\
\hline & & & & & & & $1.34 \mathrm{E}+03$ & 15.809 \\
\hline & & & & & & & $1.16 \mathrm{E}+03$ & 15.826 \\
\hline & & & & & & & $1.36 \mathrm{E}+03$ & 15.844 \\
\hline & & & & & & & $1.44 \mathrm{E}+03$ & 15.861 \\
\hline & & & & & & & $1.30 \mathrm{E}+03$ & 15.879 \\
\hline & & & & & & & $1.22 \mathrm{E}+03$ & 15.896 \\
\hline & & & & & & & $1.30 E+03$ & 15.914 \\
\hline & & & & & & & $1.37 \mathrm{E}+03$ & 15.931 \\
\hline & & & & & & & $1.38 \mathrm{E}+03$ & 15.949 \\
\hline & & & & & & & $1.52 E+03$ & 15.966 \\
\hline & & & & & & & $1.47 \mathrm{E}+03$ & 15.984 \\
\hline & & & & & & & $1.44 \mathrm{E}+03$ & 16.002 \\
\hline & & & & & & & $1.48 \mathrm{E}+03$ & 16.019 \\
\hline & & & & & & & $1.44 \mathrm{E}+03$ & 16.037 \\
\hline & & & & & & & $1.49 \mathrm{E}+03$ & 16.054 \\
\hline & & & & & & & $1.41 \mathrm{E}+03$ & 16.072 \\
\hline & & & & & & & $1.39 \mathrm{E}+03$ & 16.089 \\
\hline & & & & & & & $1.44 \mathrm{E}+03$ & 16.107 \\
\hline & & & & & & & $1.38 \mathrm{E}+03$ & 16.124 \\
\hline
\end{tabular}




\begin{tabular}{|c|c|c|c|c|c|c|c|c|}
\hline $\begin{array}{l}\text { Depth } \\
{[\mathrm{cm}]}\end{array}$ & $\begin{array}{c}\text { Age } \\
\text { cal }[k y r]\end{array}$ & $\begin{array}{c}\text { kappa } \\
{\left[10^{* *}-6 \mathrm{SI}\right]}\end{array}$ & $\begin{array}{l}\text { IRM }{ }_{300 \mathrm{mT}} \\
{[\mathrm{mA} / \mathrm{m}]}\end{array}$ & $\begin{array}{c}\text { ARM }_{100} / \text { IRM }_{100} \\
-\end{array}$ & $\begin{array}{c}\text { HIRM }_{\text {[30082700] }} \\
-\end{array}$ & $\begin{array}{c}\text { S-ratio } \\
{[30082700]} \\
-\end{array}$ & $\begin{array}{c}\mathrm{Fe} / \text { kappa } \\
{\left[\mathrm{cps} / 10^{* *}-6 \mathrm{SI}\right]}\end{array}$ & $\begin{array}{c}\text { Age } \\
\text { cal [kyr] }\end{array}$ \\
\hline & & & & & & & $1.48 \mathrm{E}+03$ & 16.142 \\
\hline & & & & & & & $1.52 \mathrm{E}+03$ & 16.159 \\
\hline & & & & & & & $1.67 E+03$ & 16.177 \\
\hline & & & & & & & $1.59 \mathrm{E}+03$ & 16.194 \\
\hline & & & & & & & $1.62 \mathrm{E}+03$ & 16.212 \\
\hline & & & & & & & $1.52 \mathrm{E}+03$ & 16.229 \\
\hline & & & & & & & $1.50 \mathrm{E}+03$ & 16.247 \\
\hline & & & & & & & $1.34 \mathrm{E}+03$ & 16.264 \\
\hline & & & & & & & $1.29 \mathrm{E}+03$ & 16.282 \\
\hline & & & & & & & $1.26 \mathrm{E}+03$ & 16.299 \\
\hline & & & & & & & $1.35 E+03$ & 16.317 \\
\hline & & & & & & & $1.45 \mathrm{E}+03$ & 16.334 \\
\hline & & & & & & & $1.47 \mathrm{E}+03$ & 16.352 \\
\hline & & & & & & & $1.56 \mathrm{E}+03$ & 16.370 \\
\hline & & & & & & & $1.63 E+03$ & 16.387 \\
\hline & & & & & & & $1.71 E+03$ & 16.405 \\
\hline & & & & & & & $1.62 E+03$ & 16.422 \\
\hline & & & & & & & $1.59 E+03$ & 16.440 \\
\hline & & & & & & & $1.54 \mathrm{E}+03$ & 16.457 \\
\hline & & & & & & & $1.49 \mathrm{E}+03$ & 16.475 \\
\hline & & & & & & & $1.43 E+03$ & 16.492 \\
\hline & & & & & & & $1.38 \mathrm{E}+03$ & 16.510 \\
\hline & & & & & & & $1.45 \mathrm{E}+03$ & 16.527 \\
\hline & & & & & & & $1.48 \mathrm{E}+03$ & 16.545 \\
\hline & & & & & & & $1.52 \mathrm{E}+03$ & 16.562 \\
\hline & & & & & & & $1.49 E+03$ & 16.580 \\
\hline
\end{tabular}




\begin{tabular}{|c|c|c|c|c|c|c|c|c|}
\hline $\begin{array}{l}\text { Depth } \\
{[\mathrm{cm}]}\end{array}$ & $\begin{array}{c}\text { Age } \\
\text { cal }[k y r]\end{array}$ & $\begin{array}{c}\text { kappa } \\
{\left[10^{* *}-6 \mathrm{SI}\right]}\end{array}$ & $\begin{array}{l}\text { IRM }{ }_{300 \mathrm{mT}} \\
{[\mathrm{mA} / \mathrm{m}]}\end{array}$ & $\begin{array}{c}\text { ARM }_{100} / \text { IRM }_{100} \\
-\end{array}$ & $\begin{array}{c}\text { HIRM }_{\text {[30082700] }} \\
-\end{array}$ & $\begin{array}{c}\text { S-ratio } \\
{[30082700]} \\
-\end{array}$ & $\begin{array}{c}\mathrm{Fe} / \text { kappa } \\
{\left[\mathrm{cps} / 10^{* *}-6 \mathrm{SI}\right]}\end{array}$ & $\begin{array}{c}\text { Age } \\
\text { cal [kyr] }\end{array}$ \\
\hline & & & & & & & $1.52 \mathrm{E}+03$ & 16.597 \\
\hline & & & & & & & $1.46 \mathrm{E}+03$ & 16.615 \\
\hline & & & & & & & $1.51 E+03$ & 16.632 \\
\hline & & & & & & & $1.51 E+03$ & 16.650 \\
\hline & & & & & & & $1.45 E+03$ & 16.667 \\
\hline & & & & & & & $1.45 E+03$ & 16.685 \\
\hline & & & & & & & $1.46 \mathrm{E}+03$ & 16.702 \\
\hline & & & & & & & $1.48 \mathrm{E}+03$ & 16.720 \\
\hline & & & & & & & $1.37 E+03$ & 16.921 \\
\hline & & & & & & & $1.28 \mathrm{E}+03$ & 17.122 \\
\hline & & & & & & & $1.28 \mathrm{E}+03$ & 17.324 \\
\hline & & & & & & & $1.29 \mathrm{E}+03$ & 17.525 \\
\hline & & & & & & & $1.30 E+03$ & 17.726 \\
\hline & & & & & & & $1.25 \mathrm{E}+03$ & 17.927 \\
\hline & & & & & & & $1.27 \mathrm{E}+03$ & 18.128 \\
\hline & & & & & & & $1.32 \mathrm{E}+03$ & 18.329 \\
\hline & & & & & & & $1.30 E+03$ & 18.531 \\
\hline & & & & & & & $1.30 \mathrm{E}+03$ & 18.732 \\
\hline & & & & & & & $1.28 \mathrm{E}+03$ & 18.933 \\
\hline & & & & & & & $1.30 \mathrm{E}+03$ & 19.134 \\
\hline & & & & & & & $1.29 E+03$ & 19.335 \\
\hline & & & & & & & $1.16 \mathrm{E}+03$ & 19.536 \\
\hline & & & & & & & $1.27 \mathrm{E}+03$ & 19.738 \\
\hline & & & & & & & $1.32 \mathrm{E}+03$ & 19.939 \\
\hline & & & & & & & $1.35 \mathrm{E}+03$ & 20.140 \\
\hline & & & & & & & $1.35 E+03$ & 20.359 \\
\hline
\end{tabular}




\begin{tabular}{|c|c|c|c|c|c|c|c|c|}
\hline $\begin{array}{c}\text { Depth } \\
{[\mathrm{cm}]}\end{array}$ & $\begin{array}{c}\text { Age } \\
\text { cal }[k y r]\end{array}$ & $\begin{array}{c}\text { kappa } \\
{\left[10^{* *}-6 \mathrm{SI}\right]}\end{array}$ & $\begin{array}{l}\mathbf{I R M}_{\mathbf{3 0 0 \mathrm { mT }}} \\
{[\mathrm{mA} / \mathrm{m}]}\end{array}$ & $\begin{array}{c}\text { ARM }_{100} / \text { IRM }_{100} \\
-\end{array}$ & $\begin{array}{c}\text { HIRM }_{\text {[300\&2700] }} \\
-\end{array}$ & $\begin{array}{c}\text { S-ratio } \\
{[30082700]} \\
-\end{array}$ & $\begin{array}{c}\mathrm{Fe} / \text { kappa } \\
{\left[\mathrm{cps} / 10^{* *}-6 \mathrm{SI}\right]}\end{array}$ & $\begin{array}{c}\text { Age } \\
\text { cal [kyr] }\end{array}$ \\
\hline & & & & & & & $1.26 \mathrm{E}+03$ & 20.560 \\
\hline & & & & & & & $1.35 \mathrm{E}+03$ & 20.762 \\
\hline & & & & & & & $1.38 \mathrm{E}+03$ & 20.963 \\
\hline & & & & & & & $1.37 E+03$ & 21.164 \\
\hline & & & & & & & $1.42 E+03$ & 21.365 \\
\hline & & & & & & & $1.39 \mathrm{E}+03$ & 21.566 \\
\hline & & & & & & & $1.47 E+03$ & 21.768 \\
\hline & & & & & & & $1.40 E+03$ & 21.969 \\
\hline & & & & & & & $1.57 \mathrm{E}+03$ & 22.170 \\
\hline
\end{tabular}




\section{GeoB3910-2}

\begin{tabular}{|c|c|c|c|c|c|c|c|}
\hline $\begin{array}{l}\text { Depth } \\
{[\mathrm{cm}]}\end{array}$ & $\begin{array}{c}\text { Age } \\
\text { cal [kyr] }\end{array}$ & $\begin{array}{c}\text { kappa } \\
{\left[10^{* *}-6 \mathrm{SI}\right]}\end{array}$ & $\begin{array}{l}\mathrm{IRM}_{\mathbf{3 0 0 \mathrm { mT }}} \\
{[\mathrm{mA} / \mathrm{m}]}\end{array}$ & $\begin{array}{c}\text { ARM }_{100} / \text { IRM }_{100} \\
-\end{array}$ & $\begin{array}{c}\text { HIRM }_{\text {[300\&2700] }} \\
- \\
\end{array}$ & $\begin{array}{c}\text { S-ratio [300\&2700] } \\
- \\
\end{array}$ & $\begin{array}{c}\text { Fe/kappa } \\
{\left[\mathrm{cps} / 10^{* *}-6 \mathrm{sI}\right]}\end{array}$ \\
\hline 6.5 & 1.99 & 80.65 & $1.42 \mathrm{E}+03$ & $1.56 \mathrm{E}-01$ & $1.12 \mathrm{E}+02$ & 0.93 & $1.64 \mathrm{E}+01$ \\
\hline 11 & 3.24 & 85.48 & $1.45 \mathrm{E}+03$ & $1.59 \mathrm{E}-01$ & $1.21 \mathrm{E}+02$ & 0.92 & $1.58 \mathrm{E}+01$ \\
\hline 15 & 4.35 & 75.81 & $1.42 \mathrm{E}+03$ & $1.62 \mathrm{E}-01$ & $1.16 \mathrm{E}+02$ & 0.92 & $1.73 E+01$ \\
\hline 20 & 5.73 & 79.03 & $1.62 \mathrm{E}+03$ & 1.69E-01 & $1.18 \mathrm{E}+02$ & 0.93 & $1.55 E+01$ \\
\hline 25 & 6.87 & 79.03 & $1.69 \mathrm{E}+03$ & $1.72 \mathrm{E}-01$ & $1.07 \mathrm{E}+02$ & 0.94 & $1.94 \mathrm{E}+01$ \\
\hline 30 & 7.65 & 91.94 & $1.71 \mathrm{E}+03$ & $1.85 \mathrm{E}-01$ & 8.79E+01 & 0.95 & $2.41 E+01$ \\
\hline 35 & 8.43 & 98.39 & $1.60 \mathrm{E}+03$ & $1.81 \mathrm{E}-01$ & $8.35 E+01$ & 0.95 & $2.26 \mathrm{E}+01$ \\
\hline 39.5 & 9.06 & 100.00 & $1.54 \mathrm{E}+03$ & 1.87E-01 & $9.89 \mathrm{E}+01$ & 0.94 & $3.74 \mathrm{E}+01$ \\
\hline 45 & 9.64 & 108.06 & $1.31 \mathrm{E}+03$ & 1.69E-01 & $7.55 \mathrm{E}+01$ & 0.95 & $7.85 E+00$ \\
\hline 50.5 & 10.23 & 108.06 & $1.31 \mathrm{E}+03$ & $1.63 \mathrm{E}-01$ & $8.70 \mathrm{E}+01$ & 0.94 & $8.92 \mathrm{E}+00$ \\
\hline 55 & 10.70 & 114.52 & $1.23 \mathrm{E}+03$ & $1.61 \mathrm{E}-01$ & $1.14 \mathrm{E}+02$ & 0.92 & $1.11 \mathrm{E}+01$ \\
\hline 60.5 & 11.26 & 119.35 & $1.05 E+03$ & $1.51 \mathrm{E}-01$ & $1.19 \mathrm{E}+02$ & 0.90 & 1.17E+01 \\
\hline 65 & 11.69 & 122.58 & $9.31 \mathrm{E}+02$ & $1.33 \mathrm{E}-01$ & $1.05 \mathrm{E}+02$ & 0.90 & $1.31 \mathrm{E}+01$ \\
\hline 70 & 12.17 & 117.74 & $8.29 E+02$ & $1.26 \mathrm{E}-01$ & $1.02 \mathrm{E}+02$ & 0.89 & $1.29 E+01$ \\
\hline 75 & 12.74 & 88.71 & $6.97 \mathrm{E}+02$ & $1.40 \mathrm{E}-01$ & $9.27 \mathrm{E}+01$ & 0.88 & $1.41 \mathrm{E}+01$ \\
\hline 80.5 & 13.51 & 95.16 & $8.26 \mathrm{E}+02$ & $1.44 \mathrm{E}-01$ & $1.26 \mathrm{E}+02$ & 0.87 & $1.21 E+01$ \\
\hline 85 & 14.13 & 90.32 & $8.73 E+02$ & $1.33 \mathrm{E}-01$ & $1.18 \mathrm{E}+02$ & 0.88 & $1.41 E+01$ \\
\hline 90 & 14.76 & 130.65 & $1.08 \mathrm{E}+03$ & $1.32 \mathrm{E}-01$ & $1.66 \mathrm{E}+02$ & 0.87 & $1.30 \mathrm{E}+01$ \\
\hline 95 & 15.27 & 133.87 & $1.07 \mathrm{E}+03$ & $1.36 \mathrm{E}-01$ & $1.76 \mathrm{E}+02$ & 0.86 & $1.55 \mathrm{E}+01$ \\
\hline 100 & 15.79 & 130.65 & $9.56 \mathrm{E}+02$ & 1.47E-01 & $1.94 \mathrm{E}+02$ & 0.83 & $1.62 E+01$ \\
\hline 105 & 16.24 & 141.94 & $1.05 E+03$ & $1.46 \mathrm{E}-01$ & $2.10 \mathrm{E}+02$ & 0.83 & $1.51 \mathrm{E}+01$ \\
\hline 111 & 16.66 & 138.71 & 1.17E+03 & $1.47 \mathrm{E}-01$ & $2.29 \mathrm{E}+02$ & 0.84 & $1.34 \mathrm{E}+01$ \\
\hline 115 & 16.89 & 174.19 & $2.74 \mathrm{E}+03$ & $7.26 \mathrm{E}-02$ & $2.53 \mathrm{E}+02$ & 0.92 & $1.29 \mathrm{E}+01$ \\
\hline 120 & 17.10 & 127.42 & $7.75 E+02$ & $1.58 \mathrm{E}-01$ & 1.79E+02 & 0.81 & $1.91 \mathrm{E}+01$ \\
\hline
\end{tabular}




\begin{tabular}{|c|c|c|c|c|c|c|c|}
\hline $\begin{array}{l}\text { Depth } \\
{[\mathrm{cm}]}\end{array}$ & $\begin{array}{c}\text { Age } \\
\text { cal [kyr] }\end{array}$ & $\begin{array}{c}\text { kappa } \\
{\left[10^{* *}-6 \mathrm{SI}\right]}\end{array}$ & $\begin{array}{l}\text { IRM } \\
{[\mathrm{mA} / \mathrm{m} / \mathrm{m}]}\end{array}$ & $\begin{array}{c}\mathrm{ARM}_{100} / \mathrm{IRM}_{100} \\
-\end{array}$ & $\begin{array}{c}\text { HIRM }_{\text {[30082700] }} \\
-\end{array}$ & $\begin{array}{c}\text { S-ratio }_{[30082700]} \\
-\end{array}$ & $\begin{array}{c}\mathrm{Fe} / \text { kappa } \\
{\left[\mathrm{cps} / 10^{* *}-6 \mathrm{SI}\right]}\end{array}$ \\
\hline 125 & 17.31 & 135.48 & $9.86 \mathrm{E}+02$ & $1.07 \mathrm{E}-01$ & $1.26 \mathrm{E}+02$ & 0.89 & $1.65 \mathrm{E}+01$ \\
\hline 130 & 17.53 & 140.32 & $1.54 \mathrm{E}+03$ & 7.69E-02 & $1.23 \mathrm{E}+02$ & 0.93 & $1.64 \mathrm{E}+01$ \\
\hline 135 & 17.74 & 133.87 & $1.37 \mathrm{E}+03$ & 7.31E-02 & $1.00 E+02$ & 0.93 & $1.75 E+01$ \\
\hline 140 & 17.96 & 145.16 & $1.54 \mathrm{E}+03$ & 7.83E-02 & $1.24 \mathrm{E}+02$ & 0.93 & $1.60 \mathrm{E}+01$ \\
\hline 145 & 18.17 & 153.23 & $1.85 \mathrm{E}+03$ & $7.38 \mathrm{E}-02$ & $1.54 \mathrm{E}+02$ & 0.92 & $1.43 \mathrm{E}+01$ \\
\hline 150 & 18.66 & 122.58 & $1.28 \mathrm{E}+03$ & $1.03 \mathrm{E}-01$ & $1.69 E+02$ & 0.88 & $1.30 \mathrm{E}+01$ \\
\hline 155 & 19.56 & 125.81 & $1.23 E+03$ & 1.07E-01 & $1.61 E+02$ & 0.88 & $1.01 E+01$ \\
\hline 160 & 20.46 & 116.13 & $1.26 \mathrm{E}+03$ & $1.09 \mathrm{E}-01$ & $1.83 \mathrm{E}+02$ & 0.87 & $8.31 \mathrm{E}+00$ \\
\hline 165 & 21.36 & 114.52 & $1.18 \mathrm{E}+03$ & $1.08 \mathrm{E}-01$ & $1.75 E+02$ & 0.87 & $1.05 E+01$ \\
\hline 170 & 22.26 & 127.42 & $1.21 E+03$ & $1.12 \mathrm{E}-01$ & $1.78 \mathrm{E}+02$ & 0.87 & $1.12 \mathrm{E}+01$ \\
\hline 174.5 & 22.92 & 129.03 & $1.19 \mathrm{E}+03$ & $1.13 \mathrm{E}-01$ & $1.77 \mathrm{E}+02$ & 0.87 & $1.11 \mathrm{E}+01$ \\
\hline 180 & 23.22 & 156.45 & $1.09 \mathrm{E}+03$ & $1.21 \mathrm{E}-01$ & $1.72 \mathrm{E}+02$ & 0.86 & $1.24 \mathrm{E}+01$ \\
\hline 185 & 23.86 & 166.13 & $8.91 \mathrm{E}+02$ & $1.28 \mathrm{E}-01$ & $1.62 \mathrm{E}+02$ & 0.85 & $1.61 \mathrm{E}+01$ \\
\hline 190 & 25.01 & 166.13 & $8.74 \mathrm{E}+02$ & $1.18 \mathrm{E}-01$ & $1.38 \mathrm{E}+02$ & 0.86 & $1.36 \mathrm{E}+01$ \\
\hline 195.5 & 25.99 & 116.13 & $8.91 E+02$ & $1.21 \mathrm{E}-01$ & $1.46 \mathrm{E}+02$ & 0.86 & $1.06 \mathrm{E}+01$ \\
\hline 200 & 26.72 & 127.42 & $1.21 \mathrm{E}+03$ & $1.04 \mathrm{E}-01$ & $1.86 \mathrm{E}+02$ & 0.87 & $1.03 E+01$ \\
\hline 205 & 27.44 & 129.03 & $1.33 E+03$ & $1.03 \mathrm{E}-01$ & $1.76 \mathrm{E}+02$ & 0.88 & $8.44 E+00$ \\
\hline 211 & 28.31 & 138.71 & $1.15 E+03$ & $1.06 \mathrm{E}-01$ & $1.42 \mathrm{E}+02$ & 0.89 & $1.43 E+01$ \\
\hline 214.5 & 28.76 & 127.42 & $9.19 E+02$ & $1.25 \mathrm{E}-01$ & $1.42 \mathrm{E}+02$ & 0.87 & $1.37 \mathrm{E}+01$ \\
\hline 220.5 & 29.20 & 127.42 & $1.10 \mathrm{E}+03$ & $1.13 \mathrm{E}-01$ & $1.61 \mathrm{E}+02$ & 0.87 & $1.49 \mathrm{E}+01$ \\
\hline 224.5 & 29.56 & 137.10 & $8.41 E+02$ & $1.35 \mathrm{E}-01$ & $1.49 \mathrm{E}+02$ & 0.85 & $1.46 \mathrm{E}+01$ \\
\hline 230 & 29.96 & 154.84 & $7.78 \mathrm{E}+02$ & $1.44 \mathrm{E}-01$ & $1.49 \mathrm{E}+02$ & 0.84 & $1.83 \mathrm{E}+01$ \\
\hline 234.5 & 30.72 & 124.19 & $7.63 E+02$ & $1.34 \mathrm{E}-01$ & $1.42 \mathrm{E}+02$ & 0.84 & $1.38 \mathrm{E}+01$ \\
\hline 240 & 31.73 & 109.68 & $1.01 \mathrm{E}+03$ & $1.13 \mathrm{E}-01$ & $1.45 \mathrm{E}+02$ & 0.87 & $1.13 \mathrm{E}+01$ \\
\hline 244 & 32.32 & 106.45 & $1.04 \mathrm{E}+03$ & $1.10 \mathrm{E}-01$ & $1.44 \mathrm{E}+02$ & 0.88 & $8.82 \mathrm{E}+00$ \\
\hline 250 & 32.90 & 127.42 & $1.09 E+03$ & $1.12 \mathrm{E}-01$ & $1.46 \mathrm{E}+02$ & 0.88 & $1.07 E+01$ \\
\hline
\end{tabular}




\begin{tabular}{|c|c|c|c|c|c|c|c|}
\hline $\begin{array}{l}\text { Depth } \\
{[\mathrm{cm}]}\end{array}$ & $\begin{array}{c}\text { Age } \\
\text { cal }[k y r]\end{array}$ & $\begin{array}{c}\text { kappa } \\
{\left[10^{* *}-6 \mathrm{SI}\right]}\end{array}$ & $\begin{array}{l}\mathrm{IRM}_{\mathbf{3 0 0 \mathrm { mT }}} \\
{[\mathrm{mA} / \mathrm{m}]}\end{array}$ & $\begin{array}{c}\mathrm{ARM}_{100} / \mathrm{IRM}_{100} \\
-\end{array}$ & $\begin{array}{c}\text { HIRM }_{\text {[300\&2700] }} \\
-\end{array}$ & $\begin{array}{c}\text { S-ratio } \\
{[300 \& 2700]} \\
-\end{array}$ & $\begin{array}{c}\text { Fe/kappa } \\
{\left[\text { cps } / 10^{* *}-6 \mathrm{SI}\right]}\end{array}$ \\
\hline 254.5 & 33.48 & 114.52 & $8.44 \mathrm{E}+02$ & $1.22 \mathrm{E}-01$ & $1.33 E+02$ & 0.86 & $1.46 \mathrm{E}+01$ \\
\hline 260 & 34.07 & 117.74 & $1.15 \mathrm{E}+03$ & $1.04 \mathrm{E}-01$ & $1.50 \mathrm{E}+02$ & 0.88 & $9.35 E+00$ \\
\hline 264.5 & 34.65 & 100.00 & $7.85 E+02$ & $1.21 \mathrm{E}-01$ & $1.27 \mathrm{E}+02$ & 0.86 & $1.42 \mathrm{E}+01$ \\
\hline 270 & 35.21 & 117.74 & $1.16 \mathrm{E}+03$ & $1.07 E-01$ & $1.40 \mathrm{E}+02$ & 0.89 & $8.27 E+00$ \\
\hline 274 & 35.72 & 122.58 & $1.25 \mathrm{E}+03$ & 1.07E-01 & $1.44 \mathrm{E}+02$ & 0.90 & $9.81 \mathrm{E}+00$ \\
\hline 280 & 36.24 & 103.23 & $7.97 E+02$ & $1.33 \mathrm{E}-01$ & $1.41 \mathrm{E}+02$ & 0.85 & $1.49 \mathrm{E}+01$ \\
\hline 284.5 & 36.75 & 103.23 & $9.61 \mathrm{E}+02$ & $1.26 \mathrm{E}-01$ & $1.33 \mathrm{E}+02$ & 0.88 & $9.57 \mathrm{E}+00$ \\
\hline 290 & 37.26 & 103.23 & $1.13 E+03$ & $1.15 \mathrm{E}-01$ & $1.41 E+02$ & 0.89 & $8.69 E+00$ \\
\hline 294.5 & 37.78 & 122.58 & $1.07 E+03$ & $1.30 \mathrm{E}-01$ & $1.55 E+02$ & 0.87 & $1.01 \mathrm{E}+01$ \\
\hline 300.5 & 38.35 & 133.87 & $8.76 E+02$ & $1.58 \mathrm{E}-01$ & $1.61 E+02$ & 0.84 & $1.48 \mathrm{E}+01$ \\
\hline 304 & 38.88 & 141.94 & $8.76 E+02$ & $1.43 \mathrm{E}-01$ & $1.52 \mathrm{E}+02$ & 0.85 & $1.76 \mathrm{E}+01$ \\
\hline 310 & 39.52 & 159.68 & $1.08 \mathrm{E}+03$ & $1.32 \mathrm{E}-01$ & $1.55 \mathrm{E}+02$ & 0.87 & $1.42 \mathrm{E}+01$ \\
\hline 315 & 40.15 & 179.03 & $2.44 \mathrm{E}+03$ & $8.20 \mathrm{E}-02$ & $1.89 \mathrm{E}+02$ & 0.93 & $1.32 \mathrm{E}+01$ \\
\hline 320 & 40.78 & 140.32 & $9.65 E+02$ & $1.28 \mathrm{E}-01$ & $1.27 E+02$ & 0.88 & $1.64 \mathrm{E}+01$ \\
\hline 325 & 41.42 & 124.19 & $1.65 E+03$ & 8.94E-02 & $1.41 \mathrm{E}+02$ & 0.92 & $1.21 \mathrm{E}+01$ \\
\hline 330 & 41.90 & 108.06 & $1.06 E+03$ & 1.19E-01 & $1.38 \mathrm{E}+02$ & 0.89 & $1.09 \mathrm{E}+01$ \\
\hline 335 & 42.15 & 122.58 & $1.04 \mathrm{E}+03$ & 1.07E-01 & $1.38 \mathrm{E}+02$ & 0.88 & $8.14 \mathrm{E}+00$ \\
\hline 340 & 42.40 & 129.03 & $9.50 E+02$ & $1.21 \mathrm{E}-01$ & $1.48 \mathrm{E}+02$ & 0.87 & $1.13 E+01$ \\
\hline 345 & 42.65 & 119.35 & $1.16 E+03$ & $1.08 \mathrm{E}-01$ & $1.36 \mathrm{E}+02$ & 0.89 & $1.02 \mathrm{E}+01$ \\
\hline 350 & 43.01 & 127.42 & $1.19 E+03$ & $1.10 \mathrm{E}-01$ & $1.55 \mathrm{E}+02$ & 0.89 & $9.68 \mathrm{E}+00$ \\
\hline 355 & 43.53 & 143.55 & $1.03 E+03$ & $1.28 \mathrm{E}-01$ & $1.51 E+02$ & 0.87 & 1.17E+01 \\
\hline 360 & 44.05 & 109.68 & $1.07 E+03$ & $1.20 \mathrm{E}-01$ & $1.57 \mathrm{E}+02$ & 0.87 & $1.13 E+01$ \\
\hline 365 & 44.57 & 106.45 & $1.13 E+03$ & $1.12 \mathrm{E}-01$ & $1.36 \mathrm{E}+02$ & 0.89 & $9.19 E+00$ \\
\hline 370 & 45.09 & 122.58 & $1.15 E+03$ & 1.17E-01 & $1.46 \mathrm{E}+02$ & 0.89 & $8.72 E+00$ \\
\hline 375 & 45.51 & 143.55 & $1.12 \mathrm{E}+03$ & $1.34 \mathrm{E}-01$ & $1.59 \mathrm{E}+02$ & 0.88 & $1.13 \mathrm{E}+01$ \\
\hline 380 & 45.79 & 146.77 & $1.09 E+03$ & $1.36 \mathrm{E}-01$ & $1.56 \mathrm{E}+02$ & 0.87 & $1.53 \mathrm{E}+01$ \\
\hline
\end{tabular}




\begin{tabular}{cccccccc}
\hline $\begin{array}{c}\text { Depth } \\
{[\mathrm{cm}]}\end{array}$ & $\begin{array}{c}\text { Age } \\
\text { cal }[\mathrm{kyr}]\end{array}$ & $\begin{array}{c}\text { kappa } \\
{\left[10^{* *}-6 \mathrm{SI}\right]}\end{array}$ & $\begin{array}{c}\text { IRM }_{\mathbf{3 0 0 m T}}[\mathrm{mA} / \mathrm{m}] \\
\text { ARM }_{\text {100 }} / \mathbf{I R M}_{\mathbf{1 0 0}}\end{array}$ & $\begin{array}{c}\text { HIRM }_{\text {[300\&2700] }} \\
-\end{array}$ & $\begin{array}{c}\text { S-ratio }_{\text {[30082700] }} \\
-\end{array}$ & $\begin{array}{c}\text { Fe/kappa } \\
{\left[c p s / 10^{* *}-6 \mathrm{SI}\right]}\end{array}$ \\
\hline 385 & 46.07 & 146.77 & $1.62 \mathrm{E}+03$ & $1.04 \mathrm{E}-01$ & $1.64 \mathrm{E}+02$ & 0.91 & $1.68 \mathrm{E}+01$ \\
390 & 46.34 & 179.03 & $2.19 \mathrm{E}+03$ & $9.68 \mathrm{E}-02$ & $2.11 \mathrm{E}+02$ & 0.91 & $1.31 \mathrm{E}+01$ \\
395 & 46.62 & 198.39 & $3.95 \mathrm{E}+03$ & $5.26 \mathrm{E}-02$ & $2.38 \mathrm{E}+02$ & 0.94 & $1.22 \mathrm{E}+01$ \\
400 & 46.90 & 145.16 & $2.35 \mathrm{E}+03$ & $7.75 \mathrm{E}-02$ & $1.76 \mathrm{E}+02$ & 0.93 & $1.23 \mathrm{E}+01$ \\
405 & 47.64 & 133.87 & $1.29 \mathrm{E}+03$ & $1.12 \mathrm{E}-01$ & $1.65 \mathrm{E}+02$ & 0.89 & $9.52 \mathrm{E}+00$ \\
410.5 & 48.46 & 124.19 & $1.12 \mathrm{E}+03$ & $1.17 \mathrm{E}-01$ & $1.55 \mathrm{E}+02$ & 0.88 & $9.49 \mathrm{E}+00$ \\
415 & 49.13 & 120.97 & $1.09 \mathrm{E}+03$ & $1.13 \mathrm{E}-01$ & $1.58 \mathrm{E}+02$ & 0.87 & $9.20 \mathrm{E}+00$ \\
420 & 49.87 & 129.03 & $1.08 \mathrm{E}+03$ & $1.12 \mathrm{E}-01$ & $1.53 \mathrm{E}+02$ & 0.88 & $8.47 \mathrm{E}+00$ \\
425 & 50.61 & 111.29 & $1.08 \mathrm{E}+03$ & $1.20 \mathrm{E}-01$ & $1.60 \mathrm{E}+02$ & 0.87 & $9.58 \mathrm{E}+00$ \\
430 & 51.36 & 117.74 & $1.06 \mathrm{E}+03$ & $1.24 \mathrm{E}-01$ & $1.65 \mathrm{E}+02$ & 0.86 & $9.47 \mathrm{E}+00$ \\
435 & 52.10 & 135.48 & $9.82 \mathrm{E}+02$ & $1.31 \mathrm{E}-01$ & $1.55 \mathrm{E}+02$ & 0.86 & $1.09 \mathrm{E}+01$ \\
440 & 52.79 & 124.19 & $8.91 \mathrm{E}+02$ & $1.29 \mathrm{E}-01$ & $1.44 \mathrm{E}+02$ & 0.86 & $1.58 \mathrm{E}+01$ \\
445 & 53.49 & 129.03 & $1.09 \mathrm{E}+03$ & $1.14 \mathrm{E}-01$ & $1.56 \mathrm{E}+02$ & 0.88 & $1.21 \mathrm{E}+01$ \\
450 & 54.18 & 138.71 & $1.04 \mathrm{E}+03$ & $1.08 \mathrm{E}-01$ & $1.46 \mathrm{E}+02$ & 0.88 & $1.05 \mathrm{E}+01$ \\
455 & 54.99 & 112.90 & $1.17 \mathrm{E}+03$ & $1.09 \mathrm{E}-01$ & $1.59 \mathrm{E}+02$ & 0.88 & $9.48 \mathrm{E}+00$ \\
460 & 55.72 & 133.87 & $1.04 \mathrm{E}+03$ & $1.22 \mathrm{E}-01$ & $1.53 \mathrm{E}+02$ & 0.87 & $1.34 \mathrm{E}+01$ \\
465 & 56.45 & 129.03 & $9.68 \mathrm{E}+02$ & $1.26 \mathrm{E}-01$ & $1.53 \mathrm{E}+02$ & 0.86 & $1.28 \mathrm{E}+01$ \\
470 & 57.18 & 140.32 & $8.98 \mathrm{E}+02$ & $1.44 \mathrm{E}-01$ & $1.64 \mathrm{E}+02$ & 0.85 & $1.51 \mathrm{E}+01$ \\
475 & 57.91 & 146.77 & $7.82 \mathrm{E}+02$ & $1.48 \mathrm{E}-01$ & $1.33 \mathrm{E}+02$ & 0.85 & $1.50 \mathrm{E}+01$ \\
480 & 58.64 & 169.35 & $1.09 \mathrm{E}+03$ & $9.75 \mathrm{E}-02$ & $1.09 \mathrm{E}+02$ & 0.91 & $1.42 \mathrm{E}+01$ \\
\hline
\end{tabular}


ANNEX IV - Element ratios

\section{GeoB3913-3}

\begin{tabular}{|c|c|c|c|c|c|}
\hline $\begin{array}{c}\text { Depth } \\
{[\mathrm{cm}]}\end{array}$ & $\begin{array}{c}\text { Age } \\
{[\text { cal kyr] }}\end{array}$ & $\begin{array}{c}\mathrm{Fe} / \mathrm{Ca} \\
{[c p s]}\end{array}$ & $\begin{array}{l}\mathbf{A l} / \mathbf{S i} \\
{[c p s]}\end{array}$ & $\begin{array}{c}\mathrm{Fe} / \mathbf{K} \\
{[c p s]}\end{array}$ & $\begin{array}{l}\text { Ti/Al } \\
\text { [cps] }\end{array}$ \\
\hline 2 & 1.34 & $1.81 \mathrm{E}-02$ & $5.40 \mathrm{E}-02$ & $3.02 E+00$ & $3.63 E+00$ \\
\hline 3 & 2.00 & $1.87 \mathrm{E}-02$ & $8.59 \mathrm{E}-02$ & $3.99 E+00$ & $2.13 E+00$ \\
\hline 4 & 2.67 & 1.67E-02 & $5.74 \mathrm{E}-02$ & $3.09 E+00$ & $3.06 E+00$ \\
\hline 5 & 3.34 & $1.40 \mathrm{E}-02$ & $6.45 \mathrm{E}-02$ & $3.98 \mathrm{E}+00$ & $3.17 E+00$ \\
\hline 6 & 4.01 & $1.09 \mathrm{E}-02$ & $7.79 E-02$ & $1.33 \mathrm{E}+01$ & $2.91 E+00$ \\
\hline 7 & 4.68 & 1.27E-02 & $5.63 \mathrm{E}-02$ & $4.72 \mathrm{E}+00$ & $2.65 E+00$ \\
\hline 8 & 5.34 & $1.36 \mathrm{E}-02$ & $8.42 \mathrm{E}-02$ & $6.03 E+00$ & $2.00 \mathrm{E}+00$ \\
\hline 9 & 6.01 & 1.98E-02 & 8.79E-02 & $4.30 \mathrm{E}+00$ & $2.00 \mathrm{E}+00$ \\
\hline 10 & 6.68 & $2.05 \mathrm{E}-02$ & $6.33 \mathrm{E}-02$ & $5.17 \mathrm{E}+00$ & $3.32 E+00$ \\
\hline 11 & 7.35 & $3.56 \mathrm{E}-02$ & 7.77E-02 & $4.86 \mathrm{E}+00$ & $3.19 E+00$ \\
\hline 12 & 8.02 & $5.34 \mathrm{E}-02$ & 8.96E-02 & $3.98 \mathrm{E}+00$ & $3.17 E+00$ \\
\hline 13 & 8.68 & 5.93E-02 & $8.33 \mathrm{E}-02$ & $4.33 E+00$ & $3.80 E+00$ \\
\hline 14 & 9.35 & 8.63E-02 & 1.07E-01 & $4.01 E+00$ & $2.68 \mathrm{E}+00$ \\
\hline 15 & 10.02 & 1.06E-01 & $1.11 \mathrm{E}-01$ & $4.42 \mathrm{E}+00$ & $2.86 \mathrm{E}+00$ \\
\hline 16 & 10.69 & $1.34 \mathrm{E}-01$ & $1.18 \mathrm{E}-01$ & $4.14 \mathrm{E}+00$ & $2.59 \mathrm{E}+00$ \\
\hline 17 & 11.36 & $1.52 \mathrm{E}-01$ & 1.19E-01 & $4.66 \mathrm{E}+00$ & $2.59 \mathrm{E}+00$ \\
\hline 18 & 13.30 & 1.17E-01 & 1.10E-01 & $4.37 \mathrm{E}+00$ & $2.68 \mathrm{E}+00$ \\
\hline 19 & 13.53 & $1.41 \mathrm{E}-01$ & $1.20 \mathrm{E}-01$ & $4.59 \mathrm{E}+00$ & $2.42 \mathrm{E}+00$ \\
\hline 20 & 13.75 & 2.67E-01 & $1.20 \mathrm{E}-01$ & $5.07 \mathrm{E}+00$ & $2.54 \mathrm{E}+00$ \\
\hline 21 & 13.98 & $2.66 \mathrm{E}-01$ & $1.24 \mathrm{E}-01$ & $4.96 \mathrm{E}+00$ & $2.53 E+00$ \\
\hline 22 & 14.20 & $2.82 \mathrm{E}-01$ & $1.25 \mathrm{E}-01$ & $4.88 \mathrm{E}+00$ & $2.35 \mathrm{E}+00$ \\
\hline 23 & 14.43 & $2.59 \mathrm{E}-01$ & $1.26 \mathrm{E}-01$ & $5.29 E+00$ & $2.66 \mathrm{E}+00$ \\
\hline 24 & 14.65 & $6.03 \mathrm{E}-01$ & $1.25 \mathrm{E}-01$ & $6.15 \mathrm{E}+00$ & $3.12 \mathrm{E}+00$ \\
\hline 25 & 14.88 & 5.79E-01 & $1.28 \mathrm{E}-01$ & $6.20 \mathrm{E}+00$ & $3.14 \mathrm{E}+00$ \\
\hline 26 & 15.10 & $6.95 \mathrm{E}-01$ & $1.38 \mathrm{E}-01$ & $6.57 E+00$ & $3.05 E+00$ \\
\hline 27 & 15.29 & $6.81 \mathrm{E}-01$ & $1.28 \mathrm{E}-01$ & $6.85 \mathrm{E}+00$ & $3.13 E+00$ \\
\hline 28 & 15.47 & 7.48E-01 & 1.17E-01 & $8.16 \mathrm{E}+00$ & $3.47 E+00$ \\
\hline 29 & 15.66 & $1.13 \mathrm{E}+00$ & $1.05 \mathrm{E}-01$ & $9.97 \mathrm{E}+00$ & $4.28 \mathrm{E}+00$ \\
\hline 30 & 15.84 & $8.28 \mathrm{E}-01$ & 1.11E-01 & $8.21 E+00$ & $3.12 \mathrm{E}+00$ \\
\hline 31 & 16.02 & 7.74E-01 & $1.31 \mathrm{E}-01$ & $5.96 \mathrm{E}+00$ & $2.94 \mathrm{E}+00$ \\
\hline 32 & 16.21 & $6.36 \mathrm{E}-01$ & 1.29E-01 & $5.46 \mathrm{E}+00$ & $3.03 E+00$ \\
\hline 33 & 16.39 & 8.97E-01 & 1.27E-01 & $5.58 \mathrm{E}+00$ & $3.19 E+00$ \\
\hline 34 & 16.58 & 7.43E-01 & $1.28 \mathrm{E}-01$ & $5.61 \mathrm{E}+00$ & $3.25 E+00$ \\
\hline 35 & 16.76 & $9.25 \mathrm{E}-01$ & $1.28 \mathrm{E}-01$ & $5.89 E+00$ & $2.94 \mathrm{E}+00$ \\
\hline 36 & 16.95 & $1.10 \mathrm{E}+00$ & $1.35 \mathrm{E}-01$ & $6.75 \mathrm{E}+00$ & $3.19 E+00$ \\
\hline 37 & 17.13 & $1.17 \mathrm{E}+00$ & $1.25 \mathrm{E}-01$ & $6.92 \mathrm{E}+00$ & $3.51 E+00$ \\
\hline 38 & 17.31 & $9.04 \mathrm{E}-01$ & $1.25 \mathrm{E}-01$ & $6.00 \mathrm{E}+00$ & $3.40 \mathrm{E}+00$ \\
\hline 39 & 17.50 & 7.22E-01 & 1.27E-01 & $5.82 \mathrm{E}+00$ & $3.32 \mathrm{E}+00$ \\
\hline 40 & 17.68 & $6.51 \mathrm{E}-01$ & $1.28 \mathrm{E}-01$ & $5.50 \mathrm{E}+00$ & $3.02 E+00$ \\
\hline
\end{tabular}




\begin{tabular}{|c|c|c|c|c|c|}
\hline $\begin{array}{c}\text { Depth } \\
{[\mathrm{cm}]}\end{array}$ & $\begin{array}{c}\text { Age } \\
{[\text { cal kyr] }}\end{array}$ & $\begin{array}{c}\mathrm{Fe} / \mathrm{Ca} \\
{[\mathrm{cps}]}\end{array}$ & $\begin{array}{l}\mathbf{A l} / \mathbf{S i} \\
{[c p s]}\end{array}$ & $\begin{array}{l}\mathrm{Fe} / \mathrm{K} \\
{[c p s]}\end{array}$ & $\begin{array}{l}\text { Ti/Al } \\
\text { [cps] }\end{array}$ \\
\hline 41 & 17.87 & $4.82 \mathrm{E}-01$ & $1.21 \mathrm{E}-01$ & $5.52 \mathrm{E}+00$ & $3.13 E+00$ \\
\hline 42 & 18.05 & 3.91E-01 & $1.26 \mathrm{E}-01$ & $4.96 \mathrm{E}+00$ & $2.87 E+00$ \\
\hline 43 & 18.23 & $3.66 \mathrm{E}-01$ & 1.19E-01 & $4.85 E+00$ & $2.81 E+00$ \\
\hline 44 & 18.42 & $3.46 \mathrm{E}-01$ & $1.28 \mathrm{E}-01$ & $4.32 \mathrm{E}+00$ & $2.43 E+00$ \\
\hline 45 & 18.60 & 2.92E-01 & $1.15 \mathrm{E}-01$ & $4.23 E+00$ & $2.60 \mathrm{E}+00$ \\
\hline 46 & 18.79 & $2.62 \mathrm{E}-01$ & 1.12E-01 & $4.20 E+00$ & $2.66 \mathrm{E}+00$ \\
\hline 47 & 18.97 & $2.41 \mathrm{E}-01$ & 1.04E-01 & $4.25 \mathrm{E}+00$ & $2.91 \mathrm{E}+00$ \\
\hline 48 & 19.15 & $2.15 \mathrm{E}-01$ & $1.08 \mathrm{E}-01$ & $4.22 \mathrm{E}+00$ & $2.92 \mathrm{E}+00$ \\
\hline 49 & 19.34 & 2.07E-01 & 1.07E-01 & $4.02 E+00$ & $2.54 \mathrm{E}+00$ \\
\hline 50 & 19.63 & 2.44E-01 & 1.16E-01 & $4.24 \mathrm{E}+00$ & $2.58 \mathrm{E}+00$ \\
\hline 51 & 19.93 & $2.50 \mathrm{E}-01$ & 1.13E-01 & $4.49 E+00$ & $2.56 \mathrm{E}+00$ \\
\hline 52 & 20.23 & 2.64E-01 & $1.18 \mathrm{E}-01$ & $4.19 E+00$ & $2.18 \mathrm{E}+00$ \\
\hline 54 & 20.82 & 2.61E-01 & 1.07E-01 & $4.23 E+00$ & $3.03 E+00$ \\
\hline 55 & 21.11 & 2.61E-01 & 1.10E-01 & $3.99 E+00$ & $2.87 E+00$ \\
\hline 56 & 21.41 & $3.32 \mathrm{E}-01$ & 1.13E-01 & $4.57 E+00$ & $2.97 E+00$ \\
\hline 57 & 21.71 & $3.59 \mathrm{E}-01$ & 1.19E-01 & $4.42 \mathrm{E}+00$ & $2.84 \mathrm{E}+00$ \\
\hline 58 & 22.00 & 5.04E-01 & $1.20 \mathrm{E}-01$ & $5.01 \mathrm{E}+00$ & $2.82 \mathrm{E}+00$ \\
\hline 59 & 22.30 & $5.05 \mathrm{E}-01$ & $1.14 \mathrm{E}-01$ & $5.03 \mathrm{E}+00$ & $3.35 \mathrm{E}+00$ \\
\hline 60 & 22.59 & 4.61E-01 & 1.19E-01 & $5.19 \mathrm{E}+00$ & $3.16 \mathrm{E}+00$ \\
\hline 61 & 22.89 & 5.97E-01 & 1.17E-01 & $5.40 \mathrm{E}+00$ & $3.39 E+00$ \\
\hline 62 & 23.19 & $6.16 \mathrm{E}-01$ & $1.08 \mathrm{E}-01$ & $6.19 \mathrm{E}+00$ & $3.72 E+00$ \\
\hline 63 & 23.48 & $7.35 \mathrm{E}-01$ & $1.24 \mathrm{E}-01$ & $5.86 \mathrm{E}+00$ & $2.80 E+00$ \\
\hline 64 & 23.78 & 3.79E-01 & 1.35E-01 & $3.86 \mathrm{E}+00$ & $2.22 \mathrm{E}+00$ \\
\hline 65 & 23.95 & 4.79E-01 & $1.25 \mathrm{E}-01$ & $4.07 E+00$ & $2.65 \mathrm{E}+00$ \\
\hline 66 & 24.12 & $5.38 \mathrm{E}-01$ & 1.29E-01 & $4.31 \mathrm{E}+00$ & $2.40 \mathrm{E}+00$ \\
\hline 67 & 24.29 & 5.89E-01 & $1.28 \mathrm{E}-01$ & $4.80 E+00$ & $2.61 E+00$ \\
\hline 68 & 24.46 & $9.32 \mathrm{E}-01$ & 1.36E-01 & $4.68 \mathrm{E}+00$ & $2.97 E+00$ \\
\hline 69 & 24.63 & $3.70 \mathrm{E}-01$ & $1.25 \mathrm{E}-01$ & $4.03 E+00$ & $2.25 \mathrm{E}+00$ \\
\hline 70 & 24.80 & 4.59E-01 & $1.31 \mathrm{E}-01$ & $4.14 \mathrm{E}+00$ & $2.15 E+00$ \\
\hline 71 & 24.97 & $2.95 \mathrm{E}-01$ & $1.26 \mathrm{E}-01$ & $3.76 \mathrm{E}+00$ & $2.39 \mathrm{E}+00$ \\
\hline 72 & 25.14 & $2.52 \mathrm{E}-01$ & 1.19E-01 & $3.62 E+00$ & $2.35 \mathrm{E}+00$ \\
\hline 73 & 25.31 & $2.46 \mathrm{E}-01$ & $1.23 \mathrm{E}-01$ & $3.63 E+00$ & $2.42 \mathrm{E}+00$ \\
\hline 74 & 25.49 & $2.31 \mathrm{E}-01$ & 1.27E-01 & $3.65 E+00$ & $2.34 \mathrm{E}+00$ \\
\hline 75 & 26.61 & 2.93E-01 & 1.20E-01 & $3.92 \mathrm{E}+00$ & $2.82 \mathrm{E}+00$ \\
\hline 76 & 27.73 & $4.24 \mathrm{E}-01$ & $1.32 \mathrm{E}-01$ & $4.26 \mathrm{E}+00$ & $2.49 E+00$ \\
\hline 77 & 27.97 & $4.02 \mathrm{E}-01$ & 1.30E-01 & $4.35 \mathrm{E}+00$ & $2.65 E+00$ \\
\hline 78 & 28.22 & $4.50 \mathrm{E}-01$ & $1.30 \mathrm{E}-01$ & $4.56 \mathrm{E}+00$ & $2.56 \mathrm{E}+00$ \\
\hline 79 & 28.46 & $5.51 \mathrm{E}-01$ & $1.34 \mathrm{E}-01$ & $4.72 \mathrm{E}+00$ & $2.45 \mathrm{E}+00$ \\
\hline 80 & 28.70 & $7.29 E-01$ & $1.38 \mathrm{E}-01$ & $5.10 \mathrm{E}+00$ & $3.00 E+00$ \\
\hline 81 & 28.94 & $8.65 \mathrm{E}-01$ & 1.39E-01 & $5.44 \mathrm{E}+00$ & $2.68 \mathrm{E}+00$ \\
\hline 82 & 29.19 & $1.01 \mathrm{E}+00$ & $1.36 \mathrm{E}-01$ & $5.27 \mathrm{E}+00$ & $2.96 \mathrm{E}+00$ \\
\hline 83 & 29.43 & $5.06 \mathrm{E}-01$ & $1.32 \mathrm{E}-01$ & $4.58 \mathrm{E}+00$ & $2.88 \mathrm{E}+00$ \\
\hline 84 & 29.67 & 7.69E-01 & $1.36 \mathrm{E}-01$ & $5.07 E+00$ & $2.84 \mathrm{E}+00$ \\
\hline
\end{tabular}




\begin{tabular}{cccccc}
\hline $\begin{array}{c}\text { Depth } \\
\text { [cm] }\end{array}$ & $\begin{array}{c}\text { Age } \\
\text { [cal kyr] }\end{array}$ & $\begin{array}{c}\text { Fe/Ca } \\
\text { [cps] }\end{array}$ & $\begin{array}{c}\text { Al/Si } \\
{[c p s]}\end{array}$ & $\begin{array}{c}\mathrm{Fe} / \mathrm{K} \\
{[\mathrm{cps}]}\end{array}$ & $\begin{array}{c}\text { Ti/Al } \\
{[c p s]}\end{array}$ \\
\hline 85 & 29.91 & $9.91 \mathrm{E}-01$ & $1.29 \mathrm{E}-01$ & $5.74 \mathrm{E}+00$ & $3.00 \mathrm{E}+00$ \\
86 & 30.16 & $1.04 \mathrm{E}+00$ & $1.30 \mathrm{E}-01$ & $6.14 \mathrm{E}+00$ & $3.38 \mathrm{E}+00$ \\
87 & 30.40 & $5.73 \mathrm{E}-01$ & $1.29 \mathrm{E}-01$ & $4.88 \mathrm{E}+00$ & $3.26 \mathrm{E}+00$ \\
88 & 30.64 & $3.41 \mathrm{E}-01$ & $1.21 \mathrm{E}-01$ & $4.49 \mathrm{E}+00$ & $2.94 \mathrm{E}+00$ \\
89 & 30.88 & $3.51 \mathrm{E}-01$ & $1.27 \mathrm{E}-01$ & $4.42 \mathrm{E}+00$ & $2.81 \mathrm{E}+00$ \\
90 & 31.13 & $3.56 \mathrm{E}-01$ & $1.17 \mathrm{E}-01$ & $5.01 \mathrm{E}+00$ & $3.12 \mathrm{E}+00$ \\
91 & 31.37 & $4.22 \mathrm{E}-01$ & $1.15 \mathrm{E}-01$ & $7.48 \mathrm{E}+00$ & $3.03 \mathrm{E}+00$ \\
92 & 31.61 & $2.65 \mathrm{E}-01$ & $1.15 \mathrm{E}-01$ & $5.14 \mathrm{E}+00$ & $2.46 \mathrm{E}+00$ \\
93 & 31.85 & $1.70 \mathrm{E}-01$ & $1.10 \mathrm{E}-01$ & $3.83 \mathrm{E}+00$ & $2.47 \mathrm{E}+00$ \\
94 & 32.10 & $1.59 \mathrm{E}-01$ & $1.12 \mathrm{E}-01$ & $3.84 \mathrm{E}+00$ & $2.60 \mathrm{E}+00$ \\
95 & 32.34 & $1.94 \mathrm{E}-01$ & $1.11 \mathrm{E}-01$ & $4.03 \mathrm{E}+00$ & $2.72 \mathrm{E}+00$ \\
96 & 32.74 & $2.11 \mathrm{E}-01$ & $1.17 \mathrm{E}-01$ & $4.19 \mathrm{E}+00$ & $2.49 \mathrm{E}+00$ \\
97 & 33.15 & $2.37 \mathrm{E}-01$ & $1.13 \mathrm{E}-01$ & $4.74 \mathrm{E}+00$ & $2.52 \mathrm{E}+00$ \\
98 & 33.56 & $1.58 \mathrm{E}-01$ & $1.07 \mathrm{E}-01$ & $3.80 \mathrm{E}+00$ & $2.78 \mathrm{E}+00$ \\
99 & 33.96 & $1.27 \mathrm{E}-01$ & $1.13 \mathrm{E}-01$ & $3.24 \mathrm{E}+00$ & $2.51 \mathrm{E}+00$ \\
100 & 34.37 & $1.35 \mathrm{E}-01$ & $1.11 \mathrm{E}-01$ & $3.38 \mathrm{E}+00$ & $2.69 \mathrm{E}+00$ \\
101 & 34.78 & $1.46 \mathrm{E}-01$ & $1.08 \mathrm{E}-01$ & $3.49 \mathrm{E}+00$ & $2.94 \mathrm{E}+00$ \\
102 & 35.18 & $1.36 \mathrm{E}-01$ & $1.17 \mathrm{E}-01$ & $3.51 \mathrm{E}+00$ & $2.58 \mathrm{E}+00$ \\
103 & 35.59 & $1.63 \mathrm{E}-01$ & $1.19 \mathrm{E}-01$ & $3.57 \mathrm{E}+00$ & $2.58 \mathrm{E}+00$ \\
104 & 36.00 & $2.70 \mathrm{E}-01$ & $1.32 \mathrm{E}-01$ & $3.58 \mathrm{E}+00$ & $2.21 \mathrm{E}+00$ \\
105 & 36.40 & $1.66 \mathrm{E}-01$ & $1.20 \mathrm{E}-01$ & $3.85 \mathrm{E}+00$ & $2.65 \mathrm{E}+00$ \\
106 & 36.81 & $1.55 \mathrm{E}-01$ & $1.20 \mathrm{E}-01$ & $3.56 \mathrm{E}+00$ & $2.37 \mathrm{E}+00$ \\
107 & 37.21 & $1.03 \mathrm{E}-01$ & $1.01 \mathrm{E}-01$ & $3.30 \mathrm{E}+00$ & $2.73 \mathrm{E}+00$ \\
108 & 37.62 & $9.63 \mathrm{E}-02$ & $1.03 \mathrm{E}-01$ & $3.20 \mathrm{E}+00$ & $2.40 \mathrm{E}+00$ \\
124 & 41.48 & $1.07 \mathrm{E}-01$ & $1.06 \mathrm{E}-01$ & $3.19 \mathrm{E}+00$ & $2.59 \mathrm{E}+00$ \\
125 & 41.65 & $1.21 \mathrm{E}-01$ & $1.14 \mathrm{E}-01$ & $3.58 \mathrm{E}+00$ & $2.56 \mathrm{E}+00$ \\
126 & 41.82 & $1.32 \mathrm{E}-01$ & $1.19 \mathrm{E}-01$ & $3.28 \mathrm{E}+00$ & $2.26 \mathrm{E}+00$ \\
127 & 41.99 & $1.31 \mathrm{E}-01$ & $1.10 \mathrm{E}-01$ & $3.37 \mathrm{E}+00$ & $2.47 \mathrm{E}+00$
\end{tabular}




\begin{tabular}{|c|c|c|c|c|c|}
\hline $\begin{array}{c}\text { Depth } \\
{[\mathrm{cm}]}\end{array}$ & $\begin{array}{c}\text { Age } \\
{[\text { cal kyr] }}\end{array}$ & $\begin{array}{c}\mathrm{Fe} / \mathrm{Ca} \\
{[c p s]}\end{array}$ & $\begin{array}{l}\mathbf{A l} / \mathbf{S i} \\
{[c p s]}\end{array}$ & $\begin{array}{l}\mathrm{Fe} / \mathrm{K} \\
{[c p s]}\end{array}$ & $\begin{array}{l}\text { Ti/Al } \\
{[c p s]}\end{array}$ \\
\hline 128 & 42.17 & $2.17 E-01$ & $1.17 E-01$ & $4.05 E+00$ & $2.59 \mathrm{E}+00$ \\
\hline 129 & 42.34 & 2.59E-01 & $1.09 \mathrm{E}-01$ & $4.65 E+00$ & $3.15 E+00$ \\
\hline 130 & 42.98 & 2.04E-01 & $1.09 \mathrm{E}-01$ & $4.27 \mathrm{E}+00$ & $3.02 E+00$ \\
\hline 131 & 43.62 & $2.65 \mathrm{E}-01$ & $1.11 \mathrm{E}-01$ & $4.72 \mathrm{E}+00$ & $3.49 E+00$ \\
\hline 132 & 44.27 & 1.19E-01 & $1.02 \mathrm{E}-01$ & $3.89 E+00$ & $3.15 E+00$ \\
\hline 133 & 44.91 & $1.35 \mathrm{E}-01$ & $9.13 \mathrm{E}-02$ & $4.14 \mathrm{E}+00$ & $4.14 \mathrm{E}+00$ \\
\hline 134 & 45.55 & $1.69 \mathrm{E}-01$ & $1.12 \mathrm{E}-01$ & $3.81 \mathrm{E}+00$ & $3.25 \mathrm{E}+00$ \\
\hline 135 & 45.77 & $4.46 \mathrm{E}-01$ & $1.18 \mathrm{E}-01$ & $4.67 \mathrm{E}+00$ & $3.57 E+00$ \\
\hline 136 & 45.99 & 7.77E-01 & $1.26 \mathrm{E}-01$ & $5.53 E+00$ & $3.78 \mathrm{E}+00$ \\
\hline 137 & 46.21 & 5.19E-01 & $1.26 \mathrm{E}-01$ & $4.58 \mathrm{E}+00$ & $2.87 E+00$ \\
\hline 138 & 46.44 & $9.66 \mathrm{E}-01$ & $1.31 \mathrm{E}-01$ & $5.53 \mathrm{E}+00$ & $3.40 E+00$ \\
\hline 139 & 46.66 & $1.09 \mathrm{E}+00$ & $1.34 \mathrm{E}-01$ & $6.00 E+00$ & $3.67 E+00$ \\
\hline 140 & 46.88 & $1.16 \mathrm{E}+00$ & $1.26 \mathrm{E}-01$ & $6.06 \mathrm{E}+00$ & $3.97 E+00$ \\
\hline 141 & 47.10 & $9.05 \mathrm{E}-01$ & $1.22 \mathrm{E}-01$ & $5.92 E+00$ & $4.11 \mathrm{E}+00$ \\
\hline 142 & 47.32 & 7.06E-01 & 1.15E-01 & $5.56 \mathrm{E}+00$ & $4.60 E+00$ \\
\hline 143 & 47.55 & $5.60 \mathrm{E}-01$ & 1.17E-01 & $5.11 E+00$ & $4.24 \mathrm{E}+00$ \\
\hline 144 & 47.77 & 4.46E-01 & $1.24 \mathrm{E}-01$ & $4.81 \mathrm{E}+00$ & $4.25 \mathrm{E}+00$ \\
\hline 145 & 47.99 & $3.25 \mathrm{E}-01$ & $1.08 \mathrm{E}-01$ & $4.33 \mathrm{E}+00$ & $4.12 \mathrm{E}+00$ \\
\hline 146 & 48.21 & $1.74 \mathrm{E}-01$ & $1.13 \mathrm{E}-01$ & $3.40 \mathrm{E}+00$ & $2.99 \mathrm{E}+00$ \\
\hline 147 & 48.43 & 1.37E-01 & $1.08 \mathrm{E}-01$ & $3.18 \mathrm{E}+00$ & $2.82 \mathrm{E}+00$ \\
\hline 148 & 49.16 & $1.39 \mathrm{E}-01$ & 1.03E-01 & $3.31 \mathrm{E}+00$ & $2.94 \mathrm{E}+00$ \\
\hline 149 & 49.89 & $1.32 \mathrm{E}-01$ & $1.23 \mathrm{E}-01$ & $3.36 \mathrm{E}+00$ & $2.44 \mathrm{E}+00$ \\
\hline 150 & 50.61 & $1.49 \mathrm{E}-01$ & $9.99 \mathrm{E}-02$ & $3.74 \mathrm{E}+00$ & $4.03 E+00$ \\
\hline 151 & 51.34 & $1.11 \mathrm{E}-01$ & $9.64 \mathrm{E}-02$ & $3.59 E+00$ & $3.16 E+00$ \\
\hline 152 & 52.06 & 8.83E-02 & 8.00E-02 & $4.14 \mathrm{E}+00$ & $3.92 \mathrm{E}+00$ \\
\hline 153 & 52.79 & 8.71E-02 & 8.77E-02 & $3.53 E+00$ & $3.69 E+00$ \\
\hline 154 & 53.52 & $4.48 \mathrm{E}-02$ & $1.05 \mathrm{E}-01$ & $2.97 E+00$ & $1.66 \mathrm{E}+00$ \\
\hline 155 & 53.85 & $8.10 \mathrm{E}-02$ & 1.17E-01 & $3.27 \mathrm{E}+00$ & $1.66 \mathrm{E}+00$ \\
\hline 156 & 54.18 & $1.76 \mathrm{E}-01$ & $1.24 \mathrm{E}-01$ & $3.58 \mathrm{E}+00$ & $1.95 \mathrm{E}+00$ \\
\hline 157 & 54.51 & $2.30 \mathrm{E}-01$ & $1.28 \mathrm{E}-01$ & $3.74 \mathrm{E}+00$ & $2.06 \mathrm{E}+00$ \\
\hline 158 & 54.83 & $2.83 \mathrm{E}-01$ & $1.31 \mathrm{E}-01$ & $4.05 E+00$ & $1.99 \mathrm{E}+00$ \\
\hline 159 & 55.16 & 2.73E-01 & $1.31 \mathrm{E}-01$ & $4.07 E+00$ & $2.08 \mathrm{E}+00$ \\
\hline 160 & 55.49 & 2.42E-01 & $1.26 \mathrm{E}-01$ & $3.92 E+00$ & $2.08 \mathrm{E}+00$ \\
\hline 161 & 55.82 & $1.84 \mathrm{E}-01$ & 1.27E-01 & $3.56 \mathrm{E}+00$ & $1.92 \mathrm{E}+00$ \\
\hline 162 & 56.15 & $1.94 \mathrm{E}-01$ & $1.30 \mathrm{E}-01$ & $3.80 E+00$ & $1.88 \mathrm{E}+00$ \\
\hline 163 & 56.48 & $1.92 \mathrm{E}-01$ & $1.26 \mathrm{E}-01$ & $3.69 \mathrm{E}+00$ & $1.89 \mathrm{E}+00$ \\
\hline 164 & 56.81 & $1.42 \mathrm{E}-01$ & $1.23 \mathrm{E}-01$ & $3.44 \mathrm{E}+00$ & $1.89 \mathrm{E}+00$ \\
\hline 165 & 57.14 & $1.11 \mathrm{E}-01$ & 1.15E-01 & $3.07 E+00$ & $1.79 \mathrm{E}+00$ \\
\hline 166 & 57.47 & $1.42 \mathrm{E}-01$ & $1.26 \mathrm{E}-01$ & $3.36 \mathrm{E}+00$ & $1.75 \mathrm{E}+00$ \\
\hline 167 & 57.80 & $1.60 \mathrm{E}-01$ & $1.21 \mathrm{E}-01$ & $3.49 E+00$ & $1.78 \mathrm{E}+00$ \\
\hline 168 & 58.13 & $2.03 \mathrm{E}-01$ & 1.30E-01 & $3.65 E+00$ & $1.82 \mathrm{E}+00$ \\
\hline 169 & 58.46 & 3.39E-01 & $1.38 \mathrm{E}-01$ & $4.22 \mathrm{E}+00$ & $1.95 \mathrm{E}+00$ \\
\hline 170 & 58.59 & $3.65 \mathrm{E}-01$ & 1.32E-01 & $4.37 \mathrm{E}+00$ & $2.09 \mathrm{E}+00$ \\
\hline
\end{tabular}




\begin{tabular}{|c|c|c|c|c|c|}
\hline $\begin{array}{c}\text { Depth } \\
{[\mathrm{cm}]} \\
\end{array}$ & $\begin{array}{c}\text { Age } \\
{[\mathrm{cal} k y r]}\end{array}$ & $\begin{array}{c}\mathrm{Fe} / \mathrm{Ca} \\
{[c p s]}\end{array}$ & $\begin{array}{l}\mathbf{A l} / \mathbf{S i} \\
\text { [cps] }\end{array}$ & $\begin{array}{l}\mathrm{Fe} / \mathrm{K} \\
{[c p s]}\end{array}$ & $\begin{array}{l}\text { Ti/Al } \\
\text { [cps] }\end{array}$ \\
\hline 171 & 58.73 & 6.85E-01 & $1.32 \mathrm{E}-01$ & $5.15 E+00$ & $2.34 \mathrm{E}+00$ \\
\hline 172 & 58.86 & 8.79E-01 & $1.31 \mathrm{E}-01$ & $5.35 E+00$ & $2.40 \mathrm{E}+00$ \\
\hline 173 & 59.00 & $9.06 \mathrm{E}-01$ & 1.43E-01 & $5.36 \mathrm{E}+00$ & $2.28 \mathrm{E}+00$ \\
\hline 174 & 59.13 & 9.38E-01 & 1.37E-01 & $5.45 \mathrm{E}+00$ & $2.31 E+00$ \\
\hline 175 & 59.27 & 8.00E-01 & 1.39E-01 & $4.95 \mathrm{E}+00$ & $2.27 \mathrm{E}+00$ \\
\hline 176 & 59.40 & 8.30E-01 & 1.43E-01 & $4.85 \mathrm{E}+00$ & $2.13 E+00$ \\
\hline 177 & 59.53 & $8.22 \mathrm{E}-01$ & 1.40E-01 & $4.78 \mathrm{E}+00$ & $2.30 E+00$ \\
\hline 178 & 59.67 & $1.07 E+00$ & $1.41 \mathrm{E}-01$ & $5.64 \mathrm{E}+00$ & $2.32 E+00$ \\
\hline 179 & 59.80 & $1.22 \mathrm{E}+00$ & $1.38 \mathrm{E}-01$ & $6.24 \mathrm{E}+00$ & $2.46 \mathrm{E}+00$ \\
\hline 180 & 59.94 & $1.69 E+00$ & $1.35 \mathrm{E}-01$ & $7.85 \mathrm{E}+00$ & $2.51 E+00$ \\
\hline 181 & 60.07 & $1.60 E+00$ & $1.34 \mathrm{E}-01$ & $7.02 E+00$ & $2.55 \mathrm{E}+00$ \\
\hline 182 & 60.21 & $1.13 E+00$ & 1.43E-01 & $5.01 \mathrm{E}+00$ & $2.26 \mathrm{E}+00$ \\
\hline 183 & 60.34 & $1.17 E+00$ & $1.42 \mathrm{E}-01$ & $5.55 \mathrm{E}+00$ & $2.29 E+00$ \\
\hline 184 & 60.48 & $1.38 \mathrm{E}+00$ & $1.41 \mathrm{E}-01$ & $6.09 E+00$ & $2.41 E+00$ \\
\hline 185 & 60.61 & $1.45 \mathrm{E}+00$ & $1.41 \mathrm{E}-01$ & $6.26 \mathrm{E}+00$ & $2.41 E+00$ \\
\hline 186 & 60.74 & $1.37 \mathrm{E}+00$ & $1.42 \mathrm{E}-01$ & $5.83 \mathrm{E}+00$ & $2.45 \mathrm{E}+00$ \\
\hline 187 & 60.88 & $1.35 \mathrm{E}+00$ & 1.37E-01 & $5.58 \mathrm{E}+00$ & $2.54 \mathrm{E}+00$ \\
\hline 188 & 61.01 & $1.43 \mathrm{E}+00$ & $1.38 \mathrm{E}-01$ & $5.56 \mathrm{E}+00$ & $2.60 E+00$ \\
\hline 189 & 61.15 & $1.18 \mathrm{E}+00$ & $1.43 \mathrm{E}-01$ & $4.87 \mathrm{E}+00$ & $2.42 \mathrm{E}+00$ \\
\hline 190 & 61.28 & $9.49 \mathrm{E}-01$ & 1.49E-01 & $4.19 E+00$ & $2.31 E+00$ \\
\hline 191 & 61.42 & $9.05 \mathrm{E}-01$ & $1.45 \mathrm{E}-01$ & $4.23 E+00$ & $2.44 \mathrm{E}+00$ \\
\hline 192 & 61.55 & 8.84E-01 & 1.49E-01 & $4.20 \mathrm{E}+00$ & $2.27 \mathrm{E}+00$ \\
\hline 193 & 61.69 & $8.24 \mathrm{E}-01$ & $1.50 \mathrm{E}-01$ & $4.14 \mathrm{E}+00$ & $2.27 E+00$ \\
\hline 194 & 61.82 & 7.65E-01 & $1.42 \mathrm{E}-01$ & $4.08 \mathrm{E}+00$ & $2.38 \mathrm{E}+00$ \\
\hline 195 & 61.96 & $6.69 \mathrm{E}-01$ & 1.43E-01 & $4.05 E+00$ & $2.26 \mathrm{E}+00$ \\
\hline 196 & 62.09 & 6.39E-01 & 1.44E-01 & $4.10 \mathrm{E}+00$ & $2.33 \mathrm{E}+00$ \\
\hline 197 & 62.22 & 4.93E-01 & 1.40E-01 & $3.83 E+00$ & $2.17 E+00$ \\
\hline 198 & 62.36 & 4.50E-01 & $1.37 \mathrm{E}-01$ & $3.85 E+00$ & $2.12 \mathrm{E}+00$ \\
\hline 199 & 62.49 & 4.26E-01 & $1.42 \mathrm{E}-01$ & $3.74 \mathrm{E}+00$ & $2.03 E+00$ \\
\hline 200 & 62.63 & 3.51E-01 & 1.35E-01 & $3.59 \mathrm{E}+00$ & $2.07 E+00$ \\
\hline 201 & 62.76 & 3.66E-01 & 1.39E-01 & $3.70 E+00$ & $2.00 E+00$ \\
\hline 202 & 62.90 & 3.53E-01 & $1.35 \mathrm{E}-01$ & $3.55 \mathrm{E}+00$ & $2.00 E+00$ \\
\hline 203 & 63.03 & $3.46 \mathrm{E}-01$ & $1.32 \mathrm{E}-01$ & $3.63 E+00$ & $2.03 \mathrm{E}+00$ \\
\hline 204 & 63.17 & 3.63E-01 & 1.39E-01 & $3.73 \mathrm{E}+00$ & $1.92 \mathrm{E}+00$ \\
\hline 205 & 63.30 & 3.87E-01 & $1.38 \mathrm{E}-01$ & $3.85 \mathrm{E}+00$ & $1.95 \mathrm{E}+00$ \\
\hline 206 & 63.43 & 3.85E-01 & $1.38 \mathrm{E}-01$ & $3.79 E+00$ & $1.85 \mathrm{E}+00$ \\
\hline 207 & 63.57 & $3.88 \mathrm{E}-01$ & $1.38 \mathrm{E}-01$ & $3.91 \mathrm{E}+00$ & $1.97 E+00$ \\
\hline 208 & 63.70 & 3.94E-01 & 1.36E-01 & $4.02 E+00$ & $2.04 E+00$ \\
\hline 209 & 63.84 & 3.75E-01 & $1.34 \mathrm{E}-01$ & $3.94 \mathrm{E}+00$ & $1.98 \mathrm{E}+00$ \\
\hline 210 & 63.97 & 3.79E-01 & 1.33E-01 & $4.02 E+00$ & $2.00 \mathrm{E}+00$ \\
\hline 211 & 64.11 & $3.68 \mathrm{E}-01$ & $1.36 \mathrm{E}-01$ & $3.99 \mathrm{E}+00$ & $1.91 \mathrm{E}+00$ \\
\hline 212 & 64.24 & 3.61E-01 & $1.34 \mathrm{E}-01$ & $3.91 \mathrm{E}+00$ & $2.03 E+00$ \\
\hline 213 & 64.38 & $2.98 \mathrm{E}-01$ & $1.28 \mathrm{E}-01$ & $3.84 \mathrm{E}+00$ & $1.98 \mathrm{E}+00$ \\
\hline
\end{tabular}




\begin{tabular}{|c|c|c|c|c|c|}
\hline $\begin{array}{c}\text { Depth } \\
{[\mathrm{cm}]}\end{array}$ & $\begin{array}{c}\text { Age } \\
{[\text { cal kyr] }}\end{array}$ & $\begin{array}{c}\mathrm{Fe} / \mathrm{Ca} \\
{[c p s]}\end{array}$ & $\begin{array}{l}\mathbf{A l} / \mathbf{S i} \\
{[c p s]}\end{array}$ & $\begin{array}{l}\mathrm{Fe} / \mathrm{K} \\
{[c p s]}\end{array}$ & $\begin{array}{l}\text { Ti/Al } \\
{[c p s]}\end{array}$ \\
\hline 214 & 64.51 & $3.05 E-01$ & $1.26 \mathrm{E}-01$ & $3.84 \mathrm{E}+00$ & $1.95 \mathrm{E}+00$ \\
\hline 215 & 64.65 & $3.06 \mathrm{E}-01$ & $1.30 \mathrm{E}-01$ & $3.88 \mathrm{E}+00$ & $2.02 \mathrm{E}+00$ \\
\hline 216 & 64.78 & $2.76 \mathrm{E}-01$ & $1.22 \mathrm{E}-01$ & $3.73 E+00$ & $2.12 \mathrm{E}+00$ \\
\hline 217 & 64.91 & $2.90 \mathrm{E}-01$ & $1.29 \mathrm{E}-01$ & $3.75 E+00$ & $1.92 \mathrm{E}+00$ \\
\hline 218 & 65.05 & $3.04 \mathrm{E}-01$ & $1.31 \mathrm{E}-01$ & $3.74 E+00$ & $1.87 \mathrm{E}+00$ \\
\hline 219 & 65.18 & 2.87E-01 & $1.26 \mathrm{E}-01$ & $3.72 E+00$ & $2.00 \mathrm{E}+00$ \\
\hline 220 & 65.32 & $2.81 \mathrm{E}-01$ & $1.30 \mathrm{E}-01$ & $3.64 \mathrm{E}+00$ & $1.92 \mathrm{E}+00$ \\
\hline 221 & 65.45 & $2.56 \mathrm{E}-01$ & $1.29 \mathrm{E}-01$ & $3.60 \mathrm{E}+00$ & $1.84 \mathrm{E}+00$ \\
\hline 222 & 65.59 & 2.17E-01 & $1.29 \mathrm{E}-01$ & $3.34 \mathrm{E}+00$ & $1.77 E+00$ \\
\hline 223 & 65.72 & $2.28 \mathrm{E}-01$ & $1.23 \mathrm{E}-01$ & $3.42 E+00$ & $1.93 \mathrm{E}+00$ \\
\hline 224 & 65.86 & $2.36 \mathrm{E}-01$ & $1.23 \mathrm{E}-01$ & $3.58 \mathrm{E}+00$ & $1.93 \mathrm{E}+00$ \\
\hline 225 & 65.99 & 2.79E-01 & $1.30 \mathrm{E}-01$ & 3.77E+00 & $1.97 E+00$ \\
\hline 226 & 66.12 & $2.21 \mathrm{E}-01$ & $1.23 \mathrm{E}-01$ & $3.57 E+00$ & $2.02 \mathrm{E}+00$ \\
\hline 227 & 66.26 & $2.78 \mathrm{E}-01$ & $1.28 \mathrm{E}-01$ & $3.79 E+00$ & $2.01 E+00$ \\
\hline 228 & 66.39 & $2.85 \mathrm{E}-01$ & $1.29 \mathrm{E}-01$ & $3.81 E+00$ & $2.00 E+00$ \\
\hline 229 & 66.53 & $1.75 \mathrm{E}-01$ & $1.18 \mathrm{E}-01$ & $3.43 E+00$ & $2.07 E+00$ \\
\hline 230 & 66.66 & $2.02 \mathrm{E}-01$ & 1.19E-01 & $3.49 \mathrm{E}+00$ & $2.14 \mathrm{E}+00$ \\
\hline 231 & 66.80 & $1.99 \mathrm{E}-01$ & $1.21 \mathrm{E}-01$ & $3.45 \mathrm{E}+00$ & $1.99 \mathrm{E}+00$ \\
\hline 232 & 66.93 & 3.11E-01 & $1.31 \mathrm{E}-01$ & $4.05 E+00$ & $2.11 E+00$ \\
\hline 233 & 67.07 & $2.47 \mathrm{E}-01$ & $1.24 \mathrm{E}-01$ & $3.89 \mathrm{E}+00$ & $2.23 \mathrm{E}+00$ \\
\hline 234 & 67.20 & $3.95 \mathrm{E}-01$ & 1.36E-01 & $4.54 \mathrm{E}+00$ & $2.15 \mathrm{E}+00$ \\
\hline 235 & 67.34 & $2.52 \mathrm{E}-01$ & $1.28 \mathrm{E}-01$ & $4.06 \mathrm{E}+00$ & $2.24 \mathrm{E}+00$ \\
\hline 236 & 67.47 & $1.66 \mathrm{E}-01$ & 1.33E-01 & $3.39 E+00$ & $1.76 \mathrm{E}+00$ \\
\hline 237 & 67.60 & $1.47 \mathrm{E}-01$ & $1.20 \mathrm{E}-01$ & $3.45 E+00$ & $2.09 \mathrm{E}+00$ \\
\hline 238 & 67.74 & $1.16 \mathrm{E}-01$ & 1.19E-01 & $3.13 E+00$ & $1.83 \mathrm{E}+00$ \\
\hline 239 & 67.87 & $9.40 \mathrm{E}-02$ & $1.21 \mathrm{E}-01$ & $2.93 E+00$ & $1.72 \mathrm{E}+00$ \\
\hline 240 & 68.01 & $9.37 \mathrm{E}-02$ & 1.16E-01 & $3.14 \mathrm{E}+00$ & $2.15 \mathrm{E}+00$ \\
\hline 241 & 68.11 & $8.51 \mathrm{E}-02$ & $1.11 \mathrm{E}-01$ & $2.99 \mathrm{E}+00$ & $2.15 \mathrm{E}+00$ \\
\hline 242 & 68.22 & $9.79 E-02$ & $1.11 \mathrm{E}-01$ & $3.13 E+00$ & $2.15 \mathrm{E}+00$ \\
\hline 243 & 68.33 & $1.01 \mathrm{E}-01$ & $1.11 \mathrm{E}-01$ & $3.27 E+00$ & $2.23 \mathrm{E}+00$ \\
\hline 244 & 68.43 & $1.40 \mathrm{E}-01$ & 1.16E-01 & $3.50 E+00$ & $2.21 E+00$ \\
\hline 245 & 68.54 & $1.87 \mathrm{E}-01$ & $1.28 \mathrm{E}-01$ & $3.71 E+00$ & $1.96 \mathrm{E}+00$ \\
\hline 246 & 68.64 & $2.46 \mathrm{E}-01$ & $1.32 \mathrm{E}-01$ & $3.85 E+00$ & $1.81 \mathrm{E}+00$ \\
\hline 247 & 68.75 & $2.78 \mathrm{E}-01$ & 1.40E-01 & 4.07E+00 & $1.79 \mathrm{E}+00$ \\
\hline 248 & 68.85 & $3.06 \mathrm{E}-01$ & $1.38 \mathrm{E}-01$ & $4.04 \mathrm{E}+00$ & $1.90 \mathrm{E}+00$ \\
\hline 249 & 68.96 & 4.31E-01 & 1.39E-01 & $4.80 \mathrm{E}+00$ & $2.10 \mathrm{E}+00$ \\
\hline 250 & 69.06 & 4.50E-01 & 1.37E-01 & $4.64 \mathrm{E}+00$ & $2.05 E+00$ \\
\hline 251 & 69.17 & 4.17E-01 & $1.35 \mathrm{E}-01$ & $4.56 \mathrm{E}+00$ & $2.11 \mathrm{E}+00$ \\
\hline 252 & 69.28 & 4.19E-01 & $1.32 \mathrm{E}-01$ & $4.59 \mathrm{E}+00$ & $2.15 E+00$ \\
\hline 253 & 69.38 & $3.90 \mathrm{E}-01$ & 1.39E-01 & $4.65 \mathrm{E}+00$ & $2.03 E+00$ \\
\hline 254 & 69.49 & 4.74E-01 & 1.30E-01 & $5.62 \mathrm{E}+00$ & $2.54 \mathrm{E}+00$ \\
\hline 256 & 69.70 & 4.33E-01 & $1.25 \mathrm{E}-01$ & $5.10 E+00$ & $2.63 \mathrm{E}+00$ \\
\hline 257 & 69.80 & 4.10E-01 & $1.27 \mathrm{E}-01$ & $4.86 \mathrm{E}+00$ & $2.46 \mathrm{E}+00$ \\
\hline
\end{tabular}




\begin{tabular}{|c|c|c|c|c|c|}
\hline $\begin{array}{c}\text { Depth } \\
{[\mathrm{cm}]}\end{array}$ & $\begin{array}{c}\text { Age } \\
{[\text { cal kyr] }}\end{array}$ & $\begin{array}{c}\mathrm{Fe} / \mathrm{Ca} \\
{[c p s]}\end{array}$ & $\begin{array}{l}\mathbf{A l} / \mathbf{S i} \\
{[c p s]}\end{array}$ & $\begin{array}{l}\mathrm{Fe} / \mathrm{K} \\
{[c p s]}\end{array}$ & $\begin{array}{l}\mathrm{Ti} / \mathrm{Al} \\
\text { [cps] }\end{array}$ \\
\hline 258 & 69.91 & 3.69E-01 & $1.31 \mathrm{E}-01$ & 4.79E+00 & $2.36 \mathrm{E}+00$ \\
\hline 259 & 70.02 & $3.28 \mathrm{E}-01$ & $1.26 \mathrm{E}-01$ & $4.94 \mathrm{E}+00$ & $2.46 \mathrm{E}+00$ \\
\hline 260 & 70.12 & $3.35 \mathrm{E}-01$ & $1.26 \mathrm{E}-01$ & $4.65 E+00$ & $2.48 \mathrm{E}+00$ \\
\hline 261 & 70.23 & $3.05 E-01$ & $1.30 \mathrm{E}-01$ & $4.17 E+00$ & $2.33 E+00$ \\
\hline 262 & 70.33 & $1.78 \mathrm{E}-01$ & $1.21 \mathrm{E}-01$ & $3.62 E+00$ & $2.07 E+00$ \\
\hline 263 & 70.44 & 2.19E-01 & 1.31E-01 & $3.77 E+00$ & $2.01 E+00$ \\
\hline 264 & 70.54 & $2.48 \mathrm{E}-01$ & $1.23 \mathrm{E}-01$ & $4.12 \mathrm{E}+00$ & $2.26 \mathrm{E}+00$ \\
\hline 265 & 70.65 & $1.12 \mathrm{E}-01$ & $1.11 \mathrm{E}-01$ & $3.29 E+00$ & $2.20 \mathrm{E}+00$ \\
\hline 266 & 70.76 & $6.54 \mathrm{E}-02$ & $9.29 \mathrm{E}-02$ & $3.05 E+00$ & $2.37 E+00$ \\
\hline 267 & 70.83 & 7.69E-02 & 1.09E-01 & $2.90 \mathrm{E}+00$ & $2.13 E+00$ \\
\hline 268 & 70.91 & 7.92E-02 & 1.17E-01 & $3.19 E+00$ & $2.04 \mathrm{E}+00$ \\
\hline 269 & 70.99 & $9.09 E-02$ & $1.08 \mathrm{E}-01$ & $3.15 E+00$ & $2.05 E+00$ \\
\hline 270 & 71.06 & $9.70 \mathrm{E}-02$ & 1.16E-01 & $3.16 \mathrm{E}+00$ & $1.90 \mathrm{E}+00$ \\
\hline 271 & 71.14 & $1.05 \mathrm{E}-01$ & $1.13 \mathrm{E}-01$ & $3.35 \mathrm{E}+00$ & $2.18 \mathrm{E}+00$ \\
\hline 272 & 71.22 & 1.18E-01 & 1.14E-01 & $3.54 E+00$ & $2.11 E+00$ \\
\hline 273 & 71.29 & $1.25 \mathrm{E}-01$ & 1.18E-01 & $3.51 E+00$ & $1.96 \mathrm{E}+00$ \\
\hline 274 & 71.37 & $1.16 \mathrm{E}-01$ & $1.22 \mathrm{E}-01$ & $3.47 \mathrm{E}+00$ & $1.93 \mathrm{E}+00$ \\
\hline 275 & 71.45 & $1.21 \mathrm{E}-01$ & $1.18 \mathrm{E}-01$ & $3.58 \mathrm{E}+00$ & $2.09 \mathrm{E}+00$ \\
\hline 276 & 71.52 & 1.10E-01 & 1.22E-01 & $3.45 E+00$ & $1.94 \mathrm{E}+00$ \\
\hline 277 & 71.60 & 1.04E-01 & 1.29E-01 & $3.31 E+00$ & $1.74 \mathrm{E}+00$ \\
\hline 278 & 71.68 & 1.12E-01 & $1.22 \mathrm{E}-01$ & $3.35 E+00$ & $2.02 \mathrm{E}+00$ \\
\hline 279 & 71.75 & $8.76 \mathrm{E}-02$ & $1.20 \mathrm{E}-01$ & $3.49 E+00$ & $1.70 \mathrm{E}+00$ \\
\hline 280 & 71.83 & $8.44 \mathrm{E}-02$ & 1.19E-01 & $3.61 \mathrm{E}+00$ & $1.85 \mathrm{E}+00$ \\
\hline 281 & 71.91 & 8.59E-02 & $1.11 \mathrm{E}-01$ & $3.34 \mathrm{E}+00$ & $2.00 \mathrm{E}+00$ \\
\hline 282 & 71.98 & 1.10E-01 & 1.19E-01 & $3.86 \mathrm{E}+00$ & $2.24 \mathrm{E}+00$ \\
\hline 283 & 72.06 & $9.75 \mathrm{E}-02$ & $1.21 \mathrm{E}-01$ & $3.80 \mathrm{E}+00$ & $2.26 \mathrm{E}+00$ \\
\hline 284 & 72.14 & 8.49E-02 & 1.19E-01 & $3.50 E+00$ & $1.89 \mathrm{E}+00$ \\
\hline 285 & 72.21 & $8.51 \mathrm{E}-02$ & $1.12 \mathrm{E}-01$ & $3.50 \mathrm{E}+00$ & $2.03 E+00$ \\
\hline 286 & 72.29 & 7.03E-02 & $1.21 \mathrm{E}-01$ & $3.26 \mathrm{E}+00$ & $1.72 \mathrm{E}+00$ \\
\hline 287 & 72.37 & 8.19E-02 & $1.20 \mathrm{E}-01$ & $3.35 \mathrm{E}+00$ & $1.83 \mathrm{E}+00$ \\
\hline 288 & 72.44 & $8.85 \mathrm{E}-02$ & 1.20E-01 & $3.47 E+00$ & $1.96 \mathrm{E}+00$ \\
\hline 289 & 72.52 & $8.86 \mathrm{E}-02$ & $1.18 \mathrm{E}-01$ & $3.47 E+00$ & $2.16 \mathrm{E}+00$ \\
\hline 290 & 72.60 & 8.57E-02 & 1.10E-01 & $3.48 \mathrm{E}+00$ & $2.16 \mathrm{E}+00$ \\
\hline 291 & 72.67 & $1.08 \mathrm{E}-01$ & $1.22 \mathrm{E}-01$ & $3.53 E+00$ & $2.03 E+00$ \\
\hline 292 & 72.75 & 1.77E-01 & 1.30E-01 & $4.00 E+00$ & $1.97 \mathrm{E}+00$ \\
\hline 293 & 72.83 & $1.36 \mathrm{E}-01$ & 1.15E-01 & $3.47 \mathrm{E}+00$ & $2.16 \mathrm{E}+00$ \\
\hline 294 & 72.90 & $1.54 \mathrm{E}-01$ & $1.22 \mathrm{E}-01$ & $3.62 E+00$ & $2.18 \mathrm{E}+00$ \\
\hline 295 & 72.98 & $2.09 \mathrm{E}-01$ & 1.17E-01 & $4.03 E+00$ & $2.33 \mathrm{E}+00$ \\
\hline 296 & 73.06 & 3.19E-01 & 1.27E-01 & $4.54 \mathrm{E}+00$ & $2.21 E+00$ \\
\hline 297 & 73.13 & 4.27E-01 & $1.23 \mathrm{E}-01$ & $4.90 E+00$ & $2.39 \mathrm{E}+00$ \\
\hline 298 & 73.21 & $3.62 \mathrm{E}-01$ & 1.26E-01 & $4.60 E+00$ & $2.31 E+00$ \\
\hline 299 & 73.29 & $2.86 \mathrm{E}-01$ & $1.28 \mathrm{E}-01$ & $4.30 \mathrm{E}+00$ & $1.93 \mathrm{E}+00$ \\
\hline 300 & 73.37 & 2.56E-01 & $1.21 \mathrm{E}-01$ & $4.13 E+00$ & $2.03 E+00$ \\
\hline
\end{tabular}




\begin{tabular}{|c|c|c|c|c|c|}
\hline $\begin{array}{c}\text { Depth } \\
{[\mathrm{cm}]}\end{array}$ & $\begin{array}{c}\text { Age } \\
\text { [cal kyr] }\end{array}$ & $\begin{array}{c}\mathrm{Fe} / \mathrm{Ca} \\
{[c p s]}\end{array}$ & $\begin{array}{l}\mathbf{A l} / \mathbf{S i} \\
{[c p s]}\end{array}$ & $\begin{array}{l}\mathbf{F e} / \mathbf{K} \\
{[c p s]}\end{array}$ & $\begin{array}{l}\text { Ti/Al } \\
\text { [cps] }\end{array}$ \\
\hline 301 & 73.67 & $3.49 \mathrm{E}-01$ & $1.25 \mathrm{E}-01$ & $4.71 E+00$ & $2.20 E+00$ \\
\hline 302 & 73.98 & $1.49 \mathrm{E}-01$ & $1.14 \mathrm{E}-01$ & $3.47 E+00$ & $2.06 \mathrm{E}+00$ \\
\hline 303 & 74.29 & 1.36E-01 & 1.10E-01 & $3.37 E+00$ & $2.20 \mathrm{E}+00$ \\
\hline 304 & 74.59 & 1.40E-01 & $1.15 \mathrm{E}-01$ & $3.37 E+00$ & $2.19 E+00$ \\
\hline 305 & 74.90 & 1.35E-01 & $1.26 \mathrm{E}-01$ & $3.08 \mathrm{E}+00$ & $1.89 \mathrm{E}+00$ \\
\hline 306 & 75.21 & 1.43E-01 & $1.11 \mathrm{E}-01$ & $3.12 \mathrm{E}+00$ & $1.86 \mathrm{E}+00$ \\
\hline 307 & 75.51 & $1.14 \mathrm{E}-01$ & $1.18 \mathrm{E}-01$ & $3.09 E+00$ & $1.82 \mathrm{E}+00$ \\
\hline 308 & 75.82 & $5.78 \mathrm{E}-02$ & $1.13 \mathrm{E}-01$ & $2.73 E+00$ & $1.60 \mathrm{E}+00$ \\
\hline 309 & 76.13 & 4.09E-02 & $1.13 \mathrm{E}-01$ & $2.76 \mathrm{E}+00$ & $1.38 \mathrm{E}+00$ \\
\hline 310 & 76.34 & $3.82 \mathrm{E}-02$ & $9.26 \mathrm{E}-02$ & $2.80 E+00$ & $1.89 \mathrm{E}+00$ \\
\hline 311 & 76.56 & $4.22 \mathrm{E}-02$ & $9.91 \mathrm{E}-02$ & $2.68 \mathrm{E}+00$ & $1.68 \mathrm{E}+00$ \\
\hline 312 & 76.78 & 3.34E-02 & $9.50 \mathrm{E}-02$ & $2.88 \mathrm{E}+00$ & $1.62 \mathrm{E}+00$ \\
\hline 313 & 77.00 & $2.45 \mathrm{E}-02$ & 7.30E-02 & $2.49 E+00$ & $1.67 \mathrm{E}+00$ \\
\hline 314 & 77.22 & $2.13 \mathrm{E}-02$ & 7.95E-02 & $2.93 \mathrm{E}+00$ & $1.98 \mathrm{E}+00$ \\
\hline 315 & 77.44 & $2.56 \mathrm{E}-02$ & $6.76 \mathrm{E}-02$ & $2.15 \mathrm{E}+00$ & $1.79 \mathrm{E}+00$ \\
\hline 316 & 77.65 & 2.29E-02 & $6.64 \mathrm{E}-02$ & $2.49 \mathrm{E}+00$ & $2.08 \mathrm{E}+00$ \\
\hline 317 & 77.87 & $2.25 \mathrm{E}-02$ & 3.75E-02 & $1.61 \mathrm{E}+00$ & $2.55 \mathrm{E}+00$ \\
\hline 318 & 78.09 & $1.68 \mathrm{E}-02$ & $2.91 \mathrm{E}-02$ & $6.13 \mathrm{E}-01$ & $8.50 \mathrm{E}-01$ \\
\hline 319 & 78.31 & $2.08 \mathrm{E}-02$ & 2.87E-02 & 7.35E-01 & $9.18 \mathrm{E}-01$ \\
\hline 320 & 78.53 & $2.22 \mathrm{E}-02$ & $2.78 \mathrm{E}-02$ & 6.06E-01 & $1.09 \mathrm{E}+00$ \\
\hline 321 & 78.75 & $1.38 \mathrm{E}-02$ & 4.33E-02 & $2.59 E+00$ & $2.12 \mathrm{E}+00$ \\
\hline 322 & 78.97 & $1.41 \mathrm{E}-02$ & $6.56 \mathrm{E}-02$ & $5.13 E+00$ & $2.36 \mathrm{E}+00$ \\
\hline 323 & 79.18 & 4.69E-02 & 6.79E-02 & $4.60 E+00$ & $1.93 \mathrm{E}+00$ \\
\hline 324 & 79.40 & $3.35 \mathrm{E}-01$ & $1.34 \mathrm{E}-01$ & $4.44 \mathrm{E}+00$ & $1.89 E+00$ \\
\hline 325 & 79.62 & 3.18E-01 & 1.27E-01 & $3.99 \mathrm{E}+00$ & $2.09 \mathrm{E}+00$ \\
\hline 326 & 79.84 & $2.54 \mathrm{E}-01$ & $1.29 \mathrm{E}-01$ & $3.68 \mathrm{E}+00$ & $2.00 \mathrm{E}+00$ \\
\hline 327 & 80.06 & $2.32 \mathrm{E}-01$ & $1.25 \mathrm{E}-01$ & $3.86 \mathrm{E}+00$ & $2.10 \mathrm{E}+00$ \\
\hline 328 & 80.28 & $1.88 \mathrm{E}-01$ & $1.20 \mathrm{E}-01$ & $3.32 \mathrm{E}+00$ & $2.05 \mathrm{E}+00$ \\
\hline 329 & 80.50 & $2.94 \mathrm{E}-01$ & $1.28 \mathrm{E}-01$ & $3.80 E+00$ & $2.04 \mathrm{E}+00$ \\
\hline 330 & 80.73 & 2.87E-01 & $1.29 \mathrm{E}-01$ & $3.89 \mathrm{E}+00$ & $2.24 \mathrm{E}+00$ \\
\hline 331 & 80.96 & $2.72 \mathrm{E}-01$ & $1.24 \mathrm{E}-01$ & $3.74 \mathrm{E}+00$ & $2.20 \mathrm{E}+00$ \\
\hline 332 & 81.19 & 3.21E-01 & $1.24 \mathrm{E}-01$ & $3.94 \mathrm{E}+00$ & $2.24 \mathrm{E}+00$ \\
\hline 333 & 81.42 & 3.10E-01 & 1.27E-01 & $4.07 E+00$ & $2.25 \mathrm{E}+00$ \\
\hline 334 & 81.64 & 2.66E-01 & $1.29 \mathrm{E}-01$ & $3.74 \mathrm{E}+00$ & $2.13 \mathrm{E}+00$ \\
\hline 335 & 81.87 & 2.85E-01 & $1.25 \mathrm{E}-01$ & $3.91 \mathrm{E}+00$ & $2.20 \mathrm{E}+00$ \\
\hline 336 & 82.10 & 2.60E-01 & $1.24 \mathrm{E}-01$ & $3.95 \mathrm{E}+00$ & $2.14 \mathrm{E}+00$ \\
\hline 337 & 82.33 & 1.27E-01 & $1.08 \mathrm{E}-01$ & $3.55 \mathrm{E}+00$ & $2.16 \mathrm{E}+00$ \\
\hline 338 & 82.55 & $9.03 \mathrm{E}-02$ & $1.02 \mathrm{E}-01$ & $3.07 E+00$ & $2.12 \mathrm{E}+00$ \\
\hline 339 & 82.78 & 7.44E-02 & $1.03 \mathrm{E}-01$ & $3.06 \mathrm{E}+00$ & $1.98 \mathrm{E}+00$ \\
\hline 340 & 83.01 & $1.62 \mathrm{E}-01$ & $1.14 \mathrm{E}-01$ & $5.36 \mathrm{E}+00$ & $1.94 \mathrm{E}+00$ \\
\hline 341 & 83.24 & 1.79E-01 & 1.16E-01 & $4.13 E+00$ & $1.99 \mathrm{E}+00$ \\
\hline 342 & 83.47 & $2.84 \mathrm{E}-01$ & $1.25 \mathrm{E}-01$ & $4.41 \mathrm{E}+00$ & $2.11 \mathrm{E}+00$ \\
\hline 343 & 83.69 & $3.41 \mathrm{E}-01$ & 1.29E-01 & $4.54 \mathrm{E}+00$ & $2.08 \mathrm{E}+00$ \\
\hline
\end{tabular}




\begin{tabular}{cccccc}
\hline $\begin{array}{c}\text { Depth } \\
{[\mathrm{cm}]}\end{array}$ & $\begin{array}{c}\text { Age } \\
{[\text { cal } k y r]}\end{array}$ & $\begin{array}{c}\mathrm{Fe} / \mathrm{Ca} \\
{[\mathrm{cps}]}\end{array}$ & $\begin{array}{c}\mathrm{Al} / \mathrm{Si} \\
{[\mathrm{cps}]}\end{array}$ & $\begin{array}{c}\mathrm{Fe} / \mathrm{K} \\
{[\mathrm{cps}]}\end{array}$ & $\begin{array}{c}\text { Ti/Al } \\
{[\mathrm{cps}]}\end{array}$ \\
\hline 344 & 83.92 & $3.34 \mathrm{E}-01$ & $1.27 \mathrm{E}-01$ & $4.36 \mathrm{E}+00$ & $2.21 \mathrm{E}+00$ \\
345 & 84.15 & $3.12 \mathrm{E}-01$ & $1.29 \mathrm{E}-01$ & $3.95 \mathrm{E}+00$ & $2.25 \mathrm{E}+00$ \\
346 & 84.38 & $3.49 \mathrm{E}-01$ & $1.33 \mathrm{E}-01$ & $4.06 \mathrm{E}+00$ & $2.26 \mathrm{E}+00$ \\
347 & 84.60 & $3.46 \mathrm{E}-01$ & $1.28 \mathrm{E}-01$ & $4.04 \mathrm{E}+00$ & $2.32 \mathrm{E}+00$ \\
348 & 84.83 & $3.43 \mathrm{E}-01$ & $1.32 \mathrm{E}-01$ & $3.73 \mathrm{E}+00$ & $2.22 \mathrm{E}+00$ \\
349 & 85.06 & $4.06 \mathrm{E}-01$ & $1.34 \mathrm{E}-01$ & $4.04 \mathrm{E}+00$ & $2.25 \mathrm{E}+00$ \\
350 & 85.29 & $3.89 \mathrm{E}-01$ & $1.35 \mathrm{E}-01$ & $4.08 \mathrm{E}+00$ & $2.18 \mathrm{E}+00$ \\
\hline
\end{tabular}


GeoB3912-1

\begin{tabular}{|c|c|c|c|c|c|}
\hline $\begin{array}{c}\text { Depth } \\
{[\mathrm{cm}]}\end{array}$ & $\begin{array}{c}\text { Age } \\
\text { [cal kyr] }\end{array}$ & $\begin{array}{c}\mathrm{Fe} / \mathrm{Ca} \\
{[c p s]}\end{array}$ & $\begin{array}{l}\mathbf{A l} / \mathbf{S i} \\
\text { [cps] }\end{array}$ & $\begin{array}{l}\mathrm{Fe} / \mathrm{K} \\
{[c p s]} \\
\end{array}$ & $\begin{array}{l}\mathrm{Ti} / \mathbf{A l} \\
\text { [cps] }\end{array}$ \\
\hline 2 & 1.27 & $5.20 \mathrm{E}-02$ & $1.01 \mathrm{E}-01$ & $2.85 E+00$ & $2.68 \mathrm{E}+00$ \\
\hline 4 & 2.05 & $5.38 \mathrm{E}-02$ & $9.88 \mathrm{E}-02$ & $2.98 \mathrm{E}+00$ & $2.79 E+00$ \\
\hline 6 & 2.85 & 5.91E-02 & $1.03 \mathrm{E}-01$ & $2.97 E+00$ & $2.46 \mathrm{E}+00$ \\
\hline 8 & 3.64 & 5.38E-02 & $9.75 \mathrm{E}-02$ & $2.80 \mathrm{E}+00$ & $2.60 \mathrm{E}+00$ \\
\hline 10 & 4.44 & 7.35E-02 & $1.01 \mathrm{E}-01$ & $3.45 E+00$ & $2.56 \mathrm{E}+00$ \\
\hline 12 & 5.37 & $9.03 \mathrm{E}-02$ & 1.17E-01 & $3.30 E+00$ & $2.44 \mathrm{E}+00$ \\
\hline 14 & 6.34 & $5.84 \mathrm{E}-02$ & $9.20 \mathrm{E}-02$ & $2.73 E+00$ & $3.64 \mathrm{E}+00$ \\
\hline 16 & 7.37 & $1.02 \mathrm{E}-01$ & $1.01 \mathrm{E}-01$ & $3.21 E+00$ & $3.39 E+00$ \\
\hline 18 & 8.45 & 2.63E-01 & 1.19E-01 & $4.12 \mathrm{E}+00$ & $2.86 \mathrm{E}+00$ \\
\hline 20 & 9.54 & 7.51E-01 & $1.29 \mathrm{E}-01$ & $4.99 E+00$ & $3.21 E+00$ \\
\hline 22 & 9.80 & 4.70E-01 & $1.33 \mathrm{E}-01$ & $3.96 \mathrm{E}+00$ & $2.84 \mathrm{E}+00$ \\
\hline 24 & 10.06 & 6.35E-01 & $1.41 \mathrm{E}-01$ & $4.11 E+00$ & $2.36 E+00$ \\
\hline 26 & 10.27 & 6.39E-01 & $1.32 \mathrm{E}-01$ & $4.57 \mathrm{E}+00$ & $2.89 E+00$ \\
\hline 28 & 10.42 & $6.06 \mathrm{E}-01$ & $1.38 \mathrm{E}-01$ & $4.39 \mathrm{E}+00$ & $2.66 \mathrm{E}+00$ \\
\hline 30 & 10.57 & $9.79 \mathrm{E}-01$ & $1.36 \mathrm{E}-01$ & $5.33 E+00$ & $3.13 E+00$ \\
\hline 32 & 10.73 & $9.89 \mathrm{E}-01$ & $1.31 \mathrm{E}-01$ & $5.30 \mathrm{E}+00$ & $3.08 \mathrm{E}+00$ \\
\hline 34 & 10.88 & $1.20 \mathrm{E}+00$ & $1.36 \mathrm{E}-01$ & $5.40 \mathrm{E}+00$ & $2.98 \mathrm{E}+00$ \\
\hline 36 & 11.03 & $1.26 \mathrm{E}+00$ & $1.34 \mathrm{E}-01$ & $5.57 \mathrm{E}+00$ & $2.96 \mathrm{E}+00$ \\
\hline 38 & 11.19 & $1.15 \mathrm{E}+00$ & $1.39 \mathrm{E}-01$ & $5.31 E+00$ & $2.81 E+00$ \\
\hline 40 & 11.35 & $1.30 \mathrm{E}+00$ & $1.39 \mathrm{E}-01$ & $5.85 E+00$ & $3.17 E+00$ \\
\hline 42 & 11.58 & $1.17 \mathrm{E}+00$ & $1.36 \mathrm{E}-01$ & $5.42 E+00$ & $2.97 E+00$ \\
\hline 44 & 11.83 & $1.21 \mathrm{E}+00$ & $1.40 \mathrm{E}-01$ & $5.53 E+00$ & $3.02 E+00$ \\
\hline 46 & 12.07 & $1.05 E+00$ & $1.38 \mathrm{E}-01$ & $5.58 \mathrm{E}+00$ & $2.95 E+00$ \\
\hline 48 & 12.32 & 8.36E-01 & $1.32 \mathrm{E}-01$ & $5.26 \mathrm{E}+00$ & $3.17 E+00$ \\
\hline 50 & 12.56 & 8.16E-01 & $1.38 \mathrm{E}-01$ & $5.39 E+00$ & $3.08 \mathrm{E}+00$ \\
\hline 52 & 12.81 & 4.39E-01 & $1.39 \mathrm{E}-01$ & $4.16 \mathrm{E}+00$ & $2.64 \mathrm{E}+00$ \\
\hline 54 & 13.05 & 3.72E-01 & $1.29 \mathrm{E}-01$ & $4.03 E+00$ & $2.89 \mathrm{E}+00$ \\
\hline 56 & 13.30 & $3.44 \mathrm{E}-01$ & $1.31 \mathrm{E}-01$ & $3.86 \mathrm{E}+00$ & $2.86 \mathrm{E}+00$ \\
\hline 58 & 13.55 & $5.82 \mathrm{E}-01$ & $1.28 \mathrm{E}-01$ & $4.72 E+00$ & $3.45 E+00$ \\
\hline 60 & 13.80 & 4.01E-01 & $1.27 \mathrm{E}-01$ & $3.92 E+00$ & $2.93 \mathrm{E}+00$ \\
\hline 62 & 14.04 & $1.10 \mathrm{E}+00$ & $1.24 \mathrm{E}-01$ & $4.84 \mathrm{E}+00$ & $3.23 \mathrm{E}+00$ \\
\hline 64 & 14.29 & $1.18 \mathrm{E}+00$ & $1.31 \mathrm{E}-01$ & $4.87 E+00$ & $3.11 E+00$ \\
\hline 66 & 14.51 & $1.24 \mathrm{E}+00$ & $1.22 \mathrm{E}-01$ & $5.19 E+00$ & $3.62 E+00$ \\
\hline 68 & 14.69 & 5.90E-01 & $1.32 \mathrm{E}-01$ & $4.87 \mathrm{E}+00$ & $2.92 \mathrm{E}+00$ \\
\hline 70 & 14.88 & $1.39 \mathrm{E}+00$ & $1.25 \mathrm{E}-01$ & $5.77 \mathrm{E}+00$ & $3.48 \mathrm{E}+00$ \\
\hline 72 & 14.99 & $1.26 \mathrm{E}+00$ & $1.31 \mathrm{E}-01$ & $5.47 \mathrm{E}+00$ & $3.09 E+00$ \\
\hline 74 & 15.10 & $1.59 \mathrm{E}+00$ & $1.23 \mathrm{E}-01$ & $5.87 E+00$ & $4.02 E+00$ \\
\hline 76 & 15.22 & $2.29 E+00$ & 1.19E-01 & $6.33 E+00$ & $4.25 E+00$ \\
\hline 78 & 15.34 & $2.32 E+00$ & $1.24 \mathrm{E}-01$ & $6.04 E+00$ & $3.54 \mathrm{E}+00$ \\
\hline 80 & 15.46 & $2.19 \mathrm{E}+00$ & $1.21 \mathrm{E}-01$ & $6.12 \mathrm{E}+00$ & $3.99 \mathrm{E}+00$ \\
\hline 82 & 15.58 & $2.43 E+00$ & $1.29 \mathrm{E}-01$ & $6.01 E+00$ & $3.44 \mathrm{E}+00$ \\
\hline 84 & 15.71 & $1.70 \mathrm{E}+00$ & $1.26 \mathrm{E}-01$ & $5.49 E+00$ & $3.24 \mathrm{E}+00$ \\
\hline
\end{tabular}




\begin{tabular}{|c|c|c|c|c|c|}
\hline $\begin{array}{c}\text { Depth } \\
{[\mathrm{cm}]}\end{array}$ & $\begin{array}{c}\text { Age } \\
\text { [cal kyr] }\end{array}$ & $\begin{array}{c}\mathrm{Fe} / \mathrm{Ca} \\
{[c p s]}\end{array}$ & $\begin{array}{l}\mathbf{A l} / \mathbf{S i} \\
{[c p s]}\end{array}$ & $\begin{array}{l}\mathbf{F e} / \mathbf{K} \\
{[c p s]}\end{array}$ & $\begin{array}{l}\text { Ti/Al } \\
\text { [cps] }\end{array}$ \\
\hline 86 & 15.83 & $2.63 E+00$ & $1.24 \mathrm{E}-01$ & $6.12 E+00$ & $3.76 \mathrm{E}+00$ \\
\hline 88 & 15.96 & $3.13 E+00$ & $1.31 \mathrm{E}-01$ & $6.47 E+00$ & $3.52 \mathrm{E}+00$ \\
\hline 90 & 16.09 & $2.58 \mathrm{E}+00$ & $1.29 \mathrm{E}-01$ & $5.84 \mathrm{E}+00$ & $3.22 \mathrm{E}+00$ \\
\hline 92 & 16.21 & $2.76 \mathrm{E}+00$ & $1.30 \mathrm{E}-01$ & $6.06 \mathrm{E}+00$ & $3.24 \mathrm{E}+00$ \\
\hline 94 & 16.34 & $2.97 E+00$ & $1.34 \mathrm{E}-01$ & $6.02 \mathrm{E}+00$ & $3.00 \mathrm{E}+00$ \\
\hline 96 & 16.46 & $2.94 \mathrm{E}+00$ & $1.35 \mathrm{E}-01$ & $5.99 \mathrm{E}+00$ & $2.93 \mathrm{E}+00$ \\
\hline 98 & 16.58 & $3.15 E+00$ & $1.36 \mathrm{E}-01$ & $6.19 E+00$ & $3.11 E+00$ \\
\hline 100 & 16.71 & $3.49 E+00$ & 1.34E-01 & $6.42 E+00$ & $3.21 E+00$ \\
\hline 102 & 16.83 & $4.13 E+00$ & $1.36 \mathrm{E}-01$ & $6.36 \mathrm{E}+00$ & $3.28 \mathrm{E}+00$ \\
\hline 104 & 16.95 & $4.23 E+00$ & $1.33 \mathrm{E}-01$ & $6.69 E+00$ & $3.47 E+00$ \\
\hline 106 & 17.06 & $5.62 E+00$ & $1.39 \mathrm{E}-01$ & $6.58 \mathrm{E}+00$ & $3.06 \mathrm{E}+00$ \\
\hline 108 & 17.16 & $3.51 E+00$ & $1.46 \mathrm{E}-01$ & $6.35 \mathrm{E}+00$ & $2.71 E+00$ \\
\hline 110 & 17.27 & $3.92 E+00$ & 1.47E-01 & $6.57 \mathrm{E}+00$ & $2.89 \mathrm{E}+00$ \\
\hline 112 & 17.37 & $2.27 E+00$ & $1.44 \mathrm{E}-01$ & $6.39 E+00$ & $2.88 \mathrm{E}+00$ \\
\hline 114 & 17.47 & $2.51 E+00$ & $1.42 \mathrm{E}-01$ & $6.35 E+00$ & $2.96 \mathrm{E}+00$ \\
\hline 116 & 17.58 & $4.24 \mathrm{E}+00$ & $1.42 \mathrm{E}-01$ & $6.65 \mathrm{E}+00$ & $3.07 E+00$ \\
\hline 118 & 17.70 & $4.09 E+00$ & $1.42 \mathrm{E}-01$ & $6.19 E+00$ & $3.07 E+00$ \\
\hline 120 & 17.82 & $3.85 \mathrm{E}+00$ & $1.42 \mathrm{E}-01$ & $6.34 \mathrm{E}+00$ & $2.94 \mathrm{E}+00$ \\
\hline 122 & 17.95 & $3.67 E+00$ & $1.43 \mathrm{E}-01$ & $6.57 E+00$ & $3.09 E+00$ \\
\hline 124 & 18.09 & $4.36 \mathrm{E}+00$ & 1.37E-01 & $6.61 E+00$ & $3.40 E+00$ \\
\hline 126 & 18.24 & $5.04 \mathrm{E}+00$ & $1.44 \mathrm{E}-01$ & $6.80 E+00$ & $3.50 \mathrm{E}+00$ \\
\hline 128 & 18.38 & $4.64 \mathrm{E}+00$ & 1.47E-01 & $6.98 \mathrm{E}+00$ & $3.44 \mathrm{E}+00$ \\
\hline 130 & 18.52 & $4.74 \mathrm{E}+00$ & $1.46 \mathrm{E}-01$ & $6.80 E+00$ & $3.53 \mathrm{E}+00$ \\
\hline 132 & 18.66 & $3.55 E+00$ & $1.45 \mathrm{E}-01$ & $6.42 E+00$ & $3.35 E+00$ \\
\hline 134 & 18.80 & $2.78 \mathrm{E}+00$ & $1.48 \mathrm{E}-01$ & $6.32 \mathrm{E}+00$ & $3.07 E+00$ \\
\hline 136 & 18.96 & $1.32 \mathrm{E}+00$ & $1.38 \mathrm{E}-01$ & $5.56 \mathrm{E}+00$ & $3.09 \mathrm{E}+00$ \\
\hline 138 & 19.15 & 5.36E-01 & $1.32 \mathrm{E}-01$ & $4.26 \mathrm{E}+00$ & $2.66 \mathrm{E}+00$ \\
\hline 140 & 19.34 & 3.16E-01 & $1.25 \mathrm{E}-01$ & $3.93 E+00$ & $2.55 \mathrm{E}+00$ \\
\hline 142 & 19.58 & 3.59E-01 & $1.26 \mathrm{E}-01$ & $3.98 \mathrm{E}+00$ & $2.75 \mathrm{E}+00$ \\
\hline 144 & 19.86 & $3.78 \mathrm{E}-01$ & $1.26 \mathrm{E}-01$ & $4.08 \mathrm{E}+00$ & $2.67 \mathrm{E}+00$ \\
\hline 146 & 20.15 & 4.44E-01 & $1.30 \mathrm{E}-01$ & $4.26 \mathrm{E}+00$ & $2.54 \mathrm{E}+00$ \\
\hline 148 & 20.43 & 3.03E-01 & $1.29 \mathrm{E}-01$ & $3.68 \mathrm{E}+00$ & $2.42 \mathrm{E}+00$ \\
\hline 150 & 20.71 & 2.93E-01 & $1.26 \mathrm{E}-01$ & $3.65 E+00$ & $2.46 \mathrm{E}+00$ \\
\hline 152 & 21.00 & $3.23 \mathrm{E}-01$ & $1.41 \mathrm{E}-01$ & $3.69 \mathrm{E}+00$ & $2.10 \mathrm{E}+00$ \\
\hline 154 & 21.29 & $2.55 \mathrm{E}-01$ & $1.29 \mathrm{E}-01$ & $3.43 \mathrm{E}+00$ & $2.22 \mathrm{E}+00$ \\
\hline 156 & 21.61 & $3.68 \mathrm{E}-01$ & $1.33 \mathrm{E}-01$ & $3.67 E+00$ & $2.33 \mathrm{E}+00$ \\
\hline 158 & 21.96 & $5.02 \mathrm{E}-01$ & $1.33 \mathrm{E}-01$ & $3.91 E+00$ & $2.42 \mathrm{E}+00$ \\
\hline 160 & 22.32 & 7.29E-01 & $1.40 \mathrm{E}-01$ & $4.32 \mathrm{E}+00$ & $2.40 E+00$ \\
\hline 162 & 22.67 & $2.32 \mathrm{E}+00$ & 1.49E-01 & $5.70 \mathrm{E}+00$ & $2.62 \mathrm{E}+00$ \\
\hline 164 & 23.05 & $1.90 \mathrm{E}+00$ & $1.42 \mathrm{E}-01$ & $5.51 \mathrm{E}+00$ & $2.85 \mathrm{E}+00$ \\
\hline 166 & 23.41 & $2.24 \mathrm{E}+00$ & 1.47E-01 & $5.79 E+00$ & $2.68 \mathrm{E}+00$ \\
\hline 168 & 23.78 & $3.53 \mathrm{E}-01$ & $1.30 \mathrm{E}-01$ & $3.85 \mathrm{E}+00$ & $2.53 \mathrm{E}+00$ \\
\hline 170 & 24.14 & $2.44 \mathrm{E}+00$ & $1.45 \mathrm{E}-01$ & $6.03 E+00$ & $2.84 \mathrm{E}+00$ \\
\hline
\end{tabular}




\begin{tabular}{|c|c|c|c|c|c|}
\hline $\begin{array}{c}\text { Depth } \\
{[\mathrm{cm}]}\end{array}$ & $\begin{array}{c}\text { Age } \\
{[\text { cal kyr] }}\end{array}$ & $\begin{array}{c}\mathrm{Fe} / \mathrm{Ca} \\
{[c p s]}\end{array}$ & $\begin{array}{l}\mathbf{A l} / \mathbf{S i} \\
{[c p s]}\end{array}$ & $\begin{array}{l}\mathrm{Fe} / \mathrm{K} \\
{[c p s]}\end{array}$ & $\begin{array}{l}\text { Ti/Al } \\
\text { [cps] }\end{array}$ \\
\hline 172 & 24.40 & $1.67 E+00$ & $1.40 \mathrm{E}-01$ & $5.71 \mathrm{E}+00$ & $3.08 E+00$ \\
\hline 174 & 24.63 & $1.04 \mathrm{E}+00$ & $1.41 \mathrm{E}-01$ & $5.11 E+00$ & $2.73 E+00$ \\
\hline 176 & 24.83 & $1.19 E+00$ & $1.36 \mathrm{E}-01$ & $4.98 \mathrm{E}+00$ & $2.91 E+00$ \\
\hline 178 & 25.02 & 7.97E-01 & $1.30 \mathrm{E}-01$ & $5.03 E+00$ & $3.37 E+00$ \\
\hline 180 & 25.21 & $1.35 \mathrm{E}+00$ & $1.28 \mathrm{E}-01$ & $5.78 \mathrm{E}+00$ & $3.81 E+00$ \\
\hline 182 & 25.40 & $9.83 \mathrm{E}-01$ & 1.40E-01 & $5.01 E+00$ & $2.98 \mathrm{E}+00$ \\
\hline 183 & 25.48 & 8.47E-01 & 1.39E-01 & $5.09 \mathrm{E}+00$ & $2.99 \mathrm{E}+00$ \\
\hline 185 & 25.66 & 5.93E-01 & $1.34 \mathrm{E}-01$ & $4.54 \mathrm{E}+00$ & $3.07 E+00$ \\
\hline 187 & 25.84 & $3.81 \mathrm{E}-01$ & $1.32 \mathrm{E}-01$ & $4.25 E+00$ & $2.89 \mathrm{E}+00$ \\
\hline 189 & 26.02 & 4.07E-01 & $1.25 \mathrm{E}-01$ & $4.44 E+00$ & $3.35 E+00$ \\
\hline 191 & 26.21 & $5.08 \mathrm{E}-01$ & $1.31 \mathrm{E}-01$ & $4.48 E+00$ & $3.17 E+00$ \\
\hline 193 & 26.41 & $8.26 \mathrm{E}-01$ & $1.38 \mathrm{E}-01$ & $4.96 \mathrm{E}+00$ & $2.99 \mathrm{E}+00$ \\
\hline 195 & 26.61 & 4.93E-01 & $1.34 \mathrm{E}-01$ & $4.38 \mathrm{E}+00$ & $2.79 E+00$ \\
\hline 197 & 26.83 & $6.79 \mathrm{E}-01$ & $1.36 \mathrm{E}-01$ & $5.16 \mathrm{E}+00$ & $3.53 E+00$ \\
\hline 199 & 27.06 & 8.97E-01 & $1.45 \mathrm{E}-01$ & $5.24 \mathrm{E}+00$ & $2.91 \mathrm{E}+00$ \\
\hline 201 & 27.28 & $6.09 \mathrm{E}-01$ & $1.21 \mathrm{E}-01$ & $4.86 \mathrm{E}+00$ & $3.71 E+00$ \\
\hline 203 & 27.51 & 7.91E-01 & $1.41 \mathrm{E}-01$ & $4.91 E+00$ & $3.02 E+00$ \\
\hline 205 & 27.73 & $1.41 \mathrm{E}+00$ & $1.42 \mathrm{E}-01$ & $5.69 E+00$ & $2.95 \mathrm{E}+00$ \\
\hline 207 & 27.95 & $1.39 \mathrm{E}+00$ & 1.42E-01 & $5.64 \mathrm{E}+00$ & $2.93 E+00$ \\
\hline 209 & 28.18 & $1.35 \mathrm{E}+00$ & $1.38 \mathrm{E}-01$ & $5.81 E+00$ & $3.10 E+00$ \\
\hline 211 & 28.40 & $1.68 \mathrm{E}+00$ & $1.44 \mathrm{E}-01$ & $5.84 \mathrm{E}+00$ & $2.83 E+00$ \\
\hline 213 & 28.62 & $2.21 E+00$ & $1.45 \mathrm{E}-01$ & $5.87 E+00$ & $2.70 E+00$ \\
\hline 215 & 28.85 & $2.68 \mathrm{E}+00$ & 1.34E-01 & $6.52 E+00$ & $3.21 E+00$ \\
\hline 217 & 29.05 & $3.92 E+00$ & $1.45 \mathrm{E}-01$ & $6.24 E+00$ & $2.84 \mathrm{E}+00$ \\
\hline 219 & 29.26 & $4.13 E+00$ & $1.38 \mathrm{E}-01$ & $6.34 E+00$ & $3.14 \mathrm{E}+00$ \\
\hline 221 & 29.50 & $3.00 E+00$ & $1.46 \mathrm{E}-01$ & $5.97 E+00$ & $2.72 \mathrm{E}+00$ \\
\hline 223 & 29.78 & $4.11 \mathrm{E}+00$ & $1.45 \mathrm{E}-01$ & $6.23 E+00$ & $2.88 \mathrm{E}+00$ \\
\hline 225 & 30.06 & $2.74 \mathrm{E}+00$ & $1.42 \mathrm{E}-01$ & $6.10 \mathrm{E}+00$ & $3.02 E+00$ \\
\hline 227 & 30.36 & $3.66 \mathrm{E}+00$ & $1.41 \mathrm{E}-01$ & $6.20 E+00$ & $3.06 \mathrm{E}+00$ \\
\hline 229 & 30.66 & $2.08 \mathrm{E}+00$ & $1.45 \mathrm{E}-01$ & $5.88 \mathrm{E}+00$ & $2.92 \mathrm{E}+00$ \\
\hline 231 & 30.96 & $2.91 E+00$ & $1.45 \mathrm{E}-01$ & $6.16 E+00$ & $3.13 E+00$ \\
\hline 233 & 31.25 & $1.36 \mathrm{E}+00$ & 1.40E-01 & $5.73 E+00$ & $3.24 \mathrm{E}+00$ \\
\hline 235 & 31.55 & $1.30 \mathrm{E}+00$ & $1.38 \mathrm{E}-01$ & $5.66 \mathrm{E}+00$ & $3.71 E+00$ \\
\hline 237 & 31.82 & 4.70E-01 & $1.31 \mathrm{E}-01$ & $4.59 \mathrm{E}+00$ & $3.41 E+00$ \\
\hline 239 & 32.09 & 4.30E-01 & 1.23E-01 & $4.63 E+00$ & $3.65 E+00$ \\
\hline 241 & 32.34 & 4.45E-01 & $1.31 \mathrm{E}-01$ & $4.51 E+00$ & $3.08 \mathrm{E}+00$ \\
\hline 243 & 32.51 & $3.92 \mathrm{E}-01$ & $1.26 \mathrm{E}-01$ & $4.44 \mathrm{E}+00$ & $3.40 \mathrm{E}+00$ \\
\hline 245 & 32.67 & $3.44 \mathrm{E}-01$ & 1.24E-01 & $4.16 \mathrm{E}+00$ & $3.31 E+00$ \\
\hline 247 & 32.82 & 3.34E-01 & $1.25 \mathrm{E}-01$ & $4.39 E+00$ & $3.44 \mathrm{E}+00$ \\
\hline 249 & 32.97 & $3.44 \mathrm{E}-01$ & $1.27 \mathrm{E}-01$ & $4.34 \mathrm{E}+00$ & $3.21 E+00$ \\
\hline 251 & 33.12 & 2.91E-01 & $1.22 \mathrm{E}-01$ & $3.88 \mathrm{E}+00$ & $2.77 E+00$ \\
\hline 253 & 33.26 & $3.53 \mathrm{E}-01$ & $1.31 \mathrm{E}-01$ & $4.08 E+00$ & $2.77 E+00$ \\
\hline 255 & 33.41 & $3.70 \mathrm{E}-01$ & $1.24 \mathrm{E}-01$ & $4.40 E+00$ & $3.37 E+00$ \\
\hline
\end{tabular}




\begin{tabular}{|c|c|c|c|c|c|}
\hline $\begin{array}{c}\text { Depth } \\
{[\mathrm{cm}]}\end{array}$ & $\begin{array}{c}\text { Age } \\
{[\text { cal kyr] }}\end{array}$ & $\begin{array}{c}\mathrm{Fe} / \mathrm{Ca} \\
{[c p s]}\end{array}$ & $\begin{array}{l}\mathbf{A l} / \mathbf{S i} \\
{[c p s]}\end{array}$ & $\begin{array}{l}\mathrm{Fe} / \mathrm{K} \\
{[c p s]}\end{array}$ & $\begin{array}{l}\text { Ti/Al } \\
\text { [cps] }\end{array}$ \\
\hline 257 & 33.56 & $4.24 \mathrm{E}-01$ & $1.33 \mathrm{E}-01$ & $4.14 \mathrm{E}+00$ & $2.79 \mathrm{E}+00$ \\
\hline 259 & 33.71 & 4.57E-01 & $1.40 \mathrm{E}-01$ & $4.20 E+00$ & $2.54 \mathrm{E}+00$ \\
\hline 261 & 33.86 & 5.43E-01 & $1.36 \mathrm{E}-01$ & $4.35 E+00$ & $2.65 E+00$ \\
\hline 263 & 34.01 & 4.79E-01 & $1.36 \mathrm{E}-01$ & $4.49 E+00$ & $2.77 E+00$ \\
\hline 265 & 34.15 & 4.44E-01 & $1.35 \mathrm{E}-01$ & $4.46 E+00$ & $3.05 E+00$ \\
\hline 267 & 34.30 & $4.85 \mathrm{E}-01$ & $1.36 \mathrm{E}-01$ & $4.43 E+00$ & $2.69 \mathrm{E}+00$ \\
\hline 269 & 34.45 & 5.35E-01 & $1.38 \mathrm{E}-01$ & $4.52 \mathrm{E}+00$ & $2.81 \mathrm{E}+00$ \\
\hline 271 & 34.59 & 5.15E-01 & 1.37E-01 & $4.49 \mathrm{E}+00$ & $2.80 \mathrm{E}+00$ \\
\hline 273 & 34.74 & $3.85 \mathrm{E}-01$ & $1.34 \mathrm{E}-01$ & $4.20 \mathrm{E}+00$ & $2.75 \mathrm{E}+00$ \\
\hline 275 & 34.89 & 4.30E-01 & $1.41 \mathrm{E}-01$ & $4.36 \mathrm{E}+00$ & $2.71 E+00$ \\
\hline 277 & 35.10 & $2.58 \mathrm{E}-01$ & 1.19E-01 & $4.16 \mathrm{E}+00$ & $3.18 \mathrm{E}+00$ \\
\hline 279 & 35.30 & $2.62 \mathrm{E}-01$ & $1.28 \mathrm{E}-01$ & $4.05 E+00$ & $2.80 E+00$ \\
\hline 281 & 35.54 & 3.15E-01 & $1.31 \mathrm{E}-01$ & $4.21 E+00$ & $2.71 E+00$ \\
\hline 285 & 36.12 & $2.84 \mathrm{E}-01$ & $1.22 \mathrm{E}-01$ & $4.09 E+00$ & $3.13 E+00$ \\
\hline 287 & 36.29 & $2.83 \mathrm{E}-01$ & $1.12 \mathrm{E}-01$ & $4.22 \mathrm{E}+00$ & $3.42 \mathrm{E}+00$ \\
\hline 289 & 36.47 & 2.97E-01 & $1.30 \mathrm{E}-01$ & $4.32 \mathrm{E}+00$ & $2.85 E+00$ \\
\hline 291 & 36.62 & 3.47E-01 & 1.37E-01 & $4.31 E+00$ & $2.49 \mathrm{E}+00$ \\
\hline 293 & 36.74 & 4.68E-01 & 1.47E-01 & $4.47 \mathrm{E}+00$ & $2.41 \mathrm{E}+00$ \\
\hline 295 & 36.86 & 5.16E-01 & $1.41 \mathrm{E}-01$ & $4.62 \mathrm{E}+00$ & $2.61 E+00$ \\
\hline 297 & 36.93 & $6.84 \mathrm{E}-01$ & $1.44 \mathrm{E}-01$ & $4.71 \mathrm{E}+00$ & $2.58 \mathrm{E}+00$ \\
\hline 299 & 37.00 & $9.41 \mathrm{E}-01$ & $1.42 \mathrm{E}-01$ & $4.98 \mathrm{E}+00$ & $2.80 E+00$ \\
\hline 301 & 37.07 & $5.62 \mathrm{E}-01$ & $1.38 \mathrm{E}-01$ & $4.89 E+00$ & $2.68 \mathrm{E}+00$ \\
\hline 303 & 37.14 & 3.35E-01 & $1.34 \mathrm{E}-01$ & $4.08 \mathrm{E}+00$ & $2.50 \mathrm{E}+00$ \\
\hline 305 & 37.21 & $2.35 \mathrm{E}-01$ & $1.27 \mathrm{E}-01$ & $3.73 E+00$ & $2.46 \mathrm{E}+00$ \\
\hline 307 & 37.28 & 3.91E-01 & $1.40 \mathrm{E}-01$ & $4.09 \mathrm{E}+00$ & $2.15 \mathrm{E}+00$ \\
\hline 309 & 37.35 & 4.90E-01 & $1.43 \mathrm{E}-01$ & $4.41 \mathrm{E}+00$ & $2.32 \mathrm{E}+00$ \\
\hline 311 & 37.42 & 5.76E-01 & $1.43 \mathrm{E}-01$ & $4.43 E+00$ & $2.34 \mathrm{E}+00$ \\
\hline 313 & 37.48 & $3.15 \mathrm{E}-01$ & $1.29 \mathrm{E}-01$ & $3.98 \mathrm{E}+00$ & $2.38 \mathrm{E}+00$ \\
\hline 315 & 37.55 & 2.71E-01 & $1.41 \mathrm{E}-01$ & $4.31 E+00$ & $2.16 \mathrm{E}+00$ \\
\hline 317 & 37.62 & 2.37E-01 & $1.37 \mathrm{E}-01$ & $3.83 E+00$ & $2.01 E+00$ \\
\hline 319 & 37.69 & $2.63 \mathrm{E}-01$ & $1.30 \mathrm{E}-01$ & $3.93 E+00$ & $2.46 \mathrm{E}+00$ \\
\hline 321 & 37.76 & $2.36 \mathrm{E}-01$ & $1.29 \mathrm{E}-01$ & $3.85 \mathrm{E}+00$ & $2.53 \mathrm{E}+00$ \\
\hline 323 & 37.83 & $6.68 \mathrm{E}-01$ & $1.43 \mathrm{E}-01$ & $4.75 E+00$ & $2.34 \mathrm{E}+00$ \\
\hline 325 & 37.89 & $1.99 \mathrm{E}+00$ & $1.48 \mathrm{E}-01$ & $5.59 \mathrm{E}+00$ & $2.53 \mathrm{E}+00$ \\
\hline 327 & 37.96 & $2.32 \mathrm{E}+00$ & 1.47E-01 & $5.80 \mathrm{E}+00$ & $2.59 \mathrm{E}+00$ \\
\hline 329 & 38.03 & $2.24 \mathrm{E}+00$ & $1.47 \mathrm{E}-01$ & $5.77 \mathrm{E}+00$ & $2.47 E+00$ \\
\hline 331 & 38.11 & $2.41 E+00$ & $1.44 \mathrm{E}-01$ & $5.74 \mathrm{E}+00$ & $2.65 \mathrm{E}+00$ \\
\hline 333 & 38.22 & $2.62 \mathrm{E}+00$ & $1.44 \mathrm{E}-01$ & $5.74 \mathrm{E}+00$ & $2.56 \mathrm{E}+00$ \\
\hline 335 & 38.32 & $2.38 \mathrm{E}+00$ & $1.43 \mathrm{E}-01$ & $5.64 \mathrm{E}+00$ & $2.64 \mathrm{E}+00$ \\
\hline 337 & 38.49 & $2.22 \mathrm{E}+00$ & $1.46 \mathrm{E}-01$ & $5.63 E+00$ & $2.58 \mathrm{E}+00$ \\
\hline 339 & 38.67 & $1.52 \mathrm{E}+00$ & $1.42 \mathrm{E}-01$ & $5.28 \mathrm{E}+00$ & $2.70 \mathrm{E}+00$ \\
\hline 341 & 38.88 & $1.78 \mathrm{E}+00$ & $1.41 \mathrm{E}-01$ & $5.59 E+00$ & $2.67 E+00$ \\
\hline 343 & 39.14 & $2.69 E+00$ & $1.38 \mathrm{E}-01$ & $5.70 E+00$ & $2.86 \mathrm{E}+00$ \\
\hline
\end{tabular}




\begin{tabular}{|c|c|c|c|c|c|}
\hline $\begin{array}{c}\text { Depth } \\
{[\mathrm{cm}]}\end{array}$ & $\begin{array}{c}\text { Age } \\
{[\text { cal kyr] }}\end{array}$ & $\begin{array}{c}\mathrm{Fe} / \mathrm{Ca} \\
{[c p s]}\end{array}$ & $\begin{array}{l}\mathbf{A l} / \mathbf{S i} \\
{[c p s]}\end{array}$ & $\begin{array}{l}\mathrm{Fe} / \mathrm{K} \\
{[c p s]}\end{array}$ & $\begin{array}{l}\text { Ti/Al } \\
\text { [cps] }\end{array}$ \\
\hline 345 & 39.40 & $2.39 E+00$ & 1.39E-01 & $5.61 E+00$ & $2.67 E+00$ \\
\hline 347 & 39.58 & $2.16 \mathrm{E}+00$ & $1.40 \mathrm{E}-01$ & $5.62 E+00$ & $2.70 \mathrm{E}+00$ \\
\hline 349 & 39.76 & $2.01 E+00$ & $1.38 \mathrm{E}-01$ & $5.45 E+00$ & $2.69 \mathrm{E}+00$ \\
\hline 351 & 39.94 & 4.92E-01 & $1.41 \mathrm{E}-01$ & $4.55 E+00$ & $2.34 \mathrm{E}+00$ \\
\hline 353 & 40.11 & $1.51 E+00$ & $1.43 \mathrm{E}-01$ & $5.43 E+00$ & $2.55 \mathrm{E}+00$ \\
\hline 355 & 40.28 & $1.39 \mathrm{E}+00$ & $1.42 \mathrm{E}-01$ & $5.35 \mathrm{E}+00$ & $2.59 E+00$ \\
\hline 357 & 40.45 & $6.52 \mathrm{E}-01$ & 1.37E-01 & $4.59 \mathrm{E}+00$ & $2.62 \mathrm{E}+00$ \\
\hline 359 & 40.62 & 5.17E-01 & 1.44E-01 & $4.27 E+00$ & $2.43 E+00$ \\
\hline 361 & 40.79 & 4.03E-01 & 1.33E-01 & $3.90 E+00$ & $2.50 E+00$ \\
\hline 363 & 40.96 & 2.91E-01 & $1.28 \mathrm{E}-01$ & $3.81 E+00$ & $2.50 E+00$ \\
\hline 365 & 41.13 & 2.19E-01 & $1.28 \mathrm{E}-01$ & $3.73 E+00$ & $2.33 \mathrm{E}+00$ \\
\hline 367 & 41.35 & 2.19E-01 & $1.22 \mathrm{E}-01$ & $3.73 E+00$ & $2.58 \mathrm{E}+00$ \\
\hline 369 & 41.57 & $2.02 \mathrm{E}-01$ & 1.33E-01 & $3.74 E+00$ & $2.42 \mathrm{E}+00$ \\
\hline 371 & 41.80 & $2.03 \mathrm{E}-01$ & $1.32 \mathrm{E}-01$ & $3.76 \mathrm{E}+00$ & $2.51 \mathrm{E}+00$ \\
\hline 373 & 42.07 & 3.14E-01 & $1.38 \mathrm{E}-01$ & $4.14 \mathrm{E}+00$ & $2.41 \mathrm{E}+00$ \\
\hline 375 & 42.34 & 7.43E-01 & $1.51 \mathrm{E}-01$ & $4.86 \mathrm{E}+00$ & $2.39 E+00$ \\
\hline 377 & 42.61 & 8.15E-01 & 1.46E-01 & $5.09 \mathrm{E}+00$ & $2.68 \mathrm{E}+00$ \\
\hline 379 & 42.88 & 9.33E-01 & $1.45 \mathrm{E}-01$ & $5.23 E+00$ & $2.89 E+00$ \\
\hline 381 & 43.25 & $8.60 \mathrm{E}-01$ & 1.49E-01 & $4.85 E+00$ & $2.50 E+00$ \\
\hline 383 & 43.73 & $8.42 \mathrm{E}-01$ & $1.51 \mathrm{E}-01$ & $4.92 E+00$ & $2.45 \mathrm{E}+00$ \\
\hline 385 & 44.20 & 3.31E-01 & 1.37E-01 & $4.01 E+00$ & $2.32 E+00$ \\
\hline 387 & 44.61 & 3.30E-01 & $1.32 \mathrm{E}-01$ & $3.98 \mathrm{E}+00$ & $2.39 E+00$ \\
\hline 389 & 45.01 & 4.25E-01 & $1.40 \mathrm{E}-01$ & $4.33 \mathrm{E}+00$ & $2.40 E+00$ \\
\hline 391 & 45.32 & 4.93E-01 & $1.42 \mathrm{E}-01$ & $4.42 \mathrm{E}+00$ & $2.31 \mathrm{E}+00$ \\
\hline 393 & 45.55 & 4.90E-01 & $1.35 \mathrm{E}-01$ & $4.08 \mathrm{E}+00$ & $2.37 \mathrm{E}+00$ \\
\hline 395 & 45.78 & 5.59E-01 & 1.30E-01 & $4.19 \mathrm{E}+00$ & $2.44 \mathrm{E}+00$ \\
\hline 397 & 46.01 & $1.10 \mathrm{E}+00$ & $1.42 \mathrm{E}-01$ & $5.04 \mathrm{E}+00$ & $2.49 E+00$ \\
\hline 399 & 46.24 & $1.47 \mathrm{E}+00$ & $1.43 \mathrm{E}-01$ & $5.40 \mathrm{E}+00$ & $2.60 E+00$ \\
\hline 401 & 46.47 & $1.70 \mathrm{E}+00$ & $1.39 \mathrm{E}-01$ & $5.53 E+00$ & $2.61 E+00$ \\
\hline 403 & 46.70 & $1.96 \mathrm{E}+00$ & $1.48 \mathrm{E}-01$ & $5.67 \mathrm{E}+00$ & $2.37 \mathrm{E}+00$ \\
\hline 405 & 46.92 & $1.50 E+00$ & $1.45 \mathrm{E}-01$ & $5.37 \mathrm{E}+00$ & $2.45 E+00$ \\
\hline 407 & 47.15 & $2.26 \mathrm{E}+00$ & $1.44 \mathrm{E}-01$ & $5.77 E+00$ & $2.61 E+00$ \\
\hline 409 & 47.39 & $2.79 E+00$ & 1.37E-01 & $5.83 \mathrm{E}+00$ & $2.88 \mathrm{E}+00$ \\
\hline 411 & 47.60 & $2.53 E+00$ & $1.38 \mathrm{E}-01$ & $5.83 \mathrm{E}+00$ & $2.97 \mathrm{E}+00$ \\
\hline 413 & 47.80 & $2.87 \mathrm{E}+00$ & $1.41 \mathrm{E}-01$ & $5.71 \mathrm{E}+00$ & $2.84 \mathrm{E}+00$ \\
\hline 415 & 48.00 & $2.96 \mathrm{E}+00$ & 1.47E-01 & $6.05 \mathrm{E}+00$ & $2.76 \mathrm{E}+00$ \\
\hline 417 & 48.09 & $1.74 \mathrm{E}+00$ & $1.35 \mathrm{E}-01$ & $5.53 \mathrm{E}+00$ & $2.99 \mathrm{E}+00$ \\
\hline 419 & 48.18 & $1.20 \mathrm{E}+00$ & 1.37E-01 & $5.52 \mathrm{E}+00$ & $2.76 \mathrm{E}+00$ \\
\hline 420 & 48.23 & 7.13E-01 & $1.43 \mathrm{E}-01$ & $4.53 \mathrm{E}+00$ & $2.39 E+00$ \\
\hline 423 & 48.43 & $5.00 \mathrm{E}-01$ & $1.32 \mathrm{E}-01$ & $4.29 E+00$ & $2.57 \mathrm{E}+00$ \\
\hline 425 & 48.57 & 4.94E-01 & $1.35 \mathrm{E}-01$ & $4.24 \mathrm{E}+00$ & $2.45 E+00$ \\
\hline 427 & 48.86 & $5.48 \mathrm{E}-01$ & $1.29 \mathrm{E}-01$ & $4.42 \mathrm{E}+00$ & $2.67 \mathrm{E}+00$ \\
\hline 429 & 49.15 & 5.86E-01 & $1.36 \mathrm{E}-01$ & $4.27 E+00$ & $2.56 \mathrm{E}+00$ \\
\hline
\end{tabular}




\begin{tabular}{|c|c|c|c|c|c|}
\hline $\begin{array}{c}\text { Depth } \\
{[\mathrm{cm}]}\end{array}$ & $\begin{array}{c}\text { Age } \\
{[\text { cal kyr] }}\end{array}$ & $\begin{array}{c}\mathrm{Fe} / \mathrm{Ca} \\
{[c p s]}\end{array}$ & $\begin{array}{l}\mathbf{A l} / \mathbf{S i} \\
{[c p s]}\end{array}$ & $\begin{array}{l}\mathrm{Fe} / \mathrm{K} \\
{[c p s]}\end{array}$ & $\begin{array}{l}\text { Ti/Al } \\
\text { [cps] }\end{array}$ \\
\hline 431 & 49.44 & $6.87 \mathrm{E}-01$ & $1.36 \mathrm{E}-01$ & $4.97 \mathrm{E}+00$ & $2.57 E+00$ \\
\hline 433 & 49.73 & $5.00 \mathrm{E}-01$ & 1.39E-01 & $4.38 \mathrm{E}+00$ & $2.41 E+00$ \\
\hline 435 & 50.02 & 4.33E-01 & $1.38 \mathrm{E}-01$ & $4.16 E+00$ & $2.47 E+00$ \\
\hline 437 & 50.31 & 5.04E-01 & 1.30E-01 & $4.39 E+00$ & $2.95 E+00$ \\
\hline 439 & 50.60 & 4.12E-01 & $1.26 \mathrm{E}-01$ & $4.19 E+00$ & $3.02 E+00$ \\
\hline 441 & 50.89 & $3.32 \mathrm{E}-01$ & $1.27 \mathrm{E}-01$ & $4.10 E+00$ & $2.85 \mathrm{E}+00$ \\
\hline 443 & 51.18 & $3.88 \mathrm{E}-01$ & $1.35 \mathrm{E}-01$ & $4.32 \mathrm{E}+00$ & $2.74 \mathrm{E}+00$ \\
\hline 445 & 51.47 & $3.54 \mathrm{E}-01$ & $1.20 \mathrm{E}-01$ & $3.96 \mathrm{E}+00$ & $3.05 E+00$ \\
\hline 447 & 51.77 & $3.24 \mathrm{E}-01$ & 1.24E-01 & $3.85 E+00$ & $2.73 E+00$ \\
\hline 449 & 52.06 & 2.97E-01 & 1.27E-01 & $3.83 E+00$ & $2.43 E+00$ \\
\hline 451 & 52.35 & 2.74E-01 & 1.33E-01 & $3.76 E+00$ & $2.25 \mathrm{E}+00$ \\
\hline 453 & 52.65 & $2.62 \mathrm{E}-01$ & $1.27 \mathrm{E}-01$ & $3.71 E+00$ & $2.17 E+00$ \\
\hline 455 & 52.94 & 3.17E-01 & 1.33E-01 & $3.82 E+00$ & $2.19 E+00$ \\
\hline 457 & 53.23 & $3.23 \mathrm{E}-01$ & 1.34E-01 & $3.63 E+00$ & $2.06 \mathrm{E}+00$ \\
\hline 459 & 53.52 & $2.98 \mathrm{E}-01$ & 1.30E-01 & $3.63 E+00$ & $2.24 \mathrm{E}+00$ \\
\hline 461 & 53.81 & $3.94 \mathrm{E}-01$ & 1.37E-01 & $4.17 E+00$ & $2.15 E+00$ \\
\hline 463 & 54.10 & $1.20 E+00$ & $1.42 \mathrm{E}-01$ & $5.36 \mathrm{E}+00$ & $2.53 E+00$ \\
\hline 465 & 54.39 & $1.68 \mathrm{E}+00$ & $1.45 \mathrm{E}-01$ & $5.57 \mathrm{E}+00$ & $2.75 \mathrm{E}+00$ \\
\hline 467 & 54.68 & $2.23 E+00$ & 1.50E-01 & $5.67 E+00$ & $2.50 E+00$ \\
\hline 469 & 54.97 & $1.92 \mathrm{E}+00$ & 1.50E-01 & $5.88 \mathrm{E}+00$ & $2.52 \mathrm{E}+00$ \\
\hline 471 & 55.26 & $1.33 \mathrm{E}+00$ & 1.43E-01 & $5.50 \mathrm{E}+00$ & $2.83 E+00$ \\
\hline 473 & 55.55 & 8.91E-01 & $1.45 \mathrm{E}-01$ & $5.11 E+00$ & $2.64 \mathrm{E}+00$ \\
\hline 475 & 55.84 & $8.62 \mathrm{E}-01$ & 1.46E-01 & $5.13 E+00$ & $2.56 \mathrm{E}+00$ \\
\hline 477 & 56.13 & $6.78 \mathrm{E}-01$ & 1.43E-01 & $4.79 E+00$ & $2.70 E+00$ \\
\hline 479 & 56.42 & $8.58 \mathrm{E}-01$ & 1.40E-01 & $4.85 E+00$ & $2.67 E+00$ \\
\hline 481 & 56.71 & 7.04E-01 & 1.37E-01 & $5.10 E+00$ & $2.71 E+00$ \\
\hline 483 & 57.00 & $6.82 \mathrm{E}-01$ & 1.24E-01 & $5.18 \mathrm{E}+00$ & $3.87 E+00$ \\
\hline 485 & 57.29 & $3.53 \mathrm{E}-01$ & 1.27E-01 & $4.10 \mathrm{E}+00$ & $2.84 \mathrm{E}+00$ \\
\hline 487 & 57.58 & $3.96 \mathrm{E}-01$ & $1.31 \mathrm{E}-01$ & $4.26 \mathrm{E}+00$ & $2.87 E+00$ \\
\hline 489 & 57.87 & 3.99E-01 & $1.32 \mathrm{E}-01$ & $4.16 \mathrm{E}+00$ & $2.51 E+00$ \\
\hline 491 & 58.16 & $5.50 \mathrm{E}-01$ & $1.38 \mathrm{E}-01$ & $4.41 E+00$ & $2.47 E+00$ \\
\hline 493 & 58.46 & $9.48 \mathrm{E}-01$ & 1.45E-01 & $5.00 \mathrm{E}+00$ & $2.50 \mathrm{E}+00$ \\
\hline 495 & 58.75 & $1.04 \mathrm{E}+00$ & 1.47E-01 & $5.18 \mathrm{E}+00$ & $2.44 \mathrm{E}+00$ \\
\hline 496 & 58.90 & $1.64 \mathrm{E}+00$ & 1.42E-01 & $5.44 \mathrm{E}+00$ & $2.60 E+00$ \\
\hline 501 & 59.62 & $2.63 \mathrm{E}+00$ & $1.42 \mathrm{E}-01$ & $5.79 E+00$ & $2.66 \mathrm{E}+00$ \\
\hline 504 & 60.06 & $2.98 \mathrm{E}+00$ & $1.45 \mathrm{E}-01$ & $6.05 E+00$ & $2.66 \mathrm{E}+00$ \\
\hline 505 & 60.20 & $2.97 \mathrm{E}+00$ & 1.40E-01 & $6.14 \mathrm{E}+00$ & $2.70 \mathrm{E}+00$ \\
\hline 507 & 60.49 & $3.16 \mathrm{E}+00$ & 1.43E-01 & $6.27 E+00$ & $2.70 E+00$ \\
\hline 509 & 60.78 & $2.94 \mathrm{E}+00$ & $1.48 \mathrm{E}-01$ & $5.98 \mathrm{E}+00$ & $2.61 \mathrm{E}+00$ \\
\hline 511 & 61.07 & $3.30 E+00$ & $1.45 \mathrm{E}-01$ & $5.96 \mathrm{E}+00$ & $2.57 E+00$ \\
\hline 513 & 61.36 & $3.98 \mathrm{E}+00$ & $1.46 \mathrm{E}-01$ & $6.20 \mathrm{E}+00$ & $2.65 \mathrm{E}+00$ \\
\hline 515 & 61.65 & $3.66 \mathrm{E}+00$ & $1.46 \mathrm{E}-01$ & $6.41 E+00$ & $2.79 E+00$ \\
\hline 517 & 61.94 & $3.68 \mathrm{E}+00$ & $1.43 \mathrm{E}-01$ & $6.42 E+00$ & $2.79 \mathrm{E}+00$ \\
\hline
\end{tabular}




\begin{tabular}{cccccc}
\hline Depth & Age & Fe/Ca & Al/Si & Fe/K & Ti/Al \\
[cm] & {$[$ cal $k y r]$} & {$[c p s]$} & {$[c p s]$} & {$[c p s]$} & {$[c p s]$} \\
\hline 519 & 62.23 & $3.51 \mathrm{E}+00$ & $1.44 \mathrm{E}-01$ & $6.33 \mathrm{E}+00$ & $2.75 \mathrm{E}+00$ \\
521 & 62.52 & $1.77 \mathrm{E}+00$ & $1.53 \mathrm{E}-01$ & $5.89 \mathrm{E}+00$ & $2.46 \mathrm{E}+00$ \\
523 & 62.81 & $3.39 \mathrm{E}+00$ & $1.49 \mathrm{E}-01$ & $6.49 \mathrm{E}+00$ & $2.59 \mathrm{E}+00$ \\
525 & 63.10 & $3.72 \mathrm{E}+00$ & $1.49 \mathrm{E}-01$ & $6.37 \mathrm{E}+00$ & $2.68 \mathrm{E}+00$ \\
527 & 63.39 & $1.50 \mathrm{E}+00$ & $1.48 \mathrm{E}-01$ & $5.86 \mathrm{E}+00$ & $2.49 \mathrm{E}+00$ \\
529 & 63.69 & $3.52 \mathrm{E}+00$ & $1.47 \mathrm{E}-01$ & $6.49 \mathrm{E}+00$ & $2.68 \mathrm{E}+00$ \\
531 & 63.98 & $3.36 \mathrm{E}+00$ & $1.49 \mathrm{E}-01$ & $6.51 \mathrm{E}+00$ & $2.80 \mathrm{E}+00$ \\
533 & 64.27 & $2.00 \mathrm{E}+00$ & $1.45 \mathrm{E}-01$ & $6.31 \mathrm{E}+00$ & $2.92 \mathrm{E}+00$ \\
535 & 64.56 & $4.26 \mathrm{E}+00$ & $1.49 \mathrm{E}-01$ & $6.43 \mathrm{E}+00$ & $2.90 \mathrm{E}+00$ \\
537 & 64.91 & $3.73 \mathrm{E}+00$ & $1.51 \mathrm{E}-01$ & $6.70 \mathrm{E}+00$ & $2.83 \mathrm{E}+00$ \\
539 & 65.25 & $9.46 \mathrm{E}-01$ & $1.43 \mathrm{E}-01$ & $5.32 \mathrm{E}+00$ & $2.67 \mathrm{E}+00$ \\
541 & 65.60 & $3.58 \mathrm{E}+00$ & $1.54 \mathrm{E}-01$ & $6.34 \mathrm{E}+00$ & $2.72 \mathrm{E}+00$ \\
543 & 66.00 & $3.10 \mathrm{E}+00$ & $1.58 \mathrm{E}-01$ & $5.89 \mathrm{E}+00$ & $2.52 \mathrm{E}+00$ \\
545 & 66.40 & $2.38 \mathrm{E}+00$ & $1.49 \mathrm{E}-01$ & $5.70 \mathrm{E}+00$ & $2.56 \mathrm{E}+00$ \\
547 & 66.80 & $1.81 \mathrm{E}+00$ & $1.48 \mathrm{E}-01$ & $5.26 \mathrm{E}+00$ & $2.51 \mathrm{E}+00$ \\
549 & 67.20 & $7.70 \mathrm{E}-01$ & $1.47 \mathrm{E}-01$ & $4.52 \mathrm{E}+00$ & $2.32 \mathrm{E}+00$ \\
551 & 67.61 & $6.28 \mathrm{E}-01$ & $1.43 \mathrm{E}-01$ & $4.43 \mathrm{E}+00$ & $2.26 \mathrm{E}+00$ \\
553 & 68.01 & $2.98 \mathrm{E}-01$ & $1.35 \mathrm{E}-01$ & $3.75 \mathrm{E}+00$ & $2.19 \mathrm{E}+00$ \\
555 & 68.41 & $3.57 \mathrm{E}-01$ & $1.15 \mathrm{E}-01$ & $3.58 \mathrm{E}+00$ & $2.37 \mathrm{E}+00$ \\
557 & 68.81 & $1.49 \mathrm{E}+00$ & $1.35 \mathrm{E}-01$ & $5.64 \mathrm{E}+00$ & $2.75 \mathrm{E}+00$ \\
559 & 69.21 & $2.45 \mathrm{E}+00$ & $1.41 \mathrm{E}-01$ & $6.21 \mathrm{E}+00$ & $2.83 \mathrm{E}+00$ \\
561 & 69.61 & $3.53 \mathrm{E}+00$ & $1.42 \mathrm{E}-01$ & $6.21 \mathrm{E}+00$ & $2.77 \mathrm{E}+00$ \\
563 & 70.01 & $3.36 \mathrm{E}+00$ & $1.53 \mathrm{E}-01$ & $6.14 \mathrm{E}+00$ & $2.54 \mathrm{E}+00$ \\
565 & 70.41 & $4.44 \mathrm{E}+00$ & $1.51 \mathrm{E}-01$ & $6.39 \mathrm{E}+00$ & $2.66 \mathrm{E}+00$ \\
567 & 70.76 & $2.26 \mathrm{E}-01$ & $1.19 \mathrm{E}-01$ & $3.76 \mathrm{E}+00$ & $2.27 \mathrm{E}+00$ \\
569 & 71.10 & $3.09 \mathrm{E}-01$ & $1.22 \mathrm{E}-01$ & $3.99 \mathrm{E}+00$ & $2.50 \mathrm{E}+00$ \\
571 & 71.43 & $2.76 \mathrm{E}-01$ & $1.32 \mathrm{E}-01$ & $4.05 \mathrm{E}+00$ & $2.36 \mathrm{E}+00$ \\
573 & 71.71 & $1.34 \mathrm{E}-01$ & $1.25 \mathrm{E}-01$ & $3.35 \mathrm{E}+00$ & $2.22 \mathrm{E}+00$ \\
591 & 75.35 & $1.77 \mathrm{E}+00$ & $1.37 \mathrm{E}-01$ & $5.84 \mathrm{E}+00$ & $2.85 \mathrm{E}+00$ \\
603 & 75.85 & $7.95 \mathrm{E}-01$ & $1.43 \mathrm{E}-01$ & $5.21 \mathrm{E}+00$ & $2.67 \mathrm{E}+00$
\end{tabular}




\begin{tabular}{cccccc}
\hline $\begin{array}{c}\text { Depth } \\
\text { [cm] }\end{array}$ & $\begin{array}{c}\text { Age } \\
{[\text { cal } k y r]}\end{array}$ & $\begin{array}{c}\text { Fe/Ca } \\
{[c p s]}\end{array}$ & $\begin{array}{c}\text { Al/Si } \\
{[c p s]}\end{array}$ & $\begin{array}{c}\text { Fe/K } \\
{[c p s]}\end{array}$ & $\begin{array}{c}\text { Ti/Al } \\
{[c p s]}\end{array}$ \\
\hline 605 & 76.13 & $1.52 \mathrm{E}-01$ & $1.21 \mathrm{E}-01$ & $3.38 \mathrm{E}+00$ & $2.50 \mathrm{E}+00$ \\
607 & 76.40 & $1.65 \mathrm{E}-01$ & $1.25 \mathrm{E}-01$ & $3.67 \mathrm{E}+00$ & $2.50 \mathrm{E}+00$ \\
609 & 76.68 & $2.12 \mathrm{E}-01$ & $1.28 \mathrm{E}-01$ & $4.11 \mathrm{E}+00$ & $2.32 \mathrm{E}+00$ \\
611 & 76.96 & $1.92 \mathrm{E}-01$ & $1.26 \mathrm{E}-01$ & $4.13 \mathrm{E}+00$ & $2.33 \mathrm{E}+00$ \\
613 & 77.24 & $1.80 \mathrm{E}-01$ & $1.25 \mathrm{E}-01$ & $3.90 \mathrm{E}+00$ & $2.44 \mathrm{E}+00$ \\
615 & 77.52 & $1.85 \mathrm{E}-01$ & $1.30 \mathrm{E}-01$ & $4.00 \mathrm{E}+00$ & $2.27 \mathrm{E}+00$ \\
617 & 77.79 & $1.67 \mathrm{E}-01$ & $1.28 \mathrm{E}-01$ & $4.01 \mathrm{E}+00$ & $2.28 \mathrm{E}+00$ \\
619 & 78.07 & $1.44 \mathrm{E}-01$ & $1.22 \mathrm{E}-01$ & $3.55 \mathrm{E}+00$ & $2.15 \mathrm{E}+00$ \\
621 & 78.34 & $1.35 \mathrm{E}-01$ & $1.29 \mathrm{E}-01$ & $3.38 \mathrm{E}+00$ & $1.97 \mathrm{E}+00$ \\
623 & 78.62 & $1.38 \mathrm{E}-01$ & $1.20 \mathrm{E}-01$ & $3.46 \mathrm{E}+00$ & $2.13 \mathrm{E}+00$ \\
625 & 78.90 & $1.41 \mathrm{E}-01$ & $1.24 \mathrm{E}-01$ & $3.42 \mathrm{E}+00$ & $2.21 \mathrm{E}+00$ \\
627 & 79.17 & $1.42 \mathrm{E}-01$ & $1.28 \mathrm{E}-01$ & $3.43 \mathrm{E}+00$ & $2.13 \mathrm{E}+00$ \\
629 & 79.45 & $1.69 \mathrm{E}-01$ & $1.28 \mathrm{E}-01$ & $3.44 \mathrm{E}+00$ & $2.31 \mathrm{E}+00$ \\
631 & 79.72 & $2.73 \mathrm{E}-01$ & $1.22 \mathrm{E}-01$ & $3.83 \mathrm{E}+00$ & $2.44 \mathrm{E}+00$ \\
633 & 80.00 & $1.71 \mathrm{E}-01$ & $1.22 \mathrm{E}-01$ & $3.34 \mathrm{E}+00$ & $2.36 \mathrm{E}+00$ \\
635 & 80.28 & $1.68 \mathrm{E}-01$ & $1.23 \mathrm{E}-01$ & $3.36 \mathrm{E}+00$ & $2.38 \mathrm{E}+00$ \\
637 & 80.55 & $3.73 \mathrm{E}-01$ & $1.36 \mathrm{E}-01$ & $4.05 \mathrm{E}+00$ & $2.28 \mathrm{E}+00$ \\
639 & 80.83 & $3.75 \mathrm{E}-01$ & $1.40 \mathrm{E}-01$ & $3.99 \mathrm{E}+00$ & $2.19 \mathrm{E}+00$ \\
641 & 81.10 & $2.07 \mathrm{E}-01$ & $1.24 \mathrm{E}-01$ & $3.36 \mathrm{E}+00$ & $2.33 \mathrm{E}+00$ \\
643 & 81.38 & $1.95 \mathrm{E}-01$ & $1.25 \mathrm{E}-01$ & $2.92 \mathrm{E}+00$ & $2.34 \mathrm{E}+00$ \\
645 & 81.66 & $2.64 \mathrm{E}-01$ & $1.26 \mathrm{E}-01$ & $3.19 \mathrm{E}+00$ & $2.36 \mathrm{E}+00$ \\
647 & 81.93 & $3.30 \mathrm{E}-01$ & $1.27 \mathrm{E}-01$ & $3.33 \mathrm{E}+00$ & $2.55 \mathrm{E}+00$ \\
649 & 82.21 & $4.71 \mathrm{E}-01$ & $1.28 \mathrm{E}-01$ & $3.80 \mathrm{E}+00$ & $2.69 \mathrm{E}+00$ \\
651 & 82.48 & $4.15 \mathrm{E}-01$ & $1.31 \mathrm{E}-01$ & $3.66 \mathrm{E}+00$ & $2.40 \mathrm{E}+00$ \\
653 & 82.76 & $7.63 \mathrm{E}-01$ & $1.37 \mathrm{E}-01$ & $4.30 \mathrm{E}+00$ & $2.46 \mathrm{E}+00$ \\
655 & 83.04 & $7.70 \mathrm{E}-01$ & $1.37 \mathrm{E}-01$ & $4.56 \mathrm{E}+00$ & $2.47 \mathrm{E}+00$ \\
657 & 83.32 & $1.23 \mathrm{E}+00$ & $1.45 \mathrm{E}-01$ & $5.16 \mathrm{E}+00$ & $2.56 \mathrm{E}+00$ \\
659 & 83.60 & $6.48 \mathrm{E}-01$ & $1.43 \mathrm{E}-01$ & $4.05 \mathrm{E}+00$ & $2.29 \mathrm{E}+00$ \\
661 & 83.87 & $1.72 \mathrm{E}+00$ & $1.43 \mathrm{E}-01$ & $5.03 \mathrm{E}+00$ & $2.44 \mathrm{E}+00$ \\
663 & 84.15 & $1.60 \mathrm{E}+00$ & $1.49 \mathrm{E}-01$ & $5.23 \mathrm{E}+00$ & $2.36 \mathrm{E}+00$ \\
665 & 84.42 & $1.79 \mathrm{E}+00$ & $1.48 \mathrm{E}-01$ & $5.54 \mathrm{E}+00$ & $2.54 \mathrm{E}+00$ \\
667 & 84.70 & $1.41 \mathrm{E}+00$ & $1.48 \mathrm{E}-01$ & $5.19 \mathrm{E}+00$ & $2.40 \mathrm{E}+00$ \\
\hline & & & & & \\
675 & & & &
\end{tabular}


GeoB3911-3

\begin{tabular}{cccccc}
\hline $\begin{array}{c}\text { Depth } \\
\text { [cm] }\end{array}$ & $\begin{array}{c}\text { Age } \\
\text { [cal kyr] }\end{array}$ & $\begin{array}{c}\text { Fe/Ca } \\
{[\text { cps] }}\end{array}$ & $\begin{array}{c}\text { Al/Si } \\
{[c p s]}\end{array}$ & $\begin{array}{c}\text { Fe/K } \\
{[c p s]}\end{array}$ & $\begin{array}{c}\text { Ti/Al } \\
{[\text { cps] }}\end{array}$ \\
\hline 1 & 0.09 & $8.07 \mathrm{E}-02$ & $9.89 \mathrm{E}-02$ & $3.85 \mathrm{E}+00$ & $3.30 \mathrm{E}+00$ \\
2 & 0.17 & $6.51 \mathrm{E}-02$ & $9.30 \mathrm{E}-02$ & $3.12 \mathrm{E}+00$ & $3.21 \mathrm{E}+00$ \\
3 & 0.26 & $6.99 \mathrm{E}-02$ & $1.07 \mathrm{E}-01$ & $3.29 \mathrm{E}+00$ & $2.69 \mathrm{E}+00$ \\
4 & 0.35 & $8.04 \mathrm{E}-02$ & $9.78 \mathrm{E}-02$ & $4.00 \mathrm{E}+00$ & $2.92 \mathrm{E}+00$ \\
5 & 0.43 & $1.22 \mathrm{E}-01$ & $9.30 \mathrm{E}-02$ & $5.38 \mathrm{E}+00$ & $3.27 \mathrm{E}+00$ \\
6 & 0.52 & $1.02 \mathrm{E}-01$ & $8.84 \mathrm{E}-02$ & $4.52 \mathrm{E}+00$ & $3.38 \mathrm{E}+00$ \\
7 & 0.61 & $6.23 \mathrm{E}-02$ & $8.48 \mathrm{E}-02$ & $2.67 \mathrm{E}+00$ & $3.16 \mathrm{E}+00$ \\
8 & 0.69 & $6.13 \mathrm{E}-02$ & $8.48 \mathrm{E}-02$ & $2.84 \mathrm{E}+00$ & $3.98 \mathrm{E}+00$ \\
9 & 0.78 & $6.46 \mathrm{E}-02$ & $9.56 \mathrm{E}-02$ & $3.17 \mathrm{E}+00$ & $3.45 \mathrm{E}+00$ \\
10 & 0.87 & $5.91 \mathrm{E}-02$ & $9.80 \mathrm{E}-02$ & $2.91 \mathrm{E}+00$ & $2.87 \mathrm{E}+00$ \\
11 & 0.96 & $5.59 \mathrm{E}-02$ & $1.17 \mathrm{E}-01$ & $2.87 \mathrm{E}+00$ & $2.49 \mathrm{E}+00$ \\
12 & 1.04 & $6.17 \mathrm{E}-02$ & $1.08 \mathrm{E}-01$ & $3.03 \mathrm{E}+00$ & $2.49 \mathrm{E}+00$ \\
13 & 1.13 & $6.62 \mathrm{E}-02$ & $1.03 \mathrm{E}-01$ & $3.54 \mathrm{E}+00$ & $2.95 \mathrm{E}+00$ \\
14 & 1.22 & $5.36 \mathrm{E}-02$ & $1.08 \mathrm{E}-01$ & $3.08 \mathrm{E}+00$ & $2.30 \mathrm{E}+00$ \\
15 & 1.30 & $5.06 \mathrm{E}-02$ & $1.05 \mathrm{E}-01$ & $2.76 \mathrm{E}+00$ & $2.31 \mathrm{E}+00$ \\
16 & 1.39 & $5.60 \mathrm{E}-02$ & $1.04 \mathrm{E}-01$ & $2.77 \mathrm{E}+00$ & $2.45 \mathrm{E}+00$ \\
17 & 1.48 & $5.69 \mathrm{E}-02$ & $9.50 \mathrm{E}-02$ & $2.67 \mathrm{E}+00$ & $2.34 \mathrm{E}+00$ \\
18 & 1.56 & $5.54 \mathrm{E}-02$ & $1.00 \mathrm{E}-01$ & $2.58 \mathrm{E}+00$ & $2.64 \mathrm{E}+00$ \\
19 & 1.65 & $5.40 \mathrm{E}-02$ & $1.02 \mathrm{E}-01$ & $2.57 \mathrm{E}+00$ & $2.62 \mathrm{E}+00$ \\
20 & 1.74 & $5.49 \mathrm{E}-02$ & $9.31 \mathrm{E}-02$ & $2.75 \mathrm{E}+00$ & $2.95 \mathrm{E}+00$ \\
21 & 1.82 & $5.50 \mathrm{E}-02$ & $9.31 \mathrm{E}-02$ & $2.53 \mathrm{E}+00$ & $2.81 \mathrm{E}+00$ \\
22 & 1.91 & $5.71 \mathrm{E}-02$ & $1.01 \mathrm{E}-01$ & $2.83 \mathrm{E}+00$ & $2.62 \mathrm{E}+00$ \\
23 & 1.98 & $5.91 \mathrm{E}-02$ & $8.81 \mathrm{E}-02$ & $2.88 \mathrm{E}+00$ & $3.01 \mathrm{E}+00$ \\
24 & 2.05 & $9.60 \mathrm{E}-02$ & $7.82 \mathrm{E}-02$ & $2.59 \mathrm{E}+00$ & $3.74 \mathrm{E}+00$ \\
25 & 2.12 & $8.16 \mathrm{E}-02$ & $8.02 \mathrm{E}-02$ & $2.54 \mathrm{E}+00$ & $3.46 \mathrm{E}+00$ \\
26 & 2.19 & $8.45 \mathrm{E}-02$ & $6.10 \mathrm{E}-02$ & $2.06 \mathrm{E}+00$ & $3.12 \mathrm{E}+00$ \\
27 & 2.26 & $1.17 \mathrm{E}-01$ & $6.43 \mathrm{E}-02$ & $2.47 \mathrm{E}+00$ & $5.03 \mathrm{E}+00$ \\
28 & 2.32 & $9.81 \mathrm{E}-02$ & $8.00 \mathrm{E}-02$ & $2.73 \mathrm{E}+00$ & $4.21 \mathrm{E}+00$ \\
39 & 3.15 & $5.92 \mathrm{E}-02$ & $8.66 \mathrm{E}-02$ & $2.91 \mathrm{E}+00$ & $3.21 \mathrm{E}+00$ \\
34 & 2.22 & $5.47 \mathrm{E}-02$ & $9.20 \mathrm{E}-02$ & $3.48 \mathrm{E}+00$ & $3.21 \mathrm{E}+00$
\end{tabular}




\begin{tabular}{|c|c|c|c|c|c|}
\hline $\begin{array}{c}\text { Depth } \\
{[\mathrm{cm}]}\end{array}$ & $\begin{array}{c}\text { Age } \\
\text { [cal kyr] }\end{array}$ & $\begin{array}{c}\mathrm{Fe} / \mathrm{Ca} \\
\text { [cps] }\end{array}$ & $\begin{array}{l}\mathbf{A l} / \mathbf{S i} \\
\text { [cps] }\end{array}$ & $\begin{array}{l}\mathbf{F e} / \mathbf{K} \\
{[c p s]}\end{array}$ & $\begin{array}{l}\text { Ti/Al } \\
\text { [cps] }\end{array}$ \\
\hline 42 & 3.29 & $5.00 \mathrm{E}-02$ & $9.46 \mathrm{E}-02$ & $3.43 E+00$ & $2.73 E+00$ \\
\hline 43 & 3.36 & $6.38 \mathrm{E}-02$ & $9.47 \mathrm{E}-02$ & $3.15 E+00$ & $3.19 E+00$ \\
\hline 44 & 3.43 & $5.85 \mathrm{E}-02$ & $1.12 \mathrm{E}-01$ & $3.43 E+00$ & $2.40 \mathrm{E}+00$ \\
\hline 45 & 3.50 & $5.68 \mathrm{E}-02$ & $9.72 \mathrm{E}-02$ & $3.54 \mathrm{E}+00$ & $3.14 E+00$ \\
\hline 46 & 3.57 & $5.16 \mathrm{E}-02$ & $9.34 \mathrm{E}-02$ & $2.90 \mathrm{E}+00$ & $2.88 \mathrm{E}+00$ \\
\hline 47 & 3.64 & $5.43 \mathrm{E}-02$ & $1.08 \mathrm{E}-01$ & $3.29 E+00$ & $2.41 E+00$ \\
\hline 48 & 3.70 & $5.42 \mathrm{E}-02$ & $9.61 \mathrm{E}-02$ & $3.03 E+00$ & $2.59 \mathrm{E}+00$ \\
\hline 49 & 3.77 & $5.61 \mathrm{E}-02$ & $1.06 \mathrm{E}-01$ & $3.37 E+00$ & $2.34 \mathrm{E}+00$ \\
\hline 50 & 3.84 & $5.50 \mathrm{E}-02$ & $1.04 \mathrm{E}-01$ & $3.30 E+00$ & $2.25 \mathrm{E}+00$ \\
\hline 51 & 3.91 & $5.46 \mathrm{E}-02$ & 1.14E-01 & $3.31 \mathrm{E}+00$ & $2.27 \mathrm{E}+00$ \\
\hline 52 & 3.98 & $5.48 \mathrm{E}-02$ & $1.03 \mathrm{E}-01$ & $3.22 \mathrm{E}+00$ & $2.57 E+00$ \\
\hline 53 & 4.01 & $5.58 \mathrm{E}-02$ & 1.17E-01 & $3.14 \mathrm{E}+00$ & $2.28 \mathrm{E}+00$ \\
\hline 54 & 4.03 & $5.76 \mathrm{E}-02$ & $1.00 \mathrm{E}-01$ & $3.21 E+00$ & $3.11 E+00$ \\
\hline 55 & 4.06 & $6.43 \mathrm{E}-02$ & $7.73 E-02$ & $3.13 E+00$ & $3.54 E+00$ \\
\hline 56 & 4.08 & $6.45 E-02$ & $9.52 \mathrm{E}-02$ & $3.06 E+00$ & $2.96 \mathrm{E}+00$ \\
\hline 57 & 4.11 & $6.18 \mathrm{E}-02$ & $8.96 \mathrm{E}-02$ & $3.33 \mathrm{E}+00$ & $3.13 E+00$ \\
\hline 58 & 4.13 & $6.40 \mathrm{E}-02$ & $1.10 \mathrm{E}-01$ & $3.23 E+00$ & $2.50 \mathrm{E}+00$ \\
\hline 59 & 4.16 & $5.86 \mathrm{E}-02$ & $1.10 \mathrm{E}-01$ & $3.21 E+00$ & $2.41 E+00$ \\
\hline 60 & 4.18 & $5.41 \mathrm{E}-02$ & $1.23 \mathrm{E}-01$ & $2.96 \mathrm{E}+00$ & $1.91 \mathrm{E}+00$ \\
\hline 61 & 4.21 & $5.66 \mathrm{E}-02$ & $1.13 \mathrm{E}-01$ & $3.28 \mathrm{E}+00$ & $2.10 E+00$ \\
\hline 62 & 4.23 & $7.08 \mathrm{E}-02$ & 1.17E-01 & $4.10 E+00$ & $2.30 E+00$ \\
\hline 63 & 4.32 & $6.71 \mathrm{E}-02$ & $1.11 \mathrm{E}-01$ & $3.79 E+00$ & $2.36 \mathrm{E}+00$ \\
\hline 64 & 4.40 & 7.07E-02 & 1.17E-01 & $3.78 \mathrm{E}+00$ & $2.40 \mathrm{E}+00$ \\
\hline 65 & 4.49 & $8.54 \mathrm{E}-02$ & $1.23 \mathrm{E}-01$ & $4.02 E+00$ & $2.10 E+00$ \\
\hline 66 & 4.57 & $8.01 \mathrm{E}-02$ & $1.21 \mathrm{E}-01$ & $3.74 E+00$ & $2.24 \mathrm{E}+00$ \\
\hline 67 & 4.66 & $8.12 \mathrm{E}-02$ & $1.21 \mathrm{E}-01$ & $3.93 E+00$ & $2.14 \mathrm{E}+00$ \\
\hline 68 & 4.74 & $8.24 \mathrm{E}-02$ & $1.30 \mathrm{E}-01$ & $3.82 \mathrm{E}+00$ & $1.98 \mathrm{E}+00$ \\
\hline 69 & 4.83 & $9.28 \mathrm{E}-02$ & $1.18 \mathrm{E}-01$ & $4.14 \mathrm{E}+00$ & $2.28 \mathrm{E}+00$ \\
\hline 70 & 4.91 & $9.36 \mathrm{E}-02$ & $1.21 \mathrm{E}-01$ & $4.09 E+00$ & $2.26 \mathrm{E}+00$ \\
\hline 71 & 5.00 & $9.63 \mathrm{E}-02$ & $1.22 \mathrm{E}-01$ & $3.98 \mathrm{E}+00$ & $2.25 \mathrm{E}+00$ \\
\hline 72 & 5.08 & 8.77E-02 & $1.22 \mathrm{E}-01$ & $3.85 E+00$ & $2.14 E+00$ \\
\hline 73 & 5.17 & $9.22 \mathrm{E}-02$ & $1.33 \mathrm{E}-01$ & $3.91 E+00$ & $2.06 \mathrm{E}+00$ \\
\hline 74 & 5.25 & 1.17E-01 & $1.35 \mathrm{E}-01$ & $4.37 E+00$ & $2.02 E+00$ \\
\hline 75 & 5.34 & $1.31 \mathrm{E}-01$ & $1.34 \mathrm{E}-01$ & $4.50 \mathrm{E}+00$ & $2.04 E+00$ \\
\hline 76 & 5.42 & $1.41 \mathrm{E}-01$ & 1.34E-01 & $4.38 \mathrm{E}+00$ & $2.22 \mathrm{E}+00$ \\
\hline 77 & 5.51 & $7.44 \mathrm{E}-02$ & $1.15 \mathrm{E}-01$ & $3.39 E+00$ & $2.36 \mathrm{E}+00$ \\
\hline 78 & 5.59 & $9.29 \mathrm{E}-02$ & $1.18 \mathrm{E}-01$ & $3.87 \mathrm{E}+00$ & $2.49 \mathrm{E}+00$ \\
\hline 79 & 5.68 & $1.48 \mathrm{E}-01$ & $1.38 \mathrm{E}-01$ & $4.55 E+00$ & $2.20 \mathrm{E}+00$ \\
\hline 80 & 5.76 & $1.55 \mathrm{E}-01$ & 1.40E-01 & $4.39 E+00$ & $2.07 E+00$ \\
\hline 81 & 5.85 & $7.08 \mathrm{E}-02$ & $1.11 \mathrm{E}-01$ & $3.37 E+00$ & $2.35 E+00$ \\
\hline 82 & 5.93 & $1.27 \mathrm{E}-01$ & $1.36 \mathrm{E}-01$ & $4.07 E+00$ & $1.98 \mathrm{E}+00$ \\
\hline 83 & 6.02 & 2.10E-01 & $1.36 \mathrm{E}-01$ & $4.36 \mathrm{E}+00$ & $2.24 \mathrm{E}+00$ \\
\hline 84 & 6.10 & $2.08 \mathrm{E}-01$ & $1.41 \mathrm{E}-01$ & $4.29 E+00$ & $2.20 \mathrm{E}+00$ \\
\hline
\end{tabular}




\begin{tabular}{|c|c|c|c|c|c|}
\hline $\begin{array}{c}\text { Depth } \\
{[\mathrm{cm}]}\end{array}$ & $\begin{array}{c}\text { Age } \\
\text { [cal kyr] }\end{array}$ & $\begin{array}{c}\mathrm{Fe} / \mathrm{Ca} \\
\text { [cps] }\end{array}$ & $\begin{array}{l}\mathbf{A l} / \mathbf{S i} \\
{[c p s]} \\
\end{array}$ & $\begin{array}{l}\mathbf{F e} / \mathbf{K} \\
{[c p s]}\end{array}$ & $\begin{array}{l}\mathrm{Ti} / \mathbf{A l} \\
\text { [cps] }\end{array}$ \\
\hline 85 & 6.19 & $2.24 \mathrm{E}-01$ & $1.35 \mathrm{E}-01$ & $4.22 E+00$ & $2.29 \mathrm{E}+00$ \\
\hline 86 & 6.27 & 2.39E-01 & $1.38 \mathrm{E}-01$ & $4.16 \mathrm{E}+00$ & $2.13 E+00$ \\
\hline 87 & 6.36 & $2.33 \mathrm{E}-01$ & 1.36E-01 & $4.18 \mathrm{E}+00$ & $2.02 \mathrm{E}+00$ \\
\hline 88 & 6.44 & $2.43 \mathrm{E}-01$ & $1.36 \mathrm{E}-01$ & $4.09 E+00$ & $2.14 \mathrm{E}+00$ \\
\hline 89 & 6.53 & $2.00 \mathrm{E}-01$ & 1.39E-01 & $4.42 E+00$ & $2.21 E+00$ \\
\hline 90 & 6.61 & 1.70E-01 & 1.33E-01 & $4.40 E+00$ & $2.14 \mathrm{E}+00$ \\
\hline 91 & 6.63 & $1.76 \mathrm{E}-01$ & $1.39 \mathrm{E}-01$ & $4.28 \mathrm{E}+00$ & $2.01 \mathrm{E}+00$ \\
\hline 92 & 6.66 & $1.72 \mathrm{E}-01$ & $1.42 \mathrm{E}-01$ & 4.37E+00 & $1.94 \mathrm{E}+00$ \\
\hline 93 & 6.68 & $1.83 \mathrm{E}-01$ & 1.41E-01 & $4.55 E+00$ & $2.12 \mathrm{E}+00$ \\
\hline 94 & 6.71 & $1.86 \mathrm{E}-01$ & $1.33 \mathrm{E}-01$ & $4.51 E+00$ & $2.29 \mathrm{E}+00$ \\
\hline 95 & 6.73 & $1.65 \mathrm{E}-01$ & 1.39E-01 & $4.32 E+00$ & $2.09 E+00$ \\
\hline 96 & 6.76 & $1.75 \mathrm{E}-01$ & 1.46E-01 & $4.50 E+00$ & $1.85 \mathrm{E}+00$ \\
\hline 98 & 6.81 & $1.46 \mathrm{E}-01$ & $1.31 \mathrm{E}-01$ & $4.38 \mathrm{E}+00$ & $2.53 \mathrm{E}+00$ \\
\hline 99 & 6.83 & $2.05 \mathrm{E}-01$ & 1.33E-01 & $4.65 E+00$ & $2.60 \mathrm{E}+00$ \\
\hline 100 & 6.86 & 2.17E-01 & 1.33E-01 & $4.73 E+00$ & $2.40 E+00$ \\
\hline 101 & 6.88 & 2.09E-01 & 1.44E-01 & $4.61 E+00$ & $2.22 \mathrm{E}+00$ \\
\hline 102 & 6.91 & $2.21 \mathrm{E}-01$ & 1.49E-01 & $4.72 \mathrm{E}+00$ & $2.28 \mathrm{E}+00$ \\
\hline 103 & 6.93 & $2.18 \mathrm{E}-01$ & $1.42 \mathrm{E}-01$ & $4.45 \mathrm{E}+00$ & $2.20 \mathrm{E}+00$ \\
\hline 104 & 6.96 & $2.24 \mathrm{E}-01$ & $1.46 \mathrm{E}-01$ & $4.61 E+00$ & $2.17 E+00$ \\
\hline 105 & 6.98 & $2.49 \mathrm{E}-01$ & $1.46 \mathrm{E}-01$ & $4.51 E+00$ & $2.09 \mathrm{E}+00$ \\
\hline 106 & 7.01 & 2.49E-01 & $1.41 \mathrm{E}-01$ & $4.48 E+00$ & $2.15 E+00$ \\
\hline 107 & 7.03 & $1.92 \mathrm{E}-01$ & 1.37E-01 & $4.24 E+00$ & $2.05 \mathrm{E}+00$ \\
\hline 108 & 7.06 & $2.02 \mathrm{E}-01$ & $1.38 \mathrm{E}-01$ & $4.41 E+00$ & $2.20 \mathrm{E}+00$ \\
\hline 109 & 7.08 & $2.40 \mathrm{E}-01$ & 1.37E-01 & $4.47 E+00$ & $2.43 E+00$ \\
\hline 110 & 7.11 & 2.39E-01 & $1.36 \mathrm{E}-01$ & $4.50 E+00$ & $2.54 \mathrm{E}+00$ \\
\hline 111 & 7.13 & $2.76 \mathrm{E}-01$ & $1.43 \mathrm{E}-01$ & $4.60 \mathrm{E}+00$ & $2.36 \mathrm{E}+00$ \\
\hline 112 & 7.16 & $2.76 \mathrm{E}-01$ & 1.35E-01 & $4.53 E+00$ & $2.39 \mathrm{E}+00$ \\
\hline 113 & 7.18 & $3.08 \mathrm{E}-01$ & 1.34E-01 & $4.75 E+00$ & $2.52 \mathrm{E}+00$ \\
\hline 114 & 7.21 & 2.77E-01 & $1.43 \mathrm{E}-01$ & $4.45 \mathrm{E}+00$ & $2.26 \mathrm{E}+00$ \\
\hline 115 & 7.23 & 3.03E-01 & 1.35E-01 & $4.51 E+00$ & $2.27 E+00$ \\
\hline 116 & 7.26 & 3.17E-01 & 1.39E-01 & $4.78 \mathrm{E}+00$ & $2.22 \mathrm{E}+00$ \\
\hline 117 & 7.28 & $3.56 \mathrm{E}-01$ & $1.35 \mathrm{E}-01$ & $4.65 E+00$ & $2.31 E+00$ \\
\hline 118 & 7.31 & $3.43 \mathrm{E}-01$ & 1.40E-01 & $4.56 E+00$ & $2.25 \mathrm{E}+00$ \\
\hline 119 & 7.33 & $3.32 \mathrm{E}-01$ & $1.38 \mathrm{E}-01$ & $4.37 E+00$ & $2.23 \mathrm{E}+00$ \\
\hline 120 & 7.36 & 3.33E-01 & $1.35 \mathrm{E}-01$ & $4.57 E+00$ & $2.30 E+00$ \\
\hline 121 & 7.40 & $3.10 \mathrm{E}-01$ & 1.35E-01 & $4.34 \mathrm{E}+00$ & $2.26 \mathrm{E}+00$ \\
\hline 122 & 7.43 & $3.38 \mathrm{E}-01$ & $1.32 \mathrm{E}-01$ & $4.54 \mathrm{E}+00$ & $2.42 \mathrm{E}+00$ \\
\hline 123 & 7.46 & $3.16 \mathrm{E}-01$ & 1.43E-01 & $4.70 \mathrm{E}+00$ & $2.35 \mathrm{E}+00$ \\
\hline 124 & 7.49 & $3.06 \mathrm{E}-01$ & 1.35E-01 & $4.53 E+00$ & $2.27 E+00$ \\
\hline 125 & 7.53 & $2.98 \mathrm{E}-01$ & $1.41 \mathrm{E}-01$ & $4.44 E+00$ & $2.25 \mathrm{E}+00$ \\
\hline 126 & 7.56 & 3.31E-01 & $1.25 \mathrm{E}-01$ & $4.67 E+00$ & $2.65 E+00$ \\
\hline 127 & 7.59 & $3.34 \mathrm{E}-01$ & 1.36E-01 & $4.61 E+00$ & $2.50 \mathrm{E}+00$ \\
\hline 128 & 7.62 & 2.93E-01 & $1.38 \mathrm{E}-01$ & $4.18 \mathrm{E}+00$ & $2.18 \mathrm{E}+00$ \\
\hline
\end{tabular}




\begin{tabular}{|c|c|c|c|c|c|}
\hline $\begin{array}{c}\text { Depth } \\
{[\mathrm{cm}]}\end{array}$ & $\begin{array}{c}\text { Age } \\
{[\text { cal kyr] }}\end{array}$ & $\begin{array}{c}\mathrm{Fe} / \mathrm{Ca} \\
{[c p s]}\end{array}$ & $\begin{array}{l}\mathbf{A l} / \mathbf{S i} \\
{[c p s]}\end{array}$ & $\begin{array}{l}\mathrm{Fe} / \mathrm{K} \\
{[c p s]}\end{array}$ & $\begin{array}{l}\text { Ti/Al } \\
{[c p s]}\end{array}$ \\
\hline 129 & 7.66 & $2.87 E-01$ & $1.31 \mathrm{E}-01$ & $4.16 \mathrm{E}+00$ & $2.33 \mathrm{E}+00$ \\
\hline 130 & 7.69 & $2.66 \mathrm{E}-01$ & $1.23 \mathrm{E}-01$ & $3.96 \mathrm{E}+00$ & $2.45 E+00$ \\
\hline 131 & 7.72 & $2.85 \mathrm{E}-01$ & $1.26 \mathrm{E}-01$ & $4.00 \mathrm{E}+00$ & $2.27 E+00$ \\
\hline 132 & 7.75 & $2.85 \mathrm{E}-01$ & $1.33 \mathrm{E}-01$ & $4.27 E+00$ & $2.22 \mathrm{E}+00$ \\
\hline 133 & 7.79 & $2.65 \mathrm{E}-01$ & $1.35 \mathrm{E}-01$ & $4.21 E+00$ & $2.30 \mathrm{E}+00$ \\
\hline 134 & 7.82 & $2.75 \mathrm{E}-01$ & $1.26 \mathrm{E}-01$ & $4.20 E+00$ & $2.33 \mathrm{E}+00$ \\
\hline 135 & 7.85 & $2.69 \mathrm{E}-01$ & $1.37 \mathrm{E}-01$ & $4.09 \mathrm{E}+00$ & $2.17 E+00$ \\
\hline 136 & 7.88 & $2.76 \mathrm{E}-01$ & $1.28 \mathrm{E}-01$ & $4.10 \mathrm{E}+00$ & $2.33 \mathrm{E}+00$ \\
\hline 137 & 7.92 & $2.58 \mathrm{E}-01$ & $1.25 \mathrm{E}-01$ & $3.97 E+00$ & $2.48 \mathrm{E}+00$ \\
\hline 138 & 7.95 & 2.81E-01 & $1.35 \mathrm{E}-01$ & $4.06 \mathrm{E}+00$ & $2.23 E+00$ \\
\hline 139 & 7.98 & $2.94 \mathrm{E}-01$ & $1.31 \mathrm{E}-01$ & $4.04 \mathrm{E}+00$ & $2.49 E+00$ \\
\hline 140 & 8.01 & $2.98 \mathrm{E}-01$ & $1.35 \mathrm{E}-01$ & $3.99 E+00$ & $2.28 \mathrm{E}+00$ \\
\hline 141 & 8.05 & $3.02 \mathrm{E}-01$ & $1.32 \mathrm{E}-01$ & $4.20 E+00$ & $2.48 \mathrm{E}+00$ \\
\hline 142 & 8.08 & $2.98 \mathrm{E}-01$ & $1.35 \mathrm{E}-01$ & $4.03 E+00$ & $2.15 E+00$ \\
\hline 143 & 8.11 & $3.46 \mathrm{E}-01$ & $1.25 \mathrm{E}-01$ & $4.34 \mathrm{E}+00$ & $2.54 \mathrm{E}+00$ \\
\hline 144 & 8.15 & $3.66 \mathrm{E}-01$ & $1.23 \mathrm{E}-01$ & $4.35 \mathrm{E}+00$ & $2.66 \mathrm{E}+00$ \\
\hline 145 & 8.18 & $3.58 \mathrm{E}-01$ & $1.28 \mathrm{E}-01$ & $4.47 \mathrm{E}+00$ & $2.89 \mathrm{E}+00$ \\
\hline 146 & 8.21 & 3.97E-01 & $1.29 \mathrm{E}-01$ & $4.39 E+00$ & $2.67 E+00$ \\
\hline 147 & 8.24 & 4.25E-01 & $1.30 \mathrm{E}-01$ & $4.58 \mathrm{E}+00$ & $2.48 \mathrm{E}+00$ \\
\hline 148 & 8.28 & $3.65 \mathrm{E}-01$ & $1.29 \mathrm{E}-01$ & $4.26 \mathrm{E}+00$ & $2.67 E+00$ \\
\hline 149 & 8.31 & $3.26 \mathrm{E}-01$ & 1.30E-01 & $4.19 E+00$ & $2.46 \mathrm{E}+00$ \\
\hline 150 & 8.34 & $3.27 \mathrm{E}-01$ & 1.29E-01 & $4.07 E+00$ & $2.38 \mathrm{E}+00$ \\
\hline 151 & 8.37 & $3.40 \mathrm{E}-01$ & $1.26 \mathrm{E}-01$ & $3.77 E+00$ & $2.30 \mathrm{E}+00$ \\
\hline 152 & 8.41 & $3.76 \mathrm{E}-01$ & $1.33 \mathrm{E}-01$ & $3.95 E+00$ & $2.32 \mathrm{E}+00$ \\
\hline 153 & 8.44 & $3.76 \mathrm{E}-01$ & $1.23 \mathrm{E}-01$ & $3.84 \mathrm{E}+00$ & $2.50 E+00$ \\
\hline 154 & 8.47 & $3.56 \mathrm{E}-01$ & $1.25 \mathrm{E}-01$ & $3.78 \mathrm{E}+00$ & $2.53 E+00$ \\
\hline 155 & 8.50 & $3.70 \mathrm{E}-01$ & $1.33 \mathrm{E}-01$ & $4.00 \mathrm{E}+00$ & $2.44 \mathrm{E}+00$ \\
\hline 156 & 8.54 & $3.72 \mathrm{E}-01$ & $1.33 \mathrm{E}-01$ & $3.97 \mathrm{E}+00$ & $2.40 \mathrm{E}+00$ \\
\hline 157 & 8.57 & $3.80 \mathrm{E}-01$ & 1.27E-01 & $3.92 \mathrm{E}+00$ & $2.40 \mathrm{E}+00$ \\
\hline 158 & 8.60 & 3.73E-01 & 1.27E-01 & $3.99 \mathrm{E}+00$ & $2.52 \mathrm{E}+00$ \\
\hline 159 & 8.63 & $3.91 \mathrm{E}-01$ & 1.33E-01 & $4.22 \mathrm{E}+00$ & $2.49 E+00$ \\
\hline 160 & 8.67 & $4.48 \mathrm{E}-01$ & $1.31 \mathrm{E}-01$ & $4.48 \mathrm{E}+00$ & $2.56 \mathrm{E}+00$ \\
\hline 161 & 8.70 & $4.21 \mathrm{E}-01$ & $1.25 \mathrm{E}-01$ & $4.26 \mathrm{E}+00$ & $2.61 E+00$ \\
\hline 162 & 8.73 & $4.83 \mathrm{E}-01$ & $1.33 \mathrm{E}-01$ & $4.41 \mathrm{E}+00$ & $2.45 E+00$ \\
\hline 163 & 8.77 & $5.12 \mathrm{E}-01$ & $1.33 \mathrm{E}-01$ & $4.82 \mathrm{E}+00$ & $2.92 \mathrm{E}+00$ \\
\hline 164 & 8.80 & 4.62E-01 & $1.30 \mathrm{E}-01$ & $4.31 E+00$ & $2.45 E+00$ \\
\hline 165 & 8.83 & $4.20 \mathrm{E}-01$ & $1.33 \mathrm{E}-01$ & $4.03 E+00$ & $2.31 \mathrm{E}+00$ \\
\hline 166 & 8.86 & $3.87 E-01$ & $1.34 \mathrm{E}-01$ & $3.94 \mathrm{E}+00$ & $2.15 \mathrm{E}+00$ \\
\hline 167 & 8.90 & 4.16E-01 & 1.30E-01 & $3.94 \mathrm{E}+00$ & $2.45 \mathrm{E}+00$ \\
\hline 168 & 8.93 & 4.59E-01 & $1.31 \mathrm{E}-01$ & $4.16 \mathrm{E}+00$ & $2.42 \mathrm{E}+00$ \\
\hline 169 & 8.96 & 4.63E-01 & $1.31 \mathrm{E}-01$ & $4.10 \mathrm{E}+00$ & $2.49 \mathrm{E}+00$ \\
\hline 170 & 8.99 & 4.83E-01 & 1.29E-01 & $4.01 E+00$ & $2.43 \mathrm{E}+00$ \\
\hline 171 & 9.03 & 4.74E-01 & $1.34 \mathrm{E}-01$ & $4.17 E+00$ & $2.37 E+00$ \\
\hline
\end{tabular}




\begin{tabular}{|c|c|c|c|c|c|}
\hline $\begin{array}{c}\text { Depth } \\
{[\mathrm{cm}]}\end{array}$ & $\begin{array}{c}\text { Age } \\
{[\text { cal kyr] }}\end{array}$ & $\begin{array}{c}\mathrm{Fe} / \mathrm{Ca} \\
{[c p s]}\end{array}$ & $\begin{array}{l}\mathbf{A l} / \mathbf{S i} \\
{[c p s]}\end{array}$ & $\begin{array}{l}\mathrm{Fe} / \mathrm{K} \\
{[c p s]}\end{array}$ & $\begin{array}{l}\text { Ti/Al } \\
{[c p s]}\end{array}$ \\
\hline 172 & 9.06 & $4.76 \mathrm{E}-01$ & $1.31 \mathrm{E}-01$ & $4.22 \mathrm{E}+00$ & $2.47 E+00$ \\
\hline 173 & 9.09 & 4.81E-01 & $1.24 \mathrm{E}-01$ & $4.08 \mathrm{E}+00$ & $2.54 \mathrm{E}+00$ \\
\hline 174 & 9.12 & $4.78 \mathrm{E}-01$ & $1.30 \mathrm{E}-01$ & $4.11 \mathrm{E}+00$ & $2.47 E+00$ \\
\hline 175 & 9.16 & $5.00 \mathrm{E}-01$ & $1.32 \mathrm{E}-01$ & $4.13 E+00$ & $2.54 \mathrm{E}+00$ \\
\hline 176 & 9.19 & $5.12 \mathrm{E}-01$ & $1.31 \mathrm{E}-01$ & $4.19 \mathrm{E}+00$ & $2.61 E+00$ \\
\hline 177 & 9.22 & $5.32 \mathrm{E}-01$ & $1.28 \mathrm{E}-01$ & $4.15 E+00$ & $2.60 \mathrm{E}+00$ \\
\hline 178 & 9.25 & $5.18 \mathrm{E}-01$ & $1.27 \mathrm{E}-01$ & $4.20 \mathrm{E}+00$ & $2.79 \mathrm{E}+00$ \\
\hline 179 & 9.29 & $5.14 \mathrm{E}-01$ & $1.32 \mathrm{E}-01$ & $4.22 \mathrm{E}+00$ & $2.56 \mathrm{E}+00$ \\
\hline 180 & 9.32 & $5.58 \mathrm{E}-01$ & $1.25 \mathrm{E}-01$ & $4.52 E+00$ & $2.99 \mathrm{E}+00$ \\
\hline 181 & 9.35 & 5.21E-01 & $1.27 \mathrm{E}-01$ & $4.35 E+00$ & $2.84 \mathrm{E}+00$ \\
\hline 182 & 9.38 & $6.42 \mathrm{E}-01$ & $1.29 \mathrm{E}-01$ & $4.53 E+00$ & $2.98 \mathrm{E}+00$ \\
\hline 183 & 9.42 & $6.28 \mathrm{E}-01$ & 1.34E-01 & $4.60 \mathrm{E}+00$ & $2.94 \mathrm{E}+00$ \\
\hline 184 & 9.45 & $6.26 \mathrm{E}-01$ & $1.27 \mathrm{E}-01$ & $4.49 E+00$ & $2.92 \mathrm{E}+00$ \\
\hline 185 & 9.48 & 5.77E-01 & $1.28 \mathrm{E}-01$ & $4.52 E+00$ & $2.87 E+00$ \\
\hline 186 & 9.52 & 5.97E-01 & 1.33E-01 & $4.51 E+00$ & $2.73 E+00$ \\
\hline 187 & 9.55 & 7.70E-01 & $1.35 \mathrm{E}-01$ & $4.42 \mathrm{E}+00$ & $2.78 \mathrm{E}+00$ \\
\hline 188 & 9.58 & $8.31 \mathrm{E}-01$ & $1.42 \mathrm{E}-01$ & $4.79 \mathrm{E}+00$ & $2.51 \mathrm{E}+00$ \\
\hline 189 & 9.61 & $8.16 \mathrm{E}-01$ & $1.42 \mathrm{E}-01$ & $4.61 \mathrm{E}+00$ & $2.43 \mathrm{E}+00$ \\
\hline 190 & 9.65 & 8.55E-01 & $1.41 \mathrm{E}-01$ & $4.54 \mathrm{E}+00$ & $2.44 \mathrm{E}+00$ \\
\hline 191 & 9.68 & 8.00E-01 & $1.40 \mathrm{E}-01$ & $4.62 \mathrm{E}+00$ & $2.37 E+00$ \\
\hline 192 & 9.71 & $9.45 \mathrm{E}-01$ & $1.35 \mathrm{E}-01$ & $4.68 \mathrm{E}+00$ & $2.79 \mathrm{E}+00$ \\
\hline 193 & 9.74 & $9.05 \mathrm{E}-01$ & 1.36E-01 & $4.58 \mathrm{E}+00$ & $2.67 E+00$ \\
\hline 194 & 9.78 & $9.18 \mathrm{E}-01$ & $1.31 \mathrm{E}-01$ & $4.38 \mathrm{E}+00$ & $2.76 \mathrm{E}+00$ \\
\hline 195 & 9.81 & 8.57E-01 & $1.26 \mathrm{E}-01$ & $4.23 E+00$ & $2.85 \mathrm{E}+00$ \\
\hline 196 & 9.84 & $9.32 \mathrm{E}-01$ & $1.30 \mathrm{E}-01$ & $4.63 \mathrm{E}+00$ & $2.86 \mathrm{E}+00$ \\
\hline 197 & 9.87 & 8.14E-01 & $1.34 \mathrm{E}-01$ & $4.63 E+00$ & $2.94 \mathrm{E}+00$ \\
\hline 198 & 9.91 & 8.91E-01 & $1.24 \mathrm{E}-01$ & $5.34 \mathrm{E}+00$ & $3.62 E+00$ \\
\hline 199 & 9.94 & $9.02 \mathrm{E}-01$ & $1.29 \mathrm{E}-01$ & $5.55 \mathrm{E}+00$ & $3.61 E+00$ \\
\hline 200 & 9.97 & 7.45E-01 & $1.31 \mathrm{E}-01$ & $4.85 E+00$ & $3.01 E+00$ \\
\hline 201 & 10.00 & 8.03E-01 & $1.29 \mathrm{E}-01$ & $5.30 \mathrm{E}+00$ & $3.42 E+00$ \\
\hline 202 & 10.04 & $8.90 \mathrm{E}-01$ & 1.29E-01 & $4.82 \mathrm{E}+00$ & $3.26 \mathrm{E}+00$ \\
\hline 203 & 10.07 & $7.55 \mathrm{E}-01$ & 1.27E-01 & $4.84 \mathrm{E}+00$ & $3.00 E+00$ \\
\hline 204 & 10.10 & 7.70E-01 & $1.35 \mathrm{E}-01$ & $4.74 \mathrm{E}+00$ & $2.74 \mathrm{E}+00$ \\
\hline 205 & 10.13 & 8.04E-01 & $1.31 \mathrm{E}-01$ & $4.90 \mathrm{E}+00$ & $3.09 E+00$ \\
\hline 206 & 10.17 & 7.07E-01 & $1.30 \mathrm{E}-01$ & 4.70E+00 & $2.92 \mathrm{E}+00$ \\
\hline 207 & 10.20 & 7.32E-01 & $1.22 \mathrm{E}-01$ & $5.00 \mathrm{E}+00$ & $3.27 E+00$ \\
\hline 208 & 10.23 & $6.95 \mathrm{E}-01$ & 1.37E-01 & $4.67 \mathrm{E}+00$ & $2.67 E+00$ \\
\hline 209 & 10.25 & $6.18 \mathrm{E}-01$ & $1.28 \mathrm{E}-01$ & $4.21 \mathrm{E}+00$ & $2.84 \mathrm{E}+00$ \\
\hline 210 & 10.28 & $7.26 \mathrm{E}-01$ & 1.33E-01 & $4.49 E+00$ & $2.43 \mathrm{E}+00$ \\
\hline 211 & 10.31 & $6.95 \mathrm{E}-01$ & 1.36E-01 & $4.22 \mathrm{E}+00$ & $2.43 \mathrm{E}+00$ \\
\hline 212 & 10.34 & 8.89E-01 & $1.35 \mathrm{E}-01$ & $4.65 E+00$ & $2.68 \mathrm{E}+00$ \\
\hline 213 & 10.36 & 8.59E-01 & 1.39E-01 & $4.67 E+00$ & $2.55 \mathrm{E}+00$ \\
\hline 214 & 10.39 & 8.97E-01 & 1.29E-01 & $4.66 \mathrm{E}+00$ & $2.85 \mathrm{E}+00$ \\
\hline
\end{tabular}




\begin{tabular}{|c|c|c|c|c|c|}
\hline $\begin{array}{c}\text { Depth } \\
{[\mathrm{cm}]}\end{array}$ & $\begin{array}{c}\text { Age } \\
{[\text { cal kyr] }}\end{array}$ & $\begin{array}{c}\mathrm{Fe} / \mathrm{Ca} \\
{[c p s]}\end{array}$ & $\begin{array}{l}\mathbf{A l} / \mathbf{S i} \\
{[c p s]}\end{array}$ & $\begin{array}{l}\mathrm{Fe} / \mathrm{K} \\
{[c p s]}\end{array}$ & $\begin{array}{l}\text { Ti/Al } \\
{[c p s]}\end{array}$ \\
\hline 215 & 10.42 & $8.83 \mathrm{E}-01$ & $1.41 \mathrm{E}-01$ & $4.52 \mathrm{E}+00$ & $2.63 E+00$ \\
\hline 216 & 10.45 & 8.80E-01 & $1.35 \mathrm{E}-01$ & $4.51 \mathrm{E}+00$ & $2.50 \mathrm{E}+00$ \\
\hline 217 & 10.47 & $9.12 \mathrm{E}-01$ & $1.41 \mathrm{E}-01$ & $4.66 \mathrm{E}+00$ & $2.35 E+00$ \\
\hline 218 & 10.50 & 8.24E-01 & $1.36 \mathrm{E}-01$ & $4.67 E+00$ & $2.67 E+00$ \\
\hline 219 & 10.53 & $9.35 \mathrm{E}-01$ & $1.44 \mathrm{E}-01$ & $5.01 E+00$ & $2.61 E+00$ \\
\hline 220 & 10.56 & $1.02 E+00$ & 1.39E-01 & $5.16 \mathrm{E}+00$ & $2.73 E+00$ \\
\hline 221 & 10.58 & $1.01 \mathrm{E}+00$ & $1.40 \mathrm{E}-01$ & $5.04 \mathrm{E}+00$ & $2.90 \mathrm{E}+00$ \\
\hline 222 & 10.61 & $9.30 \mathrm{E}-01$ & $1.38 \mathrm{E}-01$ & $4.90 \mathrm{E}+00$ & $2.71 E+00$ \\
\hline 223 & 10.64 & $1.00 \mathrm{E}+00$ & $1.38 \mathrm{E}-01$ & $5.02 \mathrm{E}+00$ & $2.73 E+00$ \\
\hline 224 & 10.67 & $1.12 \mathrm{E}+00$ & $1.44 \mathrm{E}-01$ & $5.31 E+00$ & $2.53 E+00$ \\
\hline 225 & 10.69 & $1.10 \mathrm{E}+00$ & $1.41 \mathrm{E}-01$ & $4.89 \mathrm{E}+00$ & $2.48 \mathrm{E}+00$ \\
\hline 226 & 10.72 & $1.02 \mathrm{E}+00$ & $1.35 \mathrm{E}-01$ & $5.01 \mathrm{E}+00$ & $2.50 E+00$ \\
\hline 227 & 10.75 & 8.86E-01 & 1.36E-01 & $4.81 E+00$ & $2.54 \mathrm{E}+00$ \\
\hline 228 & 10.77 & $9.13 \mathrm{E}-01$ & 1.39E-01 & $4.62 E+00$ & $2.48 \mathrm{E}+00$ \\
\hline 229 & 10.80 & $1.15 E+00$ & $1.36 \mathrm{E}-01$ & $5.22 \mathrm{E}+00$ & $2.78 \mathrm{E}+00$ \\
\hline 230 & 10.83 & $1.26 \mathrm{E}+00$ & $1.44 \mathrm{E}-01$ & $5.04 \mathrm{E}+00$ & $2.44 \mathrm{E}+00$ \\
\hline 231 & 10.86 & $1.12 \mathrm{E}+00$ & 1.44E-01 & $4.90 \mathrm{E}+00$ & $2.38 \mathrm{E}+00$ \\
\hline 232 & 10.88 & $1.32 \mathrm{E}+00$ & 1.47E-01 & $5.13 \mathrm{E}+00$ & $2.47 \mathrm{E}+00$ \\
\hline 233 & 10.91 & $1.95 \mathrm{E}+00$ & 1.47E-01 & $5.61 \mathrm{E}+00$ & $2.62 E+00$ \\
\hline 234 & 10.94 & $1.96 \mathrm{E}+00$ & $1.46 \mathrm{E}-01$ & $6.07 \mathrm{E}+00$ & $2.80 E+00$ \\
\hline 235 & 10.97 & $2.08 \mathrm{E}+00$ & $1.44 \mathrm{E}-01$ & $6.01 \mathrm{E}+00$ & $2.89 \mathrm{E}+00$ \\
\hline 236 & 10.99 & $2.57 E+00$ & 1.49E-01 & $6.13 \mathrm{E}+00$ & $2.74 \mathrm{E}+00$ \\
\hline 237 & 11.02 & $1.79 E+00$ & $1.48 \mathrm{E}-01$ & $5.75 E+00$ & $2.80 E+00$ \\
\hline 238 & 11.05 & $1.68 \mathrm{E}+00$ & $1.46 \mathrm{E}-01$ & $5.94 \mathrm{E}+00$ & $2.91 \mathrm{E}+00$ \\
\hline 239 & 11.08 & $2.56 \mathrm{E}+00$ & $1.45 \mathrm{E}-01$ & $5.92 \mathrm{E}+00$ & $3.13 E+00$ \\
\hline 240 & 11.10 & $2.31 E+00$ & $1.48 \mathrm{E}-01$ & $5.64 \mathrm{E}+00$ & $2.79 \mathrm{E}+00$ \\
\hline 241 & 11.13 & $1.43 \mathrm{E}+00$ & $1.38 \mathrm{E}-01$ & $5.29 \mathrm{E}+00$ & $2.95 \mathrm{E}+00$ \\
\hline 242 & 11.13 & $2.30 \mathrm{E}+00$ & $1.46 \mathrm{E}-01$ & $6.09 \mathrm{E}+00$ & $2.91 \mathrm{E}+00$ \\
\hline 243 & 11.14 & $3.12 \mathrm{E}+00$ & $1.45 \mathrm{E}-01$ & $6.15 \mathrm{E}+00$ & $3.03 E+00$ \\
\hline 244 & 11.14 & $1.64 \mathrm{E}+00$ & 1.43E-01 & $5.85 \mathrm{E}+00$ & $2.86 \mathrm{E}+00$ \\
\hline 245 & 11.15 & $1.56 \mathrm{E}+00$ & 1.44E-01 & $5.62 \mathrm{E}+00$ & $2.71 E+00$ \\
\hline 246 & 11.15 & $1.79 \mathrm{E}+00$ & $1.52 \mathrm{E}-01$ & $5.59 E+00$ & $2.45 \mathrm{E}+00$ \\
\hline 247 & 11.16 & $2.08 \mathrm{E}+00$ & $1.51 \mathrm{E}-01$ & $5.51 E+00$ & $2.44 \mathrm{E}+00$ \\
\hline 248 & 11.16 & $2.12 \mathrm{E}+00$ & $1.46 \mathrm{E}-01$ & $5.80 \mathrm{E}+00$ & $2.51 \mathrm{E}+00$ \\
\hline 249 & 11.17 & $1.58 \mathrm{E}+00$ & $1.49 \mathrm{E}-01$ & $5.82 \mathrm{E}+00$ & $2.60 E+00$ \\
\hline 250 & 11.17 & $1.36 \mathrm{E}+00$ & $1.48 \mathrm{E}-01$ & $5.56 \mathrm{E}+00$ & $2.48 \mathrm{E}+00$ \\
\hline 251 & 11.18 & $1.88 \mathrm{E}+00$ & $1.45 \mathrm{E}-01$ & $5.86 \mathrm{E}+00$ & $2.83 \mathrm{E}+00$ \\
\hline 252 & 11.18 & $2.22 \mathrm{E}+00$ & 1.47E-01 & $5.53 \mathrm{E}+00$ & $2.55 \mathrm{E}+00$ \\
\hline 253 & 11.19 & $2.04 \mathrm{E}+00$ & 1.49E-01 & $5.28 \mathrm{E}+00$ & $2.56 \mathrm{E}+00$ \\
\hline 254 & 11.19 & $2.05 \mathrm{E}+00$ & $1.46 \mathrm{E}-01$ & $5.70 \mathrm{E}+00$ & $2.88 \mathrm{E}+00$ \\
\hline 255 & 11.20 & $2.16 \mathrm{E}+00$ & 1.49E-01 & $5.67 \mathrm{E}+00$ & $2.81 E+00$ \\
\hline 256 & 11.20 & $2.10 E+00$ & $1.44 \mathrm{E}-01$ & $5.74 \mathrm{E}+00$ & $2.85 \mathrm{E}+00$ \\
\hline 257 & 11.21 & $2.12 E+00$ & $1.36 \mathrm{E}-01$ & $5.90 \mathrm{E}+00$ & $2.92 \mathrm{E}+00$ \\
\hline
\end{tabular}




\begin{tabular}{|c|c|c|c|c|c|}
\hline $\begin{array}{c}\text { Depth } \\
{[\mathrm{cm}]}\end{array}$ & $\begin{array}{c}\text { Age } \\
\text { [cal kyr] }\end{array}$ & $\begin{array}{c}\mathrm{Fe} / \mathrm{Ca} \\
{[c p s]}\end{array}$ & $\begin{array}{l}\mathbf{A l} / \mathbf{S i} \\
{[c p s]}\end{array}$ & $\begin{array}{l}\mathrm{Fe} / \mathrm{K} \\
{[c p s]}\end{array}$ & $\begin{array}{l}\text { Ti/Al } \\
\text { [cps] }\end{array}$ \\
\hline 258 & 11.21 & $2.24 \mathrm{E}+00$ & $1.45 \mathrm{E}-01$ & $5.64 \mathrm{E}+00$ & $2.71 E+00$ \\
\hline 259 & 11.22 & $2.20 \mathrm{E}+00$ & $1.46 \mathrm{E}-01$ & $5.47 \mathrm{E}+00$ & $2.72 E+00$ \\
\hline 260 & 11.22 & $2.11 E+00$ & $1.42 \mathrm{E}-01$ & $5.26 \mathrm{E}+00$ & $2.70 \mathrm{E}+00$ \\
\hline 261 & 11.23 & $1.95 E+00$ & 1.44E-01 & $5.16 \mathrm{E}+00$ & $2.47 E+00$ \\
\hline 262 & 11.23 & $2.03 E+00$ & $1.48 \mathrm{E}-01$ & $5.58 \mathrm{E}+00$ & $2.45 E+00$ \\
\hline 263 & 11.24 & $1.98 \mathrm{E}+00$ & $1.41 \mathrm{E}-01$ & $5.37 E+00$ & $2.58 \mathrm{E}+00$ \\
\hline 264 & 11.24 & $2.08 \mathrm{E}+00$ & $1.45 \mathrm{E}-01$ & $5.80 \mathrm{E}+00$ & $2.54 \mathrm{E}+00$ \\
\hline 265 & 11.25 & $1.86 \mathrm{E}+00$ & $1.43 \mathrm{E}-01$ & $5.36 \mathrm{E}+00$ & $2.55 E+00$ \\
\hline 266 & 11.25 & $1.74 \mathrm{E}+00$ & $1.38 \mathrm{E}-01$ & $5.17 \mathrm{E}+00$ & $2.69 E+00$ \\
\hline 267 & 11.26 & $1.35 \mathrm{E}+00$ & $1.34 \mathrm{E}-01$ & $5.28 \mathrm{E}+00$ & $2.68 \mathrm{E}+00$ \\
\hline 268 & 11.26 & $1.51 \mathrm{E}+00$ & $1.36 \mathrm{E}-01$ & $5.05 E+00$ & $2.81 E+00$ \\
\hline 269 & 11.27 & $1.66 \mathrm{E}+00$ & $1.31 \mathrm{E}-01$ & $5.39 \mathrm{E}+00$ & $2.85 \mathrm{E}+00$ \\
\hline 270 & 11.27 & $2.01 E+00$ & $1.30 \mathrm{E}-01$ & $5.67 E+00$ & $2.66 \mathrm{E}+00$ \\
\hline 271 & 11.28 & $1.78 \mathrm{E}+00$ & $1.32 \mathrm{E}-01$ & $5.18 \mathrm{E}+00$ & $2.81 E+00$ \\
\hline 272 & 11.28 & $1.87 E+00$ & $1.33 \mathrm{E}-01$ & $5.51 \mathrm{E}+00$ & $2.75 E+00$ \\
\hline 273 & 11.29 & $1.87 \mathrm{E}+00$ & $1.33 \mathrm{E}-01$ & $5.34 \mathrm{E}+00$ & $2.89 \mathrm{E}+00$ \\
\hline 274 & 11.29 & $1.92 \mathrm{E}+00$ & $1.25 \mathrm{E}-01$ & $5.57 \mathrm{E}+00$ & $3.19 E+00$ \\
\hline 275 & 11.29 & $1.78 \mathrm{E}+00$ & $1.22 \mathrm{E}-01$ & $5.38 \mathrm{E}+00$ & $3.14 \mathrm{E}+00$ \\
\hline 276 & 11.30 & $1.80 \mathrm{E}+00$ & $1.25 \mathrm{E}-01$ & $5.21 \mathrm{E}+00$ & $3.12 E+00$ \\
\hline 277 & 11.30 & $1.86 \mathrm{E}+00$ & $1.25 \mathrm{E}-01$ & $5.21 E+00$ & $3.21 E+00$ \\
\hline 278 & 11.31 & $1.88 \mathrm{E}+00$ & $1.25 \mathrm{E}-01$ & $5.48 \mathrm{E}+00$ & $3.31 E+00$ \\
\hline 279 & 11.31 & $1.96 \mathrm{E}+00$ & $1.20 \mathrm{E}-01$ & $5.45 E+00$ & $3.35 E+00$ \\
\hline 280 & 11.32 & $2.04 \mathrm{E}+00$ & $1.26 \mathrm{E}-01$ & $5.44 \mathrm{E}+00$ & $3.25 \mathrm{E}+00$ \\
\hline 281 & 11.32 & $2.12 \mathrm{E}+00$ & $1.22 \mathrm{E}-01$ & $5.58 \mathrm{E}+00$ & $3.33 E+00$ \\
\hline 282 & 11.33 & $2.09 E+00$ & $1.23 \mathrm{E}-01$ & $5.22 \mathrm{E}+00$ & $3.03 E+00$ \\
\hline 283 & 11.33 & $2.13 \mathrm{E}+00$ & $1.29 \mathrm{E}-01$ & $5.08 \mathrm{E}+00$ & $2.87 \mathrm{E}+00$ \\
\hline 284 & 11.34 & $3.01 E+00$ & 1.47E-01 & $5.76 \mathrm{E}+00$ & $2.67 E+00$ \\
\hline 285 & 11.34 & $1.99 \mathrm{E}+00$ & $1.24 \mathrm{E}-01$ & $5.18 \mathrm{E}+00$ & $3.16 \mathrm{E}+00$ \\
\hline 286 & 11.35 & $2.16 \mathrm{E}+00$ & $1.25 \mathrm{E}-01$ & $5.06 \mathrm{E}+00$ & $2.87 E+00$ \\
\hline 287 & 11.35 & $2.28 \mathrm{E}+00$ & $1.28 \mathrm{E}-01$ & $5.19 E+00$ & $2.81 E+00$ \\
\hline 288 & 11.36 & $2.06 \mathrm{E}+00$ & $1.26 \mathrm{E}-01$ & $4.98 E+00$ & $2.77 E+00$ \\
\hline 289 & 11.36 & $2.24 \mathrm{E}+00$ & $1.24 \mathrm{E}-01$ & $5.13 E+00$ & $2.90 E+00$ \\
\hline 290 & 11.37 & $2.00 \mathrm{E}+00$ & $1.25 \mathrm{E}-01$ & $5.01 \mathrm{E}+00$ & $2.99 E+00$ \\
\hline 291 & 11.37 & $2.08 \mathrm{E}+00$ & $1.27 \mathrm{E}-01$ & $5.02 E+00$ & $2.81 E+00$ \\
\hline 292 & 11.38 & $1.98 \mathrm{E}+00$ & $1.31 \mathrm{E}-01$ & $5.16 \mathrm{E}+00$ & $2.81 \mathrm{E}+00$ \\
\hline 293 & 11.38 & $2.00 \mathrm{E}+00$ & $1.25 \mathrm{E}-01$ & $5.32 \mathrm{E}+00$ & $2.93 \mathrm{E}+00$ \\
\hline 294 & 11.39 & $2.00 \mathrm{E}+00$ & $1.25 \mathrm{E}-01$ & $5.30 \mathrm{E}+00$ & $3.03 E+00$ \\
\hline 295 & 11.39 & $1.94 \mathrm{E}+00$ & $1.25 \mathrm{E}-01$ & $5.00 \mathrm{E}+00$ & $3.13 E+00$ \\
\hline 296 & 11.40 & $1.95 E+00$ & $1.31 \mathrm{E}-01$ & $5.04 \mathrm{E}+00$ & $2.88 E+00$ \\
\hline 297 & 11.40 & $1.86 \mathrm{E}+00$ & $1.25 \mathrm{E}-01$ & $5.13 E+00$ & $3.10 E+00$ \\
\hline 298 & 11.41 & $2.03 E+00$ & $1.32 \mathrm{E}-01$ & $5.11 \mathrm{E}+00$ & $2.74 \mathrm{E}+00$ \\
\hline 299 & 11.41 & $2.15 E+00$ & $1.27 \mathrm{E}-01$ & $5.08 \mathrm{E}+00$ & $2.83 E+00$ \\
\hline 300 & 11.42 & $2.06 \mathrm{E}+00$ & $1.32 \mathrm{E}-01$ & $4.98 \mathrm{E}+00$ & $2.64 \mathrm{E}+00$ \\
\hline
\end{tabular}




\begin{tabular}{|c|c|c|c|c|c|}
\hline $\begin{array}{c}\text { Depth } \\
{[\mathrm{cm}]}\end{array}$ & $\begin{array}{c}\text { Age } \\
{[\text { cal kyr] }}\end{array}$ & $\begin{array}{c}\mathrm{Fe} / \mathrm{Ca} \\
{[c p s]}\end{array}$ & $\begin{array}{l}\mathbf{A l} / \mathbf{S i} \\
{[c p s]}\end{array}$ & $\begin{array}{l}\mathrm{Fe} / \mathrm{K} \\
{[c p s]}\end{array}$ & $\begin{array}{l}\text { Ti/Al } \\
{[c p s]}\end{array}$ \\
\hline 301 & 11.42 & $2.19 \mathrm{E}+00$ & $1.30 \mathrm{E}-01$ & $5.53 E+00$ & $2.69 \mathrm{E}+00$ \\
\hline 302 & 11.43 & $1.89 \mathrm{E}+00$ & $1.30 \mathrm{E}-01$ & $5.09 \mathrm{E}+00$ & $2.64 \mathrm{E}+00$ \\
\hline 303 & 11.43 & $1.78 \mathrm{E}+00$ & $1.28 \mathrm{E}-01$ & $4.94 \mathrm{E}+00$ & $2.52 \mathrm{E}+00$ \\
\hline 304 & 11.44 & $1.87 \mathrm{E}+00$ & $1.32 \mathrm{E}-01$ & $4.91 E+00$ & $2.58 \mathrm{E}+00$ \\
\hline 305 & 11.44 & $1.79 E+00$ & $1.29 \mathrm{E}-01$ & $4.78 \mathrm{E}+00$ & $2.56 \mathrm{E}+00$ \\
\hline 306 & 11.45 & $1.83 \mathrm{E}+00$ & $1.28 \mathrm{E}-01$ & $4.89 E+00$ & $2.58 \mathrm{E}+00$ \\
\hline 307 & 11.45 & $1.86 \mathrm{E}+00$ & $1.24 \mathrm{E}-01$ & $4.94 \mathrm{E}+00$ & $2.67 E+00$ \\
\hline 308 & 11.48 & $1.89 \mathrm{E}+00$ & $1.29 \mathrm{E}-01$ & $4.95 \mathrm{E}+00$ & $2.59 \mathrm{E}+00$ \\
\hline 309 & 11.51 & $1.85 \mathrm{E}+00$ & $1.28 \mathrm{E}-01$ & $4.88 \mathrm{E}+00$ & $2.50 \mathrm{E}+00$ \\
\hline 310 & 11.54 & $1.84 \mathrm{E}+00$ & $1.30 \mathrm{E}-01$ & $5.09 E+00$ & $2.52 E+00$ \\
\hline 311 & 11.57 & $1.91 \mathrm{E}+00$ & $1.26 \mathrm{E}-01$ & $5.06 \mathrm{E}+00$ & $2.62 E+00$ \\
\hline 312 & 11.60 & $1.92 \mathrm{E}+00$ & $1.24 \mathrm{E}-01$ & $5.00 \mathrm{E}+00$ & $2.62 \mathrm{E}+00$ \\
\hline 313 & 11.62 & $1.76 \mathrm{E}+00$ & $1.30 \mathrm{E}-01$ & $4.78 \mathrm{E}+00$ & $2.57 E+00$ \\
\hline 314 & 11.65 & $1.75 \mathrm{E}+00$ & 1.29E-01 & $4.84 E+00$ & $2.43 \mathrm{E}+00$ \\
\hline 315 & 11.68 & $1.82 \mathrm{E}+00$ & $1.31 \mathrm{E}-01$ & $4.86 \mathrm{E}+00$ & $2.46 \mathrm{E}+00$ \\
\hline 316 & 11.71 & $1.79 \mathrm{E}+00$ & $1.30 \mathrm{E}-01$ & $4.85 E+00$ & $2.55 \mathrm{E}+00$ \\
\hline 317 & 11.74 & $1.75 \mathrm{E}+00$ & $1.28 \mathrm{E}-01$ & $4.85 E+00$ & $2.57 E+00$ \\
\hline 318 & 11.77 & $1.76 \mathrm{E}+00$ & $1.27 \mathrm{E}-01$ & $4.77 \mathrm{E}+00$ & $2.50 \mathrm{E}+00$ \\
\hline 319 & 11.80 & $1.87 \mathrm{E}+00$ & $1.25 \mathrm{E}-01$ & $4.64 \mathrm{E}+00$ & $2.65 \mathrm{E}+00$ \\
\hline 320 & 11.83 & $1.97 \mathrm{E}+00$ & $1.28 \mathrm{E}-01$ & $4.68 \mathrm{E}+00$ & $2.55 \mathrm{E}+00$ \\
\hline 321 & 11.86 & $2.08 \mathrm{E}+00$ & $1.26 \mathrm{E}-01$ & $4.92 \mathrm{E}+00$ & $2.56 \mathrm{E}+00$ \\
\hline 322 & 11.89 & $2.08 \mathrm{E}+00$ & $1.24 \mathrm{E}-01$ & $4.85 \mathrm{E}+00$ & $2.59 \mathrm{E}+00$ \\
\hline 323 & 11.92 & $2.20 E+00$ & 1.30E-01 & $4.79 E+00$ & $2.48 \mathrm{E}+00$ \\
\hline 324 & 11.94 & $2.02 E+00$ & $1.27 \mathrm{E}-01$ & $4.60 E+00$ & $2.53 \mathrm{E}+00$ \\
\hline 325 & 11.97 & $2.14 \mathrm{E}+00$ & $1.22 \mathrm{E}-01$ & $4.77 \mathrm{E}+00$ & $2.78 \mathrm{E}+00$ \\
\hline 326 & 12.00 & $2.23 E+00$ & $1.22 \mathrm{E}-01$ & $5.04 \mathrm{E}+00$ & $2.76 \mathrm{E}+00$ \\
\hline 327 & 12.03 & $2.19 \mathrm{E}+00$ & $1.21 \mathrm{E}-01$ & $4.78 \mathrm{E}+00$ & $2.70 E+00$ \\
\hline 328 & 12.06 & $2.08 \mathrm{E}+00$ & $1.25 \mathrm{E}-01$ & $4.80 \mathrm{E}+00$ & $2.76 \mathrm{E}+00$ \\
\hline 329 & 12.09 & $2.18 \mathrm{E}+00$ & $1.28 \mathrm{E}-01$ & $4.85 \mathrm{E}+00$ & $2.56 \mathrm{E}+00$ \\
\hline 330 & 12.09 & $1.96 \mathrm{E}+00$ & $1.29 \mathrm{E}-01$ & $4.76 \mathrm{E}+00$ & $2.62 E+00$ \\
\hline 331 & 12.09 & $2.01 \mathrm{E}+00$ & $1.25 \mathrm{E}-01$ & $4.73 E+00$ & $2.58 \mathrm{E}+00$ \\
\hline 332 & 12.10 & $1.96 \mathrm{E}+00$ & $1.28 \mathrm{E}-01$ & $4.88 \mathrm{E}+00$ & $2.50 \mathrm{E}+00$ \\
\hline 333 & 12.10 & $2.25 E+00$ & 1.30E-01 & $4.95 E+00$ & $2.53 \mathrm{E}+00$ \\
\hline 334 & 12.10 & $2.11 \mathrm{E}+00$ & $1.31 \mathrm{E}-01$ & $5.01 \mathrm{E}+00$ & $2.60 E+00$ \\
\hline 335 & 12.10 & $2.00 \mathrm{E}+00$ & $1.28 \mathrm{E}-01$ & $4.79 E+00$ & $2.62 E+00$ \\
\hline 336 & 12.10 & $2.13 \mathrm{E}+00$ & $1.28 \mathrm{E}-01$ & $4.85 \mathrm{E}+00$ & $2.56 \mathrm{E}+00$ \\
\hline 337 & 12.10 & $2.08 \mathrm{E}+00$ & $1.25 \mathrm{E}-01$ & $4.95 \mathrm{E}+00$ & $2.72 \mathrm{E}+00$ \\
\hline 338 & 12.11 & $2.02 \mathrm{E}+00$ & $1.26 \mathrm{E}-01$ & $5.10 \mathrm{E}+00$ & $2.70 \mathrm{E}+00$ \\
\hline 339 & 12.11 & $1.99 \mathrm{E}+00$ & 1.27E-01 & $4.96 \mathrm{E}+00$ & $2.76 \mathrm{E}+00$ \\
\hline 340 & 12.11 & $1.82 \mathrm{E}+00$ & $1.25 \mathrm{E}-01$ & $5.09 \mathrm{E}+00$ & $2.74 \mathrm{E}+00$ \\
\hline 341 & 12.11 & $1.97 E+00$ & $1.31 \mathrm{E}-01$ & $5.01 \mathrm{E}+00$ & $2.59 \mathrm{E}+00$ \\
\hline 342 & 12.11 & $2.01 E+00$ & 1.27E-01 & $5.03 E+00$ & $2.64 \mathrm{E}+00$ \\
\hline 343 & 12.12 & $1.92 \mathrm{E}+00$ & $1.26 \mathrm{E}-01$ & $5.17 E+00$ & $2.74 \mathrm{E}+00$ \\
\hline
\end{tabular}




\begin{tabular}{|c|c|c|c|c|c|}
\hline $\begin{array}{c}\text { Depth } \\
{[\mathrm{cm}]}\end{array}$ & $\begin{array}{c}\text { Age } \\
{[\text { cal kyr] }}\end{array}$ & $\begin{array}{c}\mathrm{Fe} / \mathrm{Ca} \\
{[c p s]}\end{array}$ & $\begin{array}{l}\mathbf{A l} / \mathbf{S i} \\
{[c p s]}\end{array}$ & $\begin{array}{l}\mathrm{Fe} / \mathrm{K} \\
{[c p s]}\end{array}$ & $\begin{array}{l}\text { Ti/Al } \\
{[c p s]}\end{array}$ \\
\hline 344 & 12.12 & $2.01 E+00$ & $1.24 \mathrm{E}-01$ & $5.07 E+00$ & $2.64 \mathrm{E}+00$ \\
\hline 345 & 12.12 & $1.90 \mathrm{E}+00$ & $1.33 \mathrm{E}-01$ & $4.85 E+00$ & $2.34 \mathrm{E}+00$ \\
\hline 346 & 12.12 & $1.95 \mathrm{E}+00$ & $1.25 \mathrm{E}-01$ & $4.89 E+00$ & $2.69 \mathrm{E}+00$ \\
\hline 347 & 12.12 & $2.06 \mathrm{E}+00$ & $1.26 \mathrm{E}-01$ & $4.85 \mathrm{E}+00$ & $2.69 E+00$ \\
\hline 348 & 12.13 & $2.30 E+00$ & $1.31 \mathrm{E}-01$ & $4.72 E+00$ & $2.56 \mathrm{E}+00$ \\
\hline 349 & 12.13 & $2.52 E+00$ & $1.29 \mathrm{E}-01$ & $5.07 E+00$ & $2.60 E+00$ \\
\hline 350 & 12.13 & $2.39 \mathrm{E}+00$ & $1.32 \mathrm{E}-01$ & $5.03 \mathrm{E}+00$ & $2.54 \mathrm{E}+00$ \\
\hline 351 & 12.13 & $2.28 \mathrm{E}+00$ & $1.31 \mathrm{E}-01$ & $4.91 \mathrm{E}+00$ & $2.64 \mathrm{E}+00$ \\
\hline 352 & 12.13 & $2.54 \mathrm{E}+00$ & $1.32 \mathrm{E}-01$ & $5.04 \mathrm{E}+00$ & $2.68 \mathrm{E}+00$ \\
\hline 353 & 12.13 & $2.42 \mathrm{E}+00$ & $1.37 \mathrm{E}-01$ & $4.81 \mathrm{E}+00$ & $2.56 \mathrm{E}+00$ \\
\hline 354 & 12.14 & $2.27 \mathrm{E}+00$ & $1.36 \mathrm{E}-01$ & $5.01 E+00$ & $2.64 \mathrm{E}+00$ \\
\hline 355 & 12.14 & $2.22 \mathrm{E}+00$ & $1.36 \mathrm{E}-01$ & $4.99 \mathrm{E}+00$ & $2.52 \mathrm{E}+00$ \\
\hline 356 & 12.14 & $2.45 \mathrm{E}+00$ & $1.35 \mathrm{E}-01$ & $5.18 \mathrm{E}+00$ & $2.64 \mathrm{E}+00$ \\
\hline 357 & 12.14 & $2.23 E+00$ & $1.31 \mathrm{E}-01$ & $5.23 E+00$ & 2.77E+00 \\
\hline 358 & 12.14 & $2.32 E+00$ & 1.33E-01 & $5.06 \mathrm{E}+00$ & $2.62 \mathrm{E}+00$ \\
\hline 359 & 12.15 & $2.18 \mathrm{E}+00$ & $1.38 \mathrm{E}-01$ & $4.92 \mathrm{E}+00$ & $2.56 \mathrm{E}+00$ \\
\hline 360 & 12.15 & $2.37 \mathrm{E}+00$ & $1.30 \mathrm{E}-01$ & $5.19 \mathrm{E}+00$ & $2.75 \mathrm{E}+00$ \\
\hline 361 & 12.15 & $2.38 \mathrm{E}+00$ & $1.34 \mathrm{E}-01$ & $5.35 \mathrm{E}+00$ & $2.70 \mathrm{E}+00$ \\
\hline 362 & 12.15 & $2.34 \mathrm{E}+00$ & $1.33 \mathrm{E}-01$ & $4.94 \mathrm{E}+00$ & $2.68 \mathrm{E}+00$ \\
\hline 363 & 12.15 & $2.52 E+00$ & $1.32 \mathrm{E}-01$ & $5.21 \mathrm{E}+00$ & $2.61 E+00$ \\
\hline 364 & 12.16 & $2.38 \mathrm{E}+00$ & $1.36 \mathrm{E}-01$ & $4.89 \mathrm{E}+00$ & $2.53 \mathrm{E}+00$ \\
\hline 365 & 12.16 & $2.74 \mathrm{E}+00$ & 1.34E-01 & $5.49 E+00$ & $2.63 E+00$ \\
\hline 366 & 12.16 & $2.61 E+00$ & 1.33E-01 & $5.33 E+00$ & $2.67 E+00$ \\
\hline 367 & 12.16 & $2.64 \mathrm{E}+00$ & $1.33 \mathrm{E}-01$ & $5.49 E+00$ & $2.67 E+00$ \\
\hline 368 & 12.16 & $2.62 E+00$ & $1.31 \mathrm{E}-01$ & $5.55 E+00$ & $2.85 E+00$ \\
\hline 369 & 12.16 & $3.00 E+00$ & $1.35 \mathrm{E}-01$ & $5.89 \mathrm{E}+00$ & $2.72 \mathrm{E}+00$ \\
\hline 370 & 12.17 & $2.77 E+00$ & $1.35 \mathrm{E}-01$ & $5.61 \mathrm{E}+00$ & $2.69 \mathrm{E}+00$ \\
\hline 371 & 12.17 & $2.48 \mathrm{E}+00$ & 1.37E-01 & $5.23 \mathrm{E}+00$ & $2.67 E+00$ \\
\hline 372 & 12.17 & $2.67 \mathrm{E}+00$ & 1.34E-01 & $5.43 \mathrm{E}+00$ & $2.86 \mathrm{E}+00$ \\
\hline 373 & 12.17 & $2.61 \mathrm{E}+00$ & $1.35 \mathrm{E}-01$ & $5.51 \mathrm{E}+00$ & $2.82 E+00$ \\
\hline 374 & 12.17 & $2.93 \mathrm{E}+00$ & 1.32E-01 & $5.61 \mathrm{E}+00$ & $2.84 \mathrm{E}+00$ \\
\hline 375 & 12.18 & $2.81 E+00$ & $1.38 \mathrm{E}-01$ & $5.39 E+00$ & $2.70 E+00$ \\
\hline 376 & 12.18 & $2.91 \mathrm{E}+00$ & $1.31 \mathrm{E}-01$ & $5.42 E+00$ & $2.79 E+00$ \\
\hline 377 & 12.18 & $2.70 E+00$ & $1.38 \mathrm{E}-01$ & $5.23 E+00$ & $2.65 E+00$ \\
\hline 378 & 12.18 & $2.65 E+00$ & $1.31 \mathrm{E}-01$ & $5.35 E+00$ & $2.75 E+00$ \\
\hline 379 & 12.18 & $2.63 \mathrm{E}+00$ & $1.34 \mathrm{E}-01$ & $5.33 \mathrm{E}+00$ & $2.85 E+00$ \\
\hline 380 & 12.19 & $2.83 \mathrm{E}+00$ & $1.31 \mathrm{E}-01$ & $5.57 \mathrm{E}+00$ & $2.84 \mathrm{E}+00$ \\
\hline 381 & 12.19 & $2.67 E+00$ & $1.36 \mathrm{E}-01$ & $5.27 \mathrm{E}+00$ & $2.73 E+00$ \\
\hline 382 & 12.19 & $2.91 E+00$ & 1.34E-01 & $5.59 \mathrm{E}+00$ & $2.82 \mathrm{E}+00$ \\
\hline 383 & 12.19 & $2.80 \mathrm{E}+00$ & 1.36E-01 & $5.26 \mathrm{E}+00$ & $2.66 \mathrm{E}+00$ \\
\hline 384 & 12.19 & $3.32 E+00$ & 1.33E-01 & $6.08 \mathrm{E}+00$ & $2.79 \mathrm{E}+00$ \\
\hline 385 & 12.19 & $2.97 E+00$ & 1.33E-01 & $5.32 E+00$ & $2.69 \mathrm{E}+00$ \\
\hline 386 & 12.20 & $3.70 E+00$ & $1.37 \mathrm{E}-01$ & $5.39 E+00$ & $2.69 \mathrm{E}+00$ \\
\hline
\end{tabular}




\begin{tabular}{|c|c|c|c|c|c|}
\hline $\begin{array}{c}\text { Depth } \\
{[\mathrm{cm}]}\end{array}$ & $\begin{array}{c}\text { Age } \\
\text { [cal kyr] }\end{array}$ & $\begin{array}{c}\mathrm{Fe} / \mathrm{Ca} \\
{[c p s]}\end{array}$ & $\begin{array}{l}\mathbf{A l} / \mathbf{S i} \\
{[c p s]}\end{array}$ & $\begin{array}{l}\mathrm{Fe} / \mathrm{K} \\
{[c p s]}\end{array}$ & $\begin{array}{l}\text { Ti/Al } \\
\text { [cps] }\end{array}$ \\
\hline 387 & 12.20 & $3.86 E+00$ & $1.31 \mathrm{E}-01$ & $5.46 \mathrm{E}+00$ & $2.87 \mathrm{E}+00$ \\
\hline 388 & 12.20 & $5.63 \mathrm{E}+00$ & $1.29 \mathrm{E}-01$ & $5.54 \mathrm{E}+00$ & $2.98 \mathrm{E}+00$ \\
\hline 389 & 12.20 & $5.39 E+00$ & $1.35 \mathrm{E}-01$ & $5.47 E+00$ & $2.91 E+00$ \\
\hline 390 & 12.20 & $3.50 \mathrm{E}+00$ & $1.36 \mathrm{E}-01$ & $5.24 \mathrm{E}+00$ & $2.88 \mathrm{E}+00$ \\
\hline 391 & 12.21 & $3.46 \mathrm{E}+00$ & $1.31 \mathrm{E}-01$ & $5.24 \mathrm{E}+00$ & $2.88 \mathrm{E}+00$ \\
\hline 392 & 12.21 & $3.49 \mathrm{E}+00$ & $1.31 \mathrm{E}-01$ & $5.39 \mathrm{E}+00$ & $3.04 \mathrm{E}+00$ \\
\hline 393 & 12.21 & $3.13 E+00$ & $1.34 \mathrm{E}-01$ & $5.58 \mathrm{E}+00$ & $3.06 \mathrm{E}+00$ \\
\hline 394 & 12.21 & $3.33 E+00$ & $1.32 \mathrm{E}-01$ & $5.59 \mathrm{E}+00$ & $2.95 E+00$ \\
\hline 395 & 12.21 & $3.42 E+00$ & $1.33 \mathrm{E}-01$ & $5.41 \mathrm{E}+00$ & $2.91 E+00$ \\
\hline 396 & 12.22 & $3.89 E+00$ & $1.32 \mathrm{E}-01$ & $5.42 \mathrm{E}+00$ & $2.84 E+00$ \\
\hline 397 & 12.22 & $4.07 E+00$ & $1.33 \mathrm{E}-01$ & $5.29 E+00$ & $2.88 \mathrm{E}+00$ \\
\hline 398 & 12.22 & $3.89 \mathrm{E}+00$ & $1.37 \mathrm{E}-01$ & $5.56 \mathrm{E}+00$ & $3.04 \mathrm{E}+00$ \\
\hline 399 & 12.22 & $3.64 \mathrm{E}+00$ & $1.38 \mathrm{E}-01$ & $5.47 E+00$ & $2.90 \mathrm{E}+00$ \\
\hline 400 & 12.22 & $3.72 E+00$ & $1.39 \mathrm{E}-01$ & $5.43 E+00$ & $2.82 E+00$ \\
\hline 401 & 12.22 & $3.95 E+00$ & $1.36 \mathrm{E}-01$ & $5.78 \mathrm{E}+00$ & $2.82 E+00$ \\
\hline 402 & 12.23 & $3.63 E+00$ & $1.37 \mathrm{E}-01$ & $5.81 E+00$ & $2.89 E+00$ \\
\hline 403 & 12.23 & $3.41 E+00$ & $1.37 \mathrm{E}-01$ & $5.66 \mathrm{E}+00$ & $2.89 E+00$ \\
\hline 404 & 12.23 & $3.54 \mathrm{E}+00$ & $1.43 \mathrm{E}-01$ & $5.71 \mathrm{E}+00$ & $2.69 E+00$ \\
\hline 405 & 12.23 & $3.78 E+00$ & $1.43 \mathrm{E}-01$ & $5.68 \mathrm{E}+00$ & $2.67 E+00$ \\
\hline 406 & 12.23 & $3.53 E+00$ & $1.41 \mathrm{E}-01$ & $5.93 E+00$ & $2.81 E+00$ \\
\hline 407 & 12.24 & $3.19 \mathrm{E}+00$ & $1.45 \mathrm{E}-01$ & $5.60 \mathrm{E}+00$ & $2.65 \mathrm{E}+00$ \\
\hline 408 & 12.24 & $3.73 E+00$ & $1.43 \mathrm{E}-01$ & $6.04 \mathrm{E}+00$ & $2.57 E+00$ \\
\hline 409 & 12.24 & $3.36 E+00$ & $1.52 \mathrm{E}-01$ & $5.67 \mathrm{E}+00$ & $2.50 E+00$ \\
\hline 410 & 12.24 & $2.98 \mathrm{E}+00$ & 1.47E-01 & $5.66 \mathrm{E}+00$ & $2.52 E+00$ \\
\hline 411 & 12.24 & $3.39 E+00$ & $1.42 \mathrm{E}-01$ & $5.76 \mathrm{E}+00$ & $2.70 E+00$ \\
\hline 412 & 12.25 & $3.40 \mathrm{E}+00$ & $1.47 \mathrm{E}-01$ & $5.74 \mathrm{E}+00$ & $2.58 \mathrm{E}+00$ \\
\hline 413 & 12.25 & $2.86 \mathrm{E}+00$ & 1.49E-01 & $5.58 \mathrm{E}+00$ & $2.59 E+00$ \\
\hline 414 & 12.25 & $2.81 E+00$ & $1.50 \mathrm{E}-01$ & $5.73 E+00$ & $2.50 E+00$ \\
\hline 415 & 12.25 & $2.67 E+00$ & $1.50 \mathrm{E}-01$ & $5.62 E+00$ & $2.56 \mathrm{E}+00$ \\
\hline 416 & 12.25 & $2.43 E+00$ & 1.49E-01 & $5.74 \mathrm{E}+00$ & $2.56 \mathrm{E}+00$ \\
\hline 417 & 12.25 & $2.60 \mathrm{E}+00$ & 1.47E-01 & $5.83 E+00$ & $2.55 E+00$ \\
\hline 418 & 12.26 & $2.55 E+00$ & $1.51 \mathrm{E}-01$ & $5.81 \mathrm{E}+00$ & $2.45 \mathrm{E}+00$ \\
\hline 419 & 12.26 & $2.47 E+00$ & $1.58 \mathrm{E}-01$ & $5.70 \mathrm{E}+00$ & $2.30 E+00$ \\
\hline 420 & 12.26 & $2.59 E+00$ & $1.53 \mathrm{E}-01$ & $5.76 \mathrm{E}+00$ & $2.40 E+00$ \\
\hline 421 & 12.26 & $2.68 \mathrm{E}+00$ & $1.54 \mathrm{E}-01$ & $5.89 \mathrm{E}+00$ & $2.41 \mathrm{E}+00$ \\
\hline 422 & 12.26 & $2.22 \mathrm{E}+00$ & 1.49E-01 & $5.83 \mathrm{E}+00$ & $2.54 \mathrm{E}+00$ \\
\hline 423 & 12.27 & $1.50 \mathrm{E}+00$ & $1.54 \mathrm{E}-01$ & $5.72 E+00$ & $2.36 \mathrm{E}+00$ \\
\hline 424 & 12.27 & $1.84 \mathrm{E}+00$ & $1.57 \mathrm{E}-01$ & $5.84 \mathrm{E}+00$ & $2.33 E+00$ \\
\hline 425 & 12.27 & $1.58 \mathrm{E}+00$ & $1.58 \mathrm{E}-01$ & $5.55 E+00$ & $2.29 E+00$ \\
\hline 426 & 12.27 & $1.56 E+00$ & $1.54 \mathrm{E}-01$ & $5.70 \mathrm{E}+00$ & $2.29 E+00$ \\
\hline 427 & 12.27 & $2.06 \mathrm{E}+00$ & $1.54 \mathrm{E}-01$ & $6.10 \mathrm{E}+00$ & $2.41 E+00$ \\
\hline 428 & 12.28 & $1.85 E+00$ & 1.57E-01 & $6.05 E+00$ & $2.41 E+00$ \\
\hline 429 & 12.28 & $1.49 \mathrm{E}+00$ & 1.60E-01 & $5.82 \mathrm{E}+00$ & $2.30 E+00$ \\
\hline
\end{tabular}




\begin{tabular}{cccccc}
\hline Depth & Age & Fe/Ca & Al/Si & Fe/K & Ti/Al \\
[cm] & {$[c a l k y r]$} & {$[c p s]$} & {$[c p s]$} & {$[c p s]$} & {$[c p s]$} \\
\hline 430 & 12.28 & $1.20 \mathrm{E}+00$ & $1.53 \mathrm{E}-01$ & $5.34 \mathrm{E}+00$ & $2.26 \mathrm{E}+00$ \\
431 & 12.28 & $9.27 \mathrm{E}-01$ & $1.50 \mathrm{E}-01$ & $5.23 \mathrm{E}+00$ & $2.25 \mathrm{E}+00$ \\
432 & 12.28 & $1.05 \mathrm{E}+00$ & $1.52 \mathrm{E}-01$ & $5.27 \mathrm{E}+00$ & $2.28 \mathrm{E}+00$ \\
433 & 12.28 & $1.04 \mathrm{E}+00$ & $1.54 \mathrm{E}-01$ & $5.20 \mathrm{E}+00$ & $2.26 \mathrm{E}+00$ \\
434 & 12.29 & $1.05 \mathrm{E}+00$ & $1.51 \mathrm{E}-01$ & $5.51 \mathrm{E}+00$ & $2.36 \mathrm{E}+00$ \\
435 & 12.29 & $9.05 \mathrm{E}-01$ & $1.54 \mathrm{E}-01$ & $4.99 \mathrm{E}+00$ & $2.21 \mathrm{E}+00$ \\
436 & 12.29 & $9.30 \mathrm{E}-01$ & $1.53 \mathrm{E}-01$ & $5.07 \mathrm{E}+00$ & $2.25 \mathrm{E}+00$ \\
437 & 12.29 & $8.23 \mathrm{E}-01$ & $1.52 \mathrm{E}-01$ & $4.91 \mathrm{E}+00$ & $2.28 \mathrm{E}+00$ \\
438 & 12.29 & $8.71 \mathrm{E}-01$ & $1.46 \mathrm{E}-01$ & $5.14 \mathrm{E}+00$ & $2.32 \mathrm{E}+00$ \\
439 & 12.30 & $9.21 \mathrm{E}-01$ & $1.47 \mathrm{E}-01$ & $5.11 \mathrm{E}+00$ & $2.41 \mathrm{E}+00$ \\
440 & 12.30 & $9.53 \mathrm{E}-01$ & $1.51 \mathrm{E}-01$ & $5.10 \mathrm{E}+00$ & $2.38 \mathrm{E}+00$ \\
441 & 12.30 & $9.15 \mathrm{E}-01$ & $1.50 \mathrm{E}-01$ & $5.16 \mathrm{E}+00$ & $2.32 \mathrm{E}+00$ \\
442 & 12.30 & $9.09 \mathrm{E}-01$ & $1.50 \mathrm{E}-01$ & $5.17 \mathrm{E}+00$ & $2.34 \mathrm{E}+00$ \\
443 & 12.30 & $9.39 \mathrm{E}-01$ & $1.54 \mathrm{E}-01$ & $4.93 \mathrm{E}+00$ & $2.27 \mathrm{E}+00$ \\
444 & 12.31 & $9.18 \mathrm{E}-01$ & $1.54 \mathrm{E}-01$ & $4.89 \mathrm{E}+00$ & $2.34 \mathrm{E}+00$ \\
445 & 12.31 & $1.05 \mathrm{E}+00$ & $1.49 \mathrm{E}-01$ & $4.88 \mathrm{E}+00$ & $2.40 \mathrm{E}+00$ \\
446 & 12.31 & $1.22 \mathrm{E}+00$ & $1.54 \mathrm{E}-01$ & $4.84 \mathrm{E}+00$ & $2.37 \mathrm{E}+00$ \\
447 & 12.31 & $1.48 \mathrm{E}+00$ & $1.51 \mathrm{E}-01$ & $4.85 \mathrm{E}+00$ & $2.43 \mathrm{E}+00$ \\
448 & 12.31 & $1.20 \mathrm{E}+00$ & $1.51 \mathrm{E}-01$ & $4.88 \mathrm{E}+00$ & $2.31 \mathrm{E}+00$ \\
449 & 12.31 & $1.20 \mathrm{E}+00$ & $1.51 \mathrm{E}-01$ & $4.99 \mathrm{E}+00$ & $2.43 \mathrm{E}+00$ \\
450 & 12.32 & $1.11 \mathrm{E}+00$ & $1.51 \mathrm{E}-01$ & $4.74 \mathrm{E}+00$ & $2.38 \mathrm{E}+00$ \\
470 & 12.88 & $3.13 \mathrm{E}+00$ & $1.54 \mathrm{E}-01$ & $5.18 \mathrm{E}+00$ & $2.56 \mathrm{E}+00$ \\
471 & 12.91 & $3.37 \mathrm{E}+00$ & $1.49 \mathrm{E}-01$ & $5.07 \mathrm{E}+00$ & $2.67 \mathrm{E}+00$ \\
472 & 12.95 & $5.50 \mathrm{E}+00$ & $1.50 \mathrm{E}-01$ & $5.26 \mathrm{E}+00$ & $2.77 \mathrm{E}+00$
\end{tabular}




\begin{tabular}{|c|c|c|c|c|c|}
\hline $\begin{array}{c}\text { Depth } \\
{[\mathrm{cm}]}\end{array}$ & $\begin{array}{c}\text { Age } \\
\text { [cal kyr] }\end{array}$ & $\begin{array}{c}\mathrm{Fe} / \mathrm{Ca} \\
{[c p s]}\end{array}$ & $\begin{array}{l}\mathbf{A l} / \mathbf{S i} \\
{[c p s]}\end{array}$ & $\begin{array}{l}\mathrm{Fe} / \mathrm{K} \\
{[c p s]}\end{array}$ & $\begin{array}{l}\text { Ti/Al } \\
\text { [cps] }\end{array}$ \\
\hline 473 & 12.98 & $4.64 E+00$ & $1.45 \mathrm{E}-01$ & $5.29 E+00$ & $2.78 \mathrm{E}+00$ \\
\hline 474 & 13.01 & $7.25 \mathrm{E}+00$ & $1.54 \mathrm{E}-01$ & $5.47 \mathrm{E}+00$ & $2.73 E+00$ \\
\hline 475 & 13.04 & $6.70 \mathrm{E}+00$ & $1.49 \mathrm{E}-01$ & $5.36 \mathrm{E}+00$ & $2.89 \mathrm{E}+00$ \\
\hline 476 & 13.07 & $3.40 E+00$ & $1.50 \mathrm{E}-01$ & $5.34 \mathrm{E}+00$ & $2.75 \mathrm{E}+00$ \\
\hline 477 & 13.10 & $4.92 E+00$ & $1.55 \mathrm{E}-01$ & $5.42 E+00$ & $2.70 \mathrm{E}+00$ \\
\hline 478 & 13.13 & $3.88 \mathrm{E}+00$ & $1.54 \mathrm{E}-01$ & $5.25 E+00$ & $2.63 E+00$ \\
\hline 479 & 13.16 & $4.98 \mathrm{E}+00$ & $1.53 \mathrm{E}-01$ & $5.39 \mathrm{E}+00$ & $2.72 \mathrm{E}+00$ \\
\hline 480 & 13.20 & $8.79 \mathrm{E}+00$ & 1.57E-01 & $5.39 \mathrm{E}+00$ & $2.71 E+00$ \\
\hline 481 & 13.23 & $8.34 \mathrm{E}+00$ & $1.56 \mathrm{E}-01$ & $5.49 \mathrm{E}+00$ & $2.68 \mathrm{E}+00$ \\
\hline 482 & 13.26 & $8.75 E+00$ & $1.52 \mathrm{E}-01$ & $5.45 \mathrm{E}+00$ & $2.86 \mathrm{E}+00$ \\
\hline 483 & 13.29 & $8.18 \mathrm{E}+00$ & $1.55 \mathrm{E}-01$ & $5.55 \mathrm{E}+00$ & $2.78 \mathrm{E}+00$ \\
\hline 484 & 13.32 & $9.11 \mathrm{E}+00$ & $1.53 \mathrm{E}-01$ & $5.42 \mathrm{E}+00$ & $2.78 \mathrm{E}+00$ \\
\hline 485 & 13.35 & $7.71 E+00$ & $1.53 \mathrm{E}-01$ & $5.40 \mathrm{E}+00$ & $2.85 \mathrm{E}+00$ \\
\hline 486 & 13.38 & $7.17 E+00$ & $1.53 \mathrm{E}-01$ & $5.43 E+00$ & $2.84 \mathrm{E}+00$ \\
\hline 487 & 13.41 & $9.59 E+00$ & $1.51 \mathrm{E}-01$ & $5.47 E+00$ & $2.96 \mathrm{E}+00$ \\
\hline 488 & 13.45 & $1.40 \mathrm{E}+01$ & $1.56 \mathrm{E}-01$ & $5.47 \mathrm{E}+00$ & $2.75 E+00$ \\
\hline 489 & 13.48 & $1.56 \mathrm{E}+01$ & $1.53 \mathrm{E}-01$ & $5.58 \mathrm{E}+00$ & $2.81 \mathrm{E}+00$ \\
\hline 490 & 13.51 & $1.52 \mathrm{E}+01$ & $1.52 \mathrm{E}-01$ & $5.49 \mathrm{E}+00$ & $2.97 \mathrm{E}+00$ \\
\hline 496 & 13.63 & $1.10 \mathrm{E}+01$ & $1.53 \mathrm{E}-01$ & $5.38 \mathrm{E}+00$ & $2.94 \mathrm{E}+00$ \\
\hline 497 & 13.64 & $9.96 \mathrm{E}+00$ & $1.55 \mathrm{E}-01$ & $5.39 \mathrm{E}+00$ & $2.94 \mathrm{E}+00$ \\
\hline 498 & 13.66 & $1.05 \mathrm{E}+01$ & $1.54 \mathrm{E}-01$ & $5.29 \mathrm{E}+00$ & $2.97 \mathrm{E}+00$ \\
\hline 499 & 13.68 & $1.29 \mathrm{E}+01$ & $1.53 \mathrm{E}-01$ & $5.29 E+00$ & $2.86 \mathrm{E}+00$ \\
\hline 500 & 13.69 & $1.13 E+01$ & $1.52 \mathrm{E}-01$ & $5.23 E+00$ & $2.97 \mathrm{E}+00$ \\
\hline 501 & 13.71 & $1.27 \mathrm{E}+01$ & $1.55 \mathrm{E}-01$ & $5.34 \mathrm{E}+00$ & $2.88 \mathrm{E}+00$ \\
\hline 502 & 13.73 & $1.01 \mathrm{E}+01$ & $1.55 \mathrm{E}-01$ & $5.39 \mathrm{E}+00$ & $2.84 \mathrm{E}+00$ \\
\hline 503 & 13.75 & $9.16 \mathrm{E}+00$ & $1.59 \mathrm{E}-01$ & $5.35 \mathrm{E}+00$ & $2.79 E+00$ \\
\hline 504 & 13.76 & $5.87 E+00$ & $1.55 \mathrm{E}-01$ & $5.16 \mathrm{E}+00$ & $2.82 \mathrm{E}+00$ \\
\hline 505 & 13.78 & $4.81 E+00$ & $1.55 \mathrm{E}-01$ & $5.16 \mathrm{E}+00$ & $2.67 \mathrm{E}+00$ \\
\hline 506 & 13.80 & $4.55 E+00$ & $1.53 \mathrm{E}-01$ & $5.16 \mathrm{E}+00$ & $2.73 E+00$ \\
\hline 507 & 13.82 & $4.37 E+00$ & $1.55 \mathrm{E}-01$ & $4.96 \mathrm{E}+00$ & $2.62 \mathrm{E}+00$ \\
\hline 508 & 13.83 & $4.01 E+00$ & $1.55 \mathrm{E}-01$ & $5.08 \mathrm{E}+00$ & $2.66 \mathrm{E}+00$ \\
\hline 509 & 13.85 & $3.76 \mathrm{E}+00$ & 1.47E-01 & $5.28 \mathrm{E}+00$ & $2.65 E+00$ \\
\hline 510 & 13.87 & $3.52 E+00$ & $1.46 \mathrm{E}-01$ & $4.92 E+00$ & $2.77 E+00$ \\
\hline 511 & 13.88 & $3.61 \mathrm{E}+00$ & $1.45 \mathrm{E}-01$ & $5.07 \mathrm{E}+00$ & $2.89 \mathrm{E}+00$ \\
\hline 512 & 13.90 & $4.16 \mathrm{E}+00$ & $1.45 \mathrm{E}-01$ & $5.02 E+00$ & $2.83 E+00$ \\
\hline 513 & 13.92 & $3.07 E+00$ & $1.35 \mathrm{E}-01$ & $5.15 \mathrm{E}+00$ & $2.93 E+00$ \\
\hline 514 & 13.94 & $2.66 \mathrm{E}+00$ & $1.34 \mathrm{E}-01$ & $5.18 \mathrm{E}+00$ & $2.94 \mathrm{E}+00$ \\
\hline 515 & 13.95 & $2.43 E+00$ & $1.29 \mathrm{E}-01$ & $5.12 \mathrm{E}+00$ & $3.02 \mathrm{E}+00$ \\
\hline 516 & 13.97 & $3.16 \mathrm{E}+00$ & $1.35 \mathrm{E}-01$ & $4.82 \mathrm{E}+00$ & $2.98 \mathrm{E}+00$ \\
\hline 517 & 13.99 & $3.02 E+00$ & $1.35 \mathrm{E}-01$ & $4.97 E+00$ & $2.91 \mathrm{E}+00$ \\
\hline 518 & 14.00 & $2.17 E+00$ & $1.29 \mathrm{E}-01$ & $5.23 \mathrm{E}+00$ & $2.94 \mathrm{E}+00$ \\
\hline 519 & 14.02 & $2.22 \mathrm{E}+00$ & $1.28 \mathrm{E}-01$ & $5.19 E+00$ & $3.10 E+00$ \\
\hline 520 & 14.04 & $2.46 \mathrm{E}+00$ & $1.27 \mathrm{E}-01$ & $5.00 E+00$ & $3.16 \mathrm{E}+00$ \\
\hline
\end{tabular}




\begin{tabular}{cccccc}
\hline $\begin{array}{c}\text { Depth } \\
\text { [cm] }\end{array}$ & $\begin{array}{c}\text { Age } \\
\text { [cal kyr] }\end{array}$ & $\begin{array}{c}\text { Fe/Ca } \\
{[\text { cps] }}\end{array}$ & $\begin{array}{c}\text { Al/Si } \\
{[c p s]}\end{array}$ & $\begin{array}{c}\text { Fe/K } \\
{[c p s]}\end{array}$ & $\begin{array}{c}\text { Ti/Al } \\
{[c p s]}\end{array}$ \\
\hline 521 & 14.06 & $2.94 \mathrm{E}+00$ & $1.31 \mathrm{E}-01$ & $5.02 \mathrm{E}+00$ & $2.97 \mathrm{E}+00$ \\
522 & 14.07 & $2.96 \mathrm{E}+00$ & $1.28 \mathrm{E}-01$ & $4.87 \mathrm{E}+00$ & $3.03 \mathrm{E}+00$ \\
523 & 14.09 & $3.87 \mathrm{E}+00$ & $1.38 \mathrm{E}-01$ & $5.08 \mathrm{E}+00$ & $2.99 \mathrm{E}+00$ \\
524 & 14.13 & $3.69 \mathrm{E}+00$ & $1.35 \mathrm{E}-01$ & $5.07 \mathrm{E}+00$ & $3.00 \mathrm{E}+00$ \\
525 & 14.17 & $2.45 \mathrm{E}+00$ & $1.22 \mathrm{E}-01$ & $5.06 \mathrm{E}+00$ & $3.16 \mathrm{E}+00$ \\
526 & 14.21 & $2.17 \mathrm{E}+00$ & $1.26 \mathrm{E}-01$ & $5.12 \mathrm{E}+00$ & $2.81 \mathrm{E}+00$ \\
527 & 14.25 & $2.09 \mathrm{E}+00$ & $1.22 \mathrm{E}-01$ & $5.27 \mathrm{E}+00$ & $3.13 \mathrm{E}+00$ \\
528 & 14.29 & $2.13 \mathrm{E}+00$ & $1.21 \mathrm{E}-01$ & $5.05 \mathrm{E}+00$ & $3.14 \mathrm{E}+00$ \\
529 & 14.33 & $2.52 \mathrm{E}+00$ & $1.17 \mathrm{E}-01$ & $4.92 \mathrm{E}+00$ & $3.46 \mathrm{E}+00$ \\
530 & 14.37 & $2.59 \mathrm{E}+00$ & $1.17 \mathrm{E}-01$ & $5.10 \mathrm{E}+00$ & $3.29 \mathrm{E}+00$ \\
531 & 14.41 & $2.43 \mathrm{E}+00$ & $1.20 \mathrm{E}-01$ & $4.99 \mathrm{E}+00$ & $3.20 \mathrm{E}+00$ \\
532 & 14.45 & $2.51 \mathrm{E}+00$ & $1.22 \mathrm{E}-01$ & $5.10 \mathrm{E}+00$ & $3.14 \mathrm{E}+00$ \\
533 & 14.49 & $2.42 \mathrm{E}+00$ & $1.24 \mathrm{E}-01$ & $4.71 \mathrm{E}+00$ & $2.93 \mathrm{E}+00$ \\
534 & 14.52 & $2.42 \mathrm{E}+00$ & $1.23 \mathrm{E}-01$ & $4.92 \mathrm{E}+00$ & $3.02 \mathrm{E}+00$ \\
535 & 14.56 & $2.43 \mathrm{E}+00$ & $1.23 \mathrm{E}-01$ & $5.02 \mathrm{E}+00$ & $3.00 \mathrm{E}+00$ \\
536 & 14.60 & $2.46 \mathrm{E}+00$ & $1.25 \mathrm{E}-01$ & $5.48 \mathrm{E}+00$ & $2.91 \mathrm{E}+00$ \\
537 & 14.64 & $2.55 \mathrm{E}+00$ & $1.22 \mathrm{E}-01$ & $5.11 \mathrm{E}+00$ & $3.03 \mathrm{E}+00$ \\
538 & 14.68 & $2.34 \mathrm{E}+00$ & $1.24 \mathrm{E}-01$ & $4.78 \mathrm{E}+00$ & $2.96 \mathrm{E}+00$ \\
539 & 14.72 & $2.45 \mathrm{E}+00$ & $1.21 \mathrm{E}-01$ & $4.79 \mathrm{E}+00$ & $3.05 \mathrm{E}+00$ \\
540 & 14.76 & $2.28 \mathrm{E}+00$ & $1.22 \mathrm{E}-01$ & $4.54 \mathrm{E}+00$ & $2.90 \mathrm{E}+00$ \\
541 & 14.80 & $2.50 \mathrm{E}+00$ & $1.19 \mathrm{E}-01$ & $4.43 \mathrm{E}+00$ & $2.99 \mathrm{E}+00$ \\
561 & 15.20 & $4.24 \mathrm{E}+00$ & $1.26 \mathrm{E}-01$ & $5.00 \mathrm{E}+00$ & $2.85 \mathrm{E}+00$ \\
562 & 15.21 & $3.45 \mathrm{E}+00$ & $1.24 \mathrm{E}-01$ & $4.95 \mathrm{E}+00$ & $3.01 \mathrm{E}+00$ \\
563 & 15.23 & $3.51 \mathrm{E}+00$ & $1.22 \mathrm{E}-01$ & $4.72 \mathrm{E}+00$ & $2.99 \mathrm{E}+00$
\end{tabular}




\begin{tabular}{|c|c|c|c|c|c|}
\hline $\begin{array}{c}\text { Depth } \\
{[\mathrm{cm}]}\end{array}$ & $\begin{array}{c}\text { Age } \\
\text { [cal kyr] }\end{array}$ & $\begin{array}{c}\mathrm{Fe} / \mathrm{Ca} \\
{[c p s]}\end{array}$ & $\begin{array}{l}\mathbf{A l} / \mathbf{S i} \\
{[c p s]}\end{array}$ & $\begin{array}{l}\mathrm{Fe} / \mathrm{K} \\
{[c p s]}\end{array}$ & $\begin{array}{l}\text { Ti/Al } \\
\text { [cps] }\end{array}$ \\
\hline 564 & 15.25 & $3.31 E+00$ & $1.24 \mathrm{E}-01$ & $4.46 \mathrm{E}+00$ & $2.86 \mathrm{E}+00$ \\
\hline 565 & 15.27 & $3.19 \mathrm{E}+00$ & $1.25 \mathrm{E}-01$ & $4.55 E+00$ & $2.80 \mathrm{E}+00$ \\
\hline 566 & 15.28 & $3.57 E+00$ & $1.24 \mathrm{E}-01$ & $4.97 E+00$ & $2.93 E+00$ \\
\hline 567 & 15.30 & $4.82 E+00$ & $1.23 \mathrm{E}-01$ & $4.41 E+00$ & $2.87 \mathrm{E}+00$ \\
\hline 568 & 15.32 & $3.55 E+00$ & $1.26 \mathrm{E}-01$ & $4.44 E+00$ & $2.72 \mathrm{E}+00$ \\
\hline 569 & 15.34 & $5.16 \mathrm{E}+00$ & $1.24 \mathrm{E}-01$ & $4.94 \mathrm{E}+00$ & $2.83 E+00$ \\
\hline 570 & 15.35 & $3.70 \mathrm{E}+00$ & $1.25 \mathrm{E}-01$ & $4.50 \mathrm{E}+00$ & $2.82 \mathrm{E}+00$ \\
\hline 571 & 15.37 & $3.51 \mathrm{E}+00$ & $1.28 \mathrm{E}-01$ & $4.44 \mathrm{E}+00$ & $2.73 E+00$ \\
\hline 572 & 15.39 & $3.80 \mathrm{E}+00$ & $1.25 \mathrm{E}-01$ & $4.37 \mathrm{E}+00$ & $2.79 \mathrm{E}+00$ \\
\hline 573 & 15.41 & $3.20 E+00$ & 1.27E-01 & 4.30E +00 & $2.61 \mathrm{E}+00$ \\
\hline 574 & 15.42 & $3.36 \mathrm{E}+00$ & $1.28 \mathrm{E}-01$ & $4.34 \mathrm{E}+00$ & $2.72 \mathrm{E}+00$ \\
\hline 575 & 15.44 & $4.02 E+00$ & $1.27 \mathrm{E}-01$ & $4.26 \mathrm{E}+00$ & $2.69 \mathrm{E}+00$ \\
\hline 576 & 15.46 & $3.83 E+00$ & $1.28 \mathrm{E}-01$ & $4.22 \mathrm{E}+00$ & $2.73 E+00$ \\
\hline 577 & 15.48 & $3.93 E+00$ & $1.28 \mathrm{E}-01$ & $4.38 \mathrm{E}+00$ & $2.87 \mathrm{E}+00$ \\
\hline 578 & 15.49 & $4.23 E+00$ & $1.25 \mathrm{E}-01$ & $4.72 \mathrm{E}+00$ & $2.93 E+00$ \\
\hline 579 & 15.51 & $3.46 \mathrm{E}+00$ & $1.27 \mathrm{E}-01$ & $4.66 \mathrm{E}+00$ & $2.81 E+00$ \\
\hline 580 & 15.53 & $3.63 E+00$ & $1.29 \mathrm{E}-01$ & $4.79 E+00$ & $2.78 \mathrm{E}+00$ \\
\hline 581 & 15.55 & $3.12 \mathrm{E}+00$ & $1.30 \mathrm{E}-01$ & $4.68 \mathrm{E}+00$ & $2.79 \mathrm{E}+00$ \\
\hline 582 & 15.56 & $3.44 \mathrm{E}+00$ & $1.24 \mathrm{E}-01$ & $4.60 \mathrm{E}+00$ & $2.93 E+00$ \\
\hline 583 & 15.58 & $4.66 \mathrm{E}+00$ & $1.24 \mathrm{E}-01$ & $4.61 \mathrm{E}+00$ & $2.82 \mathrm{E}+00$ \\
\hline 584 & 15.60 & $3.48 \mathrm{E}+00$ & $1.22 \mathrm{E}-01$ & $5.10 \mathrm{E}+00$ & $2.85 \mathrm{E}+00$ \\
\hline 585 & 15.62 & $3.30 \mathrm{E}+00$ & $1.25 \mathrm{E}-01$ & $4.45 E+00$ & $2.77 \mathrm{E}+00$ \\
\hline 586 & 15.63 & $2.86 \mathrm{E}+00$ & $1.22 \mathrm{E}-01$ & $4.72 E+00$ & $2.81 E+00$ \\
\hline 587 & 15.65 & $4.07 E+00$ & $1.28 \mathrm{E}-01$ & $4.43 E+00$ & $2.88 \mathrm{E}+00$ \\
\hline 588 & 15.67 & $3.48 \mathrm{E}+00$ & $1.26 \mathrm{E}-01$ & $4.56 \mathrm{E}+00$ & $2.84 \mathrm{E}+00$ \\
\hline 589 & 15.69 & $4.22 \mathrm{E}+00$ & $1.25 \mathrm{E}-01$ & $4.61 \mathrm{E}+00$ & $2.88 \mathrm{E}+00$ \\
\hline 590 & 15.70 & $3.93 E+00$ & $1.24 \mathrm{E}-01$ & $4.75 E+00$ & $2.80 \mathrm{E}+00$ \\
\hline 591 & 15.72 & $3.63 E+00$ & $1.28 \mathrm{E}-01$ & $4.62 E+00$ & $2.78 \mathrm{E}+00$ \\
\hline 592 & 15.74 & $4.56 \mathrm{E}+00$ & $1.27 \mathrm{E}-01$ & $4.48 \mathrm{E}+00$ & $2.80 \mathrm{E}+00$ \\
\hline 593 & 15.76 & $3.97 E+00$ & $1.29 \mathrm{E}-01$ & $4.65 \mathrm{E}+00$ & $2.75 E+00$ \\
\hline 594 & 15.77 & $3.73 E+00$ & $1.28 \mathrm{E}-01$ & $4.94 \mathrm{E}+00$ & $2.86 \mathrm{E}+00$ \\
\hline 595 & 15.79 & $4.16 \mathrm{E}+00$ & $1.28 \mathrm{E}-01$ & $5.42 \mathrm{E}+00$ & $2.79 E+00$ \\
\hline 596 & 15.81 & $4.28 \mathrm{E}+00$ & $1.29 \mathrm{E}-01$ & $5.01 E+00$ & $2.81 E+00$ \\
\hline 597 & 15.83 & $3.71 E+00$ & $1.25 \mathrm{E}-01$ & $5.18 \mathrm{E}+00$ & $3.06 \mathrm{E}+00$ \\
\hline 598 & 15.84 & $5.51 E+00$ & $1.26 \mathrm{E}-01$ & $4.92 \mathrm{E}+00$ & $2.85 E+00$ \\
\hline 599 & 15.86 & $7.76 \mathrm{E}+00$ & $1.29 \mathrm{E}-01$ & $4.99 \mathrm{E}+00$ & $2.98 \mathrm{E}+00$ \\
\hline 600 & 15.88 & $8.53 \mathrm{E}+00$ & $1.21 \mathrm{E}-01$ & $5.07 \mathrm{E}+00$ & $3.08 \mathrm{E}+00$ \\
\hline 601 & 15.90 & $9.66 \mathrm{E}+00$ & $1.26 \mathrm{E}-01$ & $5.12 \mathrm{E}+00$ & $3.16 \mathrm{E}+00$ \\
\hline 602 & 15.91 & $9.96 \mathrm{E}+00$ & $1.27 \mathrm{E}-01$ & $5.10 \mathrm{E}+00$ & $2.85 E+00$ \\
\hline 603 & 15.93 & $8.62 E+00$ & $1.28 \mathrm{E}-01$ & $4.88 \mathrm{E}+00$ & $2.68 \mathrm{E}+00$ \\
\hline 604 & 15.95 & $6.20 \mathrm{E}+00$ & $1.31 \mathrm{E}-01$ & $4.72 E+00$ & $2.60 \mathrm{E}+00$ \\
\hline 605 & 15.97 & $7.56 \mathrm{E}+00$ & $1.29 \mathrm{E}-01$ & $5.38 \mathrm{E}+00$ & $2.77 E+00$ \\
\hline 606 & 15.98 & $4.46 \mathrm{E}+00$ & $1.26 \mathrm{E}-01$ & $5.07 E+00$ & $2.74 \mathrm{E}+00$ \\
\hline
\end{tabular}




\begin{tabular}{|c|c|c|c|c|c|}
\hline $\begin{array}{c}\text { Depth } \\
{[\mathrm{cm}]}\end{array}$ & $\begin{array}{c}\text { Age } \\
{[\text { cal kyr] }}\end{array}$ & $\begin{array}{c}\mathrm{Fe} / \mathrm{Ca} \\
{[c p s]}\end{array}$ & $\begin{array}{l}\mathbf{A l} / \mathbf{S i} \\
{[c p s]}\end{array}$ & $\begin{array}{l}\mathrm{Fe} / \mathrm{K} \\
{[c p s]}\end{array}$ & $\begin{array}{l}\text { Ti/Al } \\
\text { [cps] }\end{array}$ \\
\hline 607 & 16.00 & $4.34 \mathrm{E}+00$ & $1.30 \mathrm{E}-01$ & $4.86 \mathrm{E}+00$ & $2.70 \mathrm{E}+00$ \\
\hline 608 & 16.02 & $4.99 \mathrm{E}+00$ & $1.32 \mathrm{E}-01$ & $5.03 E+00$ & $2.71 E+00$ \\
\hline 609 & 16.04 & $4.41 \mathrm{E}+00$ & $1.30 \mathrm{E}-01$ & $4.85 E+00$ & $2.63 \mathrm{E}+00$ \\
\hline 610 & 16.05 & $3.82 \mathrm{E}+00$ & $1.30 \mathrm{E}-01$ & $5.17 \mathrm{E}+00$ & $2.71 \mathrm{E}+00$ \\
\hline 611 & 16.07 & $4.68 \mathrm{E}+00$ & $1.30 \mathrm{E}-01$ & $5.08 \mathrm{E}+00$ & $2.70 \mathrm{E}+00$ \\
\hline 612 & 16.09 & $4.19 \mathrm{E}+00$ & $1.32 \mathrm{E}-01$ & $4.96 \mathrm{E}+00$ & $2.70 E+00$ \\
\hline 613 & 16.11 & 4.19E+00 & $1.30 \mathrm{E}-01$ & $5.26 \mathrm{E}+00$ & $2.63 \mathrm{E}+00$ \\
\hline 614 & 16.12 & $4.83 E+00$ & $1.32 \mathrm{E}-01$ & $4.86 \mathrm{E}+00$ & $2.61 \mathrm{E}+00$ \\
\hline 615 & 16.14 & $6.21 \mathrm{E}+00$ & $1.36 \mathrm{E}-01$ & $5.18 \mathrm{E}+00$ & $2.65 \mathrm{E}+00$ \\
\hline 616 & 16.16 & $7.83 \mathrm{E}+00$ & $1.28 \mathrm{E}-01$ & $5.21 \mathrm{E}+00$ & $2.79 \mathrm{E}+00$ \\
\hline 617 & 16.18 & $7.41 E+00$ & 1.36E-01 & $5.55 \mathrm{E}+00$ & $2.62 E+00$ \\
\hline 618 & 16.19 & $7.67 \mathrm{E}+00$ & $1.35 \mathrm{E}-01$ & $5.09 E+00$ & $2.68 \mathrm{E}+00$ \\
\hline 619 & 16.21 & $7.61 \mathrm{E}+00$ & 1.33E-01 & $5.16 \mathrm{E}+00$ & $2.62 \mathrm{E}+00$ \\
\hline 620 & 16.23 & $7.30 \mathrm{E}+00$ & $1.35 \mathrm{E}-01$ & $4.88 \mathrm{E}+00$ & $2.61 E+00$ \\
\hline 621 & 16.25 & $6.52 E+00$ & $1.34 \mathrm{E}-01$ & $4.98 \mathrm{E}+00$ & $2.64 \mathrm{E}+00$ \\
\hline 622 & 16.26 & $7.89 \mathrm{E}+00$ & $1.38 \mathrm{E}-01$ & $4.97 E+00$ & $2.65 \mathrm{E}+00$ \\
\hline 623 & 16.28 & $9.67 E+00$ & 1.39E-01 & $5.12 \mathrm{E}+00$ & $2.53 \mathrm{E}+00$ \\
\hline 624 & 16.30 & $1.01 \mathrm{E}+01$ & $1.32 \mathrm{E}-01$ & $5.25 \mathrm{E}+00$ & $2.85 \mathrm{E}+00$ \\
\hline 625 & 16.32 & $9.80 \mathrm{E}+00$ & 1.40E-01 & $5.06 \mathrm{E}+00$ & $2.58 \mathrm{E}+00$ \\
\hline 626 & 16.33 & $9.95 E+00$ & 1.39E-01 & $5.19 E+00$ & $2.62 E+00$ \\
\hline 627 & 16.35 & $9.10 \mathrm{E}+00$ & 1.44E-01 & $5.26 \mathrm{E}+00$ & $2.53 \mathrm{E}+00$ \\
\hline 628 & 16.37 & $9.28 \mathrm{E}+00$ & 1.37E-01 & $5.28 \mathrm{E}+00$ & $2.81 E+00$ \\
\hline 629 & 16.39 & $9.98 \mathrm{E}+00$ & 1.37E-01 & $5.57 E+00$ & $2.78 \mathrm{E}+00$ \\
\hline 630 & 16.40 & $9.28 \mathrm{E}+00$ & $1.41 \mathrm{E}-01$ & $5.83 E+00$ & $2.86 \mathrm{E}+00$ \\
\hline 631 & 16.42 & $6.20 \mathrm{E}+00$ & $1.41 \mathrm{E}-01$ & $5.47 \mathrm{E}+00$ & $2.80 \mathrm{E}+00$ \\
\hline 632 & 16.44 & $6.68 \mathrm{E}+00$ & 1.39E-01 & $5.67 E+00$ & $2.86 \mathrm{E}+00$ \\
\hline 633 & 16.46 & $6.69 \mathrm{E}+00$ & $1.38 \mathrm{E}-01$ & $5.63 \mathrm{E}+00$ & $2.89 \mathrm{E}+00$ \\
\hline 634 & 16.47 & $5.68 \mathrm{E}+00$ & $1.45 \mathrm{E}-01$ & $5.61 E+00$ & $2.66 \mathrm{E}+00$ \\
\hline 635 & 16.49 & $4.94 \mathrm{E}+00$ & $1.43 \mathrm{E}-01$ & $5.27 \mathrm{E}+00$ & $2.60 \mathrm{E}+00$ \\
\hline 636 & 16.51 & $4.38 \mathrm{E}+00$ & 1.40E-01 & $5.14 \mathrm{E}+00$ & $2.69 \mathrm{E}+00$ \\
\hline 637 & 16.53 & $7.30 \mathrm{E}+00$ & $1.42 \mathrm{E}-01$ & $5.37 \mathrm{E}+00$ & 2.77E+00 \\
\hline 638 & 16.54 & $7.79 \mathrm{E}+00$ & $1.48 \mathrm{E}-01$ & $5.26 \mathrm{E}+00$ & $2.71 E+00$ \\
\hline 639 & 16.56 & $5.94 \mathrm{E}+00$ & 1.43E-01 & $5.65 E+00$ & $2.78 \mathrm{E}+00$ \\
\hline 640 & 16.58 & $8.10 E+00$ & $1.44 \mathrm{E}-01$ & $5.52 \mathrm{E}+00$ & $2.68 \mathrm{E}+00$ \\
\hline 641 & 16.60 & $8.30 E+00$ & 1.46E-01 & $5.60 \mathrm{E}+00$ & $2.65 E+00$ \\
\hline 642 & 16.61 & $6.11 \mathrm{E}+00$ & 1.43E-01 & $5.42 \mathrm{E}+00$ & $2.76 \mathrm{E}+00$ \\
\hline 643 & 16.63 & $8.29 \mathrm{E}+00$ & $1.45 \mathrm{E}-01$ & $5.51 \mathrm{E}+00$ & $2.72 \mathrm{E}+00$ \\
\hline 644 & 16.65 & $1.00 \mathrm{E}+01$ & $1.42 \mathrm{E}-01$ & $5.64 \mathrm{E}+00$ & $2.84 \mathrm{E}+00$ \\
\hline 645 & 16.67 & $8.55 E+00$ & 1.44E-01 & $5.51 \mathrm{E}+00$ & $2.72 \mathrm{E}+00$ \\
\hline 646 & 16.68 & $8.76 \mathrm{E}+00$ & $1.51 \mathrm{E}-01$ & $5.65 \mathrm{E}+00$ & $2.69 \mathrm{E}+00$ \\
\hline 647 & 16.70 & $9.73 E+00$ & 1.46E-01 & $5.69 \mathrm{E}+00$ & $2.78 \mathrm{E}+00$ \\
\hline 648 & 16.72 & $8.24 \mathrm{E}+00$ & 1.47E-01 & $5.93 E+00$ & $2.70 \mathrm{E}+00$ \\
\hline 649 & 16.92 & $8.86 \mathrm{E}+00$ & $1.48 \mathrm{E}-01$ & $5.47 \mathrm{E}+00$ & $2.68 \mathrm{E}+00$ \\
\hline
\end{tabular}




\begin{tabular}{|c|c|c|c|c|c|}
\hline $\begin{array}{c}\text { Depth } \\
{[\mathrm{cm}]}\end{array}$ & $\begin{array}{c}\text { Age } \\
\text { [cal kyr] }\end{array}$ & $\begin{array}{l}\mathrm{Fe} / \mathrm{Ca} \\
{[c p s]}\end{array}$ & $\begin{array}{l}\mathbf{A l} / \mathbf{S i} \\
{[c p s]}\end{array}$ & $\begin{array}{l}\mathrm{Fe} / \mathrm{K} \\
\text { [cps] }\end{array}$ & $\begin{array}{l}\text { Ti/Al } \\
\text { [cps] }\end{array}$ \\
\hline 650 & 17.12 & $6.45 E+00$ & $1.47 \mathrm{E}-01$ & $5.30 E+00$ & $2.65 E+00$ \\
\hline 651 & 17.32 & $7.15 E+00$ & $1.53 \mathrm{E}-01$ & $5.39 E+00$ & $2.53 \mathrm{E}+00$ \\
\hline 652 & 17.52 & $1.14 \mathrm{E}+01$ & 1.47E-01 & $5.17 \mathrm{E}+00$ & $2.73 \mathrm{E}+00$ \\
\hline 653 & 17.73 & $1.08 \mathrm{E}+01$ & $1.47 \mathrm{E}-01$ & $5.30 \mathrm{E}+00$ & $2.72 E+00$ \\
\hline 654 & 17.93 & $1.05 \mathrm{E}+01$ & $1.49 \mathrm{E}-01$ & $5.31 E+00$ & $2.74 \mathrm{E}+00$ \\
\hline 655 & 18.13 & $1.08 \mathrm{E}+01$ & $1.49 \mathrm{E}-01$ & $5.26 \mathrm{E}+00$ & $2.70 \mathrm{E}+00$ \\
\hline 656 & 18.33 & $1.07 \mathrm{E}+01$ & $1.51 \mathrm{E}-01$ & $5.42 \mathrm{E}+00$ & $2.64 \mathrm{E}+00$ \\
\hline 657 & 18.53 & $9.57 E+00$ & 1.47E-01 & $5.07 E+00$ & $2.70 E+00$ \\
\hline 658 & 18.73 & $8.84 \mathrm{E}+00$ & $1.52 \mathrm{E}-01$ & $4.88 \mathrm{E}+00$ & $2.70 E+00$ \\
\hline 659 & 18.93 & $5.71 E+00$ & $1.45 \mathrm{E}-01$ & $4.74 \mathrm{E}+00$ & $2.84 \mathrm{E}+00$ \\
\hline 660 & 19.13 & $4.16 \mathrm{E}+00$ & 1.39E-01 & $4.94 \mathrm{E}+00$ & $2.93 \mathrm{E}+00$ \\
\hline 661 & 19.34 & $2.96 \mathrm{E}+00$ & 1.43E-01 & $4.95 \mathrm{E}+00$ & $2.80 E+00$ \\
\hline 662 & 19.54 & $1.52 \mathrm{E}+00$ & 1.37E-01 & $4.60 E+00$ & $2.81 E+00$ \\
\hline 663 & 19.74 & $1.94 \mathrm{E}+00$ & 1.39E-01 & $4.49 E+00$ & $2.77 E+00$ \\
\hline 664 & 19.94 & $1.99 \mathrm{E}+00$ & $1.38 \mathrm{E}-01$ & $4.34 \mathrm{E}+00$ & $2.77 E+00$ \\
\hline 665 & 20.14 & $1.75 \mathrm{E}+00$ & $1.40 \mathrm{E}-01$ & $4.28 \mathrm{E}+00$ & $2.73 \mathrm{E}+00$ \\
\hline 666 & 20.36 & $1.56 \mathrm{E}+00$ & $1.38 \mathrm{E}-01$ & $4.44 E+00$ & $2.75 \mathrm{E}+00$ \\
\hline 667 & 20.56 & $1.16 \mathrm{E}+00$ & 1.37E-01 & $4.24 E+00$ & $2.65 \mathrm{E}+00$ \\
\hline 668 & 20.76 & $1.41 \mathrm{E}+00$ & $1.38 \mathrm{E}-01$ & $4.38 \mathrm{E}+00$ & $2.73 \mathrm{E}+00$ \\
\hline 669 & 20.96 & $1.55 E+00$ & 1.39E-01 & $4.46 \mathrm{E}+00$ & $2.65 E+00$ \\
\hline 670 & 21.16 & $1.47 \mathrm{E}+00$ & 1.37E-01 & $4.42 \mathrm{E}+00$ & $2.68 \mathrm{E}+00$ \\
\hline 671 & 21.37 & $1.56 \mathrm{E}+00$ & $1.45 \mathrm{E}-01$ & $4.53 E+00$ & $2.57 E+00$ \\
\hline 672 & 21.57 & $1.44 \mathrm{E}+00$ & $1.41 \mathrm{E}-01$ & $4.45 E+00$ & $2.58 \mathrm{E}+00$ \\
\hline 673 & 21.77 & $1.73 E+00$ & $1.42 \mathrm{E}-01$ & $4.49 E+00$ & $2.69 \mathrm{E}+00$ \\
\hline 674 & 21.97 & $1.50 \mathrm{E}+00$ & $1.41 \mathrm{E}-01$ & $4.44 \mathrm{E}+00$ & $2.65 \mathrm{E}+00$ \\
\hline 675 & 22.17 & $2.54 \mathrm{E}+00$ & $1.45 \mathrm{E}-01$ & $4.27 \mathrm{E}+00$ & $2.64 \mathrm{E}+00$ \\
\hline 676 & 22.37 & $1.94 \mathrm{E}+00$ & $1.42 \mathrm{E}-01$ & $4.37 E+00$ & $2.62 E+00$ \\
\hline 681 & 23.38 & $2.82 \mathrm{E}+00$ & 1.49E-01 & $4.78 \mathrm{E}+00$ & $2.64 \mathrm{E}+00$ \\
\hline 682 & 23.58 & $1.24 \mathrm{E}+00$ & $1.35 \mathrm{E}-01$ & $4.62 \mathrm{E}+00$ & $2.83 \mathrm{E}+00$ \\
\hline 683 & 23.78 & $2.33 \mathrm{E}+00$ & $1.34 \mathrm{E}-01$ & $5.09 \mathrm{E}+00$ & $3.33 \mathrm{E}+00$ \\
\hline
\end{tabular}




\section{GeoB3910-2}

\begin{tabular}{cccc}
\hline $\begin{array}{c}\text { Depth } \\
{[\mathrm{cm}]}\end{array}$ & $\begin{array}{c}\text { Age } \\
{[\text { cal kyr] }}\end{array}$ & $\begin{array}{c}\text { Fe/Ca } \\
{[\mathrm{cps}]}\end{array}$ & $\begin{array}{c}\text { Fe/K } \\
{[\mathrm{cps}]}\end{array}$ \\
\hline 1 & 0.45 & $2.48 \mathrm{E}-01$ & $7.01 \mathrm{E}+00$ \\
2 & 0.73 & $2.54 \mathrm{E}-01$ & $7.06 \mathrm{E}+00$ \\
3 & 1.01 & $2.58 \mathrm{E}-01$ & $7.46 \mathrm{E}+00$ \\
4 & 1.29 & $2.54 \mathrm{E}-01$ & $7.26 \mathrm{E}+00$ \\
5 & 1.57 & $2.64 \mathrm{E}-01$ & $7.22 \mathrm{E}+00$ \\
8 & 2.40 & $2.29 \mathrm{E}-01$ & $6.87 \mathrm{E}+00$ \\
9 & 2.68 & $2.30 \mathrm{E}-01$ & $6.57 \mathrm{E}+00$ \\
10 & 2.96 & $2.20 \mathrm{E}-01$ & $6.39 \mathrm{E}+00$ \\
11 & 3.24 & $2.20 \mathrm{E}-01$ & $6.80 \mathrm{E}+00$ \\
12 & 3.52 & $2.23 \mathrm{E}-01$ & $6.94 \mathrm{E}+00$ \\
13 & 3.80 & $2.25 \mathrm{E}-01$ & $7.34 \mathrm{E}+00$ \\
14 & 4.08 & $2.28 \mathrm{E}-01$ & $7.82 \mathrm{E}+00$ \\
15 & 4.35 & $2.35 \mathrm{E}-01$ & $7.47 \mathrm{E}+00$ \\
16 & 4.63 & $2.26 \mathrm{E}-01$ & $7.54 \mathrm{E}+00$ \\
17 & 4.90 & $2.19 \mathrm{E}-01$ & $7.18 \mathrm{E}+00$ \\
18 & 5.18 & $2.20 \mathrm{E}-01$ & $6.98 \mathrm{E}+00$ \\
19 & 5.46 & $2.11 \mathrm{E}-01$ & $7.05 \mathrm{E}+00$ \\
20 & 5.73 & $2.10 \mathrm{E}-01$ & $7.16 \mathrm{E}+00$ \\
21 & 6.01 & $2.06 \mathrm{E}-01$ & $6.75 \mathrm{E}+00$ \\
22 & 6.28 & $2.20 \mathrm{E}-01$ & $7.20 \mathrm{E}+00$ \\
23 & 6.56 & $2.37 \mathrm{E}-01$ & $7.66 \mathrm{E}+00$ \\
24 & 6.72 & $2.57 \mathrm{E}-01$ & $7.62 \mathrm{E}+00$ \\
25 & 6.87 & $2.53 \mathrm{E}-01$ & $7.97 \mathrm{E}+00$ \\
26 & 7.03 & $2.50 \mathrm{E}-01$ & $7.72 \mathrm{E}+00$ \\
27 & 7.18 & $2.58 \mathrm{E}-01$ & $7.46 \mathrm{E}+00$ \\
28 & 7.34 & $2.77 \mathrm{E}-01$ & $7.80 \mathrm{E}+00$ \\
29 & 7.50 & $3.32 \mathrm{E}-01$ & $8.58 \mathrm{E}+00$ \\
30 & 7.65 & $3.67 \mathrm{E}-01$ & $9.21 \mathrm{E}+00$ \\
31 & 7.81 & $3.94 \mathrm{E}-01$ & $9.85 \mathrm{E}+00$ \\
32 & 7.96 & $4.35 \mathrm{E}-01$ & $1.08 \mathrm{E}+01$ \\
41.2 & 9.24 & $6.85 \mathrm{E}-01$ & $2.71 \mathrm{E}+01$ \\
33 & 8.12 & $4.10 \mathrm{E}-01$ & $9.83 \mathrm{E}+00$ \\
34 & 8.28 & $3.80 \mathrm{E}-01$ & $9.07 \mathrm{E}+00$ \\
35 & 8.43 & $3.92 \mathrm{E}-01$ & $8.97 \mathrm{E}+00$ \\
36 & 8.59 & $4.22 \mathrm{E}-01$ & $9.91 \mathrm{E}+00$ \\
37 & 8.74 & $4.36 \mathrm{E}-01$ & $1.02 \mathrm{E}+01$ \\
38 & 8.90 & $4.15 \mathrm{E}-01$ & $9.44 \mathrm{E}+00$ \\
39 & 9.01 & $5.55 \mathrm{E}-01$ & $1.19 \mathrm{E}+01$ \\
40 & 9.11 & $1.06 \mathrm{E}+00$ & $2.02 \mathrm{E}+01$ \\
& 9.22 & $5.98 \mathrm{E}-01$ & $2.12 \mathrm{E}+01$ \\
41 & $9.93 \mathrm{E}-01$ & $2.58 \mathrm{E}+01$
\end{tabular}




\begin{tabular}{|c|c|c|c|}
\hline $\begin{array}{c}\text { Depth } \\
{[\mathrm{cm}]}\end{array}$ & $\begin{array}{c}\text { Age } \\
\text { [cal kyr] }\end{array}$ & $\begin{array}{c}\mathrm{Fe} / \mathrm{Ca} \\
{[c p s]}\end{array}$ & $\begin{array}{l}\mathrm{Fe} / \mathbf{K} \\
{[c p s]}\end{array}$ \\
\hline 42 & 9.32 & $1.46 \mathrm{E}+00$ & $3.67 E+01$ \\
\hline 42.4 & 9.37 & $1.77 \mathrm{E}+00$ & $3.50 E+01$ \\
\hline 42.8 & 9.41 & $2.06 \mathrm{E}+00$ & $3.62 E+01$ \\
\hline 43.2 & 9.45 & $1.46 \mathrm{E}+00$ & $2.66 \mathrm{E}+01$ \\
\hline 43.6 & 9.49 & $1.13 E+00$ & $2.11 E+01$ \\
\hline 44 & 9.54 & $9.23 \mathrm{E}-01$ & $1.59 \mathrm{E}+01$ \\
\hline 44.4 & 9.58 & $6.16 \mathrm{E}-01$ & $1.21 \mathrm{E}+01$ \\
\hline 44.8 & 9.62 & $6.87 \mathrm{E}-01$ & $1.24 \mathrm{E}+01$ \\
\hline 45.2 & 9.66 & $6.06 \mathrm{E}-01$ & $1.15 \mathrm{E}+01$ \\
\hline 45.6 & 9.71 & $6.64 \mathrm{E}-01$ & $1.32 \mathrm{E}+01$ \\
\hline 46 & 9.75 & 7.67E-01 & $1.44 \mathrm{E}+01$ \\
\hline 46.4 & 9.79 & $6.60 \mathrm{E}-01$ & $1.26 \mathrm{E}+01$ \\
\hline 46.8 & 9.83 & $6.29 \mathrm{E}-01$ & $1.27 \mathrm{E}+01$ \\
\hline 47.2 & 9.88 & $5.71 \mathrm{E}-01$ & $1.11 \mathrm{E}+01$ \\
\hline 47.6 & 9.92 & $6.56 \mathrm{E}-01$ & $1.29 E+01$ \\
\hline 48 & 9.96 & 7.17E-01 & $1.33 E+01$ \\
\hline 48.4 & 10.00 & 7.17E-01 & $1.37 \mathrm{E}+01$ \\
\hline 48.8 & 10.04 & 7.76E-01 & $1.35 \mathrm{E}+01$ \\
\hline 49.2 & 10.09 & $6.62 \mathrm{E}-01$ & $1.26 \mathrm{E}+01$ \\
\hline 49.6 & 10.13 & $8.26 \mathrm{E}-01$ & $1.46 \mathrm{E}+01$ \\
\hline 50 & 10.17 & 7.54E-01 & $1.36 \mathrm{E}+01$ \\
\hline 50.4 & 10.21 & $6.79 \mathrm{E}-01$ & $1.34 \mathrm{E}+01$ \\
\hline 50.8 & 10.26 & 8.91E-01 & $1.64 \mathrm{E}+01$ \\
\hline 51.2 & 10.30 & $7.72 \mathrm{E}-01$ & $1.34 \mathrm{E}+01$ \\
\hline 51.6 & 10.34 & 8.69E-01 & $1.45 \mathrm{E}+01$ \\
\hline 52 & 10.38 & $1.21 \mathrm{E}+00$ & $1.81 \mathrm{E}+01$ \\
\hline 52.4 & 10.43 & $1.47 \mathrm{E}+00$ & $2.17 \mathrm{E}+01$ \\
\hline 52.8 & 10.47 & 8.63E-01 & $1.36 \mathrm{E}+01$ \\
\hline 53.2 & 10.51 & 7.11E-01 & $1.21 \mathrm{E}+01$ \\
\hline 53.6 & 10.55 & $8.28 \mathrm{E}-01$ & $1.46 \mathrm{E}+01$ \\
\hline 54 & 10.60 & $9.49 \mathrm{E}-01$ & $1.40 E+01$ \\
\hline 54.4 & 10.64 & $1.21 \mathrm{E}+00$ & $1.66 \mathrm{E}+01$ \\
\hline 54.8 & 10.68 & $1.34 \mathrm{E}+00$ & $1.81 E+01$ \\
\hline 55.2 & 10.72 & $1.16 \mathrm{E}+00$ & $1.61 E+01$ \\
\hline 55.6 & 10.77 & $1.04 \mathrm{E}+00$ & $1.71 \mathrm{E}+01$ \\
\hline 56 & 10.81 & $1.05 \mathrm{E}+00$ & $1.63 \mathrm{E}+01$ \\
\hline 56.4 & 10.85 & $1.16 \mathrm{E}+00$ & $1.66 \mathrm{E}+01$ \\
\hline 56.8 & 10.89 & $1.23 \mathrm{E}+00$ & $1.73 \mathrm{E}+01$ \\
\hline 57.2 & 10.94 & $1.33 \mathrm{E}+00$ & $1.78 \mathrm{E}+01$ \\
\hline 57.6 & 10.98 & $1.47 \mathrm{E}+00$ & $1.93 \mathrm{E}+01$ \\
\hline 58 & 11.02 & $2.04 E+00$ & $2.36 E+01$ \\
\hline 58.4 & 11.06 & $2.18 \mathrm{E}+00$ & $2.28 \mathrm{E}+01$ \\
\hline 58.8 & 11.10 & $1.49 \mathrm{E}+00$ & $1.65 E+01$ \\
\hline
\end{tabular}




\begin{tabular}{|c|c|c|c|}
\hline $\begin{array}{c}\text { Depth } \\
{[\mathrm{cm}]}\end{array}$ & $\begin{array}{c}\text { Age } \\
\text { [cal kyr] }\end{array}$ & $\begin{array}{c}\mathrm{Fe} / \mathrm{Ca} \\
{[c p s]}\end{array}$ & $\begin{array}{l}\mathrm{Fe} / \mathrm{K} \\
{[c p s]}\end{array}$ \\
\hline 59.2 & 11.14 & $2.06 \mathrm{E}+00$ & $2.15 E+01$ \\
\hline 59.6 & 11.17 & $2.12 E+00$ & $2.07 E+01$ \\
\hline 60 & 11.21 & $1.68 \mathrm{E}+00$ & $2.05 E+01$ \\
\hline 60.4 & 11.25 & $1.73 E+00$ & $1.78 \mathrm{E}+01$ \\
\hline 60.8 & 11.29 & $2.38 \mathrm{E}+00$ & $2.18 \mathrm{E}+01$ \\
\hline 61.2 & 11.33 & $1.88 \mathrm{E}+00$ & $1.89 \mathrm{E}+01$ \\
\hline 61.6 & 11.37 & $1.91 \mathrm{E}+00$ & $1.93 \mathrm{E}+01$ \\
\hline 62 & 11.40 & $2.70 \mathrm{E}+00$ & $2.37 E+01$ \\
\hline 62.4 & 11.44 & $1.96 \mathrm{E}+00$ & $1.92 \mathrm{E}+01$ \\
\hline 62.8 & 11.48 & $2.23 \mathrm{E}+00$ & $1.98 \mathrm{E}+01$ \\
\hline 63.2 & 11.52 & $2.59 E+00$ & $2.15 E+01$ \\
\hline 63.6 & 11.56 & $3.70 E+00$ & $2.37 E+01$ \\
\hline 64 & 11.60 & $4.51 \mathrm{E}+00$ & $2.41 \mathrm{E}+01$ \\
\hline 64.4 & 11.63 & $4.26 \mathrm{E}+00$ & $2.25 \mathrm{E}+01$ \\
\hline 64.8 & 11.67 & $3.72 E+00$ & $2.20 \mathrm{E}+01$ \\
\hline 65.2 & 11.71 & $3.92 E+00$ & $2.27 E+01$ \\
\hline 65.6 & 11.75 & $3.30 E+00$ & $2.19 E+01$ \\
\hline 66 & 11.79 & $3.30 E+00$ & $2.18 \mathrm{E}+01$ \\
\hline 66.4 & 11.83 & $3.01 E+00$ & $2.15 E+01$ \\
\hline 66.8 & 11.86 & $2.81 E+00$ & $2.09 \mathrm{E}+01$ \\
\hline 67.2 & 11.90 & $3.22 \mathrm{E}+00$ & $2.13 E+01$ \\
\hline 67.6 & 11.94 & $3.08 \mathrm{E}+00$ & $2.05 E+01$ \\
\hline 68 & 11.98 & $3.71 E+00$ & $2.10 \mathrm{E}+01$ \\
\hline 68.4 & 12.02 & $3.87 E+00$ & $2.22 \mathrm{E}+01$ \\
\hline 68.8 & 12.06 & $3.69 E+00$ & $2.29 \mathrm{E}+01$ \\
\hline 69.2 & 12.10 & $4.19 E+00$ & $2.09 \mathrm{E}+01$ \\
\hline 69.6 & 12.13 & $3.82 E+00$ & $2.08 \mathrm{E}+01$ \\
\hline 70 & 12.17 & $4.03 E+00$ & $1.81 \mathrm{E}+01$ \\
\hline 70.4 & 12.21 & $4.93 E+00$ & $2.05 \mathrm{E}+01$ \\
\hline 70.8 & 12.25 & $4.56 \mathrm{E}+00$ & $1.99 \mathrm{E}+01$ \\
\hline 71.2 & 12.29 & $4.70 E+00$ & $1.94 \mathrm{E}+01$ \\
\hline 71.6 & 12.33 & $5.29 E+00$ & $2.20 \mathrm{E}+01$ \\
\hline 72 & 12.36 & $3.66 \mathrm{E}+00$ & $1.83 \mathrm{E}+01$ \\
\hline 72.4 & 12.40 & $3.50 E+00$ & $2.00 E+01$ \\
\hline 72.8 & 12.44 & $2.69 E+00$ & $1.74 \mathrm{E}+01$ \\
\hline 73.2 & 12.49 & $2.49 E+00$ & $1.83 E+01$ \\
\hline 73.6 & 12.54 & $1.81 \mathrm{E}+00$ & $1.76 \mathrm{E}+01$ \\
\hline 74 & 12.60 & $1.58 \mathrm{E}+00$ & $1.67 \mathrm{E}+01$ \\
\hline 74.4 & 12.66 & $1.55 \mathrm{E}+00$ & $1.78 \mathrm{E}+01$ \\
\hline 74.8 & 12.71 & $1.64 \mathrm{E}+00$ & $1.75 E+01$ \\
\hline 75.2 & 12.77 & $1.57 \mathrm{E}+00$ & 1.67E+01 \\
\hline 75.6 & 12.82 & $1.74 \mathrm{E}+00$ & $1.85 \mathrm{E}+01$ \\
\hline 76 & 12.88 & $1.87 E+00$ & $1.78 \mathrm{E}+01$ \\
\hline
\end{tabular}




\begin{tabular}{cccc}
\hline $\begin{array}{c}\text { Depth } \\
{[c m]}\end{array}$ & $\begin{array}{c}\text { Age } \\
\text { [cal kyr] }\end{array}$ & $\begin{array}{c}\text { Fe/Ca } \\
{[c p s]}\end{array}$ & $\begin{array}{c}\text { Fe/K } \\
{[c p s]}\end{array}$ \\
\hline 76.4 & 12.93 & $1.54 \mathrm{E}+00$ & $1.71 \mathrm{E}+01$ \\
76.8 & 12.99 & $1.62 \mathrm{E}+00$ & $1.97 \mathrm{E}+01$ \\
77.2 & 13.05 & $1.39 \mathrm{E}+00$ & $1.66 \mathrm{E}+01$ \\
77.6 & 13.10 & $1.46 \mathrm{E}+00$ & $1.80 \mathrm{E}+01$ \\
78 & 13.16 & $1.31 \mathrm{E}+00$ & $1.94 \mathrm{E}+01$ \\
78.4 & 13.21 & $1.31 \mathrm{E}+00$ & $1.67 \mathrm{E}+01$ \\
78.8 & 13.27 & $1.16 \mathrm{E}+00$ & $1.63 \mathrm{E}+01$ \\
79.2 & 13.32 & $1.17 \mathrm{E}+00$ & $1.37 \mathrm{E}+01$ \\
79.6 & 13.38 & $1.10 \mathrm{E}+00$ & $1.61 \mathrm{E}+01$ \\
80 & 13.44 & $1.14 \mathrm{E}+00$ & $1.65 \mathrm{E}+01$ \\
80.4 & 13.49 & $1.03 \mathrm{E}+00$ & $1.45 \mathrm{E}+01$ \\
80.8 & 13.55 & $1.02 \mathrm{E}+00$ & $1.45 \mathrm{E}+01$ \\
81.2 & 13.60 & $1.09 \mathrm{E}+00$ & $1.59 \mathrm{E}+01$ \\
81.6 & 13.66 & $1.14 \mathrm{E}+00$ & $1.73 \mathrm{E}+01$ \\
82 & 13.71 & $1.19 \mathrm{E}+00$ & $1.54 \mathrm{E}+01$ \\
82.4 & 13.77 & $1.19 \mathrm{E}+00$ & $1.52 \mathrm{E}+01$ \\
82.8 & 13.83 & $1.14 \mathrm{E}+00$ & $1.42 \mathrm{E}+01$ \\
83.2 & 13.88 & $1.09 \mathrm{E}+00$ & $1.49 \mathrm{E}+01$ \\
83.6 & 13.94 & $9.67 \mathrm{E}-01$ & $1.41 \mathrm{E}+01$ \\
84 & 13.99 & $9.67 \mathrm{E}-01$ & $1.46 \mathrm{E}+01$ \\
84.4 & 14.05 & $1.02 \mathrm{E}+00$ & $1.48 \mathrm{E}+01$ \\
84.8 & 14.10 & $1.28 \mathrm{E}+00$ & $1.59 \mathrm{E}+01$ \\
85.2 & 14.16 & $1.42 \mathrm{E}+00$ & $1.68 \mathrm{E}+01$ \\
85.6 & 14.22 & $1.37 \mathrm{E}+00$ & $1.73 \mathrm{E}+01$ \\
86 & 14.27 & $1.41 \mathrm{E}+00$ & $1.63 \mathrm{E}+01$ \\
86.4 & 14.33 & $1.74 \mathrm{E}+00$ & $1.87 \mathrm{E}+01$ \\
86.8 & 14.38 & $2.18 \mathrm{E}+00$ & $1.80 \mathrm{E}+01$ \\
87.2 & 14.44 & $2.33 \mathrm{E}+00$ & $1.97 \mathrm{E}+01$ \\
97.4 & 15.00 & $6.01 \mathrm{E}+00$ & $2.53 \mathrm{E}+01$ \\
92.8 & 15.05 & $5.91 \mathrm{E}+00$ & $2.82 \mathrm{E}+01$ \\
93.2 & 15.09 & $6.64 \mathrm{E}+00$ & $2.67 \mathrm{E}+01$ \\
93.6 & 15.13 & $6.67 \mathrm{E}+00$ & $2.72 \mathrm{E}+01$ \\
88 & 14.49 & $2.24 \mathrm{E}+00$ & $1.94 \mathrm{E}+01$ \\
88.4 & 14.55 & $2.42 \mathrm{E}+00$ & $2.22 \mathrm{E}+01$ \\
88.8 & 14.63 & $3.57 \mathrm{E}+00$ & $2.30 \mathrm{E}+01$ \\
89.2 & 14.67 & $3.49 \mathrm{E}+00$ & $2.25 \mathrm{E}+01$ \\
89.6 & 14.72 & $2.82 \mathrm{E}+00$ & $2.19 \mathrm{E}+01$ \\
90.6 & 14.82 & $4.32 \mathrm{E}+00$ & $2.46 \mathrm{E}+01$ \\
90.8 & 14.84 & $3.93 \mathrm{E}+00$ & $2.27 \mathrm{E}+01$ \\
91.2 & 14.88 & $3.84 \mathrm{E}+00$ & $2.35 \mathrm{E}+01$ \\
91.6 & 14.92 & $3.79 \mathrm{E}+00$ & $2.16 \mathrm{E}+01$ \\
92 & 14.96 & $4.17 \mathrm{E}+00$ & $2.35 \mathrm{E}+01$ \\
& & &
\end{tabular}




\begin{tabular}{cccc}
\hline $\begin{array}{c}\text { Depth } \\
\text { [cm] }\end{array}$ & $\begin{array}{c}\text { Age } \\
\text { [cal kyr] }\end{array}$ & $\begin{array}{c}\text { Fe } / \mathrm{Ca} \\
{[\mathrm{cps}]}\end{array}$ & $\mathrm{Fe} / \mathrm{K}$ \\
\hline $\mathrm{c} p \mathrm{~s}]$ \\
\hline 94 & 15.17 & $8.08 \mathrm{E}+00$ & $2.99 \mathrm{E}+01$ \\
94.4 & 15.21 & $6.28 \mathrm{E}+00$ & $2.98 \mathrm{E}+01$ \\
94.8 & 15.25 & $6.36 \mathrm{E}+00$ & $2.81 \mathrm{E}+01$ \\
95.2 & 15.29 & $5.76 \mathrm{E}+00$ & $2.71 \mathrm{E}+01$ \\
95.6 & 15.34 & $6.50 \mathrm{E}+00$ & $2.97 \mathrm{E}+01$ \\
96 & 15.38 & $5.86 \mathrm{E}+00$ & $2.68 \mathrm{E}+01$ \\
96.4 & 15.42 & $8.09 \mathrm{E}+00$ & $2.84 \mathrm{E}+01$ \\
96.8 & 15.46 & $7.64 \mathrm{E}+00$ & $2.68 \mathrm{E}+01$ \\
97.2 & 15.50 & $9.31 \mathrm{E}+00$ & $2.89 \mathrm{E}+01$ \\
97.6 & 15.54 & $9.43 \mathrm{E}+00$ & $3.03 \mathrm{E}+01$ \\
98 & 15.58 & $7.10 \mathrm{E}+00$ & $2.87 \mathrm{E}+01$ \\
98.4 & 15.62 & $8.04 \mathrm{E}+00$ & $3.13 \mathrm{E}+01$ \\
98.8 & 15.67 & $9.16 \mathrm{E}+00$ & $2.88 \mathrm{E}+01$ \\
99.2 & 15.71 & $8.83 \mathrm{E}+00$ & $2.78 \mathrm{E}+01$ \\
99.6 & 15.75 & $7.93 \mathrm{E}+00$ & $2.68 \mathrm{E}+01$ \\
100 & 15.79 & $9.38 \mathrm{E}+00$ & $2.90 \mathrm{E}+01$ \\
100.4 & 15.83 & $9.65 \mathrm{E}+00$ & $2.70 \mathrm{E}+01$ \\
100.8 & 15.87 & $1.01 \mathrm{E}+01$ & $2.93 \mathrm{E}+01$ \\
101.2 & 15.91 & $9.99 \mathrm{E}+00$ & $2.77 \mathrm{E}+01$ \\
101.6 & 15.96 & $9.36 \mathrm{E}+00$ & $2.73 \mathrm{E}+01$ \\
102 & 16.00 & $8.77 \mathrm{E}+00$ & $2.68 \mathrm{E}+01$ \\
102.4 & 16.04 & $8.27 \mathrm{E}+00$ & $2.49 \mathrm{E}+01$ \\
102.8 & 16.08 & $9.22 \mathrm{E}+00$ & $2.59 \mathrm{E}+01$ \\
103.2 & 16.11 & $8.95 \mathrm{E}+00$ & $2.59 \mathrm{E}+01$ \\
112.4 & 16.76 & $9.01 \mathrm{E}+00$ & $2.80 \mathrm{E}+01$ \\
112.8 & 16.79 & $9.28 \mathrm{E}+00$ & $2.57 \mathrm{E}+01$ \\
113.2 & 16.81 & $9.84 \mathrm{E}+00$ & $2.76 \mathrm{E}+01$
\end{tabular}




\begin{tabular}{|c|c|c|c|}
\hline $\begin{array}{c}\text { Depth } \\
{[\mathrm{cm}]}\end{array}$ & $\begin{array}{c}\text { Age } \\
\text { [cal kyr] }\end{array}$ & $\begin{array}{c}\mathrm{Fe} / \mathrm{Ca} \\
{[c p s]}\end{array}$ & $\begin{array}{l}\mathbf{F e} / \mathbf{K} \\
{[c p s]} \\
\end{array}$ \\
\hline 113.6 & 16.83 & $1.17 \mathrm{E}+01$ & $2.51 E+01$ \\
\hline 114 & 16.84 & $1.00 \mathrm{E}+01$ & $2.62 E+01$ \\
\hline 114.4 & 16.86 & $9.29 \mathrm{E}+00$ & $2.57 \mathrm{E}+01$ \\
\hline 114.8 & 16.88 & $1.50 \mathrm{E}+01$ & $2.65 E+01$ \\
\hline 115.2 & 16.89 & $1.19 \mathrm{E}+01$ & $2.49 E+01$ \\
\hline 115.6 & 16.91 & $9.25 E+00$ & $2.46 E+01$ \\
\hline 116 & 16.93 & $1.01 \mathrm{E}+01$ & $2.61 \mathrm{E}+01$ \\
\hline 116.4 & 16.95 & $1.22 \mathrm{E}+01$ & $2.59 E+01$ \\
\hline 116.8 & 16.96 & $1.49 \mathrm{E}+01$ & $2.80 E+01$ \\
\hline 117.2 & 16.98 & $1.07 \mathrm{E}+01$ & $2.82 E+01$ \\
\hline 117.6 & 17.00 & $1.42 \mathrm{E}+01$ & $2.87 E+01$ \\
\hline 118 & 17.01 & $1.33 \mathrm{E}+01$ & $2.51 E+01$ \\
\hline 118.4 & 17.03 & $1.36 \mathrm{E}+01$ & $2.80 E+01$ \\
\hline 118.8 & 17.05 & $1.62 \mathrm{E}+01$ & $2.73 E+01$ \\
\hline 119.2 & 17.07 & $1.41 \mathrm{E}+01$ & $2.85 E+01$ \\
\hline 119.6 & 17.08 & $1.26 \mathrm{E}+01$ & $2.79 E+01$ \\
\hline 120 & 17.10 & $1.38 \mathrm{E}+01$ & $2.72 E+01$ \\
\hline 120.4 & 17.12 & $1.50 \mathrm{E}+01$ & $2.90 \mathrm{E}+01$ \\
\hline 120.8 & 17.13 & $1.22 \mathrm{E}+01$ & $2.64 \mathrm{E}+01$ \\
\hline 121.2 & 17.15 & $1.26 \mathrm{E}+01$ & $2.72 E+01$ \\
\hline 121.6 & 17.17 & $8.48 E+00$ & $2.55 E+01$ \\
\hline 122 & 17.19 & $1.83 \mathrm{E}+01$ & $2.84 E+01$ \\
\hline 122.4 & 17.20 & $2.11 E+01$ & $2.93 E+01$ \\
\hline 122.8 & 17.22 & $2.82 E+01$ & $3.26 \mathrm{E}+01$ \\
\hline 123.2 & 17.24 & $1.52 \mathrm{E}+01$ & $2.53 E+01$ \\
\hline 123.6 & 17.25 & $4.24 E+01$ & $2.48 \mathrm{E}+01$ \\
\hline 124 & 17.27 & $3.33 E+01$ & $2.65 E+01$ \\
\hline 124.4 & 17.29 & $2.00 \mathrm{E}+01$ & $2.43 E+01$ \\
\hline 124.8 & 17.31 & $2.11 E+01$ & $2.42 E+01$ \\
\hline 125.2 & 17.32 & $1.63 \mathrm{E}+01$ & $2.45 E+01$ \\
\hline 125.6 & 17.34 & $1.31 \mathrm{E}+01$ & $2.39 E+01$ \\
\hline 126 & 17.36 & $1.53 \mathrm{E}+01$ & $2.39 E+01$ \\
\hline 126.4 & 17.37 & $1.65 E+01$ & $2.51 E+01$ \\
\hline 126.8 & 17.39 & $1.41 \mathrm{E}+01$ & $2.43 E+01$ \\
\hline 127.2 & 17.41 & $1.66 \mathrm{E}+01$ & $3.92 E+01$ \\
\hline 127.6 & 17.43 & $1.58 \mathrm{E}+01$ & $2.41 \mathrm{E}+01$ \\
\hline 128 & 17.44 & $1.54 \mathrm{E}+01$ & $2.60 \mathrm{E}+01$ \\
\hline 128.4 & 17.46 & $1.13 \mathrm{E}+01$ & $2.38 \mathrm{E}+01$ \\
\hline 128.8 & 17.48 & $1.54 \mathrm{E}+01$ & $2.44 E+01$ \\
\hline 129.2 & 17.49 & $1.61 \mathrm{E}+01$ & $2.50 E+01$ \\
\hline 129.6 & 17.51 & $1.74 \mathrm{E}+01$ & $2.55 \mathrm{E}+01$ \\
\hline 130 & 17.53 & $1.74 \mathrm{E}+01$ & $2.47 E+01$ \\
\hline 130.4 & 17.55 & $2.02 E+01$ & $2.79 E+01$ \\
\hline
\end{tabular}




\begin{tabular}{|c|c|c|c|}
\hline $\begin{array}{c}\text { Depth } \\
{[\mathrm{cm}]}\end{array}$ & $\begin{array}{c}\text { Age } \\
\text { [cal kyr] }\end{array}$ & $\begin{array}{c}\mathrm{Fe} / \mathrm{Ca} \\
{[c p s]}\end{array}$ & $\begin{array}{l}\mathbf{F e} / \mathbf{K} \\
{[c p s]} \\
\end{array}$ \\
\hline 130.8 & 17.56 & $1.74 \mathrm{E}+01$ & $2.59 E+01$ \\
\hline 131.2 & 17.58 & $1.74 \mathrm{E}+01$ & $2.58 \mathrm{E}+01$ \\
\hline 131.6 & 17.60 & $1.77 \mathrm{E}+01$ & $2.43 E+01$ \\
\hline 132 & 17.61 & $1.78 \mathrm{E}+01$ & $2.39 E+01$ \\
\hline 132.4 & 17.63 & $1.73 E+01$ & $2.67 E+01$ \\
\hline 132.8 & 17.65 & $1.64 \mathrm{E}+01$ & $2.65 E+01$ \\
\hline 133.2 & 17.67 & $1.55 \mathrm{E}+01$ & $2.48 \mathrm{E}+01$ \\
\hline 133.6 & 17.68 & $1.68 \mathrm{E}+01$ & $2.65 E+01$ \\
\hline 134 & 17.70 & $1.61 \mathrm{E}+01$ & $2.63 E+01$ \\
\hline 134.4 & 17.72 & $1.75 \mathrm{E}+01$ & $4.83 E+01$ \\
\hline 134.8 & 17.73 & $1.49 \mathrm{E}+01$ & $2.58 \mathrm{E}+01$ \\
\hline 135.2 & 17.75 & $1.41 \mathrm{E}+01$ & $2.57 E+01$ \\
\hline 135.6 & 17.77 & $1.30 \mathrm{E}+01$ & $2.59 E+01$ \\
\hline 136 & 17.79 & $1.41 \mathrm{E}+01$ & $2.52 E+01$ \\
\hline 136.4 & 17.80 & $1.96 \mathrm{E}+01$ & $2.57 E+01$ \\
\hline 136.8 & 17.82 & $2.45 E+01$ & $4.41 E+01$ \\
\hline 137.2 & 17.84 & $1.67 E+01$ & $2.46 \mathrm{E}+01$ \\
\hline 137.6 & 17.85 & $1.58 \mathrm{E}+01$ & $2.47 E+01$ \\
\hline 138 & 17.87 & $1.38 \mathrm{E}+01$ & $2.33 E+01$ \\
\hline 138.4 & 17.89 & $1.03 E+01$ & $2.35 E+01$ \\
\hline 138.8 & 17.91 & $1.26 \mathrm{E}+01$ & $2.46 \mathrm{E}+01$ \\
\hline 139.2 & 17.92 & $1.47 \mathrm{E}+01$ & $2.49 E+01$ \\
\hline 139.6 & 17.94 & $1.37 \mathrm{E}+01$ & $2.44 \mathrm{E}+01$ \\
\hline 140 & 17.96 & $1.19 E+01$ & $2.35 E+01$ \\
\hline 140.4 & 17.97 & $1.19 \mathrm{E}+01$ & $2.37 E+01$ \\
\hline 140.8 & 17.99 & $1.25 \mathrm{E}+01$ & $2.22 E+01$ \\
\hline 141.2 & 18.01 & $1.17 \mathrm{E}+01$ & $2.35 \mathrm{E}+01$ \\
\hline 141.6 & 18.03 & $1.33 \mathrm{E}+01$ & $2.46 \mathrm{E}+01$ \\
\hline 142 & 18.04 & $1.24 \mathrm{E}+01$ & $2.29 E+01$ \\
\hline 142.4 & 18.06 & $9.81 E+00$ & $2.21 E+01$ \\
\hline 142.8 & 18.08 & $1.06 \mathrm{E}+01$ & $2.19 E+01$ \\
\hline 143.2 & 18.09 & $1.03 E+01$ & $2.36 \mathrm{E}+01$ \\
\hline 143.6 & 18.11 & $1.03 E+01$ & $2.38 \mathrm{E}+01$ \\
\hline 144 & 18.13 & $1.00 \mathrm{E}+01$ & $2.32 E+01$ \\
\hline 144.4 & 18.15 & $9.68 \mathrm{E}+00$ & $2.28 \mathrm{E}+01$ \\
\hline 144.8 & 18.16 & $8.61 \mathrm{E}+00$ & $2.31 \mathrm{E}+01$ \\
\hline 145.2 & 18.18 & $7.92 E+00$ & $2.29 E+01$ \\
\hline 145.6 & 18.20 & $4.80 \mathrm{E}+00$ & $2.16 \mathrm{E}+01$ \\
\hline 146 & 18.21 & $3.51 E+00$ & $1.98 \mathrm{E}+01$ \\
\hline 146.4 & 18.23 & $3.42 E+00$ & $2.11 E+01$ \\
\hline 146.8 & 18.25 & $2.44 E+00$ & $2.14 E+01$ \\
\hline 147.2 & 18.27 & $2.14 \mathrm{E}+00$ & $1.92 E+01$ \\
\hline 147.6 & 18.28 & $1.46 \mathrm{E}+00$ & $1.64 \mathrm{E}+01$ \\
\hline
\end{tabular}




\begin{tabular}{cccc}
\hline $\begin{array}{c}\text { Depth } \\
\text { [cm] }\end{array}$ & $\begin{array}{c}\text { Age } \\
\text { [cal kyr] }\end{array}$ & $\begin{array}{c}\text { Fe/Ca } \\
\text { [cps] }\end{array}$ & $\begin{array}{c}\text { Fe/K } \\
{[c p s]}\end{array}$ \\
\hline 148 & 18.30 & $1.38 \mathrm{E}+00$ & $1.58 \mathrm{E}+01$ \\
148.4 & 18.37 & $1.32 \mathrm{E}+00$ & $1.49 \mathrm{E}+01$ \\
148.8 & 18.44 & $1.41 \mathrm{E}+00$ & $1.69 \mathrm{E}+01$ \\
149.2 & 18.52 & $1.36 \mathrm{E}+00$ & $1.63 \mathrm{E}+01$ \\
149.6 & 18.59 & $1.15 \mathrm{E}+00$ & $1.50 \mathrm{E}+01$ \\
150 & 18.66 & $2.28 \mathrm{E}+00$ & $1.80 \mathrm{E}+01$ \\
150.4 & 18.73 & $1.43 \mathrm{E}+00$ & $1.54 \mathrm{E}+01$ \\
150.8 & 18.80 & $1.27 \mathrm{E}+00$ & $1.59 \mathrm{E}+01$ \\
151.2 & 18.88 & $1.39 \mathrm{E}+00$ & $1.57 \mathrm{E}+01$ \\
151.6 & 18.95 & $1.42 \mathrm{E}+00$ & $1.61 \mathrm{E}+01$ \\
152 & 19.02 & $1.38 \mathrm{E}+00$ & $1.60 \mathrm{E}+01$ \\
152.4 & 19.09 & $1.49 \mathrm{E}+00$ & $1.63 \mathrm{E}+01$ \\
152.8 & 19.16 & $1.34 \mathrm{E}+00$ & $1.51 \mathrm{E}+01$ \\
153.2 & 19.24 & $1.41 \mathrm{E}+00$ & $1.59 \mathrm{E}+01$ \\
153.6 & 19.31 & $1.59 \mathrm{E}+00$ & $1.59 \mathrm{E}+01$ \\
154 & 19.38 & $1.70 \mathrm{E}+00$ & $1.78 \mathrm{E}+01$ \\
154.4 & 19.45 & $1.73 \mathrm{E}+00$ & $1.63 \mathrm{E}+01$ \\
154.8 & 19.52 & $1.43 \mathrm{E}+00$ & $1.53 \mathrm{E}+01$ \\
155.2 & 19.60 & $1.48 \mathrm{E}+00$ & $1.56 \mathrm{E}+01$ \\
155.6 & 19.67 & $1.53 \mathrm{E}+00$ & $1.57 \mathrm{E}+01$ \\
156 & 19.74 & $1.44 \mathrm{E}+00$ & $1.53 \mathrm{E}+01$ \\
156.4 & 19.81 & $1.31 \mathrm{E}+00$ & $1.43 \mathrm{E}+01$ \\
156.8 & 19.88 & $1.35 \mathrm{E}+00$ & $1.49 \mathrm{E}+01$ \\
157.2 & 19.96 & $1.20 \mathrm{E}+00$ & $1.46 \mathrm{E}+01$ \\
157.6 & 20.03 & $1.14 \mathrm{E}+00$ & $1.40 \mathrm{E}+01$ \\
158 & 20.10 & $1.02 \mathrm{E}+00$ & $1.46 \mathrm{E}+01$ \\
163.6 & 21.11 & $1.46 \mathrm{E}+00$ & $1.62 \mathrm{E}+01$ \\
164.4 & 21.18 & $1.35 \mathrm{E}+00$ & $1.63 \mathrm{E}+01$ \\
164.8 & 21.32 & $1.37 \mathrm{E}+00$ & $1.63 \mathrm{E}+01$
\end{tabular}




\begin{tabular}{cccc}
\hline Depth & Age & Fe/Ca & Fe/K \\
[cm] & [cal kyr] & {$[c p s]$} & {$[c p s]$} \\
\hline 165.2 & 21.40 & $1.22 \mathrm{E}+00$ & $1.48 \mathrm{E}+01$ \\
165.6 & 21.47 & $1.28 \mathrm{E}+00$ & $1.48 \mathrm{E}+01$ \\
166 & 21.54 & $1.44 \mathrm{E}+00$ & $1.70 \mathrm{E}+01$ \\
166.4 & 21.61 & $1.38 \mathrm{E}+00$ & $1.68 \mathrm{E}+01$ \\
166.8 & 21.68 & $1.35 \mathrm{E}+00$ & $1.69 \mathrm{E}+01$ \\
167.2 & 21.76 & $1.29 \mathrm{E}+00$ & $1.50 \mathrm{E}+01$ \\
167.6 & 21.83 & $1.32 \mathrm{E}+00$ & $1.63 \mathrm{E}+01$ \\
168 & 21.90 & $1.19 \mathrm{E}+00$ & $1.53 \mathrm{E}+01$ \\
168.4 & 21.97 & $1.47 \mathrm{E}+00$ & $1.58 \mathrm{E}+01$ \\
168.8 & 22.04 & $1.40 \mathrm{E}+00$ & $1.58 \mathrm{E}+01$ \\
169.2 & 22.12 & $1.53 \mathrm{E}+00$ & $1.64 \mathrm{E}+01$ \\
169.6 & 22.19 & $1.50 \mathrm{E}+00$ & $1.68 \mathrm{E}+01$ \\
170 & 22.26 & $1.74 \mathrm{E}+00$ & $1.86 \mathrm{E}+01$ \\
170.4 & 22.33 & $1.79 \mathrm{E}+00$ & $1.76 \mathrm{E}+01$ \\
170.8 & 22.40 & $1.80 \mathrm{E}+00$ & $1.73 \mathrm{E}+01$ \\
171.2 & 22.48 & $1.71 \mathrm{E}+00$ & $1.73 \mathrm{E}+01$ \\
171.6 & 22.55 & $1.93 \mathrm{E}+00$ & $1.87 \mathrm{E}+01$ \\
172 & 22.62 & $2.07 \mathrm{E}+00$ & $1.86 \mathrm{E}+01$ \\
172.4 & 22.69 & $2.19 \mathrm{E}+00$ & $1.96 \mathrm{E}+01$ \\
172.8 & 22.76 & $1.93 \mathrm{E}+00$ & $1.75 \mathrm{E}+01$ \\
173.2 & 22.81 & $1.67 \mathrm{E}+00$ & $1.61 \mathrm{E}+01$ \\
173.6 & 22.84 & $1.84 \mathrm{E}+00$ & $1.68 \mathrm{E}+01$ \\
174 & 22.86 & $1.86 \mathrm{E}+00$ & $1.78 \mathrm{E}+01$ \\
174.4 & 22.88 & $1.98 \mathrm{E}+00$ & $1.88 \mathrm{E}+01$ \\
174.8 & 22.91 & $1.73 \mathrm{E}+00$ & $1.70 \mathrm{E}+01$ \\
175.2 & 22.93 & $1.68 \mathrm{E}+00$ & $1.64 \mathrm{E}+01$ \\
175.6 & 22.96 & $1.83 \mathrm{E}+00$ & $1.76 \mathrm{E}+01$ \\
176 & 22.98 & $1.74 \mathrm{E}+00$ & $1.67 \mathrm{E}+01$ \\
181.2 & 23.29 & $5.25 \mathrm{E}+00$ & $2.44 \mathrm{E}+01$ \\
181.6 & 23.32 & $6.14 \mathrm{E}+00$ & $2.84 \mathrm{E}+01$ \\
176.4 & 23.00 & $2.07 \mathrm{E}+00$ & $1.76 \mathrm{E}+01$ \\
176.8 & 23.03 & $2.32 \mathrm{E}+00$ & $1.74 \mathrm{E}+01$ \\
177.2 & 23.05 & $2.41 \mathrm{E}+00$ & $1.68 \mathrm{E}+01$ \\
177.6 & 23.08 & $2.44 \mathrm{E}+00$ & $1.71 \mathrm{E}+01$ \\
178 & 23.10 & $2.48 \mathrm{E}+00$ & $1.71 \mathrm{E}+01$ \\
178.4 & 23.12 & $3.36 \mathrm{E}+00$ & $1.82 \mathrm{E}+01$ \\
178.8 & 23.15 & $4.47 \mathrm{E}+00$ & $2.08 \mathrm{E}+01$ \\
179.2 & 23.17 & $4.88 \mathrm{E}+00$ & $2.04 \mathrm{E}+01$ \\
179.6 & 23.20 & $3.24 \mathrm{E}+00$ & $1.93 \mathrm{E}+01$ \\
180 & 23.22 & $3.32 \mathrm{E}+00$ & $1.98 \mathrm{E}+01$ \\
& 23.24 & $3.93 \mathrm{E}+00$ & $2.13 \mathrm{E}+01$ \\
180.4 & & \\
$17.87+00$ & $2.79 \mathrm{E}+01$
\end{tabular}




\begin{tabular}{|c|c|c|c|}
\hline $\begin{array}{c}\text { Depth } \\
{[\mathrm{cm}]}\end{array}$ & $\begin{array}{c}\text { Age } \\
\text { [cal kyr] }\end{array}$ & $\begin{array}{c}\mathrm{Fe} / \mathrm{Ca} \\
{[c p s]}\end{array}$ & $\begin{array}{l}\mathbf{F e} / \mathbf{K} \\
{[c p s]} \\
\end{array}$ \\
\hline 182.4 & 23.36 & $6.40 E+00$ & $2.54 \mathrm{E}+01$ \\
\hline 182.8 & 23.39 & $8.46 \mathrm{E}+00$ & $2.67 E+01$ \\
\hline 183.2 & 23.45 & $9.37 \mathrm{E}+00$ & $2.63 E+01$ \\
\hline 183.6 & 23.54 & $9.39 E+00$ & $2.73 E+01$ \\
\hline 184 & 23.63 & $1.03 E+01$ & $2.71 E+01$ \\
\hline 184.4 & 23.72 & $8.53 E+00$ & $2.65 E+01$ \\
\hline 184.8 & 23.81 & $1.04 \mathrm{E}+01$ & $2.82 \mathrm{E}+01$ \\
\hline 185.2 & 23.91 & $1.06 \mathrm{E}+01$ & $2.78 \mathrm{E}+01$ \\
\hline 185.6 & 24.00 & $1.54 \mathrm{E}+01$ & $3.68 \mathrm{E}+01$ \\
\hline 186 & 24.09 & $1.14 \mathrm{E}+01$ & $2.48 \mathrm{E}+01$ \\
\hline 186.4 & 24.18 & $9.88 \mathrm{E}+00$ & $2.48 \mathrm{E}+01$ \\
\hline 186.8 & 24.27 & $1.05 E+01$ & $2.43 E+01$ \\
\hline 187.2 & 24.37 & $1.23 \mathrm{E}+01$ & $2.49 E+01$ \\
\hline 187.6 & 24.46 & $1.09 \mathrm{E}+01$ & $2.36 \mathrm{E}+01$ \\
\hline 188 & 24.55 & $2.00 E+01$ & $2.85 E+01$ \\
\hline 188.4 & 24.64 & $1.96 \mathrm{E}+01$ & $3.46 E+01$ \\
\hline 188.8 & 24.73 & $2.52 E+01$ & $4.42 \mathrm{E}+01$ \\
\hline 189.2 & 24.83 & $1.22 \mathrm{E}+01$ & $2.47 E+01$ \\
\hline 189.6 & 24.92 & $1.28 \mathrm{E}+01$ & $2.08 \mathrm{E}+01$ \\
\hline 190 & 25.01 & $1.79 E+01$ & $2.07 E+01$ \\
\hline 190.4 & 25.10 & $2.02 E+01$ & $2.06 \mathrm{E}+01$ \\
\hline 190.8 & 25.19 & $1.25 \mathrm{E}+01$ & $2.32 E+01$ \\
\hline 191.2 & 25.29 & $1.08 \mathrm{E}+01$ & $2.30 E+01$ \\
\hline 191.6 & 25.38 & $1.32 \mathrm{E}+01$ & $2.26 \mathrm{E}+01$ \\
\hline 192 & 25.47 & $1.28 \mathrm{E}+01$ & $2.22 \mathrm{E}+01$ \\
\hline 192.4 & 25.56 & $1.11 \mathrm{E}+01$ & $2.31 E+01$ \\
\hline 192.8 & 25.65 & $6.53 \mathrm{E}+00$ & $2.07 E+01$ \\
\hline 193.2 & 25.73 & $5.14 \mathrm{E}+00$ & $2.01 E+01$ \\
\hline 193.6 & 25.79 & $5.25 \mathrm{E}+00$ & $1.94 \mathrm{E}+01$ \\
\hline 194 & 25.85 & $4.97 E+00$ & $2.14 \mathrm{E}+01$ \\
\hline 194.4 & 25.90 & $3.71 E+00$ & $1.99 \mathrm{E}+01$ \\
\hline 194.8 & 25.96 & $1.62 \mathrm{E}+00$ & $1.48 \mathrm{E}+01$ \\
\hline 195.2 & 26.02 & $1.75 E+00$ & $1.63 E+01$ \\
\hline 195.6 & 26.08 & $1.71 \mathrm{E}+00$ & $1.68 \mathrm{E}+01$ \\
\hline 196 & 26.14 & $1.71 \mathrm{E}+00$ & $1.66 \mathrm{E}+01$ \\
\hline 196.4 & 26.19 & $2.07 E+00$ & $1.87 \mathrm{E}+01$ \\
\hline 196.8 & 26.25 & $2.33 \mathrm{E}+00$ & $1.87 \mathrm{E}+01$ \\
\hline 197.2 & 26.31 & $2.64 \mathrm{E}+00$ & $1.83 \mathrm{E}+01$ \\
\hline 197.6 & 26.37 & $2.28 \mathrm{E}+00$ & $1.80 E+01$ \\
\hline 198 & 26.43 & $2.45 \mathrm{E}+00$ & $1.87 \mathrm{E}+01$ \\
\hline 198.4 & 26.48 & $2.05 E+00$ & $1.70 \mathrm{E}+01$ \\
\hline 198.8 & 26.54 & $2.02 E+00$ & $1.75 E+01$ \\
\hline 199.2 & 26.60 & $2.04 E+00$ & $1.74 \mathrm{E}+01$ \\
\hline
\end{tabular}




\begin{tabular}{cccc}
\hline Depth & Age & Fe/Ca & Fe/K \\
[cm] & {$[$ cal kyr] } & {$[c p s]$} & {$[c p s]$} \\
\hline 199.6 & 26.66 & $1.45 \mathrm{E}+00$ & $1.48 \mathrm{E}+01$ \\
200 & 26.72 & $1.72 \mathrm{E}+00$ & $1.67 \mathrm{E}+01$ \\
200.4 & 26.77 & $1.39 \mathrm{E}+00$ & $1.51 \mathrm{E}+01$ \\
200.8 & 26.83 & $1.29 \mathrm{E}+00$ & $1.51 \mathrm{E}+01$ \\
201.2 & 26.89 & $1.60 \mathrm{E}+00$ & $1.54 \mathrm{E}+01$ \\
201.6 & 26.95 & $1.37 \mathrm{E}+00$ & $1.63 \mathrm{E}+01$ \\
202 & 27.01 & $1.30 \mathrm{E}+00$ & $1.52 \mathrm{E}+01$ \\
202.4 & 27.06 & $1.39 \mathrm{E}+00$ & $1.41 \mathrm{E}+01$ \\
202.8 & 27.12 & $1.34 \mathrm{E}+00$ & $1.38 \mathrm{E}+01$ \\
203.2 & 27.18 & $1.36 \mathrm{E}+00$ & $1.49 \mathrm{E}+01$ \\
203.6 & 27.24 & $1.24 \mathrm{E}+00$ & $1.55 \mathrm{E}+01$ \\
204 & 27.30 & $1.25 \mathrm{E}+00$ & $1.46 \mathrm{E}+01$ \\
204.4 & 27.35 & $1.25 \mathrm{E}+00$ & $1.50 \mathrm{E}+01$ \\
204.8 & 27.41 & $1.24 \mathrm{E}+00$ & $1.61 \mathrm{E}+01$ \\
205.2 & 27.47 & $1.29 \mathrm{E}+00$ & $1.53 \mathrm{E}+01$ \\
205.6 & 27.53 & $1.37 \mathrm{E}+00$ & $1.55 \mathrm{E}+01$ \\
206 & 27.59 & $1.32 \mathrm{E}+00$ & $1.53 \mathrm{E}+01$ \\
206.4 & 27.64 & $1.37 \mathrm{E}+00$ & $1.53 \mathrm{E}+01$ \\
206.8 & 27.70 & $1.64 \mathrm{E}+00$ & $1.64 \mathrm{E}+01$ \\
207.2 & 27.76 & $1.62 \mathrm{E}+00$ & $1.61 \mathrm{E}+01$ \\
207.6 & 27.82 & $1.71 \mathrm{E}+00$ & $1.87 \mathrm{E}+01$ \\
208.8 & 27.99 & $1.96 \mathrm{E}+00$ & $1.91 \mathrm{E}+01$ \\
209.2 & 28.05 & $1.92 \mathrm{E}+00$ & $1.67 \mathrm{E}+01$ \\
216.4 & 28.87 & $3.25 \mathrm{E}+00$ & $2.61 \mathrm{E}+01$ \\
216.8 & 28.90 & $3.15 \mathrm{E}+00$ & $2.18 \mathrm{E}+01$ \\
217.2 & 28.94 & $2.57 \mathrm{E}+00$ & $2.14 \mathrm{E}+01$ \\
210 & 28.11 & $2.18 \mathrm{E}+00$ & $1.79 \mathrm{E}+01$ \\
210.4 & 28.17 & $2.91 \mathrm{E}+00$ & $2.06 \mathrm{E}+01$ \\
210.8 & 28.22 & $2.99 \mathrm{E}+00$ & $2.22 \mathrm{E}+01$ \\
211.2 & 28.34 & $3.24 \mathrm{E}+00$ & $2.47 \mathrm{E}+01$ \\
211.6 & 28.40 & $3.06 \mathrm{E}+00$ & $1.94 \mathrm{E}+01$ \\
212 & 28.46 & $3.01 \mathrm{E}+00$ & $2.05 \mathrm{E}+01$ \\
212.4 & 28.51 & $4.47 \mathrm{E}+00$ & $2.43 \mathrm{E}+01$ \\
212.8 & 28.57 & $2.66 \mathrm{E}+00$ & $2.19 \mathrm{E}+01$ \\
213.2 & 28.62 & $4.39 \mathrm{E}+00$ & $2.50 \mathrm{E}+01$ \\
213.6 & 28.65 & $3.58 \mathrm{E}+00$ & $2.18 \mathrm{E}+01$ \\
214 & 28.68 & $4.21 \mathrm{E}+00$ & $2.07 \mathrm{E}+01$ \\
214.4 & 28.71 & $2.68 \mathrm{E}+00$ & $1.95 \mathrm{E}+01$ \\
28.74 & $2.93 \mathrm{E}+00$ & $1.96 \mathrm{E}+01$ \\
216.78 & $3.19 \mathrm{E}+00$ & $2.06 \mathrm{E}+01$ \\
281 & $2.94 \mathrm{E}+00$ & $2.10 \mathrm{E}+01$ \\
& & &
\end{tabular}




\begin{tabular}{cccc}
\hline Depth & Age & Fe/Ca & Fe/K \\
{$[$ cm] } & {$[$ cal $k y r]$} & {$[c p s]$} & {$[c p s]$} \\
\hline 217.6 & 28.97 & $2.66 \mathrm{E}+00$ & $2.12 \mathrm{E}+01$ \\
218 & 29.00 & $2.82 \mathrm{E}+00$ & $2.34 \mathrm{E}+01$ \\
218.4 & 29.03 & $2.35 \mathrm{E}+00$ & $2.08 \mathrm{E}+01$ \\
218.8 & 29.06 & $2.84 \mathrm{E}+00$ & $2.28 \mathrm{E}+01$ \\
219.2 & 29.10 & $2.97 \mathrm{E}+00$ & $2.67 \mathrm{E}+01$ \\
219.6 & 29.13 & $3.97 \mathrm{E}+00$ & $3.12 \mathrm{E}+01$ \\
220 & 29.16 & $3.34 \mathrm{E}+00$ & $2.77 \mathrm{E}+01$ \\
220.4 & 29.19 & $3.18 \mathrm{E}+00$ & $2.56 \mathrm{E}+01$ \\
220.8 & 29.22 & $1.79 \mathrm{E}+00$ & $1.69 \mathrm{E}+01$ \\
221.2 & 29.26 & $1.89 \mathrm{E}+00$ & $1.76 \mathrm{E}+01$ \\
221.6 & 29.29 & $2.44 \mathrm{E}+00$ & $1.74 \mathrm{E}+01$ \\
222 & 29.32 & $2.50 \mathrm{E}+00$ & $1.92 \mathrm{E}+01$ \\
222.4 & 29.35 & $4.28 \mathrm{E}+00$ & $2.05 \mathrm{E}+01$ \\
222.8 & 29.38 & $3.95 \mathrm{E}+00$ & $2.06 \mathrm{E}+01$ \\
223.2 & 29.42 & $4.16 \mathrm{E}+00$ & $2.19 \mathrm{E}+01$ \\
223.6 & 29.45 & $3.83 \mathrm{E}+00$ & $2.36 \mathrm{E}+01$ \\
224 & 29.48 & $4.90 \mathrm{E}+00$ & $2.14 \mathrm{E}+01$ \\
224.4 & 29.51 & $5.05 \mathrm{E}+00$ & $2.08 \mathrm{E}+01$ \\
224.8 & 29.54 & $5.18 \mathrm{E}+00$ & $2.27 \mathrm{E}+01$ \\
225.2 & 29.58 & $6.09 \mathrm{E}+00$ & $2.17 \mathrm{E}+01$ \\
225.6 & 29.61 & $8.09 \mathrm{E}+00$ & $2.31 \mathrm{E}+01$ \\
226 & 29.64 & $7.12 \mathrm{E}+00$ & $2.16 \mathrm{E}+01$ \\
226.4 & 29.67 & $8.16 \mathrm{E}+00$ & $2.44 \mathrm{E}+01$ \\
226.8 & 29.70 & $1.03 \mathrm{E}+01$ & $2.58 \mathrm{E}+01$ \\
227.2 & 29.74 & $1.01 \mathrm{E}+01$ & $2.70 \mathrm{E}+01$ \\
227.6 & 29.77 & $7.07 \mathrm{E}+00$ & $2.42 \mathrm{E}+01$ \\
233.4 & 29.80 & $5.17 \mathrm{E}+00$ & $2.25 \mathrm{E}+01$ \\
233.6 & 30.36 & $5.03 \mathrm{E}+00$ & $2.21 \mathrm{E}+01$ \\
2328 & 30.46 & $4.31 \mathrm{E}+00$ & $2.33 \mathrm{E}+01$ \\
23.4 & 30.56 & $3.00 \mathrm{E}+00$ & $2.03 \mathrm{E}+01$
\end{tabular}




\begin{tabular}{|c|c|c|c|}
\hline $\begin{array}{c}\text { Depth } \\
{[\mathrm{cm}]}\end{array}$ & $\begin{array}{c}\text { Age } \\
\text { [cal kyr] }\end{array}$ & $\begin{array}{c}\mathrm{Fe} / \mathrm{Ca} \\
{[c p s]}\end{array}$ & $\begin{array}{l}\mathrm{Fe} / \mathrm{K} \\
{[c p s]}\end{array}$ \\
\hline 234.8 & 30.67 & $2.87 E+00$ & $2.05 E+01$ \\
\hline 235.2 & 30.77 & $2.84 \mathrm{E}+00$ & $2.06 \mathrm{E}+01$ \\
\hline 235.6 & 30.88 & $3.21 E+00$ & $2.00 \mathrm{E}+01$ \\
\hline 236 & 30.98 & $5.31 E+00$ & $2.20 E+01$ \\
\hline 236.4 & 31.08 & $2.47 E+00$ & $1.84 \mathrm{E}+01$ \\
\hline 236.8 & 31.19 & $3.02 E+00$ & $2.04 E+01$ \\
\hline 237.2 & 31.29 & $2.79 \mathrm{E}+00$ & $2.01 \mathrm{E}+01$ \\
\hline 237.6 & 31.40 & $1.82 \mathrm{E}+00$ & $1.81 \mathrm{E}+01$ \\
\hline 238 & 31.50 & $1.52 \mathrm{E}+00$ & $1.67 \mathrm{E}+01$ \\
\hline 238.4 & 31.55 & $9.95 \mathrm{E}-01$ & $1.56 \mathrm{E}+01$ \\
\hline 238.8 & 31.59 & $1.04 \mathrm{E}+00$ & $1.57 \mathrm{E}+01$ \\
\hline 239.2 & 31.64 & $1.11 \mathrm{E}+00$ & $1.61 E+01$ \\
\hline 239.6 & 31.69 & $1.38 \mathrm{E}+00$ & $1.63 \mathrm{E}+01$ \\
\hline 240 & 31.73 & $1.30 \mathrm{E}+00$ & $1.72 \mathrm{E}+01$ \\
\hline 240.4 & 31.78 & $1.24 \mathrm{E}+00$ & $1.70 E+01$ \\
\hline 240.8 & 31.83 & $1.21 \mathrm{E}+00$ & $1.75 \mathrm{E}+01$ \\
\hline 241.2 & 31.87 & $1.32 \mathrm{E}+00$ & $1.68 \mathrm{E}+01$ \\
\hline 241.6 & 31.92 & $1.29 E+00$ & $1.70 E+01$ \\
\hline 242 & 31.97 & $1.16 \mathrm{E}+00$ & $1.61 \mathrm{E}+01$ \\
\hline 242.4 & 32.01 & $1.15 E+00$ & $1.72 \mathrm{E}+01$ \\
\hline 242.8 & 32.06 & $1.05 \mathrm{E}+00$ & $1.61 \mathrm{E}+01$ \\
\hline 243.2 & 32.11 & $9.43 \mathrm{E}-01$ & $1.64 \mathrm{E}+01$ \\
\hline 243.6 & 32.15 & $1.05 \mathrm{E}+00$ & $1.59 E+01$ \\
\hline 244 & 32.20 & 9.67E-01 & $1.62 E+01$ \\
\hline 244.4 & 32.25 & $1.04 \mathrm{E}+00$ & $1.60 \mathrm{E}+01$ \\
\hline 244.8 & 32.29 & $8.36 \mathrm{E}-01$ & $1.26 \mathrm{E}+01$ \\
\hline 245.2 & 32.34 & 8.41E-01 & $1.38 \mathrm{E}+01$ \\
\hline 245.6 & 32.39 & $1.07 \mathrm{E}+00$ & $1.43 E+01$ \\
\hline 246 & 32.43 & $1.14 \mathrm{E}+00$ & $1.47 \mathrm{E}+01$ \\
\hline 246.4 & 32.48 & 9.67E-01 & $1.41 \mathrm{E}+01$ \\
\hline 246.8 & 32.53 & $1.07 \mathrm{E}+00$ & $1.65 \mathrm{E}+01$ \\
\hline 247.2 & 32.57 & $1.05 \mathrm{E}+00$ & $1.56 \mathrm{E}+01$ \\
\hline 247.6 & 32.62 & $1.13 E+00$ & $1.55 \mathrm{E}+01$ \\
\hline 248 & 32.67 & $1.15 \mathrm{E}+00$ & $1.61 \mathrm{E}+01$ \\
\hline 248.4 & 32.71 & $1.44 \mathrm{E}+00$ & $1.59 E+01$ \\
\hline 248.8 & 32.76 & $1.59 \mathrm{E}+00$ & $1.80 \mathrm{E}+01$ \\
\hline 249.2 & 32.81 & $1.39 \mathrm{E}+00$ & $1.71 \mathrm{E}+01$ \\
\hline 249.6 & 32.85 & $1.52 \mathrm{E}+00$ & $1.60 \mathrm{E}+01$ \\
\hline 250 & 32.90 & $1.68 \mathrm{E}+00$ & $1.72 \mathrm{E}+01$ \\
\hline 250.4 & 32.95 & $1.53 \mathrm{E}+00$ & $1.68 \mathrm{E}+01$ \\
\hline 250.8 & 32.99 & $2.16 \mathrm{E}+00$ & $1.85 \mathrm{E}+01$ \\
\hline 251.2 & 33.04 & $2.22 \mathrm{E}+00$ & $1.94 \mathrm{E}+01$ \\
\hline 251.6 & 33.09 & $2.73 E+00$ & $2.28 \mathrm{E}+01$ \\
\hline
\end{tabular}




\begin{tabular}{|c|c|c|c|}
\hline $\begin{array}{c}\text { Depth } \\
{[\mathrm{cm}]}\end{array}$ & $\begin{array}{c}\text { Age } \\
\text { [cal kyr] }\end{array}$ & $\begin{array}{c}\mathrm{Fe} / \mathrm{Ca} \\
{[c p s]}\end{array}$ & $\begin{array}{l}\mathrm{Fe} / \mathrm{K} \\
{[c p s]}\end{array}$ \\
\hline 252 & 33.13 & $2.83 E+00$ & $2.37 E+01$ \\
\hline 252.4 & 33.18 & $2.81 E+00$ & $1.97 \mathrm{E}+01$ \\
\hline 252.8 & 33.23 & $2.67 E+00$ & $2.01 E+01$ \\
\hline 253.2 & 33.27 & $3.94 \mathrm{E}+00$ & $2.60 \mathrm{E}+01$ \\
\hline 253.6 & 33.32 & $2.18 \mathrm{E}+00$ & $1.92 \mathrm{E}+01$ \\
\hline 254 & 33.37 & $2.56 \mathrm{E}+00$ & $2.04 \mathrm{E}+01$ \\
\hline 254.4 & 33.41 & $2.24 \mathrm{E}+00$ & $1.93 \mathrm{E}+01$ \\
\hline 254.8 & 33.46 & $2.90 E+00$ & $2.23 E+01$ \\
\hline 255.2 & 33.51 & $1.92 \mathrm{E}+00$ & $1.92 \mathrm{E}+01$ \\
\hline 255.6 & 33.55 & $1.59 \mathrm{E}+00$ & $1.81 \mathrm{E}+01$ \\
\hline 256 & 33.60 & $1.60 \mathrm{E}+00$ & $1.92 \mathrm{E}+01$ \\
\hline 256.4 & 33.65 & $2.36 \mathrm{E}+00$ & $2.29 E+01$ \\
\hline 256.8 & 33.69 & $2.40 E+00$ & $2.14 E+01$ \\
\hline 257.2 & 33.74 & $1.77 \mathrm{E}+00$ & $1.88 \mathrm{E}+01$ \\
\hline 257.6 & 33.79 & $1.47 E+00$ & $1.74 \mathrm{E}+01$ \\
\hline 258 & 33.83 & $1.36 \mathrm{E}+00$ & $1.94 \mathrm{E}+01$ \\
\hline 258.4 & 33.88 & $1.15 E+00$ & $1.80 \mathrm{E}+01$ \\
\hline 258.8 & 33.93 & $1.55 \mathrm{E}+00$ & $2.13 E+01$ \\
\hline 259.2 & 33.97 & $1.31 \mathrm{E}+00$ & $1.75 \mathrm{E}+01$ \\
\hline 259.6 & 34.02 & $1.04 \mathrm{E}+00$ & $1.41 \mathrm{E}+01$ \\
\hline 260 & 34.07 & $9.80 \mathrm{E}-01$ & $1.46 \mathrm{E}+01$ \\
\hline 260.4 & 34.11 & $1.28 \mathrm{E}+00$ & $1.37 E+01$ \\
\hline 260.8 & 34.16 & $1.29 E+00$ & $1.50 E+01$ \\
\hline 261.2 & 34.21 & $1.32 \mathrm{E}+00$ & $1.61 E+01$ \\
\hline 261.6 & 34.25 & $1.42 \mathrm{E}+00$ & $1.61 \mathrm{E}+01$ \\
\hline 262 & 34.30 & $1.81 E+00$ & $1.85 \mathrm{E}+01$ \\
\hline 262.4 & 34.35 & $2.09 E+00$ & $1.74 \mathrm{E}+01$ \\
\hline 262.8 & 34.39 & $1.77 \mathrm{E}+00$ & $1.72 \mathrm{E}+01$ \\
\hline 263.2 & 34.44 & $1.66 \mathrm{E}+00$ & $1.73 E+01$ \\
\hline 263.6 & 34.49 & $1.90 \mathrm{E}+00$ & $1.81 \mathrm{E}+01$ \\
\hline 264 & 34.53 & $1.72 \mathrm{E}+00$ & $1.95 \mathrm{E}+01$ \\
\hline 264.4 & 34.58 & $1.87 \mathrm{E}+00$ & $1.82 \mathrm{E}+01$ \\
\hline 264.8 & 34.63 & $1.85 \mathrm{E}+00$ & $1.71 \mathrm{E}+01$ \\
\hline 265.2 & 34.67 & $1.54 \mathrm{E}+00$ & $1.78 \mathrm{E}+01$ \\
\hline 265.6 & 34.72 & $1.49 \mathrm{E}+00$ & $1.73 E+01$ \\
\hline 266 & 34.77 & $1.37 \mathrm{E}+00$ & $1.64 \mathrm{E}+01$ \\
\hline 266.4 & 34.81 & $8.25 \mathrm{E}-01$ & $1.35 \mathrm{E}+01$ \\
\hline 266.8 & 34.86 & $1.04 \mathrm{E}+00$ & $1.60 \mathrm{E}+01$ \\
\hline 267.2 & 34.91 & $1.07 \mathrm{E}+00$ & $1.59 E+01$ \\
\hline 267.6 & 34.95 & $9.75 \mathrm{E}-01$ & $1.55 \mathrm{E}+01$ \\
\hline 268 & 35.00 & 8.13E-01 & $1.60 E+01$ \\
\hline 268.4 & 35.04 & $8.21 \mathrm{E}-01$ & $1.49 \mathrm{E}+01$ \\
\hline 268.8 & 35.08 & 7.46E-01 & $1.42 \mathrm{E}+01$ \\
\hline
\end{tabular}




\begin{tabular}{cccc}
\hline Depth & Age & Fe/Ca & Fe/K \\
[cm] & [cal kyr] & {$[c p s]$} & {$[c p s]$} \\
\hline 269.2 & 35.12 & $9.04 \mathrm{E}-01$ & $1.56 \mathrm{E}+01$ \\
269.6 & 35.16 & $8.20 \mathrm{E}-01$ & $1.56 \mathrm{E}+01$ \\
270 & 35.21 & $8.14 \mathrm{E}-01$ & $1.37 \mathrm{E}+01$ \\
270.4 & 35.25 & $1.03 \mathrm{E}+00$ & $1.58 \mathrm{E}+01$ \\
270.8 & 35.29 & $1.24 \mathrm{E}+00$ & $1.69 \mathrm{E}+01$ \\
271.2 & 35.33 & $1.06 \mathrm{E}+00$ & $1.61 \mathrm{E}+01$ \\
271.6 & 35.37 & $8.01 \mathrm{E}-01$ & $1.26 \mathrm{E}+01$ \\
272 & 35.41 & $8.70 \mathrm{E}-01$ & $1.39 \mathrm{E}+01$ \\
272.4 & 35.45 & $9.25 \mathrm{E}-01$ & $1.48 \mathrm{E}+01$ \\
272.8 & 35.49 & $9.83 \mathrm{E}-01$ & $1.42 \mathrm{E}+01$ \\
273.2 & 35.54 & $1.11 \mathrm{E}+00$ & $1.45 \mathrm{E}+01$ \\
273.6 & 35.58 & $1.07 \mathrm{E}+00$ & $1.41 \mathrm{E}+01$ \\
274 & 35.62 & $1.26 \mathrm{E}+00$ & $1.49 \mathrm{E}+01$ \\
274.4 & 35.66 & $1.18 \mathrm{E}+00$ & $1.52 \mathrm{E}+01$ \\
274.8 & 35.70 & $1.37 \mathrm{E}+00$ & $1.65 \mathrm{E}+01$ \\
275.2 & 35.74 & $1.11 \mathrm{E}+00$ & $1.55 \mathrm{E}+01$ \\
275.6 & 35.78 & $1.07 \mathrm{E}+00$ & $1.35 \mathrm{E}+01$ \\
276 & 35.82 & $1.24 \mathrm{E}+00$ & $1.60 \mathrm{E}+01$ \\
276.4 & 35.86 & $1.44 \mathrm{E}+00$ & $1.68 \mathrm{E}+01$ \\
276.8 & 35.91 & $1.51 \mathrm{E}+00$ & $1.72 \mathrm{E}+01$ \\
277.2 & 35.95 & $1.72 \mathrm{E}+00$ & $1.76 \mathrm{E}+01$ \\
277.6 & 35.99 & $1.80 \mathrm{E}+00$ & $1.98 \mathrm{E}+01$ \\
278 & 36.03 & $1.85 \mathrm{E}+00$ & $1.88 \mathrm{E}+01$ \\
278.4 & 36.07 & $1.59 \mathrm{E}+00$ & $1.78 \mathrm{E}+01$ \\
278.8 & 36.11 & $1.84 \mathrm{E}+00$ & $1.73 \mathrm{E}+01$ \\
279.2 & 36.15 & $1.78 \mathrm{E}+00$ & $1.76 \mathrm{E}+01$ \\
279.6 & 36.19 & $1.71 \mathrm{E}+00$ & $1.79 \mathrm{E}+01$ \\
284.8 & 36.24 & $1.95 \mathrm{E}+00$ & $1.86 \mathrm{E}+01$ \\
285.2 & 36.77 & $6.44 \mathrm{E}-01$ & $1.12 \mathrm{E}+01$ \\
286 & 36.81 & $6.87 \mathrm{E}-01$ & $1.35 \mathrm{E}+01$ \\
280.4 & 36.28 & $2.13 \mathrm{E}+00$ & $1.96 \mathrm{E}+01$ \\
280.8 & 36.32 & $1.88 \mathrm{E}+00$ & $1.82 \mathrm{E}+01$ \\
281.2 & 36.36 & $1.57 \mathrm{E}+00$ & $1.64 \mathrm{E}+01$ \\
281.6 & 36.40 & $1.68 \mathrm{E}+00$ & $1.82 \mathrm{E}+01$ \\
282 & 36.44 & $1.44 \mathrm{E}+00$ & $1.59 \mathrm{E}+01$ \\
282.4 & 36.48 & $1.38 \mathrm{E}+00$ & $1.71 \mathrm{E}+01$ \\
282.8 & 36.52 & $1.43 \mathrm{E}+00$ & $1.70 \mathrm{E}+01$ \\
283.2 & 36.56 & $1.66 \mathrm{E}+00$ & $1.72 \mathrm{E}+01$ \\
283.6 & 36.61 & $2.04 \mathrm{E}+00$ & $2.18 \mathrm{E}+01$ \\
284 & 36.65 & $1.86 \mathrm{E}+00$ & $2.08 \mathrm{E}+01$ \\
& 36.69 & $1.17 \mathrm{E}+00$ & $1.76 \mathrm{E}+01$ \\
$28.73+00$ & $1.63 \mathrm{E}+01$
\end{tabular}




\begin{tabular}{cccc}
\hline Depth & Age & Fe/Ca & Fe/K \\
[cm] & [cal kyr] & {$[c p s]$} & {$[c p s]$} \\
\hline 286.4 & 36.89 & $9.69 \mathrm{E}-01$ & $1.45 \mathrm{E}+01$ \\
286.8 & 36.94 & $5.58 \mathrm{E}-01$ & $1.08 \mathrm{E}+01$ \\
287.2 & 36.98 & $6.78 \mathrm{E}-01$ & $1.29 \mathrm{E}+01$ \\
287.6 & 37.02 & $6.11 \mathrm{E}-01$ & $1.07 \mathrm{E}+01$ \\
288 & 37.06 & $6.78 \mathrm{E}-01$ & $1.23 \mathrm{E}+01$ \\
288.4 & 37.10 & $5.58 \mathrm{E}-01$ & $9.92 \mathrm{E}+00$ \\
288.8 & 37.14 & $6.45 \mathrm{E}-01$ & $1.21 \mathrm{E}+01$ \\
289.2 & 37.18 & $6.84 \mathrm{E}-01$ & $1.30 \mathrm{E}+01$ \\
289.6 & 37.22 & $7.94 \mathrm{E}-01$ & $1.27 \mathrm{E}+01$ \\
290 & 37.26 & $7.60 \mathrm{E}-01$ & $1.53 \mathrm{E}+01$ \\
290.4 & 37.31 & $7.27 \mathrm{E}-01$ & $1.30 \mathrm{E}+01$ \\
290.8 & 37.35 & $6.92 \mathrm{E}-01$ & $1.26 \mathrm{E}+01$ \\
291.2 & 37.39 & $7.46 \mathrm{E}-01$ & $1.36 \mathrm{E}+01$ \\
291.6 & 37.43 & $9.52 \mathrm{E}-01$ & $1.57 \mathrm{E}+01$ \\
292 & 37.47 & $9.34 \mathrm{E}-01$ & $1.44 \mathrm{E}+01$ \\
292.4 & 37.51 & $1.08 \mathrm{E}+00$ & $1.66 \mathrm{E}+01$ \\
292.8 & 37.55 & $1.04 \mathrm{E}+00$ & $1.47 \mathrm{E}+01$ \\
293.2 & 37.59 & $1.01 \mathrm{E}+00$ & $1.53 \mathrm{E}+01$ \\
293.6 & 37.64 & $1.03 \mathrm{E}+00$ & $1.53 \mathrm{E}+01$ \\
294 & 37.68 & $1.07 \mathrm{E}+00$ & $1.55 \mathrm{E}+01$ \\
294.4 & 37.72 & $1.21 \mathrm{E}+00$ & $1.64 \mathrm{E}+01$ \\
294.8 & 37.76 & $1.10 \mathrm{E}+00$ & $1.55 \mathrm{E}+01$ \\
295.2 & 37.80 & $1.26 \mathrm{E}+00$ & $1.66 \mathrm{E}+01$ \\
295.6 & 37.84 & $1.47 \mathrm{E}+00$ & $1.57 \mathrm{E}+01$ \\
296 & 37.88 & $1.98 \mathrm{E}+00$ & $1.83 \mathrm{E}+01$ \\
296.4 & 37.92 & $1.81 \mathrm{E}+00$ & $1.66 \mathrm{E}+01$ \\
296.8 & 37.96 & $2.71 \mathrm{E}+00$ & $1.94 \mathrm{E}+01$ \\
297.2 & 38.01 & $3.14 \mathrm{E}+00$ & $2.07 \mathrm{E}+01$ \\
302.4 & 38.55 & $4.77 \mathrm{E}+00$ & $2.20 \mathrm{E}+01$ \\
302.8 & 38.60 & $5.16 \mathrm{E}+00$ & $2.31 \mathrm{E}+01$ \\
303.2 & 38.65 & $8.92 \mathrm{E}+00$ & $2.56 \mathrm{E}+01$
\end{tabular}




\begin{tabular}{|c|c|c|c|}
\hline $\begin{array}{c}\text { Depth } \\
{[\mathrm{cm}]}\end{array}$ & $\begin{array}{c}\text { Age } \\
\text { [cal kyr] }\end{array}$ & $\begin{array}{c}\mathrm{Fe} / \mathrm{Ca} \\
\text { [cps] }\end{array}$ & $\begin{array}{l}\mathbf{F e} / \mathbf{K} \\
{[c p s]} \\
\end{array}$ \\
\hline 303.6 & 38.70 & $8.78 \mathrm{E}+00$ & $2.72 E+01$ \\
\hline 304 & 38.75 & $8.49 E+00$ & $2.60 E+01$ \\
\hline 304.4 & 38.80 & $1.17 \mathrm{E}+01$ & $2.80 \mathrm{E}+01$ \\
\hline 304.8 & 38.86 & $1.21 \mathrm{E}+01$ & $2.88 \mathrm{E}+01$ \\
\hline 305.2 & 38.91 & $2.63 E+01$ & $3.33 E+01$ \\
\hline 305.6 & 38.96 & $1.76 \mathrm{E}+01$ & $3.38 \mathrm{E}+01$ \\
\hline 306 & 39.01 & $1.54 \mathrm{E}+01$ & $2.66 \mathrm{E}+01$ \\
\hline 306.4 & 39.06 & $1.74 \mathrm{E}+01$ & $2.74 \mathrm{E}+01$ \\
\hline 306.8 & 39.11 & $1.61 \mathrm{E}+01$ & $2.52 E+01$ \\
\hline 307.2 & 39.16 & $1.64 \mathrm{E}+01$ & $2.55 E+01$ \\
\hline 307.6 & 39.21 & $1.53 \mathrm{E}+01$ & $2.58 \mathrm{E}+01$ \\
\hline 307.8 & 39.24 & $1.37 \mathrm{E}+01$ & $2.23 E+01$ \\
\hline 308.2 & 39.29 & $1.43 E+01$ & $2.69 E+01$ \\
\hline 308.6 & 39.34 & $1.59 \mathrm{E}+01$ & $2.46 \mathrm{E}+01$ \\
\hline 309 & 39.39 & $1.77 E+01$ & $2.64 E+01$ \\
\hline 309.4 & 39.44 & $2.02 E+01$ & $2.66 E+01$ \\
\hline 309.8 & 39.49 & $1.24 \mathrm{E}+01$ & $2.55 E+01$ \\
\hline 310.2 & 39.54 & $7.94 \mathrm{E}+00$ & $2.51 E+01$ \\
\hline 310.6 & 39.59 & $1.33 \mathrm{E}+01$ & $2.80 E+01$ \\
\hline 311 & 39.64 & $1.74 \mathrm{E}+01$ & $2.43 E+01$ \\
\hline 311.4 & 39.69 & $1.71 E+01$ & $2.71 E+01$ \\
\hline 311.8 & 39.74 & $1.63 E+01$ & $2.73 E+01$ \\
\hline 312.2 & 39.79 & $1.87 \mathrm{E}+01$ & $2.66 \mathrm{E}+01$ \\
\hline 312.6 & 39.85 & $2.07 E+01$ & $2.76 E+01$ \\
\hline 313 & 39.90 & $1.97 \mathrm{E}+01$ & $2.65 E+01$ \\
\hline 313.4 & 39.95 & $2.11 E+01$ & $2.80 E+01$ \\
\hline 313.8 & 40.00 & $1.55 \mathrm{E}+01$ & $2.54 \mathrm{E}+01$ \\
\hline 314.2 & 40.05 & $1.65 \mathrm{E}+01$ & $2.69 E+01$ \\
\hline 314.6 & 40.10 & $1.79 \mathrm{E}+01$ & $2.58 \mathrm{E}+01$ \\
\hline 315 & 40.15 & $1.94 \mathrm{E}+01$ & $2.60 E+01$ \\
\hline 315.4 & 40.20 & $1.87 \mathrm{E}+01$ & $2.57 E+01$ \\
\hline 315.8 & 40.25 & $1.59 \mathrm{E}+01$ & $2.72 \mathrm{E}+01$ \\
\hline 316.2 & 40.30 & $1.48 \mathrm{E}+01$ & $2.56 \mathrm{E}+01$ \\
\hline 316.6 & 40.35 & $7.56 \mathrm{E}+00$ & $2.33 E+01$ \\
\hline 317 & 40.40 & $7.58 \mathrm{E}+00$ & $2.35 E+01$ \\
\hline 317.4 & 40.45 & $1.60 \mathrm{E}+01$ & $2.33 E+01$ \\
\hline 317.8 & 40.51 & $1.61 \mathrm{E}+01$ & $2.46 \mathrm{E}+01$ \\
\hline 318.2 & 40.56 & $1.27 \mathrm{E}+01$ & $2.45 \mathrm{E}+01$ \\
\hline 318.6 & 40.61 & $1.32 \mathrm{E}+01$ & $2.67 E+01$ \\
\hline 319 & 40.66 & $1.12 \mathrm{E}+01$ & $2.66 \mathrm{E}+01$ \\
\hline 319.4 & 40.71 & $1.16 \mathrm{E}+01$ & $2.53 E+01$ \\
\hline 319.8 & 40.76 & $1.24 \mathrm{E}+01$ & $2.53 E+01$ \\
\hline 320.2 & 40.81 & $9.39 E+00$ & $2.41 E+01$ \\
\hline
\end{tabular}




\begin{tabular}{cccc}
\hline $\begin{array}{c}\text { Depth } \\
\text { [cm] }\end{array}$ & $\begin{array}{c}\text { Age } \\
\text { [cal kyr] }\end{array}$ & $\begin{array}{c}\text { Fe/Ca } \\
\text { [cps] }\end{array}$ & $\begin{array}{c}\text { Fe/K } \\
{[c p s]}\end{array}$ \\
\hline 320.6 & 40.86 & $1.03 \mathrm{E}+01$ & $2.50 \mathrm{E}+01$ \\
321 & 40.91 & $7.98 \mathrm{E}+00$ & $2.38 \mathrm{E}+01$ \\
321.4 & 40.96 & $8.42 \mathrm{E}+00$ & $2.56 \mathrm{E}+01$ \\
321.8 & 41.01 & $7.07 \mathrm{E}+00$ & $2.20 \mathrm{E}+01$ \\
322.2 & 41.06 & $6.95 \mathrm{E}+00$ & $2.23 \mathrm{E}+01$ \\
322.6 & 41.11 & $5.05 \mathrm{E}+00$ & $2.01 \mathrm{E}+01$ \\
323 & 41.17 & $6.91 \mathrm{E}+00$ & $2.24 \mathrm{E}+01$ \\
323.4 & 41.22 & $7.17 \mathrm{E}+00$ & $2.47 \mathrm{E}+01$ \\
323.8 & 41.27 & $7.56 \mathrm{E}+00$ & $2.42 \mathrm{E}+01$ \\
324.2 & 41.32 & $6.91 \mathrm{E}+00$ & $2.33 \mathrm{E}+01$ \\
324.6 & 41.37 & $2.40 \mathrm{E}+00$ & $1.90 \mathrm{E}+01$ \\
325 & 41.42 & $2.42 \mathrm{E}+00$ & $2.02 \mathrm{E}+01$ \\
325.4 & 41.47 & $2.41 \mathrm{E}+00$ & $1.99 \mathrm{E}+01$ \\
325.8 & 41.52 & $1.55 \mathrm{E}+00$ & $1.71 \mathrm{E}+01$ \\
326.2 & 41.57 & $1.44 \mathrm{E}+00$ & $1.77 \mathrm{E}+01$ \\
326.6 & 41.62 & $1.32 \mathrm{E}+00$ & $1.64 \mathrm{E}+01$ \\
327 & 41.67 & $9.93 \mathrm{E}-01$ & $1.36 \mathrm{E}+01$ \\
327.4 & 41.72 & $1.11 \mathrm{E}+00$ & $1.63 \mathrm{E}+01$ \\
327.8 & 41.77 & $1.28 \mathrm{E}+00$ & $1.63 \mathrm{E}+01$ \\
328.2 & 41.81 & $9.90 \mathrm{E}-01$ & $1.51 \mathrm{E}+01$ \\
328.6 & 41.83 & $9.03 \mathrm{E}-01$ & $1.39 \mathrm{E}+01$ \\
329 & 41.85 & $8.83 \mathrm{E}-01$ & $1.46 \mathrm{E}+01$ \\
329.4 & 41.87 & $1.07 \mathrm{E}+00$ & $1.52 \mathrm{E}+01$ \\
329.8 & 41.89 & $1.35 \mathrm{E}+00$ & $1.79 \mathrm{E}+01$ \\
330.2 & 41.91 & $8.43 \mathrm{E}-01$ & $1.44 \mathrm{E}+01$ \\
330.6 & 41.93 & $7.18 \mathrm{E}-01$ & $1.40 \mathrm{E}+01$ \\
331 & 41.95 & $8.37 \mathrm{E}-01$ & $1.32 \mathrm{E}+01$ \\
331.4 & 41.97 & $8.15 \mathrm{E}-01$ & $1.40 \mathrm{E}+01$ \\
336.2 & 42.21 & $1.52 \mathrm{E}+00$ & $1.62 \mathrm{E}+01$ \\
331.8 & 41.99 & $8.72 \mathrm{E}-01$ & $1.54 \mathrm{E}+01$ \\
332.2 & 42.01 & $6.83 \mathrm{E}-01$ & $1.14 \mathrm{E}+01$ \\
332.6 & 42.03 & $7.06 \mathrm{E}-01$ & $1.13 \mathrm{E}+01$ \\
333 & 42.05 & $7.37 \mathrm{E}-01$ & $1.25 \mathrm{E}+01$ \\
333.4 & 42.07 & $9.49 \mathrm{E}-01$ & $1.51 \mathrm{E}+01$ \\
333.8 & 42.09 & $7.06 \mathrm{E}-01$ & $1.36 \mathrm{E}+01$ \\
334.2 & 42.11 & $5.34 \mathrm{E}-01$ & $1.03 \mathrm{E}+01$ \\
334.6 & 42.13 & $7.77 \mathrm{E}-01$ & $1.20 \mathrm{E}+01$ \\
335 & 42.15 & $9.17 \mathrm{E}-01$ & $1.57 \mathrm{E}+01$ \\
33.4 & 42.17 & $1.12 \mathrm{E}+00$ & $1.53 \mathrm{E}+01$ \\
33.23 & $1.48 \mathrm{E}+00$ & $1.55 \mathrm{E}+01$ \\
32.27 & $1.98 \mathrm{E}+00$ & $1.85 \mathrm{E}+01$
\end{tabular}




\begin{tabular}{cccc}
\hline $\begin{array}{c}\text { Depth } \\
\text { [cm] }\end{array}$ & $\begin{array}{c}\text { Age } \\
\text { [cal kyr] }\end{array}$ & $\begin{array}{c}\text { Fe/Ca } \\
{[c p s]}\end{array}$ & Fe/K \\
{$[c p s]$} \\
\hline 337.8 & 42.29 & $1.88 \mathrm{E}+00$ & $2.01 \mathrm{E}+01$ \\
338.2 & 42.31 & $1.52 \mathrm{E}+00$ & $1.76 \mathrm{E}+01$ \\
338.6 & 42.33 & $2.04 \mathrm{E}+00$ & $2.00 \mathrm{E}+01$ \\
339 & 42.35 & $2.27 \mathrm{E}+00$ & $1.97 \mathrm{E}+01$ \\
339.4 & 42.37 & $1.87 \mathrm{E}+00$ & $1.80 \mathrm{E}+01$ \\
339.8 & 42.39 & $1.68 \mathrm{E}+00$ & $1.74 \mathrm{E}+01$ \\
340.2 & 42.41 & $1.72 \mathrm{E}+00$ & $1.83 \mathrm{E}+01$ \\
340.6 & 42.43 & $1.92 \mathrm{E}+00$ & $1.96 \mathrm{E}+01$ \\
341 & 42.45 & $2.18 \mathrm{E}+00$ & $1.79 \mathrm{E}+01$ \\
341.4 & 42.47 & $2.51 \mathrm{E}+00$ & $1.89 \mathrm{E}+01$ \\
341.8 & 42.49 & $2.73 \mathrm{E}+00$ & $1.93 \mathrm{E}+01$ \\
342.2 & 42.51 & $2.74 \mathrm{E}+00$ & $1.89 \mathrm{E}+01$ \\
342.6 & 42.53 & $2.66 \mathrm{E}+00$ & $2.06 \mathrm{E}+01$ \\
343 & 42.55 & $2.41 \mathrm{E}+00$ & $1.93 \mathrm{E}+01$ \\
343.4 & 42.57 & $2.50 \mathrm{E}+00$ & $1.95 \mathrm{E}+01$ \\
343.8 & 42.59 & $2.22 \mathrm{E}+00$ & $2.02 \mathrm{E}+01$ \\
344.2 & 42.61 & $1.41 \mathrm{E}+00$ & $1.70 \mathrm{E}+01$ \\
344.6 & 42.63 & $1.40 \mathrm{E}+00$ & $1.77 \mathrm{E}+01$ \\
345 & 42.65 & $1.21 \mathrm{E}+00$ & $1.64 \mathrm{E}+01$ \\
345.4 & 42.67 & $1.13 \mathrm{E}+00$ & $1.46 \mathrm{E}+01$ \\
345.8 & 42.69 & $1.14 \mathrm{E}+00$ & $1.58 \mathrm{E}+01$ \\
346.2 & 42.71 & $1.20 \mathrm{E}+00$ & $1.55 \mathrm{E}+01$ \\
346.6 & 42.73 & $1.14 \mathrm{E}+00$ & $1.76 \mathrm{E}+01$ \\
347 & 42.75 & $1.06 \mathrm{E}+00$ & $1.64 \mathrm{E}+01$ \\
347.4 & 42.77 & $1.04 \mathrm{E}+00$ & $1.46 \mathrm{E}+01$ \\
347.8 & 42.79 & $8.62 \mathrm{E}-01$ & $1.34 \mathrm{E}+01$ \\
348.2 & 42.82 & $7.81 \mathrm{E}-01$ & $1.15 \mathrm{E}+01$ \\
348.6 & 42.86 & $9.52 \mathrm{E}-01$ & $1.42 \mathrm{E}+01$ \\
353.4 & 43.36 & $2.42 \mathrm{E}+00$ & $1.86 \mathrm{E}+01$ \\
353.8 & 43.40 & $2.89 \mathrm{E}+00$ & $1.99 \mathrm{E}+01$ \\
354.2 & 43.44 & $3.26 \mathrm{E}+00$ & $2.09 \mathrm{E}+01$ \\
354.6 & 43.49 & $3.30 \mathrm{E}+00$ & $1.93 \mathrm{E}+01$
\end{tabular}




\begin{tabular}{cccc}
\hline $\begin{array}{c}\text { Depth } \\
\text { [cm] }\end{array}$ & $\begin{array}{c}\text { Age } \\
\text { [cal kyr] }\end{array}$ & $\begin{array}{c}\text { Fe/Ca } \\
{[c p s]}\end{array}$ & Fe/K \\
[cps] \\
\hline 355 & 43.53 & $2.59 \mathrm{E}+00$ & $1.82 \mathrm{E}+01$ \\
355.4 & 43.57 & $3.30 \mathrm{E}+00$ & $1.90 \mathrm{E}+01$ \\
355.8 & 43.61 & $3.56 \mathrm{E}+00$ & $2.00 \mathrm{E}+01$ \\
356.2 & 43.65 & $4.01 \mathrm{E}+00$ & $2.07 \mathrm{E}+01$ \\
356.6 & 43.69 & $3.91 \mathrm{E}+00$ & $2.27 \mathrm{E}+01$ \\
357 & 43.74 & $3.83 \mathrm{E}+00$ & $2.30 \mathrm{E}+01$ \\
357.4 & 43.78 & $3.47 \mathrm{E}+00$ & $2.11 \mathrm{E}+01$ \\
357.8 & 43.82 & $3.63 \mathrm{E}+00$ & $2.17 \mathrm{E}+01$ \\
358.2 & 43.86 & $4.73 \mathrm{E}+00$ & $2.91 \mathrm{E}+01$ \\
358.6 & 43.90 & $3.60 \mathrm{E}+00$ & $2.26 \mathrm{E}+01$ \\
359 & 43.94 & $2.65 \mathrm{E}+00$ & $2.13 \mathrm{E}+01$ \\
359.4 & 43.99 & $1.99 \mathrm{E}+00$ & $1.76 \mathrm{E}+01$ \\
359.8 & 44.03 & $1.64 \mathrm{E}+00$ & $1.60 \mathrm{E}+01$ \\
360.2 & 44.07 & $1.26 \mathrm{E}+00$ & $1.53 \mathrm{E}+01$ \\
360.6 & 44.11 & $8.94 \mathrm{E}-01$ & $1.35 \mathrm{E}+01$ \\
361 & 44.15 & $8.61 \mathrm{E}-01$ & $1.37 \mathrm{E}+01$ \\
361.4 & 44.19 & $8.93 \mathrm{E}-01$ & $1.38 \mathrm{E}+01$ \\
361.8 & 44.24 & $8.10 \mathrm{E}-01$ & $1.49 \mathrm{E}+01$ \\
362.2 & 44.28 & $8.40 \mathrm{E}-01$ & $1.33 \mathrm{E}+01$ \\
362.6 & 44.32 & $8.80 \mathrm{E}-01$ & $1.42 \mathrm{E}+01$ \\
363 & 44.36 & $9.04 \mathrm{E}-01$ & $1.43 \mathrm{E}+01$ \\
363.4 & 44.40 & $9.36 \mathrm{E}-01$ & $1.35 \mathrm{E}+01$ \\
363.8 & 44.44 & $8.89 \mathrm{E}-01$ & $1.41 \mathrm{E}+01$ \\
364.2 & 44.48 & $8.14 \mathrm{E}-01$ & $1.42 \mathrm{E}+01$ \\
364.6 & 44.53 & $7.95 \mathrm{E}-01$ & $1.44 \mathrm{E}+01$ \\
365 & 44.57 & $7.83 \mathrm{E}-01$ & $1.34 \mathrm{E}+01$ \\
365.4 & 44.61 & $7.35 \mathrm{E}-01$ & $1.33 \mathrm{E}+01$ \\
365.8 & 44.65 & $7.74 \mathrm{E}-01$ & $1.31 \mathrm{E}+01$ \\
366.2 & 44.69 & $8.00 \mathrm{E}-01$ & $1.32 \mathrm{E}+01$ \\
371.4 & 45.23 & $1.23 \mathrm{E}+00$ & $1.54 \mathrm{E}+01$ \\
371.8 & 45.28 & $1.08 \mathrm{E}+00$ & $1.58 \mathrm{E}+01$
\end{tabular}




\begin{tabular}{|c|c|c|c|}
\hline $\begin{array}{c}\text { Depth } \\
{[\mathrm{cm}]}\end{array}$ & $\begin{array}{c}\text { Age } \\
\text { [cal kyr] }\end{array}$ & $\begin{array}{c}\mathrm{Fe} / \mathrm{Ca} \\
{[c p s]}\end{array}$ & $\begin{array}{l}\mathrm{Fe} / \mathbf{K} \\
{[c p s]} \\
\end{array}$ \\
\hline 372.2 & 45.32 & $1.51 \mathrm{E}+00$ & $1.79 E+01$ \\
\hline 372.6 & 45.36 & $1.87 \mathrm{E}+00$ & $1.86 \mathrm{E}+01$ \\
\hline 373 & 45.40 & $1.79 E+00$ & $1.90 \mathrm{E}+01$ \\
\hline 373.4 & 45.42 & $1.51 \mathrm{E}+00$ & $1.78 \mathrm{E}+01$ \\
\hline 373.8 & 45.44 & $1.26 \mathrm{E}+00$ & $1.60 \mathrm{E}+01$ \\
\hline 374.2 & 45.47 & $1.58 \mathrm{E}+00$ & $1.51 \mathrm{E}+01$ \\
\hline 374.6 & 45.49 & $2.23 \mathrm{E}+00$ & 1.77E+01 \\
\hline 375 & 45.51 & $2.25 \mathrm{E}+00$ & $1.87 \mathrm{E}+01$ \\
\hline 375.4 & 45.53 & $2.68 \mathrm{E}+00$ & $1.94 \mathrm{E}+01$ \\
\hline 375.8 & 45.56 & $3.38 \mathrm{E}+00$ & $2.17 \mathrm{E}+01$ \\
\hline 376.2 & 45.58 & $4.05 E+00$ & $2.20 \mathrm{E}+01$ \\
\hline 376.6 & 45.60 & $4.89 E+00$ & $2.23 E+01$ \\
\hline 377 & 45.62 & $6.35 E+00$ & $2.52 E+01$ \\
\hline 377.4 & 45.64 & $6.03 E+00$ & $2.34 \mathrm{E}+01$ \\
\hline 377.8 & 45.67 & $7.49 E+00$ & $2.59 E+01$ \\
\hline 378.2 & 45.69 & $7.07 E+00$ & $2.60 E+01$ \\
\hline 378.6 & 45.71 & $7.00 E+00$ & $2.45 \mathrm{E}+01$ \\
\hline 379 & 45.73 & $1.02 \mathrm{E}+01$ & $2.86 \mathrm{E}+01$ \\
\hline 379.4 & 45.76 & $9.72 E+00$ & $2.92 \mathrm{E}+01$ \\
\hline 379.8 & 45.78 & $1.13 E+01$ & $2.93 E+01$ \\
\hline 380.2 & 45.80 & $5.01 E+00$ & $2.29 E+01$ \\
\hline 380.6 & 45.82 & $1.14 \mathrm{E}+01$ & $2.95 \mathrm{E}+01$ \\
\hline 381 & 45.84 & $1.13 \mathrm{E}+01$ & $3.02 E+01$ \\
\hline 381.4 & 45.87 & $8.62 E+00$ & $2.56 E+01$ \\
\hline 381.8 & 45.89 & $7.72 E+00$ & $2.45 \mathrm{E}+01$ \\
\hline 382.2 & 45.91 & $1.07 \mathrm{E}+01$ & $2.37 E+01$ \\
\hline 382.6 & 45.93 & $8.52 E+00$ & $2.32 E+01$ \\
\hline 383 & 45.96 & $9.39 E+00$ & $2.41 E+01$ \\
\hline 383.4 & 45.98 & $1.16 \mathrm{E}+01$ & $2.56 \mathrm{E}+01$ \\
\hline 383.8 & 46.00 & $2.28 \mathrm{E}+01$ & $2.86 \mathrm{E}+01$ \\
\hline 384.2 & 46.02 & $1.54 \mathrm{E}+01$ & $2.61 E+01$ \\
\hline 384.6 & 46.04 & $2.15 E+01$ & $2.44 \mathrm{E}+01$ \\
\hline 385 & 46.07 & $2.15 E+01$ & $2.35 E+01$ \\
\hline 385.4 & 46.09 & $2.09 E+01$ & $2.52 E+01$ \\
\hline 385.8 & 46.11 & $1.61 \mathrm{E}+01$ & $2.47 E+01$ \\
\hline 386.2 & 46.13 & $6.14 \mathrm{E}+00$ & $2.10 E+01$ \\
\hline 386.6 & 46.16 & $4.96 \mathrm{E}+00$ & $2.26 \mathrm{E}+01$ \\
\hline 387 & 46.18 & $1.58 \mathrm{E}+01$ & $2.39 E+01$ \\
\hline 387.4 & 46.20 & $1.20 \mathrm{E}+01$ & $2.59 E+01$ \\
\hline 387.8 & 46.22 & $5.92 \mathrm{E}+00$ & $2.11 E+01$ \\
\hline 388.2 & 46.24 & $1.46 \mathrm{E}+01$ & $2.38 E+01$ \\
\hline 388.6 & 46.27 & $1.44 \mathrm{E}+01$ & $2.49 E+01$ \\
\hline 389 & 46.29 & $9.73 E+00$ & $2.45 E+01$ \\
\hline
\end{tabular}




\begin{tabular}{|c|c|c|c|}
\hline $\begin{array}{c}\text { Depth } \\
{[\mathrm{cm}]}\end{array}$ & $\begin{array}{c}\text { Age } \\
\text { [cal kyr] }\end{array}$ & $\begin{array}{c}\mathrm{Fe} / \mathrm{Ca} \\
\text { [cps] }\end{array}$ & $\begin{array}{l}\mathbf{F e} / \mathbf{K} \\
{[c p s]} \\
\end{array}$ \\
\hline 389.4 & 46.31 & $1.09 \mathrm{E}+01$ & $2.46 \mathrm{E}+01$ \\
\hline 389.8 & 46.33 & $1.40 \mathrm{E}+01$ & $2.56 \mathrm{E}+01$ \\
\hline 390.2 & 46.36 & $1.45 \mathrm{E}+01$ & $2.51 E+01$ \\
\hline 390.6 & 46.38 & $1.86 \mathrm{E}+01$ & $2.45 E+01$ \\
\hline 391 & 46.40 & $1.73 E+01$ & $2.60 E+01$ \\
\hline 391.4 & 46.42 & $1.82 \mathrm{E}+01$ & $2.61 E+01$ \\
\hline 391.8 & 46.44 & $1.66 \mathrm{E}+01$ & $2.52 \mathrm{E}+01$ \\
\hline 392.2 & 46.47 & $1.64 \mathrm{E}+01$ & $2.57 E+01$ \\
\hline 392.6 & 46.49 & $1.30 \mathrm{E}+01$ & $2.49 E+01$ \\
\hline 393 & 46.51 & $1.08 \mathrm{E}+01$ & $2.62 E+01$ \\
\hline 393.4 & 46.53 & $1.85 \mathrm{E}+01$ & $2.42 \mathrm{E}+01$ \\
\hline 393.8 & 46.56 & $1.55 \mathrm{E}+01$ & $2.34 \mathrm{E}+01$ \\
\hline 394.2 & 46.58 & $1.70 \mathrm{E}+01$ & $2.33 E+01$ \\
\hline 394.6 & 46.60 & $1.65 E+01$ & $2.42 \mathrm{E}+01$ \\
\hline 395 & 46.62 & $1.69 \mathrm{E}+01$ & $2.34 \mathrm{E}+01$ \\
\hline 395.4 & 46.64 & $1.83 \mathrm{E}+01$ & $2.25 \mathrm{E}+01$ \\
\hline 395.8 & 46.67 & $1.89 \mathrm{E}+01$ & $2.20 E+01$ \\
\hline 396.2 & 46.69 & $1.69 \mathrm{E}+01$ & $2.41 E+01$ \\
\hline 396.6 & 46.71 & $1.46 \mathrm{E}+01$ & $2.33 E+01$ \\
\hline 397 & 46.73 & $1.30 \mathrm{E}+01$ & $2.34 \mathrm{E}+01$ \\
\hline 397.4 & 46.76 & $1.33 \mathrm{E}+01$ & $2.25 \mathrm{E}+01$ \\
\hline 397.8 & 46.78 & $1.31 \mathrm{E}+01$ & $2.23 E+01$ \\
\hline 398.2 & 46.80 & $1.26 \mathrm{E}+01$ & $2.20 \mathrm{E}+01$ \\
\hline 398.6 & 46.82 & $1.21 \mathrm{E}+01$ & $2.21 E+01$ \\
\hline 399 & 46.84 & $8.78 \mathrm{E}+00$ & $2.20 \mathrm{E}+01$ \\
\hline 399.4 & 46.87 & $6.49 E+00$ & $2.00 E+01$ \\
\hline 399.8 & 46.89 & $3.22 \mathrm{E}+00$ & $1.96 \mathrm{E}+01$ \\
\hline 400.2 & 46.93 & $2.26 \mathrm{E}+00$ & $1.71 \mathrm{E}+01$ \\
\hline 400.6 & 46.99 & $2.11 E+00$ & $1.72 \mathrm{E}+01$ \\
\hline 401 & 47.05 & $3.35 E+00$ & $1.99 \mathrm{E}+01$ \\
\hline 401.4 & 47.11 & $3.22 \mathrm{E}+00$ & $1.98 \mathrm{E}+01$ \\
\hline 401.8 & 47.17 & $2.35 \mathrm{E}+00$ & $1.66 \mathrm{E}+01$ \\
\hline 402.2 & 47.23 & $1.79 \mathrm{E}+00$ & $1.55 E+01$ \\
\hline 402.6 & 47.29 & $1.84 \mathrm{E}+00$ & $1.68 \mathrm{E}+01$ \\
\hline 403 & 47.35 & $1.81 \mathrm{E}+00$ & $1.77 \mathrm{E}+01$ \\
\hline 403.4 & 47.41 & $1.08 \mathrm{E}+00$ & $1.56 \mathrm{E}+01$ \\
\hline 403.8 & 47.46 & $1.13 \mathrm{E}+00$ & $1.55 E+01$ \\
\hline 404.2 & 47.52 & $1.08 \mathrm{E}+00$ & $1.43 \mathrm{E}+01$ \\
\hline 404.6 & 47.58 & $1.32 \mathrm{E}+00$ & $1.48 \mathrm{E}+01$ \\
\hline 405 & 47.64 & $1.40 \mathrm{E}+00$ & $1.55 \mathrm{E}+01$ \\
\hline 405.4 & 47.70 & $1.60 \mathrm{E}+00$ & $1.56 \mathrm{E}+01$ \\
\hline 405.8 & 47.76 & $1.53 \mathrm{E}+00$ & $1.54 \mathrm{E}+01$ \\
\hline 406.2 & 47.82 & $1.44 \mathrm{E}+00$ & $1.39 E+01$ \\
\hline
\end{tabular}




\begin{tabular}{cccc}
\hline Depth & Age & Fe/Ca & Fe/K \\
[cm] & {$[c a l k y r]$} & {$[c p s]$} & {$[c p s]$} \\
\hline 406.6 & 47.88 & $2.68 \mathrm{E}+00$ & $1.71 \mathrm{E}+01$ \\
407.8 & 48.06 & $1.64 \mathrm{E}+00$ & $1.67 \mathrm{E}+01$ \\
408.2 & 48.12 & $1.43 \mathrm{E}+00$ & $1.51 \mathrm{E}+01$ \\
408.6 & 48.18 & $1.04 \mathrm{E}+00$ & $1.42 \mathrm{E}+01$ \\
409 & 48.24 & $1.12 \mathrm{E}+00$ & $1.59 \mathrm{E}+01$ \\
409.4 & 48.30 & $1.10 \mathrm{E}+00$ & $1.51 \mathrm{E}+01$ \\
409.8 & 48.36 & $1.21 \mathrm{E}+00$ & $1.58 \mathrm{E}+01$ \\
410.2 & 48.42 & $1.27 \mathrm{E}+00$ & $1.73 \mathrm{E}+01$ \\
410.6 & 48.47 & $1.16 \mathrm{E}+00$ & $1.47 \mathrm{E}+01$ \\
411 & 48.53 & $1.13 \mathrm{E}+00$ & $1.46 \mathrm{E}+01$ \\
411.4 & 48.59 & $1.23 \mathrm{E}+00$ & $1.72 \mathrm{E}+01$ \\
411.8 & 48.65 & $1.31 \mathrm{E}+00$ & $1.69 \mathrm{E}+01$ \\
412.2 & 48.71 & $1.30 \mathrm{E}+00$ & $1.53 \mathrm{E}+01$ \\
412.6 & 48.77 & $1.19 \mathrm{E}+00$ & $1.34 \mathrm{E}+01$ \\
413 & 48.83 & $1.25 \mathrm{E}+00$ & $1.66 \mathrm{E}+01$ \\
413.4 & 48.89 & $1.20 \mathrm{E}+00$ & $1.38 \mathrm{E}+01$ \\
413.8 & 48.95 & $1.12 \mathrm{E}+00$ & $1.46 \mathrm{E}+01$ \\
414.2 & 49.01 & $9.40 \mathrm{E}-01$ & $1.26 \mathrm{E}+01$ \\
414.6 & 49.07 & $9.84 \mathrm{E}-01$ & $1.44 \mathrm{E}+01$ \\
415 & 49.13 & $9.56 \mathrm{E}-01$ & $1.46 \mathrm{E}+01$ \\
415.4 & 49.19 & $9.79 \mathrm{E}-01$ & $1.39 \mathrm{E}+01$ \\
415.8 & 49.25 & $9.80 \mathrm{E}-01$ & $1.39 \mathrm{E}+01$ \\
416.2 & 49.31 & $1.12 \mathrm{E}+00$ & $1.50 \mathrm{E}+01$ \\
416.6 & 49.37 & $1.02 \mathrm{E}+00$ & $1.57 \mathrm{E}+01$ \\
417 & 49.43 & $1.35 \mathrm{E}+00$ & $1.53 \mathrm{E}+01$ \\
417.4 & 49.49 & $1.22 \mathrm{E}+00$ & $1.45 \mathrm{E}+01$ \\
417.8 & 49.54 & $1.62 \mathrm{E}+00$ & $1.70 \mathrm{E}+01$ \\
418.2 & 49.60 & $1.78 \mathrm{E}+00$ & $1.96 \mathrm{E}+01$ \\
418.6 & 49.66 & $1.54 \mathrm{E}+00$ & $1.78 \mathrm{E}+01$ \\
423.4 & 50.38 & $1.20 \mathrm{E}+00$ & $1.43 \mathrm{E}+01$ \\
424.2 & 50.44 & $1.17 \mathrm{E}+00$ & $1.41 \mathrm{E}+01$ \\
4219 & 49.72 & $1.41 \mathrm{E}+00$ & $1.48 \mathrm{E}+01$ \\
419.4 & 49.78 & $1.14 \mathrm{E}+00$ & $1.37 \mathrm{E}+01$ \\
419.8 & 49.84 & $1.04 \mathrm{E}+00$ & $1.34 \mathrm{E}+01$ \\
420.2 & 49.90 & $1.01 \mathrm{E}+00$ & $1.29 \mathrm{E}+01$ \\
420.6 & 49.96 & $1.17 \mathrm{E}+00$ & $1.45 \mathrm{E}+01$ \\
421 & 50.02 & $1.35 \mathrm{E}+00$ & $1.53 \mathrm{E}+01$ \\
421.4 & 50.08 & $1.35 \mathrm{E}+00$ & $1.60 \mathrm{E}+01$ \\
& 50.14 & $1.50 \mathrm{E}+00$ & $1.63 \mathrm{E}+01$ \\
50.20 & $1.45 \mathrm{E}+00$ & $1.62 \mathrm{E}+01$ \\
& 50.26 & $1.62 \mathrm{E}+00$ & $1.66 \mathrm{E}+01$ \\
& & & $1.52 \mathrm{E}+01$
\end{tabular}




\begin{tabular}{cccc}
\hline Depth & Age & Fe/Ca & Fe/K \\
[cm] & [cal kyr] & {$[c p s]$} & {$[c p s]$} \\
\hline 424.6 & 50.55 & $1.20 \mathrm{E}+00$ & $1.50 \mathrm{E}+01$ \\
425 & 50.61 & $1.02 \mathrm{E}+00$ & $1.45 \mathrm{E}+01$ \\
425.4 & 50.67 & $8.95 \mathrm{E}-01$ & $1.41 \mathrm{E}+01$ \\
425.8 & 50.73 & $9.89 \mathrm{E}-01$ & $1.43 \mathrm{E}+01$ \\
426.2 & 50.79 & $9.65 \mathrm{E}-01$ & $1.61 \mathrm{E}+01$ \\
426.6 & 50.85 & $8.41 \mathrm{E}-01$ & $1.26 \mathrm{E}+01$ \\
427 & 50.91 & $8.27 \mathrm{E}-01$ & $1.22 \mathrm{E}+01$ \\
427.4 & 50.97 & $8.41 \mathrm{E}-01$ & $1.38 \mathrm{E}+01$ \\
427.8 & 51.03 & $1.03 \mathrm{E}+00$ & $1.49 \mathrm{E}+01$ \\
428.2 & 51.09 & $9.54 \mathrm{E}-01$ & $1.31 \mathrm{E}+01$ \\
428.6 & 51.15 & $9.65 \mathrm{E}-01$ & $1.42 \mathrm{E}+01$ \\
429 & 51.21 & $8.51 \mathrm{E}-01$ & $1.38 \mathrm{E}+01$ \\
429.4 & 51.27 & $9.18 \mathrm{E}-01$ & $1.45 \mathrm{E}+01$ \\
429.8 & 51.33 & $8.67 \mathrm{E}-01$ & $1.38 \mathrm{E}+01$ \\
430.2 & 51.39 & $9.18 \mathrm{E}-01$ & $1.36 \mathrm{E}+01$ \\
430.6 & 51.45 & $9.00 \mathrm{E}-01$ & $1.41 \mathrm{E}+01$ \\
431 & 51.51 & $9.22 \mathrm{E}-01$ & $1.45 \mathrm{E}+01$ \\
431.4 & 51.57 & $8.59 \mathrm{E}-01$ & $1.47 \mathrm{E}+01$ \\
431.8 & 51.62 & $1.12 \mathrm{E}+00$ & $1.64 \mathrm{E}+01$ \\
432.2 & 51.68 & $1.21 \mathrm{E}+00$ & $1.59 \mathrm{E}+01$ \\
432.6 & 51.74 & $1.12 \mathrm{E}+00$ & $1.59 \mathrm{E}+01$ \\
433 & 51.80 & $1.18 \mathrm{E}+00$ & $1.65 \mathrm{E}+01$ \\
433.4 & 51.86 & $1.28 \mathrm{E}+00$ & $1.62 \mathrm{E}+01$ \\
433.8 & 51.92 & $1.50 \mathrm{E}+00$ & $1.50 \mathrm{E}+01$ \\
434.2 & 51.98 & $1.72 \mathrm{E}+00$ & $1.73 \mathrm{E}+01$ \\
434.6 & 52.04 & $2.20 \mathrm{E}+00$ & $1.90 \mathrm{E}+01$ \\
435 & 52.10 & $1.85 \mathrm{E}+00$ & $1.77 \mathrm{E}+01$ \\
440.6 & 52.88 & $2.97 \mathrm{E}+00$ & $1.97 \mathrm{E}+01$ \\
435.4 & 52.16 & $2.94 \mathrm{E}+00$ & $2.20 \mathrm{E}+01$ \\
435.8 & 52.21 & $3.40 \mathrm{E}+00$ & $2.09 \mathrm{E}+01$ \\
436.2 & 52.27 & $3.12 \mathrm{E}+00$ & $2.18 \mathrm{E}+01$ \\
436.6 & 52.32 & $3.79 \mathrm{E}+00$ & $2.14 \mathrm{E}+01$ \\
437 & 52.38 & $3.99 \mathrm{E}+00$ & $2.19 \mathrm{E}+01$ \\
437.4 & 52.43 & $4.21 \mathrm{E}+00$ & $2.39 \mathrm{E}+01$ \\
437.8 & 52.49 & $2.67 \mathrm{E}+00$ & $1.90 \mathrm{E}+01$ \\
438.2 & 52.54 & $3.32 \mathrm{E}+00$ & $2.03 \mathrm{E}+01$ \\
438.6 & 52.60 & $5.08 \mathrm{E}+00$ & $2.68 \mathrm{E}+01$ \\
439 & 52.66 & $4.79 \mathrm{E}+00$ & $2.55 \mathrm{E}+01$ \\
439.4 & 52.71 & $4.01 \mathrm{E}+00$ & $2.22 \mathrm{E}+01$ \\
& 52.77 & $3.37 \mathrm{E}+00$ & $2.16 \mathrm{E}+01$ \\
42.99 & $2.58 \mathrm{E}+00$ & $1.78 \mathrm{E}+01$
\end{tabular}




\begin{tabular}{cccc}
\hline Depth & Age & Fe/Ca & Fe/K \\
[cm] & [cal kyr] & {$[c p s]$} & {$[c p s]$} \\
\hline 441.8 & 53.04 & $2.32 \mathrm{E}+00$ & $1.90 \mathrm{E}+01$ \\
442.2 & 53.10 & $2.38 \mathrm{E}+00$ & $1.91 \mathrm{E}+01$ \\
442.6 & 53.16 & $2.55 \mathrm{E}+00$ & $1.80 \mathrm{E}+01$ \\
443 & 53.21 & $2.06 \mathrm{E}+00$ & $1.85 \mathrm{E}+01$ \\
443.4 & 53.27 & $2.41 \mathrm{E}+00$ & $1.95 \mathrm{E}+01$ \\
443.8 & 53.32 & $1.97 \mathrm{E}+00$ & $1.79 \mathrm{E}+01$ \\
444.2 & 53.38 & $1.83 \mathrm{E}+00$ & $1.67 \mathrm{E}+01$ \\
444.6 & 53.43 & $1.86 \mathrm{E}+00$ & $1.77 \mathrm{E}+01$ \\
445 & 53.49 & $2.03 \mathrm{E}+00$ & $1.76 \mathrm{E}+01$ \\
445.4 & 53.54 & $1.96 \mathrm{E}+00$ & $1.84 \mathrm{E}+01$ \\
445.8 & 53.60 & $2.07 \mathrm{E}+00$ & $1.75 \mathrm{E}+01$ \\
446.2 & 53.66 & $3.14 \mathrm{E}+00$ & $2.03 \mathrm{E}+01$ \\
446.6 & 53.71 & $2.56 \mathrm{E}+00$ & $1.82 \mathrm{E}+01$ \\
447 & 53.77 & $2.66 \mathrm{E}+00$ & $1.91 \mathrm{E}+01$ \\
447.4 & 53.82 & $2.42 \mathrm{E}+00$ & $1.89 \mathrm{E}+01$ \\
447.8 & 53.88 & $2.02 \mathrm{E}+00$ & $1.77 \mathrm{E}+01$ \\
448.2 & 53.93 & $2.18 \mathrm{E}+00$ & $1.83 \mathrm{E}+01$ \\
448.6 & 53.99 & $2.82 \mathrm{E}+00$ & $1.89 \mathrm{E}+01$ \\
449 & 54.04 & $2.65 \mathrm{E}+00$ & $1.89 \mathrm{E}+01$ \\
449.4 & 54.10 & $3.68 \mathrm{E}+00$ & $2.28 \mathrm{E}+01$ \\
449.8 & 54.16 & $4.18 \mathrm{E}+00$ & $2.77 \mathrm{E}+01$ \\
450.2 & 54.21 & $2.71 \mathrm{E}+00$ & $1.94 \mathrm{E}+01$ \\
450.6 & 54.27 & $2.65 \mathrm{E}+00$ & $1.81 \mathrm{E}+01$ \\
451 & 54.32 & $2.76 \mathrm{E}+00$ & $1.85 \mathrm{E}+01$ \\
451.4 & 54.38 & $2.54 \mathrm{E}+00$ & $1.77 \mathrm{E}+01$ \\
451.8 & 54.43 & $2.45 \mathrm{E}+00$ & $1.76 \mathrm{E}+01$ \\
452.2 & 54.49 & $2.35 \mathrm{E}+00$ & $1.75 \mathrm{E}+01$ \\
457.4 & 55.20 & $1.37 \mathrm{E}+00$ & $1.71 \mathrm{E}+01$ \\
458.6 & 55.25 & $1.48 \mathrm{E}+00$ & $1.73 \mathrm{E}+01$ \\
458.6 & 55.31 & $1.42 \mathrm{E}+00$ & $1.62 \mathrm{E}+01$ \\
453 & 54.60 & $1.26 \mathrm{E}+00$ & $1.68 \mathrm{E}+01$ \\
453.4 & 54.65 & $1.35 \mathrm{E}+00$ & $1.76 \mathrm{E}+01$ \\
453.8 & 54.71 & $1.30 \mathrm{E}+00$ & $2.03 \mathrm{E}+01$ \\
454.2 & 54.76 & $9.72 \mathrm{E}-01$ & $1.52 \mathrm{E}+01$ \\
454.6 & 54.82 & $7.30 \mathrm{E}-01$ & $1.22 \mathrm{E}+01$ \\
455 & 54.87 & $8.24 \mathrm{E}-01$ & $1.49 \mathrm{E}+01$ \\
455.4 & 54.93 & $7.72 \mathrm{E}-01$ & $1.18 \mathrm{E}+01$ \\
455.8 & 54.98 & $8.39 \mathrm{E}-01$ & $1.24 \mathrm{E}+01$ \\
456.2 & 55.04 & $8.33 \mathrm{E}-01$ & $1.36 \mathrm{E}+01$ \\
456.6 & 55.09 & $9.09 \mathrm{E}-01$ & $1.38 \mathrm{E}+01$ \\
457 & 55.14 & $9.18 \mathrm{E}-01$ & $1.31 \mathrm{E}+01$
\end{tabular}




\begin{tabular}{|c|c|c|c|}
\hline $\begin{array}{c}\text { Depth } \\
{[\mathrm{cm}]}\end{array}$ & $\begin{array}{c}\text { Age } \\
\text { [cal kyr] }\end{array}$ & $\begin{array}{c}\mathrm{Fe} / \mathrm{Ca} \\
{[c p s]}\end{array}$ & $\begin{array}{l}\mathrm{Fe} / \mathbf{K} \\
{[c p s]} \\
\end{array}$ \\
\hline 459 & 55.42 & $1.55 \mathrm{E}+00$ & $1.67 E+01$ \\
\hline 459.4 & 55.47 & $1.64 \mathrm{E}+00$ & $1.54 \mathrm{E}+01$ \\
\hline 459.8 & 55.52 & $1.65 E+00$ & $1.71 \mathrm{E}+01$ \\
\hline 460.2 & 55.58 & $1.81 E+00$ & $1.89 \mathrm{E}+01$ \\
\hline 460.6 & 55.63 & $1.87 \mathrm{E}+00$ & $1.92 E+01$ \\
\hline 461 & 55.69 & $2.17 E+00$ & $2.05 \mathrm{E}+01$ \\
\hline 461.4 & 55.74 & $2.43 \mathrm{E}+00$ & $2.31 \mathrm{E}+01$ \\
\hline 461.8 & 55.80 & $2.26 \mathrm{E}+00$ & $2.07 \mathrm{E}+01$ \\
\hline 462.2 & 55.85 & $1.90 E+00$ & $1.76 \mathrm{E}+01$ \\
\hline 462.6 & 55.91 & $1.76 \mathrm{E}+00$ & $1.68 \mathrm{E}+01$ \\
\hline 463 & 55.96 & $2.45 E+00$ & $1.84 \mathrm{E}+01$ \\
\hline 463.4 & 56.01 & $2.25 E+00$ & $1.73 \mathrm{E}+01$ \\
\hline 463.8 & 56.07 & $1.55 \mathrm{E}+00$ & $1.60 \mathrm{E}+01$ \\
\hline 464.2 & 56.12 & $1.80 E+00$ & $1.69 E+01$ \\
\hline 464.6 & 56.18 & $1.86 E+00$ & $1.71 \mathrm{E}+01$ \\
\hline 465 & 56.23 & $1.89 E+00$ & $1.64 \mathrm{E}+01$ \\
\hline 465.4 & 56.29 & $1.53 \mathrm{E}+00$ & $1.58 \mathrm{E}+01$ \\
\hline 465.8 & 56.34 & $1.55 \mathrm{E}+00$ & $1.77 \mathrm{E}+01$ \\
\hline 466.2 & 56.40 & $2.21 E+00$ & $1.98 \mathrm{E}+01$ \\
\hline 466.6 & 56.45 & $2.15 E+00$ & $2.00 E+01$ \\
\hline 467 & 56.50 & $2.39 E+00$ & $1.92 \mathrm{E}+01$ \\
\hline 467.4 & 56.56 & $2.16 E+00$ & $1.98 \mathrm{E}+01$ \\
\hline 467.8 & 56.61 & $2.55 \mathrm{E}+00$ & $1.97 \mathrm{E}+01$ \\
\hline 468.2 & 56.67 & $3.01 E+00$ & $1.94 \mathrm{E}+01$ \\
\hline 468.6 & 56.72 & $3.96 \mathrm{E}+00$ & $2.32 \mathrm{E}+01$ \\
\hline 469 & 56.78 & $3.91 E+00$ & $2.15 E+01$ \\
\hline 469.4 & 56.83 & $4.44 \mathrm{E}+00$ & $2.25 \mathrm{E}+01$ \\
\hline 469.8 & 56.88 & $5.32 \mathrm{E}+00$ & $2.30 \mathrm{E}+01$ \\
\hline 470.2 & 56.94 & $5.04 \mathrm{E}+00$ & $2.11 E+01$ \\
\hline 470.6 & 56.99 & $5.43 E+00$ & $2.29 E+01$ \\
\hline 471 & 57.05 & $5.47 \mathrm{E}+00$ & $2.18 \mathrm{E}+01$ \\
\hline 471.4 & 57.10 & $5.09 \mathrm{E}+00$ & $2.25 \mathrm{E}+01$ \\
\hline 471.8 & 57.16 & $5.20 E+00$ & $2.32 E+01$ \\
\hline 472.2 & 57.21 & $6.35 E+00$ & $2.68 \mathrm{E}+01$ \\
\hline 472.6 & 57.27 & $1.05 \mathrm{E}+01$ & $3.15 E+01$ \\
\hline 473 & 57.32 & $8.76 \mathrm{E}+00$ & $2.76 \mathrm{E}+01$ \\
\hline 473.4 & 57.37 & $1.12 \mathrm{E}+01$ & $2.68 \mathrm{E}+01$ \\
\hline 473.8 & 57.43 & $6.86 \mathrm{E}+00$ & $2.42 \mathrm{E}+01$ \\
\hline 474.2 & 57.48 & $1.66 \mathrm{E}+01$ & $2.55 E+01$ \\
\hline 474.6 & 57.54 & $7.09 \mathrm{E}+00$ & $2.17 E+01$ \\
\hline 475 & 57.59 & $1.39 \mathrm{E}+01$ & $2.35 E+01$ \\
\hline 475.4 & 57.65 & $1.46 \mathrm{E}+01$ & $2.28 \mathrm{E}+01$ \\
\hline 475.8 & 57.70 & $1.61 \mathrm{E}+01$ & $2.30 E+01$ \\
\hline
\end{tabular}




\begin{tabular}{cccc}
\hline $\begin{array}{c}\text { Depth } \\
{[\mathrm{cm}]}\end{array}$ & $\begin{array}{c}\text { Age } \\
{[\mathrm{cal} k \mathrm{kr}]}\end{array}$ & $\begin{array}{c}\mathrm{Fe} / \mathrm{Ca} \\
{[\mathrm{cps}]}\end{array}$ & $\begin{array}{c}\mathrm{Fe} / \mathrm{K} \\
{[\mathrm{cps}]}\end{array}$ \\
\hline 476.2 & 57.76 & $1.31 \mathrm{E}+01$ & $2.19 \mathrm{E}+01$ \\
476.6 & 57.81 & $1.47 \mathrm{E}+01$ & $2.29 \mathrm{E}+01$ \\
477 & 57.86 & $1.30 \mathrm{E}+01$ & $2.33 \mathrm{E}+01$ \\
477.4 & 57.92 & $1.73 \mathrm{E}+01$ & $2.28 \mathrm{E}+01$ \\
477.8 & 57.97 & $2.30 \mathrm{E}+01$ & $2.45 \mathrm{E}+01$ \\
478.2 & 58.36 & $2.08 \mathrm{E}+01$ & $2.57 \mathrm{E}+01$ \\
478.6 & 58.42 & $2.49 \mathrm{E}+01$ & $2.40 \mathrm{E}+01$ \\
479 & 58.48 & $2.62 \mathrm{E}+01$ & $2.48 \mathrm{E}+01$ \\
479.4 & 58.54 & $2.58 \mathrm{E}+01$ & $2.58 \mathrm{E}+01$ \\
479.8 & 58.59 & $3.09 \mathrm{E}+01$ & $2.43 \mathrm{E}+01$ \\
480.2 & 58.65 & $2.97 \mathrm{E}+01$ & $2.65 \mathrm{E}+01$ \\
480.6 & 58.71 & $2.78 \mathrm{E}+01$ & $4.07 \mathrm{E}+01$ \\
\hline
\end{tabular}


ANNEX V - Input data for the end-member modelling. Data only in digital format. Media in the library of IAG/USP. 
ANNEX VI - R-Square data from unmixing of cores

\begin{tabular}{crrrr}
\hline $\begin{array}{c}\text { Number of end- } \\
\text { members }\end{array}$ & GeoB3913-3 & GeoB3912-1 & GeoB3910-2 & GeoB3911-3 \\
\hline 2 & 0.94446 & 0.96881 & 0.92075 & 0.94419 \\
3 & 0.96584 & 0.98195 & 0.94021 & 0.97522 \\
4 & 0.97784 & 0.9864 & 0.95372 & 0.98092 \\
5 & 0.98445 & 0.9895 & 0.96616 & 0.98689 \\
6 & 0.99098 & 0.99132 & 0.97949 & 0.99082 \\
7 & 0.99464 & 0.99378 & 0.9847 & 0.99508 \\
8 & 0.99606 & 0.99517 & 0.98943 & 0.99652 \\
9 & 0.99731 & 0.99623 & 0.99237 & 0.9975 \\
\hline
\end{tabular}


ANNEX VII - End-member contribution and IRM "synthetic" curve for core

\section{GeoB3911-3}

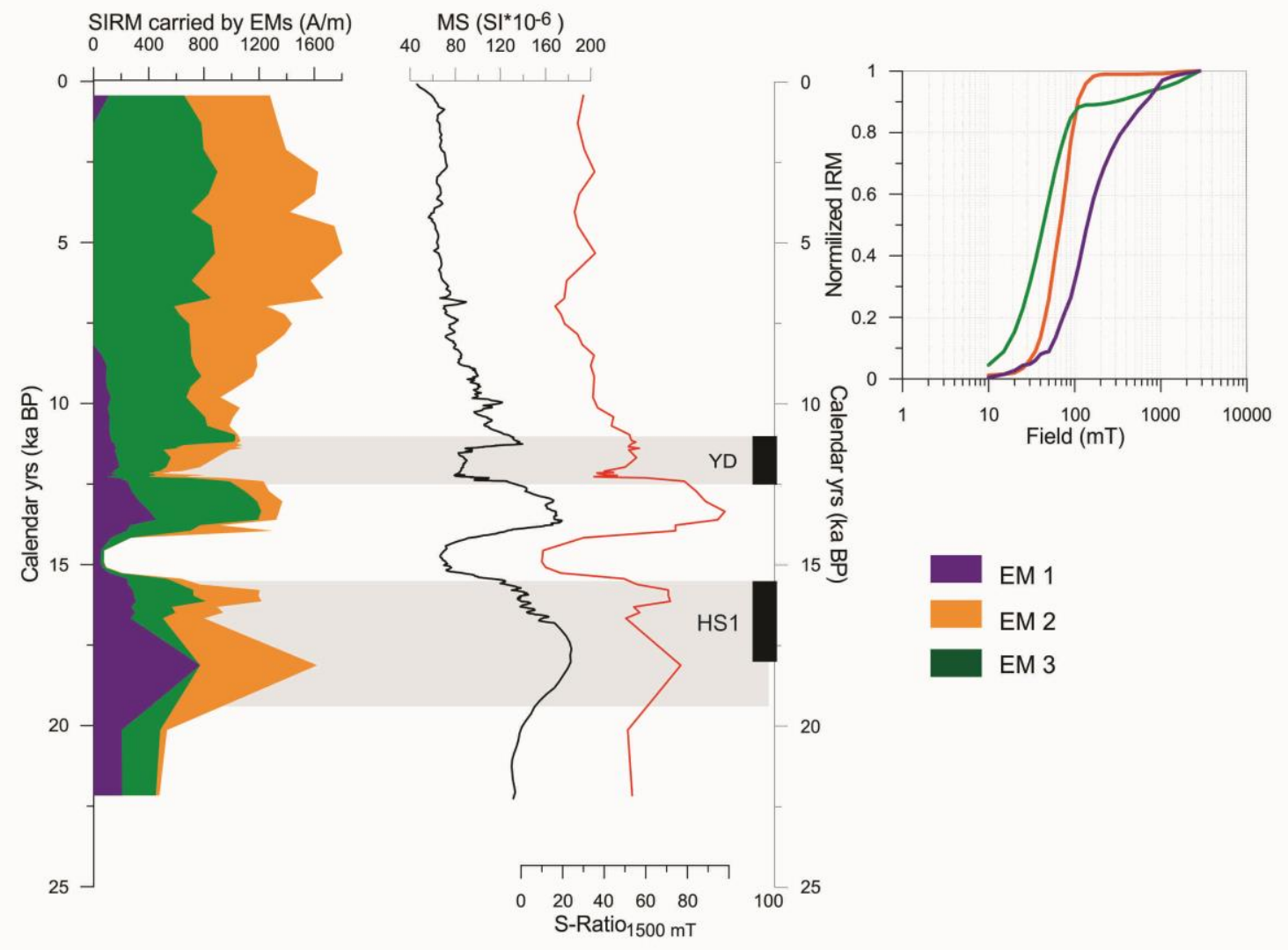


ANNEX VIII - Output data from the end-member analysis.

\begin{tabular}{|c|c|c|c|c|c|c|c|}
\hline \multicolumn{8}{|c|}{ GeoB3913-3 } \\
\hline \multicolumn{4}{|c|}{ IRM "synthetic" curves } & \multicolumn{4}{|c|}{ End-member total contributions } \\
\hline $\begin{array}{l}\text { Field } \\
{[\mathrm{mT}]}\end{array}$ & EM1 & EM2 & EM3 & $\begin{array}{c}\text { Age } \\
\text { cal }[k y r]\end{array}$ & IRM EM1 & IRM EM2 & IRM EM3 \\
\hline 0 & 0 & 0 & 0 & 3.3397 & 0 & 197.1728 & 176.9172 \\
\hline 10 & 0.012277 & 0.025645 & 0.032073 & 6.6794 & 0 & 226.2026 & 253.2674 \\
\hline 15 & 0.03254 & 0.047311 & 0.072131 & 10.0191 & 149.255 & 252.676 & 383.109 \\
\hline 20 & 0.060776 & 0.076563 & 0.115379 & 13.7525 & 442.9035 & 232.079 & 257.6175 \\
\hline 25 & 0.100948 & 0.113907 & 0.173435 & 14.8788 & 941.459 & 219.9387 & 38.53237 \\
\hline 30 & 0.147156 & 0.146989 & 0.244893 & 15.8405 & 543.799 & 255.9896 & 61.76138 \\
\hline 35 & 0.195099 & 0.190956 & 0.309131 & 16.7612 & 628.2554 & 385.7265 & 62.62805 \\
\hline 40 & 0.233689 & 0.222896 & 0.380378 & 17.6818 & 546.071 & 625.4361 & 146.0829 \\
\hline 45 & 0.271651 & 0.246861 & 0.448538 & 18.6025 & 329.7993 & 949.7094 & 181.8513 \\
\hline 50 & 0.313851 & 0.272823 & 0.500066 & 19.6349 & 255.1937 & 807.2301 & 253.9362 \\
\hline 60 & 0.387292 & 0.338143 & 0.627261 & 21.1142 & 314.2598 & 858.722 & 280.8782 \\
\hline 70 & 0.446356 & 0.371587 & 0.718092 & 22.5935 & 428.7799 & 659.7667 & 225.1734 \\
\hline 80 & 0.486171 & 0.416573 & 0.789719 & 23.9478 & 677.3262 & 233.3497 & 631.644 \\
\hline 90 & 0.520785 & 0.45059 & 0.850925 & 24.8018 & 668.6396 & 239.1512 & 612.3592 \\
\hline 110 & 0.567805 & 0.514801 & 0.919292 & 26.608 & 381.9629 & 196.115 & 578.2121 \\
\hline 140 & 0.610478 & 0.619969 & 0.951177 & 28.7009 & 636.3274 & 115.7399 & 473.2727 \\
\hline 165 & 0.630532 & 0.694415 & 0.958179 & 29.9133 & 610.0133 & 132.0979 & 390.8688 \\
\hline 190 & 0.645023 & 0.74842 & 0.961829 & 31.1256 & 553.4863 & 121.3518 & 453.0819 \\
\hline 220 & 0.659533 & 0.794164 & 0.964942 & 32.338 & 382.7588 & 109.7772 & 414.484 \\
\hline 275 & 0.681596 & 0.843164 & 0.969959 & 34.3699 & 384.4762 & 108.9865 & 410.3473 \\
\hline 335 & 0.700793 & 0.873121 & 0.974669 & 36.4018 & 462.5938 & 123.7777 & 493.1685 \\
\hline 430 & 0.727406 & 0.897125 & 0.981292 & 37.8395 & 318.7454 & 69.83107 & 446.0135 \\
\hline 550 & 0.756266 & 0.916852 & 0.987338 & 38.3858 & 670.4207 & 66.40869 & 432.9006 \\
\hline 750 & 0.798433 & 0.937721 & 0.993214 & 40.2543 & 519.803 & 90.28083 & 406.0362 \\
\hline 1045 & 0.839358 & 0.949829 & 0.998623 & 41.6504 & 326.563 & 106.5294 & 318.6375 \\
\hline 1255 & 0.86626 & 0.960727 & 0.99899 & 42.981 & 341.8202 & 88.47608 & 445.2137 \\
\hline 1580 & 0.902485 & 0.972956 & 1 & 45.7709 & 367.0637 & 53.49847 & 385.8478 \\
\hline 2090 & 0.950186 & 0.986752 & 1 & 46.8805 & 814.8933 & 67.22981 & 512.3069 \\
\hline \multirow[t]{11}{*}{2845} & 1 & 1 & 1 & 47.9902 & 524.6107 & 118.1989 & 592.3904 \\
\hline & & & & 50.6124 & 293.771 & 98.38875 & 517.9402 \\
\hline & & & & 53.8464 & 334.3718 & 41.87081 & 334.7274 \\
\hline & & & & 55.4934 & 421.7407 & 85.16091 & 511.7484 \\
\hline & & & & 57.1404 & 327.3741 & 104.4058 & 487.3302 \\
\hline & & & & 58.5925 & 565.2729 & 33.88084 & 380.7163 \\
\hline & & & & 59.265 & 741.449 & 4.204522 & 347.0264 \\
\hline & & & & 59.9376 & 645.6957 & 26.61 & 320.7643 \\
\hline & & & & 60.6101 & 674.6012 & 31.05335 & 292.9255 \\
\hline & & & & 61.2826 & 643.5322 & 62.3778 & 0 \\
\hline & & & & 61.9552 & 678.8314 & 103.1502 & 276.8283 \\
\hline
\end{tabular}




$\begin{array}{rrrr}62.6277 & 690.7155 & 177.4909 & 453.7236 \\ 63.3003 & 617.8925 & 223.6916 & 434.8258 \\ 63.9728 & 678.0859 & 192.6359 & 488.2082 \\ 64.6453 & 650.9615 & 243.1145 & 647.034 \\ 65.3179 & 696.5114 & 232.8604 & 594.1282 \\ 65.9904 & 567.6276 & 183.2349 & 535.5876 \\ 66.6629 & 407.1588 & 162.4329 & 626.6283 \\ 67.3355 & 361.1729 & 75.9834 & 551.9537 \\ 68.008 & 189.7548 & 57.11402 & 551.7112 \\ 68.5363 & 392.4622 & 71.66172 & 530.0561 \\ 69.0645 & 681.59 & 17.39122 & 511.1988 \\ 69.6985 & 505.2395 & 0.809919 & 409.7206 \\ 70.1211 & 500.1059 & 10.14127 & 377.3729 \\ 70.6493 & 300.0504 & 13.6234 & 416.8862 \\ 71.0621 & 244.6671 & 30.15057 & 565.6023 \\ 71.4459 & 329.2952 & 22.38235 & 731.0025 \\ 71.8297 & 231.9705 & 21.66459 & 565.4149 \\ 72.2135 & 221.5146 & 60.10341 & 654.372 \\ 72.5974 & 170.6147 & 17.12341 & 646.2619 \\ 72.9812 & 232.7528 & 40.88387 & 617.9133 \\ 73.365 & 535.6436 & 75.15741 & 531.119 \\ 74.8989 & 240.3179 & 126.8529 & 673.5493 \\ 76.3444 & 256.1228 & 99.0763 & 556.3409 \\ 77.4365 & 114.5701 & 41.38418 & 469.2658 \\ 78.5286 & 47.44926 & 27.89354 & 314.9872 \\ 79.6207 & 35.56917 & 35.98605 & 201.9648 \\ 80.7316 & 701.9493 & 150.1067 & 501.224 \\ 81.8708 & 783.2817 & 168.5683 & 514.1199 \\ 83.0099 & 386.2578 & 98.22289 & 297.4993 \\ 84.149 & 475.6898 & 84.65396 & 386.2063 \\ 85.2881 & 688.9781 & 95.30692 & 336.7049\end{array}$




\begin{tabular}{|c|c|c|c|c|c|c|c|}
\hline \multicolumn{8}{|c|}{ GeoB3912-1 } \\
\hline \multicolumn{4}{|c|}{ IRM "synthetic" curves } & \multicolumn{4}{|c|}{ End-member total contributions } \\
\hline $\begin{array}{l}\text { Field } \\
{[\mathrm{mT}]}\end{array}$ & EM1 & EM2 & EM3 & $\begin{array}{c}\text { Age } \\
\text { cal [kyr] }\end{array}$ & IRM EM1 & IRM EM2 & IRM EM3 \\
\hline 0 & 0 & 0 & 0 & 2.446 & 0 & 0 & 0 \\
\hline 10 & 0.044895 & 0.004667 & 0.018448 & 4.643 & 684.0858 & 271.9317 & 50.84244 \\
\hline 15 & 0.082749 & 0.012152 & 0.036489 & 6.828 & 905.4458 & 0 & 323.8342 \\
\hline 20 & 0.136161 & 0.022718 & 0.067742 & 9.537 & 623.6384 & 9.625281 & 439.1663 \\
\hline 25 & 0.197236 & 0.041006 & 0.105795 & 10.190 & 1109.109 & 126.0982 & 23.08301 \\
\hline 30 & 0.26594 & 0.05929 & 0.152182 & 10.573 & 924.6968 & 157.225 & 15.74819 \\
\hline 35 & 0.330284 & 0.089516 & 0.205348 & 10.954 & 838.7367 & 233.251 & 61.4623 \\
\hline 40 & 0.386466 & 0.126213 & 0.270283 & 11.395 & 673.9042 & 251.1558 & 82.19004 \\
\hline 45 & 0.451657 & 0.164686 & 0.33958 & 11.951 & 553.2923 & 242.4354 & 132.8223 \\
\hline 50 & 0.509421 & 0.210282 & 0.404377 & 12.560 & 226.5623 & 229.0989 & 279.4888 \\
\hline 60 & 0.598211 & 0.321597 & 0.553949 & 13.178 & 447.6811 & 77.68221 & 248.8767 \\
\hline 70 & 0.675558 & 0.39232 & 0.669113 & 13.920 & 485.2201 & 100.4442 & 249.3958 \\
\hline 80 & 0.73753 & 0.457589 & 0.773465 & 14.412 & 376.7834 & 239.9238 & 337.9528 \\
\hline 90 & 0.788969 & 0.507147 & 0.8466 & 14.879 & 226.4138 & 479.2977 & 595.7286 \\
\hline 110 & 0.840331 & 0.582493 & 0.937442 & 15.161 & 194.1086 & 361.1626 & 724.0788 \\
\hline 135 & 0.862978 & 0.619998 & 0.971417 & 15.522 & 313.5242 & 609.8346 & 303.2512 \\
\hline 160 & 0.877257 & 0.638827 & 0.979851 & 15.769 & 273.3258 & 591.2849 & 301.3893 \\
\hline 185 & 0.885992 & 0.653127 & 0.982749 & 16.119 & 142.0945 & 597.8606 & 438.1749 \\
\hline 215 & 0.894114 & 0.667243 & 0.984252 & 16.397 & 212.6132 & 493.5148 & 391.902 \\
\hline 265 & 0.903762 & 0.687558 & 0.985963 & 16.738 & 217.9003 & 523.6658 & 330.9838 \\
\hline 325 & 0.91073 & 0.708985 & 0.987519 & 17.006 & 257.1938 & 528.2825 & 137.3538 \\
\hline 420 & 0.91913 & 0.737338 & 0.989653 & 17.292 & 185.8345 & 408.9877 & 212.4078 \\
\hline 530 & 0.925536 & 0.766322 & 0.990995 & 17.526 & 208.4542 & 324.5674 & 153.0085 \\
\hline 720 & 0.934964 & 0.809326 & 0.992543 & 17.874 & 185.3706 & 306.0621 & 229.0272 \\
\hline 1060 & 0.955673 & 0.861258 & 1.000529 & 18.165 & 156.6939 & 328.624 & 100.4821 \\
\hline 1325 & 0.961784 & 0.88543 & 1.000813 & 18.551 & 73.24312 & 398.4757 & 207.2812 \\
\hline 1595 & 0.97327 & 0.910602 & 0.997128 & 18.867 & 174.7319 & 274.6706 & 113.9575 \\
\hline 2105 & 0.983115 & 0.954492 & 0.999776 & 19.434 & 195.6946 & 265.7948 & 87.62062 \\
\hline \multirow[t]{13}{*}{2870} & 1 & 1 & 1 & 20.004 & 330.6199 & 166.7213 & 223.9989 \\
\hline & & & & 20.786 & 277.306 & 201.9232 & 205.5409 \\
\hline & & & & 21.435 & 403.2549 & 147.3884 & 236.9066 \\
\hline & & & & 22.580 & 371.5101 & 161.0442 & 238.6356 \\
\hline & & & & 23.233 & 479.7618 & 235.3699 & 264.2783 \\
\hline & & & & 24.230 & 359.9343 & 331.0028 & 223.1829 \\
\hline & & & & 24.740 & 516.0388 & 276.2381 & 106.2331 \\
\hline & & & & 25.395 & 445.4721 & 270.6211 & 10.22681 \\
\hline & & & & 25.663 & 390.172 & 243.3376 & 104.8505 \\
\hline & & & & 26.159 & 363.8684 & 190.5289 & 109.7027 \\
\hline & & & & 26.607 & 346.5508 & 190.4784 & 311.0409 \\
\hline & & & & 27.224 & 213.968 & 231.6146 & 320.7874 \\
\hline & & & & 27.731 & 229.0003 & 260.2881 & 347.2016 \\
\hline
\end{tabular}




\begin{tabular}{rrrr}
28.288 & 38.10489 & 291.2997 & 491.6254 \\
28.846 & 153.9635 & 236.4109 & 419.8156 \\
29.366 & 121.7339 & 242.0408 & 367.3853 \\
30.059 & 77.35641 & 277.6728 & 383.6908 \\
30.881 & 96.41512 & 329.1833 & 259.9216 \\
31.552 & 171.1953 & 352.9655 & 157.0792 \\
32.296 & 210.3082 & 298.2908 & 151.531 \\
32.674 & 250.7068 & 257.814 & 222.8192 \\
33.083 & 112.0282 & 213.7973 & 404.2446 \\
33.410 & 227.13 & 173.3399 & 374.5301 \\
33.783 & 158.0531 & 174.7414 & 354.5455 \\
34.153 & 144.0403 & 187.8143 & 330.8553 \\
34.519 & 220.6231 & 167.7718 & 274.355 \\
34.892 & 200.4108 & 221.6438 & 266.9555 \\
35.402 & 192.4339 & 178.0481 & 344.358 \\
36.116 & 143.3896 & 206.2578 & 532.3126 \\
36.561 & 59.73637 & 291.8462 & 379.4274 \\
36.859 & 171.7044 & 253.9976 & 314.6679 \\
37.037 & 196.2833 & 232.5959 & 421.2508 \\
37.212 & 112.3435 & 254.2111 & 554.7954 \\
37.382 & 266.3796 & 275.7915 & 395.1089 \\
37.552 & 247.1807 & 352.1925 & 400.9068 \\
37.774 & 177.4642 & 395.0544 & 454.4714 \\
37.893 & 136.0177 & 454.0934 & 355.8789 \\
38.086 & 81.98122 & 586.8257 & 286.4031 \\
38.322 & 258.3362 & 528.6379 & 133.6559 \\
38.754 & 307.1416 & 517.7784 & 0 \\
39.398 & 260.6362 & 570.9338 & \\
39.895 & 135.4105 & 181.32 & 397.2695 \\
40.279 & 146.1787 & 133.5633 & 461.198 \\
40.620 & 204.8226 & 229.5093 & 310.1281 \\
41.134 & 141.3033 & 239.1962 & 389.6805 \\
41.734 & 51.75814 & 240.9057 & 513.5761 \\
42.339 & 189.9847 & 251.3058 & 362.9095 \\
43.011 & 251.42 & 246.9527 & 385.6672 \\
44.204 & 275.4562 & 227.7557 & 421.9581 \\
45.207 & 344.1549 & 226.3285 & 342.8765 \\
45.776 & 335.6824 & 275.6321 & 303.1055 \\
46.297 & 247.1844 & 336.7383 & 465.5873 \\
46.923 & 111.1575 & 370.5797 & 420.3128 \\
47.502 & 49.42492 & 502.95 & 450.6651 \\
47.996 & 235.298 & 442.011 & 230.301 \\
48.227 & 342.5965 & 434.495 & 127.7685 \\
48.572 & 219.6192 & 291.6241 & 428.8067 \\
49.298 & 302.678 & 239.6294 & 418.7726 \\
& & & 205 \\
\hline
\end{tabular}




\begin{tabular}{|c|c|c|c|}
\hline 50.022 & 249.5293 & 248.5729 & 474.0478 \\
\hline 50.748 & 251.935 & 231.2511 & 457.0239 \\
\hline 51.472 & 273.8083 & 198.72 & 427.9717 \\
\hline 52.206 & 118.0789 & 257.5089 & 526.4522 \\
\hline 52.938 & 259.2478 & 201.9668 & 428.9453 \\
\hline 53.662 & 220.7517 & 227.2969 & 454.1714 \\
\hline 54.388 & 115.1878 & 235.5729 & 517.6694 \\
\hline 55.112 & 32.37031 & 318.7706 & 427.9591 \\
\hline 55.838 & 144.4998 & 292.0228 & 312.3374 \\
\hline 56.488 & 189.2612 & 241.673 & 427.7858 \\
\hline 57.285 & 184.8406 & 262.1996 & 462.0098 \\
\hline 58.090 & 173.6058 & 267.8595 & 634.0148 \\
\hline 58.752 & 330.044 & 249.9474 & 340.9686 \\
\hline 59.550 & 59.46909 & 404.7524 & 609.3085 \\
\hline 60.202 & 0 & 502.0879 & 505.0821 \\
\hline 61.000 & 42.51998 & 511.2873 & 441.8927 \\
\hline 61.652 & 2.096045 & 480.7777 & 535.4263 \\
\hline 62.450 & 80.8875 & 421.1959 & 440.2966 \\
\hline 63.102 & 101.8117 & 413.0417 & 458.3866 \\
\hline 63.905 & 0 & 449.6232 & 474.9568 \\
\hline 64.562 & 120.5403 & 372.8069 & 398.6528 \\
\hline 65.600 & 127.6586 & 421.9717 & 222.3997 \\
\hline 66.400 & 188.5133 & 381.6672 & 150.0895 \\
\hline 67.505 & 276.8293 & 401.5775 & 31.96318 \\
\hline 68.410 & 436.5252 & 291.5647 & 197.7601 \\
\hline 69.510 & 384.9215 & 268.9164 & 553.1721 \\
\hline 70.410 & 204.882 & 516.9767 & 350.4713 \\
\hline 71.360 & 207.2768 & 448.3709 & 376.8323 \\
\hline 71.986 & 438.4834 & 138.6003 & 832.8763 \\
\hline 72.606 & 416.2103 & 107.9878 & 819.3519 \\
\hline 73.365 & 262.3527 & 156.4594 & 740.3779 \\
\hline 74.194 & 120.2844 & 299.0873 & 804.2082 \\
\hline 74.746 & 77.09015 & 371.7194 & 825.2504 \\
\hline 75.505 & 115.5088 & 378.7772 & 757.704 \\
\hline 76.126 & 226.7914 & 364.7653 & 484.8233 \\
\hline 76.890 & 257.1668 & 232.5762 & 797.847 \\
\hline 77.516 & 484.9471 & 116.8039 & 835.129 \\
\hline 78.206 & 591.1368 & 86.65005 & 767.3231 \\
\hline 78.896 & 454.1157 & 32.7562 & 1089.608 \\
\hline 79.586 & 465.949 & 26.00267 & 935.8383 \\
\hline 80.276 & 393.7949 & 65.46749 & 1243.248 \\
\hline 80.966 & 452.1655 & 50.97582 & 806.0487 \\
\hline 81.656 & 237.3685 & 140.9976 & 920.5139 \\
\hline 82.415 & 188.2453 & 250.5955 & 841.9791 \\
\hline 83.040 & 586.6843 & 306.3862 & 686.3694 \\
\hline
\end{tabular}




\begin{tabular}{|c|c|c|c|c|c|c|c|}
\hline & & & & $\begin{array}{l}83.87 \\
84.42\end{array}$ & $\begin{array}{r}248.569 \\
63.284\end{array}$ & $\begin{array}{l}299.810 \\
348.846\end{array}$ & $\begin{array}{l}738.8797 \\
656.8388\end{array}$ \\
\hline \multicolumn{8}{|c|}{ GeoB3911-3 } \\
\hline \multicolumn{4}{|c|}{ IRM "synthetic" curves } & \multicolumn{4}{|c|}{ End-member total contributions } \\
\hline $\begin{array}{l}\text { Field } \\
{[\mathrm{mT}]}\end{array}$ & EM1 & EM2 & EM3 & $\begin{array}{c}\text { Age } \\
\text { cal [kyr] }\end{array}$ & IRM EM1 & IRM EM2 & IRM EM3 \\
\hline 0 & 0 & 0 & 0 & 0.434 & 544.7771 & 112.3132 & 621.1598 \\
\hline 10 & 0.004975 & 0.045352 & 0.012136 & 1.302 & 781.6955 & 0 & 554.9245 \\
\hline 15 & 0.014744 & 0.088741 & 0.015209 & 2.117 & 797.6968 & 0 & 597.8832 \\
\hline 20 & 0.027216 & 0.152378 & 0.019723 & 2.807 & 898.9558 & 0 & 728.9742 \\
\hline 25 & 0.04402 & 0.228665 & 0.034648 & 3.497 & 834.1714 & 0 & 770.7386 \\
\hline 30 & 0.047686 & 0.308577 & 0.060898 & 4.055 & 708.043 & 0 & 714.817 \\
\hline 35 & 0.060444 & 0.383581 & 0.090297 & 4.485 & 855.362 & 0 & 889.338 \\
\hline 40 & 0.079735 & 0.455747 & 0.133511 & 5.335 & 881.0864 & 0 & 925.1936 \\
\hline 45 & 0.086065 & 0.522299 & 0.196932 & 6.185 & 711.8231 & 0 & 861.3169 \\
\hline 50 & 0.088724 & 0.581327 & 0.25747 & 6.734 & 853.6721 & 0 & 813.4179 \\
\hline 60 & 0.134742 & 0.681689 & 0.409172 & 6.982 & 583.6376 & 0 & 670.8024 \\
\hline 70 & 0.187244 & 0.755063 & 0.529381 & 7.231 & 623.1474 & 0 & 762.4926 \\
\hline 80 & 0.228714 & 0.809271 & 0.650627 & 7.526 & 693.7931 & 0 & 744.6769 \\
\hline 90 & 0.263259 & 0.847702 & 0.771789 & 7.852 & 697.1128 & 0 & 688.5572 \\
\hline 110 & 0.362939 & 0.881697 & 0.906921 & 8.178 & 703.6025 & 1.305173 & 587.5823 \\
\hline 135 & 0.48231 & 0.890182 & 0.959584 & 8.504 & 647.9112 & 58.46641 & 473.1224 \\
\hline 165 & 0.583009 & 0.890182 & 0.982608 & 8.830 & 635.9247 & 95.84051 & 454.5948 \\
\hline 190 & 0.639249 & 0.891978 & 0.987607 & 9.156 & 690.856 & 90.45653 & 375.7975 \\
\hline 220 & 0.687719 & 0.89387 & 0.989637 & 9.483 & 609.0316 & 94.51628 & 338.8821 \\
\hline 270 & 0.74439 & 0.898313 & 0.989637 & 9.809 & 546.9815 & 125.2558 & 246.8028 \\
\hline 335 & 0.793431 & 0.904286 & 0.989637 & 10.135 & 639.5115 & 103.4031 & 317.7853 \\
\hline 545 & 0.873067 & 0.922 & 0.989637 & 10.419 & 691.8197 & 116.3865 & 204.7838 \\
\hline 745 & 0.914726 & 0.934806 & 0.991247 & 10.692 & 711.2298 & 112.4587 & 159.5915 \\
\hline 1040 & 0.969629 & 0.945525 & 0.991247 & 10.966 & 908.2017 & 118.4687 & 20.18958 \\
\hline 1305 & 0.980569 & 0.95467 & 0.99405 & 11.149 & 896.4082 & 130.4362 & 37.42563 \\
\hline 1570 & 0.986769 & 0.963439 & 0.996708 & 11.198 & 873.4754 & 136.1082 & 45.56645 \\
\hline 2075 & 0.994294 & 0.981145 & 0.99905 & 11.246 & 651.0103 & 152.3154 & 234.0143 \\
\hline \multirow[t]{12}{*}{2825} & 1 & 1 & 1 & 11.295 & 496.3479 & 153.9821 & 429.88 \\
\hline & & & & 11.343 & 456.982 & 157.361 & 412.2569 \\
\hline & & & & 11.392 & 434.2088 & 167.6363 & 478.9349 \\
\hline & & & & 11.440 & 352.9305 & 155.242 & 477.4974 \\
\hline & & & & 11.683 & 390.338 & 169.7718 & 327.3101 \\
\hline & & & & 11.974 & 340.5653 & 187.1948 & 245.0599 \\
\hline & & & & 12.101 & 334.5219 & 144.4358 & 157.6624 \\
\hline & & & & 12.120 & 286.3575 & 148.3135 & 114.469 \\
\hline & & & & 12.139 & 293.0421 & 154.921 & 105.8069 \\
\hline & & & & 12.157 & 277.453 & 132.0768 & 86.75014 \\
\hline & & & & 12.176 & 272.8446 & 129.3359 & 117.3695 \\
\hline & & & & 12.195 & 303.0915 & 134.8435 & 172.0951 \\
\hline
\end{tabular}




\begin{tabular}{rrrr}
12.213 & 295.1139 & 155.4947 & 310.7014 \\
12.232 & 274.4442 & 172.7016 & 354.4642 \\
12.251 & 280.5479 & 133.1511 & 271.491 \\
12.270 & 298.3424 & 102.9748 & 279.5127 \\
12.288 & 375.2665 & 112.1321 & 322.8113 \\
12.307 & 515.4712 & 182.8685 & 246.4703 \\
12.414 & 739.6812 & 244.8781 & 247.2506 \\
12.727 & 822.6342 & 276.6413 & 173.1945 \\
13.039 & 854.4974 & 331.8658 & 182.6968 \\
13.352 & 807.3919 & 407.5403 & 129.8778 \\
13.609 & 739.3415 & 453.6176 & 131.4109 \\
13.781 & 504.4965 & 266.6847 & 147.6288 \\
13.953 & 462.3497 & 239.3685 & 596.2818 \\
14.169 & 146.2275 & 124.8121 & 0.060347 \\
14.564 & 22.9841 & 53.76832 & 0.697586 \\
14.915 & 24.53266 & 49.91734 & 0 \\
15.090 & 26.01936 & 62.20414 & 4.966502 \\
15.266 & 81.77857 & 115.326 & 14.53547 \\
15.441 & 290.216 & 244.358 & 103.7061 \\
15.616 & 379.3089 & 250.3003 & 137.0709 \\
15.791 & 437.3991 & 285.3583 & 481.0426 \\
15.966 & 433.8415 & 290.6657 & 471.0728 \\
16.142 & 505.5753 & 308.6823 & 403.4324 \\
16.317 & 294.8663 & 272.7143 & 328.5693 \\
16.492 & 291.811 & 302.3525 & 345.6465 \\
16.667 & 235.2107 & 267.3432 & 298.7261 \\
18.128 & 0 & 772.6585 & 847.8115 \\
20.140 & 279.7791 & 203.6883 & 49.00258 \\
22.170 & 243.2877 & 207.8333 & 26.13902 \\
\hline & & &
\end{tabular}




\begin{tabular}{|c|c|c|c|c|c|c|c|}
\hline \multicolumn{8}{|c|}{ GeoB3910-2 } \\
\hline \multicolumn{4}{|c|}{ IRM "synthetic" curves } & \multicolumn{4}{|c|}{ End-member total contributions } \\
\hline $\begin{array}{l}\text { Field } \\
{[\mathrm{mT}]}\end{array}$ & EM1 & EM2 & EM3 & $\begin{array}{c}\text { Age } \\
\text { cal [kyr] }\end{array}$ & IRM EM1 & IRM EM2 & IRM EM3 \\
\hline 0 & 0 & 0 & 0 & 1.985 & 369.0038 & 698.9196 & 418.4566 \\
\hline 10 & 0 & 0.005786 & 0.047499 & 3.242 & 384.6172 & 672.7945 & 466.3383 \\
\hline 15 & 0.010437 & 0.005876 & 0.102055 & 4.352 & 345.1646 & 691.0379 & 457.1075 \\
\hline 20 & 0.031515 & 0.009399 & 0.152825 & 5.732 & 298.3371 & 841.1937 & 556.5091 \\
\hline 25 & 0.068635 & 0.020057 & 0.232356 & 6.872 & 219.1175 & 913.9949 & 626.6176 \\
\hline 30 & 0.112745 & 0.035516 & 0.345135 & 7.652 & 213.7625 & 385.058 & 1164.39 \\
\hline 40 & 0.214351 & 0.053208 & 0.47332 & 8.432 & 210.1096 & 221.5531 & 1211.537 \\
\hline 45 & 0.271482 & 0.072769 & 0.516687 & 9.059 & 396.6688 & 60.97451 & 1144.227 \\
\hline 50 & 0.314687 & 0.106862 & 0.596476 & 9.642 & 414.6185 & 0 & 934.2915 \\
\hline 55 & 0.370581 & 0.115693 & 0.642764 & 10.225 & 497.1793 & 0 & 864.7407 \\
\hline 65 & 0.465221 & 0.159506 & 0.769942 & 10.702 & 555.0627 & 0 & 736.0973 \\
\hline 75 & 0.52833 & 0.231422 & 0.85132 & 11.260 & 554.4971 & 0 & 574.3129 \\
\hline 85 & 0.573869 & 0.314419 & 0.935403 & 11.692 & 529.1138 & 0 & 466.3662 \\
\hline 95 & 0.629851 & 0.396487 & 0.948922 & 12.172 & 492.7106 & 23.73011 & 370.5093 \\
\hline 115 & 0.686343 & 0.575239 & 0.955749 & 12.739 & 458.1225 & 84.37 & 207.2275 \\
\hline 140 & 0.725548 & 0.719978 & 0.955749 & 13.505 & 623.9714 & 36.83832 & 237.9103 \\
\hline 170 & 0.751826 & 0.822137 & 0.957164 & 14.132 & 658.8709 & 53.74249 & 230.2966 \\
\hline 200 & 0.767254 & 0.870858 & 0.965685 & 14.757 & 917.4062 & 62.82495 & 193.0088 \\
\hline 230 & 0.77786 & 0.898677 & 0.974018 & 15.273 & 933.0446 & 58.68636 & 174.909 \\
\hline 280 & 0.793692 & 0.922932 & 0.979977 & 15.790 & 972.805 & 53.80127 & 33.35368 \\
\hline 345 & 0.809252 & 0.940602 & 0.985724 & 16.240 & 1006.897 & 107.4111 & 35.24168 \\
\hline 450 & 0.8304 & 0.954173 & 0.989598 & 16.660 & 917.7482 & 377.4218 & 0 \\
\hline 570 & 0.849551 & 0.962938 & 0.991574 & 16.886 & 887.9124 & 1827.095 & 190.6729 \\
\hline 785 & 0.877655 & 0.972329 & 0.993434 & 17.100 & 819.5699 & 49.87012 & 0 \\
\hline 1020 & 0.901371 & 0.977644 & 0.995918 & 17.314 & 613.8113 & 379.8809 & 70.64778 \\
\hline 1230 & 0.917971 & 0.981832 & 0.995918 & 17.529 & 473.3196 & 1159.34 & 0 \\
\hline 1550 & 0.939529 & 0.986964 & 0.996707 & 17.743 & 372.0272 & 1046.538 & 33.61506 \\
\hline 2045 & 0.968225 & 0.992921 & 0.999151 & 17.957 & 409.8342 & 1204.866 & 14.78021 \\
\hline \multirow[t]{13}{*}{2790} & 1 & 1 & 1 & 18.171 & 334.1324 & 1620.668 & 0 \\
\hline & & & & 18.660 & 797.4888 & 333.0303 & 240.5809 \\
\hline & & & & 19.560 & 809.1372 & 263.4792 & 241.2436 \\
\hline & & & & 20.460 & 852.2892 & 241.0038 & 255.777 \\
\hline & & & & 21.360 & 843.9363 & 190.6595 & 226.9441 \\
\hline & & & & 22.260 & 869.725 & 178.9233 & 243.6517 \\
\hline & & & & 22.920 & 859.6902 & 141.1048 & 275.815 \\
\hline & & & & 23.220 & 861.2518 & 133.3343 & 183.1739 \\
\hline & & & & 23.860 & 799.6926 & 10.25902 & 165.9083 \\
\hline & & & & 25.010 & 659.2792 & 125.8332 & 156.2376 \\
\hline & & & & 25.990 & 711.9158 & 133.877 & 122.1672 \\
\hline & & & & 26.715 & 921.7434 & 148.1896 & 241.1269 \\
\hline & & & & 27.440 & 963.6188 & 182.7563 & 270.2149 \\
\hline
\end{tabular}




$\begin{array}{rrrr}28.310 & 815.6266 & 158.4485 & 255.9949 \\ 28.760 & 739.5698 & 123.1215 & 131.5987 \\ 29.200 & 858.1978 & 97.41488 & 231.2673 \\ 29.560 & 786.9261 & 0.23023 & 133.9037 \\ 29.960 & 744.9173 & 52.2778 & 57.48493 \\ 30.720 & 702.879 & 59.51817 & 74.32279 \\ 31.733 & 733.1261 & 130.7955 & 228.4284 \\ 32.317 & 765.5923 & 88.79712 & 259.6106 \\ 32.900 & 818.4227 & 144.5084 & 206.9789 \\ 33.483 & 708.5984 & 54.50344 & 153.7682 \\ 34.067 & 828.3568 & 131.8374 & 271.6457 \\ 34.650 & 653.0219 & 71.50218 & 129.7459 \\ 35.206 & 770.2875 & 144.927 & 317.7055 \\ 35.721 & 803.231 & 155.1432 & 364.7558 \\ 36.235 & 709.1872 & 21.91081 & 141.112 \\ 36.750 & 688.8877 & 145.7121 & 197.7802 \\ 37.265 & 760.9403 & 123.0235 & 326.7161 \\ 37.779 & 809.7732 & 84.20469 & 249.0721 \\ 38.346 & 806.6367 & 11.82007 & 133.0533 \\ 38.881 & 730.5657 & 105.2336 & 111.8507 \\ 39.515 & 668.7619 & 437.2742 & 49.2439 \\ 40.150 & 435.514 & 2103.2 & 12.20588 \\ 40.785 & 511.3392 & 493.4928 & 20.50802 \\ 41.419 & 529.678 & 1144.641 & 61.3713 \\ 41.900 & 757.1623 & 197.1097 & 174.248 \\ 42.150 & 739.2554 & 127.4074 & 252.7771 \\ 42.400 & 775.6572 & 81.6819 & 172.0609 \\ 42.650 & 741.6913 & 177.3791 & 309.9097 \\ 43.008 & 803.711 & 159.7938 & 307.0852 \\ 43.528 & 753.8384 & 206.4149 & 155.5768 \\ 44.048 & 780.1673 & 118.6463 & 250.9063 \\ 44.568 & 709.8627 & 140.0781 & 348.4092 \\ 45.088 & 746.91 & 138.5448 & 333.5052 \\ 45.511 & 822.9597 & 55.42946 & 305.2008 \\ 45.789 & 772.6903 & 204.5618 & 177.8778 \\ 46.067 & 585.6905 & 1013.366 & 100.1738 \\ 46.344 & 516.7456 & 1788.874 & \\ 46.622 & 0.531019 & 4085.325 & 17.4439 \\ 46.900 & 342.9973 & 1976.381 & 130.0118 \\ 47.643 & 781.6231 & 265.2675 & 317.4593 \\ 48.460 & 751.1826 & 125.4239 & 316.9635 \\ 49.129 & 753.0288 & 71.86646 & 355.6048 \\ 49.871 & 721.8912 & 112.4892 & 329.6897 \\ 50.614 & 850.9968 & 116.2947 & 208.2986 \\ 51.357 & 886.9966 & 15.04182 & 252.7615\end{array}$




\begin{tabular}{rrrr}
52.100 & 845.3367 & 28.63105 & 195.0723 \\
52.794 & 774.3237 & 61.24639 & 138.2599 \\
53.489 & 824.8914 & 184.826 & 167.8926 \\
54.183 & 800.2864 & 85.16146 & 232.4221 \\
54.988 & 881.2706 & 52.83335 & 324.466 \\
55.717 & 869.6601 & 112.9668 & 71.00312 \\
56.447 & 849.6965 & 57.91415 & 67.41937 \\
57.176 & 861.6183 & 37.98174 & 0 \\
57.906 & 649.7434 & 135.1466 & 0 \\
58.635 & 469.8503 & 586.2562 & 39.67352 \\
\hline
\end{tabular}

